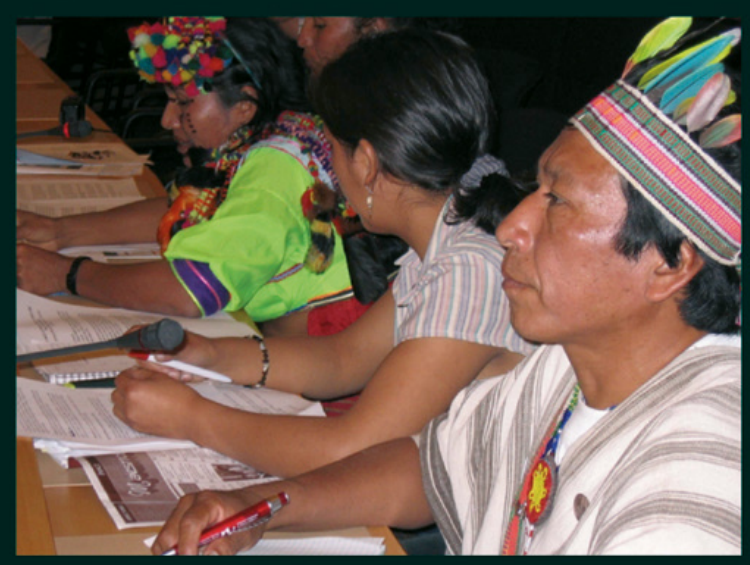

Maren RöBler

Zwischion

Amazonas und

East River

Indigene Bewegungen

und ihre Repräsentation

in Peru und hei der UNO

[transcript] Kultur und soziale Praxis 
Maren Rößler

Zwischen Amazonas und East River 
Maren Rößler (Dr. phil.) arbeitet als Vermittlungsberaterin bei Ingeus in Nürnberg. Ihr wissenschaftliches Interesse gilt der Ethnologie Lateinamerikas, der Politikethnologie sowie der indigenen Repräsentation. 
MAREN RÖSSLER

\section{Zwischen Amazonas und East River}

Indigene Bewegungen und ihre Repräsentation

in Peru und bei der UNO

[transcript] 
Gedruckt mit Hilfe der Johanna und Fritz Buch Gedächtnis-Stiftung in Hamburg sowie der Geschwister Boehringer Ingelheim Stiftung für Geisteswissenschaften in Ingelheim am Rhein.

\section{Bibliografische Information der Deutschen Bibliothek}

Die Deutsche Bibliothek verzeichnet diese Publikation in der Deutschen Nationalbibliografie; detaillierte bibliografische Daten sind im Internet über http://dnb.ddb.de abrufbar.

\section{(C) 2008 transcript Verlag, Bielefeld}

\section{(c) $(\mathcal{Q} \Theta \Theta$}

This work is licensed under a Creative Commons

Attribution-NonCommercial-NoDerivatives 3.0 License.

Umschlaggestaltung: Kordula Röckenhaus, Bielefeld

Umschlagabbildung: (C) Dorothy Hodgson, Genf 2004

Lektorat \& Satz: Maren Rößler

Druck: Majuskel Medienproduktion GmbH, Wetzlar

ISBN 978-3-89942-857-5

Gedruckt auf alterungsbeständigem Papier mit chlorfrei gebleichtem Zellstoff.

Besuchen Sie uns im Internet: http://www.transcript-verlag.de

Bitte fordern Sie unser Gesamtverzeichnis und andere Broschüren an unter: info@transcript-verlag.de 


\section{Inhalt}

Prolog: Das große dicke Schwein

TEIL 1: ZWISCHEN ANPASSUNG UND WIDERSTAND:

INEUE، FormEn INDIGENER SELBSTORGanisation

Kapitel I

Schauplätze und zentrale Fragen der Forschung

\section{Kapitel II}

Theoretische Grundlagen und Zielsetzungen einer >Ethnologie indigener Bewegungen

1. Indigene Bewegungen als soziale Bewegungen 31

2. Das >Prinzip Indigenität` als globale Mobilisierungskraft 34

3. Indigene Bewegungen im Lichte bestehender Kategorien der $\begin{array}{ll}\text { Bewegungsforschung } & 37\end{array}$

4. Die `Ethnologie indigener Bewegungen

5. Wille des Akteurs und Zwänge des Systems 46

6. >Kultur $<$ - mehr als nur ein Kampf um handlungsrelevante Ressourcen $\quad 52$

TEIL 2: Die UNO ALS POLITISCher HANDLUNGSRAUm INDIGENER BEWEGUNGEN

\section{Kapitel III}

Die Genese einer transnationalen panindigenen Bewegung 59

1. Indigene im Feld der internationalen Beziehungen

2. Geschichte indigener Bewegungen im Kontext von Völkerbund und Vereinten Nationen

3. Die UNO-Instanzen für indigene Völker 73

4. Definition sindigene Völker : grundlegende Begriffe 78 


\section{Kapitel IV}

Kultur als Politikum $\quad 91$

1. Die ethnologische Debatte um den Begriff >indigene Völkerく 92

2. Kulturalismus und Metakultur 94

\section{Kapitel V}

Das Ständige Forum für indigene Angelegenheiten als

politisches Feld - ein globaler Raum zur Lösung lokaler Probleme?

1. Die Gruppen im Feld

2. Mai 2005: Ein Sitzungstag am Forum 108

3. Die Kräfteverhältnisse am Forum 124

4. Repräsentation, Authentizität und Autorität 131

$\begin{array}{ll}\text { 5. Motivationen zur Teilnahme am Forum } & 140\end{array}$

6. Lokalpolitiker und Repräsentationsfachleute 143

\section{Kapitel VI}

Politische Ermächtigung Marginalisierter oder Marginalisierung des Politischen - indigene Repräsentation im Feld der internationalen Beziehungen

\section{Teil 3: Die Indigene BeWegung im PeRUANischen Amazonasgebiet}

\section{Kapitel VII}

Leitmotive: Politische Integration und kulturelle Abgrenzung

\section{Kapitel VIII}

Ein- und Ausschlussprozesse im kolonialen und nationalen Kontext 175

$\begin{array}{ll}\text { 1. Die Kolonialzeit } & 176\end{array}$

2. Der junge Nationalstaat 177

3. Peru in der ersten Hälfte des 20. Jahrhunderts 179

4. Die Militärregierungen: 1968-1980 182

5. Die Zeit nach $1980 \quad 186$

6. Von der politischen Atomisierung zum panethnischen Zusammenschluss 188

7. Exkurs: peruanischer Indigenismus und Indianismus 190 


\section{Kapitel IX}

Entwicklung der >neuen` indigenen Bewegung im Amazonasgebiet 195

1. Erste Organisationsgründungen 195

2. Entstehung des nationalen Zusammenschlusses AIDESEP 198

3. Zukunftsvisionen von AIDESEP und CONAP: Autonomie versus Integration

4. Die staatliche >Indigenenpolitik am Anfang des 21. Jahrhunderts

5. Die COPPIP: Idee einer nationalen panindigenen Bewegung

6. Schluss: Indigene Akteure auf den >battlefields` um politische Macht, Wissen und Projekte

\section{Kapitel X}

Die indigenen Organisationen im Tiefland als Vermittlungsinstanz: Funktionszuweisungen an die Zusammenschlüsse sowie ihre Vertreter

1. Juli 2005: Besuch in einer comunidad nativa Huitoto

2. Don Sebastiano und die Organisationsgründung

3. Indianische Führungspersönlichkeiten im peruanischen Tiefland:

Statusführer, Despoten, Amtsinhaber

4. Die kategoriale Wahrnehmung der Repräsentanten als Spiegelung sozialer Differenzierungsprozesse

5. Die instabile Vermittlerposition des Repräsentanten:

Ordnungsprinzipien im entwicklungspolitischen Feld

\section{Kapitel XI}

Big Man oder Funktionär - Probleme indigener Selbstorganisation in nationalstaatlichen Zusammenhängen

Schlußbetrachtungen: Politisches Engagement durch wissenschaftliche Objektivierung? Praxisrelevanz einer >Ethnologie indigener Bewegungen

1. Das Problem der Entfremdung: Kongruenz und Inkongruenz zwischen politischem Handeln und politischem Verhalten

2. Praxisbezogene Überlegungen zur Unterstützung der `neuen` indigenen Organisationsprozesse in Peru 
3. Das Ständige Forum für indigene Angelegenheiten eine Empfehlungsfabrik?

4. Ausblick

Epilog: Manuel Ijuma und seine Organisation im Juli 2005 »Ich denke, ich habe meine Pflicht als Präsident getan und Dinge in Bewegung gesetzt $\ll$.

\section{ANHANG}

1. Abkürzungsverzeichnis

2. Glossar spanischer und indigener Begriffe

3. Spanische Originalversionen verwendeter Interviewund Gesprächspassagen

4. Ethnolinguistische Karte des peruanischen Amazonasgebietes

6. Chronologie: Indigene Repräsentation im UN-Kontext

7. Chronologie: Genese nationalstaatlich geprägter Formen indigener Selbstorganisation im peruanischen Tiefland (1959-1987)

8. Abbildungs- und Literaturverzeichnis 


\section{Danksagung}

Diese Studie wurde als Dissertation am 31.08.2006 an der Fakultät für Geschichte, Kunst- und Orientwissenschaften der Universität Leipzig eingereicht, von selbiger angenommen und am 24.01.2007 verteidigt. ${ }^{1}$ Auch wenn ich alleine für den Inhalt des vorliegenden Buches verantwortlich bin, haben viele Personen und Institutionen auf unterschiedliche Art und Weise dazu beigetragen, dass ich das Projekt erfolgreich abschließen konnte. Ihnen gebührt mein herzlichster Dank.

An erster Stelle möchte ich meinen Doktorvater Prof. Dr. Bernhard Streck nennen, dessen Denkanstöße und kritischen Anmerkungen die Studie bereichert haben. Auch die Gespräche mit meinen Gutachtern Prof. Dr. Mark Münzel und Prof. Dr. Michael Riekenberg brachten mich auf wertvolle neue Ideen. Prof. Dr. Clarita Müller-Plantenberg bestärkte mich in der Wahl meines Forschungsthemas und vermittelte mir wichtige Forschungskontakte in Peru. Prof. Dr. Bruno Illius unterstützte mich während der Antragsphase des Vorhabens.

Besonders herzlich danke ich allen Personen in Peru, Ecuador, New York und Genf, die sich zu Interviews und Gesprächen bereit erklärt, mir Literatur und Archivmaterial zur Verfügung gestellt sowie mir Ihre Gastfreundschaft entgegengebracht haben. Insbesondere möchte ich in diesem Zusammenhang folgende Personen nennen: Rosario del Aguila, Lilia Arenas Avila, Ernesto Arirama und seine Frau Rita, Rosa Barbarán, Christiam Beteta, Wildo Cárdenas Rodríguez, Dr. Alberto Chirif, Luzmila Chirisente, Alfonso García und seine Frau Rebeca, Dr. Jürg Gasché, Käthe Meentzen, Adrián Orozco, Luis Pinedo und seine Frau Zarai, Dr. Klaus Rummenhöller, Rainer Schwark, Dr. Richard Chase Smith, Karin Werner.

Für die kritische Lektüre früherer Versionen des Buches oder einzelner Kapitel desselben, die mir viele neue Anregungen brachte, danke ich besonders meinen Eltern Elke und Helmut Rößler, des Weiteren Susanne Günther, Johannes Ries, Eva Spieß und Markus Verne. Beim Layout und bei der Erstellung von Schaubildern und Kartenmaterial standen mir Torsten Hartmann und Carsten Möller tatkräftig zur Seite.

Von folgenden Einrichtungen erhielt ich dankenswerter Weise Unterstützung: vom Institut für Ethnologie der Universität Leipzig, vom DAAD (der meinen ersten Forschungsaufenthalt in Peru finanzierte) und von der FriedrichEbert-Stiftung (die mich im Anschluss an den DAAD bis zum Abschluss der Promotion im In- und Ausland mit einem Promotionsstipendium förderte).

1 Die Dissertation trug den Titel Big Man oder Funtionär. Der Traum vom großen dicken Schwein. Neue indigene Bewegungen und ihre Repräsentanten im lokalen, nationalen und internationalen politischen Feld am Beispiel Peru. 



\section{Prolog: Das große dicke Schwein}

Im Februar 2004 besuchte ich Manuel Ijuma ${ }^{1}$, den Präsidenten einer indigenen Organisation der Cocama-Cocamilla, die im und um den Nationalpark Pacaya Samiria siedeln. Dieses Naturschutzgebiet erstreckt sich über eine Fläche von zwei Millionen Hektar im Nordosten des peruanischen Amazonasgebietes. Bereits in den 1940er Jahren erklärte die peruanische Regierung Teile Pacaya Samirias zur Schutzzone, um den Bestand des Paiche-Fisches künstlich zu vergrößern. In den 1960er Jahren wurde das Gebiet erweitert und verschiedene, vom Aussterben bedrohte Tierarten unter Schutz gestellt. Holzschlag, Fischerei und Jagd zu privaten Zwecken waren von nun an untersagt. Nur staatliche Unternehmen erhielten die Erlaubnis, die Ressourcen des Gebietes - unter anderem Erdöl - abzubauen bzw. zu fördern. Auch gegenwärtig gibt es noch Bohrstationen in Pacaya Samiria, die zwar nicht in Betrieb sind, aber jederzeit genutzt werden könnten. Zudem dringen Holzfäller- und Tierfängerbanden auf Grund mangelhafter Kontrollen von staatlicher Seite nahezu ungehindert in das Gebiet ein.

Im Februar 2004 war Manuel Ijuma seit gut sechs Monaten Präsident der indigenen Organisation. Der Mitte Vierzigjährige lebte zusammen mit seiner Frau, seinen fünf Töchtern und drei Enkelkindern in einem 340-Seelen Dorf, gelegen in unmittelbarer Nähe des Nationalparks. Als Kind hatte er sechs Jahre lang die Schule besucht, später den Militärdienst absolviert und ein Jahr für eine Ölfirma gearbeitet, bevor er versuchte, mit dem erwirtschafteten Geld eine Rinderzucht aufzubauen. Dieser Versuch war gescheitert. Seitdem lebten Manuel Ijuma und seine Familie weitestgehend von der Subsistenzwirtschaft. Bevor Manuel Ijuma Präsident der indigenen Organisation wurde, hatte er in seiner Gemeinde das Amt des Dorfvorstehers inne.

1 Personenname geändert. 
Die Siedlung liegt anderthalb Schiffstagesreisen entfernt von Iquitos, der Hauptstadt der Region Loreto, zu der Pacaya Samiria gehört. Von dort brach ich am 18. Februar 2004 auf. Ich war erst vor kurzem im peruanischen Tiefland angekommen, und dies sollte mein zweiter Besuch einer lokalen Indianerorganisation sein. Leider hatte ich dem Präsidenten der Organisation meinen Besuch nicht ankündigen können, da ich ihn per Funk nicht erreichen konnte. Mitarbeiter einer spanischen Entwicklungsorganisation nahmen mich mit ihrem Schnellboot mit. Sie wollten indianische Gemeinden innerhalb des Naturschutzgebietes besuchen. Während der Fahrt machten sie mich mit den ihrer Meinung nach wichtigen Besonderheiten des Wohnortes von Manuel Ijuma vertraut: Der Ort diene Holzfällerbanden als Ausgangspunkt für Aktivitäten im Naturschutzgebiet. 1998 war es zu einem Zwischenfall in einer Kontrollstation des Nationalparks gekommen: Bewaffnete, illegale Holzfäller hatten die diensthabenden Wächter erschossen. Die Täter wurden in Ijumas Gemeinde gestellt, woher einige unter ihnen angeblich auch stammten. Viele Dorfbewohner hätten Alkoholprobleme und hätten sich in der Vergangenheit als "wenig kooperativ « erwiesen, weshalb sie bei internationalen Entwicklungsprojekten, die in diesem Gebiet in indianischen Gemeinden durchgeführt wurden, meistens nicht berücksichtigt worden seien. Kaum jemand im Dorf würde sich zudem selbst als Cocama-Cocamilla bezeichnen.

Am frühen Nachmittag legten wir am Hafen des Ortes an. Neugierige Blicke begleiteten unsere Ankunft. Gleich neben der Anlegestelle befand sich eine Kneipe, an diese schloss sich eine heruntergekommene Herberge an. An den Tischen, die vor der Kneipe aufgestellt waren, saßen eine Handvoll Menschen, die zu dieser Stunde des Tages nicht mehr alle ganz nüchtern schienen. Ein älterer Mann stand jedoch gleich bereitwillig auf, um mich zum Haus von Manuel Ijuma zu begleiten. Dieses lag am anderen Ende des Dorfes am Fußballplatz, nur fünf Minuten Gehzeit vom Hafen entfernt. Auf dem Weg zählte ich zwei weitere Kneipen. Als wir an dem halb offenen, auf Stelzen gebauten Holzhaus mit Palmdach ankamen, begrüßte uns ein etwa 16-jähriges Mädchen, das mit einem Baby im Arm in einer Hängematte lag. Neben ihr saß ein etwa 14-jähriges Mädchen auf einem Stuhl. Auf Geheiß meines Begleiters erhob sich das auf dem Stuhl sitzende Mädchen und machte sich auf die Suche nach ihrer Mutter, die, wie sie sagte, auf dem Feld sei, um Maniok zu ernten. Der Vater repariere sein Boot und käme erst abends zurück ins Dorf.

Kurze Zeit später erschien Soledad ${ }^{2}$, die Frau des Präsidenten der Organisation der Cocama-Cocamilla. Sie stellte ihren prall mit Maniokwurzeln gefüllten Korb in der Küche ab und begrüßte mich freundlich. Noch bevor ich meine Entschuldigung für diesen unangekündigten Besuch zu Ende vorbringen konnte, unterbrach Soledad mich mit einer schnellen Handbewegung:

2 Personenname geändert. 
Strahlend erzählte sie mir, dass sie von meinem Kommen geträumt hätte. Erst gestern sei ihr im Schlaf ein großes dickes Schwein erschienen. Dieser Traum bedeute, dass man Besuch bekäme. Das habe ihr Vater ihr erzählt.

Soledads Mann Manuel kam am frühen Abend nach Hause. Er schien weniger euphorisch als seine Frau ob meiner Ankunft. Ich verwies auf den Traum seiner Frau, hielt ihm aber gleichzeitig ein Empfehlungsschreiben des Präsidenten eines regionalen indianischen Dachverbandes hin, dem Manuels Organisation angehörte. Nach einem kurzen Blick auf das Papier lud Manuel mich ein, in seinem Haus zu übernachten. Ich erzählte ihm, dass ich mehr über die Arbeit des Zusammenschlusses der Cocama-Cocamilla erfahren und zu diesem Zweck gerne mit ihm auch einige der Mitgliedsgemeinden bereisen würde. Er schien wenig begeistert von dieser Idee.

Am nächsten Morgen erhielt ich eine Ahnung, warum ihn mein Plan vielleicht mit gemischten Gefühlen erfüllte: Manuel führte mich in eine halb zerfallene Hütte, die neben seinem Haus stand. Ein Regal und ein Tisch schmückten als einzige Möbelstücke den tristen Raum, dessen zementierter Boden mit kleinen Pfützen bedeckt war. »Die ehemalige Grundschule des Ortes«, erklärte Manuel und wies dann mit dem Finger auf ein Zementhaus mit Wellblechdach und winzigen Fenstern auf der anderen Seite des Fußballfeldes: "Dort steht die neue Schule, aber momentan haben wir mal wieder Probleme mit dem Lehrer. Der erscheint nur selten zum Unterricht. "Dann zeigte Manuel auf eine Reihe von Aktenordnern, die ihm sein Amtsvorgänger nach der Wahl zum Präsidenten ausgehändigt hatte. Es waren dreizehn an der Zahl - fast alle leer. Manuel erläuterte dazu: »Vor mir kamen alle Präsidenten der Organisation und die meisten der zehn Ressortchefs aus zwei aneinandergrenzenden Gemeinden innerhalb des Naturschutzgebietes. In einer von beiden hatte die Organisation bis zu meiner Wahl ihren Sitz." 1992 wurde der Zusammenschluss gegründet. Die Organisationsziele umfassten: Besitztitel für das Land der zusammengeschlossenen Gemeinden vom Staat erwirken, sich für Schutz und nachhaltigen Umgang mit den natürlichen Ressourcen einsetzen und den Bewohnern der Mitgliedsgemeinden Zugang zu Fortbildungsmaßnahmen in verschiedenen Bereichen ermöglichen. Allerdings konnten die meisten Dörfer ihr Land bisher nicht titulieren lassen, da sie innerhalb oder am Rand der Naturschutzzone liegen. Auch wenn eine nationale Gesetzgebung die Titulierung kommunalen Landes für Indigene ermöglichte, berief sich die peruanische Regierung in diesem Fall darauf, dass Schutzgebiete öffentliche und damit staatliche Zonen seien, in denen keine privaten Titel zugeteilt werden könnten.

Finanziell unterstützt wurde der Zusammenschluss bei seinen Aktivitäten bis 2003 von ausländischen Geldgebern, die ein Umweltschutzprojekt in Pacaya Samiria durchführten. Dieses zielte auf die Einbindung lokaler, indigener Akteure in Pflege und Schutz des Nationalparks ab. Allen bisherigen Prä- 
sidenten, so erläuterte mir Manuel, seien die Besuche der Mitgliedsgemeinden und Reisen nach Iquitos immer von Seiten der Entwicklungsorganisation bezahlt worden. Überhaupt sei das meiste Geld in die beiden Dörfer investiert worden, aus denen der Vorstand kam. Das habe bei der letzten Wahl im Herbst 2003 dazu geführt, dass die anderen Mitgliedsgemeinden einen Wechsel des Sitzes der Direktive und dessen Dezentralisierung einforderten: Nun kämen die zehn Ressortchefs, der Vizepräsident und er selbst alle aus unterschiedlichen Gemeinden. Er habe nie im Sinn gehabt, Präsident der Organisation zu werden. An der letzten Versammlung, sechs Monate vor meiner Ankunft, nahm Manuel in seiner Funktion als Dorfvorsteher seiner Gemeinde teil. Ganz überraschend hätten ihn einige der Anwesenden jedoch als dritten Kandidaten bei der Wahl aufgestellt. Manuel gewann. Einer der Gründe für seinen Erfolg sei gewesen, dass er noch ein paar Worte Cocama spreche. Nun gäbe es aber keine Gelder aus dem Entwicklungsprojekt mehr, und er wisse nicht, wie er die Mitgliedsgemeinden besuchen solle. Auch ein Treffen der Direktive sei noch nicht zustande gekommen, denn die Ressortchefs würden sich nur aus ihren Dörfern wegbewegen, wenn er ihre Reisekosten abdecken könne. Doch seine diesbezüglich beim Bürgermeister des Distrikts eingereichten Gesuche wären bisher erfolglos gewesen, er werde immer mit leeren Versprechungen abgefertigt. Deshalb habe er jetzt angefangen, den Bürgermeister zu imitieren und die Gemeinden auf die gleiche Art zu vertrösten. Wie solle er aber auch selbst die Reisen finanzieren? Er sei froh, seine Familie ernähren zu können. Wenn er für die Organisation tätig würde, läge derweil seine Arbeit brach und keiner aus den Mitgliedsgemeinden käme für eine Entlohnung seiner Tätigkeit auf. Im Gegenteil: Alle würden glauben, er bekäme Gelder von den Entwicklungsorganisationen und würde diese in die eigene Tasche stecken. Sie forderten von ihm, dass er Projekte besorge, schloss Manuel seinen Bericht $a b$.

Bereits am selben Nachmittag machten wir uns zu einem Besuch der Nachbargemeinde auf, die eine halbe Stunde Fußmarsch von Manuels Siedlung entfernt liegt. Aus der Gemeinde stammte der aktuelle Vize-Präsident des regionalen indigenen Dachverbandes sowie eine consejera regional ${ }^{3}$. Beide lebten inzwischen in Iquitos. Die consejera arbeitete innerhalb der Verwaltungsstrukturen der regionalen Regierung, der Vize-Präsident des regionalen Dachverbandes im Büro der Organisation. Die Dorfbewohner schienen jedoch von beiden Personen gleichermaßen enttäuscht - sie hatten sich von ihnen Unterstützung für ihre Gemeinde versprochen. Zum Beispiel warteten sie schon seit Monaten vergeblich auf den Bau einer neuen Grundschule, die ihnen von der Regionalregierung zugesichert worden war. Am Tag unseres Be-

3 Dt. >Mitglied des Regionalrats ‘; politisches Amt innerhalb der staatlichen Strukturen auf regionaler Ebene. 
suches kam die consejera zufällig für einen Wochenendbesuch nach Hause. Einige Tage zuvor hatte ich sie bereits in Iquitos in ihrem Büro besucht: "Von den Dorfbewohnern werde ich vor allem nach Projekten und nach persönlichen Darlehen gefragt. Man sagt mir immer: Wir haben deine Kandidatur unterstützt, damit du dich für uns in Iquitos einsetzt«, erzählte sie mir. »Aber ich kann nicht direkt über Gelder verfügen. Das verstehen die Dorfbewohner nicht.« Als sie in ihrer Heimatgemeinde eintraf, rief sie Manuel zu sich heran: »Komm in mein Büro nach Iquitos und ich unterstütze dich. Allerdings nicht mit Geld." Auch Manuel musste sich in der von ihm und vom Dorfvorsteher einberufenen Versammlung gegen die verbalen Angriffe der Einwohner des Ortes verteidigen. Sie kritisierten ihn, weil er in seiner bisherigen Amtszeit noch keinerlei Aktivitäten in die Wege geleitet hätte. Auch beschwerte man sich über die regionalen und nationalen Vertreter: "Wir wissen nicht, wer uns gerade auf nationaler Ebene vertritt. In der regionalen Organisation kennen wir den Vize-Präsidenten, aber auch nur, weil er aus unserem Dorf stammt.« Am Anfang habe man geglaubt, so erläuterte mir ein Teilnehmer nach der Versammlung, dass man durch die Organisation viele Vergünstigungen erhalte und ein besseres Leben führen könne. Aber diese Hoffnung würde sich wohl nur erfüllen, wenn sich ein Präsident finden ließe, der es schaffe, an alle zu denken und den Egoismus zu überwinden: „Ein guter Führer ist einer, der sich für seine Leute einsetzt und weiß, wie man Dinge organisiert."

Immer wieder rechtfertigte sich Manuel: Er erläuterte, wie er sich bisher vergeblich um finanzielle Unterstützung für eine Versammlung mit seinen Ressortchefs bemüht habe, wie er dabei von den entsprechenden Regierungsstellen hingehalten oder zurückgewiesen wurde. Er verwies auf die in seinen Augen miserable Lage des regionalen Dachverbandes, von dem auch keine Unterstützung zu erwarten sei: "Besucht das Büro in Iquitos und ihr werdet sehen, wie es dort aussieht. Es ist alles total verlassen! « Mir erzählte Manuel von seiner Teilnahme an einem Arbeitstreffen der regionalen Organisation, das im Januar stattgefunden hatte. Zusammen mit acht weiteren Präsidenten verschiedener Föderationen hätten sie im Büro des Dachverbandes gesessen und auf den Vorstand gewartet. Der Vize-Präsident sei erst am späten Nachmittag erschienen, der Präsident überhaupt nicht. Wofür habe man sie dann nach Iquitos gerufen? Jetzt habe man sich auf ein Treffen im Mai geeinigt, um Neuwahlen abzuhalten. Dann erläuterte mir Manuel seine eigenen Arbeitspläne: Er wollte am Hafen seiner Gemeinde ein neues Büro für die Organisation bauen. Außerdem wollte er Fortbildungsmaßnahmen für Jugendliche erwirken. Sie sollten darin ausgebildet werden, wie man eine Organisation leitet.

Nach dem Abendessen ging Manuel ins Dorf, während ich mit seiner Frau Soledad in der Küche zusammensaß. Sie erzählte mir, dass ihr Mann auch bereit gewesen wäre, in das Dorf zu ziehen, in dem bisher das Büro ihres Zu- 
sammenschlusses war. Natürlich wären sie und die Kinder mitgegangen. Der Ort gefalle ihr sehr gut und außerdem unterstütze sie die Aktivitäten ihres Mannes. Das sei allerdings nicht selbstverständlich, viele Frauen hätten etwas dagegen, dass ihre Männer für die Organisationen arbeiteten. Sie wollten nicht, dass diese ständig unterwegs waren und weder auf dem Feld mithalfen, noch zur Jagd oder zum Fischfang gingen. Solange die Männer wenigstens Geld mit nach Hause brächten, wäre der Ausfall der Arbeitskraft noch zu verschmerzen. Aber diesbezüglich habe Manuel bisher kein Glück bei seiner Organisation gehabt. Dennoch würde sie ihren Mann immer ermutigen, sich einzusetzen: "Du wirst schon noch deine Chance bekommen, sage ich ihm, wenn er mutlos ist. Und habe ich nicht von deiner Ankunft geträumt? «fügte sie schmunzelnd hinzu.

Die Besuche in den anderen Mitgliedsgemeinden des Zusammenschlusses, die Manuel und ich in den nächsten Tagen unternahmen, liefen nach ähnlichem Muster ab wie das Treffen im Nachbardorf. Inzwischen hatten wir uns jedoch geeinigt, dass ich Manuel die Schifffahrt nach Iquitos bezahle, damit er dort bei Behörden und Organisationen vorstellig werden konnte. Dies benutzte er in den jeweils einberufenen Dorfversammlungen: Er nannte den genauen Betrag, den ich ihm zahlen würde und betonte, mit dieser Unterstützung könne er nun endlich die anstehenden Aufgaben erledigen. Die misstrauischen Fragen an Manuel rissen dennoch kaum ab: "Die Organisation besitzt doch Geld, was ist damit passiert? « schlug es ihm allerorts entgegen. Nur in den Mitgliedsgemeinden, aus denen die ehemaligen Repräsentanten der Organisation kamen, blieben ihm diese Fragen erspart. Dort präsentierte man mir stattdessen den öffentlichen Fernsehraum, die Herberge und das Modellschulungszentrum für zweisprachige Lehrer - Projekte, die von ausländischen Geldgebern finanziert worden waren. Manuel wurde ermahnt: »Komm uns öfter besuchen und berate dich mit uns. Wir haben Erfahrung in der Organisation«. Er konterte: „Gerne würde ich von euch lernen. Aber was ist zum Beispiel mit den Aktenordnern, die ihr mir gegeben habt? Die waren leer. Was ist mit dem Motorboot, das der Organisation gehört? Das war kaputt, als ihr es mir gegeben habt."

Auf den langen Bootsfahrten zu den einzelnen Mitgliedsgemeinden des Zusammenschlusses erläuterte mir Manuel ausführlich die Herausforderungen, denen die indigenen Organisationen und er als Präsident eines solchen Verbandes seiner Meinung nach gegenüberstanden: "Den meisten von uns fehlt das Bewusstsein für den Wert unserer Kultur. In meinem Dorf zum Beispiel wollen viele wie die Mestizen sein. In anderen Dörfern, die innerhalb des Naturschutzgebietes liegen, gibt es mehr Bewusstsein. Deshalb läuft dort vieles besser: Eines der Dörfer wurde zum Beispiel vom Projekt begünstigt und außerdem gibt es Einnahmemöglichkeiten durch den Tourismus. Wir müssen uns wieder mehr auf unsere Geschichte, also die der Cocama-Coca- 
milla, besinnen. Die Welt schaut auf die indigenen Völker und bewundert sie für ihre Jahrtausende alten Kulturen, für ihre enge Verbindung mit der Natur. Es gibt Gesetze für die Rechte indigener Völker, die müssen wir studieren. Wir müssen uns gegen den Staat wehren, gegen diejenigen, die unsere Kultur missachten. Du hast mir von einem indigenen Forum an der UNO erzählt, da müssen wir unsere Probleme darstellen und Hilfe erbitten. Als Präsident einer Organisation muss man über diese Dinge Bescheid wissen und seine Leute informieren, sich für sie einsetzen. Für mich ist es schwierig, ich muss erst noch die richtigen Personen kennen lernen.« 



\section{Teil 1: \\ Zwischen Anpassung und \\ Widerstand: >Neuer Formen indigener Selbstorganisation}

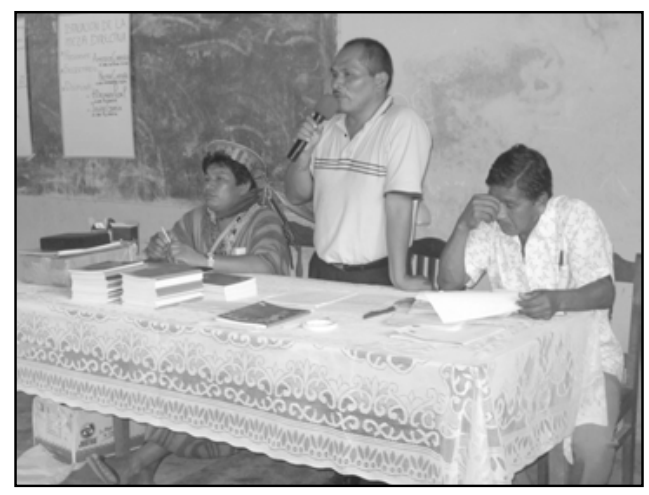

Abbildung 1: Kongress einer indianischen Organisation im peruanischen Tiefland (Foto: Maren Rößler 2005).

Abbildung 2: Indianische Repräsentanten aus dem peruanischen Tiefland bei der UNO in Genf (Foto: Dorothy Hodgson 2004).

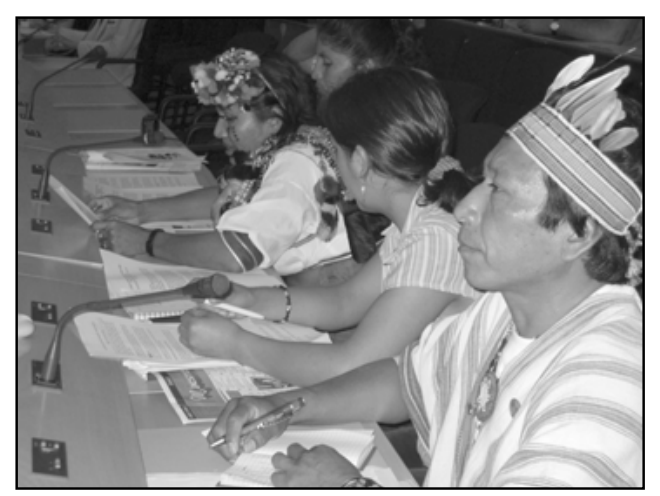





\section{Kapitel I \\ Schauplätze und zentrale Fragen der Forschung}

Wie ich im Verlauf meiner Forschung feststellen konnte, sind Manuel Ijumas Ansichten und Probleme als Präsident einer lokalen indigenen Organisation alles andere als außergewöhnlich. Sie prägen den Alltag und die Selbstdefinition vieler Repräsentanten indigener politischer Zusammenschlüsse, die ich sowohl während meiner Zeit in Peru als auch bei der UNO kennen lernte. Manuels Ausführungen zur Organisationsarbeit, die ich an das Ende des Prologs gestellt habe, verdeutlichen die komplexe Geschichte indigener Bewegungen. In dieser spiegeln sich die engen Verflechtungen zwischen lokalen und globalen Prozessen wider: »Die Welt schaut auf die indigenen Völker und bewundert sie für ihre Jahrtausende alten Kulturen.« Dieses Wissen um die Macht von Symbolen steht bei Manuel der ernüchternden Erkenntnis gegenüber, dass das internationale Interesse sich dennoch auf lokaler Ebene nicht so einfach in politisches Kapital verwandeln lässt. Verfügt er über die notwendigen Handlungsressourcen, um sich gegenüber der fordernden und kritikfreudigen Haltung seiner politischen Gemeinschaft durchzusetzen; um mächtige und finanzkräftige externe Unterstützer, möglichst aus dem Ausland, für sich zu gewinnen; um sich gegenüber den Funktionären des Staates und anderen Akteuren, die »die Kultur der Cocama-Cocamilla missachten«, zu behaupten? Welche Erklärungen lassen sich sowohl für sein Verhalten als auch für das seiner politischen Gemeinschaft finden?

Die Beschreibung meines Aufenthaltes in Manuels Dorf setzt den Rahmen dieser Studie, die ich als eine Ethnografie ıneuer Formen indigener Selbstorganisation definieren möchte. Diese werden in der Literatur unter dem Thema >indigene Bewegungen< behandelt. Das Beiwort >neu< erlangt deshalb zentrale Bedeutung, weil meine Analysen sich auf die Ausdrucksformen konzentrieren, die nach dem zweiten Weltkrieg im Kontext globaler politischer Entwicklungen - u. a. dem Entkolonisierungsprozess, der Etablierung interna- 
tionaler Institutionen wie der UNO oder der Formierung von Befreiungs- und Bürgerrechtsbewegungen - an Bedeutung gewannen und sich in der Gründung von sogenannten indigenen Organisationen offenbaren. Diese Entwicklungen unterscheiden sich in Lateinamerika von früheren Manifestationen ১indianischen Widerstands`, da die neuen Zusammenschlüsse die bestehenden nationalstaatlichen Ordnungssysteme meist nicht radikal ablehnen und gewaltvoll bekämpfen, sondern innerhalb der Logik derselben agieren. Sie fordern nicht die Loslösung ihrer politischen Gemeinschaften aus bestehenden Nationen, sondern deren Neudefinition als multikulturelle Staatsgebilde. Die vorliegende Studie setzt sich mit den systematischen Bedingungen auseinander, unter denen die Akteure indigener Verbände versuchen, Anhänger zu mobilisieren, an politische Macht zu gelangen und ihre spezifischen Ziele umzusetzen. Sie beschäftigt sich mit einer zentralen Dimension von Politik dem Aspekt der Repräsentation: Wer vertritt wen, und wie wird diese Frage innerhalb und außerhalb der Organisationen diskutiert? Dabei rücken die historischen Grundlagen und gegenwärtigen Erscheinungsformen indigener Bewegungen an zwei sehr unterschiedlichen Schauplätzen ins Zentrum der Betrachtungen: bei der UNO in New York und im peruanischen Amazonasgebiet. Die Studie will einen Beitrag zum Verständnis der komplexen und spannungsreichen Beziehungen und Dynamiken leisten, welche die politischen Felder prägen, in denen >Indigenität als Handlungsressource im nationalstaatlichen Kontext und darüber hinaus an Bedeutung gewinnt.

\section{Forschungsschauplätze und -fragen}

Die Wahl der beiden Forschungsräume ist in diesem Zusammenhang alles andere als zufällig. Im UN-Hauptgebäude in New York tagt seit 2002 einmal im Jahr zwei Wochen lang das Ständige Forum für indigene Angelegenheiten ${ }^{1}$. Das Forum gehört zum Wirtschafts- und Sozialrat (ECOSOC) der Vereinten Nationen. Viele Aktivisten bezeichnen es als Meilenstein in der Geschichte indigener Bewegungen, da dem Forum neben acht von Regierungen benannten Experten auch acht sogenannte >unabhängige indigene Experten ‘ angehören, die direkt von indigenen Organisationen nominiert werden. Dieser Umstand verkörpert für viele Aktivisten deshalb einen großen politischen Erfolg, weil sie zum ersten Mal ihre eigenen Interessenvertreter auf internationaler Ebene nominieren können. Sie erhoffen sich dadurch in Zukunft mehr Mitspracherecht bei der Ausarbeitung von Entwicklungsprogrammen und politischen Richtlinien der UNO in Bezug auf >indigene Belange «. Zudem sind die Sitzungen des Forums auch für Repräsentanten kleiner, lokaler Organisatio-

1 Im Folgenden steht die Kurzbezeichnung >Forum` für das Ständige Forum für indigene Angelegenheiten. 
nen zugänglich. Die jährlichen Treffen bilden somit auch für eine ethnografische Forschung den globalen Kristallisationspunkt indigener Bewegungen, an dem die politische Mobilisierungskraft, die wichtigsten Themen und Konflikte sowie die Bandbreite der involvierten Akteure in verdichteter Form zugänglich werden.

Im peruanischen Amazonasgebiet leben rund 300.000 Indianer, die sich jeweils einer von 65 ethno-linguistischen Gruppen zuordnen lassen. Selbst in ihrer Gesamtheit stellen sie im nationalen Kontext eine kleine Minderheit unter den über 26 Millionen Einwohnern Perus dar. Die indianische Bevölkerung des peruanischen Tieflands blieb für die nationale Öffentlichkeit bis in die zweite Hälfte des 20. Jahrhunderts hinein politisch weitestgehend unsichtbar. Inzwischen gehört sie mehrheitlich dauerhaften supralokalen Verbänden an, welche vor allem ab Ende der 1960er Jahre gegründet wurden. Diese Zusammenschlüsse sind auf Leitungsebene nach dem Vorbild von swestlichen Parteien und Gewerkschaften strukturiert, verfolgen aber ein anderes Mitgliedschaftsprinzip: Den indigenen Organisationen im peruanischen Tiefland treten nicht Individuen, sondern Dorfgemeinschaften bei. Diese Kollektivierungsform erinnert an ethnische und panethnische Föderationen, die den indianischen Tieflandbewohnern in der Vergangenheit zur Umsetzung spezifischer Ziele, wie zum Beispiel der Kriegsführung gegen andere Gruppen oder dem Widerstand gegen Fremdherrschaft, dienten. Aber im Gegensatz zu jenen meist kurzen, von Freiwilligkeit und Auflösbarkeit bestimmten Zusammenschlüssen, durchliefen die neuen indigenen Organisationen in den letzten dreißig Jahren Institutionalisierungsprozesse. Sie etablierten sich als dauerhafte politische Repräsentationsinstanzen und bildeten hierarchische Strukturen aus.

Die Repräsentanten der Verbände vertreten, ihrem Selbstverständnis nach, die politischen Interessen der indigenen Völker des Tieflands gegenüber dem peruanischen Staat, transnationalen Unternehmen sowie nationalen und internationalen Entwicklungsorganisationen. Dabei verfügen sie als Vertreter von Minderheiten innerhalb des Staatsgefüges nur über geringe Machtressourcen. Ihre Verbände haben vor dem peruanischen Gesetz den Status von NichtRegierungsorganisationen (NGOs), das heißt, sie sind institutionell nicht innerhalb der staatlichen Regierungsstrukturen, sondern im sogenannten $>$ Dritten Sektor< (vgl. Jelin 1998) verankert. Die Selbstdefinition als >indigene Völker bietet den indianischen Interessengruppen jedoch seit Mitte der 1980er Jahre eine politisch wirksame Methode, ihre Präsenz zu vergrößern und zu stärken - sowohl auf nationaler als auch auf internationaler Ebene.

Als offizielle Selbstbezeichnung indigener Zusammenschlüsse erscheint der Begriff erstmalig 1975 mit der Gründung einer internationalen Organisation, dem World Council of Indigenous Peoples. Indigena ist ein lateinisches Wort, mit dem im römischen Reich die `Eingeborenen` eines Ortes von den 
advenae, den `Zugewanderten<, unterschieden wurden (vgl. Siebert 1997b: 78). Heute wird der Begriff vielfältiger verwendet, denn auch in Asien oder Afrika gibt es zum Beispiel zahlreiche Gruppen, die unter dem Banner der >Indigenität` von ihren jeweiligen Regierungen Land- und Selbstbestimmungsrechte fordern. Im Gegensatz zur Situation in ehemaligen Siedlerkolonien - den Ländern Nord- und Südamerikas, Australien oder Neuseeland scheint es in jenen Weltregionen jedoch wenig sinnvoll, zwischen >Eingeborenen $<$ und Zugewanderten $<$ zu unterscheiden.

Das Wort >Völker` wirft derweil die Frage nach dem politischen Status der so bezeichneten Gemeinschaften innerhalb der jeweiligen Nationalstaaten auf. $\mathrm{Zu}$ den wichtigsten Forderungen indigener Organisationen gehört die Anerkennung der von ihnen vertretenen politischen Einheiten als selbstständige Völkerrechtssubjekte. Während dieser Status im klassischen Völkerrecht nur souveränen Staaten zugestanden wird, weitete man den Begriff im 20. Jahrhundert auch auf $\gg$ Menschenverbände mit eigener rechtlicher Ordnung der inneren Verhältnisse, vor allem in Gestalt von Staaten, Staatsteilen und staatsähnlichen Organisationen< aus (Dreher 1995: 13). >Indigene Völkerく sind somit aus Sicht ihrer Repräsentanten imagined communities (Anderson 1983) ohne eigenen Staat. >Indigene Organisationen lassen sich, in ihrer überwiegenden Mehrheit, als parapolitische Zusammenschlüsse innerhalb der bestehenden Nationalstaaten definieren.

In den politischen Auseinandersetzungen auf nationaler und internationaler Ebene hat die Klassifikation als indigenes Volk aber auch deshalb eine zentrale Bedeutung, weil sie für einen moralischen Gegenentwurf zur >westlichen Z Zivilisation steht: Die dialogische Einbindung Indigener in ihre natürliche Umwelt - Pflanzen, Menschen, Tiere - wird dem >nicht-indigenen< Bestreben nach Unterwerfung derselben gegenübergestellt. Dieser Entwurf besitzt große Symbolkraft und bildet - zusammen mit der Eigendefinition als Volk - das grundlegende politische Kapital der Bewegungen. In der wissenschaftlichen Auseinandersetzung mit dem Phänomen sindigene Bewegungen< findet derweil die Frage, welche Beziehung zwischen den politischen Klassifikationen und dem realen >Wir-Gefühl der darunter subsumierten Menschen besteht, selten Beachtung.

Im Rahmen dieser Studie und ausgehend von den gerade erfolgten Definitionen und Überlegungen stellen sich mir bei der Beschäftigung mit den neuen Formen indigener Selbstorganisation und den zentralen Akteuren dieser Prozesse deshalb mehrere, miteinander zusammenhängende, grundlegende Fragen. Bei diesen geht es zum einen um die Wahrnehmung der Organisationen und ihrer Repräsentanten von Seiten der Repräsentierten, also zum Beispiel darum, welche Gemeinsamkeiten der Bewohner eines AsháninkaDorfes im peruanischen Tiefland zwischen sich und seinem nationalen Vertreter oder einem indigenen Experten am Ständigen Forum für indigene Ange- 
legenheiten sieht. Wie definiert er die Aufgaben seiner politischen Vertreter? In diesem Zusammenhang gilt es gleichfalls kritisch zu beleuchten, ob die Durchführung demokratischer Wahlen den Anspruch der Repräsentanten rechtfertigen kann, >Volksvertreter $\mathrm{zu}$ sein und als solche von Regierungen und Unterstützerseite behandelt zu werden. Gelten die panethnischen Zusammenschlüsse in den Augen von Dorfbewohnern tatsächlich als legitime, >staatsähnliche< Repräsentationsinstanzen?

Zum anderen dürfen bei der Beschäftigung mit diesen zentralen Fragen der Legitimierung von Repräsentationsansprüchen aber auch die systematischen Bedingungen nicht aus dem Blickfeld geraten, welche die politischen Handlungsmöglichkeiten indigener Repräsentanten prägen und begrenzen. So bemerkt zum Beispiel Volkmar Blum: »Eine indianische Organisation, die keine Basis vorweisen kann und ihren Anspruch nicht durch Wahlen legitimieren kann, wird heute nur noch von einigen NGOs unterstützt, kaum mehr aber von Regierungen und internationalen Organisationen« (Blum 2001: 173f.). Die Einbindung indigener Akteure in nationale und internationale politische Zusammenhänge ist ein wichtiger Aspekt bei der Beschäftigung mit indigenen Bewegungen. Wie diese Studie zeigen wird, werden die Repräsentanten dadurch mit teilweise sehr widersprüchlichen Forderungen bei ihrer Tätigkeit konfrontiert. Inwiefern können sie diesen von verschiedenen Seiten und mit unterschiedlichen Schwerpunktsetzungen gestellten Forderungen gerecht werden? Welche Schwierigkeiten ergeben sich für indigene Vertreter aus ihrer Position als Vermittler zwischen ungleichen sozialen Formationen?

\section{Forschungs- und Analysemethoden}

Die meiner Studie zugrunde liegenden Forschungen führten mich zwischen 2003 und 2005 an verschiedene Orte in Nord- und Südamerika sowie Europa: 2003 übernahm ich für vier Monate die Interimsleitung eines Entwicklungsprojekts einer deutschen NGO in den Nebelwäldern Ecuadors. Auch wenn sich dieses nicht an die $>$ Zielgruppe Indigene r richtete, erhielt ich wichtige Einblicke in den Kontext der Entwicklungszusammenarbeit, der auch die Ausrichtung indigener Organisationen in Peru nachhaltig prägt. Zudem führte ich während meines Aufenthaltes Interviews mit dem damaligen Koordinator des transnationalen Zusammenschlusses indigener Verbände des Amazonasgebietes, $\mathrm{COICA}^{2}$, sowie mit Repräsentanten der nationalen Indianerorganisation Ecuadors, CONAIE ${ }^{3}$. Des Weiteren konnte ich an einer internationalen Konferenz von Regierungsvertretern, Managern von Ölfirmen und indigenen

2 Coordinadora de Organizaciones Indígenas de la Cuenca Amazónica; dt. >Koordinationsstelle indigener Organisationen des Amazonasbeckens`.

3 Confederación de Nacionalidades Indigenas del Ecuador; dt. >Konföderation indigener Nationalitäten Ecuadors`. 
Repräsentanten teilnehmen. 2004 und 2005 reiste ich für insgesamt sechs Monate in verschiedene Regionen Perus. Ich sprach mit Repräsentanten nationaler indianischer Verbände, mit Angestellten von Regierungsinstitutionen, Vertretern von UN-Organisationen und NGOs in Lima, Satipo und Iquitos. Außerdem besuchte ich für jeweils ein bis zwei Wochen indianische Dörfer im peruanischen Tiefland, die lokalen Föderationen der Asháninka, Huitoto, Bora, Yagua und Cocama-Cocamilla angehören. In manche Gemeinden kam ich nur einmal, in andere kehrte ich öfter zurück. Zwischen 2003 und 2005 nahm ich zudem dreimal über die volle Länge an den zweiwöchigen Sitzungen des Ständigen Forums für indigene Angelegenheiten in New York teil, 2004 am einwöchigen Treffen der Arbeitsgruppe indigene Völker in Genf.

Das Primärmaterial für meine Analysen besteht einerseits aus auf Tonträgern aufgezeichneten Experteninterviews mit vorbereiteten Leitfäden, die ich mit Mitgliedern des Forums, Vertretern von UN-Organisationen in Lima sowie internationalen Repräsentanten indigener Organisationen in New York, Genf und Quito führte. Im nationalen und lokalen Kontext in Peru zeichnete ich andererseits eine Reihe narrativer Interviews mit nationalen und lokalen indigenen Repräsentanten, nicht-indigenen Unterstützern sowie Dorfbewohnern auf. Das dieser Studie zugrunde liegende Datenmaterial besteht ferner aus Gedächtnisprotokollen, die nach zahlreichen informellen und semi-formellen Gesprächen entstanden. Auch verwende ich meine in Forschungstagebüchern aufgezeichneten Beobachtungen, die allgemeiner Natur sind und Anekdoten sowie persönliche Eindrücke enthalten. In privaten Archiven von nicht-indigenen Unterstützern der indigenen Verbände konnte ich zudem Einblick in öffentlich kaum bzw. schwer zugängliche historische Dokumente wie persönliche Korrespondenzen, vergriffene Zeitschriften, Fotos, Projekt- und Redeentwürfe bekommen, die mir halfen, die Entwicklung der indigenen Bewegung des peruanischen Tieflands nachzuvollziehen.

Die Auswertung der Interviews und Gespräche erfolgte in mehreren aufeinanderfolgenden Schritten. Nach der Transkription und Sichtung des aufgezeichneten Materials sowie der Gedächtnisprotokolle aus den informellen und semi-formellen Gesprächen kategorisierte ich meine Gesprächspartner wie folgt: Dorfbewohner, lokale, regionale, nationale und internationale Repräsentanten bildeten jeweils eigene Gruppen, die in ihrer Gesamtheit jedoch derjenigen der >Nicht-Indigenen` gegenüberstanden. Letztere differenzierte ich wiederum intern aus in: Wissenschaftler, Mitarbeiter von UN-Organisationen, internationalen und nationalen NGOs sowie anderen unabhängigen Unterstützern indigener Bewegungen. Manche Personen der Gruppe >Nicht-Indigene` gehörten zugleich mehreren Untergruppen an. Damit folgte ich der Kategorisierung der Akteure selbst, welche in unseren Gesprächen zumindest immer zwischen >Indigenen $<$ und >Nicht-Indigenen` unterschieden, aber auch inner- 
halb dieser groben, dichotomisierenden Einteilung meist ähnliche Ausdifferenzierungen vornahmen.

Nach dieser ersten Kategorisierung filterte ich grundlegende Themen in den einzelnen Gruppen heraus. Dabei unterschied ich nach Interviewformen: Auf der einen Seite standen die Antworten zu den von mir in den Experteninterviews vorgegebenen Gesprächsinhalten, auf der anderen Seite die stärker von den Interessen meiner Informanten geleiteten Themen der narrativen Interviews sowie der semi-formellen und informellen Gespräche. Schnittmengen ergaben sich in den thematischen Schwerpunktsetzungen aller Gruppen vor allem in der Bewertung der internen und externen Probleme und Herausforderungen, denen die indigenen Organisationen gegenüberstehen. Hierbei waren immer die Aufgabenbestimmung der Verbände und ihrer Repräsentanten sowie die Definition sindigener Gemeinschaft $\prec$ zentrale Themen. Dieses Ergebnis beeinflusste entscheidend den weiteren Verlauf meines Auswertungsprozesses, in dem ich mich auf die Wahrnehmung der Zusammenschlüsse und vor allem ihrer zentralen Akteure von verschiedenen Seiten konzentrierte. Zusammen mit der Analyse des geschichtlichen Entstehungskontexts indigener Bewegungen auf globaler und lokaler Ebene ergab sich bald ein komplexes Bild systematischer Bedingungen, welche die politischen Felder, in denen sich die indigenen Akteure bewegen, prägen. Die Darstellung dieser Zusammenhänge erscheint mir deshalb von grundlegender wissenschaftlicher Bedeutung bei der Auseinandersetzung mit dem Phänomen indigene Bewegungen. Ich folge dabei vor allem den Diskurslinien verschiedener Akteure, betrachte diese aber auch im Zusammenspiel mit ihrer Praxis.

Die auf Tonträgern aufgezeichneten Interviews entstanden mit der expliziten Genehmigung der Interviewten. Sie verzichteten ferner auf eine Anonymisierung ihrer Daten. Im Text habe ich diese Passagen als Interviews kenntlich gemacht. An anderen Stellen werden Zitate als Ausschnitte aus Gesprächen gekennzeichnet. Dies bedeutet, dass die Aufzeichnung während oder nach den Gesprächen allein in schriftlicher Form erfolgte. Einige Gesprächspartner wollten anonym bleiben. Ich habe im Text ihre Namen geändert und dies durch Kursivsetzung kenntlich gemacht. Wörtliche Zitate spanischsprachiger Gesprächspartner habe ich ins Deutsche übersetzt und im Anhang im Original abgedruckt.

Die ethnologische Forschungsmethode bringt es mit sich, dass manche Schlussfolgerungen teilweise auf den Aufzeichnungen von Beobachtungen beruhen. Diese lassen sich schwer in herkömmlicher wissenschaftlicher Form belegen. Um diesem Umstand Rechnung zu tragen und dem Leser die Vorzüge der ethnologischen Forschungsmethode zugänglich zu machen, habe ich mich für eine Präsentationsform entschieden, die wissenschaftliche Darstellung mit >literarischen` Elementen verbindet. Nicht nur im Prolog, sondern auch in den beiden empirischen Teilen der Studie - bei der Analyse des Stän- 
digen Forums für indigene Angelegenheiten und der Organisationsprozesse im peruanischen Tiefland - nehme ich den Leser mit auf die Forschungsreise und schildere paradigmatische Begegnungen und Gespräche. Die Schilderungen unterliegen dabei einem Selektions- und Synthetisierungsprozess, indem ich die für mich wichtigsten, zeitlich teilweise auseinanderliegenden Erlebnisse und Gespräche in komprimierter Form zugänglich mache. Ferner habe ich die Namen meiner Gesprächspartner geändert und dies im Text kenntlich gemacht sowie auf Ortsnamen verzichtet. Es sind persönliche Schilderungen, von denen ich dennoch hoffe, dass sie den Leser zu weiteren Assoziationen und Erkenntnissen anregen. Die Erzählungen im ersten und zweiten Teil bilden dabei die Grundlage für die sich jeweils anschließenden Analysen.

\section{Einordnung in bestehende ethnologische Forschungsansätze}

Die Vielzahl der Forschungsschauplätze und Gesprächspartner sowie die zwangsläufig geringere Zeitspanne, die ich an jedem Ort und mit jedem von ihnen verbringen konnte, zeigt, dass die vorliegende Studie keine >klassischeく Ethnografie ist. Mein »kosmopolitischer« (vgl. Hannerz 1996), multi-lokaler Ansatz und die deduktive Vorgehensweise beim Analyseprozess, die von relativ allgemeinen Grundfragen ausging und erst im Verlauf der Forschung und Auswertung konkrete Gestalt annahm, weisen in eine andere Richtung: Meine Studie testet Möglichkeiten und Beschränkungen der Methode einer multisited fieldwork (Marcus 1995), die mir als Forschungsrichtung für eine Ethnografie neuer Formen indigener Selbstorganisation sinnvoll erschien. Mir ist zudem keine ethnologische Auseinandersetzung mit dem Thema bekannt, die diesen Versuch in der vorliegenden Form bisher unternommen hat. Was aber will die Methode der multisited fieldwork, die im deutschen >multilokale< oder >mobile< Forschung (Schlee 1985: 203; vgl. auch Weißköppel 2005) genannt wird? Das Konzept der multi-lokalen Forschung beinhaltet zweierlei: Erstens postuliert es, dass man die Methode der stationären Feldforschung auf verschiedene Schauplätze kulturellen Geschehens ausdehnt. Zweitens verweist es auf die Konstruktionstätigkeit der Forscher, die Subjekte in diskontinuierlichen Handlungsräumen entwerfen, in denen diese agieren (vgl. Weißköppel 2005: 45). Dabei werden die Subjekte mit unterschiedlichen, oft im Konflikt miteinander stehenden Normen und Werten konfrontiert.

Schon bevor Marcus 1995 den Begriff der multisited fieldwork prägte, wurde die Vorgehensweise angewendet - so zum Beispiel von Mintz in seiner berühmten Kulturgeschichte des Zuckers (1985). Die Methode entwickelte sich einerseits aus den ethnologischen Arbeiten der 1980er Jahre, die sich mit dem >Weltsystem $`$ auseinandersetzen und eine stärker historisch geprägte Perspektive einnehmen, andererseits aus solchen, die sich mit Verbreitungswegen von Kulturgütern beschäftigen (vgl. Marcus 1995). Ethnologen fragen im Zu- 
ge dieser wissenschaftlichen Studien verstärkt nach den Zusammenhängen zwischen den Ergebnissen ihrer lokalen Beobachtungen und den größeren gesellschaftlichen Kontexten. Erfolgreich wurde die Methode der multi-lokalen Forschung vor allem im Rahmen einer »Ethnologie der Globalisierung« (Hauser-Schäublin und Braukämper 2002; Inda und Rosaldo 2002), die sich mit Fluss, Dynamik und Wandelbarkeit von >Kultur(en)< auseinandersetzt (vgl. z. B. Appadurai 1996; Hannerz 1987, 1996). Auch wenn die ethnologischen Forschungen, welche ethnografische Daten ins Weltsystem einbetten, innerhalb des Ansatzes der marxistischen Ethnologie entstanden sind, ist dieses wissenschaftliche Paradigma im Zuge der Postmoderne aufgebrochen worden. Es hat, beeinflusst unter anderem durch die poststrukturalistischen Arbeiten zum Thema Macht und Widerstand - allen voran durch die Schriften Michel Foucaults - Vorstellungen von diffuser Machtverteilung Platz gemacht. Globale Zusammenhänge werden meist nicht mehr in dichotomisierenden Gegenüberstellungen von >Zentrum` und >Peripherieく, >Unterdrücker und >Unterdrückte < betrachtet; Verbindungslinien und Brüche werden nicht mehr in erster Linie räumlich, sondern vor allem sozial verortet (vgl. Coronil 2000: 367; Marcus 1995).

Weißköppel (2005: 49f.) verweist darauf, dass nicht nur geografische, sondern auch mentale Flexibilität gefragt ist beim Aufspüren von Stellen, an denen eine multi-lokale Forschung in Bezug auf die jeweils vom Wissenschaftler gestellten Fragen relevant wird. Die Bedeutungsketten werden dabei durch die Akteure gelegt, die Forscher gehen ihnen nach und werden, so Weißköppel, zu »Spurensuchern« (Geertz 1997). Eine multi-lokale Forschung entsteht durch Verkettung, Überschneidung und Gegenüberstellung von Handlungsräumen, die durch eine inhärente Logik miteinander verknüpft sind und an denen die Ethnografen ihre Präsenz etablieren. ${ }^{4}$ Mobilen Forschungen liegt die Frage nach Produktions- und Verbreitungszusammenhängen der beobachteten kulturellen Phänomene zugrunde. Anders formuliert: Die Suche nach den Verbindungen zwischen >lokalen` und >globalen` Entwicklungen bestimmt diese Forschungsmethode. Das >Globale $<$ ist dabei nicht als Gegensatz zum >Lokalen zu verstehen, sondern als eine Dimension der Diskussion über die Verbindungslinien zwischen verschiedenen Handlungsräumen (vgl. Marcus 1995; Hannerz 1996; Massey 1994). Die Anwendung der multi-lokalen Forschungsmethode ermöglicht es mir somit in Bezug auf meine Forschungsfragen, Vernetzungen und Brüche zwischen den einzelnen Organisationsebenen indigener Bewegungen und in diesem Zusammenhang vor allem die Ver-

4 Für einen Überblick über die verschiedenen Analyserichtungen, die bei einer multisited fieldwork eingeschlagen werden können, siehe zum Beispiel Marcus 1995 und Weißköppel 2005. 
bindungen zwischen Dorfbewohnern und nationalen sowie internationalen Repräsentanten ins Blickfeld zu rücken.

\section{Aufbau des Buches}

Den Schwerpunkt dieser Studie bilden die beiden empirischen Teile (Kapitel III bis XI). Im ersten empirischen Teil beschreibe und analysiere ich die internationalen Prozesse indigener Selbstorganisation im Kontext der UNO, unter Rückgriff auf das von Pierre Bourdieu formulierte Konzept des »politischen Feldes«. Mit diesem lassen sich grundlegende Ordnungs- und Hierarchisierungsprozesse am Ständigen Forum für indigene Angelegenheiten herausarbeiten, welche die zentrale Bedeutung der Repräsentationsfrage innerhalb und außerhalb indigener Bewegungen verdeutlichen. Die komplexe Verschachtelung der neuen Formen indigener Selbstorganisation mit lokalen, nationalen und internationalen Entwicklungen ist Thema des zweiten empirischen Teils der Studie, der sich mit der Situation im peruanischen Tiefland auseinandersetzt. Dabei steht neben der historischen Aufarbeitung der Organisationsprozesse der Widerstreit unterschiedlicher Legitimationsmodelle politischer Macht im Zentrum der Betrachtungen. In den Schlussbetrachtungen verarbeite ich die Ergebnisse der Untersuchungen beider Handlungsräume - der >globalen « und der >lokalen « -, indem ich Theorie und Praxis miteinander in Verbindung bringe und weiterführende Forschungsfragen formuliere.

Zunächst gebe ich jedoch im zweiten Kapitel dieses ersten Teils einen kurzen Überblick über die bisherigen Forschungsansätze zum Thema >indigene Bewegungen $<$. Dabei bildet die ethnologische Auseinandersetzung mit dem Phänomen einen Schwerpunkt der Betrachtungen. Darauf aufbauend erläutere ich die theoretischen Grundlagen meines eigenen Ansatzes. Auf diese Art möchte ich den Leser in die verschiedenen theoretischen Aspekte einführen, die beim Studium neuer Formen indigener Selbstorganisation relevant werden, und dabei gleichfalls den vorliegenden Beitrag in bestehende Diskurstraditionen einordnen bzw. von diesen abgrenzen. 


\section{Kapitel II \\ Theoretische Grundlagen und Zielsetzungen einer /Ethnologie indigener Bewegungen`}

\section{Indigene Bewegungen als soziale Bewegungen}

Die heterogene Organisationslandschaft, die in der wissenschaftlichen Literatur unter der Bezeichnung >indigene Bewegungen` subsumiert wird, ist Teil des Phänomens, das mit dem Begriff >soziale Bewegungen` erfasst wird. Während man früher soziale Bewegungen mit Gewerkschaften bzw. Arbeiterbewegungen gleichsetzte und diese studierte, wird heute die Etikettierung vielfältig angewendet. Dabei unterscheidet man seit den 1980er Jahren meist zwischen >alten` und sneuen` sozialen Bewegungen. Während Bauern- bzw. Arbeiterbewegungen dieser Einteilung zufolge als ıalte<, auf sozioökonomischen Klassifizierungsprinzipien basierende Protestgruppen gelten, manifestieren sich die >neuen Umwelt- und Schwulenbewegungen, aber auch ethnischen bzw. indigenen Bewegungen. Sie gelten als >identitätsbasiert und >werteorientiert<. Aus diesem Grund wird den >neuen sozialen Bewegungen $<$ - allen voran den indigenen Bewegungen - im lateinamerikanischen Kontext eine große Bedeutung für die Stärkung der >jungen Demokratien` zugesprochen. Welche wissenschaftlichen Konzepte verbergen sich hinter den genannten Etikettierungen? 


\section{Definition ssoziale Bewegungen}

Es gibt zahlreiche Definitionen sozialer Bewegungen. Die meisten beinhalten jedoch eine oder mehrere der folgenden Kriterien: Soziale Bewegungen sind organisierte Kollektive von Individuen mit ähnlichen Werten, Interessen und Zielen. Sie weisen eine gewisse zeitliche Kontinuität auf, sind aber räumlich nicht unbedingt gebunden. Soziale Bewegungen entstehen immer im Kontrast zu anderen gesellschaftlichen Gruppen.

Ein zentraler Aspekt der Definition ist das Moment der Abgrenzung und des Widerstands gegenüber anderen gesellschaftlichen Kräften. Dabei können sich soziale Bewegungen entweder für den Erhalt bestehender Werte bzw. die Wiederherstellung zuvor gültiger Normen einsetzen. Oder sie entwickeln Alternativen, die auf Traditionsbruch und Neuerung abzielen. Viele gegenwärtige soziale Bewegungen berufen sich dabei auf $>$ Rechte $<$ und wollen strukturelle Reformen, nicht Revolution. Sie verfolgen, so Jean Cohen (1985: 669), eine Art »selbstregulierten Radikalismus« und sind »anti-fundamentalistisch«.

Die tatsächlichen Auswirkungen sozialer Bewegungen auf gesellschaftliche Veränderung sind jedoch meist schwierig zu ermitteln und kaum in einer allgemeingültigen Theorie zu verdichten. Verlauf und Auswirkungen sozialer Bewegungen lassen sich nur für jeden Einzelfall separat erfassen (vgl. Wimmer 1991: 291). So sind im internationalen Vergleich soziale Bewegungen mit ähnlichen übergeordneten Zielen - wie im Falle der indigenen Bewegungen - je nach Land unterschiedlich erfolgreich. Diese Differenzen lassen sich vor allem mit bestehenden Machtstrukturen und Dispositionen der involvierten Akteure erklären (vgl. Lipsky 1968; Eisinger 1973), aber auch mit dem jeder Bewegung inhärenten Institutionalisierungsprozess: Soziale Bewegungen müssen Organisationen aufbauen, um eine Mobilisierung ihrer Anhänger über einen längeren Zeitraum zu gewährleisten. Ihre Zielsetzungen sind in den meisten Fällen nicht unmittelbar zu erreichen und bedürfen wiederholter sowie vielfältiger Aktionen. Für die Koordinierung, Finanzierung und Durchführung ihrer Arbeit bedarf es deshalb zumindest grundlegender Strukturen (vgl. McAdam und Snow 1997: XXII).

Die meisten sozialen Bewegungen drücken sich aus diesem Grund in einer Bandbreite von Verbänden aus. Diese unterscheiden sich dadurch von anderen, dass sie auf gesellschaftliche oder individuelle Veränderung abzielen und nicht - wie zum Beispiel Hilfsorganisationen - grundlegende Infrastruktur bereitstellen wollen (vgl. Zald und Garner 1994: 123). Ihre Zielsetzungen implizieren somit immer ethisch-normative Grundsätze. Innerhalb einer sozialen Bewegung können sich jedoch eine Vielzahl von Organisationen bilden, die miteinander um Macht, Aufmerksamkeit und Finanzen konkurrieren. Anhaltender interner und externer Druck wirken sich auf die geschaffenen Struk- 
turen sowie das Erreichen der Ziele einer Bewegung aus. Drei Phänomene des Wandels sind in diesem Prozess zu beobachten:

- Zieltransformation

- Hinwendung zum Erhalt der Organisation und

- Machtkonzentration in den Händen einer Minderheit (vgl. Michels 1949).

Zald und Garner (1994: 122ff.) ergänzen Michels Modell des Institutionalisierungsprozesses. Dabei folgen sie dem von Selznick (1948) entwickelten Ansatz der >organisatorischen< bzw. >institutionellen`Analyse. Selznick definiert große Organisationen als eine Ansammlung von Gruppen, die durch verschiedene Anreize und Interessen zusammenkommen und relativ explizite Ziele verfolgen. Mittel und Ziele von Untergruppen können dabei in Konflikt geraten mit denen, die von den Autoritätsinhabern des Zusammenschlusses gesetzt werden. Es kann zu Auseinandersetzungen über die Verteilung von Macht und Anerkennung innerhalb der Organisation kommen. Auch die generellen gesellschaftlichen Bedingungen, unter denen soziale Bewegungen entstehen, spielen bei diesen Prozessen eine wichtige Rolle: Organisationen leben in einer dynamischen, von abrupten sowie schleichenden Veränderungen geprägten Umwelt, an die sie sich anpassen müssen. Diese Anpassungsleistung prägt den Wandel der Zielsetzungen sowie interne Umstrukturierungen. Schismogenese und Fraktionsbildung sind dabei Phänomene, die viele soziale Bewegungen prägen. Hervorgerufen werden sie meist durch zwei Bedingungen, die von Soziologen bisher wenig Aufmerksamkeit erhalten haben (vgl. Zald und Garner 1994: 134):

- durch die Heterogenität der sozialen Zusammensetzung,

- durch die doktrinäre Basis von Autoritätszuweisung innerhalb der Organisationsstrukturen (hierbei kann auch das Anliegen, die >doktrinäre Reinheit ` aufrecht zu erhalten, zu Konflikten und zur Teilung führen).

Beiden Aspekten kommen in Bezug auf die Untersuchung indigener Bewegungen zentrale Bedeutung zu: Abgrenzungs- und Differenzierungsprozesse, unter anderem in Form von Schismogenese und Fraktionsbildungen, prägen sowohl die Zusammenkünfte des Ständigen Forums für indigene Angelegenheiten als auch den Alltag indianischer Verbände im peruanischen Tiefland. In beiden Handlungsräumen sind die indigenen Bewegungen von großer kultureller und sozialer Heterogenität gekennzeichnet, ein Umstand, der viele Konflikte provoziert. Im Amazonasgebiet Perus müssen diese Phänomene darüber hinaus aber auch mit älteren indigenen Formen politischer Selbstorganisation in Verbindung gebracht werden, welche die politische Legitimation der doktrinären Basis von Autoritätszuweisung grundlegend in Frage stellen. Die ethisch-moralischen Grundsätze, die das indigene Kollektiv in der Außendarstellung zusammenhalten, werden einerseits im Innern kontrovers 
diskutiert und besitzen zum anderen oftmals weniger Mobilisierungskraft als pragmatische Zielsetzungen. Bei Verfolgung letzterer verschwimmen, wie schon im Prolog deutlich wurde, die Grenzen zwischen der von Zald und Garner getroffenen Unterscheidung zwischen sapolitischen und politisch motivierten Verbänden.

\section{Das ২Prinzip Indigenität als globale Mobilisierungskraft}

Anknüpfend an die eingangs erfolgte Definition sozialer Bewegungen lässt sich feststellen, dass die sneuen indigenen Bewegungen alle genannten Aspekte zugleich verkörpern: Ihrer politischen Selbstdefinition zufolge wollen sie bestehende Gesellschaftsverhältnisse ändern, während sie straditionelle Lebensformen $^{1}$ in ihren Mitgliedsgemeinden bewahren möchten. Indigene Bewegungen setzen sich somit gleichzeitig für \Erhalt` und für >Traditionsbruch ein. Dabei verfolgen sie einen >reformerischen « Ansatz: Sie fordern von staatlicher Seite, die kulturelle Differenz indigener Völker rechtlich und gesellschaftlich zu verankern. Ihre Genese und Zusammensetzung spiegelt gleichzeitig eben jene geschichtlichen Entwicklungen - die Intensivierung sowie qualitative Veränderung der interethnischen Kontaktsituation - wider, gegen die sie Stellung beziehen (vgl. Mader 2001: 80). In den empirischen Teilen der vorliegenden Studie treten diese Widersprüche deutlich zutage: Während die zentralen Akteure indigener Bewegungen nach außen als $>$ Wächter der Traditionen a auftreten, gelten sie nach innen meistens als soziale Aufsteiger im nationalen Kontext. Sie stellen somit eher den Prototyp des progressiven Erneuerers und des »janusköpfigen Brokers« (Wolf 1956) als den des konservativen Bewahrers dar. Auch wenn die Stärkung bzw. Revitalisierung ethnischer Identität ein Effekt ihrer Bemühungen sein kann, so wird diese Identität von ihnen gleichzeitig neu formuliert und interpretiert.

In Südamerika entstand 1964 im ecuadorianischen Amazonasgebiet die erste ethnische Föderation des Tieflands - mit der Unterstützung von Missionaren des Salesianer-Ordens: Shuar und Achuar schlossen sich zusammen, um gemeinsam Forderungen nach Anerkennung ihrer Kultur »als konstitutives Element der ecuadorianischen Gesellschaft« sowie dessen »autonome Entwicklung « (Blum 2001: 150) gegenüber dem Staat zu vertreten (vgl. auch Mader und Sharup 1993; Mader 2001). Auch in anderen Teilen des Amazonasgebietes bildeten sich in der Folge ethnische Zusammenschlüsse mit ähnli-

1 Unter den $\mathrm{zu}$ bewahrenden straditionellen Lebensformen Organisationen vor allem Sprachen, die sozio-politische Organisation, Techniken der Landnutzung und Jagd, sowie das Gewohnheitsrecht. 
chen Zielsetzungen. Diese Prozesse verliefen parallel zu Organisationsgründungen in anderen Ländern und Kontinenten sowie zur Bildung internationaler Vertretungsinstanzen. ${ }^{2}$ Als die Arbeitsgruppe indigene Völker ${ }^{3} 1982$ ins Leben gerufen wurde, eroberten die sneuen endgültig einen Platz als international wahrgenommene politische Akteure. Im Kontext der UNO wurden sie zu Vertretern >indigener Völkerく und schufen damit eine neue Kategorie politischer Gemeinschaft: das weltumspannende panindigene Kollektiv. Die Mobilisierungskraft des Indigenitätskonzepts beruht dabei einerseits auf ähnlichen Prinzipien wie ethnische Abgrenzungsprozesse: der kontinuierlichen Dichotomisierung von Mitgliedern und Außenstehenden (vgl. Barth 1996 [1969]: 79). Andererseits kennt das globale panindigene Kollektiv in der politischen Außendarstellung nicht vielfältige Gegenüber - wie dies in ethnischen Abgrenzungsprozessen der Fall sein kann sondern nur einen: die nicht-indigene, >westliche Zivilisation. Im Gegensatz zur ethnischen Grenzziehung, die dem Prinzip des Partikularismus verpflichtet bleibt, ist >Indigenitätく somit eine universale, homogenisierende Kraft, die möglichst viele, teilweise kulturell sehr verschiedene Gruppen unter ihrem Banner vereinen kann. Niezen meint dazu:

»Indigenism [...] is not a particularized identity but a global one that acts almost the same way as ethnic particularism. It sets social groups and networks apart from others in a global >we-they< dichotomy. It identifies a boundary of membership and experience that can be crossed only by birth or hard-won international recognition [...] (Niezen 2003: 9).

Indigene Identität wird dabei, wie bereits erwähnt, vor allem auch an einer besonderen Beziehung ihrer Träger zur natürlichen Umwelt festgemacht. Sie wird somit in bestimmten Gebieten - abseits urbaner Zentren - lokalisiert und festgeschrieben.

2 Auf die Entwicklungen indigener Organisationen im internationalen Kontext komme ich ausführlich im 2. Teil dieser Studie zu sprechen.

3 Die offizielle Bezeichnung dieser Einrichtung führt nicht den Begriff >indigene Völkerく im Titel, sondern bezieht sich auf >indigene Bevölkerungsgruppen`. Jedoch hat sich im Deutschen allgemein die Bezeichnung Arbeitsgruppe indigene Völker durchgesetzt. Ich übernehme sie deshalb in der vorliegenden Studie. 


\section{Zusammenhänge zwischen lokalen und globalen Entwicklungen}

In vielen Gebieten, in denen indigene Verbände mit Verweis auf >kulturelle Differenz` vor allem Zugang zu Ressourcen und Demarkierung von Land fordern, stehen ihre Interessen im Wettstreit mit denen nationaler Regierungen, transnationaler Unternehmen und anderer zivilgesellschaftlicher Interessengruppen. Dadurch sind sie gezwungen, nicht nur im lokalen oder nationalen Kontext Forderungen aufzustellen, sondern auch international zu agieren. Die weltweite Öffentlichkeit wird so zum wichtigsten Unterstützer der Bewegungen. Von indigener Seite erhofft man sich durch die Hinwendung zu Instanzen wie UNO, $\mathrm{OAS}^{4}$ oder Weltbank oft größere Chancen der Einflussnahme auf die Regierung im eigenen Land.

Auch wenn die Ausformulierung spezifischer Ziele auf internationaler Ebene schwierig erscheint, gehen von dieser wichtige Impulse für lokale Zusammenhänge aus. Angeregt durch globale Entwicklungen können neue kollektive Identifikationsprozesse angeschoben werden, die gemeinschaftliches Handeln unterstützen (vgl. McAdam et al. 2001). Im Falle der indigenen Bewegungen lässt sich dies u.a. an folgenden Tatsachen verdeutlichen:

- Im Rahmen der Entwicklung einer globalen indigenen Bewegung entstand der Begriff >indigene Völker`. Dieser wirkte zum Beispiel von den Treffen der Arbeitsgruppe indigene Völker in Genf in den 1980er Jahren auf den internationalen Zusammenschluss der Organisationen des Amazonasbecken, COICA, zurück. Von hier aus verbreitete sich der Gebrauch des Terminus auf die nationalen Mitgliedsverbände (vgl. Gasché 2001; Greene 2004).

- Die Diskussion um >Selbstbestimmung im Rahmen der Entkolonisierungspolitik der UNO in den 1960er Jahren wurde in der Folge von indigenen Bewegungen aufgenommen und auf die Situation in ihren jeweiligen Heimatländern angewandt, indem man auf die Situation sinterner Kolonisierung/ verwies (vgl. Brysk 2000: 32). Auch hier machte somit ein internationaler Begriff in verschiedenen Weltteilen \Karriere`, wobei sich jeweils seine semantische Bedeutung verschob. Während zum Beispiel die norwegischen Samen sich bereits selbst verwalten, verbinden indigene Gruppen aus Afrika mit dem Begriff ihre legale Anerkennung und, darauf aufbauend, Möglichkeiten der politischen Partizipation (vgl. Dahl 2004).

- Mit der wachsenden Aufmerksamkeit, die dem >Thema Indigene Ebene der UNO und allgemein in der internationalen Entwicklungspolitik ab den späten 1980er Jahren zuteil wurde, war auch wiederum weltweit

4 Organisation of American States. 
ein Erstarken und Anwachsen indigener Bewegungen auf lokaler Ebene zu verzeichnen (vgl. Hodgson 2002; Greene 2004).

Dennoch bleibt der Staat, gerade auch in Lateinamerika, letztendlich der zentrale Adressat der Forderungen indigener Bewegungen. Staatliche Akteure und Institutionen besitzen weiterhin politisch wichtige Möglichkeiten, die Auswirkungen der transnationalen, vor allem wirtschaftlichen Verflechtungen auf indianische Gemeinden durch entsprechende Gesetzgebungen sowie die Kontrolle der Umsetzung selbiger zu steuern.

\section{Indigene Bewegungen im Lichte bestehender Kategorien der Bewegungsforschung}

\section{Geschichte der Bewegungsforschung}

In sozialpsychologisch orientierten Studien der 1930er Jahre werden soziale Bewegungen als >Nebenprodukte< von schnellem gesellschaftlichem Wandel und Desintegration definiert, die durch Kriege, wirtschaftliche Krisen oder Katastrophen provoziert würden. Sie manifestieren sich, so die zentrale These, als ephemere, spontane und überwiegend irrationale kollektive Ausbrüche. Dieser Ansatz wird ab den 1960er Jahren zunehmend hinterfragt. Grund dafür sind zum einen die Studenten-, Frauen-, Umwelt- und Bürgerrechtsbewegungen in den USA und Europa. Zum anderen erschüttern zur gleichen Zeit in anderen Erdteilen antikoloniale Befreiungskämpfe und religiöse Erneuerungskulte die bestehenden politischen Ordnungen. Diese Manifestationen sozialer Organisation außerhalb etablierter parteipolitischer Strukturen wirken in der Folge auf die wissenschaftliche Beschäftigung mit dem Phänomen >kollektive Mobilisierung zurück. Soziale Bewegungen, so das Fazit, entstehen nicht nur in Reaktion auf einschneidende Ereignisse, da Konflikt und Ungewissheit auch den Alltag prägen. Mitte der 1970er Jahre bilden sich zwei neue wissenschaftliche Paradigmen heraus, die sich jedoch nicht zu kompletten Schulen verdichten:

- In den USA beschäftigen sich Autoren wie McCarthy, Zald und MacAdam vor allem mit den formalen Strukturen und Strategien von sozialen Bewegungen. Sie definieren diese als zweckgebundene Interessengemeinschaften und richten das Augenmerk auf politische Möglichkeiten und Mobilisierungstaktiken der organisierten Kollektive. Deren Erfolg wird in erster Linie an der Erreichung angestrebter Ziele gemessen - zum Beispiel an Hand von Gesetzesänderungen.

- In Europa entwickeln Autoren wie Laclau, Mouffe, Touraine und Melucci den Ansatz der >Neuen Sozialen Bewegungen` (New Social Movements, 
kurz NSM). Sie sehen kollektive Mobilisierung im Lichte einer Identitätskrise postindustrieller Gesellschaften. In deren Folge entstünde eine wachsende Zahl von Kollektiven, die sich nicht nach ihren sozioökonomischen Positionen innerhalb der Gesellschaften, sondern über partikuläre Identitäten definierten. Diese neuen sozialen Bewegungen kämpfen, den Autoren zufolge, für ihre jeweils spezifischen kulturellen, ethischen und sozialen Modelle und streben vor allem ideelle, nicht materielle Veränderungen an (Edelman 2001: 287ff.; vgl. auch Boris 1998; Escobar und Alvarez 1992; Alvarez et al. 1998).

In den 1990er Jahren wird verstärkt der Ruf nach einer Zusammenführung beider Ansätze laut (z.B. Foweraker 1995). Die Umsetzung dieser Forderung manifestiert sich zum Beispiel in den lateinamerikabezogenen Sammelbänden von Escobar und Alvarez (1992) und Alvarez et al. (1998).

\section{Ethnologische Beiträge zur Theoriebildung}

Ethnologen beginnen sich intensiver mit sozialen Bewegungen zu beschäftigen, als antikoloniale Befreiungskämpfe und religiöse Erneuerungskulte ihre straditionellen< Forschungsgebiete erfassen. Der Vietnamkrieg sowie die militanten politischen Bewegungen der späten 1960er Jahre lassen vor allem ihr Interesse an Bauernbewegungen sprunghaft ansteigen. Ab den 1970er Jahren rücken dann die ethnischen Revitalisierungsbestrebungen in den Mittelpunkt des ethnologischen Diskurses über soziale Bewegungen (Wimmer 1991: 290). ${ }^{5}$ Dennoch bleiben die Fachvertreter zu großen Teilen am Rand der Theoriebildung. Ausnahmen bilden Eric Wolfs Peasant Wars of the 20th century (1969), Paul Friedrichs Agrarian Revolt in a Mexican Village (1970) oder Karen Blus The Lumbee Problem (1980) sowie Studien zu Cargo-Kulten (vgl. Ortner 1984: 150). ${ }^{6}$

Der zögerliche Beitrag ethnologischer Theoriebildung zum Phänomen >soziale Bewegungen` lässt sich unter anderem mit dem partikulären, auf den

5 Ich erhebe keinen Anspruch auf vollständige Erfassung des ethnologischen Beitrags zur Theoriebildung, sondern möchte lediglich Grundtendenzen skizzieren. Bei Wimmer (1991: 290) finden sich Verweise auf Überblickswerke zu Forschungen über religiöse und ethnisch-nationalistische Bewegungen, Bauernbewegungen und städtische Bewegungen aus ethnologischer Sicht.

6 In der deutschen Ethnologie entwickelte Wilhelm E. Mühlmann in seiner Studie Chiliasmus und Nativismus (1961) einen Erklärungsansatz für sogenannte snativistische Bewegungen`. Hierbei beschäftigte er sich mit dem Phänomen jedoch weiterhin aus sozialpsychologischer Sicht und unter dem direkten Eindruck der Erfahrungen der Massenmobilisierung im Dritten Reich. So charakterisierte für ihn das »Spontane« und »Triebhafte« nativistische Bewegungen, die seiner Meinung nach erlahmten, wenn die formale Organisation zunahm. 
Mikrokosmos gerichteten Blick der Ethnologen und einem gewissen Misstrauen gegenüber Schematisierungen erklären. In diesen beiden Aspekten unterscheiden sie sich grundlegend von Soziologen und Politikwissenschaftlern. Die von Ethnologen konstatierte Heterogenität lokaler Lebenswelten erlaubt Rückschlüsse auf den fragmentarischen sowie chaotischen Charakter der meisten Bewegungen und führt zu differenzierten Einschätzungen regionaler Entwicklungen: Studien dieser Art ermöglichen detaillierte Einblicke in ideologische Differenzen innerhalb von Bewegungen und in den Ablauf von Protestaktionen. Diese Aspekte werden in soziologischen und politologischen Studien meist vernachlässigt. Im Gegenzug erschwert das ethnologische Erkenntnisinteresse Generalisierungen und Modellbildungen. In den 1980er und vor allem 1990er Jahren sind die Vertreter der Disziplin zudem vor allem von alltäglichen Formen des Widerstands fasziniert. Unter dem Einfluss Foucaults setzen sie sich bevorzugt mit Macht in seinen weniger institutionalisierten, versteckten Formen auseinander (vgl. Edelman 2001: 309; Brown 1996: 729; Ortner 1995: 174f.).

\section{Soziale Bewegungen in Lateinamerika}

In Lateinamerika sind bislang nur wenige theoretische Ansätze zur Entstehung sozialer Bewegungen entwickelt worden. Es lässt sich aber tendenziell eine größere Nähe der Wissenschaftler zum europäischen Ansatz der NSM verzeichnen (vgl. Edelman 2001). Dabei hebt Greene (2004: 39ff.) hervor, dass eine Reihe der besten Beiträge zum Studium sozialer Bewegungen an Hand lateinamerikanischer Beispiele entstanden sind (z.B. Jaquette 1994; Alvarez 1990; Slater 1985; Paley 2001; Eckstein 1989; Stokes 1995). So weckte zum Beispiel auch die 1994 in Mexiko in Erscheinung getretene Ejército Zapatista de Liberación Nacional (EZLN) ${ }^{7}$ umfangreiches sozialwissenschaftliches Interesse. In den Analysen wird die EZLN unter anderem als »Informationsguerilla« (Castells 1997), "postmoderne Guerilla« (Nash 1997) oder »demokratische Guerilla« (Touraine 2000) bezeichnet, und die Unterschiede zu anderen bzw. früheren (lateinamerikanischen) Guerillabewegungen werden untersucht (vgl. Edelman 2001: 293). Auch die Erfolge der indigenen Bewegung in Ecuador in den 1990er Jahren sowie Anfang des neuen Jahrtausends werden als Zeichen eines >Demokratisierungsprozesses von unten bei dem die >Stimmen der Marginalisierten` von der Peripherie ins Zentrum rücken und zur maßgeblichen Kraft von Transformationsprozessen werden. Diese Prozesse umfassen für Autoren wie Alvarez et al. (1998: 2) neben Veränderungen des politischen Systems auch den Wandel wirtschaftlicher, sozialer und kultureller Praktiken im gesamtgesellschaftlichen Kontext.

7 Dt. `Zapatistische nationale Befreiungsarmee`. 
Die Übertragung des NSM-Ansatzes auf Lateinamerika, vor allem der postulierte Beitrag sozialer Bewegungen zum Demokratisierungsprozess, erfährt jedoch auch kritische Betrachtung. So stellt zum Beispiel Wolfgang Gabbert fest: »Das `Neue Soziale Bewegungen< - Konzept vermischt die Betroffenen- mit der Beobachterperspektive [...] in der Beschreibung und Analyse und ist normativ geprägt « (Gabbert 1993: 429f.). Alvarez und Escobar (1992: 323) betonen, dass soziale Bewegungen meist gekennzeichnet sind durch ein komplexes Zusammenspiel von ideologischer Autonomie und politischem Pragmatismus, Widerstand und Anpassung, Protest und Verhandlung. Auch der britische Ethnologe John Gledhill bemerkt:

»The NSMs in Latin America [...] came to be seen as >new actors`, distinct from established political parties and bureaucratized trade unions. Many inferred from this that their internal organization was also democratic and participatory [...]. Yet the very heterogeneity of the new movements raised questions« (Gledhill 2000: 186).

\section{Einordnung indigener Bewegungen in die bestehenden Paradigmen}

Da sich die indigenen Bewegungen bei der Formulierung ihrer Forderungen vor allem auf >kulturelle Differenzen` und grundlegend andere Normen und Werte ihrer Gemeinschaften berufen, sich in vielen Fällen bewusst von etablierten politischen Parteien oder Gewerkschaften abgrenzen und als eine Art saußerparlamentarische Opposition` auftreten, kategorisieren sie viele Wissenschaftler als NSM. Diese Einteilung erweist sich jedoch auch im gegebenen Fall als problematisch: Die Organisationen, die sich als Teil der indigenen Bewegungen verstehen, können durchaus konträre Ziele verfolgen. Ferner gibt es inzwischen indigene Parteien (z.B. die Pachakutic in Ecuador) oder indigene Selbstverwaltungen (z.B. der norwegischen Samen). Die Positionierung außerhalb etablierter parteipolitischer Strukturen ist somit nicht mehr in jedem Fall gegeben. Indigene Bewegungen haben einerseits in den letzten dreißig Jahren vielerorts markante Institutionalisierungsprozesse durchlaufen: Sie sind in den Gesellschaften >angekommen<, an oder gegen die sich ihre Forderungen richten. Andererseits zeigt sich auch bei der Betrachtung ihres historischen Entstehungskontextes, dass sie mit der Gründung ihrer Zusammenschlüsse nicht nur politisch-normative, sondern meist ebenso sehr konkrete materielle Forderungen verbinden (vgl. Warren und Jackson 2003; Mader 2001). Ob indigene Bewegungen dabei die >Demokratisierung< gesamtgesellschaftlicher Zusammenhänge im Auge haben oder dies zumindest ein $>$ Nebenprodukt $<$ ihrer Bemühungen sein kann, lässt sich somit nicht generalisieren. Dass jedoch in indigenen Verbänden nicht unbedingt nach westlichem Demokratieverständnis gearbeitet wird und mit dem Verweis auf >eigene kul- 
turelle Traditionen im Umgang mit anderen gesellschaftlichen Sektoren angeschoben werden, betonen vor allem Ethnologen (z.B. Hodgson 1999, 2002; Sylvain 2002; Kuper 2003; Greene 2004). Viele von ihnen fordern eine Abkehr von Untersuchungen, die das >Hervorkommen neuer Identitäten` auf >Grundlage kultureller Praktiken ‘ beschwören, ohne detaillierte historische Beweise dafür zu liefern. Erforderlich sind hingegen - nach Meinung dieser Autoren - ethnografische Untersuchungen darüber, wie kulturelle Praktiken das politische Handeln der Akteure sozialer Bewegungen beeinflussen. Nur so könnten die Thesen des NSM-Ansatzes an empirischem Material überprüfbar werden (vgl. z.B. Greene 2004; Warren 1998; Jackson und Warren 2002).

Diese Kritik erscheint mir äußerst fruchtbar bei der Bestimmung einer ethnologischen Perspektive auf das Phänomen >indigene Bewegungen Analyse der historischen Prozesse, die zur Entstehung der neuen indigenen Bewegungen führten, muss zusammengebracht werden mit einer Untersuchung der realen Beziehungen, die zwischen politischen Klassifikationen und den >Wir-Gefühlen` der unter diesen Kategorisierungen Subsumierten bestehen. Die Repräsentationsfrage bleibt meiner Meinung nach eine der grundlegendsten, weil darüber Prozesse sozialen und politischen Wandels ins Blickfeld geraten. Nur so kann man jenseits ideologisch geprägter Debatten die politische Bedeutung indigener Bewegungen adäquat erfassen.

Welches Erkenntnisinteresse hat bisher die >Ethnologie indigener Bewegungen< geleitet?

\section{Die sEthnologie indigener Bewegungen}

Im Laufe der 1990er Jahre sowie Anfang des neuen Jahrtausends entstehen vor allem im anglo-amerikanischen Raum eine Reihe wissenschaftlicher Arbeiten zum Thema sindigene Bewegungen in Lateinamerikar. Während anfangs politologische Studien dominieren (z.B. Brysk 1995, 2000; Van Cott 1994, 2000; Yashar 1999, 2005; Assies et al. 2000; Siedler 2002), melden sich in den letzten Jahren verstärkt Ethnologen zu Wort (z.B. Ramos 1994, 1998, 2002; Warren 1998; Warren und Jackson 2003; Turner 1999; MayburyLewis 2002; Greene 2004; Grey Postero und Zamosc 2004; Grey Postero 2006). Die ethnologische Beschäftigung mit dem Thema indigene Bewegungen oszilliert zwischen Politikethnologie mit dem Ziel der wissenschaftlichen Objektivierung zu Erkenntniszwecken und politischer Ethnologie mit dem Wunsch, Aktionsprogramme zu entwerfen und ins politische Geschehen einzugreifen. Die fachliche Diskussion des letzten Jahrzehnts umfasst dabei eine Bandbreite von Aspekten, mit besonderem Fokus auf den Themen Repräsentation, politische Anerkennung, Ressourcennutzung und Rechte (vgl. Hodgs- 
on 2002: 1040f.). ${ }^{8}$ Im Folgenden möchte ich kurz Grundtendenzen und Probleme der ethnologischen Auseinandersetzung mit dem Thema indigene Bewegungen skizzieren.

\section{Theoretische und empirische Beiträge zum Studium der indigenen Bewegungen Lateinamerikas}

Warren und Jackson (2003) sehen im Anfang der 1990er Jahre erschienenen Sammelband von Urban und Sherzer (1991) den ersten Meilenstein in der Beschäftigung mit den neuen indigenen Bewegungen Lateinamerikas im englischsprachigen Raum. Den beiden Autorinnen zufolge haben Wissenschaftler sich zuvor meist aus historischer Perspektive mit indianischem Widerstand beschäftigt. Die Zukunft der indigenen Bevölkerung Lateinamerikas sei hingegen in Begriffen von >Assimilation< und >Desintegration< beschrieben worden. Warren und Jackson sind der Meinung, dass viele Wissenschaftler die dramatischen Veränderungen im indianischem Aktivismus der 1960er und 70er Jahre verpasst hätten. Nur unter Berücksichtigung der frühen nationalen und transnationalen Bewegungen heutiger Prägung könne die gegenwärtige Situation hingegen angemessen erfasst werden.

In Lateinamerika, zum Beispiel in Peru (u.a. Stefano Varese) oder Mexiko (u.a. Rodolfo Stavenhagen, Bonfil Batalla), begleiten Ethnologen die neuen ethnischen Organisationsprozesse jedoch seit ihren Anfängen in den 1960er und 70er Jahren - nicht nur auf wissenschaftlicher, sondern oft auch auf politischer Ebene. Dieses frühe und kontinuierliche Interesse lateinamerikanischer Ethnologen an den Organisationsprozessen lässt sich unter anderem mit dem 1971 auf der ersten Barbados-Konferenz erarbeiteten aktionsethnologischen Ansatz in Verbindung bringen. Dessen Vertreter möchten indianische >Emanzipationsprozesse ‘ aktiv unterstützen und engagieren sich für die bis dato im nationalstaatlichen Kontext politisch unsichtbaren Akteure indianischer Verbände. ${ }^{9}$ Jedoch nehmen die in diese Prozesse involvierten Ethnologen dabei eine stärker soziologisch geprägte Perspektive in Theorie und Praxis ein (vgl. Santos Granero 1996).

Während sich in Lateinamerika die Grenzen zwischen akademischer Ethnologie und praxisbezogenem Engagement durchlässig und flexibel zeigen, markiert zum Beispiel im deutschsprachigen Raum ein größerer Bruch das Verhältnis zwischen >Praktikern` und >Akademikern`. Auch hier erscheinen

8 Für einen Literaturüberblick zu den jeweiligen Themen siehe Hodgson (2002).

9 Die auf dieser Tagung versammelten, zumeist lateinamerikanischen Fachvertreter sprachen sich für eine »dekolonisierte Ethnologie« aus. Die Ethnologie sollte »den kolonisierten Völkern alle anthropologischen Kenntnisse [...] vermitteln, sowohl über sich als auch über die Gesellschaft, die sie beherrscht, um zu ihrer Befreiung beizutragen« (Erklärung Barbados I; zitiert in Maihold 1986: 202). 
bereits ab den späten 1970er Jahren - verstärkt jedoch seit den 1990er Jahren - Sammelbände und Aufsätze, die sich mit den neuen Formen indianischer Selbstorganisation im nationalstaatlichen Kontext auseinandersetzen (z.B. Drostal 1975, 1976; Münzel 1978, 1984, 1985, 1986, 1993; Dulon 1982; Ströbele-Gregor 1992, 1994, 2000; Mader und Sharup 1993; Blum 1994a, 1994b, 1995, 2001; Gleich 1996; Mader 2001). Die Diskussion um die Repräsentativität der neuen indigenen Vertreter wird dabei manchmal mit aufgegriffen. So merkt zum Beispiel Münzel $(1985,1993)$ kritisch an, dass die Repräsentanten der neuen indianischen Verbände häufig als >traditionelle< indianische Stimmen und >Volksvertreter $`$ demokratischer Prägung betrachtet und damit entscheidende Dimensionen der die Organisationsprozesse begleitenden gesellschaftlichen Veränderungen im lokalen Kontext ausgeblendet würden.

Die zuweilen unkritische Solidarisierung mit den neuen indigenen Führungspersönlichkeiten von euro-amerikanischer Seite lässt sich teilweise als Resultat eines ethischen Dilemmas, auch für engagierte Wissenschaftler, begreifen: In Anbetracht der prekären Lage, in der sich die indigenen Völker Lateinamerikas befinden, scheint es Forschern kaum gestattet, die Meinungen und Handlungen ihrer >Studiensubjekte` distanziert zu betrachten. Ist es ethisch vertretbar, sich kritisch mit der politischen Legitimation der neuen politischen Führungspersönlichkeiten auseinander zu setzen? Spielt man dadurch nicht den Interessen ihrer Gegner im nationalen Kontext in die Hände? Neben diesem moralischen Dilemma tritt auch ein analytisches Problem zutage - vor allem, wenn man sich mit einer weiteren Dimension der Repräsentationsfrage auseinandersetzt: Wie soll man wissenschaftlich mit indigenen Repräsentationen umgehen, die kulturelle Kontinuität trotz offensichtlich gegenteiliger Entwicklungen betonen (vgl. Warren und Jackson 2003)? Primordialistische Erklärungen von Ethnizität und essentialistische Definitionen von Kultur durch die Akteure indigener Bewegungen stehen den konstruktivistischen Interpretationen von ethnischen Abgrenzungsprozessen, welche die meisten Wissenschaftler heute vertreten, entgegen. Die Darstellungen von klar abgrenzbaren kulturellen Einheiten verlaufen eindeutig konträr zum postmodernen ethnologischen Kulturdiskurs, der >Fluss`, Dynamik und Wandelbarkeit kultureller Identitäten betont und (ironischerweise) oftmals gerade darin das >Ermächtigungspotential ‘ür >Subalterneく sieht (vgl. z.B. Hannerz 1996; Appadurai 1996; Hall 1997; Hauser-Schäublin und Braukämper 2002; Inda und Rosaldo 2002).

Greene (2004: 38ff.) macht andererseits genau dieses veränderte Kulturverständnis für eine neue Offenheit ethnologischer Forscher gegenüber dem Thema >indigene Bewegungen` verantwortlich, die er - wie Warren und Jackson - zu Beginn der 1990er Jahre verortet. Die Entwicklung prozessualer Ansätze in den 1970er und 1980er Jahren gibt Wissenschaftlern das nötige Rüst- 
zeug in die Hand, um bestehende Ethnizitätskonzepte ${ }^{10}$ und strukturfunktionalistische Ansätze innerhalb der Ethnologie zu hinterfragen. Die dichotomisierende Gegenüberstellung von >Tradition` und >Moderne`, mit der einhergehenden Kategorisierung indigener Gesellschaften als Verkörperung >traditioneller Gesellschaften`, wird im Zuge dessen aufgegeben. Die Verflechtungen zwischen verschiedenen Gesellschaftsformationen rücken im Anschluss aus veränderter Perspektive erneut ins Zentrum der Forschungen. So werden die neuen politischen Organisationsformen indianischer Gruppen im nationalstaatlichen Kontext zu legitimen ethnologischen Untersuchungsfeldern. >Indigenitätく und >Moderneく schließen sich nicht länger gegenseitig aus. Indigene Organisationen gelten nicht länger als nicht-indianisches >Akkulturationsproblem`, sondern schlicht und einfach als `kulturelles Phänomen`, das man mit ethnologischen Mitteln untersuchen kann.

\section{Die sEthnologie indigener Bewegungens zwischen politischem Engagement und wissenschaftlicher Objektivierung}

Seit Mitte der 1990er Jahre entstehen im deutschsprachigen Raum Monographien, die sich als ethnologische Diskussionsbeiträge zum Thema >indigene Bewegungen $<$ aus dieser neuen Blickrichtung lesen lassen. Dies sind zum Beispiel Magisterarbeiten, die sich mit der Arbeitsgruppe indigene Völker (Dreher 1995), dem in diesem Rahmen erarbeiteten Konzept von >Indigenität (Siebert 1997) oder den indigenen Bewegungen in einzelnen lateinamerikanischen Ländern (z.B. Kollewe 2002; Lunnebach 2004; Rößler 2004) auseinandersetzen. ${ }^{11}$ Dies entspricht den wissenschaftlichen Entwicklungen im angloamerikanischen Raum. Wobei dort jedoch weiterhin eine stärkere Reflexion der politisch-moralischen Verantwortung von Ethnologen stattfindet. Diese wird gefördert durch Kritik von Seiten indigener Intellektueller und Aktivisten (z.B. Montejo und Akab' 1992; Montejo 1993; Menchú 1998; vgl. Sam Colop 1991; vgl. Warren 1998; Warren und Jackson 2003), welche weiterhin die einseitige, hierarchische Beziehung zwischen Ethnologen und `Studierten thematisieren, in der letztere $\mathrm{zu}$ passiven Objekten werden. Viele Wissenschaftler, die $\mathrm{zu}$ indigenen Bewegungen forschen, sind deshalb darum be-

10 Als früher Vorläufer der heute geführten Debatten wird zumeist Frederik Barths Neukonzeptionalisierung von Ethnizität (1969) gesehen, wobei Barths Fokus nicht so sehr auf Politik oder Geschichte lag, sondern auf der symbolischen Dimension von Ethnizität im interethnischen Beziehungssystem.

11 Dies sind lediglich die mir bekannten Magisterarbeiten zu dieser Thematik. Da sie zumeist nicht veröffentlicht werden, liegt die Vermutung nahe, dass eine wesentlich größere Zahl von Arbeiten zu dieser Thematik in den letzten 10 Jahren entstanden ist. 
müht, ein partnerschaftliches Verhältnis zu ihren >Studiensubjekten` aufzubauen: Sie setzen ihre Arbeiten der Kritik indigener Organisationsvertreter und Intellektueller aus (z.B. Warren 1998; Greene 2004; Hodgson 1999, 2002), veröffentlichen mit ihnen gemeinsam Sammelbände (z.B. Fischer und Brown 1996) oder unterstützen sie bei Projektanträgen, Schulungen und Lobbyarbeit, wie dies z.B. Joanne Rappaport, Jean Jackson, Kay B. Warren, Terence Turner und viele andere im akademischen Kontext verankerten Ethnologen tun (vgl. Warren und Jackson 2003: 3ff.). Dennoch, so konstatieren Warren und Jackson, stehen selbst diese Wissenschaftler weiterhin vor einem grundlegenden Dilemma: »[...] representing the cultural continuity that indigenous movements assert in the face of so much evidence to the contrary « (Warren und Jackson 2003: 3). Zwischen spolitischer Ethnologie r als Aktionsprogramm und Politikethnologie als wissenschaftlichem Objektivierungsprozess bleibt die Notwendigkeit einer Grenzziehung bestehen, um auch Widersprüche und politische Prozesse im Innern indigener Bewegungen angemessen erfassen und darstellen zu können.

\section{Die ıEthnologie indigener Bewegungen jenseits politischer Programmatik}

Neuere ethnologische Studien zur Repräsentationsebene indigener Bewegungen haben sich weitestgehend von den Debatten über kulturelle Authentizität und Essentialisierung gelöst (vgl. Hodgson 2002: 1040). Sie gehen stattdessen der Frage nach, wie historische, soziale, politische und wirtschaftliche Kontexte bestimmte Selbstbilder indigener Gruppen prägten und prägen. Warren und Jackson definieren die neuen Studieninhalte einer >Ethnologie indigener Bewegungen dabei wie folgt:

$»[\ldots]$ the anthropology of indigenous organizing becomes the study of the choices that people in different settings make in the ongoing process of their own identity formation. Clearly these are not unencumbered choices; rather they are contingent on wider political and economic pressures as well as on local history « (Warren und Jackson 2003: 11).

Auch die vorliegende Studie versteht sich als Beitrag zu dem Projekt, die indigenen Bewegungen in größere politische und soziale Zusammenhänge zu stellen. Ich möchte verschiedene politische und soziale Ordnungsprinzipien freilegen, welche die indigenen Organisations- und Repräsentationsprozesse prägen. Trotz des Fokus' auf strukturelle Rahmenbedingungen soll jedoch die Handlungspraxis der Akteure nicht vollständig aus dem Blickfeld geraten. Ich orientiere mich deshalb an dem praxeologischen Ansatz Pierre Bourdieus, der eine »Theorie des Erzeugungsmodus der Praxisformen« (Bourdieu 1979: 164) 
entwirft, um objektivistische und subjektivistische Ansätze zusammenzuführen. ${ }^{12}$ Ziel seines Ansatzes ist es, ein System objektiver Relationen zu erstellen, in dem die dialektischen Beziehungen zwischen den Strukturen und den Dispositionen der Handelnden, welche die Strukturen aktualisieren und reproduzieren, erfasst werden (Bourdieu 1979: 147). Den Ausgangspunkt bildet dabei die Annahme, dass sich Akteure nicht voraussetzungslos begegnen. Im Gegenteil: Sie tragen ihre Geschichte und Sozialisation in Form einverleibter Dispositionen - von Bourdieu »Habitus« genannt - mit sich herum. ${ }^{13}$ Diese erlernten Umgangs- und Verhaltensformen definieren und begrenzen die Aktionsmöglichkeiten des Einzelnen. Innerhalb der gesetzten Grenzen kann der Handelnde jedoch erfinderisch sein, das heißt, seine Reaktionen und Aktionen sind keinesfalls immer vorhersehbar. Damit wird die strukturelle Determiniertheit der sozialen Akteure relativiert, und Phänomene gesellschaftlichen Wandels werden berücksichtigt bzw. erfassbar (vgl. Bourdieu 1997: 33).

\section{Wille des Akteurs und Zwänge des Systems}

Pierre Bourdieus erkenntnistheoretisches Interesse ist es, über die Analyse sozialer Beziehungen Ordnungsprinzipien und Formen der Herrschaftssicherung herauszuarbeiten, wie sie in der alltäglichen Praxis der Handelnden erzeugt und reproduziert bzw. verändert werden. Dafür vergegenständlicht er die soziale Welt $^{14}$ als mehrdimensionalen Raum, der von Unterscheidungs- sowie

12 Beim objektivistischen Ansatz (z.B. Strukturalismus) wird soziales Verhalten erklärt, indem Regelwerke aufgestellt werden, denen das Benehmen eines Akteurs in all seinen möglichen Erscheinungsformen folgt. Diese Regelwerke strukturieren das Unbewusste des Individuums, wodurch strategischen Handlungen Einzelner oder nicht intendierte historische Konsequenzen derselben kein Platz zugebilligt wird. Geschichte und Wandel können somit vom Strukturalismus nicht oder nur schwer erfasst werden - wobei dies natürlich auch nicht sein Erkenntnisinteresse ist. Beim subjektivistischen Ansatz (z.B. Transaktionalismus) wird die Analyse auf einzelne Akteure als >individuelle Strategen kussiert. Hierdurch können zwar Handlungsspielräume sichtbar gemacht werden, die systematische Natur sozialen Verhaltens bleibt hingegen meist unterbelichtet (vgl. Gledhill 2000: 138f.).

13 Der Habitus wird grundlegend durch die Nachahmung der Handlung anderer inkorporiert. Bourdieu (1987) unterscheidet bei diesem Prozess jedoch drei Formen der Einprägung des Habitus, die in jeder Gesellschaft zum Tragen kommen: 1. unmerkliches Vertrautwerden, 2. ausdrückliche Überlieferung kraft Anordnung und Vorschrift, 3. strukturale Übungen in Spielform (dazu gehören auch Rituale). Auch Zeit- und Raumstrukturen prägen sich so dem Individuum ein (Fröhlich 1994: 39).

14 Bourdieu vermeidet es, den Begriff >Gesellschaft zu verwenden, um ein soziales Ganzes zu erfassen. Er verwendet stattdessen die Bezeichnung >soziale Welt‘, die eine spezifische Definition des jeweils untersuchten Kontexts zulässt. 
Verteilungsprinzipien strukturiert wird. Diesen sozialen Raum definiert Bourdieu als Kräftefeld, das sich allen Eintretenden als Zwang auferlegt. Unter den Unterscheidungs- und Verteilungsprinzipien versteht er »die Gesamtheit der Eigenschaften (bzw. Merkmale), die innerhalb eines fraglichen Universums wirksam sind, das heißt darin ihrem Träger Stärke bzw. Macht verleihen« (Bourdieu 1985: 9). Er differenziert sie in drei grundsätzliche Formen aus: ökonomisches, soziales und kulturelles Kapital: ${ }^{15}$

- ökonomisches Kapital: unmittelbar und direkt in Geld konvertierbar, eignet sich zur Institutionalisierung in Form von Eigentumsrecht.

- soziales Kapital: Ressource, die auf Zugehörigkeit zu einer Gruppe beruht; kennzeichnet den Besitz eines dauerhaften Netzes von mehr oder weniger institutionalisierten Beziehungen gegenseitigen Kennens bzw. Anerkennens. Zur Aufrechterhaltung und Vermehrung des sozialen Kapitals ist unaufhörliche Beziehungsarbeit in Form von Austauschakten erforderlich.

- kulturelles Kapital: differenziert Bourdieu in a) inkorporiertes, b) objektiviertes und c) institutionalisiertes Kulturkapital aus. Inkorporiertes Kulturkapital ist körpergebunden und kostet Lernzeit. Es beruht auf individueller Aneignung und kann nicht übertragen werden. Objektiviertes Kulturkapital in Form von kulturell als wertvoll eingestuften Gegenständen ist hingegen auf andere übertragbar. Institutionalisiertes Kulturkapital ist schulisch sanktioniert und wird durch Titel belegt. Derart erworbenes Kapital steht nicht unter ständigem Beweiszwang, sondern ist objektiviert. Seine Geltung ist relativ unabhängig von den realen Fähigkeiten seines Trägers (Bourdieu 1997: 53ff.). Der Zugang zu beiden Formen kulturellen Kapitals - inkorporiertem und institutionalisiertem - wird kontrolliert: Nicht allen stehen die gleichen Möglichkeiten offen (vgl. Wimmer 1995: 60). Kulturelles Kapital trägt somit zur sozialen Statusdifferenzierung bei.

Die drei genannten Kapitalformen sind untereinander unter jeweils zu bestimmenden Voraussetzungen konvertierbar. Mit Bourdieus Kapitalbegriff lassen sich verschiedene Handlungsressourcen der Akteure erfassen:

- einverleibte, personengebundene (Wissen)

- vergegenständlichte und institutionalisierte (Dinge, Titel)

- soziale Beziehungsnetze

Zum Einsatz kommen sie in Form einer vierten Handlungsressource: dem symbolischen Kapital. Dieses beruht auf Anerkennung - in Form von An-

15 Damit greift er zwar Marx Kapitalbegriff auf, belässt ihn aber nicht in der ökonomischen Sphäre, sondern überträgt ihn auf alle gesellschaftlichen Bereiche. Dies stellt »eine wichtige Erweiterung des politikökonomischen Ansatzes, der nur zwei Machtquellen kennt« dar (Wimmer 1995: 60; vgl. auch Eder 1989: 15). 
sehen, gutem Ruf, Ehre, Prestige. Es verkörpert die »wahrgenommene und als legitim anerkannte Form « (Bourdieu 1985: 11) des ökonomischen, sozialen und kulturellen Kapitals und begründet die Macht ihres jeweiligen Trägers »im Kampf um Durchsetzung der legitimen Sicht von sozialer Welt« (Bourdieu 1985: 22). In allen Gesellschaften verleiht symbolisches Kapital seinen Besitzern das Vermögen, die Wahrnehmung des sozialen Raumes zu prägen und die eigenen Differenzierungsprinzipien zu legitimieren.

Der soziale Raum ist dabei immer ein asymmetrischer, auf Differenzen beruhender und diese beständig produzierender Raum. Die Akteure bringen in ihrem `Stellungskampf` die verschiedenen, ihnen zur Verfügung stehenden Kapitalsorten ein. Die Position des Einzelnen innerhalb des sozialen Raumes wird aber nicht so sehr durch seine absolute Menge an akkumuliertem Kapital bestimmt, sondern nach der relativen Verfügung über jeweils relevante Handlungsressourcen. Die Handelnden lassen sich in `Klassen zusammenfassen, in Gruppen von Akteuren mit ähnlichen Positionen im Raum (vgl. Bourdieu 1985: 12). Dabei besitzen diese Klassen jedoch einen rein erkenntnistheoretischen Charakter: Sie werden vom Wissenschaftler konstruiert und müssen nicht unbedingt der Wahrnehmung der Akteure entsprechen. Eine kollektive Mobilisierung der "Nächsten« ist grundsätzlich ebenso nicht voraussetzbar wie die »Annäherung der Fernsten« nie unmöglich ist (Bourdieu 1985: 13). Dennoch hält Bourdieu fest: »Sozialer Raum: das meint, daß man nicht jeden mit jedem zusammenbringen kann - unter Missachtung der grundlegenden, zumal ökonomischen und kulturellen Unterschiede« (Bourdieu 1985: 14).

Viele mehr oder weniger sichtbare Trennlinien durchziehen somit den sozialen Raum - entlang dieser befinden sich symbolische Grenzposten und die dazugehörenden Wächter, aber auch Menschen, die entweder die Grenze an sich oder aber ihre individuelle bzw. gruppenspezifische Positionierung in Bezug zu selbiger in Frage stellen. Durch letztere können neue Differenzierungsprinzipien entstehen und Gültigkeit erlangen.

\section{Das Feld als sozialer Mikrokosmos}

Innerhalb des Makrokosmos des sozialen Raumes unterscheidet Bourdieu verschiedene Handlungsräume - von ihm »Felder« genannt (vgl. Bourdieu 1985: 10). Mit dem Feldbegriff knüpft Bourdieu an Konzepte an, die in der Ethnologie ab den 1960er Jahren im Rahmen der Entwicklung prozessualer Theorien Anwendung finden: Gegenwärtige Gesellschaften werden als dynamische Gebilde begriffen, deren einzelne Teile womöglich nur lose integriert sind. Da die Forscher konstatieren müssen, dass es schwierig ist, alle Faktoren zu erfassen, welche das jeweils untersuchte soziale Feld ausmachen, isolieren sie einzelne Untereinheiten bzw. Sektoren, um Aussagen über Prozesse in diesem Abschnitt zu treffen. So untersuchen sie zum Beispiel das >politische 
Feld (vgl. Swartz et al. 2002 [1966]: 103ff.). Sie richten dabei das Augenmerk nahezu ausschließlich auf einzelne Akteure bzw. Akteursgruppen und beziehen den größeren Kontext nur insoweit ein, wie er für die Analyse des lokalen Untersuchungsfeldes von Bedeutung ist.

Pierre Bourdieu geht zunächst einmal ähnlich vor. Für ihn ist jedes Feld das religiöse, politische, wirtschaftliche, kulturelle etc. - ein relativ autonomer Mikrokosmos mit eigenen Gesetzen und Verhaltensregeln, die in den anderen keine Gültigkeit besitzen. Die in dem jeweiligen Feld Handelnden kämpfen um den Erhalt des gültigen Status Quo bzw. um dessen Veränderung. Sie schließen sich dafür in Gruppen zusammen. Um aber überhaupt eintreten zu können und nicht vom sofortigen Ausschluss bedroht zu sein, müssen neu Hinzukommende bestimmte Regeln und Gesetze akzeptieren. In den einzelnen Handlungsräumen sind somit jeweils spezifische Formen des Kapitals und des Handelns relevant (vgl. Bourdieu 1997: 14, 2001: 41f.).

Jedes Feld ist ein um die Produktion eines materiellen oder symbolischen Gutes herum strukturierter, dynamischer Handlungsraum (vgl. Janning 1991: 44). Ein weiteres wichtiges Charakteristikum der verschiedenen Felder liegt in ihren unscharfen Grenzen: So können Einzelne zum Beispiel in mehreren Handlungsräumen gleichzeitig agieren oder verschiedene Akteure unterschiedliche Ziele verfolgen. Auch nimmt man beim Denken und Handeln meist keine bewusste Trennung zwischen den einzelnen Feldern - Wirtschaft, Politik, Kunst etc. - vor (vgl. Rehbein 2003: 89). Einerseits erschwert dies unter Umständen die Herauslösung eines bestimmten Feldes zu analytischen Zwecken. Andererseits kann man in jedem untersuchten Feld allgemeinen Regeln der Ordnungsbildung und Herrschaftssicherung auf die Spur kommen. Der Blick auf den jeweiligen Mikrokosmos dient somit Rückschlüssen auf den Makrokosmos des sozialen Raums. Während die Politikethnologen der 1960er Jahre, in ihrem Bemühen, die Defizite des strukturfunktionalistischen Ansatzes zu überwinden, sich weitestgehend von dem Vorhaben, Systeme zu erfassen, abwenden, zielt Bourdieu mit der Analyse von >Untereinheiten` wieder auf die Erfassung der Strukturen des sozialen Raumes ab.

\section{Das politische Feld}

Das politische Feld konstituiert sich durch hierarchiebildende Ein- und Ausschlussprozesse im Kampf um sein zentrales Gut: politische Macht. Diese Prozesse basieren auf feldspezifischen Mechanismen der Differenzierung. Grundsätzlich sind dabei zwei Vorgänge von besonderer Bedeutung:

- die Abgrenzung des Feldes nach außen

- die feldinternen Klassifizierungen 
Abgrenzungsprozesse bezeichnet Bourdieu (1991: 129) als »Akte sozialer Magie«. Mit diesem Ausdruck verdeutlicht er die Kraft unsichtbarer, aber sozial äußerst wirksamer Ein- und Ausschlussmechanismen, welche die Handlungsmöglichkeiten einzelner Akteure entscheidend beeinflussen.

Bourdieu vergleicht das politische Feld mit dem religiösen: Beide beruhen zuvorderst auf einer Trennung in Eingeweihte und Nicht-Eingeweihte - auf einer Trennung in Kleriker und Laien bzw. Politiker (Professionelle) und Laien. In beiden Handlungsräumen müssen Neophyten eine Verwandlung durchlaufen, um überhaupt aufgenommen zu werden: Erst wenn sie bestimmte feldspezifische Regeln anerkennen, wird ihnen Zutritt gewährt. Der Skandal ist zum Beispiel ein wichtiges Anzeichen für diese impliziten Normen. Ferner regelt die relative Verfügung über ökonomisches, kulturelles und soziales Kapital sowohl den Zutritt als auch im Folgenden die internen Differenzierungsprozesse (vgl. Bourdieu 2001: 42ff.).

Beim Abkoppelungsprozess von den Nicht-Eingeweihten werden Definition und Erwerb >politischer Kompetenz` im politischen Feld zu Schlüsselprinzipien: Die Professionellen sehen auf Grund ihrer erworbenen Fähigkeiten meist auf die Laien herab und schließen diese aus. Dennoch brauchen Politiker, wie die Kleriker, weiterhin eine gewisse Unterstützung von Seiten der Ausgeschlossenen. Sie müssen diese von ihren Ideen überzeugen, um sie repräsentieren zu können (vgl. Bourdieu 2001: 48). Eine vollständige Abkoppelung des politischen Feldes ist deshalb nicht möglich. Die Entwicklung von politischen Strategien, die mit den Interessen sozialer Gruppen außerhalb des primären Handlungsraumes (dem politischen Feld) in Einklang zu bringen sind, bilden das Fundament des Erfolgs der Profis. Politiker müssen Ideen und Visionen entwickeln, die ihnen Unterstützung und Gefolgschaft sichern.

Für Vertreter von Minderheiten ergibt sich jedoch ein fundamentales Problem: Die Position marginalisierter Gruppen im politischen Feld ist auf Grund ihres Mangels an symbolischem Kapital sehr schwach. Sie brauchen besonders dringend permanente Organisationsstrukturen, die auf die Eroberung von Macht, auf Anerkennung der Gruppe abzielen (vgl. Bourdieu 2001: 72). Um zu einem ernstzunehmenden Mitspieler im politischen Feld zu werden, müssen sie somit - zumindest in der Außendarstellung - zu »moralischen Teams « (Bailey 1969) avancieren, das heißt, einen von Normen und ethischen Werten geprägten Diskurs entfalten. Dieser kann sich schnell zu einer salternativen Orthodoxie` entwickeln. Unter >alternativer Orthodoxie` verstehe ich die Herausbildung von Begriffen und Konzepten, die, selbst als häretischer Diskurs in Opposition zum herrschenden Status Quo entstanden, nach und nach ihrerseits den Status >unhinterfragbarer Wahrheit zugewiesen bekommen. Damit einhergehend formiert sich eine Gruppe von Grenzwächtern, die allen potentiellen >Diskurshäretikern` in den eigenen Reihen mit Ächtung und Ausschluss drohen. Diejenigen, die angetreten sind, die `Stimme der Stimmlosen 
zu werden, unterdrücken somit nun ihrerseits nicht-konforme Meinungen und sorgen für neue Differenzierungsprozesse im Innern ihrer Gruppe. Die >Institutionalisierung der Revolution< erweist sich in diesem Sinne als Widerspruch in sich selbst - ein Umstand, für den man in der jüngeren Geschichte Lateinamerikas zahlreiche Belege finden kann, u.a. in der mexikanischen und kubanischen Geschichte sowie in Peru zum Beispiel in der Entwicklung der Guerillagruppe Leuchtender Pfad.

Während ein Spannungsfeld in der nach außen gerichteten Abgrenzung zwischen Profis und Laien besteht, so ergibt sich ein zweites innerhalb des politischen Handlungsraumes. Hier lässt sich vor allem der Lokalpolitiker vom regional oder national Tätigen trennen. Für Ersteren bestimmen der direkte Bezug zur Wählerschaft sowie ein gutes Ansehen bei dieser das politische Kapital - eine »elementare politische Kompetenz« (Bourdieu 2001: 47) genügt. Auf höherer Ebene wird jedoch die Parteizugehörigkeit wichtig. Prestige, als wahrgenommene Form des politischen Kapitals, erhält der Einzelne dann durch das Renommee seiner Partei sowie durch die von ihm in dieser erkämpften Stellung. Mit dem Schritt von der lokalen zur regionalen bzw. nationalen Ebene beginnt die ideologische Sozialisation in eine politische Kultur, die hauptsächlich über Konfrontationen erlernt wird (Bourdieu 2001: 48). Die politische Kultur definiert sich über eine bestimmte Sprache und grundlegende Verhaltensweisen. Die ausgetragenen Konflikte wiederum drehen sich um die Definition der Klassifizierungsprinzipien des sozialen Raumes. Die Legitimität ihrer jeweiligen Weltsicht untermauern die Akteure dabei durch den Umfang der Gefolgschaft innerhalb und außerhalb des politischen Feldes. Ein wichtiges Mittel, symbolische Macht und damit politisches Kapital anzuhäufen - sowohl im lokalen als auch im nationalen Kontext - ergibt sich somit weiterhin aus dem Prinzip der Delegation. Einzelne können ihr politisches Kapital potenzieren, indem sie sich zu Wortführern möglichst großer Gruppen machen. Als solche eignen sie sich die Stimme (bzw. das Schweigen) und die Stärke der von ihnen Vertretenen an. Dazu müssen die Wortführer ihre Versprechen oder Prognosen den Repräsentierten gegenüber so überzeugend darstellen, dass diese an deren Autorität glauben. Kurzum: Sie müssen einen >guten Ruf^, also Prestige genießen. Das fundamentale Kapital des Politikers beruht auf Vertrauen. Deshalb ist er besonders anfällig für Verdächtigungen und Verleumdungen, die das in ihn gesetzte Vertrauen unterminieren. Er muss sich sein Ansehen durch ständige Arbeit bewahren (Bourdieu 2001: 93ff.). Nur durch Institutionalisierung in Form von Ämtern und Posten erlangt er eine relative Unabhängigkeit gegenüber den Sanktionen der Wähler. 


\section{6. sKultur - mehr als nur ein Kampf um handlungsrelevante Ressourcen}

Die »dichte Beschreibung« (Geertz 1987) als »Herzstück der ethnografischen Methode« (Ortner 1995: 174) muss immer die Ambivalenz der Subjekte sozialer Bewegungen im Auge behalten. Hier bricht das Dilemma zwischen Struktur und Handlung erneut hervor: Wie entkommt man einerseits dem idealen Konstrukt des freien Individuums und behält andererseits trotzdem noch ein Gefühl für die Kapazitäten des Einzelnen (Ortner 1995: 185)? Pierre Bourdieu liefert zur Beantwortung dieser Frage eine Reihe nützlicher Begriffe, die in der vorliegenden Studie an verschiedenen Stellen hilfreich sein werden. Dennoch bergen seine Konzepte auch gewisse Probleme. So kann der Begriff des Habitus' mit seiner Betonung der unbewussten, vom Individuum mit der Sozialisation einverleibten Handlungs- und Wahrnehmungsmuster dazu verleiten, in psychologischen Determinismus zu verfallen. Ich verzichte auf seine direkte Anwendung, halte aber die Auseinandersetzung mit dem sozialen und kulturellen Hintergrund der Akteure indigener Bewegungen für wichtig, um die ihre Handlungsoptionen eingrenzenden Zwänge besser nachvollziehen zu können: Die neuen indigenen Repräsentanten sind Vermittler zwischen verschiedenen gesellschaftlichen Formationen, in denen ein bestimmtes Verhalten in dem einen Kontext gut geheißen, in einem anderen aber verurteilt werden kann. Die Handlungen und Diskurse der Vertreter indigener Organisationen, der von ihnen Repräsentierten sowie von Unterstützern und Gegnern verdeutlichen diese Komplexität sozialer Dynamiken. Manuel Ijuma, die in seiner Organisation zusammengeschlossen Bewohner verschiedener Dörfer und die Mitglieder vieler anderer Verbände haben ihre eigenen Vorstellungen davon, wozu ihnen >große dicke Schweine` nützen können. Sie verfolgen Ziele, die sehr wohl ihrer politischen Ermächtigung im nationalen und lokalen Kontext dienen. Dennoch bleibt das >Schwein neue soziale Differenzierungsprozesse fördert und nicht-vorhersehbare bzw. nicht-intendierte Entwicklungen produziert.

Auch Bourdieus Darstellung zwischenmenschlicher Beziehungen als von (Macht-)kämpfen dominiert kann eventuell zu einer einseitigen Darstellung des sozialen Raumes verleiten. In seinen Schriften erscheinen Erzeugung und Reproduktion sozialer Ungleichheit weitestgehend als die einzigen gesellschaftlich relevanten Kräfte. >Kultur` begreift Bourdieu als Handlungsrepertoire, das im ständigen Klassifikationskampf um den sozialen Status als symbolisches Kapital eingesetzt wird (vgl. Ebrecht und Hillebrandt 2004: 9f.; Rehbein 2003: 77). Die Einnahme dieser Perspektive kann den Blick auf entgegengesetzte kulturelle Kräfte verstellen, die Herstellung von Symmetrie und Reziprozität zum Ziel haben. So stellt auch Ortner fest: 
»Patterns of cooperation, reciprocity, and solidarity constitute the other side of the coin of social being. In this post-seventies context, views of the social in terms of sharing, exchange, and moral obligation [...] are treated largely as ideology. Often of course they are ideology. Yet a Hobbesian view of social life is surely as biased as one that harks back to Rousseau. An adequate modell must encompass the full set« (Ortner 1984: 157).

Die neuen indigenen Organisationsprozesse in lokalen und globalen Zusammenhängen werden von beiden sozialen Kräften getragen. Die Herstellung von Gleichheit steht dabei in einem ambivalenten Verhältnis zur Erzeugung von Differenz. Mit dieser Aussage beziehe ich mich unter anderem auf folgende Phänomene: Auch wenn Konflikte sowie soziale Differenzierungsprozesse bei der Analyse des Ständigen Forums für indigene Angelegenheiten und im peruanischen Kontext im Vordergrund dieser Studie stehen, sind Solidarisierungsprozesse sowohl zwischen verschiedenen ethnischen Gruppen als auch zwischen >Indigenen $<$ und >Nicht-Indigenen tor für die Genese und Entwicklung indigener Bewegungen. Ferner wird bei näherer Betrachtung der indianischen Gesellschaften im peruanischen Tiefland und vor allem bei der Analyse des aktuellen Verhältnisses zwischen Dorfbewohnern und Repräsentanten deutlich, dass Reziprozität und Symmetrie in einem unauflöslichen Verhältnis zu Asymmetrie und Hierarchie stehen.

Die Auswirkungen des Widerstreits unterschiedlicher kultureller Normen gilt es somit in dieser Studie besonders zu berücksichtigen. Dabei sind die verschiedenen sozialen Formationen im peruanischen Kontext nicht klar voneinander abzugrenzen, sondern befinden sich in einem Zustand der Überlappung und des fließenden Übergangs. Genauso wenig wie sich Peru kaum als >nationale Einheit` definieren lässt, kann man in den wenigsten Fällen starre Grenzen zwischen einzelnen ethnischen Gruppen oder sozialen Formationen ausmachen. Das >postmoderne ethnologische Kulturverständnis gibt den Blick auf Fluss, Dynamik und Veränderbarkeit ethnischer und nationaler Identitäten frei. Die von allen involvierten Akteuren aus jeweils spezifischer Perspektive als abgrenzbar konstruierten sozialen und kulturellen Einheiten befinden sich in der Realität in einem beständigen Prozess der Neudefinition. Dabei passiert, was Bourdieu (1991: 120) mit der Schaffung von Diskontinuitäten aus Kontinuitäten bezeichnet: Im sozialen Raum werden Trennlinien zu politischen Zwecken gezogen. Politisch meint dabei: zum Zwecke der Herstellung, Bestätigung oder Unterwanderung des Legitimitäts- und Machtanspruchs einer Gruppe. Diese politischen Prozesse sind sowohl auf institutioneller Ebene zu beobachten, wie zum Beispiel bei der Entwicklung der indigenen Organisationen, als auch in der alltäglichen diskursiven Praxis, zum Beispiel bei der Definition ethnischer bzw. indigener Identität von Seiten der Dorfbewohner und ihrer Wahrnehmung der politischen Repräsentanten. 
Vor allem Bourdieus Konzepte des (politischen) Feldes und der Kapitalsorten - mit besonderem Augenmerk auf der Bedeutung institutionalisiertem (Kultur)Kapitals - kommen in den empirischen Untersuchungen der vorliegenden Studie zum Tragen. Dabei findet das Konzept des politischen Feldes nur bei der Analyse des Ständigen Forums für indigene Angelegenheiten direkte Anwendung. Dies ergibt sich aus dem Umstand, dass das Forum einen zu analytischen Zwecken abgrenzbaren Handlungsraum konstituiert. Jedoch kristallisiert sich schon bei der Betrachtung dieses Feldes heraus, was im peruanischen Kontext zentrale Bedeutung erlangt: Nur einzelne Akteure indigener Bewegungen betätigen sich im >klassischen zahl der Vertreter indigener Verbände bewegen sich in einem Handlungsraum, den man, in Anlehnung an Bierschenk und Olivier de Sardan (2001), das >entwicklungspolitische Feld nennen kann. In diesem überschneiden sich staatliche und nicht-staatliche, politische und wirtschaftliche Aktionsbereiche. Auch hier haben sich im Laufe eines Institutionalisierungsprozesses feldspezifische Regeln und Normen etabliert, deren Missachtung zum sofortigen Ausschluss führen können.

Diejenigen, die als Vertreter >indigener Völker agieren, bewegen sich erst seit rund dreißig Jahren auf nationaler und internationaler Ebene im entwicklungspolitischen Handlungsraum. Sie haben dabei ein ıneues`, politisch wirksames Teilungsprinzip im Feld durchsetzen können: die Trennung von >Indigenen $<$ und >Nicht-Indigenen $\prec$ Indigene Repräsentanten gelten im entwicklungspolitischen Handlungsraum als kulturelle und politische Broker. Als solche verfolgen sie ihre eigenen Interessen, werden dabei aber von widerstreitenden sozialen Normen geprägt und gezügelt. Sie sind, um eine Formulierung Boissevains (1974: 6) aufzugreifen, »homo manipulator und moralisches Lebewesen « in einem. Ihr (politischer) Erfolg hängt dabei weitestgehend von der erfolgreichen Mobilisierung und Kanalisierung externer ökonomischer Ressourcen ab. Damit geraten sie in eine doppelte Abhängigkeit: Zum einen stellen die von ihnen Repräsentierten spezifische Ansprüche, deren NichtErfüllung mit dem Entzug des Delegationskapitals geahndet werden kann. Diesen Ansprüchen können die Repräsentanten zwar mit einem Aufstieg in höhere Organisationsebenen entkommen - der dafür von ihnen zu zahlende Preis besteht jedoch in der sozialen Entfremdung von den von ihnen Vertretenen. Auch so verlieren sie ihr politisches Delegationskapital. Zum anderen müssen die Repräsentanten ihre Arbeit, vor allem im nationalen und internationalen Kontext, nach den Vorstellungen der Geldgeber ausrichten - sowohl der staatlichen als auch der nicht-staatlichen. Kommen die Vermittler den Ansprüchen letzterer nicht nach, werden sie für jene uninteressant und können auch so >des Feldes verwiesen werden<. Das von Ethnologen schon in den 1930er und 40er Jahren untersuchte Vermittlungswesen hat sich somit in die Entwicklungspolitik verschoben (vgl. Bierschenk und Olivier de Sardan 2001: 
15). Dort sind die Machtverhältnisse weitaus diffuser, da das entwicklungspolitische Feld selbst an der Schnittstelle zwischen Staat und Zivilgesellschaft, zwischen Politik und Wirtschaft liegt. Dabei treten die Repräsentanten indigener Organisationen als >Unterhändler`zwischen den verschiedenen Teilbereichen des Feldes in Erscheinung: Sie vermitteln zwischen Gruppen von Akteuren, die auf Grund der unterschiedlichen Qualität ihrer Ressourcen und verschieden gelagerter Zielsetzungen meist nicht direkt miteinander kommunizieren können oder wollen (vgl. Wimmer 1995: 66). Vom Erfolg ihrer Vermittlungsarbeit hängt der Grad ihrer Anerkennung ab.

Die sneuen< Formen indigener Selbstorganisation besitzen eine straditionsreicher Geschichte und eine lebendige Gegenwart, die von Anpassung und Widerstand handeln. Darstellung und Analyse dieser Prozesse rücken nun am ersten Schauplatz meiner empirischen Forschungen ins Zentrum der Betrachtungen: am Ständigen Forum für indigene Angelegenheiten, dem internationalen politischen Feld indigener Bewegungen. 



\section{Teil 2: \\ Die UNO als politischer Handlungsraum indigener Bewegungen}

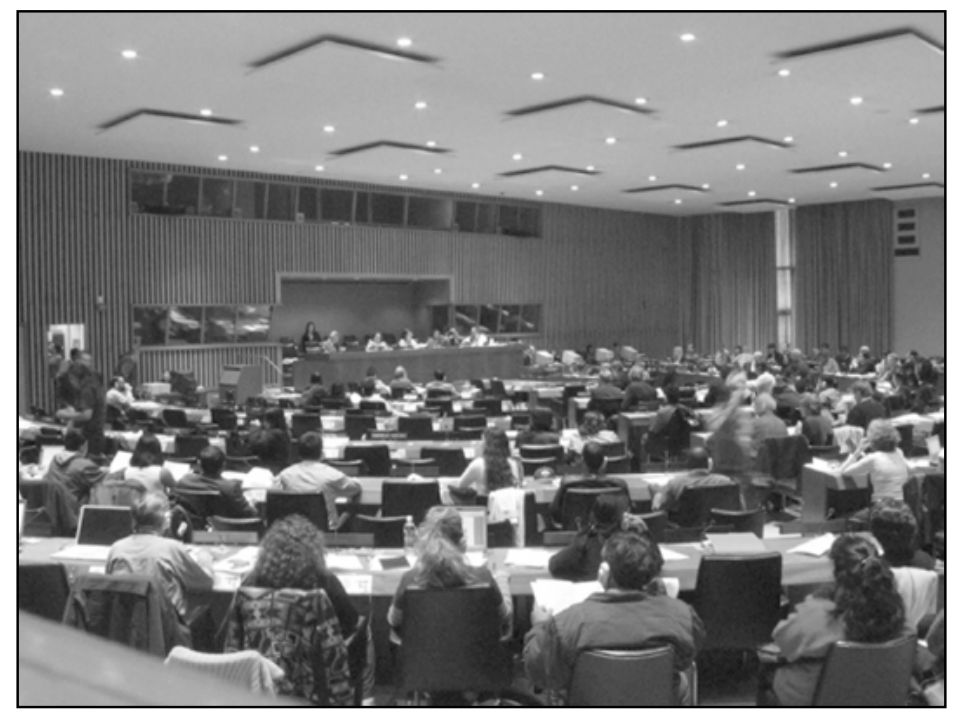

Abbildung 3: Sitzung des Ständigen Forums für indigene Angelegenheiten am UN-Hauptquartier in New York (Foto: Maren Rößler 2005). 



\section{Kapitel III \\ Die Genese einer transnationalen panindigenen Bewegung}

\section{Indigene im Feld der internationalen Beziehungen}

»Die internationalen Räume sind politische Räume, in denen Probleme sichtbar gemacht werden können. Aber es sind nicht die wichtigsten Räume [...]. Auf internationaler Ebene werden die Zusammenkünfte und Feiern gemacht, aber von dort aus muss einer die Idee in die Praxis umsetzen. Und diese Person hat dann meist nicht die Mittel« (Interview Manchineri, Koordinator der COICA, 24. 10. 2003).

In den 1990er Jahren fanden so viele Weltkonferenzen statt wie nie zuvor. Hauptziel der Zusammenkünfte war es, nationale Regierungen zu verpflichten, auf internationaler Ebene beschlossene Aktionsprogramme im eigenen Land umzusetzen. Viele sprachen in diesem Zusammenhang vom Beginn einer neuen Epoche des >Weltregierens $\measuredangle$. Zum einen, weil an diesen Konferenzen neben staatlichen Repräsentanten eine große Zahl Vertreter von NGOs teilnahmen. Zum anderen, weil man bemüht war, globale Aktionspläne auszuarbeiten, welche die verschiedenen Handlungsräume - lokal, national, international - enger miteinander verknüpfen sollten. So entstand zum Beispiel im Rahmen der Konferenz für Umwelt und Entwicklung (1992) in Rio de Janeiro die Agenda 21, ein Aktionsplan für nachhaltige Entwicklung. »Think globally, act locally« wurde in der Folge zu einem allseits zitierten Leitspruch der neuen Initiative. ${ }^{1}$

1 Mit der Agenda 21, die von 178 Staaten verabschiedet wurde, wurden auch die Organisationen der indigenen Völker als Partner im Umweltschutz anerkannt (vgl. Blum 2001: 165). 
Die eingangs zitierte Einschätzung eines international erfahrenen indigenen Repräsentanten deutet indes darauf hin, dass die Umsetzung dieses Mottos eine große Herausforderung darstellt. Aufwand und Wirkkraft von Megaereignissen wie den Weltkonferenzen laufen Gefahr, in einem unausgewogenen Verhältnis zu stehen. Die konkrete Umsetzung der beschlossenen Programme bleibt meist hinter den hohen Erwartungen zurück, unter anderem weil die politischen Kräfteverhältnisse in den `Zielländern « extrem diffus sind. Die im Zusammenhang mit den Weltkonferenzen beschworene Durchbrechung des Monopols staatlicher Macht bei der Gestaltung der internationalen Beziehungen wirft dabei neue Fragen nach den für die Umsetzung von Aktionsplänen zur Verantwortung zu ziehenden Instanzen auf. Ob wirklich eine neue Epoche in der Weltpolitik eingeleitet wurde, bleibt weiterhin eine kontrovers diskutierte Frage. Dennoch ist die von globalen Zusammenschlüssen und Konferenzen ausgehende politische Mobilisierungskraft eindrücklich belegt, betrachtet man zum Beispiel die Geschichte der UNO-Foren für indigene Völker.

Das Ständige Forum für indigene Angelegenheiten am Wirtschafts- und Sozialrat (ECOSOC) in New York ist eine Art jährlicher Weltkonferenz, die seit ihrem ersten Sitzungsjahr 2002 großen Zuspruch erfährt: Jedes Jahr im Mai reisen mehrere hundert Indigene aus aller Welt an den UN-Hauptsitz in New York. Sie kommen, um am »Gipfeltreffen indigener Völker« (Interview Choquehuanca 18.05.2003) teilzunehmen. Das Forum tagt, und die angereisten Teilnehmer nutzen die UNO, um ihre politischen Forderungen zu vermitteln und Strategien kollektiven Handelns zu entwickeln. Dabei, so bemerkt Marcos Matías Alonso, mexikanisches Mitglied des Forums für die Sitzungsperioden von 2002 bis 2004, sei der Name der Veranstaltung irreführend. Das Forum sei nicht wirklich ständig, da keine periodischen Aktivitäten von den Mitgliedern durchgeführt würden, an deren Ende dann das jährliche Treffen im Mai stünde (Interview Matías Alonso 19.05.2004). Eine beständige Arbeit leistet hingegen das Sekretariat des Forums, das mit bezahlten Mitarbeitern sowie Praktikanten ausgestattet ist und die Verbindung zu den verschiedenen UN-Einrichtungen hält.

Politisch engagierte Ethnologen verfolgen und unterstützen die Aktivitäten indigener Aktivisten auf UN-Ebene seit den 1970er Jahren. Im akademischen Kontext haben sich Ethnologen jedoch mit der UNO als einem Schauplatz indigener Bewegungen bislang nicht sehr intensiv beschäftigt. Das Interesse lebte erst in den 1990er Jahren auf und nimmt seit der Jahrtausendwende zu. 1995, mehr als ein Jahrzehnt nach der ersten Sitzung der Arbeitsgruppe indigene Völker in Genf wurde in Deutschland die erste Magisterarbeit dazu veröffentlicht (Dreher 1995). Es folgte eine weitere (unveröffentlichte) im Jahr 1997 (Siebert 1997a) sowie ein Zeitschriftenartikel (Siebert 
1997b). ${ }^{2}$ Des Weiteren erschienen in US-amerikanischen ethnologischen Zeitschriften zwischen 2001 und 2005 eine Handvoll Beiträge zu diesem Thema (z. B. Muehlebach 2001, 2003; Chernela 2005; Oliver-Smith 2005). Vor allem aber entbrannte, ausgelöst durch einen Beitrag Adam Kupers (2003) im Current Anthropology, eine Debatte um das im UN-Kontext in den 1980er Jahren entstandene Konzept >indigene Völker . Zu dieser Diskussion gibt es, unterschiedlichen Argumentationslinien folgend, seit den frühen 1990er Jahren immer wieder Beiträge in verschiedenen Zeitschriften (z. B. Linnekin 1992; Friedman 1993; Siebert 1997b; Béteille 1998; Brown und Delgado 1999; Field 1999; Bowen 2000).

Neben dieser anhaltend heftigen Auseinandersetzung um den Begriff >indigene Völker richtete sich das Augenmerk von Ethnologen, Juristen und Politologen bisher meist auf juristische Aspekte: Die Unterscheidung zwischen Minderheitenrechten und indigenen Rechten sowie die in diesem $\mathrm{Zu}-$ sammenhang vor allem geführte Diskussion um das $>$ Recht auf Selbstbestimmung haben eine umfangreiche Literatur produziert (z. B. Anaya 1992, 1995; Barsh 1986; Corntassel und Hopkins 1995; Daes 1989, 1994; Dandler et al. 1994; Kymlicka 1999; Posey und Dutfield 1996; Turner 1997).

Rechtsfragen erlangten nicht zufällig zentrale Bedeutung: Die UNO steht symbolisch für eine Ära, in der Menschenrechte in zunehmendem Maße an Bedeutung gewonnen haben. ${ }^{3}$ Dabei lässt sich beobachten, dass der Begriff in der jüngeren Vergangenheit für eine Vielzahl unterschiedlicher politischer Projekte eingesetzt wurde, die sich durchaus konträr zueinander verhalten können: Zum Beispiel wird er, seit der Präsidentschaft von Jimmy Carter, vor allem von den USA gerne zur Rechtfertigung einer globalen Interventionspolitik benutzt. Aber er dient auch marginalisierten Gruppen innerhalb von Nationalstaaten im Kampf um Landrechte, politische Beteiligung und Aufwertung ihrer stigmatisierten Identitäten.

Für Vertreter indigener Völker öffnete sich die UNO erst in den 1970er und vor allem 1980er Jahren. Die Geschichte indigener Bewegungen auf internationaler Ebene beginnt dennoch schon lange vor der zweiten Hälfte des 20. Jahrhunderts. Sie bildet deshalb einen Fokuspunkt der Betrachtungen in diesem Teil des Buches. Daneben spielt der für die UNO relevante Kulturbegriff im Rahmen der Debatte um die konzeptionellen Implikationen des Begriffs >indigene Völkerく eine Rolle. Dennoch verstehe ich meine Studie nicht als weiteren Beitrag zur Debatte um Essentialismus und Konstruktivismus des Indigenitätsdiskurses. Vielmehr rücke ich das Ständige Forum für indigene Angelegenheiten als »politisches Feld« (Bourdieu 2001) der indi-

2 Vgl. Ausführungen Kapitel II.

3 So war bekanntermaßen der Gründungsgedanke der UNO selbst die Schaffung einer Instanz für Weltfrieden und Menschenrechte. 
genen Bewegungen in den Mittelpunkt. Es geht mir um eine Sichtbarmachung der verschiedenen politischen Kräfte, die in diesem Feld im Wettstreit miteinander stehen. Hauptakzent wird dabei auf der Gruppe indigener Teilnehmer der Treffen des Forums liegen. Welche Bedeutung besitzt diese politische Plattform für die Akteure indigener Bewegungen? Welche Gruppen sind am Forum präsent, welche Spannungen ergeben sich in ihrem Verhältnis untereinander? Wie kann man sich diese Spannungen erklären?

\section{Geschichte indigener Bewegungen im Kontext von Völkerbund und Vereinten Nationen}

Anfang des 20. Jahrhunderts war der Völkerbund ${ }^{4}$ die erste zwischenstaatliche Organisation, die auch für Indigene Relevanz besaß, da sie den Schutz von Minderheitenrechten - zuvor eine Angelegenheit des Vertragsschlusses zwischen einzelnen Staaten - zu einer ihrer wichtigsten Aufgaben erklärte. Allerdings wurde der Völkerbund von damals bereits existierenden indigenen Zusammenschlüssen aus den USA, Kanada, Neuseeland oder Skandinavien relativ selten genutzt, wohl auch, weil diesbezügliche Versuche zumeist zum Scheitern verurteilt waren. Die Schutzmaßnahmen des Völkerbundes konzentrierten sich auf Minderheiten in Zentral- und Westeuropa (vgl. Morin 1992: 493).

1923 unternahm dennoch ein indianischer Repräsentant aus Nordamerika den Versuch, an einem Treffen des Völkerbundes teilzunehmen: Deskaheh, der Sprecher des Council of the Iroquoi Confederation of Canada, reiste nach Genf an den Sitz der Organisation. Die Iroquesen hatten im Bund der Six $\mathrm{Na}$ tions versucht, einen lokalen Autonomiestatus zu erhalten, den ihnen die kanadische Regierung aber nicht zubilligte. Stattdessen wollte diese die Stammesführung durch ein neues, demokratisch zu wählendes Organ ersetzen. Es kam zu internen Konflikten und einer Aufspaltung der Six Nations in die sogenannten >Traditionalisten $<$ und >Modernisten . Chief Deskaheh reiste in der Folge als Sprecher der >Traditionalisten hatte den Fall auf die Agenda eines Treffens der Generalversammlung gesetzt. Die englische Regierung erreichte jedoch, dass der Tagesordnungspunkt gestrichen wurde - sie erklärten den Konflikt zu einer internen Angelegenheit der Britischen Krone (vgl. Minde 2005: o. S.; Anaya 1995: 46; Niezen 2003: 31ff.). Minde (2005: o. S.) erscheint es ungewöhnlich, dass ein straditioneller Stammesführer der Erste war, der auf internationaler Ebene versuchte, einen lokalen Konflikt zu lösen: Der Völkerbund symbolisierte eine Weltordnung, gegen die sich die >Traditionalisten $`$ wehrten. Sie erkannten die politische Le-

4 Vorläufer der UNO, gegründet nach dem 1. Weltkrieg; engl.: League of Nations. 
gitimität der kanadischen Regierung nicht an. Dennoch: Der einzige Ort, an dem man sich gegen den Eingriff Kanadas in die innere Autonomie des Bündnisses der Six Nations zur Wehr setzen konnte, war eine Instanz, die als dem Staat >übergeordnet` verstanden wurde. Da die kanadische Regierung bereits eine Spaltung im Innern ihrer Gruppe verursacht hatte, blieb dem Council of the Iroquoi Confederation of Canada nur dieser Weg, den internen und externen Machtkampf für sich zu entscheiden. Doch die Möglichkeiten der politischen Einflussnahme blieben auch auf Ebene des Völkerbundes ungleich verteilt, und so scheiterte ihr Plan, ebenso wie andere frühe Versuche, über internationale Instanzen Druck auf die Regierung im eigenen Land auszuüben - eine Situation, die sich erst mit der zweiten indigenen Organisationswelle in den 1960er und 70er Jahren ändern sollte. Ein interessanter Aspekt der Kampagne von Deskaheh ist jedoch, dass er die gleichen Mittel benutzte, die auch heute von indigenen Lobbygruppen verwendet werden: Aufruf zu öffentlicher Solidarisierung durch die Medien, Gespräche mit einzelnen Staatsrepräsentanten, bei denen er eine kurze schriftliche Zusammenfassung der Probleme überreichte, Zuhilfenahme eines Rechtsanwaltes und die Anwendung einer legalen Staatsrhetorik, um den Ansprüchen Kanadas zu begegnen (Niezen 2003: 50). Deskahehs Misserfolg entsprang also nicht seiner methodischen Herangehensweise, sondern der Übermacht des dominanten internationalen Ordnungssystems: Der Völkerbund sollte Beziehungen zwischen souveränen Nationalstaaten regeln und enthielt sich der Einmischung in innere Angelegenheiten seiner Mitglieder. Dieses Selbstverständnis wandelte sich erst nach dem zweiten Weltkrieg mit der Etablierung der Vereinten Nationen (UNO).

Bei Einrichtung der UNO nach dem zweiten Weltkrieg wurde die Fokussierung auf Minderheitenfragen zugunsten individueller Menschenrechte aufgegeben. Die Legitimation dafür las sich folgendermaßen: Wenn Angehörige von Minderheiten zu gleichberechtigten Staatsbürgern erklärt würden, besäBen sie die gleichen Rechte und müssten keine Diskriminierung mehr fürchten. Vor allem die Repräsentanten lateinamerikanischer Staaten, aber auch die USA wehrten sich heftig gegen einen Vorstoß der damaligen UDSSR und Jugoslawiens, Minderheitenrechte mit in die Allgemeine Erklärung der Menschenrechte aufzunehmen (Minde 2005: o. S.; Morin 1992: 493f.). ${ }^{5}$

Die Gründungscharta der UNO aus dem Jahr 1945 legte unter anderem Normen und Regeln für das Verhalten der Mitgliedsstaaten untereinander sowie teilweise in Bezug auf deren Innenpolitik fest. Konträre Interessen der

5 Morin und Saladin d'Anglure merken dazu an: »La Déclaration de 1948 reflète, en fait, beaucoup plus le système de valeur dominant en Europe occidentale depuis la fin du XVIIIe siècle que celui mis en avant par le régime soviétique en URSS« (Morin und Saladin d'Anglure 1994: 193). 
Mitgliedsstaaten prägten den Entstehungsprozess. Das schlug sich in strukturellen Besonderheiten nieder: Zum einen wollten die Siegermächte des zweiten Weltkriegs eine Institution schaffen, die den Weltfrieden sicherte, aber auch der neuen Weltordnung Ausdruck verlieh. Dabei symbolisierte die Zusammensetzung und Funktionsweise des Sicherheitsrates diese neue Weltordnung. Zum anderen forderte der Ost-West Konflikt Kompromisse bei der Aushandlung der Organisationsstrukturen. So entstand zum Beispiel der Wirtschafts- und Sozialrat auf Bestreben der sozialistischen Länder. Damit unterschieden sich die Vereinten Nationen vom Völkerbund, der vergeblich versucht hatte, eine internationale Zusammenarbeit zur Lösung wirtschaftlicher, sozialer und kultureller Probleme im Rahmen der Organisation zu institutionalisieren (vgl. Gareis und Varwick 2002: 218). US-amerikanische NGOs wiederum setzten sich für die Schaffung der Menschenrechtskommission ein. Sie wollten damit gewährleisten, dass kein Staat je wieder uneingeschränkte Macht über das Individuum ausüben könne. Staaten wie Großbritannien oder die USA stimmten dem nur zögerlich zu. Während die britische Regierung Angst hatte, dass ihre Indienpolitik an der Menschenrechtskommission in die Kritik geraten könnte, fürchtete die US-amerikanische Regierung Auseinandersetzungen um ihren Umgang mit der schwarzen Bevölkerung des Landes (vgl. Morin und D'Anglure 1994: 191).

Die ausgehandelten Kompromisse im Aufgabenfeld und in der Struktur der UNO machten diese zu einer Instanz, die sich einerseits bis heute mit dem Vorwurf mangelnder Effizienz und Umsetzungskraft auseinandersetzen muss. Andererseits entstanden gerade durch die widersprüchlichen Bedürfnisse der verschiedenen Mitgliedsstaaten in der Folge Räume zur Diskussion und Infragestellung der etablierten Ordnung, die das Emporkommen neuer politischer Akteure wie die der indigenen Bewegungen begünstigte. Hierbei spielte der ECOSOC eine zentrale Rolle, denn in seiner Struktur war die Aufnahme nicht-staatlicher Akteure in die Vereinten Nationen angelegt. Der Wirtschafts- und Sozialrat ist, so Kofi Annan,

»das einzige Organ der Vereinten Nationen, dem in der Charta ausdrücklich der Auftrag zur Koordinierung der Tätigkeiten der Sonderorganisationen und zur Konsultation mit nichtstaatlichen Organisationen erteilt wird. Unter seiner Schirmherrschaft ist ein Netz von Fach- und Regionalkommissionen tätig, die ihre Arbeit zunehmend auf die Verwirklichung von Entwicklungszielen abstellen. [...] Der Wirtschafts- und Sozialrat stand jedoch in der Vergangenheit allzu häufig am Rand der globalen wirtschaftlichen und sozialen Ordnungsstruktur« (United Nations 2002b: 47f.). 
Die Grundlagen dieser »globalen wirtschaftlichen und sozialen Ordnungsstruktur « manifestierten sich nach dem zweiten Weltkrieg in einem ideologischen Sendungsbewusstsein der Siegermächte. Man begann eine »industrielle, technologische und wohlfahrtsorientierte Kolonisierung « (Minde 2005: o. S.) peripherer Gebiete. Bei seiner Amtantrittsrede 1949 bezeichnete der damalige US-Präsident Harry Truman die Hälfte der Erdbevölkerung als `ökonomisch unterentwickelt‘ und prägte damit ein Entwicklungsparadigma, das die Unterschiede zwischen und innerhalb von Gesellschaften evolutionistisch begründete. Ein erstmals 1940 durchgeführter globaler statistischer Vergleich des Pro-Kopf-Einkommens teilte die Welt in arm und reich. Mit Gründung internationaler Organisationen wie Weltbank und Internationalem Währungsfond (IWF) im Jahre 1944 institutionalisierte sich der Glauben an wirtschaftliche Entwicklung als Garant einer friedlichen und gerechten Weltordnung. Die politisch-strategische Dimension dieses Entwicklungsparadigmas zeigte sich im Zuge der Entkolonisierungspolitik der 1960er Jahre eindrücklich in der Dreiteilung der Welt in die industrialisierte Erste, die kommunistische Zweite und die nicht-industrialisierte Dritte Welt (vgl. Escobar 1995: 23, 34, 40).

\section{Die UNO und das Indigenenproblemı}

1921 fertigte die International Labour Organisation (ILO) eine Studie zu den Arbeitsbedingungen indigener Arbeitnehmer an, deren Ergebnisse aber erst 1953 in dem Buch Indigenous Peoples: Living and Working Conditions of Aboriginal Populations in Independent Countries veröffentlicht wurden. 1957 verabschiedete die ILO die Konvention 107 zum Schutz >tribaler und indigener Gruppen` mit einem grundsätzlich assimilatorischen Ansatz. Die Konvention 107 stand damit ganz im Zeichen des eben ausgeführten dominanten (entwicklungs)politischen Klassifizierungssystems. Dennoch blieb sie bis 1989 die weltweit einzige verbindliche Übereinkunft, die sich überhaupt mit >indigenen Bevölkerungsgruppen` beschäftigte, deren Rechte benannte und Regierungen auf ihre diesbezüglichen Verpflichtungen verwies. Ferner sollte durch die Konvention gewährleistet werden, dass indigenes Gewohnheitsrecht und zu einem gewissen Maße die nicht-industrielle materielle Lebensgrundlage ethnischer Minderheiten geschützt würden.

In den 1970er Jahren regte sich Kritik an der ILO-Konvention 107 von Seiten der sich neu gründenden indigenen Organisationen. Deren Sprecher bemängelten vor allem, dass das Dokument ohne Beteiligung indigener Repräsentanten erarbeitet worden sei. Der in der Konvention verfolgte assimilatorische Ansatz offenbarte sich derweil auch noch in einer anderen internationalen Organisation dieser Zeit - dem 1940 etablierten Instituto Indige- 
nista Interamericano ${ }^{6}$. Auch dieses Institut, heute eine Behörde der Organisation Amerikanischer Staaten (OAS), wollte die indigenen Bevölkerungsgruppen in die modernen Nationalstaaten assimilieren und führte dementsprechende Entwicklungsprogramme in indianischen Gemeinden durch.

Trotz der Kritik indigener Organisationen spricht Anaya (1995) sowohl der ILO Konvention 107 als auch dem Instituto Indigenista Interamericano eine entscheidende Rolle für die weiteren Entwicklungen zu:

$»[\ldots]$ with these programs the subject of people identified by their indigenousness vis-à-vis majority or dominant populations established a foothold in the international system through the conceptual and institutional medium of human rights. That foothold and the language of human rights became the basis for a much enhanced international concern for indigenous peoples and a reformed normative regime regarding them« (Anaya 1995: 45).

Aber auch an anderer Stelle innerhalb der UNO gab es eine Reihe von Versuchen, die Situation ethnischer Minderheiten mitzubedenken. So wurde 1946 die Menschenrechtskommission vom Wirtschafts- und Sozialrat damit beauftragt, Vorschläge und Berichte zum Thema Minderheitenschutz zu erarbeiten. 1947 rief man zu diesem Zweck eine Unterkommission ${ }^{7}$ ins Leben. Diese erarbeitete in der Folge eine Reihe von Definitionen der Konzepte >Minderheiten`, >indigene Bevölkerungsgruppen` und `indigene Völker`. 1948 schlug die bolivianische Regierung vor, eine weitere Unterkommission für das Studium sozialer Probleme Indigener einzurichten. 1949 verabschiedete der Wirtschafts- und Sozialrat eine Resolution für eine Studie zu den »sozialen Problemen Eingeborener und anderer unterentwickelter Gruppen des amerikanischen Kontinents « (vgl. Anaya 1995: 44). Doch die Umsetzung dieser Studie wurde von den betroffenen Staaten verhindert. Ende der 1960er Jahre bildeten sich zivilgesellschaftliche Organisationen wie die International Work Group on Indigenous Affairs (IWGIA) und Survival International ${ }^{8}$, die Druck auf die

6 Dt. >Interamerikanisches Indigenismus-Institut<.

7 Die Kommission zur Verhinderung von Diskriminierung und zum Schutz von Minderheiten. Auf Grund ihres niederen Ranges innerhalb der UNO-Hierarchie hat die Kommission nur wenige Erfolge feiern können. Allerdings hat sie es geschafft, den Artikel 27 in den Pakt zu zivilen und politischen Rechten einzuführen, der Regierungen dazu aufruft, auf ihrem Staatsgebiet lebenden Minderheiten die Möglichkeiten zur Ausübung ihrer Religion, Sprache und Kultur einzuräumen. Dennoch werden die Minderheitenrechte auch in diesem Pakt als Individualrechte und nicht als Kollektivrechte behandelt.

8 IWGIA entstand nach dem XXXVII. Südamerikanistenkongress in Stuttgart (August 1968) als Initiative politisch engagierter Ethnologen (Schüler Frederik Barths), die mit der Organisationsgründung auf Massentötungen an Indianern in Kolumbien und Brasilien reagierten. Survival International wurde 1969 ins Leben gerufen. In den USA wurde 1972 die Organisation Cultural Survival von 
Regierungen ihrer Länder ausübten, damit diese sich bei der UNO für Maßnahmen zum Schutz indigener Gruppen einsetzten. Vor allem IWGIA konzentrierte sich bei ihrer Lobbyarbeit auf die UNO. Sie wurde im Laufe der letzten dreißig Jahre zu einer der wichtigsten internationalen Organisationen für die Durchsetzung indigener Rechte. ${ }^{9}$

Diese Bemühungen euro-amerikanischer NGOs wurden bestärkt durch die 1969 vom UN- Sonderberichterstatter Hernán Santa Cruz vorgelegte Studie zu Rassendiskriminierung auf wirtschaftichem, politischem, sozialem und kulturellem Gebiet. In einem Kapitel dieser Studie befasste sich der Autor mit der Lage Indigener und regte seinerseits an, eine umfassende Studie zur Thematik zu erstellen. So empfahl der Wirtschafts- und Sozialrat 1971 die Durchführung zweier Studien: eine zum Problem der Diskriminierung indigener Bevölkerungen, die zweite zur Situation von Minderheiten. Damit unterschied man im UN- Kontext erstmals beide Gruppen voneinander (vgl. Morin und Saladin D'Anglure 1994: 194).

Die Studie zu indigenen Bevölkerungen übertrug man dem Ecuadorianer Alfonso Martínez Cobo, einem Mitglied der Kommission zur Verhinderung von Diskriminierung und zum Schutz von Minderheiten. Nach zwölf Jahren legte dieser einen Bericht vor - bestehend aus fünf Bänden und auf der Grundlage von Informationen aus siebenunddreißig UN-Mitgliedstaaten. Er empfahl die Ausarbeitung einer Deklaration über die Rechte und Freiheiten indigener Völker als mögliche Grundlage für eine spätere Konvention. ${ }^{10}$ Ferner lieferte Martínez Cobo eine Definition des Begriffes >indigene Völker^. Mit dieser stieß er jedoch zunächst auf den Widerstand des World Council of Indigenous Peoples (WCIP). Daraufhin ergänzte Martínez Cobo die Definition durch das Kriterium der Selbstidentifikation. Weil die Definition sehr weit gefasst ist, halten die Diskussionen um sie bis zum heutigen Tage an. Folgender Kriterienkatalog für die Kategorie sindigene Völker` wird von ihr aufgestellt:

- Erstankömmlingsrecht in Bezug auf die Besetzung und die Nutzung eines bestimmten Territoriums;

Ethnologen der Harvard Universität gegründet (vgl. Brysk 2000: 10, 88; Saladin d'Anglure 1992: 525).

9 Die älteste Lobbyorganisation dieser Art ist die Society for the Protection of Aboriginies, die bereits 1837 in Großbritannien gegründet wurde und sich 1909 mit der Anti-Slavery Society zusammenschloss (Saladin d'Anglure 1992: 526).

10 Die Tatsache, dass es nun eine eigene Studie zur Situation indigener Bevölkerungsgruppen gab bedeutete für die UNO, dass die Bedürfnisse Indigener getrennt von denen der Minderheiten wahrgenommen werden mussten. Somit ebnete diese Studie das Terrain für Debatten über den völkerrechtlichen Status indigener Gruppen, die bis heute andauern und sich am eindrücklichsten im jahrelangen Ringen um die Verabschiedung der Erklärung der Rechte indigener Völker manifestiert haben. 
- freiwillige Aufrechterhaltung kultureller Differenz, die folgende Aspekte beinhalten kann: Sprache, soziale Organisation, Religion, spirituelle Werte, Produktionstechniken, Gesetze, Institutionen;

- Selbstidentifizierung und Anerkennung der Andersartigkeit von Seiten anderer Gruppen sowie von staatlicher Seite;

- Erfahrung der Unterwerfung, Marginalisierung, des Ausschlusses und der Diskriminierung, unabhängig davon, ob diese Bedingungen gegenwärtig weiter existieren. ${ }^{11}$

Trotz der Kontroversen, die um diesen Begriff geführt werden, lehnen indigene Teilnehmer der UNO-Foren die Notwendigkeit einer stärkeren Eingrenzung der Kategorie zumeist ab. ${ }^{12}$ Sie wollen selber bestimmen, wer zur Gruppe der >indigenen Völker` gehört und sehen zunächst einmal die Vorteile einer weitgefassten Klassifizierung: Mit der Gruppengröße wächst die Präsenz an der UNO und damit die politische Wirkkraft (vgl. Dreher 1995: 3ff.; Hodgson 2002: 1039; Pritchard 2001: 301; Stamatopoulou 1994: 66; Saugestad 2004: 264).

Die Entwicklungen an der UNO sind eng verbunden mit Prozessen indigener Selbstorganisation auf regionaler bzw. lokaler Ebene. Für die Herausbildung einer transnationalen panindigenen Bewegung spielten vor allem Organisationen aus Nordamerika eine zentrale Rolle. Während sich in Lateinamerika ab den 1950er Jahren lokale Organisationen bildeten und auch hier frühe Vorläufer bereits Anfang des 20. Jahrhunderts entstanden, waren die Aktions- und Verhandlungsmöglichkeiten auf Grund der politischen Lage in weiten Teilen Lateinamerikas wesentlich eingeschränkter als in Nordamerika. Dennoch waren ab den 1970er Jahren auch lateinamerikanische Akteure auf allen wichtigen internationalen Konferenzen zugegen. Diese gründeten ihrerseits in der Folge regionale indigene Zusammenschlüsse.

11 Martínez Cobo hatte bei der Definition vor allem Gruppen im Blick, die in Australien, Nord- und Südamerika oder Neuseeland leben. Auch einige afrikanische Gruppen werden in seinem Bericht von 1986 explizit genannt - z. B. die Maasai, Tuareg, Khoi-San (Dreher 1995: 9).

12 Dreher (1995) und Siebert (1997b) verweisen auf die Schwierigkeiten, die das Kriterium der Selbstidentifikation als indigen in sich bergen. So meldete sich zum Beispiel bei der Sitzung der Arbeitsgruppe im Juli 1994 die ultrarechte burische Afrikanische Volksfront zu Wort und bezeichnete sich als indigen. Sie verweisen aber auch auf die Reaktionen der anderen Teilnehmer, die Protest einlegten bzw. während des Redebeitrags geschlossen den Saal verließen. Diese Reaktionen deuten sie als >indigenen< Regulationsmechanismus zur Eigendefinition von Gruppengrenzen. 


\section{Die sneuen indigenen Bewegungen im 20. Jahrhundert}

1944 wurde die erste dauerhafte indigene Organisation in den USA ins Leben gerufen, nachdem zur Jahrhundertwende und Anfang des 20. Jahrhunderts bereits eine Reihe Vorläuferorganisationen gegründet worden waren. Diese setzten sich, zumindest in Nordamerika, zumeist aus der Stammesführerschicht zusammen. Auch in Neuseeland gab es bereits in den 1920er und 30er Jahren eine Reihe von Maori-Gruppen, die sich für lokale Selbstbestimmung einsetzten. Minde verweist auf den interessanten Umstand, dass diese Stammesführer ihre Forderungen auch auf Wohlfahrtsmaßnahmen ausdehnten, während auf staatlicher Ebene legal verankerte indigene Repräsentanten sich auf Kulturthemen spezialisierten: »Many accepted assimilation and were against discrimination, but at the same time were often in favour of preserving and practising their distinctive cultural forms« (Minde 2005: o. S.). Die größere soziale Distanz zur >Basis` der von staatlicher Seite eingesetzten MaoriVertreter ließ diese gleichzeitig eine Art museale Sicht auf die Lebensweise der Maori entwickeln: Der Wunsch, kulturelle Differenzen zu pflegen und zu erhalten, wurde in diesem Fall bei denjenigen zu einem Anliegen, deren politische Legitimität in der eigenen Gruppe wohl am stärksten hinterfragt worden sein dürfte. Die Beobachtung von Matías Alonso, dem bereits erwähnten Delegierten der mexikanischen Regierung am Ständigen Forum für indigene Angelegenheiten zwischen 2002 und 2004, gibt weiteren Aufschluss zu diesem Punkt. Matías Alonso meint: »Wenn kulturelle Themen wie Erziehung oder Pflege der eigenen Sprache und Gewohnheiten diskutiert werden, beunruhigt dies die Regierungen nicht. Was sie nicht wollen ist, dass man politische Themen wie Autonomie, Selbstbestimmung und Territorialfragen anspricht« (Gespräch Matías Alonso 23.05.2005). Die Spezialisierung auf kulturelle Themen der von Seiten der neuseeländischen Regierung eingesetzten Maori-Repräsentanten entsprach somit wahrscheinlich ihren minimalen politischen Möglichkeiten.

In den 1960er und 70er Jahre begann eine neue Welle indigener Organisationsgründungen in verschiedenen Erdteilen: Im lokalen, nationalen und internationalen Kontext entstanden Zusammenschlüsse, die sich für die Anerkennung marginalisierter Gruppen auf Grund ethnischer und kultureller Merkmale einsetzten. Damit wurden territoriale Ansprüche sowie wirtschaftliche und soziale Forderungen mit einem aus der Ethnologie vertrauten Anliegen legitimiert: dem Erhalt der kulturellen Vielfalt. Kultur wurde zum Politikum. Gerade im Fall Lateinamerikas spielten religiöse Institutionen bei diesen Entwicklungen eine wichtige Rolle: So richtete 1971 der World Council of Churches die bereits erwähnte erste Barbados-Konferenz - eine Zusammenkunft zwischen Regierungsvertretern und Ethnologen - mit aus. 
1975 fand die >indigene Version< dieser Veranstaltung statt: in Port Alberni, Kanada, kamen Vertreter nord- und lateinamerikanischer indigener Organisationen, aber auch Vertreter aus Europa und Neuseeland, zusammen und gründeten den WCIP. Diese transnationale indigene Organisation wollte bereits bestehende Kontakte zwischen Indigenen verschiedener Kontinente stärken und diese an der UNO vertreten (vgl. Siebert 1997: 78). Auch entwickelten ihre Mitglieder - bereits auf einer ihre Gründungssitzung vorbereitenden Konferenz im Jahre 1974 - folgende Definition für den Begriff >indigene Völker`:

»The term indigenous people refers to people living in countries which have a population composed of differing ethnic or racial groups who are descendants of the earliest populations living in the area and who do not as a group control the national government of the countries within which they live« (Sanders 1980: o. S.).

Im urbanen Kontext lebende US-amerikanische Indianer hatten Anfang der 1970er Jahre die American Indian Movement, mit Sitz in Detroit, ins Leben gerufen. Sie verlangten von der US-amerikanischen Regierung, die während der Kolonialzeit unterzeichneten Verträge einzuhalten. Um diese Forderung durchzusetzen, bauten sie verstärkt auf internationalen Druck. $\mathrm{Zu}$ diesem Zweck gründeten sie 1974 den International Indian Treaty Council (IITC). Der IITC beantragte 1977 vor der UNO den Beraterstatus für Nicht-Regierungsorganisationen ${ }^{13}$ und bekam als zweite indigene Organisation Teilnahmerechte innerhalb von UN-Gremien. Zuvor hatte bereits 1974 die National Indian Brotherhood of Canada diesen Status erhalten, den sie bei Gründung des WCIP jedoch an den >übergeordneten 1980: o. S.). Beide Organisationen, IITC und WCIP, prägten in der Folge die Arbeit indigener Bewegungen im UN-Kontext. Mit dem Beraterstatus am Wirtschafts- und Sozialrat erlangten sie zum Beispiel direkten Zugang zu internationalen Konferenzen wie dem Russel Tribunal in Rotterdam, das 1980 stattfand. ${ }^{14}$ Die Führungsrolle dieser indigenen Zusammenschlüsse im internationalen Kontext wurde aber auch deutlich, als die UNO das IITC offiziell

13 Staaten, Völkerrechtssubjekte und nicht-staatliche Organisationen, die keine reguläre Mitgliedschaft bei den Vereinten Nationen anstreben oder erhalten können, haben die Möglichkeit, einen Beraterstatus zu beantragen. Dieser erlaubt es ihnen, an den Sitzungen des Wirtschafts- und Sozialrats ohne Stimmrecht teilzunehmen. Sie können Sachfragen auf die Tagesordnung setzen, Beobachter entsenden und auf Antrag oder Anfrage förmlich konsultiert werden.

14 Das Russell Tribunal zu den Rechten der Indianer beider Amerikas wurde 1980 in Rotterdam abgehalten, um an indigenen Völkern verübte Verbrechen zu verurteilen. Mehr als die Hälfte der Jury und der Berater waren Ethnologen. Das Russel Tribunal wird von vielen indigenen Repräsentanten als Katalysator für die transnationale indigene Bewegung gesehen (Brysk 2000: 87). 
beauftragte, für die Teilnahme indigener Organisationen an der ersten Internationalen NGO-Konferenz zur Diskriminierung indigener Bevölkerungsgruppen beider Amerikas im Jahre 1977 in Genf zu sorgen. Einige Autoren sehen diese Tagung als Wendepunkt im Umgang der Vereinten Nationen mit indigenen Bevölkerungsgruppen (z. B. Morin 1992; Morin und Saladin d'Anglure 1994; Anaya 1995): Zum ersten Mal traten hier mehrere hundert Indianer aus ganz Amerika öffentlich auf. Sie forderten, als Völker und nicht als Minderheiten anerkannt zu werden. \Landrechte $<$ und `Selbstbestimmung waren ihre Schlagworte. Ferner forderten sie eine Revision der ILO-Konvention 107 und riefen die UNO zur Gründung einer eigenen Arbeitsgruppe für indigene Völker auf. Zwei weitere Konferenzen folgten 1978 und 1981. Bei der zweiten verabschiedete man eine Erklärung, in der »das Recht indigener Völker auf die Aufrechterhaltung ihrer traditionellen wirtschaftlichen und kulturellen Strukturen sowie ihrer eigenen Sprachen« gefordert und »die besondere Beziehung Indigener zu ihrem Land « herausgestellt wurde, woraus sich »ein Recht auf ihre angestammten Territorien ergebe« (Morin 1992: 500). An dieser Konferenz nahmen nicht nur Vertreter indigener Organisationen aus Nord- und Südamerika, sondern auch Repräsentanten aus Australien und Norwegen teil. Dennoch beeinflussten am Anfang vor allem die Zusammenschlüsse nordamerikanischer Indianer in entscheidendem Maße Form und Inhalt der Diskussionen über indigene Völker an der UNO. Heute beteiligen sich auch verstärkt Gruppen aus Lateinamerika, Nordeuropa und Ozeanien sowie aus wohlhabenderen Ländern Afrikas und Asiens an den Diskussionen (vgl. Minde 2005: o. S; Dreher 1995: 12). Festzuhalten bleibt, dass ohne politische Organisationsmöglichkeiten auf nationaler Ebene auch die Teilnahme an internationalen Treffen für diese Gruppen kaum möglich ist.

Bezüglich politischer Partizpationsmöglichkeiten auf nationaler Ebene vollzogen sich in den 1970er Jahren entscheidende Veränderungen. So hatte zum Beispiel die US-amerikanische Regierung 1975 den indianischen Gruppen interne Selbstbestimmung zugesichert. Allerdings mussten diese dafür offiziell ihre Zugehörigkeit zur US-amerikanischen Nation bestätigen. Kanada verhandelte seit 1974 mit indigenen Gruppen über Landrechte. In den skandinavischen Ländern wiederum übten verschiedene nicht-indigene Unterstützergruppen Druck auf ihre Regierungen aus. Durch diese Lobbyarbeit konnten viele indigene Aktivisten internationale Foren besuchen. Dort brachten sie ihre politischen Forderungen in Zusammenhang mit Menschenrechtsdiskursen und nutzten dabei auch die Entkolonisierungspolitik der UNO.

\section{Der Entkolonisierungsprozess bei der UNO}

In einer Resolution aus dem Jahr 1960, der Deklaration über die Gewährung der Unabhängigkeit für koloniale Länder und Völker, wurde die Entkoloni- 
sierung von ehemaligen afrikanischen und asiatischen Kolonien in der UNGeneralversammlung beschlossen. Das >Recht auf Selbstbestimmungく erlangte in diesem Zusammenhang zentrale Bedeutung. Dabei wurden die Träger des Selbstbestimmungsrechts jedoch nicht näher definiert. Man knüpfte stattdessen weitestgehend an die koloniale Grenzziehung an. Den Gedanken der Selbstbestimmung griffen Gruppen aus ehemaligen Siedlerkolonien wie den USA, Kanada, Australien und Neuseeland in den 1970er Jahren auf. Sie machten das >Indigenenproblem rung. Denn, so lautete die Argumentation, in Asien oder Afrika sei die Urbevölkerung entkolonisiert worden. In Ländern wie den USA aber habe es lediglich eine Unabhängigkeit vom europäischen Mutterland gegeben, die einstigen Kolonisatoren seien weiter im Land geblieben (Siebert 1997b: 86; Pritchard 2001: 316; vgl. auch Stamatopoulou 1994). Auch in Lateinamerika war die Sprache transnationaler panindianischer Zusammenschlüsse wie die des Consejo Indio de Sudamérica (CISA), der Ende der 1970er Jahre entstand, geprägt vom Anti-Kolonialismus-Diskurs. Zwei Typen sozialer Bewegungen aus anderen Weltteilen, welche die Anerkennung der Identität der Kolonisierten forderten, formten das Selbstverständnis von CISA: Schwarzenbewegungen wie die Black Power Movement, Negritude und der Panafrikanismus sowie die nordamerikanischen indianischen Bewegungen. Sie unterstrichen die interne Kolonisierungssituation, der sie in ihren Ländern ausgesetzt waren. Auch der CISA argumentierte auf dieser Grundlage und betonte die Bedeutung früherer indigener Zivilisationen, die es wiederherzustellen galt (Smith 2002a: 13).

Die zahlreichen Aktivitäten von indigener und nicht-indigener Seite führten 1982 zur Gründung der Arbeitsgruppe indigene Völker ${ }^{15}$. Diese setzte es sich zur Aufgabe, die internationalen Rechtsstandards zu reformieren, indem >indigene Völker` darin Aufnahme fänden. Die ILO verabschiedete wiederum Ende der 1980er Jahre die Konvention 169, eine revidierte Fassung der 1957 erarbeiteten Konvention 107. Während letztere, wie bereits dargestellt, auf die Assimilierung indigener Bevölkerungsgruppen gesetzt hatte, hob man in der neuen Konvention den Aspekt ihrer Selbstbestimmung hervor.

Hatten in den 1980er Jahren Organisationen aus Nord- und, in kleinerem Umfang, Südamerika die Treffen der Arbeitsgruppe dominiert, traten in den 1990er Jahren auch verstärkt afrikanische und asiatische Gruppen in Erscheinung. Da die Definition, wer in diesen Ländern als indigen gelten könne, jedoch ungleich schwerer erschien als zum Beispiel in Nord- und Südamerika, entbrannten neue heftige Diskussionen um die von Martínez Cobo erarbeitete UN-Definition zu indigenen Völkern. Die wachsende internationale politische

15 Im Folgenden steht die Kurzbezeichnung >Arbeitsgruppe〈 für Arbeitsgruppe indigene Völker. 
Präsenz Indigener fand jedoch in den 1990er Jahren auf verschiedene Art symbolischen Ausdruck: 1992 würdigte man die langjährige Arbeit der Quiché-Maya Menschenrechtlerin Rigoberta Menchú Tum mit dem Friedensnobelpreis; das Jahr 1993 erklärte die UN-Generalversammlung zum >Internationalen Jahr der Indigenen weltweit<, gefolgt von zwei Internationalen Dekaden (1995-2004 und 2005-2014) zum gleichen Thema.

\section{Die UNO-Instanzen für indigene Völker}

\section{Die Arbeitsgruppe indigene Völker}

Die 1982 ins Leben gerufene Arbeitsgruppe indigene Völker traf sich bis 2007 jedes Jahr im Juli für eine Woche in Genf. Ursprünglich war sie in der UN-Hierarchie auf unterster Ebene angesiedelt: als Arbeitsgruppe einer Unterkommission der Menschenrechtskommission, die wiederum dem Wirtschafts- und Sozialrat unterstand. Die Menschenrechtskommission wurde jedoch Anfang April 2006 aufgelöst und an ihrer Stelle der Menschenrechtsrat ins Leben gerufen, der innerhalb eines Jahres über die Zukunft der Arbeitsgruppe entscheiden sollte (vgl. Schaubilder im Anhang). Der Menschenrechtsrat untersteht direkt der UN-Generalversammlung. Er setzt sich aus siebenundvierzig Mitgliedsstaaten zusammen, die für jeweils drei Jahre, mit der Möglichkeit einer einmaligen direkten Wiederwahl, von der Generalversammlung bestimmt werden (vgl. United Nations 2006: 3). Bei seiner sechsten Versammlung im Dezember 2007 verabschiedete der Menschenrechtsrat eine Resolution zur Schaffung eines neues Expertengremiums zu den Rechten indigener Völker. Dessen übergeordnetes Mandat besteht darin, den Menschenrechtsrat mit thematischem Fachwissen zur Situation der Menschenrechte indigener Völker zu versorgen.

Auch die Arbeitsgruppe indigene Völker verfolgte diese Aufgabe im Bereich Menschenrechte. Sie besaß zwei Mandate:

- Beobachtung nationaler Entwicklungen, welche die Förderung der Menschenrechte indigener Völker betreffen;

- Ausarbeitung internationaler rechtlicher Standards für diese Völker.

Die Arbeitsgruppe bestand aus fünf unabhängigen Experten. Am ersten Treffen 1982 nahmen rund 30 Personen teil. Die indigenen Teilnehmer darunter stammten aus Nord- und Südamerika sowie Nordeuropa. Seitdem stieg die Zahl der Teilnehmer kontinuierlich, vor allem in den 1990er Jahren. In den letzten Jahren nahmen jährlich rund 800 Personen aus aller Welt am Treffen teil. Die Arbeitsgruppe war, im Gegensatz zu anderen UN-Instanzen, offen für alle Institutionen sowie Organisationen - ohne Berücksichtigung, ob sie 
einen UN-Beraterstatus haben oder nicht. Sie erarbeitete wichtige Studien zu folgenden Themen: Verträge und Abkommen zwischen Regierungen und Indigenen, kulturelle und intellektuelle Eigentumsrechte Indigener, die Beziehung Indigener zu ihrem Land. Als ihre wichtigste Errungenschaft gilt jedoch die Ausarbeitung und Annahme der vorläufigen Erklärung der Rechte indigener Völker. ${ }^{16}$ Die Erklärung umfasst acht Kapitel: allgemeine Politik (Anerkennung des Rechts auf Selbstbestimmung), Menschenrechte, Identität, Bildung, wirtschaftliche und soziale Rechte, Territorium, Selbstverwaltung, Überwachung und Durchführung der Deklaration. Bedeutung misst man der Erklärung vor allem in Bezug auf ihren Einfluss bei, den sie auf Programme internationaler Organisationen sowie multilateraler Finanzinstitutionen haben könnte. Mehr als 10 Jahre beschäftigte sich die eigens eingerichtete Arbeitsgruppe zur vorläufigen Erklärung der Rechte indigener Völker damit, die endgültige Fassung zu erstellen. Besondere Streitpunkte zwischen Regierungsvertretern und Repräsentanten indigener Organisationen bildeten die zu-

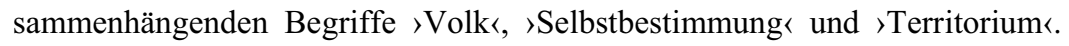
Als positiv an dem langwierigen Prozess wird bewertet, dass mehr als 100 indigene Organisationen die Möglichkeit der aktiven Teilnahme an den Sitzungen der Arbeitsgruppe zur vorläufigen Erklärung der Rechte indigener Völker bekommen haben:

»After half a decade of negotiations, the Intersessional's chair guaranteed indigenous activists that no decision would be taken unless all participants, governmental and nongovernmental, reach consensus over matters discussed. This logic of consenus has provided indigenous delegates with a de facto veto right over any formal decision made at the forum « (Muehlebach 2003: 248).

Inzwischen ist die Erklärung vom neu eingerichteten UN-Menschenrechtsrat angenommen und am 13.September 2007 auch von der Generalversammlung verabschiedet worden.

\section{Das Ständige Forum für indigene Angelegenheiten}

Die Arbeitsgruppe indigene Völker war der Hauptmotor für die Einrichtung eines Ständigen Forums für indigene Angelegenheiten. Durch die Weltmenschenrechtskonferenz in Wien im Jahr 1993 kam der Vorschlag auf die Agen-

161988 wurde die erste Fassung vom Vorsitzenden der Arbeitsgruppe präsentiert, in den darauffolgenden Jahren wurde sie diskutiert und 1993 verabschiedet. 1994 nahm auch die Unterkommission zur Verhinderung von Diskriminierung und zum Schutz von Minderheiten den Entwurf an und leitete ihn an die Menschenrechtskommission weiter. Diese setzte eine Arbeitsgruppe zur vorläufigen Erklärung der Rechte indigener Völker ein. 
da der UNO. Die UN-Generalversammlung griff die Idee eines Forums in ihrer Resolution 48/163 vom 21.12.1993 auf, um mit der Einrichtung das >geistige und kulturelle Erbe der indigenen Völker`zu schützen. Für einige Autoren liegt die besondere Möglichkeit des Forums darin, sich als Bindeglied zwischen Regierungen, indigenen Völkern und dem UN-System zu etablieren (vgl. Dreher 1995; García-Alix 1999). Im Jahr 2000 beschloss der Wirtschafts- und Sozialrat (Resolution 2000/22) die Einrichtung des Forums, im Mai 2002 fand die erste Sitzung am UN-Hauptsitz in New York statt. Das Ständige Forum für indigene Angelegenheiten übernimmt eine beratende Funktion für den Wirtschafts- und Sozialrat ${ }^{17}$ (vgl. Schaubilder im Anhang).

Auch das Mandat des Forums ist von seiner Stellung im UN-System bestimmt. Es bestehen zwei qualitative Unterschiede des Forums gegenüber der Arbeitsgruppe: Zum einen nehmen am Forum indigene Experten als Mitglieder teil; zum anderen ist es auf höherer Ebene innerhalb der UN-Strukturen angesiedelt. An der Arbeitsgruppe indigene Völker wurde in der Vergangenheit neben ihrer Zusammensetzung vor allem bemängelt, dass sie kein Organ mit politischer Macht sei. Die Arbeitsgruppe könne, da sie auf unterster Ebene der UN-Hierarchie angesiedelt sei, leicht durch andere UN-Institutionen politisch isoliert und neutralisiert werden (vgl. García-Alix 1999, 2003). Gleichfalls bleibt meiner Meinung nach aber auch der Zugewinn an Einflussmöglichkeiten am Forum kritisch zu hinterfragen. Der Wirtschafts- und Sozialrat unterliegt der Autorität der Generalversammlung und gilt allgemein als politisch schwach. Die UN-Charta weist dem ECOSOC Aufgaben der Koordinierung, Politiküberprüfung und des Politikdialogs auf wirtschaftlichem, sozialem, kulturellem und humanitärem Gebiet zu. Der Rat kann Empfehlungen an die UN-Generalversammlung und die UN-Sonderorganisationen abgeben, Übereinkommen zur internationalen Zusammenarbeit auf diesen Gebieten vorlegen oder mit Genehmigung der Generalversammlung Verträge mit den Sonderorganisationen abschließen. Der Wirtschafts- und Sozialrat besitzt jedoch keine Durchsetzungsbefugnisse. Vor allem gegenüber der Weltbank und dem Internationalen Währungsfonds besitzt er somit eine schwache Stel-

17 Der Wirtschafts- und Sozialrat (ECOSOC) besteht aus 54 Mitgliedern, wobei die sogenannten Entwicklungsländer seit den 1970er Jahren - durch die Entkolonisierungspolitik der UNO - überproportional vertreten sind. Der ECOSOC ist eines der fünf Hauptorgane der UNO. Seine Aufgabe ist die Überwachung und Koordinierung der wirtschaftlichen und sozialen Aktivitäten. Er koordiniert neun funktionale und fünf regionale Kommissionen sowie 14 spezialisierte Organisationen; er entwickelt Richtlinien für die UNO und seine Mitgliedsstaaten. Die Kommissionen des ECOSOC sind zwischenstaatlich, d.h. nur Regierungen sind Mitglieder und besitzen Stimmrecht. NGOs mit Beraterstatus können an den Sitzungen ebenfalls teilnehmen, sind jedoch ohne Stimmrecht (vgl. Unser 1997). 
lung. ${ }^{18}$ Zudem leisten heute zahlreiche Nebenorgane einen Großteil der Arbeit des ECOSOC, was ihm den Vorwurf »organisatorischen Wildwuchses" (Trauttmansdorff 1999: 38; zitiert nach Gareis und Varwick 2002: 53) eingebracht hat. Gareis und Varwick merken ferner an, dass »die Generalversammlung mit der Schaffung von Spezialorganen wie dem Entwicklungsprogramm (UNDP) oder der Konferenz für Handel (UNCTAD) dem ECOSOC weitere Kompetenzen im Entwicklungsbereich entzogen [hat] « (Gareis und Varwick 2002: 54).

Kaum Erwähnung in den Vergleichen zwischen Forum und Arbeitsgruppe findet der grundsätzlich andere Ansatz des Ersteren: Während die Arbeitsgruppe stark von den Debatten um den legalen Status sindigener Völker ' geprägt ist, ist das Forum eine Plattform für die Verhandlung von Entwicklungsrichtlinien. Es geht um die Frage, wie Indigene in den Entwicklungsprogrammen der UN-Einrichtungen derzeit Berücksichtigung finden und wie sie sich eine zukünftige Einbeziehung vorstellen. Damit erhöht sich auch der Druck auf indigene Organisationen, ihre Forderungen mit international normierten Vorstellungen von 〉Entwicklung〈 und `Fortschritt` abzugleichen. Das Forum will sich als Koordinationsinstrument zwischen den einzelnen UNOrganisationen etablieren und dadurch implizit auch Kontrollfunktionen erwerben (vgl. Dreher 1995; García-Alix 2003; Hausotter 2002). Das Ergebnis eines Berichts des UN-Generalsekretärs aus dem Jahre 1996 bestätigt, dass eine zentrale Zusammenführungsinstanz für die UN-Aktivitäten bezüglich Indigener fehle (vgl. United Nations 1996). Folgende Einrichtungen werden in diesem Zusammenhang von Seiten indigener Aktivisten und ihrer Unterstützer als besonders relevant betrachtet: die Kommission für nachhaltige Entwicklung am Wirtschafts- und Sozialrat, UNEP, UNDP, UNHCR, UNHCHR, WHO, UNESCO, ILO und die Weltbankgruppe. ${ }^{19}$ Alle diese Institutionen führen Aktivitäten durch, die Indigene betreffen, integrieren diese aber nur bedingt in die Ausarbeitung ihrer Programme (García-Alix 1999: 51ff.).

Das Sekretariat des Forums unter Leitung der Juristin Elsa Stamatopoulou hat 2003 begonnen, die einzelnen Instanzen nach ihren kurz-, mittel- und langfristigen Projektzielen im Umgang mit Indigenen zu befragen und die Ergebnisse zu katalogisieren. Jedes Jahr zum Treffen des Forums im Mai werden Auskünfte über die erfolgten Aktivitäten erbeten. Diese können dann mit den angestrebten Zielen abgeglichen werden. Stamatopoulou misst den Erfolg

18 Die Gründer der Vereinten Nationen hatten sich bereits 1944 in Bretton Woods auf die Schaffung internationaler Finanzinstitutionen geeinigt und diesen neben verschiedenen Sonderorganisationen auch eine Welthandelsorganisation zur Seite stellen wollen. Damit beabsichtigten sie eine Dezentralisierung der internationalen Entscheidungsfindung im Wirtschaftsbereich (vgl. United Nations 2002b).

19 Für die ausgeschriebenen Bezeichnungen sowie eine nähere Beschreibung der Aufgabenfelder der hier aufgelisteten Organisationen siehe Anhang. 
des Forums in den ersten Jahren seiner Existenz deshalb hauptsächlich an der Kooperationsbereitschaft der entsprechenden UN-Organisationen. In diesem Zusammenhang spielen für sie auch an Forumsmitglieder erfolgte Einladungen zu Konferenzen eine wichtige Rolle (Gespräch Stamatopoulou 20.05. 2004).

Das Ständige Forum für indigene Angelegenheiten besitzt neben acht von Regierungen nominierten Mitgliedern auch acht sogenannte unabhängige indigene Experten mit gleichem Stimmrecht. Das gilt als Neuerung innerhalb des UN-Systems. Die Mitglieder werden nach den fünf offiziellen Regionen der UNO ausgewählt, wobei indigene Organisationen Kandidaten für die Posten der unabhängigen indigenen Experten dem Wirtschafts- und Sozialrat vorschlagen können. Für viele indigene und nicht-indigene Aktivisten liegt hierin wiederum die besondere Bedeutung des Forums: Indigene Repräsentanten treten zum ersten Mal in der Geschichte der UNO als gleichwertige Gesprächsund Verhandlungspartner gegenüber Regierungen auf (Interview Matías Alonso 19.05.2004; Interview Lux de Cotí 19.05.2004; Interview Choquehuanca 18.05.2004). Das Forum konzentriert seine Arbeit auf drei Bereiche:

- Es entwickelt Vorschläge und Empfehlungen für Regierungen und UNOrganisationen in sechs Mandatsbereichen: wirtschaftliche und soziale Entwicklung, Umwelt, Gesundheit, Menschenrechte, Kultur und Bildung;

- es koordiniert und evaluiert für Indigene relevante Einzelaktivitäten innerhalb der UNO;

- es verbreitet Informationen zu indigenen Völkern innerhalb des UNSystems.

Genauso wie die Arbeitsgruppe indigene Völker ist auch das Ständige Forum für indigene Angelegenheiten offen für alle Institutionen und Organisationen, unabhängig davon ob sie einen Beraterstatus am Wirtschafts- und Sozialrat besitzen oder nicht. Alle bei der Sitzung anwesenden Organisationen können ihre Vorschläge und Empfehlungen während der zweiwöchigen Treffen an die sechszehn Forumsmitglieder weiterleiten - allerdings stimmen nur diese über die Vorschläge ab. Die Teilnehmerzahlen stiegen in den ersten drei Jahren kontinuierlich an und beliefen sich 2005 auf ca. 1000 Personen aus aller Welt. Jedes Jahr gruppiert sich das Treffen des Forums um einen thematischen Schwerpunkt: 2002 war dies die Arbeitsweise und Funktion des Forums, 2003 indigene Kinder und Jugendliche, 2004 indigene Frauen. 2005 standen die Millenniums-Entwicklungsziele (MDGs) ${ }^{20}$ der UNO auf der Agenda, vor al-

20 Die Millenniums-Entwicklungsziele umfassen 8 übergeordnete Ziele: 1. extremen Hunger + Armut beseitigen; 2. Grundschulbildung für alle Kinder erreichen; 3. Gleichstellung und größeren Einfluss der Frauen durchsetzen; 4. Kindersterblichkeit senken; 5. Gesundheit der Mütter verbessern; 6. AIDS, Malaria und andere Krankheiten bekämpfen; 7. nachhaltigen Schutz der Umwelt ge- 
lem die Ziele der Armutsreduzierung und der weltweiten Durchsetzung der Einschulung aller Kinder bis zum Jahr 2015 (vgl. United Nations 2002b).

Bevor die Analyse der politischen Kräfteverhältnisse am Ständigen Forum für indigene Angelegenheiten ins Zentrum der Betrachtungen rückt, gilt es im Folgenden, grundlegende Begriffe des Indigenitätsdiskurses sowie das Verhältnis zwischen Ethnologie und indigenem Aktivismus näher zu betrachten, um den politischen Handlungsraum, in dem sich die Akteure indigener $\mathrm{Zu}-$ sammenschlüsse bewegen, besser erfassen zu können.

\section{Definition sindigene Völker : grundlegende Begriffe}

Das Sekretariat des Ständigen Forums für indigene Angelegenheiten weist in einem Dokument (United Nations 2004b) darauf hin, dass kein Körper des UN-Systems bisher eine offizielle Definition des Konzeptes >indigene Völker per Beschluss angenommen hat. Dies sei auf Grund der kulturellen Vielfalt indigener Völker nicht geschehen. Die Definition des UN-Sonderberichterstatters Martínez Cobo dient derweil als Grundlage für das Verständnis des Begriffs von Seiten internationaler Institutionen. So definiert die ILO-Konvention 169 ihren Gültigkeitsbereich für:

»Völker in unabhängigen Ländern, die als Eingeborene gelten, weil sie von Bevölkerungsgruppen abstammen, die in dem Land oder in einem geographischen Gebiet, zu dem das Land gehört, zur Zeit der Eroberung oder Kolonisierung oder der Festlegung der gegenwärtigen Staatsgrenzen ansässig waren und die, unbeschadet ihrer Rechtsstellung, einige oder alle ihrer traditionellen sozialen, wirtschaftlichen, kulturellen und politischen Einrichtungen beibehalten « (Artikel 1, ILO-Konvention 169; zitiert nach Dandler et al. 1994:89).

Dabei gilt `Selbstidentifikation als ausschlaggebendes Kriterium der Anerkennung. Gleichzeitig wird betont, dass der Begriff >Völker` nicht nach internationalem Recht verstanden werden darf, das heißt, keine staatlichen Autonomierechte impliziert. Die ILO-Konvention 169 ist bis heute das einzige internationale Abkommen zum Schutz der Rechte indigener Völker.

und andere Krankheiten bekämpfen; 7. nachhaltigen Schutz der Umwelt gewährleisten; 8. globale Partnerschaft im Dienst der Entwicklung schaffen. Diese acht Ziele werden wiederum in insgesamt 18 Zielstellungen konkretisiert, wobei 48 Indikatoren zum Einsatz kommen. Die Ziele wurden von einer Expertengruppe, bestehend aus Mitgliedern des UN-Generalsekretariats, IWF, OECD und Weltbank, erstellt. 
Auch die Erklärung der Rechte indigener Völker und ein gleichnamiges Dokument der OAS ${ }^{21}$ (GT/DADIN/doc.139/03) vermeiden eine exakte Definition des Begriffes >indigene Völkerく. Das subjektive Kriterium der Selbstidentifikation als indigen wird wiederum zum ausschlaggebenden Moment. Die OAS-Erklärung legt dabei in Abschnitt 1, Artikel 1 wiederum fest, dass der Begriff `Volk« nicht nach internationalem Recht gebraucht wird.

Für die Repräsentanten indigener Bewegungen bleibt die Selbstdefinition als Völker dennoch oftmals das zentrale Moment ihrer politischen Kämpfe vor allem in Abgrenzung zur Bezeichnung >Minderheit<. Welche Konsequenzen ergeben sich aus der vorgenommenen Abgrenzung?

\section{Indigene: Minderheiten oder Völker?}

Im Anschluss an den Westfälischen Frieden (1648) und vor allem in Folge der Französischen Revolution entwickelte sich das moderne Nationalstaatskonzept zur stärksten, das Völkerrecht tragenden Legitimitätsvorstellung. Damit einhergehend bildete sich der Begriff des nationalen Selbstbestimmungsrechts heraus, das dem >Volk als nationaler Gemeinschaft zugesprochen wurde. Jedoch entwickelte sich gleichzeitig auch die Idee eines möglichen Eingriffs in die staatliche Souveränität, um Individualrechte von Minderheiten, das heißt von Gruppen, die sich nicht als Teil der nationalen Gemeinschaft verstanden, zu schützen. Beeinflusst durch Interessenkonflikte zwischen Nationalstaaten und einzelnen Gruppen im Innern derselben hat sich das internationale Recht in den letzten fünfzig Jahren stark verändert. Die Definition des Rechts auf Selbstbestimmung spielte bei diesen Auseinandersetzungen eine zentrale Rolle.

Minderheitenrechte werden im Völkerrecht als Erweiterung des Schutzes von Individualrechten verstanden. Die entsprechenden Gruppen besitzen somit keinen Anspruch auf Selbstbestimmung. Artikel 27 des zivilen und politischen Menschenrechtspakts von 1966 weist Minderheiten das Recht zu, ihre Kultur in der Gemeinschaft auszuüben. Dabei handelt es sich aber um sogenannte >negative< Rechte, d. h. die Regierungen der entsprechenden Länder dürfen die entsprechenden Aktivitäten (freie Meinungsäußerung, Versammlungsrecht etc.) nicht unterbinden. Andererseits haben sie aber auch nicht die >positive Pflicht, differente Gruppen anzuerkennen und mit öffentlichen Geldern zu unterstützen (vgl. Kymlicka 1999: 283f.). Minderheiten werden somit nicht als Volk innerhalb einer Nation, sondern als lose Gruppe von Individuen definiert. Da die Unterscheidung zwischen Minderheit und Volk je-

21 Auch die OAS verfügte 1989, dass die Interamerikanische Kommission für Menschenrechte ein juristisches Instrument zu den Rechten Indigener vorbereiten solle. Somit laufen die Bemühungen auf UN-Ebene parallel zu denen auf regionaler Ebene in Nord- und Südamerika. 
doch unter Juristen umstritten ist, gibt es Uneinigkeiten bei der Abgrenzung beider Kategorien. Nach Pritchard (2001: 323) werden drei relative Unterscheidungskriterien zwischen Volk und Minderheit im Völkerrecht festgehalten:

- Ein Volk muss im Sinne des Selbstbestimmungsrechts in einem abgegrenzten Gebiet leben bzw. mit einem solchen Gebiet historisch verbunden sein;

- der Ausprägungsgrad eines subjektiven Kollektivbewusstseins ist bei einer Minderheit niedriger als bei einem Volk;

- ein Volk muss, im Sinne des Selbstbestimmungsrechts, über relativ repräsentative und handlungsfähige Organe verfügen.

Die Akteure indigener Bewegungen wehrten sich von Anfang an dagegen, als Minderheiten kategorisiert zu werden: Sie argumentierten für ihre politische, wirtschaftliche, soziale und kulturelle Selbstbestimmung. Auf Grundlage geltenden Völkerrechts sei ihnen dies als Minderheit im Staatsgefüge nicht möglich.

Während individuelle, ethnische und religiöse Rechte in demokratischen Verfassungen bestehender Nationalstaaten verankert sind, gibt es keine Handhabung für die Rechte sindigener Völker<. Deshalb wollten die indigenen Interessenvertreter verfassungsrechtliche Änderungen der Staaten erreichen, in denen sie leben. Das Selbstbestimmungsrecht konsolidiert dabei die grundsätzliche >Andersartigkeit` Indigener: Es impliziert, dass Menschen, die sich als Mitglieder indigener Völker definieren, sich vorwiegend oder gar ausschließlich kulturell und politisch mit dieser Gemeinschaft identifizieren und sich von den sie umschließenden Nationalstaaten nicht repräsentiert fühlen (vgl. United Nations 2000: 5).

Mit der ILO-Konvention 169 erhielten indigene Bewegungen ein nützliches Instrument zur Forderung nach Verfassungsänderungen auf nationalstaatlicher Ebene. Viele, gerade lateinamerikanische Regierungen, ratifizierten die Konvention in den 1990er Jahren und erklärten ihre Staaten in der Folge zu pluriethnischen und multikulturellen Gebilden. 1992 verabschiedete die UNO auch eine Erklärung der Rechte von Minderheiten und 2007, wie bereits erwähnt, die Erklärung der Rechte indigener Völker. Daes und Eide fassen den Unterschied zwischen Minderheitenrechten und solchen für indigene Völker wie folgt zusammen: »Whereas the Minority Declaration and other instruments concerning persons belonging to minorities aim at ensuring a space for pluralism in togetherness, the instruments concerning indigenous peoples are intended to allow for a high degree of autonomous development« (United Nations 2000: 3).

Damit liegt das Distinktionskriterium im Grad der Autonomie: Indigene sollen selbst entscheiden können, inwieweit sie sich als Teil der sie einschlie- 
ßenden Staaten verstehen, ihnen soll die Möglichkeit gegeben werden, diese Verbindung so locker wie möglich zu halten. Die Autoren weisen aber darauf hin, dass eine eindeutige Trennung zwischen Minderheiten und indigenen Völkern dennoch diskutierbar sei. Während die Erklärung der Rechte von Minderheiten vorwiegend aus der Erfahrung der Europäer entstanden sei, basiere die Erklärung der Rechte indigener Völker auf der Geschichte der beiden Amerikas. Daes und Eide schlussfolgern: »The distinction is probably much less useful for standard-setting concerning group accomodation in Asia and Africa« (United Nations 2000: 5). Das Recht auf Autonomie bzw. >Selbstbestimmung< erweist sich somit als komplexer, vieldeutiger Begriff. Welche Dokumente sind in diesem Zusammenhang für indigene Interessenvertreter relevant? Verstehen Akteure aus Nord- und Südamerika, Asien oder Afrika dasselbe unter dem Begriff 〉Selbstbestimmung $\ll$ ?

\section{Selbstbestimmung}

In der Erklärung der Rechte indigener Völker beziehen sich zwölf der fünfundvierzig Artikel auf das Recht Indigener, ihre kulturelle Identität bewahren und ihre >Traditionen ${ }^{22}$ praktizieren zu dürfen. Damit soll Assimilationsbestrebungen von Seiten der Staaten, in denen indigene Gruppen leben, begegnet werden. Einerseits greift das Dokument auf bereits bestehende Rechtsinstrumente zurück: unter anderem auf die Allgemeine Erklärung der Menschenrechte, die Menschenrechtspakte von 1966 sowie die ILO 169. Andererseits kommt in Artikel 7, Abschnitt 2 das Recht auf Schutz vor Ethnozid bzw. kulturellem Genozid neu hinzu (vgl. United Nations 1994). ${ }^{23}$ Auch in den Punkten Selbstbestimmung, Land- und Ressourcenrechte und politische Partizipation geht die Erklärung über die ILO Konvention 169 hinaus (vgl. Dreher 1995: 60ff.). So postuliert Artikel 3 der Erklärung, dass Indigene ein Recht auf Selbstbestimmung haben sollen: »Indigenous peoples have the right of self-determination. By virtue of that right they freely determine their political status and freely pursue their economic, social and cultural development« (United Nations 1994).

In den Auseinandersetzungen um die Verabschiedung der UN-Erklärung der Rechte indigener Völker spielte diese Bestimmung eine zentrale Rolle. In der Diskussion verhalf die bereits angesprochene Entkolonisierungspolitik der

22 Unter »Traditionen« werden in diesem Zusammenhang unter anderem Sprache, Religion, Institutionen, Kunst verstanden.

23 Unter Ethnozid bzw. kulturellem Genozid fallen laut des Dokuments unter anderem Angriffe auf die Integrität Indigener als Mitglieder differenter Völker bzw. auf ihre kulturellen Werte, die Enteignung ihrer Siedlungsgebiete, Zwangsumsiedlung sowie kulturelle Assimilationsbestrebungen von Seiten der nationalen Gesellschaften. 
UNO den indigenen Akteuren zu einem wichtigen Argument: Kolonialismus wurde nicht mehr nur als ein durch externe Mächte herbeigeführter Missstand definiert, sondern auch als interner Zustand vieler Nationalstaaten diagnostiziert. Dabei setzten interessanterweise nicht nur Indigenenvertreter diese erweiterte Kolonialismusdefinition als politisches Mittel ein. Seit der Konferenz zu Sicherheit und Kooperation in Europa, die 1975 in Helsinki stattfand, sowie unter der Präsidentschaft von Jimmy Carter in den USA griffen auch die Weltmächte indirekt diesen Gedanken auf. Sie verfolgten damit jedoch andere Ziele als indigene Bewegungen. Während letztere sich einen Zuwachs an lokaler Autonomie erhofften, suchten erstere - allen voran die USA - nach neuen Mitteln, den Kalten Krieg für sich zu entscheiden. Dennoch trugen sie dadurch letztendlich zur Aufweichung des Anspruchs nationalstaatlicher Souveränität bei. Das stärkte indirekt auch die Forderungen indigener Repräsentanten. Des Weiteren wurde im Verlauf der 1970er Jahre zweimal das südafrikanische Apartheidsregime von der UNO öffentlich verurteilt, indem man darauf verwies, dass das Recht auf Selbstbestimmung der schwarzen Bevölkerung vorenthalten werde. Muehlebach (2003: 48) verweist in diesem Zusammenhang darauf, dass ironischerweise heute viele Regierungsvertreter indigene Forderungen nach Selbstbestimmung als Versuche bezeichneten, Apartheidsstrukturen zu schaffen. Im Zuge der Verhandlungen um die Verabschiedung der Erklärung der Rechte indigener Völker begannen jedoch auch eine ganze Reihe von Staaten, Selbstbestimmung als Grundlage für alle weiteren in der Erklärung enthaltenen Rechte zu sehen. ${ }^{24}$ Anaya (1995) definiert Selbstbestimmung international als zentrale juristische Kategorie zur Bewertung von Regierungsstrukturen:

$»$ While human beings fundamentally are the beneficiaries of the principle of selfdetermination, the principle bears upon the institutions of government under which human beings live. Self-determination is extraordinary as a vehicle for coalescing international concern for the essential character of government structures, a concern that may extend to the point of enjoining them to yield authority or territory« (Anaya 1995: 76).

Innerhalb der transnationalen panindigenen Bewegung sind die Vorstellungen von Selbstbestimmung jedoch genauso unterschiedlich wie diesbezügliche Auslegungen von Staatsseite. Der jeweilige nationale Kontext beeinflusst dabei in entscheidendem Maße die Definition des Konzepts. So steht die Forderung nach >voller souveräner Unabhängigkeit ` - von Seiten der Kanaken NeuKaledoniens - neben der nach >interner Autonomie` im Falle Lateinamerikas.

24 Dänemark zeigte sich 1993 als erstes Land dazu bereit, es folgten Mexiko, Ecuador, Costa Rica, Peru, Cuba, Guatemala, Finnland und Norwegen, in jüngster Zeit auch die USA (Muehlebach 2003: 249). 
Einige Gruppen verwalten sich bereits selbst - so die Inuit in Grönland ${ }^{25}$ oder die Samen in Norwegen, die eine eigene `Beratende Versammlung « besitzen. Indigene Organisationen aus Afrika hingegen verbinden mit dem Begriff zuvorderst die legale Anerkennung als Indigene und darauf aufbauend die Möglichkeit, politische Entscheidungen zu beeinflussen (vgl. Crawhall 2004). Während indigene Repräsentanten aus Asien oder Afrika somit in den Verhandlungen zur Erklärung der Rechte indigener Völker in puncto Selbstbestimmung zu den größten Zugeständnissen bereit waren, zeigten sich Vertreter aus Nord- und Lateinamerika sowie Neuseeland wenig kompromissbereit. Gerade auch für Gruppen aus den USA, die sich auf bestehende Verträge nach internationalem Recht zwischen ihnen und der US-Regierung berufen können, würde eine Umformulierung des Satzes »Indigene Völker haben das Recht auf Selbstbestimmung« legal bereits Erreichtes unterminieren. Zusammen mit Vertretern aus Lateinamerika nehmen sie oft, auch während der Sitzungen des Ständigen Forums für indigene Angelegenheiten, die aggressivsten und kritischsten Haltungen gegenüber Regierungsvertretern ein. Sie weisen darauf hin, dass die begrenzten Mandate der Arbeitsgruppe und des Forums keine gezielten Maßnahmen gegen Menschenrechtsverletzungen an Indigenen ermöglichen. Der größte Schwachpunkt der UNO liegt somit aus Perspektive dieser Repräsentanten darin, dass die Regierungen ihr gegenüber nicht weisungsgebunden sind (Gespräch Matías Alonso 20.05.2005; Gespräch Alarcón 16.05.2003; Dahl 2004: 14ff.; Hodgson 2002: 1043).

Indigene Forderungen nach Selbstbestimmung fanden jedoch in den 1990er Jahren verstärkt Gehör, als sich verschuldete Staaten unter Druck des IWF und der Weltbank wirtschaftlich liberalisieren mussten. ${ }^{26}$ IWF und Weltbank setzen auf Dezentralisierung sowie Partizipation der Zivilgesellschaft. So versuchen sie zum Beispiel lateinamerikanische Staaten zu verpflichten, funktionierende öffentliche Instanzen für die Belange Indigener zu schaffen, in denen diese selber mitwirken. Auch ohne dass es eine eindeutige Definition

25 Sie erhielten bereits 1979 ihre politische Unabhängigkeit von Dänemark, eine eigene Verfassung (Home Rule) und eine regionale Regierung (Morin und Saladin D'Anglure 1994: 198).

26 IWF und Weltbank entwarfen in Reaktion auf die Schuldenkrise Anfang der 1980er Jahre sogenannte Strukturanpassungsprogramme (SAPs) für die hochverschuldeten Staaten der >Dritten Welt durch die Nehmerländer Bedingung für weitere Kredite und Schuldenerlass war. Die Ziele der SAPs sind: Stabilisierung der Währung, Sicherung bzw. Wiederherstellung der Schuldendienstfähigkeit und Ausrichtung der Wirtschaft auf die Anforderungen des Weltmarktes. Auf Grund zahlreicher Kritik an der engen ökonomischen Ausrichtung der SAPs, die soziale Missstände in den Nehmerländern noch verschärfte, wurden in den 1990er Jahren soziale und ökologische Komponenten mit aufgenommen. Diese umfassen auch Programme für die indigene Bevölkerung des jeweiligen Landes. 
gibt, was Selbstbestimmung für Indigene bedeuten kann, oder vielleicht gerade weil diese vermieden wird, zeigen die beschriebenen Entwicklungen, dass sich die Kategorie >indigene Völker auf internationaler wie nationaler Ebene institutionalisiert hat.

\section{Territorium}

Neben der Forderung nach Selbstbestimmung steht die nach Landrechten, einschließlich der Kontrolle der Nutzung natürlicher Ressourcen, an zentraler Stelle auf der politischen Agenda indigener Bewegungen. Beide Forderungen sind eng miteinander verknüpft und bedingen sich gegenseitig. So betont Miguel Alfonso Martínez, Mitglied der Arbeitsgruppe indigene Völker, in einem Redebeitrag während der Sitzungsperiode 2004, dass der grundlegende Konflikt zwischen indigenen Gruppen und Regierungen der um Land sei. Dies schließe die Nutzung der natürlichen Ressourcen mit ein. Er argumentiert: "Selbstbestimmung ist ohne Land nicht möglich" (eigene Aufzeichnungen 18.06.2004). Die Forderung wird durch eine Verknüpfung von indigener Identität und snatürlichem Habitat< legitimiert, die sich zum Beispiel in einer Weltbankrichtlinie (OP 4.10) zu indigenen Völkern widerspiegelt. Dort heißt es in Abschnitt 2: »The Bank recognizes that the identities and cultures of Indigenous Peoples are inextricably linked to the lands on which they live and the natural resources on which they depend. ${ }^{27}$

Wie auch beim Thema Selbstbestimmung sind dabei die derzeitigen legalen Standards je nach Land unterschiedlich. Bereits ein kurzer Blick auf die Situation verschiedener Länder Südamerikas belegt dies: Kolumbien gilt, aus der Perspektive indigener Akteure, als das lateinamerikanische Land mit der fortschrittlichsten Gesetzgebung. Auch wenn sich laut offizieller Statistik nur zwei Prozent der Bevölkerung des Landes als indigen identifiziert, so verfügt diese numerische Minderheit dennoch über ein Viertel des staatlichen Territoriums (Santamaria 2006: 42). In Brasilien sind derzeit elf Prozent des Amazonasgebietes tituliertes indigenes Territorium, in Peru hingegen etwas mehr als fünf Prozent. Während in Kolumbien, Bolivien, Brasilien und Ecuador Gesetzgebungen zu Landrechten für indigene Völker - meist jedoch bezeichnet als >ethnische Gruppen vergibt die peruanische Regierung kollektive Landtitel nur an dörfliche Einheiten. Diese indigenen Siedlungen genießen jedoch eingeschränkte autonome Verwaltungsrechte. Auch in Bolivien und Kolumbien beinhaltet die legale Anerkennung indigener Territorien begrenzte Autonomierechte, in Ecuador

27 Die OP 4.10 der Weltbank ist online zugänglich unter: http://wbln0018.world bank.org/Institutional/Manuals/OpManual.nsf/023c7107f95b76b88525705c002 281b1/0f7d6f3f04dd70398525672c007d08ed?OpenDocument [20.05.2006] 
hingegen gibt es bisher keine klaren legalen Standards diesbezüglich (vgl. Roldán Ortega 2004: 47ff.; Blum 2001: 149; vgl. auch CEREC und Gaia Foundation 1993).

Die Einforderung von Landrechten war einer der Ausgangspunkte und Hauptfokus indigener Bewegungen der 1960er und 70er Jahre. Die Sicherung von Land gilt auch weiterhin als Basis, um das Überleben indigener Völker zu sichern. Im Laufe der Jahre verbanden sich die Ideen von Selbstbestimmungsund Landrechten und wurden zu Forderungen nach (eingeschränkter) territorialer Autonomie. Nur ein uneingeschränkter Zugang zu Land und Ressourcen, so die Argumentationslinie indigener Akteure, ermögliche politische Autonomie sowie die Aufrechterhaltung indigener Wirtschaftssysteme. Einerseits verweisen die indigenen Interessenvertreter dabei auf das Erstankömmlingsrecht der von ihnen repräsentierten Gemeinschaften gegenüber den europäischen Kolonisatoren bzw. denjenigen, die heute die Regierungen der jeweiligen Staaten stellen. ${ }^{28}$ Andererseits bauen sie ihre Ansprüche aber auch auf einer sanderen spirituellen und materiellen Beziehung`zur Umwelt auf eine Idee, die nicht nur in der Richtlinie der Weltbank, sondern auch in der UN-Erklärung der Rechte indigener Völker (Artikel 25) sowie in der vorläufigen Erklärung der OAS (Preambel, Artikel 3) Aufnahme fand.

Mit dieser Legitimierung der Territorialansprüche greifen die indigenen Bewegungen indirekt auf moralische Argumente zurück, die schon seit der Eroberung Amerikas in Europa kursieren. Auf Grundlage der Vorstellungen vom `edlen Wilden`, die abendländische Philosophen wie Rousseau, Montaigne oder Moore generiert haben, erschaffen sie die >indigene< Zivilisation als Gegenbild zur >westlichen` (vgl. Gutiérrez Estévez 2003; Conklin und Graham 1995). Diese Dichotomisierung baut auf einer Gegenüberstellung von naturerhaltenden und naturzerstörenden Zivilisationen auf. Damit greifen die Akteure indigener Bewegungen Vorstellungen von Entwicklung, Modernität, Fortschritt und Zivilisation, die auch im Westen ambivalente Assoziationen hervorrufen, auf und an: die »Mobilisierung von Scham $\aleph^{29}$ wird zum wichtigen politischen Mittel (Muehlebach 2001: 417; vgl. auch Kapitel I). Durch die große politische Wirkkraft dieser Gegenüberstellung werden kollektive Abgrenzungsprozesse unterstützt oder gar erst angeschoben. Es scheint so, als ob indigene Bewegungen nur erfolgreich sein können, wenn sie auf einer unauflöslichen Verbindung zwischen >indigenen Völkern` und `natürlichem Habitat $<$ beharren. Erst durch diese Gleichsetzung können sie in politischen Verhandlungen auch für ihre kulturelle und wirtschaftliche Selbstbestimmung

28 Siehe UN-Definition >indigene Völker` von Martínez Cobo.

29 Muehlebach (2001) verweist in ihrem Artikel auf einen indigenen Teilnehmer eines Treffens bei der Arbeitsgruppe indigene Völker, der diesen Begriff benutzte. 
eintreten: Nur wenn ihnen gestattet ist, ihre Territorien selbst zu verwalten, so ihre Argumentationslinie, können indigene Völker den Industrienationen alternative Lebenskonzepte entgegensetzen. Die Gleichsetzung von kultureller und territorialer Eigenständigkeit wird zum Dreh- und Angelpunkt der Forderungen nach autonomen Territorien.

Deutlich wird dies zum Beispiel in einer Aussage Nilo Cayuqueos. Der Mapuche erlebte und gestaltete die Organisationsanfänge der transnationalen panindigenen Bewegung in den 1970er Jahren. Er verweist auf die markanten Differenzen zwischen marxistisch geprägten Bauernbewegungen und indigenen Bewegungen in Lateinamerika, welche vor allem am Anfang in politischen Auseinandersetzungen eine wichtige Rolle spielten: Erstere sahen Landrechte nicht in der umfassenden kulturellen Bedeutung, welche die indigenen Organisationen ihnen von Anbeginn an zuschrieben (Gespräch Cayuqueo 24.05.2005).

Die sandere spirituelle Beziehung zum Land wurde vor allem für die indigenen Bewegungen des Amazonasgebietes in den 1980er Jahren zur zentralen Argumentationshilfe in ihrem Kampf um Territorien. Diese grundsätzliche $>$ Andersartigkeit` bescherte ihnen international verhältnismäßig große politische Erfolge, obwohl sie zahlenmäßig eine eher unbedeutende Gruppe darstellen. Zwei wichtige internationale Entwicklungen legten dafür den Grundstein: Zum einen gewann in den 1980er Jahren die Ökologiebewegung international an Bedeutung. Vor allem der südamerikanische Regenwald erlangte dabei Symbolstatus im Kampf der Umweltschützer. Zum anderen vollzog sich zur gleichen Zeit mit der Erarbeitung des Konzepts der >nachhaltigen Entwicklung ein Paradigmenwechsel in der Entwicklungszusammenarbeit. >Lokale Wissenssysteme`rückten ins Zentrum der Betrachtungen: Man ging nun davon aus, dass Entwicklungshilfe nur dann erfolgreich sein könne, wenn die Zielgruppen und ihre Vorstellungen von Entwicklung bei Projektausarbeitung und -durchführung mit einbezogen würden.

Die indigenen Organisationen des Amazonasgebietes wussten diesen Paradigmenwechsel politisch zu nutzen. Sie organisierten sich zum Beispiel im Zusammenschluss mit dem europäischen Klimabündnis und gingen Allianzen mit großen Umweltschutzorganisationen wie Conservation International (CI), World Wildlife Funds (WWF) oder The Nature Conservancy (TNC) ein. Ihre Bewirtschaftungsform des Regenwalds erfuhr im Zuge dieser Entwicklungen neue Anerkennung als eine Methode >nachhaltiger Entwicklungく (vgl. Morin und Saldin d'Anglure 1994: 201).

Conklin und Graham (1995: 696f.) sehen dabei den politischen Nutzen der Gleichsetzung zwischen >westlichen` Nachhaltigkeitskonzepten und indigener Landnutzung als zweifelhaft an und verweisen in diesem Zusammenhang auch auf kritische indigene Stimmen. Andere Autoren interpretieren hingegen die konzeptionelle >Verwestlichung/ indigener Lebensweise, die 
sich auf Grundlage der Dichotomisierung indigener und nicht-indigener Weltsichten (Stichwort >andere Spiritualität<) vollzieht, als »strategischen Essentialismus« (Spivak 1988) komplexer Beziehungen, die zur Erreichung politischer Ziele notwendig sei (z. B. Warren und Jackson 2003; Greene 2004). Bei diesen Autoren steht der Aspekt der Mobilisierung einer breiten Unterstützerfront zur Erreichung der Zielsetzung - territoriale Selbstbestimmungsrechte - im Vordergrund. Diese Unterstützerfront müsse vor allem >im Westen<, zum Beispiel in Europa, gewonnen werden. Dort ließen sich die Machtzentren lokalisieren, deren finanzielle und politische Kraft von den indigenen Bewegungen gebraucht würden, um entsprechende Gesetzesänderungen im eigenen Land zu bewirken. So hebt Smith (2002a) die Notwendigkeit des Zusammenschlusses zwischen Umweltschutzverbänden und indigenen Organisationen am Beispiel Perus hervor. Auch er bewertet die eingegangenen Allianzen dabei als einen wichtigen politischen Erfolg: Bis dahin hätten die Umweltschutzorganisationen auf Grund ihrer größeren Finanzkraft im Wettstreit mit indigenen Organisationen um die Ausweisung von Schutzgebieten meist gewonnen. Heute sei es WWF, TNC, CI oder anderen NGOs nicht mehr ganz so einfach möglich, ohne die Rücksprache mit und Beteiligung von indigenen Zusammenschlüssen oder über die Interessen lokaler Gemeinden hinweg Schutzgebiete ausgewiesen zu bekommen.

Die Allianzen mit diesen mächtigen Partnern gestalteten sich indes bislang durchaus problematisch und führten zu tiefgreifenden Konflikten. Rummenhöller stellt bei seinem Vergleich der Interessen von Naturschutzverbänden und indigenen Organisationen in Peru fest:

»Die Ersteren streben die Ausweisung staatlicher und privater Naturschutzgebiete an, um repräsentative Ökosysteme in ihrer Biodiversität zu bewahren. [...] Die indigenen Organisationen streben die Demarkierung von Landrechten und die zumindest teilweise Rekonstruktion der durch historische Verdrängungsprozesse verloren gegangenen indigenen Territorien und ihre selbstbestimmte Bewirtschaftung an« (Rummenhöller 2005: 2).

Fragen `sozialer Gerechtigkeit` oder Bedürfnisse lokaler Bevölkerungen stehen meist nicht auf den Programmen finanzkräftiger Umweltschutzorganisationen. Bündnisse zwischen diesen und den indigenen Bewegungen erweisen sich deshalb letztendlich als wenig effektiv. Die divergierenden Zielsetzungen treten deutlich und schnell zutage. Ein weiterer wichtiger Punkt sind die unterschiedlichen Interessen, die innerhalb der indigenen Bewegungen selbst mit dem Konzept des Territoriums verbunden sind. Ähnlich wie beim Begriff der Selbstbestimmung gibt es divergierende Vorstellungen darüber, was unter der Forderung nach Landrechten zu verstehen ist. Für die einen sind diese gleichbedeutend mit Eigentumsrechten im marktwirtschaft- 
lichen Sinn, andere verstehen darunter eine Demarkierung von Territorien zum Schutz der Flächen vor unkontrolliertem Ressourcenabbau durch Dritte. Vielerorts entstehen Konflikte um die Nutzungsrechte an den Ressourcen in Territorien, die indigenen Gruppen legal zuerkannt wurden. Diese Konflikte entfalten sich vor allem zwischen indigenen Gemeinden und nationalen Regierungen bzw. transnationalen Unternehmen, die sich in den entsprechenden Gebieten ansiedeln. ${ }^{30}$ Ein indigener Repräsentant aus Kanada erläuterte einen wichtigen Aspekt dieser Vorgänge in einer Veranstaltung während des Treffens der Arbeitsgruppe indigene Völker (2004) an Hand des Unterschieds zwischen den Begriffen >subsistance` und >livelihoodk. Während indigenen Gruppen von der kanadischen Regierung lediglich Subsistenzrechte zuerkannt werden, fordern sie, die natürlichen Ressourcen des eigenen Territoriums auch über die Abdeckung der Grundbedürfnisse hinaus nutzen zu können. `Livelihood`sei in diesem Sinne ein umfassenderes Konzept als >subsistance (eigene Aufzeichnungen 20.06.2004). Diese Unterscheidung spielt auch im südamerikanischen Kontext eine wichtige Rolle.

Ein Vertreter aus Mexiko erstaunte das Publikum einer Veranstaltung in Berlin im Rahmen einer Rundreise indigener Repräsentanten aus Lateinamerika im Dezember 2002, als es um die knapper werdende Ressource Trinkwasser ging. Er führte aus, dass dieses Problem indigenen Völkern eine neue wirtschaftliche Chance eröffnen könne, da sie oftmals in Gebieten lebten, wo die größten Süßwasservorräte bestünden. Wäre es nicht ein Fortschritt, so die Frage des Repräsentanten, wenn man demnächst Wasser von >indigenen Unternehmen kaufen könne? ${ }^{31}$ Das hinter dieser Aussage zum Vorschein tretende Verständnis von Landrechten als Eigentumsrechten im marktwirtschaftlichen Sinn lässt sich nicht mit stereotypen Darstellungen des >indianischen Umweltschützers` verbinden. Diesem zufolge verkörpern indigene Repräsentanten den Prototypen des überzeugten Naturschutzaktivisten westlicher Prägung. Auch Greene (2004: 47f.) verweist in seiner Studie über die moderne Organisationsgeschichte der Aguaruna im peruanischen Amazonasgebiet auf den Umstand, dass indigene Repräsentanten durchaus an privaten Geschäften mit den natürlichen Ressourcen auf indigenen Territorien interessiert sein können und ihre privilegierte Position diesbezüglich ausnutzen. Dies fordert aber nicht nur romantische Vorstellungen von >Indigen-Sein< heraus, sondern erweist sich auch als eine wichtige Facette des Problems, wie

30 Natürlich entstehen auch im Innern der indigenen Gemeinschaften oft Konflikte um Ressourcennutzung. Dies wird bei einem Blick auf lokale Ebene deutlich. Diese Diskrepanzen können hier nur erwähnt, nicht aber diskutiert werden, da sie eine detaillierte Auseinandersetzung erfordern.

31 Persönliche Aufzeichnungen bei einer öffentlichen Veranstaltung im Vorfeld einer von der Heinrich-Böll-Stiftung unterstützten Fachtagung indigener Repräsentanten aus Lateinamerika in Berlin, 6.12.2002. 
indigene Repräsentation im nationalen und internationalen Kontext politisch legitimiert ist. "Strategische Essentialisierungen« können auch dazu dienen, Interessen einer neuen >indigenen Elite zu stützen, die im Namen von >Völkern versuchen, ihre soziale Position in gesamtgesellschaftlichen Zusammenhängen zu verbessern. Die enge Verbindung zwischen Naturschutz und Rechten indigener Völker kann ferner zu politischen Bestrebungen führen, die Rummenhöller (2005) für Peru beschreibt: dem »unter Naturschutz-Stellen von Sammlern und Jägern«. 



\section{Kapitel IV \\ Kultur als Politikum}

Den Blick auf die Komplexität lokaler Verhältnisse gerichtet, diskutieren Ethnologen immer wieder die inhärenten Widersprüche der politischen Forderungen der Vertreter indigener Organisationen. Die Debatten entfalten sich meist am Konzept sindigene Völker` und weiten sich schnell zu Grundsatzdiskussionen über den dahinter stehenden Kulturbegriff indigener Bewegungen aus. Im Folgenden sollen vor allem zwei Aspekte dieser Diskussion näher beleuchtet werden, um die Ambivalenz des politisierten Kulturbegriffs zu verdeutlichen:

- die direkte ethnologische Auseinandersetzung mit dem Begriff >indigene Völker<;

- die Bestimmung des politischen Kulturbegriffs.

Hierbei zeigt sich auf analytischer Ebene, was schon bei der Diskussion der grundlegenden Begriffe zur Definition indigener Völker (vgl. Kapitel III.4) anklang: Der politische Kulturbegriff erweist sich nicht nur als neue zentrale Ressource marginalisierter Gruppen im Kampf um Macht, sondern auch als alternative Orthodoxie (vgl. Kapitel II.5), die Differenzen festschreibt und ihnen einen von den jeweiligen Trägern unabhängigen Eigenwert verleiht. 


\section{Die ethnologische Debatte um den Begriff sindigene Völker}

Wie jeder politische Akteur brachten die Vertreter indigener Organisationen spezifische Forderungen und Ziele mit, als sie sich Anfang der 1980er Jahre an der UNO etablierten. Ihre Zielsetzungen kristallisierten sich in den bereits

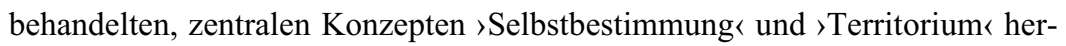
aus. Symbolisch zusammengeführt wurden beide Konzepte im Begriff >indigene Völker^.

Durch die Studie des UN-Sonderbeauftragten Martínez Cobo ${ }^{1}$ erlangte dieser breite Aufmerksamkeit und setzte sich in der Folge als offizielle Eigenbezeichnung durch: die Vertreter indigener Organisationen wurden zu Repräsentanten indigener Völker. Heute identifizieren sich viele Gruppen auf lokaler, nationaler und internationaler Ebene als >indigene Völker und treten auf dieser Grundlage als politische Akteure in Erscheinung.

Unter Ethnologen wird der Begriff >indigene Völker` derweil kontrovers diskutiert, vor allem im Zusammenhang mit den daraus abgeleiteten Territorialforderungen von Seiten indigener Organisationen. Im Zentrum steht jedoch der von den indigenen Aktivisten zugrunde gelegte Kulturbegriff. Die Debatte läuft dabei oft Gefahr, in einer politischen Grundsatzdiskussion zu erstarren. An deren Polen stehen sich zwei Parteien gegenüber, die ich im Folgenden als >Stimme der Kritiker` und >Stimme der Befürworter` bezeichne: Erstere sehen den Diskurs indigener Aktivisten als soziale Konstruktion der Wirklichkeit, die als tendenziell rassistisch einzustufen ist. Letztere bestätigen zwar meist ebenfalls den Konstruktionscharakter dieses Diskurses, feiern ihn dabei aber vor allem als erfolgreiche Widerstandsstrategie >Subalterner<.

\section{Die Stimme der Kritiker}

Wissenschaftler wie Béteille (1998), Bowen (2000) und Kuper (2003) beurteilen die Verwendung des Begriffs >indigene Völker genen Bewegungen und ihrer Unterstützer als essentialistisch und reaktionär. Sie beruhe auf einem obsolet gewordenen Kulturverständnis, das die heutigen Lebensumstände der meisten Indigenen nicht angemessen wiedergebe. Kuper, wie auch Bowen, bezieht sich dabei vor allem auf die Legitimierungsgrundlage der zentralen Forderung der Bewegungen nach Landrechten - verkörpert in der UN-Definition von Martínez Cobo. Bei der Definition von Martínez Cobo spielt das >Erstankömmlingsrechtく in Bezug auf ein bestimm-

1 Siehe Abschnitt Die UNO und das >Indigenenproblem` (Kapitel III.2) für die Begriffsdefinition von Martínez Cobo aus dem Jahr 1986. 
tes Territorium eine wichtige, dennoch nicht ausschließliche Rolle bei der Bestimmung von >Indigenität<. Kuper findet diesbezüglich:

»But whatever the political inspiration, the conventional lines of argument currently used to justify indigenous land claims rely on obsolete anthropological notions and on a romantic and false ethnographic vision. Fostering essentialist ideologies of culture and identity, they may have dangerous political consequences« (Kuper 2003: 395).

Kuper sieht die Gefahr, dass man durch den Gebrauch essentialistischer Kulturkonzepte Unterschiede zwischen ethnischen Gruppen erst schaffe bzw. verstärke und dadurch Konflikte provoziere. Stelle man sich hinter die Argumentation der indigenen Bewegungen, unterstütze man Tendenzen, die den Begriff >indigen` als Ersatz für >primitiv` erscheinen ließen. Den Begriff >Kultur< deutet er in diesem Fall als Euphemismus für >Rasse (Kuper 2003: 389, 395). Die klare Abgrenzung von indigenen und nicht-indigenen Gruppen mit sich diametral gegenüberstehenden Lebenskonzepten hält er für obsolet.

Vertreter dieser Sichtweise betonen meist, dass die jüngeren wissenschaftlichen Erkenntnisse die Konstruktion sozialer Wirklichkeit durch die gesellschaftlichen Akteure hinlänglich belegt haben. Aus dieser Perspektive heraus erscheint ihnen die Unterstützung von kulturell begründeten Forderungen der indigenen Bewegungen kontraproduktiv und gefährlich. Sie können neue Marginalisierungs- und Diskriminierungsprozesse fördern und vereinfachen komplexe politische Realitäten auf unzulässige Art und Weise.

\section{Die Stimme der Befürworter}

Sympathisanten der indigenen Bewegungen interpretieren den politischen Charakter des Konzepts >indigene Völker hingegen anders (vgl. Ramos 2003b; Kenrick und Lewis 2004; Saugestad 2004; Barnard 2004). Sie verstehen dessen Gebrauch als Widerstandsstrategie von gesellschaftlich marginalisierten Gruppen - das Potenzial zur Aufwertung ihres sozialen Status' liege in der Aneignung einer Argumentationsweise, die international gebräuchlich und damit sim Westen « verständlich wäre. Der Nationsgedanke gründe auf den Konzepten 〉Territorium « und `Selbstbestimmung und verkörpere ein essentialistisches Verständnis kultureller Identität. Gruppen, die durch den Expansionsdrang von Nationalstaaten in der Vergangenheit ihres Lebensraumes sowie eigenständiger kultureller Ausdrucksformen beraubt worden seien, könnten durch den Gebrauch der gleichen Rhetorik ihren Forderungen Kraft verleihen: Ihr Beharren auf der eigenen `Nationalität` sei der einzige Weg, den asymmetrischen politischen Kräfteverhältnissen wirkungsvoll zu begegnen. Die Autoren sehen somit die Aneignung dominanter Diskurse als wirk- 
same Strategie zur Subversion bestehender Ordnungsmodelle. In diesem Sinne sei >indigen , auch nicht als essentialistische, sondern als relationale Kategorie zu deuten, in Anlehnung an die Bedeutung, die der Begriff >ethnisch< heute in der ethnologischen Debatte einnehme (vgl. Saugestad 2001; Kenrick und Lewis 2004). Brown und Delgado (1999: 212) betonen dabei, dass der Begriff >indigen` nicht von außen an diese Bevölkerungsgruppen herangetragen worden sei, sondern für ein »neues Kapitel indigenen Widerstandes« stünde: Heute äußert sich indigener Widertand für diese Autoren im politischen Kampf mit legalen Mitteln, nicht mehr in gewaltsamen, kriegerischen Konfrontationen.

Andere Wissenschaftler sehen sich bei der Debatte um den Begriff >indigene Völker` gefangen im bereits beschriebenen moralischen >Positionierungsdilemma< der Ethnologie als Wissenschaft, die von 〉Eroberern schaffen worden sei und sich mit >Eroberten〈 beschäftige (vgl. Kapitel II.4). Die Kritik an der Verwendung eines essentialistischen Kulturkonzeptes, das Ethnologen überholt und nicht mehr zur Beschreibung der Wirklichkeit geeignet erschiene, berücksichtige nicht die ungleichen Machtverhältnisse, in denen sich der Kampf der indigenen Aktivisten entfalte. So meint zum Beispiel Ramos (2003b: 397): »[...] to put Western powers of conquest on an equal footing with ethnic demands for recognition is either to ignore or to minimize the violence of Western expansion."

Darf man also das essentialistische Kulturverständnis der politisch Mächtigen, nicht aber das der Marginalisierten kritisieren? Was kennzeichnet den politischen Kulturbegriff? Wie entwickelte er sich im Kontext der UNO?

\section{Kulturalismus und Metakultur}

Die Begriffe >Recht $\iota$ und >Kultur sind im internationalen Rechtsdiskurs seit der Etablierung des Nationskonzepts unauflöslich miteinander verbunden. Jedoch veränderte sich in der zweiten Hälfte des 20. Jahrhunderts zusehends das Verhältnis beider Begriffe zueinander. Das internationale Recht näherte sich wieder dem naturalistischen Verständnis seiner klassischen Ära an, in der Gesetze von idealen Vorstellungen eines >Soll-Zustandes` und nicht wie im nachfolgenden, nationalstaatlichen Recht vom >Ist-Zustand ausgingen. ${ }^{2}$ Die

2 Im naturalistischen Verständnis der klassischen Ära gab es eine über dem Souverän stehende normative Ordnung, die zurückging auf den mittelalterlichen kirchlichen Humanismus. Diesem zufolge hatten zum Beispiel die eingeborenen Völker Amerikas als >rationale Menschen` ein moralisches Anrecht auf gewisse Autonomie- und Landrechte. Nach nationalstaatlichem Recht wurden die indigenen Völker Teil der nationalen Gemeinschaft und offiziell zu Staatsbürgern erklärt, die keine gesonderten Rechtsansprüche stellen konnten. 
Dichotomie zwischen Individuum und Staat mit einer übergeordneten Funktion des Staates wurde in zunehmendem Maße aufgeweicht (vgl. Anaya 1995: 40ff.). Man ersetzte sie durch ein Verständnis von Staaten als heterogene Räume, in denen verschiedene kulturelle Gruppen zusammengeschlossen sind. Die UNO wurde in diesem Prozess zum institutionellen Vehikel für die Veränderungen im internationalen Recht. Durch ihren Anspruch, die moralische Instanz der neuen Weltordnung zu verkörpern, entfernte sich die Organisation seit ihrer Gründung stetig von einem Rechtsverständnis, das die bestehenden nationalstaatlichen Machtverhältnisse als `gerecht` begriff.

\section{Die Zusammenführung von sKulturs und Rechten` im Kontext der UNO}

Im Rahmen ihres Einsatzes für die Sicherung und Umsetzung von Menschenrechten beschäftigt sich die UNO seit ihren Anfängen mit dem Kulturbegriff.

Auch Ethnologen schalten sich immer wieder direkt und indirekt in diese Debatte ein. ${ }^{3}$ So warnt die American Anthropological Association (AAA) unter Leitung von Melville Herskovits vor der Verabschiedung der Allgemeinen Erklärung der Menschenrechte 1948 mit ihrem Statement on Human Rights (1947) die UNO davor, universelle Menschenrechte ohne Rücksicht auf kulturelle Unterschiede zu proklamieren. Der in der Menschenrechtserklärung postulierten Universalität menschlicher Grundbedürfnisse wird in dem Dokument die Bedeutung kulturell verschieden geprägter Auffassungen derselben entgegengehalten.

Dieser Widerstreit zwischen gruppenbezogenem Partikularismus und individuumsbezogenem Universalismus im Verständnis von >Rechten<, der sich schon durch die Erklärung der AAA 1947 manifestiert, verstärkt sich im Kontext der UNO vor allem im Zuge der Entkolonisierungspolitik. Er manifestiert sich mit der sogenannten >zweiten Generation von Menschenrechten<: den wirtschaftlichen, sozialen und kulturellen Rechten, die in den Menschenrechtspakten von 1966 festgelegt werden (vgl. Kapitel III.2). Während die UN-Menschenrechtserklärung von 1948 sich auf Individuen bezieht, werden mit den beiden Menschenrechtspakten kollektive Rechte neu fokussiert. ${ }^{4}$ Die Mitgliedsstaaten der UNO gelten nicht mehr als homogene, sondern heter-

3 Siehe zum Beispiel die verschiedenen Aufsätze zu Anthropology and Human Rights in a New Key, dem Schwerpunktthema der ersten Ausgabe des American Anthropologist 2006.

4 In den Menschenrechtspakten von 1966 [1976] werden die Begriffe >Land >Volkı synonym gebraucht. Das bedeutet, Gruppen, die sich als kulturell verschieden von ihrer Umgebung wahrnehmen, müssen sich als Völker definieren und gleichzeitig nachweisen, dass sie auf einem bestimmten Territorium leben. In diesem Gebiet müssen überwiegend Vertreter ihrer Kultur zu finden sein, damit sie ein Recht auf kollektive Rechte geltend machen können. 
ogene Gesellschaften: Sie bestehen nicht aus einem freiwilligen Zusammenschluss von Individuen, deren gleichrechtliche Behandlung es ohne Unterschiede abzusichern gilt, sondern aus einer mehr oder weniger freiwilligen Zusammenführung verschiedener Gruppen, die auf Grund ihrer jeweiligen kulturellen Besonderheiten in bestimmten Aspekten autonom agieren sollen. Eine differente Kultur zu 〉besitzen<, wird somit zum Grundstein für politische Forderungen von Gemeinschaften, die in bestehenden nationalstaatlichen Gefügen marginalisiert werden. Ihnen räumen die Menschenrechtspakte von 1966 erstmalig eine legale Chance ein, Sonderrechte geltend zu machen.

In der sogenannten >dritten Generation von Menschenrechten` wird die Berücksichtigung kultureller Differenzen schließlich zum Leitmotiv der Entwicklungspolitik, einem wichtigen Betätigungsfeld der UNO, erklärt. Die Weltkonferenz über Kulturpolitik im Jahre 1982 in Mexiko Stadt bildet den Ausgangspunkt dieser Veränderungen. Im Lichte des Scheiterns einer Vielzahl von Großprojekten in den 1970er Jahren wird der ökonomische und technische Blick auf Entwicklungsfragen als evolutionistisches und monokausales Konzept gescholten. Die UNO ruft in der Folge eine Weltdekade für kulturelle Entwicklung (1988-1997) aus. Innerhalb dieses Jahrzehnts veröffentlicht die UNESCO 1995 den Bericht Our Creative Diversity, mit dem sie `Kulturく als Grundkonzept bei der Ausarbeitung von Entwicklungsprojekten zu verankern sucht (vgl. Van Hasselt 1998: 65). Auch die Ausrufung zweier konsekutiver Dekaden für indigene Völker (1995-2004 und 2005-2014) erscheint in diesem Sinne als nächster Schritt in der Zusammenführung von `Kultur` und $>$ Rechten $<$ im Kontext der UNO.

\section{Kulturalismus}

Die bewusste Mobilisierung kultureller Differenzen für politische Zwecke bezeichnen Appadurai (1996) und Sahlins (1993) als >Kulturalismus $<$. Dabei werden zum einen sogenannte objektive Kriterien der Differenzierung herangezogen, wie Sprache, Kleidung, Gebräuche. Zum anderen ermöglicht erst das subjektive Kriterium der individuellen Identifikation mit einer >kulturell differenten ¿ Gruppe die Schaffung einer politisch relevanten Gemeinschaft. Kulturalismus betreiben nicht nur nationale Regierungen, sondern diverse Gruppen innerhalb dieser Staaten. Die eigene Lebensform wird dabei als ein übergeordneter, autonomer - quasi biologischer - Wert verstanden und deren Ausübung deshalb als politisches Recht proklamiert. Dies geschieht oftmals vor dem Hintergrund eines empfundenen drohenden Verlustes der differenten Lebensart. Vertreter indigener Organisationen gehören zu den Gruppen, die ihre Forderungen explizit kulturalistisch artikulieren. Mit dem Verweis auf ihre kulturelle Andersartigkeit legitimieren sie wirtschaftliche und soziale Forderungen, die sich an die Regierungen der Staaten richten, in denen sie le- 
ben. Darüber hinaus geht es ihnen aber auch um politische Mitbestimmungsrechte im nationalen Kontext, also um den aktiven Einbezug in bestehende Regierungssysteme. Indigene Bewegungen fordern, wie gesehen, meist nicht die Loslösung aus den bestehenden staatlichen Gebilden. Sie streben stattdessen einen >selbstbestimmten Strukturen an. Dabei definieren sie ihre politischen Gemeinschaften über kulturelle Gemeinsamkeiten und erklären die Aufrechterhaltung der auf dieser Grundlage von ihnen gezogenen Gruppengrenzen zum Ziel. Borofsky (2001) unterscheidet zwei politische Kulturbegriffe:

- ein politisches Verständnis von Kultur als Widerstand gegen »westliche Modernisierungstendenzen «;

- ein ebenso politisches Verständnis, das sich im Nationsgedanken kristallisiert und sich am Bild von abgrenzbaren Gemeinschaften orientiert, die sich durch eine partikuläre Lebensweise von anderen ebensolchen Gemeinschaften unterscheiden.

Die beiden politischen Kulturbegriffe bedingen und ergänzen sich jedoch gegenseitig, da sie auf den gleichen Grundlagen basieren: Auch wenn Kultur als Widerstandsmoment zu politischen Zwecken eingesetzt wird, ist dies ein Versuch, homogene, abgrenzbare Gemeinschaften mit partikulärer Lebensweise zu kreieren. Kulturelle Identität wird gleichgesetzt mit politischer. Dies wird deutlich, wenn man sich das Konzept der >Metakultur८, wie es von Turner (1993) und Hannerz (1996) entworfen wird, anschaut.

\section{Metakultur}

Turner (1993) stellt die politische Verwendung des Kulturbegriffs in Zusammenhang mit sozialen und ökonomischen Interessen. Auch er argumentiert dabei für ein Verständnis dieses Kulturbegriffs als Ermächtigungsstrategie für ausgegrenzte Gruppen, die sich durch dessen Verwendung politische Rechte erkämpfen könnten. Für Turner wird `Kultur〈 relevant, wenn man Widerstand gegen zentrale politische Autoritäten und hegemoniale nationale Identitäten mobilisieren möchte. Unterstützt würden diese Ermächtigungsprozesse durch neue Formen des Konsums, in denen Waren als symbolisches Medium zur Selbstkonstruktion (lifestyles, life-politics etc.) verwendet würden. Diese Entwicklungen hätten die Wahrnehmung von Kultur als etwas, das man selbst produzieren und konstruieren könne - losgelöst von durch den Staat definierten normativen sozialen und politischen Werten - begünstigt. `Kulturく habe somit neue Bedeutungen und Konnotationen angenommen. Sie sei zu einem symbolischen Medium geworden.

Die wichtigste Bedeutung von >Kultur` liegt für Turner in der Vorstellung, dass diese als Unterscheidungsmerkmal von Nationen Kollektivrechte wie 
zum Beispiel Selbstbestimmung verkörpere. Diese Kollektivrechte würden nun von Gruppen innerhalb der nationalstaatlichen Strukturen beansprucht: >Kultur` würde so zum politischen Werkzeug, zur Quelle von übergeordneten Werten, welche die Legitimität der herrschenden Ordnung in Frage stellen könnten. Für Turner wird sie zu einer universalen Kategorie - der Metakultur $^{5}$. Als solche erhielte der Begriff die Qualität eines kollektiven Menschenrechts. Mit dem Verweis auf `Kultur könne politische Repräsentation in der öffentlichen Sphäre eingefordert werden. Erhebe man den Begriff zu einem Menschenrecht, müsse man aber einige gemeinsame Eigenschaften von Kultur definieren und anerkennen (Turner 1993: 423ff.). Durch diese Festlegung wird der politische Kulturbegriff objektiviert.

Markowitz (2004: 332) stellt die von Turner vorgenommene Zusammenführung von Kultur und Menschenrechten in den Zusammenhang mit Diskussionen um Globalisierung, von ihm verstanden als Intensivierung der weltweiten Interaktion zwischen verschiedenen Gruppen: Kultur sei im Zuge dessen zu etwas geworden, das jeder haben wolle, zu einem politischen Projekt. Es sei nicht nur ein Euphemismus für »Rasse« (vgl. Kuper 2003), sondern auch Inbegriff eines "provokanten politischen Projekts und ein Schrei nach sozialer Wertschätzung « (Markowitz 2004: 332; vgl. auch Taylor 1994; Turner 1993, 1997). Kulturelle Differenzen erklären nach diesem Modell nicht mehr nur den Ist-Zustand einer Gemeinschaft oder Gesellschaft, sondern verwandeln sich in eine »fundamentale Idee« (Bourdieu 2001), die politische Kräfte zur Veränderung dieses Zustands mobilisiert. In politischen Auseinandersetzungen ist somit ein Paradigmenwechsel zu konstatieren, der sich vor allem in den 1980er Jahren vollzieht: Gegenwärtig werden wirtschaftliche, soziale und politische Forderungen bevorzugt mit dem Verweis auf `Kultur< vorgebracht, während man noch in den 1960er und 70er Jahren ebensolche Forderungen meist anhand des Begriffs der $>$ Klasse $<$ aufstellt. Soziale und ökonomische Differenzen treten hinter kulturellen zurück. Das bestehende Nationalstaatsmodell wird in Frage gestellt, ihm wird die Vision von multikulturellen Staaten entgegengestellt.

Auch Hannerz (1996: 10-11) benutzt den Begriff der Metakultur, differenziert ihn aber weiter aus, indem er zwei gegenläufige Tendenzen unterscheidet:

- eine Metakultur der Ähnlichkeit als Ausdruck der Moderne, die von oben nach unten arbeitet (»Modernisierung der Indigenität «);

- eine Metakultur der Differenz als politisches Instrument des Widerstands, die von unten nach oben arbeitet (»Indigenisierung der Moderne«).

$5 \mathrm{Zu}$ anderen Verwendungen des Begriffs der Metakultur siehe Urban 2001 oder Oakdale 2004. 
Das zweite Diskursmodell würde von denen benutzt, die keine Chancen hätten, sich der Einflusssphäre der Moderne, das heißt der politischen Einteilung der Welt in Nationalstaaten, zu entziehen. Sahlins (1993) bezeichnet diesen Prozess als »Indigenisierung der Moderne« - ein kultureller Aneignungsprozess von Seiten der durch Kolonisation an den Rand gedrängten Gruppen, der auf erneute Heterogenisierung der Strukturen abzielt. Hannerz betont hingegen, dass die »Metakultur der Ähnlichkeit« weiterhin einen domestizierenden Einfluss auf die »Metakultur der Differenz« ausübe. Diesen Prozess nennt er die »Modernisierung der Indigenität« - die kolonisierten Völker fangen an, wie Nationalstaaten zu sehen und zu handeln. Hannerz' Zweiteilung entspricht somit zwar Borofskys (2001) Unterscheidung, sie beleuchtet aber stärker die Interdependenzen und gemeinsamen systematischen Grundlagen der beiden Diskursmodelle.

\section{Fazit}

Ein Paradoxon kennzeichnet unweigerlich den politischen Kulturbegriff indigener Bewegungen: Über Abgrenzung möchte man Einschluss bewirken; durch den Verweis auf Differenzen möchte man die Anerkennung als Gleiche erreichen. Auch die, die eine Metakultur der Differenz verfolgen, postulieren letztendlich, dass eine geteilte Kultur gleichzusetzen ist mit geteilten Interessen und Werten. Der politische Kulturbegriff in seinen zwei grundlegenden Erscheinungsformen - Nationskonzept und Kultur als Widerstandspotential - ist ein zweckgerichteter Metadiskurs über Differenz, der zur Legitimierung politischer Zielsetzungen verschiedener Interessengruppen herangezogen wird. Er vereinfacht komplexe soziale Zusammenhänge und bietet den Konstituenten der jeweiligen politischen Gemeinschaften emotional wirksames Identifikationspotential. Den politischen Kulturbegriff zur Erklärung sozialer Realitäten und zur Reform bestehender Nationsmodelle zu verwenden, birgt jedoch unweigerlich Gefahren, nicht zuletzt dadurch, dass kultureller Identität dabei ein quasi biologischer Eigenwert zukommt, der unabhängig von seinen jeweiligen Trägern zu bestehen scheint. Eine Politik des kulturellen Überlebens kann schnell den Charakter von Artenschutz annehmen und zu neuen Ausschlussprozessen führen. Die Kategorie >indigenes Volk eine bedeutende, weil an herrschende Diskursmodelle angepasste, aber deshalb auch äußerst ambivalente politische Mobilisierungskraft für marginalisierte Gruppen innerhalb bestehender Nationalstaaten. 



\section{Kapitel V}

\section{Das Ständige Forum für indigene Angelegenheiten als politisches Feld - ein globaler Raum zur Lösung lokaler Probleme?}

Wie aus den historischen Betrachtungen deutlich wurde, konnten sich die unterschiedlichsten Gruppen unter dem Begriff >indigene Völker` innerhalb des Systems der Vereinten Nationen etablieren und teilweise sogar das Beitrittsrecht dieser Einrichtung reformieren. Ich erinnere daran, dass die UNO als zwischenstaatliche Organisation Akteuren der Zivilgesellschaft normalerweise nur Zutritt über NGOs gewährt, die einen UN-Beraterstatus besitzen. Das Ständige Forum für indigene Angelegenheiten bildet diesbezüglich genauso eine Ausnahme wie die Arbeitsgruppe indigene Völker. Auch wenn der Zutritt zur UNO für Vertreter indigener Völker somit zumindest partiell offen erscheint, gestaltet sich deren Teilnahme für viele von ihnen dennoch schwierig. Vor allem mangelndes ökonomisches Kapital und die Visapflicht bei der Einreise in die USA schränken die Teilnahmemöglichkeiten für viele stark ein. Ausgehend von Bourdieus (2001) Definition des politischen Feldes, die ich bereits dargelegt habe (vgl. Kapitel II.5), möchte ich im Folgenden untersuchen, welche Kräfte die Dynamik dieses Feldes bestimmen: Wofür steht das Forum? Was wird an dieser Einrichtung verhandelt? Und welche indigenen Stimmen können sich dort bevorzugt Gehör verschaffen? 


\section{Die Gruppen im Feld}

Zunächst möchte ich die bei den Sitzungen des Ständigen Forum für indigene Angelegenheiten vertretenen Gruppen kurz charakterisieren und die Rollen bzw. Ziele der jeweiligen Teilnehmer grob definieren. Es sind anzutreffen:

- die Mitarbeiter des Sekretariats

- die sechszehn Mitglieder des Forums

- die Vertreter des UN-Systems und anderer zwischenstaatlicher Organisationen

- Regierungsvertreter

- Repräsentanten indigener Organisationen

- NGO-Vertreter

- Mitarbeiter wissenschaftlicher Einrichtungen

\section{Die Mitarbeiter des Sekretariats}

Das Sekretariat des Forums ist am UN-Hauptsitz in New York angesiedelt und wird derzeit von der griechischen Juristin Elsa Stamatopoulou geleitet, die über langjährige Erfahrung im UN-Kontext verfügt. Es besteht aus fünf Fachkräften, zwei Verwaltungsmitarbeitern und einer wechselnden Zahl von Praktikanten. Das Sekretariat wird aus dem regulären Budget der Vereinten Nationen finanziert. Es organisiert die jährlichen Treffen des Forums, betreibt Forschungsarbeit und >Bewusstseinsförderung〈zur umfassenden Integration indigener Themen in das UN-System. Zu diesem Zweck sammeln und publizieren die Mitarbeiter relevante Informationen zu indigenen Themen.

\section{Die sechzehn Mitglieder des Forums}

$\mathrm{Zu}$ den jährlichen Sitzungen im Mai reisen die sechzehn Mitglieder des Forums aus den verschiedenen Weltregionen an - acht Experten werden von Regierungen entsandt, acht von indigenen Organisationen vorgeschlagen. Alle drei Jahre werden die Mitglieder neu gewählt, dabei ist es möglich, dass Einzelne für eine zweite Amtsperiode bestätigt werden. Dem Präsidenten des ECOSOC obliegt die Auswahl unter den Kandidaten. Dabei spielt vor allem die nationale und internationale politische Erfahrung der vorgeschlagenen Personen eine wichtige Rolle.

Die sechzehn Mitglieder teilen sich die anfallende Arbeit untereinander auf. Neben der Leitung der Sitzungen gilt es, die von Teilnehmerseite eingehenden Informationen und Vorschläge zu systematisieren. Das Forum arbeitet zu folgenden Themen: Umwelt, wirtschaftliche und soziale Entwicklung, Kultur, Bildung, Gesundheit und Menschenrechte. Hinzu kommt jedes Jahr eine besondere Schwerpunktsetzung (vgl. Kapitel III.3). Während des Jahres folgen die Mitglieder des Forums Einladungen von UN-Organisationen zu Seminaren und Konferenzen, um dort die indigenen Positionen zu den jeweili- 
gen Themen zu vertreten. Laut den Angaben eines ihrer ehemaligen Mitglieder, dem von der mexikanischen Regierung entsandten Marcos Matías Alonso, standen die ersten Forumsmitglieder - gewählt für die Sitzungsperioden 2002 bis 2004 - in eher losem E-Mail-Kontakt. Politische Divergenzen, sprachliche Barrieren, fehlende finanzielle Mittel und andere Arbeitsverpflichtungen hätten den regelmäßigen Austausch beeinträchtigt. Matías Alonso schreibt es aber vor allem unterschiedlichen ideologischen Grundeinstellungen zu, dass die Kommunikation und damit für ihn teilweise auch die Aktionskraft der Mitglieder eingeschränkt wurde (Interview Matías Alonso 19.05.2004). Die Mitglieder werden für ihre Arbeit am Forum nicht bezahlt, erhalten jedoch eine Aufwandsentschädigung für ihre jeweiligen Einsätze.

\section{Die Vertreter des UN-Systems}

und anderer zwischenstaatlicher Organisationen

Neben den sechzehn Mitgliedern des Forums sind Delegierte der Mitgliedsorganisationen des UN-Systems und anderer zwischenstaatlicher Organisationen als Teilnehmer von hervorgehobener Bedeutung (vgl. Schaubild im Anhang). Das UN-System umfasst alle Einrichtungen, die direkt und indirekt mit den Vereinten Nationen in Verbindung stehen, das heißt: a) Sonderorganisationen wie die FAO, ILO, WHO, UNESCO, WIPO, Weltbank (indirekte Verbindung) b) Regionalkommissionen (bis 2005 nahm nur CEPAL teil) und Fachkommissionen wie die Kommission für nachhaltige Entwicklung oder die Kommission für soziale Entwicklung (direkte Verbindung) c) Spezialorgane und Programme wie UNFPA, UNDP, UNHCR, UNICEF, UNEP (direkte Verbindung). ${ }^{1}$ Andere zwischenstaatliche Organisationen, die Delegierte zu den Treffen des Forums schicken, sind unter anderem die Afrikanische Union, die Europäische Kommission und die Interamerikanische Entwicklungsbank. Ich verwies bereits darauf, dass das Ziel des Forums eine stärkere Sichtbarmachung Indigener im UN-Kontext ist. Konkret bedeutet das: Die Kategorie >Indigene< soll in den Richtlinien und Projekten der Sonderorganisationen, Kommissionen und Spezialorgane Aufnahme finden und die zielgruppenspezifischen Etats erhöht werden. $\mathrm{Zu}$ den einzelnen Themen im Tagungsprogramm sprechen deshalb meist Vertreter von UN-Organisationen als sogenannte keynotespeakers, die danach auf Fragen der Forumsmitglieder reagieren müssen. Viele der erwähnten Einrichtungen nutzen den Raum, der ihnen das Forum bietet, aber auch zur Selbstpräsentation. Sie organisieren entsprechende Sonderveranstaltungen in den Mittagspausen oder Abendstunden.

1 Für die ausgeschriebenen Bezeichnungen der einzelnen Organisationen siehe Anhang. 


\section{Die Regierungsvertreter}

Die Regierungsvertreter sind eine eher kleine Gruppe von Teilnehmern. Die Zahl der durch Delegationen vertretenen Regierungen stieg von achtundfünfzig Ländern im Jahr 2003 auf sechsundsiebzig bei der darauffolgenden Sitzungsperiode an. 2005 nahmen achtundsechzig Regierungsvertreter teil (vgl. United Nations 2003, 2004, 2005). Einige Botschaften laden abends ausgewählte Personen, zum Beispiel Forumsmitglieder, zu Empfängen ein. In den offiziellen Sitzungen spielen sie, trotz häufiger Redebeiträge, eine eher marginale Rolle.

Die Regierungsvertreter können, im Wechsel mit Vertretern der NGOs und indigener Organisationen, zu den einzelnen Tagungspunkten sprechen. Dabei heben sie zumeist das Engagement ihrer Regierung hervor und sehen diese auf dem Weg zur Herstellung von >Chancengleichheit` und >Entwicklungsperspektiven` für die in ihrem Staat lebenden indigenen Bevölkerungsgruppen. Auch wenn sie in der Regel nicht von sindigenen Völkern`, sondern >Bevölkerungen`sprechen, erkennen sie die Existenz der im Forum vertretenen indigenen Gruppen als solche verbal an. Lediglich einige asiatische und afrikanische Regierungen gehen auf offenen Konfrontationskurs und negieren die Existenz Indigener in ihrem Land - z.B. Bangladesh. In einem Redebeitrag 2005 stellte die Regierungsvertreterin Bangladeshs fest: »Bangladesh hat keine indigenen Völker. Wir haben einige ethnische Minderheiten, die nicht als >indigene Völkerく im wirklichen Sinn bezeichnet werden können«. Den >wirklichen Sinn` definierte sie wie folgt: »>Indigene Völker [...] sind die ursprünglichen Einwohner eines bestimmten Gebiets oder Landes« (Redebeitrag Jahan Ahmed, erste Sekretärin der Ständigen Mission Bangladeshs an den Vereinten Nationen, 24.05.2005). ${ }^{2}$ An diesen Punkten tritt der bereits beschriebene Konflikt zwischen Regierungen und Repräsentanten indigener Organisationen um die Definition als >Minderheit $<$ oder >Volk « sichtbar zu Tage. Jedoch bestimmen diese Auseinandersetzungen zumeist nicht den offiziellen Sitzungsverlauf, sind aber häufig Gegenstand empörter Kommentare von Seiten indigener Repräsentanten in privaten Gesprächen.

\section{Die Repräsentanten indigener Organisationen}

Die größte Gruppe der Teilnehmer stellen die Repräsentanten indigener Organisationen aus allen Weltregionen. Ihre Reisen werden meist von UNEinrichtungen und europäischen Unterstützer-NGOs bezahlt, einige Gesprächspartner gaben aber auch an, die Reise selbstständig finanziert zu haben. Auf Grund der hohen Kosten, die Flug und Aufenthalt in New York bedeuten, können die meisten jedoch nicht ohne externe Unterstützung anreisen.

2 Originalbeitrag auf Englisch, eigene Übersetzung ins Deutsche. 
Es gibt zudem einen eigens eingerichteten UN-Fonds ${ }^{3}$ für diese Zwecke, aus dem jedes Jahr einer Reihe indigener Repräsentanten Stipendien für die Teilnahme gewährt wird.

Die indigenen Teilnehmer reisen mit den unterschiedlichsten Erwartungen und großen Wissensunterschieden bezüglich Sinn und Zweck sowie Lobbymöglichkeiten innerhalb des Forums an. Zum einen trifft man sprofessionelle Indigenisten $<$ - Personen, die für international anerkannte, etablierte indigene Organisationen arbeiten. Sie verfügen zumeist über mehrere Jahre oder sogar Jahrzehnte Lobbyerfahrung im UN-Kontext. Oftmals sind es ausgebildete Juristen oder zumindest gut über UN-relevante Themen informierte Personen. Sie wissen zum Beispiel, was die OP $4.10^{4}$ der Weltbank oder die MDGs sind und warum 'free, prior and informed consent $\varsigma^{5}$ so wichtig für indigene Völker ist. Ein Großteil dieser Personen nimmt über den gesamten Sitzungsverlauf am Treffen teil. Sie kennen Schlüsselpersonen in den verschiedenen UNOrganisationen, führen Verhandlungen mit diesen oder treten bei deren für die Sitzungspausen organisierten Veranstaltungen als Sprecher auf. Für sie ist das Forum »eines der globalen Ereignisse, das man als Indigener nicht verpassen sollte« und bei dem man »Konzepte präsentieren kann, welche die indigenen Vorstellungen von Entwicklung verdeutlichen«. Die Themen >Land und Selbstbestimmung « werden von diesen Vertretern zumeist als die »zentralen Themen der indigenen Agenda« bezeichnet (eigene Aufzeichnungen 19./20./24.05.2005).

Am anderen Pol dieser Gruppe indigener Repräsentanten befinden sich die >Laien<. Sie sind eher Lokalpolitiker, welche die Probleme in ihren Gemeinden gut kennen, hingegen wenig über die Weltbankpolitik oder die Millenniums-Entwicklungsziele wissen. Meistens bleiben sie eine, selten zwei Wochen. Sie konnten, wenn sie Glück hatten, im Vorfeld des Treffens an einer mehrtägigen Einführung in die Funktionsweise sowie Sinn und Zweck

3 Der Voluntary Fund wurde 1984 eingerichtet. Er dient dazu, Repräsentanten indigener Organisationen die Teilnahme an den Treffen der Arbeitsgruppe indigene Völker und auch an den Treffen des Ständigen Forums für indigene Angelegenheiten zu ermöglichen. Ferner finanziert er kleine Projekte auf lokaler Ebene (vor allem Seminare zu UN-relevanten Themen).

4 OP 4.10 steht für Operational Policiy 4.10. Die Weltbank verabschiedete 1982 das erste Mal Richtlinien zum Umgang mit Indigenen. Diese Richtlinien bezogen sich vor allem auf den Schutz von Landrechten und die Versorgung mit Gesundheitsdiensten - besonders für solche Gruppen, die von Weltbank-unterstützten Projekten betroffen waren. 1991 wurden die Richtlinien das erste Mal überarbeitet, im Juni 2005 trat eine erneut überarbeitete Version in Kraft.

5 Diese Richtlinie, die in die OP 4.10 Aufnahme gefunden hat, wird zum Beispiel relevant im Zusammenhang mit industriellen Großprojekten in Gebieten, in denen Indigene siedeln. Sie soll sicherstellen, dass Projekte nur umgesetzt werden, wenn indigene Gruppen in Kenntnis der Sachlage ihre Einwilligung geben. 
des Forums teilnehmen. Diese Einführungen werden von Unterstützer-NGOs bezahlt und von den indigenen Profis im Feld geleitet.

\section{Die NGO-Vertreter}

Viele der beim Forum vertretenen NGOs finanzieren die Teilnahme einer oder mehrerer indigener Interessenvertreter von Organisationen, mit denen sie auch das Jahr über zusammenarbeiten. Auch hier gibt es eine Reihe großer, etablierter Organisationen, die einen Beraterstatus am ECOSOC besitzen und regelmäßig an UN-Veranstaltungen teilnehmen. Sie richten oft, genau wie einzelne UN-Organisationen, Veranstaltungen in den Sitzungspausen aus. Dem gegenüber stehen die Vertreter kleiner NGOs, die wenig Prestige und/oder kaum Erfahrung im UN-Kontext besitzen. Sie können mit ihrer Teilnahme aber auch durchaus im politischen Kontext irrelevante Ziele verfolgen, zum Beispiel, wenn sie auf der Suche nach Geschäftskontakten für Tourismusprojekte oder für die Organisation spiritueller Workshops sind. Der offene Charakter der Sitzungen des Forums macht aus selbigem ein hochgradig heterogenes Feld in Bezug auf Zusammensetzung und Interessen sowie individuelle Zielsetzungen der Teilnehmer.

\section{Die Mitarbeiter wissenschafticher Einrichtungen}

Die Vertreter wissenschaftlicher Einrichtungen bilden eine zahlenmäßig eher unbedeutende Gruppe von Personen, die sich teilweise untereinander kennen oder auf dem Treffen zufällig kennen lernen. Man tauscht Erfahrungen aus, ist aber ansonsten bemüht, eigene Wege zu gehen und mit den Gruppen in Kontakt zu kommen, die für die jeweilige Forschung relevant sind. Einige Wissenschaftler verknüpfen auch ihr Forschungsinteresse mit politischer Lobbyarbeit für indigene Bewegungen. Sie sehen das Forum als wichtigen Ort, um neueste Informationen aus ihren Forschungsregionen zu bekommen sowie Kontaktpersonen aus den entsprechenden Ländern zu treffen. In der Gruppe der Wissenschaftler gibt es einige Ethnologen, die das Treffen besuchen. Sie spielen insgesamt eine Außenseiterrolle und sind für die Analyse des politischen Feldes eher von untergeordneter Bedeutung. In Gesprächen mit indigenen Aktivisten wird vor allem Ethnologen jedoch oft mit grundlegender Kritik begegnet: Sinn und Zweck ihrer Forschung wird in Frage gestellt, da sie einem grundsätzlich >kolonialem` Prinzip der Degradierung Indigener $\mathrm{zu}>$ Studienobjekten` folgten und sich anmaßten, ihre Kultur und Stimme zu repräsentieren.

\section{Sitzordnung}

Hinzuweisen ist noch auf die Sitzordnung im Konferenzsaal. Die Regierungsvertreter und die Delegierten der UN-Organisationen sowie die Mitglieder des 
Forums sitzen an fest zugewiesenen Plätzen im Plenarsaal. Auf einem Podest nehmen der Leiter der Sitzung, zusammen mit den keynotespeakers der jeweiligen Themenblöcke, einem oder mehreren Angestellten des Sekretariats des Forums sowie der Schriftführer (ebenfalls Mitglied des Forums) Platz. Unmittelbar darunter sitzen im Halbkreis die anderen Forumsmitglieder. Vom Podest aus betrachtet nehmen die Regierungsvertreter zum größten Teil auf der linken Seite des Raumes und in der Mitte, die Delegierten der UN-Organisationen in der Mitte sowie auf der rechten Seite Platz. Größere NGOs und indigene Organisationen (meist die mit UN-Beraterstatus) suchen sich ebenfalls feste Plätze im Tagungsraum. Diese markieren sie manchmal, indem sie selbstgefertigte Namensschilder aufstellen. Meist entsteht aber auch ohne diese Markierung eine Art ungeschriebene Sitzordnung. Die Vertreter kleinerer indigener und nicht-indigener Organisationen sowie die wissenschaftlichen Teilnehmer verfügen hingegen über keine festen Plätze.

\section{Teilnehmerzahlen 2002 bis 2005}

Beim Vergleich der Teilnehmerzahlen ${ }^{6}$ aus den Jahren 2002 bis 2005 fällt Folgendes auf: Einerseits ist die Zahl von Regierungsvertretern sowie Delegierten von UN-Einrichtungen und anderen zwischenstaatlichen Organisationen stetig gewachsen; andererseits sind große Schwankungen bei den Zahlen der am Forum teilnehmenden Repräsentanten indigener Organisationen zu verzeichnen. Nach einem ersten Anstieg der Zahlen 2003 und 2004, fielen sie 2005 ungefähr auf den Stand des ersten Jahres zurück. Dieser Rückgang korrespondiert mit einer Ernüchterung vieler indigener Teilnehmer, die diese mir gegenüber in Bezug auf die Relevanz des Forums für ihre Arbeit in den jeweiligen Heimatregionen 2004 und 2005 vermehrt äußerten. Ersichtlich wird jedoch gleichfalls, dass die Repräsentanten indigener Organisationen weiterhin mit Abstand die größte Gruppe der Teilnehmer darstellen.

Genaue Angaben zu den Personenzahlen kann man den entsprechenden UN-Dokumenten hingegen nicht entnehmen. Bis 2004 stiegen die Teilnehmerzahlen jedoch, laut Elsa Stamatopoulou, von ca. 800 auf 1200 Personen (Gespräch Stamatopoulou 20.05.2004).

6 Die entsprechenden Angaben in der untenstehenden Tabelle beruhen auf eigenen Berechnungen an Hand der Sitzungsberichte aus den Jahren 2002 bis 2005. Leichte Abweichungen sind deshalb möglich (vgl. United Nations 2002a, 2003, 2004a, 2005). 
Tabelle 1: Teilnehmerzahlen 2002-2005

\begin{tabular}{|l|l|l|l|l|l|}
\hline Jahr & $\begin{array}{l}\text { Regie- } \\
\text { rungen }\end{array}$ & $\begin{array}{l}\text { UN-Einricht- } \\
\text { ungen } \\
\text { (\& andere } \\
\text { zwischen- } \\
\text { staatliche } \\
\text { Organisatio- } \\
\text { nen) }\end{array}$ & $\begin{array}{l}\text { Indigene Or- } \\
\text { ganisationen } \\
\text { (mit \& ohne } \\
\text { Beraterstatus } \\
\text { am ECOSOC) }\end{array}$ & $\begin{array}{l}\text { NGOs } \\
\text { (mit \& ohne } \\
\text { Berater- } \\
\text { status am } \\
\text { ECOSOC) }\end{array}$ & $\begin{array}{l}\text { Wissen- } \\
\text { schaftliche } \\
\text { Einrichtun- } \\
\text { gen }\end{array}$ \\
\hline $2002^{7}$ & 29 & 11 & 152 & 32 & 25 \\
\hline 2003 & 57 & 23 & 199 & 50 & 23 \\
\hline 2004 & 70 & 31 & 246 & 73 & 27 \\
\hline 2005 & 66 & 34 & 149 & 38 & 19 \\
\hline
\end{tabular}

Abbildung 4: Teilnehmerzahlen 2002-2005
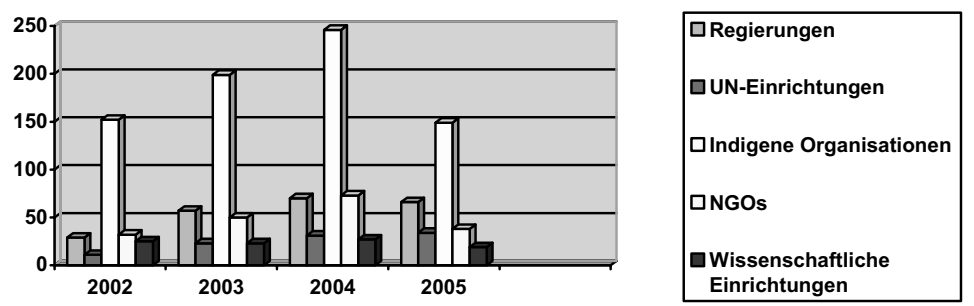

\section{Mai 2005: Ein Sitzungstag am Forum}

Um sich eine Vorstellung vom Konferenzalltag während der Treffen des Forums machen zu können, schildere ich im Folgenden einen typischen Sitzungstag. Die eingenommene Perspektive ist die der ethnologischen Forscherin, also einer Vertreterin der siebten Gruppe im Feld (vgl. Kapitel V.1). Die geschilderten Erlebnisse und Diskussionen mit verschiedenen Teilnehmern des Forums stellen eine Synthese der Erfahrungen dar, die ich während meiner Teilnahme an der Sitzungsperiode des Forums im Jahr 2005 im Verlauf der zwei Wochen gemacht habe. Die Eindrücke und Gespräche aus den Jahren 2003 und 2004 fließen aber indirekt ebenfalls mit ein. Die Schilderungen

7 Zu den Zahlen aus dem Jahr 2002 gilt es anzumerken, dass die Rubrik sindigene Organisationen a auch >nicht-indigene Organisationen sprechenden Jahr noch nicht zwischen diesen beiden Kategorien, sondern zwischen Organisationen mit und ohne Beraterstatus am ECOSOC unterschieden wurde. 
bilden die Grundlage für die danach folgende Analyse des politischen Feldes (vgl. Kapitel II.5). Sie geben Einblicke in die strukturellen Bedingungen des Forums und die Dynamik der Sitzungen, aber auch in die Erwartungen und Vorstellungen der Teilnehmer - vor allem der indigenen.

Kurz vor neun Uhr bog ich in die First Avenue, Höhe 42. Straße, ein und steuerte direkt auf das hohe, schmale UNO-Gebäude zu. Vor mir liefen zwei Männer in dunklen Anzügen, die sich auf französisch unterhielten. Eine Frau in schicken Kleidern überholte mich - in der Hand einen Kaffeebecher, um den Hals eine etwas schmucklose Kette, an deren Ende ein UN-Pass baumelte. Ich erkannte sie als Vertreterin einer großen europäischen NGO, die indigene Organisationen unterstützt. Während die zwei Männer, offensichtlich Angestellte der UNO, das Gebäude durch den Haupteingang betraten, steuerten die Frau und ich als Teilnehmer am Ständigen Forum für indigene Angelegenheiten mit unseren Pässen den Besuchereingang an. Dort hatte sich bereits eine Schlange an der Sicherheitskontrolle gebildet. Gerade lief eine mit traditionellem Gewand bekleidete und reich mit Schmuck verzierte Maasai durch die Sicherheitsschranke. Ein Signal ertönte, sie schaute den Beamten zögerlich an, doch der winkte sie durch. Am dritten Tag der Konferenz war sich dieser Beamte anscheinend sicher, dass nur der Schmuck das Signal ausgelöst haben konnte.

Im Gebäude angekommen, schlug mir klimatisierte Luft und im Vergleich zur Hektik der Straße eine angenehme Ruhe entgegen. Die ersten Besuchergruppen saßen bereits auf den weichen Lederbänken im Eingangsbereich und warteten auf den Beginn der Führungen. Ich stieg eine Treppe hinab, durchquerte die Zone der Souvenir-Läden und passierte einen weiteren Sicherheitsbeamten mit leichtem Kopfnicken - der UN-Pass baumelte nun auch gut sichtbar um meinen Hals. Ein fensterloser Gang führte mich direkt auf die ebenfalls fensterlose Cafeteria zu, die zu dieser Stunde noch viele freie Plätze aufwies. An den bereits belegten Tischen saßen Teilnehmer des Forums, zum Teil mit Laptops und Kaffee, einzeln oder in Gespräche mit anderen vertieft. Es wurde geraucht und diskutiert. Ich blickte mich suchend um, ob ich einen potentiellen Gesprächspartner ausfindig machen konnte. Es war das dritte Jahr, das ich an der zweiwöchigen Sitzung des Forums teilnahm. Ich erkannte inzwischen eine Vielzahl von Gesichtern unter den über tausend Teilnehmern und konnte die indigenen unter ihnen, auch wenn sie mir unbekannt waren, meist einer von zwei groben Kategorien zuordnen: Die erfahrenen Teilnehmer waren beständig damit beschäftigt, Leute zu grüßen, kurze und längere Gespräche zu führen und betriebsam durch die Gänge zu laufen. Im Konferenzsaal traf man sie nur zu den rentscheidenden Sitzungen - bei der Eröffnungssitzung, bei der Abschlusssitzung, wenn sie selbst einen Redebeitrag hatten oder wenn für ihre Arbeit wichtige Personen sprachen. Die Neuen be- 
wegten sich hingegen häufig in Gruppen fort, an deren Spitze manchmal ein UN-erfahrener Indigener lief. Dann ging es meist zu einer Veranstaltung, in welcher der erfahrene UN-Teilnehmer vielleicht selber sprach oder die er zumindest als besonders wichtig für die anderen identifiziert hatte. Die Neuen sah man auch regelmäßiger im Sitzungssaal, wo sie jedoch fast ausschließlich in der Rolle der Zuhörer waren oder sich die auf Tischen kostenlos ausliegenden Informationsmaterialien, Redebeiträge, Ankündigungen und Publikationen anschauten.

An diesem Morgen hatte ich bei meiner Gesprächspartnersuche in der Cafeteria kein Glück. Eigentlich hatte ich mir sowieso vorgenommen, am Caucustreffen teilzunehmen. Das fand eine Stunde vor dem offiziellen Sitzungsbeginn, ab 9:00 Uhr im Konferenzsaal statt. Mit dem Wort Caucus wurden Arbeitsgruppen bezeichnet, die zum inoffiziellen Programm des Forums gehörten. Der Caucus wurde in der Arbeitsgruppe indigene Völker in Genf eingeführt und danach auch ans Forum übertragen. Er diente der Positionsabsprache unter den indigenen Teilnehmern sowie zur Erarbeitung gemeinsamer Redebeiträge. Jedes Jahr gab es die festen Caucustreffen, zu denen das morgendliche Gesamtcaucus- und die regionalen Gruppentreffen der Indigenen am Abend gehörten. Zudem entstanden in den ersten Tagen meist eine Reihe von thematischen Arbeitsgruppen, die kollektive Redebeiträge zu den entsprechenden Punkten des Tagungsprogramms entwickelten. Am morgendlichen Caucus im Konferenzsaal konnte jeder teilnehmen, doch eigentlich war es ein Treffen der indigenen Teilnehmer. Bei den regionalen Treffen fühlte man sich als nicht-indigener Teilnehmer schnell als Fremdkörper und wurde neugierig beäugt, wenn man den Raum betrat. Da die Gruppen kleiner waren und oft auch interne Streitigkeiten diskutiert wurden, konnte die Anwesenheit Außenstehender schnell als störend empfunden werden.

In Gedanken hing ich dem Lateinamerika-Caucus des Vorabends nach, der die ersten Anzeichen von Teilnehmerschwund gezeigt hatte. Man wollte ein gemeinsames Papier zum Thema Landrechte erarbeiten. Nachdem an den ersten Abenden von einigen wenigen lange Grundsatzreden gehalten worden waren und fast ein Streit entbrannt war, wer den vorzubereitenden Beitrag hinterher in der offiziellen Sitzung verlesen dürfe, hatten sich inzwischen die Wogen geglättet. Übriggeblieben waren diejenigen, die bereit waren, am Papier aktiv mitzuwirken, selbst wenn sie es selber nicht präsentieren durften. Man hatte sich am Vorabend auf zwei junge, neue Teilnehmer des Forums als Vortragende geeinigt: eine Vertreterin aus Kolumbien und einen Repräsentanten aus Ecuador. Damit ließen sich die latenten Spannungen in der Gruppe lösen, die sich zwischen erfahrenen und neueren Teilnehmern gebildet hatten. Die Erfahrenen leiteten die Caucustreffen und traten auch in den offiziellen Sitzungen oft als Redner in Erscheinung. Die allgemeine Stimmung in der Gruppe deutete indes darauf hin, dass die Neuen sich nicht angemessen betei- 
ligt und repräsentiert fühlten. Die erfahrenen Caucusleiter erkannten rechtzeitig die gereizte Stimmung im Raum. Vor allem ein Aymara, der als Jurist seit langen Jahren mit der UNO zu tun hatte, setzte sich für die jungen Redner ein. Ich kannte ihn seit meiner ersten Teilnahme am Forum im Jahr 2003, wo wir uns auf einer der allabendlich stattfindenden offiziellen und inoffiziellen Zusammenkünfte über seinen mehrjährigen Aufenthalt in Paris unterhalten hatten. Er wollte mich für die Idee einer indigenen Diplomatenschule gewinnen. Bald hatte ich ihm aber erfolgreich vermittelt, dass meine Position in der akademischen Hierarchie zu unbedeutend war, um als Zugpferd für die Umsetzung dieser Idee in Deutschland Gelder eintreiben zu können. Im zweiten Jahr meiner Teilnahme, 2004, sah ich ihn kaum. Stattdessen lagen auf den Tischen vor und im Sitzungssaal offene Briefe aus, die ihn beschuldigten, sich "am indigenen Thema zu bereichern" und eine fiktive Basisorganisation in seinem Heimatland Peru geschaffen zu haben. Er sei ein »profesional mestizo ${ }^{8}$, der weder Aymara noch Quechua spreche, aber im Namen der Indigenen finanzielle Unterstützung von nationalen und internationalen Organismen erhalte. Er zöge sich an wie ein indio, "ohne wie einer zu fühlen oder einer zu sein«. Die Schreiber des Briefes konnte ich leider auf der Konferenz nicht ausfindig machen. Sie bezeichneten sich als »Forschungsgruppe junger Studenten, die sich mit der Sache der Aymara und Quechua verbunden fühlten«. Die von ihnen geäußerten Vorwürfe waren mir jedoch vertraut, da sie in Peru schnell dem jeweiligen politischen Gegner in der indigenen Organisationslandschaft gemacht wurden. Vor allem Personen, die auf UN-Ebene als indigene Experten ausgewiesen waren, wurden von den unterschiedlichsten Gesprächspartnern in Peru immer wieder als »Nutznießer der indigenen Sache» bezeichnet.

Die unangenehme Situation des Vorjahres hatte sich in diesem Jahr für den Aymara komplett gewandelt. Seine politischen Gegner waren weitestgehend verstummt und hatten seinem Ruf anscheinend keinen dauerhaften Schaden zufügen können. Stattdessen hatte er im Laufe des Jahres an mehreren UN-Konferenzen und Seminaren teilgenommen und die diesjährige Einführung für die Neuen, die von einer Unterstützer-NGO finanziert wurde, geleitet. Auch im Caucustreffen verteilte er seine Positionspapiere sowie Redebeiträge für das Forum und machte Werbung für die von ihm geleiteten Einführungskurse ins UN-System. Auch mir und meiner Forschung gegenüber zeigte er sich offen. Das konnte allerdings auch an meiner Mittlerfunktion zwischen ihm und einer Deutschen liegen, mit der zusammen er ein Projekt zum Thema Menschenrechtsbildung in indigenen Gemeinden bei der Europäischen Kommission einreichen wollte. Inzwischen hatte ich verstanden, dass die Position der Vermittlerin für mich als Forscherin durchaus von Vorteil

8 Dt. >mestizischer Akademiker<. 
sein konnte. War ich doch als Gesprächspartnerin für alle anwesenden Indigenen ansonsten eher uninteressant und musste mich besonders bemühen, um eine Einladung für eine gemeinsame Abendgestaltung oder auch nur einen Platz in der Gesprächsrunde am Tisch der Cafeteria zu bekommen. Die Jagd nach derlei Einladungen bestimmte demnach einen nicht unerheblichen Teil meiner täglichen Forschungsarbeit. Denn: Das waren die Gelegenheiten, bei denen die politische Situation im Heimatland, interne Konflikte unter den anwesenden Teilnehmern und die Ereignisse am Forum in Ruhe durchgesprochen wurden. Hier erhielt man die erforderlichen Informationen, die zur Entschlüsselung des Feldes entscheidend beitragen konnten und die interne Dynamik des Forums verständlicher machten.

Will man an der UNO nicht nur die offiziellen Diskursstrategien der Teilnehmer nachvollziehen und analysieren, sondern die Dynamik des politischen Feldes begreifen, hat man es bei der Forschung schwer. Man selbst ist Neuling im Feld, noch dazu in der Rolle des Zuschauers festgelegt, auch wenn man von den indigenen Teilnehmern zuerst einmal in die Gruppe der NGOVertreter, also der potentiellen Projektfinanzierer, gesteckt wird. Dies bringt besondere Schwierigkeiten bei der Kontaktaufnahme mit sich, da die Erwartungen an Sinn und Zweck des Gespräches grundsätzlich unterschiedlicher Natur sind: Die indigenen Repräsentanten hoffen, einem eventuellen Projektpartner gegenüberzusitzen und lenken das Gespräch in die entsprechende Richtung. Die Ethnologin hofft hingegen, einem potentiellen Informanden gegenüberzusitzen, mit dem sie vielleicht eine längerfristige Arbeitsbeziehung aufbauen kann. Sie versucht, mehr über die persönlichen Einstellungen des Gegenüber herauszufinden. Beide Seiten werden bei diesen konträren Interessenlagen oft enttäuscht.

Inzwischen hatte ich die Eingänge zum Sitzungssaal erreicht. Auf den weichen Lederbänken im Flur saßen vereinzelt kleinere Personengruppen ins Gespräch vertieft. Es stand eine lange Reihe von Computern bereit, an denen man kostenlos im Internet surfen konnte. Auch an diesen fand man zu morgendlicher Stunde noch relativ leicht einen Sitzplatz. Ab 10:00 Uhr-dem Beginn der offiziellen Sitzungen - jedoch musste man schnell sein, um einen freiwerdenden Computer zu bekommen. Ich trat in den Sitzungssaal ein. Bis auf die Leiter des Caucustreffens war er noch leer. Sie saßen auf dem Podium, das ansonsten für die Forumsmitglieder, Sekretariatsmitarbeiter und eingeladenen Sprecher vorgesehen war. Ein Blick auf die Uhr verriet mir, dass es bereits 9:15 Uhr war - das Treffen musste eigentlich schon in Gang sein, aber es fehlte offensichtlich an Teilnehmern.

Ich verließ den Saal wieder und ging zurück zur Cafeteria. Dort fiel mein Blick auf einen schlanken, bärtigen Niederländer Ende vierzig. Auf seiner Nase saß eine Brille, die sich modischen Zwängen widersetzte; er trug einen königsblauen Anzug. Konzentriert blätterte er in seinen Papieren, während er 
einen Kaffee trank. Am Tag zuvor hatte ich ihn durch den Konferenzsaal laufen sehen, um Appellbriefe zu verteilen. Diese waren an die brasilianische Regierung gerichtet und forderten sie auf, sich um das Schicksal einer indigenen Gruppe im Mato Grosso zu kümmern. Dem Briefkopf konnte ich entnehmen, dass der Mann Vertreter einer kleinen europäischen NGO war, die politische Lobbyarbeit für die >Indigenenproblematik betrieb. Er selbst wurde mir im Vorjahr in Genf beim Treffen der Arbeitsgruppe indigene Völker von einem Gesprächspartner als langjähriger Kenner und Teilnehmer der Arbeitsgruppe beschrieben. Deshalb war ich auch nicht erstaunt, ihn nun in New York wiederzusehen. Mit meinem Kaffee setzte ich mich an seinen Nachbartisch und sprach ihn an. Er erzählte, dass er zum ersten Mal in New York sei und auch nur ein paar Tage bleiben könne, da seine Organisation kaum finanzielle Mittel besäße. Auf den Appellbrief vom Vortag angesprochen, redete er sich schnell in Rage. Zuerst über die Indigenenpolitik der brasilianischen Regierung, bald aber auch über das Verhalten vieler indigener Forumsteilnehmer. Sie würden politisch nichts wagen und die Möglichkeiten des Forums nicht nutzen, um Druck auf ihre Regierungen auszuüben. Die Mitglieder seiner Organisation, so führte er auf meine Nachfrage hin aus, hatten sich aus unterschiedlichen linken Strömungen der 1970er und 80er Jahre zusammengeschlossen, darunter Marxisten, Anhänger der katholischen Befreiungstheologie und der Ökologie-Bewegung. Mein Gesprächspartner nahm seit Mitte der 1980er Jahre an den Treffen der Arbeitsgruppe teil. Er erzählte, dass dort am Anfang viele Minister, vor allem der kanadischen und australischen Regierung, mit Kamera- und Radioteams auftraten. Jeden Abend hätte es einen Empfang in einer anderen Botschaft gegeben. Die Regierungen hätten versucht, den von Indigenen gewonnenen politischen Raum zu besetzen. Gegenwärtig sei dies nicht mehr so extrem zu beobachten, da das Thema stärker im politischen Mainstream angekommen sei. Dann zeigte er mir eine Reihe von Personen an anderen Tischen und erzählte, dass sie zur »internationalen indigenen Elite» gehören würden: Sie kämen aus Familien, in denen die Eltern vielleicht selbst noch traditionell lebten, allerdings auch schon immer eine hervorgehobene Rolle in ihren Gemeinschaften gespielt hätten. Ihren Kindern hätten sie eine Universitätsausbildung oder ähnliches ermöglicht. Heute seien dies die wortangebenden indigenen Führer auf internationaler Ebene, die selbst das Leben ihrer Vorfahren nur noch aus Erzählungen kannten. Als ich ihn fragte, warum er denn zum Forum komme, da er diesen Ort anscheinend recht kritisch beurteile, erhielt ich eine stark emotionale Antwort: Sie hätten lange gekämpft, um in diesen politischen Raum vorzustoßen, es sei ein großer Erfolg. Leider träten mit dem Erfolg auch negative Auswirkungen zutage. Zum Beispiel sei für große NGOs und Entwicklungsinstitutionen aus den USA und Europa die Arbeit mit indigenen Basisorganisationen meist zu mühsam, da die "Indigenen langsam und sehr konfliktfreudig 
seien«. Die Unterstützer arbeiteten deshalb lieber mit großen NGOs in den entsprechenden Ländern zusammen und überließen diesen die Basisarbeit, mit dem Ergebnis, das man zum Beispiel an Konferenzen wie dem Forum leider manchmal ablesen könne. Dennoch sei die Geschichte der indigenen Bewegungen im UN-Kontext ein großer Erfolg. Man müsse sich nur die Zusammensetzung der UN-Organisationen anschauen, die schon länger zum Thema Indigene arbeiteten. Sie alle hätten inzwischen auch indigene Angestellte.

Über dem Gespräch war die Zeit schnell vergangen, und ein Blick auf die Uhr bestätigte meine Vermutung: Wenn der Caucus sich heute getroffen hatte, war die Sitzung ohne mich vonstatten gegangen. Bald begann der offizielle Teil des Tages. Ich verabschiedete mich von meinem Gesprächspartner und steuerte erneut den Sitzungssaal an. Vor mir lief Victoria Tauli-Corpuz, Igorot aus den Philippinen und neues Mitglied im Forum. Sie war dieses Jahr zur Vorsitzenden und damit zur Leiterin der Sitzungen gewählt worden. Frau Tauli-Corpuz war Direktorin der Tebtebba Foundation, einer indigenen Organisation mit Beraterstatus am ECOSOC, die in den letzten Jahren im UNKontext stark an Bedeutung gewonnen hatte. Ihre Eröffnungsrede der diesjährigen Sitzung kam mir, auch im Zusammenhang mit dem gerade geführten Gespräch, in den Sinn: Das Forum sei eines der globalen Ereignisse, die man nicht verpassen dürfe. Die Lobbyarbeit der Mitglieder des Forums während des vergangenen Jahres habe zur Erarbeitung von Richtlinien und gemeinsamen Projekten zwischen Indigenen und der UNO geführt. Doch müssten stärker regionale Lösungen im Forum gesucht werden. Um den Dialog zu verbessern, würden deshalb dieses Jahr drei regionale Treffen innerhalb der Sitzungszeiten stattfinden: zu Asien, Afrika und Lateinamerika. Ideen für konkrete Aktionen müssten gefunden und die Hindernisse bei deren Umsetzung identifiziert werden. Eine große Herausforderung für das Forum sei es, zu einer wirklichen Verbesserung der Lebensverhältnisse in indigenen Gemeinden beizutragen. Allein daran ließe sich der tatsächliche Erfolg des Forums messen. Sie beschwor die anwesenden indigenen Teilnehmer: "Sisters and brothers, we have come a long way since the idea of the Forum was forged. Now let's plan where we want to be in ten years from now."

Der Sitzungssaal war gut gefüllt. Einige Tischreihen, an denen die Regierungsvertreter ihren festen Platz hatten, waren allerdings noch nicht besetzt. Auf dem Podium saßen der Schriftführer, die keynotespeakers, die Leiterin der Sitzung und die Chefin des Sekretariats, die Griechin Elsa Stamatopoulou. Unterhalb des Podiums befanden sich im halbrunden Kreis die Plätze der anderen Forumsmitglieder. Dahinter begannen die Reihen für die Teilnehmer. Linkerhand saßen die Regierungsvertreter, rechterhand hatten die teilnehmenden UN-Organisationen ausgewiesene Plätze. Der Rest stand den NGOs zur freien Verfügung. An diesem Morgen stand das MilleniumsEntwicklungsziel (MDG) der weltweiten Armutsreduzierung bis 2015 auf dem 
Programm. Mark Malloch-Brown vom United Nations Development Programme (UNDP) war der erste keynotespeaker zum Tagungspunkt. Er sorgte einleitend für positive Stimmung unter den Zuhörern, indem er feststellte, dass die Diversität der im Saal anwesenden Personen, ihre bunten Kleider und die hohe Anzahl an weiblichen Teilnehmern viel besser als andere Treffen repräsentiere, wofür die UNO eigentlich stünde. Doch die globale Wirtschaft setze dieser Vielfalt ein Programm entgegen, das auf Vereinheitlichung abziele. Mit den MDGs versuche die UNO dennoch, diesem Trend entgegenzuwirken. Armut habe eine kulturelle Dimension und Indigene würden leider bislang in den nationalen Statistiken zu Armut versteckt, da keine ethnischen Kriterien zugrunde gelegt würden. Armut müsse mit der Durchsetzung von Menschenrechten bekämpft werden. Deshalb arbeite das UNDP eng mit der Hohen Kommissarin für Menschenrechte (UNHCHR) zusammen.

Der Leiter des Millenium Projekts ${ }^{9}$ der UNO, der Wirtschafts-Professor Jeffrey Sachs, schloss sich an den Redner des UNDP an. Er erklärte, dass die Gegenden, in denen Indigene lebten, die am schwersten zu entwickelnden Regionen seien. Es handele sich um Gebirge oder um dichte Wälder. Dies seien die Gebiete, in denen Indigene traditionell lebten oder in die sie zurückgedrängt worden seien. Ziel des Millenium Projekts sei es, die Bedürfnisse auf lokaler Ebene zu bestimmen, um sich der Beantwortung folgender Frage zu nähern: Wie könnten Bewohner abgelegener, ländlicher Gebiete Zugang bekommen zu den Maßnahmen, die im Zuge der Millenniums-Entwicklungsziele (MDGs) umgesetzt würden? Im Millenium Projekt habe man einen Aktionsplan entwickelt, um in den Gemeinden, auf lokaler Ebene, die notwendigen Maßnahmen zur Erreichung der MDGs zu identifizieren. Im Abschlussbericht des Projektes habe man die Regierungen auf die Notwendigkeit verwiesen, nationale Strategiepapiere unter Beteiligung der betroffenen Bevölkerung zu erarbeiten und schnell zu handeln, damit die Ziele noch erreicht werden können. Doch auch indigenen Organisationen falle eine wichtige Aufgabe zu: Damit die MDGs auf Gemeindeebene umgesetzt werden könnten, müssten die indigenen Organisationen dafür sorgen, dass die Dörfer die Kontrolle hätten. Sie könnten zur Informationsverbreitung über die MDGs beitragen und auch dazu, dass ihre Umsetzung erfolgreich eingefordert werden könnte.

Nach ihren Beiträgen mussten sich die beiden keynotespeakers einer Fragerunde durch die Forumsmitglieder stellen. Dieser >interaktive Dialog wurde 2005 neu im Forum eingeführt. Er zielte darauf ab, eine effizientere

9 Das Millenium Projekt wurde vom UN-Generalsekretär 2002 ins Leben gerufen, um einen Aktionsplan zur Bekämpfung von Hunger, Armut und Epidemien zu entwickeln. Im Januar 2005 präsentierte dieses unabhängige beratende Organ seine abschließenden Empfehlungen in dem Bericht Investing in Development: A Practical Plan to Achieve the Millenium Development Goals. Das Mandat des Millenium Project wurde bis Ende 2006 verlängert. 
Kommunikation zwischen den Teilnehmern der Veranstaltung zu erreichen. Im Anschluss an diesen Dialog wurde die offizielle Rednerliste eröffnet: Vertreter von Regierungen, Repräsentanten indigener Organisationen und Delegierte anderer UN-Einrichtungen kamen abwechselnd zu Wort. Da vor allem von indigener Seite die Zahl der auf der Liste eingetragenen Personen sehr umfangreich war, wurden ihnen strenge Kriterien auferlegt: Bevorzugte Behandlung erfuhren sogenannte >collective statements< - von Delegierten verschiedener Organisationen gemeinsam verfasste Beiträge. Die entsprechenden Redner kamen als Erste an die Reihe, und ihnen wurden fünf Minuten für den Vortrag gewährt. Die Leiterin der Sitzung überwachte das Zeitlimit mit Hilfe einer Ampel und ermahnte Sprecher, die es überschritten. Sogenannten Einzelbeiträgen von nur einer indigenen Organisation wurden drei Minuten Sprechzeit eingeräumt. Applaus oder andere Reaktionen auf Redebeiträge waren nicht gestattet. Dieses Verbot wurde mit Zeitmangel begründet. Da jedem der in der Sitzung zu behandelnden Themen eine festgelegte Zeit im Konferenzprogramm zugedacht war, entfielen regelmäßig eine Reihe von Einzelbeiträgen. Das Programm erwies sich diesbezüglich als unflexibel. Diese strenge Organisation führte zu Frustrationen unter den indigenen Teilnehmern.

War die Sprecherliste nach dem sinteraktiven Dialog geöffnet, wurden auch die folgenden Sprecher von der Sitzungsleitung dazu aufgefordert, den keynotespeakers Fragen zu stellen und damit zum Dialog beizutragen. Diese antworteten aber aus Zeitmangel nicht mehr auf die Fragen. Da man sich, wie beschrieben, bereits im Vorfeld in die Sprecherliste eintragen musste, der Redebeitrag drei bis fünf Minuten nicht übersteigen sollte und man über die erforderliche Sachkenntnis bzgl. der Programme und Ziele der jeweiligen UN-Einrichtungen verfügen musste, waren dem Einbezug aller in diesen Dialog darüber hinaus Grenzen gesetzt.

Neben mir nahm eine 23- jährige Frau aus Salazaca, Ecuador, Platz. Sie war ungefähr 1,65 m groß und hatte ihr langes schwarzes Haar zu einem Zopf geflochten. Ein lilafarbener Poncho bedeckte ihre Schultern, sie trug einen farbigen Rock, bunte Ohrringe und mehrere Ketten. 2004 war sie mit ihren Brüdern für zwei Monate durch Europa gereist, um dort Musik zu machen und Kunsthandwerk zu verkaufen. Seit zwei Jahren engagierte sie sich in einer indigenen Organisation. Zwischenzeitlich, so erzählte sie mir, habe sie allerdings schon wieder aufhören wollen, denn sie »habe die Botschaft der Organisation nicht verstanden«. Inzwischen begreife sie schon besser, was die Organisation wolle und wie sie funktioniere. Auf meine interessierte Nachfrage gab sie folgende Auskunft: "Die Organisation vertritt Standpunkte, die ich erlernen musste. Auch wusste ich anfangs nicht, wie ich mich auf Versammlungen zu verhalten hätte oder was eigentlich genau meine Aufgabe sei. Langsam begreife ich erst, wofür die Organisation steht.«Den letzten Satz 
konnte oder wollte sie mir allerdings nicht näher erläutern. Das Forum gefiel ihr, sie hatte sich mit Maasai-Frauen aus Kenia und Tanzania angefreundet. Auch wenn die Kommunikation schwierig sei, fände sie es spannend, dass man hier Menschen aus allen möglichen Ländern kennen lerne.

Um kurz nach 13:00 Uhr verließ ich den Sitzungssaal. Während der Sitzungspause zwischen 13:00 und 15:00 Uhr gab es jeden Tag eine Reihe von Veranstaltungen, die von UN-Einrichtungen und großen NGOs organisiert wurden. Heute wollte ich an einer Diskussion der überarbeiteten Weltbankrichtlinie (Operational Policy 4.10, kurz OP 4.10) teilnehmen. Sie bezog sich auf Verhaltensmaßregeln für den Umgang mit indigenen Völkern, die in Gebieten siedelten, in denen von der Weltbank unterstützte Entwicklungsprojekte durchgeführt werden sollten. Es ging dabei im Speziellen um >free, prior and informed consent<, ein heiß diskutiertes Thema am Forum. Die Weltbank hatte diese Richtlinie, die unter anderem besagte, dass indigene Gemeinden ihre Zustimmung geben mussten, wenn zum Beispiel in ihrem Siedlungsgebiet Öl gefördert werden sollte, in ihrer OP 4.10 umgeändert in >free, prior and informed consultation<. Nun wurden die semantischen Differenzen zwischen den Begriffen consent und consultation diskutiert. Am 1. Juni 2005 sollte die neue Richtlinie der Weltbank in Kraft treten. Die geänderte Weltbankpolitik war eines der Hauptthemen unter den erfahrenen indigenen Teilnehmern bei der diesjährigen Forumssitzung: Einerseits wurde gewürdigt, dass auch die Weltbank inzwischen das Recht auf Selbstbestimmung indigener Völker anerkannt hätte. In den Richtlinien würde ausdrücklich vermerkt, dass die Weltbank keine Regierungsprojekte in indigenen Gebieten fördern sollte, die nicht zuvor eine breite Unterstützung der entsprechenden Gemeinden erhalten hätten. Dennoch bliebe die Richtlinie hinter bereits existierenden internationalen Normen zurück. Der Begriff consultation sei zu wässrig und böte Manipulationen noch mehr Raum. Die Projektleiter könnten zum Beispiel den willfährigen Teil einer Gemeinde zusammenrufen und dies als >Beratung deklarieren. Oder sie träfen sich mit ausgewählten bzw. selbsternannten Repräsentanten und verkündeten dann, sich beraten zu haben. Die sbreite Unterstützung der Gemeinder, die in der Richtlinie der Bank gefordert würde, sei auch nicht näher definiert. Außerdem müssten Indigene nun ihre stiefe Verbundenheit mit dem Land, auf dem sie siedelten, beweisen. Wie, bitte schön, stelle sich die Weltbank das konkret vor? Die Kritik an der veränderten OP 4.10 manifestierte sich während der Veranstaltung und auch in vielen Gruppen- und Einzelgesprächen, die ich mit erfahrenen Teilnehmern im Laufe der Konferenz führte. Es fand sich eine kleine Arbeitsgruppe erfahrener indigener Teilnehmer zusammen, die eine Presseerklärung verfassen wollte, in der die neue Richtlinie der Weltbank kritisch analysiert wurde. Neue im Feld wussten hingegen meist weder, was die OP 4.10 war, noch, was >free, prior and informed consent $<$ bedeutete. Aber sie wussten sehr wohl, dass die Weltbank die Institu- 
tionalisierung indigener Interessen in verschiedenen Ländern fördert und dass über die Verwendung der dafür bereitgestellten Gelder, wie im Falle Perus, bereits heftige Konflikte entstanden waren. Man befürchtete, die Weltbank könne mit ihrer Politik die indigene Bewegung entzweien. Beim Thema Geld, so die Meinung der meisten, käme es schnell zu Uneinigkeit. Geld sei immer schon ein Mittel gewesen, »die Armen zu entzweien«.

Beim Mittagessen im UN-eigenen Restaurant, zu dem ich mich nach dem Besuch der Veranstaltung zur Weltbankrichtlinie entschlossen hatte, traf ich auf drei indigene Vertreter aus Südamerika: einen Mapuche aus Argentinien, der seit den 1970er Jahren in der internationalen indigenen Bewegung mitwirkte, an den wichtigsten internationalen Konferenzen seit diesen Tagen teilgenommen hatte und auch an der Erarbeitung einer Presseerklärung zur OP 4.10 aktiv mitwirkte; außerdem einen indigenen Vertreter aus Brasilien, der als junger Mann als Pilot für die FUNAI ${ }^{10}$ gearbeitet, sich in nationalen und internationalen indigenen Organisationen des Amazonasbeckens engagiert hatte und nun eine internationale Konferenz zu biologischer Vielfalt in Brasilien organisierte. Er wollte »mehr Bewusstsein schaffen im Westen für indigene Spiritualität und Lebensweise" und hatte in der Vergangenheit regelmäßig diesbezügliche Beiträge für Zeitungen in Brasilien geschrieben. Der dritte Tischpartner war ein Vertreter aus Kolumbien, der zwischen 2002 und 2004 als unabhängiger indigener Experte Mitglied des Forums war und sich schon lange auf nationaler und internationaler Ebene in der indigenen Bewegung des Amazonasgebietes engagierte. Sie griffen das Thema der Vormittagssitzung wieder auf: Was sei Armut im indigenen Kontext? Es hätte sich ein Diskurs der pobretología ${ }^{11}$ entwickelt. Die so genannten >armen indigenen Völker hätten aber ihr eigenes Wirtschaftssystem auf Grundlage der lokalen Gemeinschaften, welches es zu stärken gelte. Die indigene Agenda bestünde doch zudem aus anderen Themen - Kultur, Autonomie und Land. Diese grundlegenden Themen müsse man in praxisrelevante Eckpfeiler der Arbeit der UN-Organisationen verwandeln. Die Reflexion des Vertreters aus Argentinien, der seit langen Jahren in Kalifornien lebte und von dort aus für die indigene Bewegung aktiv war, traf auf breite Zustimmung in der Tischgemeinschaft. Der Repräsentant aus Brasilien wies darauf hin, dass auch im Lateinamerika-Caucus mehrfach die Meinung vertreten worden sei, dass das Thema Armut für Indigene in der Form, wie es bei der UNO und von den Regierungen diskutiert wurde, keine Relevanz besäße. Landrechte, Sprache und Spiritualität, das wären indigene Themen. Der Vertreter aus Kolumbien warf ein,

10 Fundação Nacional do Índio; dt. `Nationale Stiftung des Indianers «. Staatliche Behörde in Brasilien, die für >indigene Belange zuständig ist.

11 Dt. >Armutologie < - eine ironische Wortschöpfung, die das Sprechen über Armut von Regierungen und UNO als einen abstrakten, realitätsfernen Diskurs kennzeichnen möchte. 
dass Indigene nun wirklich nicht arm seien, sondern verarmt . Sie wollten von den nationalen Regierungen das Recht anerkannt bekommen, selber über ihre Territorien und natürlichen Ressourcen zu bestimmen. Beim Thema Armut würden Indigene unter die allgemeinen Wohlfahrtsprogramme subsumiert. Das käme den Regierungen, nicht aber den Indigenen entgegen. Dann wechselte der indigene Vertreter aus Kolumbien das Thema und erzählte, dass er nun, nach dem Ende seiner Amtszeit am Forum, für den Senat in seinem Heimatland kandidieren wollte. Dort gäbe es zwei nicht an Parteien gebundene Sitze für Indigene. Doch ungefähr zehn indigene Kandidaten würden untereinander um den knappen politischen Raum kämpfen. Er fühle sich fehl am Platz bei der diesjährigen Sitzung des Forums, da er jetzt mehr Zeit in Kolumbien verbringen müsse, um Wahlkampf zu machen. Dort bekäme er schließlich seine Stimmen, nicht am Forum.

Als wir wieder den Sitzungssaal ansteuerten, lief ich einer Ethnologin in die Arme, mit der ich im Jahr zuvor beim Arbeitsgruppentreffen in Genf Bekanntschaft geschlossen hatte. Auch sie forschte zur indigenen Bewegung im Kontext der UNO. Sie befragte mich nach dem bisherigen Verlauf meines Forschungstages. Ich berichtete von meinen Eindrücken und fragte nach ihrem Befinden. Sie seufzte leise und meinte mit einem ironischen Lächeln, sie fände es weniger mühsam, stundenlang durch die Savannen Afrikas zu laufen, um Informanden zu besuchen als an der Sitzung des Forums teilzunehmen. Wir teilten das leichte Gefühl von Beklommenheit und Befremden, das uns an diesem Ort überkam. Was war hier unsere Aufgabe als Wissenschaftlerinnen? In welchem Verhältnis standen wir zu unseren Forschungssubjekten, und wonach genau suchten wir in diesem Raum? Die große Zahl von Themen, Meinungen und Interessen legte sich schnell wie ein Schleier über die eigenen Forschungsfragen.

Ich begrüßte einen Aymara aus Puno, den ich bereits im letzten Jahr in Peru kennen gelernt und später am Forum erneut getroffen hatte. Er war nun das dritte Jahr in Folge zur Sitzung des Forums angereist, die Reise hatte er aus eigenen Mitteln finanziert. Dieses Jahr hoffte er, Sponsoren für seinen politischen Wahlkampf in Peru zu finden. Man hatte ihm von einem reichen Araber erzählt, der solche Zwecke finanziell unterstütze. Der Aymara hatte sich einer Partei angeschlossen, die sich >Indigene Bewegung Perus nannte und in seiner Region bei den nächsten Wahlen 2006 kandidieren wollte. Doch für einen erfolgreichen Wahlkampf brauchte es nach seiner Einschätzung in erster Linie eine gute finanzielle Grundlage.

Er erkundigte sich nach einem gemeinsamen Bekannten in Lima, der dort eine NGO ins Leben gerufen hatte, um Gemeinden in seiner Herkunftsregion Ayacucho zu unterstützen. Der Aymara wunderte sich, unseren Bekannten nicht in New York zu sehen: Der >besäßer doch eine NGO, die hätten doch Geld. Es war eine mir wohlbekannte Annahme, die unter indigenen Organisa- 
tionen in Peru gepflegt wurde. NGOs gehörten für sie erst einmal zu den >Profiteuren der indigenen Bewegung. Dieser Umstand ergab sich unter anderem aus den knappen finanziellen Ressourcen, die zur Verfügung standen und um den die beiden Organisationstypen konkurrierten. Auch wenn sie legal den gleichen Status besaßen, also beides NGOs nach peruanischem Recht waren, war die Unterscheidung zwischen indigener Organisation und nichtindigener NGO im Kontext der indigenen Bewegung sehr wichtig. Sie wurde wie folgt definiert: Eine indigene Organisation verfügte über eine Basis - die Gemeinden - und wählte ihre Repräsentanten nach demokratischen Prinzipien, während eine NGO von Fachspezialisten ins Leben gerufen wurde. Sie konnte nicht für sich beanspruchen, im Namen der Gemeinden zu sprechen. Von indigenen Organisationsvertretern wurde den NGOs oft vorgeworfen, Abhängigkeitsverhältnisse zwischen den Gemeinden und ihren Einrichtungen zu schaffen. Sie seien nicht an der >politischen Ermächtigung`Indigener interessiert und profitierten von deren schwacher sozialer Stellung.

Mein Bekannter begann, über einen anderen Aymara zu klagen, dem er heute begegnet war: "Obwohl wir beide Aymara sind und er über viele Kontakte bei der UNO verfügt, will er mir nicht helfen. Das ist typisch unter uns cholos. ${ }^{12}$ Wir diskriminieren uns untereinander, der Diskurs von Brüderlichkeit und Solidarität ist nur nach außen gerichtet." Er wies mich darauf hin, dass er am Nachmittag einen Redebeitrag hätte, in dem er die Situation der Indigenen in Peru schildern würde.

Nach der Nachmittagssitzung tagte wieder der Lateinamerika-Caucus. Doch dieses Mal ging man bereits nach einer Stunde auseinander, da die meisten ihren Beitrag zum Thema Landrechte noch nicht fertig redigiert hatten. Auch der Sitzungssaal sowie die angrenzenden Räume, Flure und die Cafeteria leerten sich relativ zügig. Gegen $19.30 \mathrm{Uhr}$ fand sich eine Gruppe lateinamerikanischer Indigener zusammen, um gemeinsam Abend zu essen. Auch ich wurde eingeladen, und so steuerten wir ein italienisches Restaurant in der Nähe des UN-Gebäudes an. Auf dem Weg unterhielt ich mich mit einer Repräsentantin aus Kolumbien. Wir sprachen über das Migrationsproblem in den Gemeinden. Die Zahl der Indigenen, die in Städte abwanderten, stieg kontinuierlich. Ich fragte sie, warum man von indigenen Organisationen so wenig zu diesem Thema höre. Sie definierte Migration als eine persönliche Entscheidung und keine kollektive Angelegenheit. »Der Indigene kehrt immer in sein Gebiet zurück, er ist verbunden mit seinem Land. Persönliche Interessen sowie die staatliche Politik verleiten Einzelne dazu, ihre indigene Le-

12 Cholo: Als cholo werden in Peru Menschen mit indigenem - vor allem andinem - Phänotypus bezeichnet. Der Begriff kann sowohl als Eigenbezeichnung als auch als abwertende Fremdbezeichnung der Indigenen der Andenregion dienen. Zur Begriffsgeschichte und den vielfältigen Bedeutungen, in denen der Begriff verwendet wird siehe Laufer (1998: 152ff.; 199ff.). 
bensweise aufzugeben. Aber es ist kein Problem, das unsere Politik als Kollektiv verändern darf. Wir gehören in unsere Gemeinden." Bei den Sitzungen des Forums aber, so ihre angeschlossene Kritik, würden viele sprechen, die keine Verbindung mehr zu diesem Kollektiv hätten. Es sei zudem schwierig, die lokalen Probleme in etwas zu verwandeln, das man am Forum diskutieren könne. "Der Diskurs ist hier sehr abstrakt. Es ist eine andere Realität."

Beim Essen saß ich neben dem Teilnehmer aus Brasilien, mit dem ich an diesem Tag auch schon zu Mittag gegessen hatte. Ich fragte ihn, ob er meinen Eindruck teile, dass im Lateinamerika-Caucus eine latente Spannung zwischen verschiedenen Gruppen von Teilnehmern herrsche. Er bejahte die Frage, was mich dazu ermunterte, mich nach seiner Erklärung für diese Differenzen zu erkundigen. Er erklärte, dass auch Indigene in verschiedene Lager geteilt seien. Dies könne man zum Beispiel am Thema Landrechte sehen. Eine Gruppe würde Land als >Eigentum betrachten, während andere die Demarkierung der Territorien wollen, um die zweckentfremdete Nutzung des Gebietes durch Dritte zu verhindern. Letzteres sei für ihn eine Forderung, die mit der indigenen Lebensphilosophie in Einklang stehe. Eigentum sei hingegen ein westliches Konzept, das zumindest der Weltsicht der Indigenen des Amazonasgebietes nicht entspreche. Bezeichnend sei auch, dass das Thema sindigenes Territorium oftmals besonders vehement von denen vorgetragen würde, die gar nicht mehr in ihren ursprünglichen Gebieten lebten. Gleichfalls gäbe es verschiedene Rollen in der indigenen Bewegung. Eine Gruppe kümmere sich um $>$ lo indígena ${ }^{13}$, sie schaffe ein ideales Bild, zum Beispiel von der comunidad als Solidargemeinschaft. Im Amazonasgebiet sei das Konzept der Gemeinschaft aber anders als zum Beispiel in den Anden. »Im Amazonas sind die Beziehungen um verwandtschaftlich organisierte Wirtschaftseinheiten herum aufgebaut. Das Konzept einer Dorfgemeinschaft als solidarisch wirtschaftender Bauernkooperative funktioniert dort nicht. Das gleiche gilt für das Thema Umweltschutz. Die Art und Weise, wie darüber im Westen nachgedacht und gesprochen wird, entspricht nicht der Denkweise eines indigenen Amazonasbewohners. Umweltschutz wird nicht als Pflege und Bewahrung der Natur im westlichen Sinne verstanden. Ein Amazonasindianer lebt von und mit den Pflanzen und Tieren, die ihn umgeben. Er versteht sich als Teil der Natur und will sie nicht zu einem Museumsobjekt machen."

Ich fragte ihn, ob es über diese ideologischen Differenzen hinaus im Caucus nicht auch einen Konflikt zwischen neuen und erfahrenen Teilnehmern gäbe. Ja, so seine Antwort, auch dieser würde die Arbeit erschweren. Der Caucus sei ein sehr heterogener Raum, in den jeder mit seinen lokalen Problemen käme. Man könne sich deshalb immer nur mühsam auf ein Programm einigen, welche Themen beim Treffen des Caucus zu besprechen seien. Das

13 Dt. >das Indigene<. 
Problem sei auch, dass die Neuen oft mit wenig klaren Vorstellungen davon kämen, wozu die UNO genützt werden könne. Aber es sei ganz natürlich, dass man als Neuer erst einmal die Arbeitsweise des Forums erlernen müsse. Die UNO sei ein Raum, in dem globale indigene Themen verhandelt würden. Die Kenntnisse über diese Themen besäßen aber die Repräsentanten von Basisorganisationen nur indirekt, über ihre lokale Erfahrung. Doch um diese für die UNO relevant zu machen, müsse man sie mit übergreifenden Themen wie Menschenrechte, biologische Vielfalt oder nachhaltige Entwicklung in Verbindung setzen. Die UNO sei ein bedeutender politischer Ort zur Entwicklung und Neuformulierung internationaler Normen und Standards. Für den Eintritt in diesen von staatlichen Interessen dominierten Raum hätten einige der anwesenden erfahrenen Teilnehmer über lange Jahre hinweg gekämpft. Heute kämen viele junge Leute, die den Raum als sgegeben hinnähmen und ihn für Partikularinteressen nutzten. Es fehle darüber hinaus an Respekt vor den Alten. Mit den >Alten meine er aber vor allem die traditionellen Führer indigener Gemeinschaften. Die fehlten am Forum. »Wenn hier indigene Stimmen zu Wort kommen sollen und die indigene Sicht auf Entwicklung Einzug bei der UNO erhalten soll, muss man diese Menschen nach New York bringen." Deshalb habe er auch beim Caucus dafür plädiert, dass man sich für eine Redezeit für traditionelle Führer einsetze. Die Stimmen der Alten, welche indigene Weltsichten am besten verkörperten, könnten diesem Forum eine andere Richtung geben.

Es war 23.00 Uhr, wir baten um die Rechnung. Sie entsprach den in New York üblichen, hohen Preisen. Die junge Frau aus Kolumbien, die zum ersten Mal am Forumstreffen teilnahm, schaute etwas verzweifelt auf das Stück Papier. Der in den USA lebende und arbeitende Mapuche, mit dem ich auch zu Mittag gegessen hatte, zückte derweil seine Kreditkarte und erklärte, er übernehme die Rechnung. Es gab nur schwachen Protest. Alle waren müde, und einige blickten sehr dankbar ob dieser großzügigen Geste. Ich verabschiedete mich und machte mich auf den Weg zu meiner Unterkunft. Mein Arbeitstag am Ständigen Forum für indigene Angelegenheiten war zu Ende. Die Gespräche und Begegnungen bildeten wichtige Ausgangspunkte für eine Analyse des politischen Feldes der indigenen Bewegungen bei der UNO. 


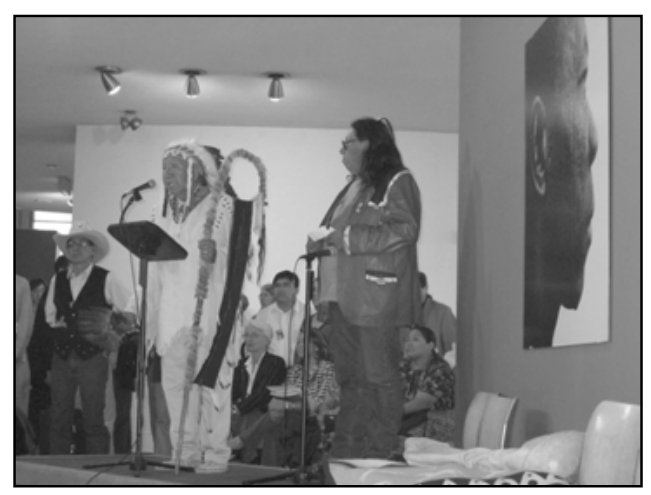

Abbildung 5: Von indigenen Teilnehmern gestalteter Empfang zu Beginn jeder Sitzungsperiode des Forums (Foto: Maren Rößler 2005).

Abbildung 6: Die Cafeteriabeliebter Treffpunkt der Teilnehmer während der Sitzunger. des Ständigen Forums für indigene Angelegenheiten (Foto: Maren Rößler 2005).
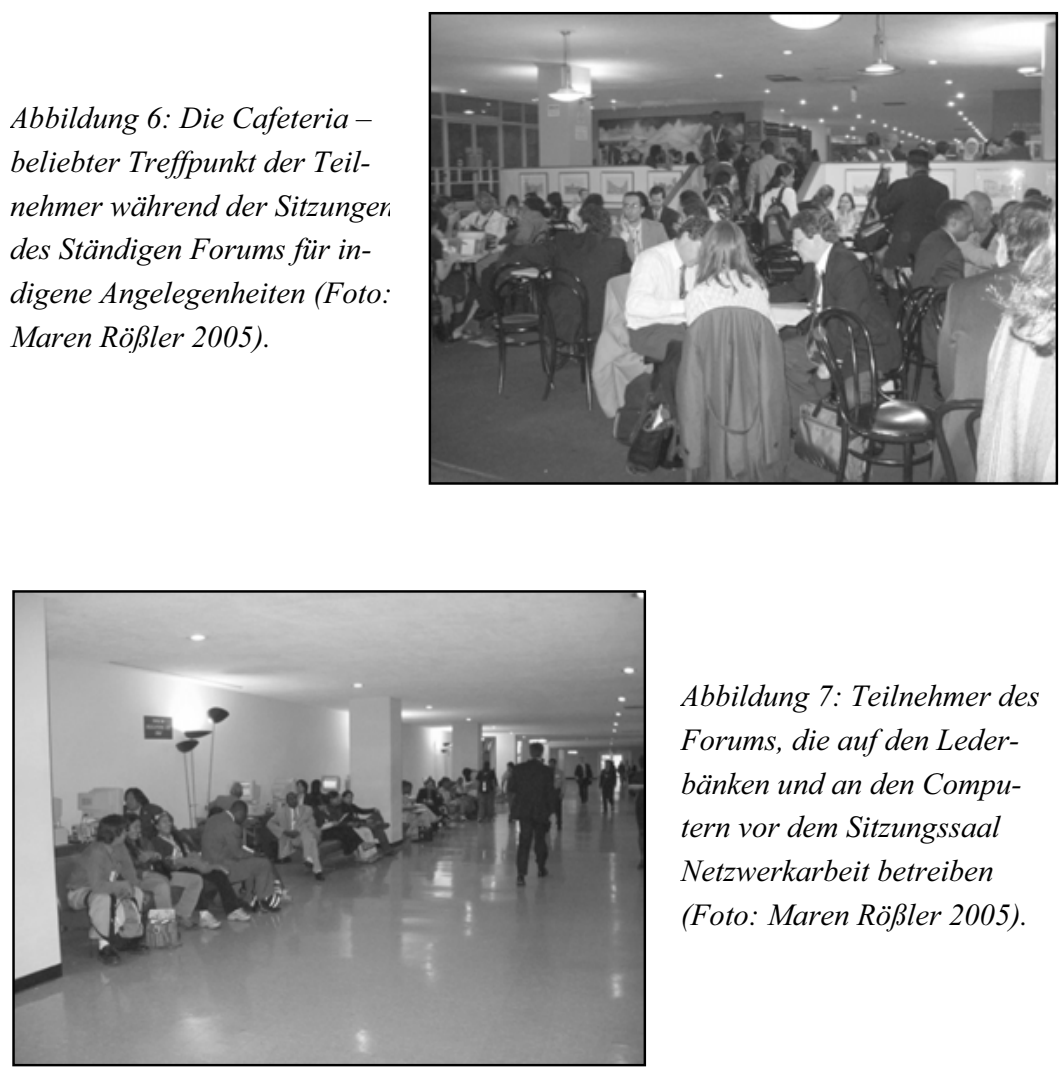

Abbildung 7: Teilnehmer des Forums, die auf den Lederbänken und an den Computern vor dem Sitzungssaal Netzwerkarbeit betreiben (Foto: Maren Rößler 2005). 
Abbildung 8: Vom Lateinamerika-Caucus bestimmte Sprecher tragen einen gemeinsam erarbeiteten Redebeitrag in der offiziellen Sitzung vor (Foto: Maren Rößler 2005).
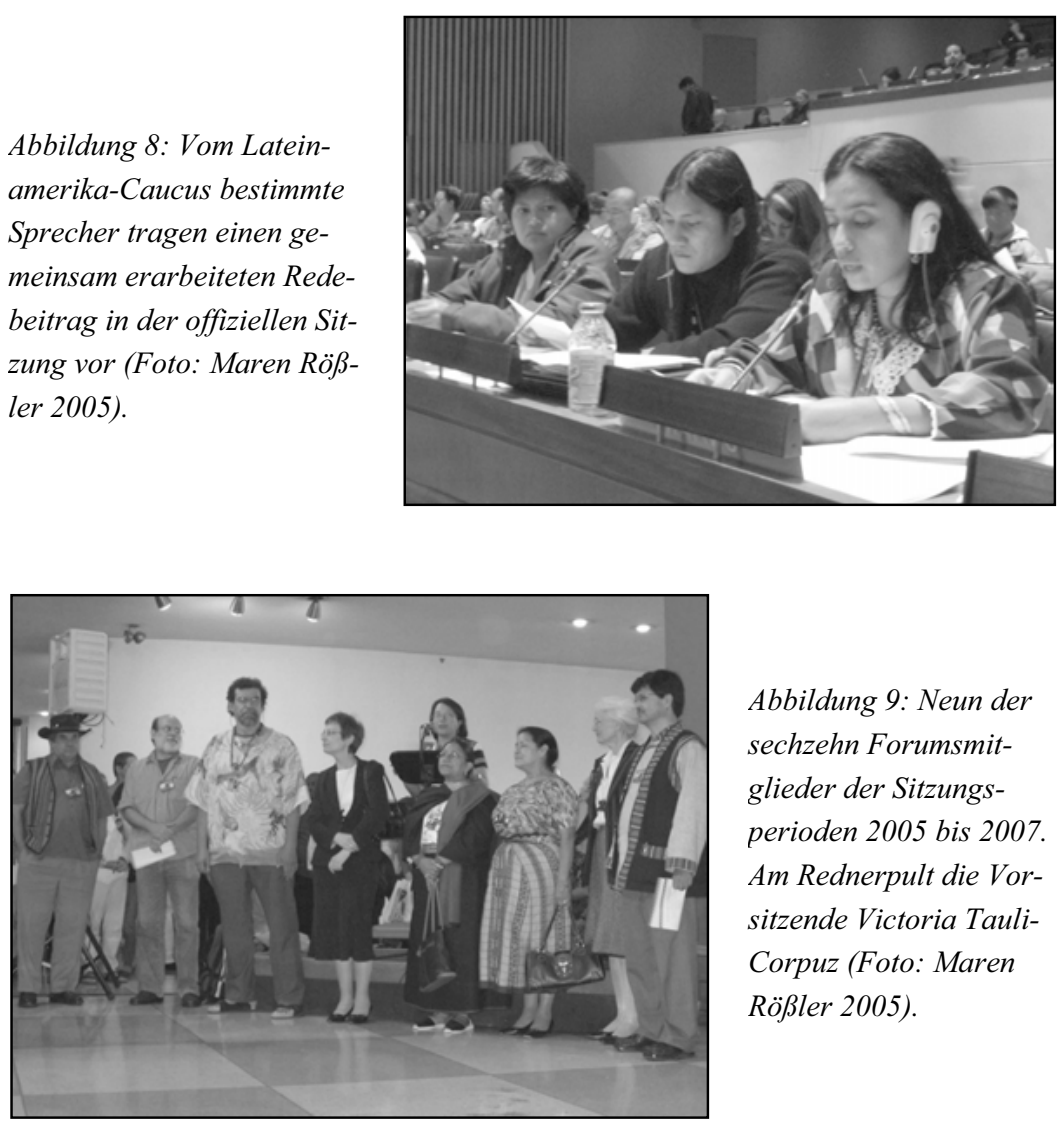

Abbildung 9: Neun der sechzehn Forumsmitglieder der Sitzungsperioden 2005 bis 2007. Am Rednerpult die Vorsitzende Victoria TauliCorpuz (Foto: Maren Rößler 2005).

\section{Die Kräfteverhältnisse am Forum}

»Die wichtigsten Themen für indigene Völker stimmen nicht mit den priorisierten Themen der Staaten und der UN-Organisationen überein [...] ein Beispiel dafür ist das Thema der Demarkierung von Territorien [...] Indigene Völker interessieren Themen wie Artenvielfalt oder Schutz natürlicher Ressourcen oft nicht [...] sie möchten erst ihre Gebiete demarkieren und dann sehen, was es darin gibt« (Interview Matías Alonso 19.05.2004).

Marcos Matías Alonso spricht das Problem der grundlegenden Interessensdifferenzen zwischen den drei wichtigsten Gruppen am Forum an: den Vertretern von Regierungen, UN-Organisationen und indigenen Organisationen. Auf dieser Grundlage gilt es, die Kräfteverhältnisse am Ständigen Forum für 
indigene Angelegenheiten näher zu betrachten. Welche Themen werden priorisiert, und wer kann sich dabei erfolgreich einbringen?

\section{Spezifisches Diskurswissen}

Aus den Gesprächen und Beobachtungen, die ich gerade dargestellt habe, lassen sich zunächst einmal einige grundsätzliche Regeln des Feldes ableiten. An erster Stelle stehen die spezifischen Fachkenntnisse, die für eine erfolgreiche Teilnahme am Forum notwendig sind: Es ist sinnvoll zu wissen, was die OP 4.10 der Weltbank ist, zu welchen Themen UNICEF, UNIFEM, UNDP und andere UN-Einrichtungen arbeiten oder was die Millenniums-Entwicklungsziele, kurz MDGs, beinhalten. Auch erleichtern Englischkenntnisse die Kommunikation, Computerkenntnisse die spontane Umarbeitung und Anpassung der mitgebrachten Redebeiträge. Eine Guaraní-Vertreterin aus Bolivien erklärt:

»Es gibt im Forum sehr unterschiedliche Niveaus der Vorbereitung. Ich kann zum Beispiel kein Englisch sprechen und bin bisher nie mit der UNO in Berührung gekommen. Um diesen Raum wirklich nutzen zu können, bräuchte ich ein ganzes Jahr Vorbereitung. Dieser Raum ist nichts für mich. Ich kann eine gute Politikerin in meiner Gemeinde sein, aber hier nicht. Hier muss man sich vorbereiten, um gute Vorschläge zu machen und Kontakte zu knüpfen« (Gespräch Cabrera 20.05.2005).

Die Guaraní-Vertreterin wirft damit im Gegenzug aber auch indirekt die Frage auf, inwieweit die Kenntnisse der relevanten Themen des Forums wichtig für die Arbeit auf nationaler oder lokaler Ebene sind, inwieweit am Forum geknüpfte Kontakte zu einer langfristigen Zusammenarbeit führen können, inwieweit man diese in Verhandlungen mit lokalen Regierungen oder Konzernen wirklich nutzen kann. Eine Repräsentantin der CONAIE $^{14}$ aus Ecuador verwies im Gespräch zum Beispiel darauf, dass sie die am Forum besprochenen Themen nur schwer in ihren heimatlichen Kontext übertragen könne (Gespräch $\operatorname{Vargas}^{15}$ 13.05.2004). Ähnlich äußerte sich die Delegierte eines nationalen Zusammenschlusses indigener Tieflandbewohner Perus (Interview Antazú 19.01.2004).

Lokalpolitiker und wenig im UN-System geschulte nationale Vertreter indigener Organisationen haben es auf Grund des geforderten Abstraktionsgra-

14 Confederación de Nacionalidades Indígenas del Ecuador; dt. >Konföderation indigener Nationen Ecuadors<, nationaler Zusammenschluss indigener Organisationen aus dem Tiefland, Hochland und der Küstenregion Ecuadors.

15 Wie in Kapitel I bereits ausgeführt, habe ich die Namen meiner Gesprächspartner, die anonym bleiben wollten, verändert und markiere dies durch Kursivsetzung. 
des der Redebeiträge (der Einbettung lokaler Probleme in allgemeine Diskurse über Menschenrechte, nachhaltige Entwicklung etc.) und vor allem auf Grund des geforderten Fachwissens über die Funktionsweise der Vereinten Nationen schwer, aktiv an den Sitzungen teilzunehmen. Die UNO ist ein hochkomplexer bürokratischer Apparat, in dem sich Neue schwer zurechtfinden. So führt auch ein unabhängiger indigener Experte der Sitzungsperioden 2002-2004 aus: »Das größte Problem in unseren Regionen, nicht nur in Lateinamerika und der Karibik, sondern auch zum Beispiel in Afrika und Asien, ist, dass nur sehr wenige Mitglieder unserer Völker oder unserer Fachleute sich im System der UNO auskennen« (Interview Choquehuanca 18.05.2003).

Selbst unter den indigenen Teilnehmern, die auf nationaler Ebene wichtige Rollen in der indigenen Bewegung spielen, ist das Interesse am Forum gering. Sie besitzen zwar das nötige Fachwissen über entwicklungspolitische Diskurse und Menschenrechtsthemen, sehen aber keinen direkten politischen Nutzen der Zusammenkünfte: »Die Regierungsvertreter, die den Sitzungen beiwohnen, haben nur geringe Verhandlungsbefugnisse. Sie nutzen diesen Raum eher zur Imagepflege« (Gespräch Antazú 17.05.2004).

So nahmen zum Beispiel Vertreter des internationalen Zusammenschlusses der indigenen Organisationen des Amazonasgebietes, COICA, weder an der Sitzung des Forums 2004 noch an der im Jahr 2005 teil. Aus Peru kam zwar eine nationale Vertreterin von $\operatorname{AIDESEP}^{16}$, aber auch sie sagte, dass sie nicht wisse, was sie über dieses Forum in ihrer Organisation berichten solle. Es sei sehr schwierig, konkrete Eindrücke, Vorschläge und Lösungen, die für die Probleme in ihrem Heimatland von Belang seien, von den Treffen mit nach Hause zu nehmen. Zudem merkte sie an, dass die Kooperation unter den indigenen Teilnehmern im Forum, wenn es zum Beispiel um die Ausarbeitung gemeinsamer Redebeiträge ginge, sich oft schwierig gestalte. Es bildeten sich schnell Gruppen, die mehr gegeneinander als miteinander arbeiteten, und es sei mühsam, Redebeiträge mit anderen zu koordinieren. Das läge vielleicht auch daran, dass es wenige allgemein anerkannte Autoritäten unter den indigenen Teilnehmern gäbe, die es verstünden, viele Leute zur Mitarbeit zu animieren (Gespräch Antazú 17.05.2004). Eine indigene Basisrepräsentantin aus dem Amazonasgebiet Ecuadors brachte dieses Dilemma wie folgt zum Ausdruck: »Wenn wir bei der UNO ankommen, werden wir vom System konsumiert. Hier geht jeder seinen eigenen Weg. Ich habe nicht das Gefühl, dass ich mit den indigenen Experten des Forums reden könnte. Sie bewegen sich auf einer anderen Ebene als ich« (Gespräch Aranda 19.05.2005).

16 AIDESEP: Asociación Interétnica de Desarrollo de la Selva Peruana; dt. >Interethnischer Zusammenschluss für die Entwicklung des peruanischen Amazonasgebiet<. 
Der Raum erweist sich als wenig übersichtlich und letztendlich zu groß für ein geschlossenes Auftreten der indigenen Gruppe. Diese ist zudem sehr heterogen in ihrer Zusammensetzung. Die individuell sehr unterschiedlichen Hintergründe, Voraussetzungen, Ziele und Vorstellungen, mit denen die Teilnehmer anreisen, führen zu Interessenvielfalt und damit zwangsläufig auch zu Interessenkonflikten.

\section{Einbettung ins UN-System}

Auch ein Blick auf die Kriterien, die indigene Organisationen wie alle anderen NGOs für die Erlangung eines Beraterstatus am ECOSOC erfüllen müssen, gibt Aufschluss über die Kräfteverhältnisse des Feldes. ${ }^{17}$ Folgendes muss gewährleistet sein:

- Die Organisation muss sich um Probleme kümmern, die in den Aufgabenbereich des ECOSOC fallen;

- ihre Ziele müssen mit UNO-Prinzipien in Einklang zu bringen sein;

- sie muss die Arbeit der UNO unterstützen und bewerben;

- sie muss auf ihrem Gebiet eine anerkannte Größe sein;

- sie muss einen Hauptsitz mit leitendem Geschäftsführer haben.

Vor allem in Bezug auf das fünfte Kriterium haben indigene Organisationen in der Vergangenheit oft Beschwerde eingelegt. Sie meinen, dass die Strukturen von NGOs nicht kompatibel seien mit ihren historischen Regierungsformen (vgl. United Nations 1996). Die Repräsentanten indigener Organisationen verstehen ihre Zusammenschlüsse als politische Vertretungsorgane von Völkern und möchten sie als solche gewürdigt wissen. Bei der Teilnehmerliste des Forums wird deshalb unterschieden zwischen »indigenous peoples organizations" und »non-governmental organizations« (vgl. u.a. United Nations 2003, 2004a). Diese Unterscheidung erweist sich jedoch in der Praxis oft als schwierig bzw. umstritten, zumindest unter südamerikanischen Teilnehmern. Sie weisen explizit auf den Unterschied zwischen politischen Organisationen mit >Basismandat` und NGOs mit nicht-gewählten Fachkräften hin. Im Kontext der UNO findet diese Unterscheidung keine Berücksichtigung. Aber auch das vierte Kriterium, eine »anerkannte Größe auf ihrem Gebiet« zu sein, wirft die Frage auf, welche Beurteilungsmaßstäbe vom ECOSOC herangezogen werden.

In der Teilnehmerliste der Sitzung des Forums im Jahr 2004 erschienen dreizehn indigene Organisationen mit Beraterstatus. Demgegenüber standen 233 ohne einen derartigen Status. Aus der Beteiligung an den offiziellen Sit-

17 Für eine Analyse von zwölf der dreizehn Organisationen, die bislang einen Beraterstatus am ECOSOC besitzen, siehe Barsh (1991). 
zungen und den Veranstaltungen, die in den Pausen abgehalten werden, kann man eine hervorgehobene Bedeutung von Organisationen mit Beraterstatus ablesen. So sind etwa die Vertreter des Saami Council, der Comision Jurídica para el Autodesarrollo de los Pueblos Originarios Andinos ${ }^{18}$ oder der Tebtebba Foundation zentrale Akteure der Sitzungen. Sie treten auch häufig in den Veranstaltungen von UN-Organisationen wie UNDP, UNIFEM etc. auf, was auf eine ganzjährige Zusammenarbeit und engere Kontakte mit diesen Einrichtungen hindeutet. Der Metis National Council, auch mit Beraterstatus beim ECOSOC, bot dem Forum 100.000 Dollar bei der ersten Sitzung 2002, um jedes Jahr ein Mitglied seiner Organisation zur Unterstützung ins Sekretariat des Forums schicken zu dürfen (eigene Aufzeichnungen 13.05.2003). Dieses Angebot wurde zwar mit dem Verweis auf die Rechtslage, die dies nicht zuließe, abgelehnt. Dennoch kann man daran ablesen, dass es große Unterschiede zwischen den am Forum vertretenen indigenen Organisationen gibt - vor allem bezüglich ihrer finanziellen und personellen Ausstattung. Die größeren, etablierten Organisationen kämpfen dabei untereinander um die Führung. So entbrannte 2005 im Vorfeld des Treffens ein Streit zwischen der Tebtebba Foundation, dem Saami Council und dem Inuit Circumpolar Council auf der einen und dem International Indian Treaty Council (IITC) auf der anderen Seite. Anlass war der drohende erfolglose Abschluss der Treffen der Arbeitsgruppe zur Erarbeitung der Erklärung der Rechte indigener Völker. Während die einen eine Verlängerung des Mandats bis zur erfolgreichen Verabschiedung der Erklärung wollten, vertrat der IITC die Meinung, man solle die Treffen erst einmal suspendieren, um umfassende Beratungen mit indigenen Organisationen durchzuführen und neue Bedingungen der Verhandlungen festzulegen. Beide Parteien riefen per Internet weltweit indigene Organisationen dazu auf, sich ihrer Erklärung per Unterschrift anzuschließen. Der bereits mehrfach erwähnte Matías Alonso merkt dazu an, dass die streitenden Parteien derzeit die indigenen Entscheidungsträger auf internationaler Ebene seien. Diese Organisationen entwickelten Führungsansprüche und besäßen die nötigen Gelder und Kontakte, um diese durchzusetzen. Sie stellten die indigene Stimme im UN-Kontext dar. Gleichzeitig, so Matías Alonso weiter, fehlten aber auch viele Organisationen, die auf nationaler oder regionaler Ebene bedeutend seien, beim Treffen des Forums. Dies könne er zumindest für Lateinamerika mit Sicherheit feststellen, habe aber den Eindruck, dass diese Beobachtung auch auf andere Weltregionen übertragbar sei:

»Vielleicht ist es schön, New York oder Genf kennen zu lernen, aber wenn du nicht die Themen kennst, die behandelt werden, langweilst du dich sehr. Es gibt eine gro-

18 Dt. >Juristische Kommission für die selbstständige Entwicklung der ursprünglichen andinen Völker`, NGO mit Sitz in Peru, dessen Vorsitzender auf UNEbene Lobbyarbeit für indigene Rechte betreibt. 
ße Distanz zwischen den in den Ländern und auf lokaler Ebene wichtigen Themen und solchen, die hier verhandelt werden« (Gespräch Matías Alonso 23.05.2005).

Dies erkläre, so Matías Alonso weiter, warum indigene Akteure, die im lokalen und nationalen Kontext in Lateinamerika eine wichtige Rolle spielten, am Forum zumeist keine bedeutende Stimme darstellten.

\section{Themenwahl}

Der offiziell bekundete politische Wunsch fast aller Gruppen, der Mitglieder des Forums, der UN-Einrichtungen, der indigenen Experten und der Neuen im Feld, ist die Lösungssuche für lokale Probleme. Gleichzeitig wird von erfahrenen indigenen Teilnehmern oft darauf verwiesen, dass das Forum nicht die gleiche Funktion habe wie die Arbeitsgruppe, in der man konkrete Fälle von Menschenrechtsverletzungen vortragen könne. Am Forum sollten Lösungen für Entwicklungsfragen gesucht werden, indem die UN-Organisationen mit Vorschlägen versorgt würden, wie Indigene stärker in ihre Programme und Richtlinien integriert werden könnten. Vertreter der UNO sehen dies ähnlich. Die Themen des Forums sind bestimmt durch die Schwerpunktsetzung der UN-Entwicklungspolitik. Dies kann man an den Sitzungsperioden des Forums in den Jahren 2005 und 2006 ablesen - die Millenniums-Entwicklungsziele (MDGs).

Im September 2005 fand der UN-Millenium +5 Gipfel $^{19}$ statt. Im Vorfeld wollte man am Forum die Relevanz der MDGs für indigene Völker näher betrachten. Da diese bisher als Gruppe in der Milleniumserklärung der Staaten sowie ihrer Entwicklungsziele keine Erwähnung fanden, schien dem Sekretariat des Forums die Aufnahme dieses Themas besonders relevant (Gespräch Jacanamijoy 18.05.2005). Indigene Organisationen hatten bei den Diskussionen um die thematische Schwerpunktsetzung des Folgejahres bei der Forumssitzung 2004 hingegen Themen wie >Bewaffneter Konflikt` und >Politische Partizipation< vorgeschlagen (eigene Aufzeichnungen 20.05.2004). Die MDGs waren wohl zu diesem Zeitpunkt den wenigsten indigenen Teilnehmern des Forums bekannt. Sie wurden nicht von ihnen formuliert, und während der Sitzung des Forums 2005 äußerten sowohl neue, aber auch erfahrene Teilnehmer in Gesprächen immer wieder ihr Unverständnis darüber, wie das Thema an

19 Treffen der UN-Mitgliedsstaaten vom 14.-16. September 2005 am UN-Hauptsitz in New York, um die angestrebten Reformen der UNO sowie die Erreichung der Millenniums-Entwicklungsziele bis $2015 \mathrm{zu}$ diskutieren. 
zentrale Stelle des Treffens gesetzt werden konnte (eigene Aufzeichnungen 16./18./20.05.2005). ${ }^{20}$

Nun scheint es darum zu gehen, die Forderungen indigener Organisationen in diesen bestehenden Ansatz einzupassen. Es ist davon auszugehen, dass bei diesem Bestreben vor allem auch der umgekehrte Prozess angeschoben werden soll: die MDGs der UNO unter den indigenen Teilnehmern bekannt zu machen. Dadurch sollen global erarbeitete Themen auf lokale Ebene übertragen werden. Im Gegenzug ist es jedoch fraglich, welche Rolle der ECOSOC, und damit indirekt das Ständige Forum für indigene Angelegenheiten als Sprachrohr indigener Interessen innerhalb der UNO, bei der Umsetzung von entwicklungspolitischen Zielsetzungen spielt. Wie bereits ausgeführt, bekam der Wirtschafts- und Sozialrat keinerlei Durchsetzungsbefugnisse und spielt gegenüber Weltbank und IWF eine untergeordnete Rolle im internationalen Machtgefüge. Seine Stellung sollte zwar im Rahmen allgemeiner Reformpläne der UNO aufgewertet werden, jedoch erweist sich der Prozess als langsam und von divergierenden Interessen der UN-Mitgliedsstaaten geprägt (vgl. Kapitel III.2).

\section{Verbindungen zur lokalen Ebene}

Erfahrene Teilnehmer und Neulinge sind sich vor allem darin einig, dass die Verbindung zwischen lokaler und globaler Ebene bisher am Forum nicht hinreichend verwirklicht wurde. So sagt zum Beispiel die Vorsitzende des Forums:

»The foundation for building constructive dialogues between indigenous peoples, governments and inter-governmental bodies has been set within the Permanent Forum. What is needed at this point is to ensure that the gains achieved in this Forum are felt by the indigenous peoples in their communities« (Rede Tauli-Corpuz 16.05.2005; zitiert aus eigene Aufzeichnungen 16.05.2005). ${ }^{21}$

Dennoch ermahnte sie als Sitzungsleiterin die indigenen Redner immer wieder dazu, nicht ihre lokalen Probleme vorzutragen, sondern diese auch für einen globalen Kontext relevant zu machen und daraus konkrete Vorschläge an UN-Organisationen abzuleiten. Eine indigene Repräsentantin aus Bolivien brachte das schwierige Verhältnis zwischen lokalem Bezug und globaler Lösungssuche wie folgt zum Ausdruck:

20 Vgl. hierzu auch Kapitel IV.2, in dem sich verschiedene indigene Akteure kritisch mit dem Begriff der Armut und der Wahl des MDG Ziels der Armutsreduzierung bis 2015 als zentrales Thema des Treffens auseinandersetzen.

21 Die Rede ist in schriftlicher Form online zugänglich unter: http://www.docip. org/pfii/2005/pfii4_D.pdf 
»Ich weiß sehr wenig vom Forum. Man sagt, es sei ein Forum für indigene Fragen, aber wir nehmen gar nicht an der Ausarbeitung der Themen und Regeln teil. Das Programm ist schon fertig, man kann es nicht mehr ändern. Ich wollte mit einem Redebeitrag teilnehmen und habe mich in die Sprecherliste eingetragen, habe dabei aber vergessen dazuzuschreiben, dass es ein kollektiver Redebeitrag ist. Da diese aber bevorzugt werden, bin ich nicht mehr an die Reihe gekommen« (Gespräch Cabrera 20.05.2005).

Ein weiteres Problem ist die räumliche Distanz zwischen dem Forum und den Orten, an denen indigene Forderungen umgesetzt werden sollen. Die Kontrolle der Adressaten dieser Forderungen erweist sich als kaum durchführbar, da letztendlich die direkte verpflichtende Zuweisung der Zuständigkeit fehlt. Eine Gruppe, die ihre politischen Forderungen am Forum stellt, kann zwar Regierungen und UN-Einrichtungen zum Handeln auffordern, doch keiner ist letztendlich verpflichtet, diesen Aufforderungen nachzukommen. Das liegt zum einen daran, dass das Mandat des Forums nur darin besteht, Empfehlungen auszusprechen. Zum anderen übersteigt die Fülle der Forderungen und Empfehlungen die Kapazitäten des Forums. So wurde 2004 und 2005 verstärkt von Mitgliedern des Forums darauf hingewiesen, dass das Forum Gefahr laufe, sich in eine »Produktionsmaschine für Forderungen« (Interview Matías Alonso 19.05.2004) zu verwandeln. Bezeichnend sind in diesem Zusammenhang zum Beispiel die Ausführungen des Vertreters der CEPAL, der auf Nachfrage von indigener Seite hin erläuterte, dass es in seiner Institution kein Mandat zur Überwachung der MDGs in Bezug auf indigene Völker gäbe. Jedoch gäbe es einzelne Mitarbeiter, die sich mit diesem Thema auseinandersetzten (eigene Aufzeichnungen 17.05.2005).

\section{Repräsentation, Authentizität und Autorität}

Auf einer Informationsveranstaltung des UN Voluntary Fund for Indigenous Populations $^{22}$ im Rahmen des Treffens der Arbeitsgruppe indigene Völker 2004 in Genf wurden die Kriterien erläutert, die indigene Repräsentanten erfüllen müssen, um sich für ein Stipendium für die Teilnahme an den Treffen der Arbeitsgruppe oder des Forums bewerben zu können. Der Kandidat muss:

- eine der offiziellen UN-Sprachen beherrschen;

221985 richtete die UN-Generalversammlung den UN Voluntary Fund for Indigenous Populations ein, der seit 1987 Vertretern indigener Organisationen die Teilnahme an den Sitzungen der Arbeitsgruppe und - seit 2002 - auch an den Sitzungen des Forums finanziert. Der Fond speist sich aus freiwilligen Beiträgen von Regierungen, NGOs und anderen privaten und öffentlichen Institutionen und wird vom Generalsekretariat verwaltet (Dreher 1995: 39). 
- $\quad$ eine indigene Organisation vertreten;

- eine sindigene Person sein< (eigene Aufzeichnungen 20.06.2004). ${ }^{23}$

An der Veranstaltung teilnehmende Vertreter indigener Organisationen waren vor allem interessiert an Auskünften dazu, wie von Seiten der UNO gegen >falsche Indigene` vorgegangen würde. Die Mitarbeiterin erläuterte, dass Organisationen bzw. lokale Gemeinden vorher und schriftlich über diejenigen berichten müssten, die sie nicht für indigen hielten. Das Sekretariat sei sehr interessiert an entsprechenden Informationen, könne aber nur mit schriftlichen Beweismitteln in Aktion treten. Am besten sei es, wenn das Dokument von einer Reihe von lokalen Gemeinden unterschrieben würde (eigene Aufzeichnungen 20.06.2004).

Ein Mapuche, der seit den ersten UN-Konferenzen die Entwicklungen in diesem Kontext verfolgt, gibt diesbezüglich zu bedenken: »Der Voluntary Fund for Indigenous Populations wird von Nicht-Indigenen geleitet. Es gibt jedes Jahr Tausende von Anträgen, aber die Auswahlkriterien sind nicht transparent « (Gespräch Cayuqueo 24.05.2005).

Beim Problem der Repräsentation, das ich als grundlegendes im politischen Feld bezeichnet habe (vgl. Kapitel II.5), können im Falle der indigenen Bewegungen zunächst einmal zwei zentrale Aspekte unterschieden werden:

- es geht um die Frage, wer wen repräsentiert, wer mit wem zusammenarbeitet und wie diese Dimension der Repräsentation innerhalb und außerhalb der Bewegungen diskutiert wird;

- es geht um die Art und Weise, wie lokale Gemeinschaften oder indigene Organisationen ihre Kultur gegenüber dem Staat, den Medien, Entwicklungsorganisationen und internationalen Instanzen darstellen (Warren und Jackson 2003: 12).

Unter den Teilnehmern am Forum herrscht nicht immer Einigkeit in Bezug auf die Frage, wie >indigene Kulturen` gegenüber Außenstehenden darzustellen seien. Vor allem entstehen jedoch Konflikte um die Frage, wer wen mit welcher politischen Legitimation vertritt. Einige Vertreter indigener Organisationen beziehen ihre Legitimation aus periodisch stattfindenden Wahlen, andere leiten Verbände, ohne sich einem Votum der >Basis`stellen zu müssen. Im Folgenden geht es mir um eine nähere Betrachtung der beiden genannten Aspekte von Repräsentation, wobei deutlich wird, dass sie in der Praxis dazu tendieren, ineinander zu greifen.

23 Die Formulare des Voluntary Fund for Indigenous Populations für Stipendienanträge sind online zugänglich unter: http://www.docip.org/anglais/news_en /news_en.html [21.05.2005] 


\section{Kontrolle der Repräsentanten durch die Repräsentierten}

Das Ständige Forum für indigene Angelegenheiten liegt in großer räumlicher Distanz zu den Herkunftsregionen der Teilnehmer. Gerade dieser Tatbestand sorgt für interne Spannungen innerhalb der Gruppe indigener Teilnehmer. Eine Shuar-Vertreterin aus Ecuador meint:

»Bevor ich hier ankam, glaubte ich, dass das Forum wie jedes andere Treffen sei, auf dem man sprechen kann und gemeinsam Lösungen sucht. Aber so ist das nicht. Hier sprechen nur Leute, die Schlüsselpositionen auf nationaler und internationaler Ebene innehaben. Die reden von anderen Dingen als ich. Ich kann nicht sprechen wie ich will, ich bin hier nur als Beobachterin« (Gespräch Tsawant 20.05.2003).

Vor allem das Fehlen einer >gemeinsamen Sprache` zwischen erfahrenen und unerfahrenen Teilnehmern des Forums führt zu Misstrauen und dem Gefühl des Ausschlusses von Seiten der Neulinge im Feld. Repräsentanten, die eine hervorgehobene Rolle am Forum spielen, geraten bei ihnen sehr schnell in den Verdacht, sich von ihrer Basis entfernt zu haben und eine personalisierte Politik zu betreiben. So werden indigene Experten, die zum Beispiel die Einführungsseminare für neue Teilnehmer leiten, von den anwesenden Neulingen meist als eine eigene soziale Klasse wahrgenommen. Ihr UN-spezifisches Fachwissen wird als kulturelles Kapital interpretiert, das Ihnen Zugang zu privilegierten Beziehungen mit UN-Einrichtungen und damit auch zu Finanzquellen verschafft. Dieses institutionalisierte kulturelle Kapital, das sich an >westlichen`Standards orientiert, lässt sich in ökonomisches, soziales und letztendlich symbolisches Kapital verwandeln. Gerade indigene Experten werden deshalb oft beschuldigt, keine echten Vertreter zu sein, sondern sich auf Kosten lokaler Gemeinden persönliche Vorteile zu verschaffen. Sie würden sich nicht solidarisch gegenüber ihren >indigenen Brüdern und Schwestern verhalten und damit ihren eigenen Diskurs vom moralisch überlegenen Sozialverhalten Indigener ad absurdum führen - so ein oft geäußerter Kommentar meiner Gesprächspartner. Vertreter von sogenannten >Basisorganisationen`, Zusammenschlüsse, die ihre Repräsentanten durch Wahl bestimmen und regelmäßig bestätigen bzw. auswechseln, verweisen besonders häufig auf den zweifelhaften Status vieler Indigenen-Vertreter im UN-Kontext:

»Ich kenne zum Beispiel Leute aus Brasilien, die angegeben haben, einem bestimmten Volk anzugehören, aber das stimmte nicht. Ein anderes Mal, bei einer Sitzung [des Forums] war da jemand aus Peru, der sagte, er nehme im Namen einer bestimmten Organisation teil, aber das stimmte nicht. [...] Es ist ein offener Raum für alle, in dem jeder seine Meinung sagen darf [...] Aber es ist so: Es ist nicht klar, wer von den Teilnehmern wirklich eine Organisation oder ein Volk repräsentiert. Man muss bei der UNO keine Beweise erbringen« (Interview Manchineri 24.10.2003). 
Misstrauensäußerungen bezüglich der Repräsentationsbefugnis eines indigenen Vertreters können mit Bourdieu (2001: 93ff.) als Versuch interpretiert werden, den jeweiligen Personen den Zugang zu einer zentralen Ressource im politischen Feld zu entziehen: dem Delegationskapital. Die Umwandlung sozialen, ökonomischen und institutionalisierten kulturellen Kapitals in symbolisches Kapital soll auf diese Art und Weise verhindert werden (vgl. Kapitel II.5).

Auch ein Repräsentant des nationalen Zusammenschlusses indigener Organisationen des brasilianischen Amazonasgebietes verwies im Gespräch darauf, dass ein Problem der indigenen Bewegungen, gerade auch im internationalen Kontext, die mangelnde Repräsentativität vieler Vertreter sei. Er erzählte in diesem Zusammenhang von einer Initiative aus Brasilien, die diesem Legitimationsmangel Abhilfe verschaffen wollte. Dort würde seine Organisation ein Projekt mit der Ford-Stiftung ausarbeiten, um den Status >indigener Diplomat $\mathrm{zu}$ institutionalisieren: Diesen erhielten Indigene, die in Englisch und Spanisch ausgebildet würden und einen offiziellen Ausweis als Diplomaten bekämen (Gespräch Ceto 19.05.2005). Damit wird das Problem der >Authentifizierung \ der Repräsentativität aber auch als eines verstanden, das man mit offiziellen Dokumenten lösen kann. Indigene Diplomatenschulen lassen sich als Teil eines Ausschluss- und Trennungsmechanismus lesen, der einsetzt, sobald sich eine Gruppe im politischen Feld nationalstaatlicher Prägung etabliert hat. Das Beitrittsrecht zum politischen Feld wurde somit bislang von Seiten indigener Akteure nur teilweise reformiert. Viele Repräsentanten indigener Organisationen scheinen indess bestrebt, staatlich geprägte Vorstellungen von Legitimität politischer Interessenvertretetung zu übernehmen.

Die Kontrolle, wer rechtmäßig im Namen welcher Gruppe spricht, ist dennoch am Forum schwer zu gewährleisten. Die UNO ist in dem Sinne ein doppelt abgetrennter Mikrokosmos - zum einen durch die interne Differenzierung in Experten und Lokalpolitiker, bei der zwischen ersteren und letzteren ein ähnliches Verhältnis wie zwischen Professionellen und Laien herrscht (vgl. Kapitel II.5); zum anderen durch die räumliche Loslösung von den jeweiligen Heimatregionen, welche die an der UNO handelnden Repräsentanten von sozialer Kontrolle weitestgehend abkoppeln. Die offensichtliche Folgenlosigkeit der Kampagne gegen den Aymara während der Sitzung des Forums im Jahr 2004 belegt dies (vgl. Kapitel V.2).

\section{Relevante ıIndigenitäts-Marker` für die Außendarstellung}

Entgegen der weiter oben zitierten Auffassung von Manchineri, im UNKontext seien keine Beweise für die eigene Repräsentativität von Seiten indigener Teilnehmer zu erbringen, bin ich der Meinung, dass dennoch auch dort >Indigen-Sein beständig nachgewiesen werden muss. Dabei werden jedoch 
kontextbedingt andere Kriterien relevant. Im Zusammentreffen mit außerhalb der Gemeinschaft Stehenden erreicht man Authentizität durch Symbole wie Grußworte in der eigenen Sprache, Kleidung, Tänze etc., während innerhalb der eigenen Gruppe andere Legitimationskriterien gelten. Im Falle indigener Repräsentanten des Amazonasgebietes zum Beispiel wird die Legitimität Einzelner unter anderem daran gemessen, was sie für ihre Verwandtschaft bzw. ihre jeweilige Unterstützergruppe leisten. Fassbare Beweise, wie Entwicklungsprojekte, Landtitulierungsurkunden etc. sind zu erbringen. In beiden Fällen jedoch, sowohl in der Interaktion mit Regierungsvertretern oder Mitarbeitern von UN-Einrichtungen als auch beim Auftritt vor der eigenen Gruppe, entsteht Authentizität und Autorität in der Interaktion. Authentizität und Autorität müssen dem, der sie beansprucht, von anderen attestiert werden. Eine wichtige Grundlage hierfür ist, dass man für die jeweilige Zielgruppe >verständlichく redet, das heißt ihre Erwartungen erfüllt. Entscheidend sind somit die jeweils sozial anerkannten Kriterien, die zur Beurteilung von Authentizität herangezogen werden.

Seit den Anfängen ihrer Präsenz bei der UNO haben sich die meisten indigenen Teilnehmer gegen eine eindeutige Definition von Indigenität gewehrt. Damit wollten sie einer Festlegung von Seiten der Regierungen entgegenwirken und einer möglichst großen Zahl von Personen die Identifizierung mit dieser Kategorie ermöglichen. Welche Marker der Indigenität spielen im internationalen Kontext eine Rolle?

Auf internationaler Ebene soll politische Unterstützung von Entwicklungsinstitutionen, NGOs oder UN-Einrichtungen mobilisiert werden. Dafür müssen Probleme und Forderungen zwangsläufig in Englisch, Spanisch oder Französisch vermittelt werden. Jackson (2003) und Graham (2003) sehen indigene Sprachen dennoch als wichtigstes Definitionskriterium für >authentische Indigenität<, auch wenn gerade der Gebrauch dieser Sprachen die primäre Kommunikation mit den Adressaten der Botschaft erschwert. Beim Gebrauch der eigenen Sprache ist die übermittelte symbolische Botschaft das zentrale Element: »Ich bin ein authentischer Indigener«. Denn: Je besser die Akteure indigener Bewegungen mit den `Kolonialsprachen` umgehen können, desto eher laufen sie ironischerweise im Umgang mit Regierungsvertretern und Unterstützern Gefahr, ihren Status als >authentischeく Repräsentanten zu verlieren. ${ }^{24}$ Gleichzeitig ist die Beherrschung des internationalen Vokabulars

24 Vgl. hierzu die Kontroverse um den Yanomami-Sprecher Davi Kopenawa, dessen Glaubwürdigkeit von Chagnon (1992a, 1992b) auch auf Grund seiner guten Kenntnisse des Spanischen angezweifelt wurde. Graham (2003: 184) sieht in diesem Vorwurf westliche Vorstellungen von einer engen Verbindung zwischen Sprache und Identität verkörpert. Sie verweist in ihrem Aufsatz auf die politischen Implikationen, welche die Wahl der Sprache für Vertreter indigener Bewegungen haben. 
aber Voraussetzung für erfolgreiche politische Arbeit. Hieraus ergibt sich ein grundlegender Konflikt für die Vertreter, den sie auf unterschiedliche Art und Weise lösen: In internationalen Foren werden Kleidung, Grußworte, Tänze, Gesänge und Rituale zum Ausdruck der >authentischen< Verbindung mit der Kultur, die man repräsentieren möchte. So kleideten sich zum Beispiel die Maasai in den von mir besuchten Sitzungen des Forums regelmäßig und über die gesamte Tagungszeit hinweg in ihre >traditionellen Gewänder $\measuredangle$ Sie traten ferner jedes Jahr am zweiten Tag der Konferenz bei einer offiziellen Eröffnungsfeier mit anschließendem Empfang auf. $\mathrm{Zu}$ diesem leisteten verschiedene Gruppen Beiträge in Form von Tänzen, Gesängen und Ansprachen. Meist waren Auftritte nordamerikanischer Indianergruppen, von Maori sowie Maasai fester Bestandteil dieses Ereignisses. Dass durch den Einsatz dieser Elemente im Rahmen der UNO erfolgreich Autorität zu erlangen ist, verdeutlicht folgendes Zitat aus einem Aufsatz des Direktors von IWGIA, der die Erfolge der transnationalen panindigenen Bewegung im Kontext der UNO analysiert:

»Most conspicuous is the traditional dress worn by many indigenous representatives, and which so strikingly sets indigenous meetings apart from all other UN meetings. Indigenous people have thus been able to bring their culture into the $\mathrm{UN}$, and most remarkably, to change the meeting agenda. When indigenous peoples first asked for permission to open the $\mathrm{WGIP}^{25}$ meetings with a prayer, it was strongly opposed by the chair [...] Today these ceremonies are not only accepted but also appreciated by most government representatives. In these matters, indigenous peoples have managed to get government representatives on their side and have them respect their cultures and traditions« (Dahl 2004: 11f.).

Akte der Theatralisierung, mit denen Gruppen sich zur Schau stellen, gelten nach Bourdieu (2001) als elementare Form, mit der man Teilungsprinzipien in einem Feld objektiviert und manifestiert. Folkloristische Auftritte, die >Differenzen« sichtbar machen, sind deshalb von fundamentaler Bedeutung im Umgang mit Regierungen und Einrichtungen der UNO. Dies wurde deutlich am Kommentar des UNDP-Mitarbeiters, der betonte, die >Buntheit` des Forums (sowohl in Bezug auf die Kleidungsordnung als auch in Bezug auf den hohen Anteil weiblicher Teilnehmer) würde besser als jedes andere UN-Treffen den Sinn dieser internationalen Instanz verdeutlichen (vgl. Kapitel V.2). In diesem Zusammenhang fällt auf, dass Frauen besonders oft durch ihre straditionelle Kleidung \ervorstechen. Eine mögliche Erklärung dafür ist, dass sie die Rolle der >authentischen Indigenen` besonders überzeugend verkörpern können: Frauen wird auf Grund ihrer Rolle als Mütter oftmals eine zentrale Funktion

25 WGIP: Working Group on Indigenous Populations; die englische Abkürzung für die Arbeitsgruppe indigene Völker. 
für den Erhalt >indigener Traditionen` zugewiesen. Dies belegen zum Beispiel Studien der Maya-Bewegung in Guatemala (vgl. Rößler 2004).

\section{Gruppeninterne Markierung von sIndigenitätı}

Untereinander ziehen die indigenen Teilnehmer jedoch auch im internationalen Kontext teilweise andere Kriterien zur Klärung heran, ob jemand authentisch erscheint. So betonten einige indigene Repräsentanten in ihren Ansprachen vor der UNO, dass Indigen-Sein auf >tieferliegenden` Werten beruhe: »Being indigenous is not just dressing in colourful clothes on weekend or special events but it's in the depth of the soul« (eigene Aufzeichnungen 14.05.2003). Überzeugungen, Werte, ein bestimmtes Verhalten charakterisieren nach Meinung dieses Sprechers >Indigen-Sein<. Unter den indigenen Teilnehmern wird sogar oftmals den >traditionell Bekleideten` das größte Misstrauen entgegengebracht - allerdings nur, wenn diese gleichzeitig mit dem UN-Fachvokabular besonders professionell umgehen können und aus der Heimatregion stammen, so dass es leichter wird, ihr Auftreten aus der eigenen Erfahrung heraus zu beurteilen. Den entsprechenden Personen wird vorgeworfen, sich zu >verkleiden`. Auf diese Einschätzung traf ich immer wieder unter Teilnehmern aus Lateinamerika. So erklärt die bereits erwähnte Guaraní-Vertreterin aus Bolivien:

»Es gibt hier Repräsentanten, die ihre traditionellen Kleider im Koffer tragen. Sie verkleiden sich damit. Als ich in Genf beim Arbeitsgruppentreffen ankam, fragte mich eine Teilnehmerin: Warum tragen Sie nicht ihre traditionelle Kleidung? Ich verstand ihre Frage nicht. Ich würde doch meine Großeltern beleidigen. In meiner Gemeinde laufe ich genauso wenig in diesen Kleidern herum. Wenn ich es eines Tages machen sollte, dann werde ich sie auch anbehalten« (Gespräch Cabrera 20.05. 2005).

Ein anderer Teilnehmer verweist darauf, dass traditionelle Kleidung eine Folklorisierung der eigenen Kultur darstelle: »Wir müssen die Konzepte verändern. Viele Ethnologen zum Beispiel sehen Indigene nur als FolkloreObjekte, der Indio ist der, der ohne Schuhe in seiner typischen Kleidung geht« (Gespräch Orozco 14.05.2003).

Demgegenüber steht jedoch die positive Aufmerksamkeit, die manchen Neulingen am Forum gezollt wird, wenn sie in >traditioneller Kleidung erscheinen. 2003 traten zum Beispiel zwei Yanomami aus Brasilien mit Federschmuck und Bemalung auf. Sie wurden begleitet von der Vertreterin einer europäischen NGO und besuchten das Forum zum ersten Mal. Ihr Redebeitrag wurde mit viel Interesse verfolgt, und einige Teilnehmer eilten herbei, um ein Foto von ihnen zu machen. Hierbei waren es vor allem Repräsentanten 
aus Afrika, Asien und Nordamerika sowie NGO-Vertreter, die den Auftritt der Yanomami bildlich festhielten.

Mit Friedman kann man die internen Auseinandersetzungen um Authentizität und Repräsentation als Bestätigung bzw. Hinterfragung >existentieller Authentizität `(Friedman 1993: 761) lesen. Für denjenigen, der eine kulturelle Identität schafft, ist >Authentizität` eine grundlegende Frage der praktischen Beziehung zwischen dem Subjekt und der repräsentierten Gemeinschaft:

»Authenticity in this case refers to the state of integrity of the members of an identifying group. Inauthenticity would thus consist in the relative alienation from the cultural model, a lack of engagement, a social distance with respect to the values and categories embodied in a tradition or program of action« (Friedman 1993: 761).

Geteilte Erfahrungen bestimmen den Erfolg und die Resonanz von Realitätsmodellen der sie Praktizierenden. Doch die Erfahrungshorizonte der am Forum teilnehmenden indigenen Vertreter erweisen sich als sehr unterschiedlich. Die immer wiederkehrenden internen Auseinandersetzungen um die Repräsentativität exponierter Stimmen verdeutlichen, dass Diskurs und Praxis an einem Ort wie dem Forum in einem besonders schwierigen Verhältnis zueinander stehen. Es gibt keine unmittelbaren Prüfmöglichkeiten, um das Gesprochene und die Handlung, Repräsentation und Repräsentiertes, miteinander abzugleichen. Vor allem die räumliche Distanz macht dies unmöglich, aber auch die Strukturen des Raumes, in dem repräsentiert wird - in diesem Fall die UNO: Das Forum garantiert demjenigen Erfolg, der überzeugend Sprechen und Versprechen kann - jedoch nicht gegenüber einer >heimatlichen Wählerschaft`, sondern im Umgang mit NGOs und UN-Einrichtungen. Der Referenzrahmen wird durch die Erfahrungen und Erwartungen der Vertreter dieser Institutionen gesetzt. Sie stützen sich in der Beurteilung der Glaubwürdigkeit eines indigenen Vertreters auf Kriterien, die in dem institutionellen Rahmen entwickelt wurden, in den sie eingebettet sind bzw. die ihrem persönlichen Erfahrungshorizont, Vorstellungen und Erwartungen entsprechen.

\section{Fazit: Politische Relevanz von Authentizität für Indigenen-Vertreter am Forum}

Im politischen Feld erweist sich die Legitimation des eigenen Delegationskapitals als zentrales Element im Kampf um politische Macht. Dabei wird die Authentizität eines Repräsentanten auch angezweifelt, um den politischen Gegner bzw. Konkurrenten zu disqualifizieren. Gelingt die >Rufschädigung`, läuft der entsprechende Repräsentant Gefahr, sein symbolisches Kapital einzubüßen, ist dieses doch Prestigekapital, das heißt, an seinen Bekanntheitsgrad gebunden. Gleichzeitig beruht es auf Vertrauen. Deshalb sind Politiker 
besonders anfällig für Verdächtigungen und Verleumdungen - und dies umso mehr, je weniger sie ihr Kapital der Delegation verdanken. Nur durch ständige Arbeit kann im politischen Feld relevantes Kapital bewahrt werden (vgl. Bourdieu 2001; vgl. auch Kapitel II.5). Das Prestigekapital indigener Politiker ist somit beständig gefährdet: Während Außenstehende misstrauisch werden können, wenn Indigene sich zu gut mit dem >westlichen ‘ politischen System auskennen, kann im Gegenzug die Autorität in der eigenen Gruppe unter anderem durch zu große Anerkennung von außen in Gefahr geraten. Dem Aymara, der sich während der Sitzungsperiode 2004 den Angriffen auf sein Prestigekapital ausgesetzt sah (vgl. Kapitel V.2), scheint es dennoch gelungen zu sein, seine Beziehungen im UN-Kontext weiter auszubauen und darüber seine Position wieder zu festigen. Dies lässt darauf schließen, dass im Umgang mit Vertretern von UN-Organisationen weniger Authentizität im Sinne einer engen Verbindung zu Realitätsmodellen und Erwartungen der repräsentierten Gruppe eine Rolle spielt, als die Beherrschung des in diesem Raum notwendigen, fachspezifischen Wissens. Auch die Spezialisierung auf ein bestimmtes Themenfeld - zum Beispiel Biodiversität, Genderfragen oder Rechtsverträge - hilft bei der Etablierung im Feld. In jedem Fall muss man sein Expertenwissen unter Beweis stellen, um als Gesprächspartner für UN-Einrichungen und Regierungen an Bedeutung zu gewinnen. Diese überragende Bedeutung fachspezifischen Wissens für eine erfolgreiche Teilnahme an UNO-Sitzungen tritt unter anderem auch dann zu Tage, wenn man sich das wichtigste Auswahlkriterium für die Mitglieder des Forums verdeutlicht: die (entwicklungs-) politische Erfahrung des Bewerbers auf nationaler und internationaler Ebene. Die Lebensläufe der Mitglieder des Forums belegen dies eindrücklich. ${ }^{26}$

Prestigekapital bei der UNO ist demnach weniger abhängig vom Bekanntheitsgrad innerhalb der eigenen Gruppe. Es erlangt in dieser Hinsicht eine größere Autonomie als auf lokaler Ebene. Der Raum ist geografisch so weit von den Heimatregionen der Teilnehmer entkoppelt, dass die eigene Gesetzmäßigkeit des Feldes greift. Hier manifestiert sich, was Bourdieu in seiner Studie des politischen Feldes beschreibt: »Je mehr sich ein politischer Raum verselbstständigt, desto mehr entwickelt er eine eigene Logik, desto mehr tendiert er dazu, nach den dem Feld inhärenten Interessen zu funktionieren, und desto größer wird der Bruch mit den Laien« (Bourdieu 2001: 47).

26 Vgl. hierzu die Lebensläufe der Forumsmitglieder, zugänglich unter: http://www.un.org/esa/socdev/unpfii/en/members.html. [10.11.2005] 


\section{Motivationen zur Teilnahme am Forum}

Die Motivationen indigener Teilnehmer, zu den Treffen des Forums zu reisen, können sehr unterschiedlich sein. Teilweise stehen explizit persönliche Interessen im Vordergrund, auch die politischen Zielsetzungen variieren stark. Man kann dennoch vier idealtypische indigene Besucher des Forums mit jeweils eigenen zentralen Teilnahmegründen unterscheiden. Diese Kategorisierungen erscheinen mir wichtig, um im Folgenden die Konfliktlinien innerhalb der Gruppe indigener Teilnehmer im Detail fokussieren zu können. Es lassen sich unterscheiden:

- Indigene Experten

- International erfahrene indigene Politiker

- Indigene Lokalpolitiker

- Indigene >Privatpersonen

\section{Indigene Experten}

Die indigenen Experten, viele von ihnen Juristen, bewegen sich zumeist seit vielen Jahren im UN-Kontext. Sie sind eine Art >Diplomatenzunft $<$ und verstehen sich auch selbst als solche. Ihre Kontakte zur Basis in den Heimatländern sind eher sporadischer Natur, oft spielen sie im Kontext der nationalen indigenen Bewegung, zumindest im Falle Perus, kaum eine Rolle. Sie werden in ihrer Heimat deshalb manchmal als >Trittbrettfahrer bewertet, die sich »auf Kosten der Indigenen« international einen Namen machen würden. Friedman bezeichnet sie als »neue Elite innerhalb der globalen Sphäre«, die aber von den wirklich Mächtigen und deren Geldern abhängen: »They may have global spheres of their own, like the World Council of Indigenous Peoples (WCIP) and they sometimes mingle with higher ranked elites, but they are primarily local clients in the global mesh of neo-feudal dependencies« (Friedman 1999: 13). ${ }^{27}$

Doch bestehen auch in diesem Feld der >globalen Elite< Unterschiede. Zum einen gibt es diejenigen, die flexibel einsetzbares Fachwissen mitbringen, in diesem Zusammenhang vor allem die Juristen. Zum anderen jene, die sich durch ihre politischen Aktivitäten innerhalb der internationalen Bewegung etabliert haben und nicht immer ein Universitätsdiplom besitzen. Während die ausgebildeten Fachkräfte Arbeit finden können in UN-Organisationen, sind nicht formal ausgebildete politische Aktivsten stärker abhängig vom Mandat in einer indigenen Organisation und ihren nicht-indigenen Unterstützern. Aber, je stärker das Thema >indigene Völker` im UN-System

27 Dies erinnert an die Gegenüberstellung von Kosmopoliten und lokalen Eliten bei Robert Merton (1957): Während Kosmopoliten aufgrund ihres Wissens an jedem Ort zur Elite gehören können, sind lokale Eliten von ihren Beziehungen zu mächtigeren Partnern abhängig (Hannerz 1996: 102; 108). 
verankert wird, je mehr Stellen für indigene Angestellte geschaffen werden, desto stärker spezialisiert und normiert sich auch der indigene Aktivismus: Fachwissen zu biologischer Vielfalt, zu indigenen Rechten, Ressourcennutzung, Bildung, Kommunikation etc. wird relevant. $\mathrm{Zu}$ jedem dieser Themen existieren wichtige Studien, Positionspapiere und die entsprechenden Experten. Für die weitere Entwicklung in diesem Feld lässt sich daraus ablesen, dass Fachwissen immer mehr an Bedeutung gewinnt und sich snicht-diplomierte` Organisationsvertreter einem stärker werdenden Konkurrenzdruck von Seiten ihrer diplomierten Mitstreiter ausgesetzt fühlen. Diese Entwicklungen sind in Peru auch im nationalen Kontext zu beobachten.

\section{International erfahrene indigene Politiker}

Eine zweite Kategorie von Teilnehmern sind die Vertreter großer nationaler oder internationaler Organisationen. Sie haben oftmals ein zeitlich beschränktes politisches Mandat der Zusammenschlüsse, die sie repräsentieren, und nehmen deshalb meist nicht über längere Jahre am Treffen des Forums teil. Diese indigenen Politiker nutzen die Sitzung, um bestehende Kontakte mit Organisationsvertretern aus anderen Ländern - zumeist aus ihrer Heimatregion - aufzufrischen. Auch sie sind oftmals Spezialisten für bestimmte Themengebiete, dabei aber häufig keine Studierten mit Diplom. Sie haben keinen festen Platz im UN-Kontext und nehmen nur gelegentlich an UNSeminaren und Konferenzen teil. Oft legen sie eine skeptische Haltung an den Tag in Bezug auf den Nutzen der UN-Mechanismen für ihre Arbeit im nationalen Kontext. Das UNO-Treffen hat für sie keine herausgehobene Bedeutung unter den zahlreichen, von ihnen besuchten internationalen Tagungen. Eine intensive Vorbereitung im Vorfeld findet oft aus Zeitmangel nicht statt. Diese Einstellung trat in Gesprächen mit lateinamerikanischen Repräsentanten zutage. Sie scheint mir aber auch auf andere Weltregionen übertragbar, sofern es sich um Organisationen handelt, deren Vorstand durch Wahlen regelmäßig erneuert wird.

\section{Indigene Lokalpolitiker}

Die dritte Kategorie besteht aus lokalen Vertretern von Basisorganisationen. Sie suchen nach Geldgebern für Projekte und sehen die UNO diesbezüglich als `Kontaktbörseく. So kam es oft vor, dass man mich ansprach, um zu erfahren, wie man mit Vertretern großer Entwicklungsorganisationen in Kontakt kommen könne. Oder aber man holte die Visitenkarten von Mitarbeitern der Gesellschaft für technische Zusammenarbeit (GTZ), der Interamerikanischen Entwicklungsbank oder von UN-Sonderorganisationen hervor und wähnte diese als `Eintrittskarte〈, um auf nationaler Ebene leichter mit entsprechenden Stellen Kontakt aufnehmen zu können. Zwei langjährige Mitarbeiter einer großen europäischen Unterstützer-NGO waren der Meinung, die 
Neuen im Feld könne man daran erkennen, dass sie Projektanträge in der Tasche trügen. Zudem seien die Reisespesen und das mit einer Reise nach Genf oder New York verbundene Prestige in der Heimat sehr wichtige Teilnahmegründe. Sie erzählten das Beispiel eines Repräsentanten, der das Faxgerät seiner Organisation bei sich zu Hause installiert hätte, um als Erster und ausschließlich über eingehende Einladungen informiert $\mathrm{zu}$ sein (eigene Aufzeichnungen 22.05.2005). Eine Repräsentantin aus Peru berichtete, dass sie alle Unterstützer-Organisationen immer bitte, ihr relevante Informationen noch einmal persönlich zukommen zu lassen, da sie sonst an verschiedenen Stellen in der Organisation >hängenblieben (eigene Aufzeichnungen 23.05.2005). Die Kontakte zu Finanzinstitutionen und Unterstützer-Organisationen sind eine heiß umkämpfte Ressource, die man höchstens mit den engsten Verbündeten teilt. Die Suche nach Geldgebern ist für Vertreter großer nationaler Organisationen als Teilnahmegrund am Forum eher zweitrangig, da sie zumeist bereits über solide Kontakte verfügen. Sie vermuten bei der UNO eine Schar von >Bauernfängern`, westliche NGOs, die an den Treffen teilnähmen, um zu erfahren, welche Projekte zur Zeit förderungswürdig seien. Dann würden sie sich indigenen Organisationen nähern und diesbezügliche Vorschläge äußern. Die Projektsummen seien meist geringfügig und zielten eher darauf $\mathrm{ab}$, die NGO am Leben zu halten als Indigenen zu helfen (Interview Manchineri 24.10.2003).

\section{Indigene >Privatpersonen}

Die vierte Kategorie von Teilnehmern setzt sich aus denjenigen zusammen, die explizit persönliche Ziele verfolgen und das Forum als Kontaktbörse bzw. Verkaufsfläche wahrnehmen. Auf Grund der offenen Struktur des Forums, an dessen Sitzungen jeder teilnehmen kann, der seine Anbindung an eine Institution auf dem Anmeldeformular bestätigt, sind die Treffen Anlaufpunkt für alle, die sich im breitesten Sinne für >indigene Themen interessieren: für kulturelle, politische oder spirituelle Fragen. So erhält man von einer in den USA lebenden, aus Peru stammenden Besitzerin einer Tanzschule, die bei den Sitzungen des Forums in Kleidern der Quechua-Frauen aus Cuzco erscheint, Werbezettel für ihren Tanzunterricht. Man trifft den Schamanen aus Otavalo, Ecuador, der die Hälfte des Jahres durch die USA und Kanada reist, um zu heilen und Seminare abzuhalten. Zum Treffen des Forums kommt er, um neue Kontakte zu knüpfen und alte Bekannte wiederzusehen. Ein anderer Schamane aus Ecuador, der in New York lebt, verteilt ungefragt Visitenkarten an nicht-indigene Teilnehmer. Er kann davon ausgehen, auf diese Art potentielle Kunden anzuwerben. Man begegnet einer Aymara aus Bolivien, die seit drei Jahren mit Säcken voller Handwerkskunst anreist und während der zwei Wochen so viel Umsatz macht, dass sich die Reise trotz das teuren Flugtickets und der hohen Lebenshaltungskosten in New York finanziell auszahlt. Sie in- 
teressiert sich weniger für die offiziellen Sitzungen, sondern verbringt die meiste Zeit mit dem Verkauf ihrer Ware. Ihre wirtschaftlichen Aktivitäten bezeichnet sie im Gespräch als »direkte Entwicklungshilfe« (Gespräch Ontiveros 20.05.2004). Das Forum ist in diesem Sinne ein globales >Happening und Umschlagplatz für Waren, Kontakte sowie Informationen zum Thema >Indigene $<$.

\section{Lokalpolitiker und Repräsentationsfachleute}

»Einerseits ist es positiv, dass die UNO die Beteiligung lokaler indigener Organisationen mit Hilfe des Voluntary Funds for Indigenous Populations fördern will. Andererseits werden in den UNO-Foren die politischen Linien der internationalen indigenen Bewegung diskutiert, und dazu braucht es erfahrene Repräsentanten. Diese Diskussionen kommen am Forum jedoch selten zustande. Stattdessen gibt es viele individuelle Kämpfe um Positionen und unterschiedliche Schwerpunktsetzungen. Das kommt der UNO und den Regierungen entgegen. Aber es schadet der Bewegung« (Gespräch Cayuqueo 24.05.2005).

Nilo Cayuqueo spricht die für ihn grundlegenden Probleme am Forum an:

- Man benötigt eine große Detailkenntnis internationaler politischer Prozesse, um erfolgreich an den Sitzungen teilnehmen zu können;

- die Beteiligung lokaler Akteure hemmt deshalb den Fortschritt der politischen Diskussionen in den Augen der erfahrenen Teilnehmer;

- die Gruppe der Indigenen erweist sich, auch auf Grund von Punkt 2, als äußerst heterogen. Diese Stimmen- und Interessenvielfalt schwächt ihre politische Kraft im Auftritt gegenüber den >Kontrahenten` im Feld: UNO und Regierungen. Diese beiden Instanzen werden als >geschlossene Front< wahrgenommen.

Im Folgenden soll das Verhältnis zwischen den Laien und Profis im Feld näher beleuchtet werden, da diese Gruppen politische Zielsetzungen verfolgen und sich somit für die Analyse des politischen Feldes relevante Kommunikationsprozesse innerhalb der Gruppe der Indigenen in erster Linie zwischen ihnen abspielen. Während ich unter >Laien` vor allem indigene Lokalpolitiker, aber durchaus auch manche national erfolgreichen Vertreter verstehe, kann man die Profis im UN-Kontext als Repräsentationsfachleute bzw. professionelle Indigenisten ${ }^{28}$ bezeichnen. Beide Gruppen erfüllen unterschiedliche

28 Bei den Indigenisten handelt es sich in diesem Fall nicht um engagierte Dritte, die einen Diskurs im Sinne des in Lateinamerika geprägten Indigenismus vertreten, sondern um Aktivisten, die sich selber als indigen bezeichnen und - um bei den lateinamerikanischen Begrifflichkeiten zu bleiben - einen indianistischen 
Funktionen im Handlungsraum des Forums. Ihr Verhältnis zueinander ist von Spannungen gekennzeichnet. Diese erwachsen primär aus einem zentralen Attribut, das sowohl in der Außendarstellung indigener Repräsentanten als auch zur Legitimation innerhalb der indigenen Bewegungen Relevanz besitzt: der Selbstdarstellung als legitimierte Interessenvertreter lokaler Gemeinschaften.

\section{Die (Un)Möglichkeit des Rückbezugs auf lokale Interessen}

Das Konzept der Gemeinschaft - und hierbei vor allem der lokalen Gemeinschaft - spielt als politischer Bezugspunkt der indigenen Bewegungen eine wichtige Rolle - auch am Ständigen Forum für indigene Angelegenheiten. So schreibt zum Beispiel Brysk:

»Collective action in general, and Indian rights movement in particular, come out of communities - self-defined and evolving units of political interaction and mobilization. Community often coincides with village but may include much larger units of political interaction and mobilization« (Brysk 2000: 33).

Wie bereits ausgeführt, untermauern indigene Vertreter auch am Forum ihre Legitimitätsansprüche gerne durch den Verweis auf eine breite Basis, die nicht durch individuelle, sondern kollektive Mitgliedschaft verkörpert wird durch die indigene Gemeinschaft, deren Herzstück die Dorfgemeinschaft ist. Man muss sich als (demokratisch legitimierter) Führer einer großen Gruppe darstellen. Dies hängt auch mit dem Anspruch des Forums zusammen, indigene Völker, verstanden als territorial verankerte Gruppen (vgl. Kapitel III.2 und III.3), in ihren kulturellen Besonderheiten zu erfassen und an ihre Vorstellungen angepasste Programme und Richtlinien innerhalb des UN-Systems durchzusetzen. So kommt es, dass die Vorsitzende der Mitglieder des Forums, Victoria Tauli-Corpuz, betont, dass der Erfolg des Forums sich nur an einer erfolgreichen Umsetzung der UN-Programme auf Dorfebene messen lasse (vgl. Kapitel V.3).

Am Forum wie im nationalen Kontext, zum Beispiel in Peru, gilt: Es ist wichtig, sich auf eine große Zahl lokaler Gemeinden berufen zu können, die im Verband zusammengeschlossen sind und den jeweiligen Repräsentanten zu ihrem legitimen Vertreter gewählt haben. Die lokale Gemeinschaft ist das ideologische Fundament der Bewegungen, die sich als von unten gewachsener Widerstand verstehen. Insofern muss Brysks Feststellung, dass indigene Bewegungen aus (selbstdefinierten) Gemeinschaften erwachsen, präzisiert werden: Auch wenn sie sich in größeren politischen Einheiten zusammenschlie-

Diskurs vertreten. Ich meine jedoch, dass beide Ausprägungen lediglich Variationen eines Grundansatzes darstellen. Siehe hierzu Ausführungen in Kapitel VII.7. 
ßen, bildet der Rückbezug auf die ethnisch definierte Dorfgemeinschaft das ideologische Herzstück ihrer Politik. Gerade dadurch konnten sie ein erfolgreiches \Gegenmodell zum klassenbasierten Ansatz zuvor dominanter marxistisch geprägter Bauernbewegungen entwickeln. Dies gilt zumindest für Lateinamerika, wo vielen marxistisch geprägten Guerrillabewegungen der 1970er Jahre unter anderem vorgeworfen wurde, einen von städtischen Intellektuellen auf das bäuerlich-ländliche Umfeld übertragenen >top-down〈Ansatz zu verkörpern. Indigene Bewegungen hingegen stehen für das Modell eines von unten gewachsenen >dörflichen Widerstandsprojekts - mit einer breiten Basis sowie beständiger Rückkoppelung zwischen nationaler oder internationaler Leitung und den lokalen Gemeinden. So verkörpern sie für Brysk (2000) wie auch für Varese (1995) oder Conklin und Graham (1995) die Umkehrung des Leitspruchs der Ökologiebewegung: »Think globally, act locally« sei von den indigenen Bewegungen zu einem »Think locally, act globally« verkehrt worden.

Dieser >lokalisierende` Ansatz lässt sich auf die bereits diskutierte Grundlage indigener Forderungen nach Territorien mit dem Verweis auf ihre ‘kulturellen Differenzen` zurückführen. Diesen kulturellen Differenzen will man im Kontext der UNO zu stärkerer Berücksichtigung in Entwicklungsrichtlinien verhelfen. Die postulierte enge Verbindung zwischen Kultur und Entwicklung wird im Abschlussbericht der Sitzung des Forums im Jahr 2004 wie folgt hervorgehoben: »Culture, loosely defined as shared values, beliefs, practices, in short >as a way of life<, is intimately interwoven with the process of development and thus become infused with power relations on a global scale« (United Nations 2004a).

Dieses Erklärungsmodell der strukturellen Grundlagen politischer Machtunterschiede macht die Anwesenheit von Lokalpolitikern am Forum zwingend notwendig: Sie legitimieren Anspruch, Aufgabe und Ansatz der Einrichtung: die stärkere Berücksichtigung lokaler Wissens- und Wertesysteme bei der Ausarbeitung >globaler Strategien zu fördern. Jedoch zeichnet dieser Ansatz meiner Meinung nach ein unscharfes Bild der Möglichkeiten und Beschränkungen >globaler`politischer Felder für lokale Akteure. Dies führt zu Frustrationen auf beiden Seiten: unter den lokal verankerten Teilnehmern genauso wie unter den indigenen Experten. Beide Gruppen reden saneinander vorbeiく. Dabei sehen die Repräsentationsfachleute eine klare Aufgabentrennung als notwendig an: Sie sind im Kontext der UNO die Experten (vgl. Zitat Cayuqueo), deren Verhandlungspotential eher durch die `Einmischung〈 lokaler Akteure gestört wird. Sie sehen sich selbst als kulturelle Broker zwischen lokalen und nationalen bzw. internationalen Verhandlungspartnern. Indigene Repräsentationsfachleute, die sich bevorzugt im UNKontext bewegen, bilden Teil einer »transnationalen Kultur« (Hannerz 1996), einer Gruppe von Menschen, die eine gemeinsame Sprache entwickelt haben, 
sich aber sozial kaum mehr lokal verorten lassen. Sebastião Manchineri, zum Zeitpunkt des Interviews Koordinator der COICA, fasst die Entwicklung wie folgt zusammen:

»Die UNO sagt: Wir wollen, dass Leute der Basis kommen, von einem Volk, aus den Gemeinden. [...] Aber die wissen nicht Bescheid. Die kommen mit dem Wissen darüber, was in den Gemeinden los ist. Aber bei der UNO sind die Probleme umfassender, [...] deshalb entwickeln sich Experten in solchen Foren« (Interview Manchineri 24.10.2003).

Das >bottom-up $<$ Prinzip hat sich im Kontext der UNO wieder in ein stopdown Prinzip verkehrt: Erst eine >homöopathische Dosis` lokalen Wissens macht den indigenen Politiker zum exzellenten Mitspieler im Feld der UNO. Dies liegt vor allem am realen Kräfteverhältnis zwischen den drei großen Gruppen des Feldes: >Indigene Völker`, UN-Organisationen und Regierungen. Letztere sind tonangebend, auch wenn sie die Gruppe sind, die in den Sitzungen des Forums nur eine untergeordnete Rolle spielt. Sie sind es zum Beispiel, die es davon zu überzeugen gilt, Indigene in die MDGs mit aufzunehmen. Deshalb ist die Frage, ob die MDGs von den lokalen Gemeinschaften gekannt und als relevant eingestuft werden, im Kontext des Forums von untergeordneter Bedeutung. Sie verwandelt sich dort vielmehr in zwei neue Fragestellungen:

- Wie kann für die Bedeutung der MDGs unter den indigenen Organisationen Bewusstsein geschaffen werden?

- Wie können Regierungen dazu bewegt werden, >indigene Völkerく als Zielgruppe der MDGs zu definieren?

>Wichtige Themen sind am Forum solche, die innerhalb des Systems der UNO entstanden sind. Die sindigenen Völker ben nun Zutritt zur Diskussion dieser Themen, aber sie haben sie nicht auf das Programm gesetzt. Sie müssen sich nach den Spielregeln richten, die das Feld bereits vor ihrem Eintritt bestimmt haben.

\section{Das kreative Potenzial der Bürokratie: »Indigenisierung der Moderne«?}

Die verschiedenen Akteure im politischen Feld sind mit unterschiedlichen Möglichkeiten ausgestattet, ihre Weltsicht durchzusetzen. Sie sind abhängig von ihrem wirtschaftlichen, sozialen und kulturellen Kapital (vgl. Bourdieu 2001). Auch wenn indigene Akteure aus diesem Grund weniger politische Macht besitzen, verweist Muehlebach (2003: 254) mit Recht auf das kreative Potenzial, das sich für diese an bürokratischen Instanzen wie der UNO den- 
noch entfalten kann. Die Vereinten Nationen bestehen zum einen aus sogenannten Vertragsorganen - Einrichtungen, die mit der Durchführung bzw. Durchsetzung von Konventionen betraut sind - zum anderen aus Organen, in denen politische Verträge verabschiedet werden. Während letztere mit Regierungsrepräsentanten besetzt sind, werden erstere von unabhängigen Experten geleitet. Diese ließen sich in der Vergangenheit stärker auf einen Dialog mit indigenen Aktivisten ein. Das trug zum Beispiel auch dazu bei, dass sich die Wahrnehmung des Konzepts der `Selbstbestimmung` im UN-Kontext veränderte. Diese Modifikationen wiederum wirkten sich positiv auf die Verhandlungsgrundlage indigener Repräsentanten mit Regierungsvertretern aus, denn sie konnten auf entsprechende juristische Entwicklungen in den Vertragsausschüssen der UNO verweisen. Somit beeinflussen die UNO-Foren natürlich nicht nur einseitig Inhalte und Strukturen der indigenen Organisationen, die sich für eine Lobbyarbeit auf internationaler Ebene entschieden haben. Diese wirken im Gegenzug auch auf Entwicklungen im UN-Kontext ein und beteiligen sich an der Schaffung legaler Instrumente wie der ILO-Konvention 169. Kreatives Potenzial eröffnet sich im UN-Kontext somit vor allem für Juristen, die hier Einfluss auf die Entwicklung des internationalen Rechts nehmen können. Das Forum besitzt jedoch primär eine andere Aufgabe: Im Forum werden nicht wie in der Arbeitsgruppe indigene Völker Rechtsstandards in Bezug auf Indigene untersucht und kritisiert, sondern es wird versucht, auf das Entwicklungskonzept der UN-Institutionen Einfluss zu nehmen. Natürlich kann auch darüber indirekt eine Veränderung internationaler Rechtsnormen bewirkt bzw. das Entwicklungsparadigma kritisch hinterfragt werden. Am Forum stehen jedoch nicht mehr die politischen Ausgangsforderungen im Zentrum, mit denen Anfang des 20. Jahrhunderts bzw. in den 1970er Jahren indigene Vertreter an die UNO kamen: Land und Autonomie. Stattdessen geht es um ২Realpolitik : Es geht darum, bestehende entwicklungspolitische Richtlinien zu beeinflussen bzw. Indigenen besseren Zugang zu nationalen Entwicklungsprogrammen zu ermöglichen. Die politisch-ideologischen Eckpfeiler, die >fundamentalen Ideen zur Mobilisierung von Anhängerschaft (vor allem von finanzkräftigen Unterstützern) - Territorium und Selbstbestimmung - treten dabei zwangsläufig in den Hintergrund. Auch wenn gerade diese beiden Konzepte häufig im abendlichen Caucus (vgl. Kapitel V.2) der lateinamerikanischen Vertreter indigener Organisationen thematisiert werden. Jedoch verdeutlicht der Kommentar eines im UN-Kontext erfahrenen indigenen Profis die Entwicklungen, welche die Experten in diesem Handlungsraum durchlaufen haben:

»Territorium und Selbstbestimmung - das sind natürlich auch weiterhin fundamentale Forderungen unserer Bewegung. Aber am Forum müssen wir uns vor allem darauf konzentrieren darzustellen, wie wir uns eine selbstbestimmte Entwicklung vor- 
stellen und welche Maßnahmen dazu von Regierungs- und UN-Seite ergriffen werden müssen« (Gespräch Cayuqueo 24. 05. 2005).

Das Forum stellt sich als ein Raum für politische Lobbyarbeit dar, in dem es in erster Linie darum geht, Mitarbeiter, die an einflussreichen Stellen innerhalb der einzelnen Organisationen sitzen, dazu zu bewegen, >indigene Völker als Empfänger von Entwicklungsgeldern und -programmen stärker zu berücksichtigen. Dieser Umstand macht das Forum auch weniger interessant für indigene Juristen, die oftmals in Gesprächen auf die für sie übergeordnete Bedeutung der Arbeitsgruppe indigene Völker und allgemein der ehemaligen Kommission für Menschenrechte verweisen (Gespräch Alarcón 24. 05. 2005). Im Forum sind vor allem professionelle Politiker gefragt, die es verstehen, Kontakte zu nutzen bzw. Begriffe wie Armut, Entwicklung, Bildung mit ihren politischen Forderungen abzugleichen und sich für eine entsprechende Aufnahme des Begriffs >indigene Völker in die UN-Programme und -Einrichtungen zu engagieren. Dies führt einerseits zur Abgrenzung zwischen Lokalpolitikern und international erfahrenen $>$ Indigenisten $\measuredangle$. Andererseits finden auch innerhalb der Gruppe der Repräsentationsfachleute Differenzierungsprozesse statt. So führt ein im UN-Kontext geschulter indigener Jurist aus:

»Ich bin einverstanden mit den Brüdern, die sich über mangelnden Informationsfluss von Seiten ihrer internationalen Repräsentanten beschweren. Es ist Aufgabe der repräsentativen Organismen, die Verbindung zur Basis aufrechtzuerhalten. Wir Experten haben hingegen eine beratende Funktion. [...] Wir stehen unseren Delegierten gerne beratend zur Verfügung. Aber man fragt uns viel zu wenig« (Gespräch Alarcón 24.05.2005).

Die Gruppe der Repräsentationsfachleute lässt sich somit wiederum unterteilen in >indigene Berufspolitiker und sindigene Experten`. Letztere sehen ihre Aufgabe in der Schaffung internationaler Rechtsstandards sowie in legalen Beratertätigkeiten. Sie weisen den indigenen Politikern die Aufgabe zu, sich um die praktische Umsetzung der im UN-Kontext entwickelten Standards zu kümmern.

\section{Abgrenzungsprozesse zwischen den indigenen Teilnehmern}

Zwischen und innerhalb der beiden am Forum politisch relevanten Gruppen indigener Teilnehmer sind verschiedene Konfliktlinien auszumachen: Auf der einen Seite stehen Lokalpolitiker und die Vertreter nationaler >Basisorganisationen`, die oftmals gleichermaßen in die Rolle des Laien verwiesen werden, auf der anderen Seite die Repräsentationsfachleute, die sich in indigene Experten und im UN-Kontext renommierte indigene Politiker untergliedern las- 
sen. Die Repräsentationsfachleute sind am Forum die dominanten Stimmen unter den indigenen Teilnehmern. Zwischen ihnen und den Laien verläuft somit eine Konfliktlinie. Eine weitere ergibt sich durch die undefinierte Beziehung zwischen >Basisvertretern men die klaren Trennlinien zwischen demokratisch gewählten Repräsentanten und Mitarbeitern bzw. Leitern von NGOs. So wird die Organisation des eben zitierten indigenen legalen Experten genauso unter der Rubrik >indigene Organisationen im Abschlussbericht des Forums geführt (vgl. United Nations 2004a) wie die sogenannten indigenen politischen Organisationen, die einen >Basisauftragく erfüllen. In ihrem Auftreten gegenüber UN-Organisationen oder Regierungen gehören beide Gruppen gleichermaßen zur Kategorie der indigenen Repräsentanten, denen Autorität als >lokale Stimmen< zugesprochen wird. >Lokal« steht ferner im UN-Kontext für >authentisch « - es legitimiert die Stimme des Sprechers und weist ihn als >Autorität für indigene Fragen aus. Die soziale Nähe der sich selbst als Repräsentanten bezeichnenden indigenen Teilnehmer zu den von ihnen Vertretenen lässt sich am Forum nur schwer nachprüfen. Es kann deshalb leicht durch >folkloristischeく Elemente objektive `kulturelleく Kriterien wie Sprache, Kleidung, Tänze - ersetzt werden.

Von Seiten der UN-Vertreter wird innerhalb der Gruppe indigener Organisationen nur zwischen Teilnehmern mit und ohne Beraterstatus am ECOSOC unterschieden. Erstere besitzen eine privilegierte Beziehung zur UNO: Sie können zum Beispiel auch an anderen Sitzungen, die nur NGOs mit Beraterstatus offen stehen, teilnehmen und dadurch ihre Präsenz und Einflussmöglichkeiten weiter ausbauen.

Somit ergeben sich Probleme bei der Zuweisung von Zuständigkeiten innerhalb der Gruppe indigener Teilnehmer: Bei den Vereinten Nationen haben sich indigene Organisationen mit unterschiedlichen Organisationsstrukturen und verschiedensten Zielsetzungen etabliert. Sie werden jedoch in diesem Kontext weitestgehend als ein homogener Block erfasst. So wird zum Beispiel nicht zwischen >gewählten Vertretern schieden. Beide Gruppen sprechen am Forum sim Namen der Indigenen Doch während gewählte `Basisvertreter` womöglich nur ein oder zwei Jahre lang zur UNO reisen können, da sie danach abgewählt werden, haben die Leiter anderer Organisationen als Experten die Möglichkeit, Kontakte über lange Jahre hin aufzubauen und sich mit den Besonderheiten der Vereinten Nationen vertraut zu machen. Sie werden zu verlässlichen Ansprechpartnern der UN-Einrichtungen und damit zu etablierten Mitspielern im politischen Feld der UNO. 
Abbildungen 10, 11 und 12: Grafische Darstellungen der Abgrenzungsprozesse zwischen indigenen Teilnehmern

A) Unterscheidung von Lokalpolitikern und Repräsentationsfachleuten

\begin{tabular}{|l|}
\multicolumn{1}{|c|}{ (Laien` } \\
$\begin{array}{l}\text { (Lokalpolitiker/gewählte } \\
\text { Sertreter von Basionen) }\end{array}$
\end{tabular}

B) Unterscheidung von gewählten Vertretern und Leitern/Mitarbeitern von NGOs

\begin{tabular}{|l|c|}
\hline $\begin{array}{l}\text { Basisorganisationen } \\
\text { (gewählte Vertreter) }\end{array}$ & NGOs \\
(Fachspezialisten)
\end{tabular}

C) Offizielle Einteilung indigener Teilnehmer von Seiten der UNO

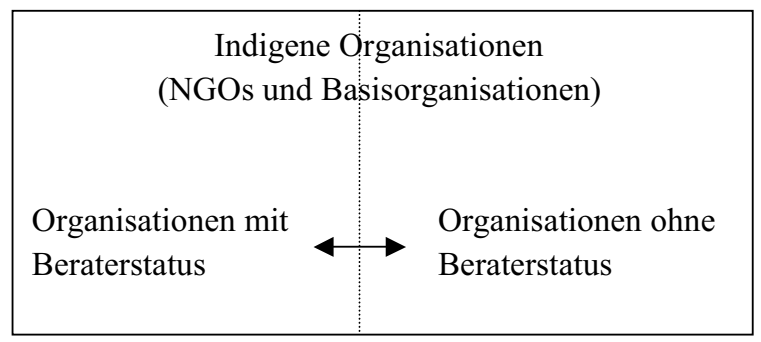

\section{Das zähmende Potenzial der Bürokratie: »Modernisierung der Indigenität«?}

Die Teilnahme lokaler Akteure am Forum kann nur dann ihrer >Ermächtigung dienen, wenn sie sich umfassend auf den Eintritt in das Feld der UNO 
vorbereiten. Das setzt die Professionalisierung des eigenen Politikstils voraus. So sagte die bereits zitierte lokale Repräsentantin der Shuar aus Ecuador:

»Ich müsste mich ein Jahr lang intensiv auf dieses Forumstreffen vorbereiten: Englisch studieren, mit dem Computer umgehen lernen, die hier relevanten Themen aufarbeiten, mich mit den einzelnen UN-Organisationen beschäftigen. Dann aber hätte ich keine Zeit und Kraft mehr, mich mit den Problemen meiner Gemeindemitglieder auseinander zu setzen. Die UNO ist deshalb nichts für mich« (Gespräch Tsawant 19.05.2003).

Zwischen den Laien und den Profis im Feld besteht ein Graben, der durch unterschiedliche Kommunikationsvoraussetzungen und -ziele entsteht. Es braucht Spezialisten für die UNO. Die lokale Gemeinschaft interessiert letztendlich nicht in ihrer Partikularität. Die elementare politische Kompetenz des Lokalpolitikers, das heißt, seine Wähler gut zu kennen und bei ihnen >gut angeschrieben zu sein (Bourdieu 2001: 48), ist im Forum nicht gefragt. Sein spezifisches Wissen macht den Lokalpolitiker zum wichtigen Akteur auf lokaler Ebene, im internationalen Kontext bleibt er damit der oftmals frustrierte Zuschauer. Diese Rolle kann er nur durchbrechen, wenn er etwas >Spektakuläres` zu berichten hat, wie zum Beispiel ein Pygmäenvertreter bei der Sitzung des Forums im Jahr 2003, der von einem Massaker an einer Pygmäengruppe im Kongo berichtete. ${ }^{29}$

Dies erscheint auf den ersten Blick zynisch, entspringt aber gleichzeitig den realen Möglichkeiten, welche die UNO zu bieten hat. Die Vielfalt der Probleme, Meinungen und Interessen kann hier nicht angemessen bearbeitet oder repräsentiert werden. Die Kommunikation zwischen Laien und Profis ist deshalb gestört. Am Forum ist der Hauptadressat die UNO und nicht die heimatliche Wählerschaft. Hier Repräsentativität im Sinne von lokalen Stimmen, denen die größte >Authentizitätく zugesprochen wird, erreichen zu wollen, ist deshalb fast ein Widerspruch in sich. Ist diese Authentizität trotzdem in Form einzelner lokaler Vertreter präsent, entsteht ein Konflikt zwischen beiden Gruppen, denn die Lokalpolitiker erkennen kaum Ähnlichkeit zwischen sich und den Repräsentationsfachleuten. Ähnlich ergeht es nationalen Repräsentanten politischer Organisationen, die oftmals noch vehementer die Legitimität der Repräsentationsfachleute anzweifeln, verfügen sie doch ihrerseits meist bereits über Erfahrung im internationalen Kontext. Sie haben jedoch, im Gegensatz zu den Experten, das Mandat einer Basisorganisation und fühlen sich demnach wiederum als rechtmäßige Sprecher ihrer Gruppen. Deshalb behindern sich die zwei Gruppen indigener Teilnehmer - Laien und Profis -

29 Wobei auch in diesem Fall noch zu überprüfen bliebe, ob es sich bei dem entsprechenden Vertreter um einen >Lokalpolitiker` oder um einen NGO-Vertreter mit stärkerer Anbindung an den internationalen Kontext handelt. 
im Feld der UNO tendenziell eher gegenseitig, anstatt ihre Kraft als in diesem Rahmen zahlenmäßig überlegene Gruppe politisch wirksam zu machen. Es fehlt eine eindeutige Zuweisung der Kompetenzbereiche und Aufgaben. 


\section{Kapitel VI \\ Politische Ermächtigung Marginalisierter oder Marginalisierung des Politischen - indigene Repräsentation im Feld der internationalen Beziehungen}

Die Vertreter indigener Völker konnten sich innerhalb weniger Jahrzehnte als politische Akteure auf internationaler Ebene etablieren. Die UNO erwies sich dabei für sie als politisch bedeutsamer Raum mit besonderem kreativen Potenzial - paradoxerweise auch auf Grund struktureller Schwächen dieser Einrichtung wie der heterogenen Zusammensetzung, geringer politischer Weisungsbefugnisse und des umfassenden bzw. oftmals offen definierten Aufgabengebiets. Politische Prozesse wie Entkolonisierung, Kritik am Entwicklungskonzept oder der Ost-West-Konflikt spielten für den Erfolg einer transnationalen panindigenen Bewegung eine wichtige Rolle (vgl. Kapitel III.2). Grundlegend war dabei jedoch die dominante Stellung, die dem Konzept der Menschenrechte in der zweiten Hälfte des 20. Jahrhunderts im Kontext der UNO zugewiesen wurde. Menschenrechtsverletzungen wurden in zunehmendem Maße als wichtiger Grund empfunden, sich in die inneren Angelegenheiten ansonsten als autonom verstandener Nationalstaaten einzumischen. In diesem Sinne blieb die UNO nicht eine zwischenstaatliche Instanz, sondern entwickelte sich zu einer Art übergeordnetem, globalem Ethikrat - allerdings mit äußerst eingeschränkter Exekutivgewalt. Jüngster Ausdruck dieser besonderen Stellung von Menschenrechten war, im Rahmen einer ansonsten stockend verlaufenden Reform der UNO, die Einigung der Mitgliedsstaaten auf dem UN-Gipfel im September 2005, das Budget des Hochkommissars für Menschenrechte $\mathrm{zu}$ verdoppeln und den bereits erwähnten neuen Menschenrechtsrat zu bilden, der 2006 seine Arbeit aufnahm. 
Die enge Verflechtung der Begriffe Menschenrechte und Kultur, die sich durch die Fokussierung auf kollektive Rechte vollzog, begünstigte die Formulierung eines >subversiven` politischen Kulturbegriffs, der von vielen als Ermächtigungsstrategie marginalisierter Gruppen verstanden wurde. Als problematisch an dieser »Politik der Differenz« (Taylor 1992) erwies sich jedoch, dass mit der Einforderung des Rechts auf Eigenart interne Differenzen verdeckt und neue Ausschlussmechanismen in Gang gesetzt wurden, die weniger Beachtung finden.

Wegmarken konnten die indigenen Bewegungen vor allem auf legaler und symbolischer Ebene setzen. Eindrückliche Belege dafür sind: die ILO Konvention 169, die Verfassungsänderungen vieler lateinamerikanischer Staaten zugunsten multikultureller Nationskonzepte nach sich zog, die umfassende Diskussion des Begriffs der Selbstbestimmung und des Stellenwerts kollektiver Menschenrechte auf legaler Ebene sowie die Ausrufung zweier konsekutiver Dekaden indigener Völker im Kontext der UNO und die Verleihung des Friedensnobelpreises an die Quiché-Maya und Menschenrechtlerin Rigoberta Menchú Tum. ${ }^{1}$ Die Analyse des Ständigen Forums für indigene Angelegenheiten erlaubte jedoch einen differenzierten Blick auf den Prozess indigener Selbstorganisation jenseits dieser zu Recht als herausragend gefeierten Erfolge. Hier offenbarte sich das schwierige Kräfteverhältnis zwischen indigenen Organisationen, Regierungen und UN-Institutionen auf der einen sowie innerhalb der Gruppe der indigenen Akteure auf der anderen Seite. Es wurde deutlich, dass der Eintritt ins politische Feld der UNO, der als Ermächtigung marginalisierter Völker gefeiert wird, zu neuen Ein- und Ausschlussmechanismen innerhalb der sehr heterogenen Gruppe, die unter dem Begriff >Indigener subsumiert wird, führte. Die Dominanz und Legitimität bestehender Diskursmodelle konnte von ihren zentralen Akteuren bisher nicht durchbrochen werden.

\section{Prozesse der Isomorphisierung und Heteromorphisierung}

Das Forum bietet in der Praxis wenig Raum für lokale Stimmen. Vielmehr wird die Sprache der Indigenität in den Rahmen der UNO eingepasst, um sie mit diesem System kompatibel zu machen. Dies verdeutlicht das am Forum häufig gebrauchte Wort `mainstreaming`. Bestes Beispiel dafür ist die Wahl des Schwerpunktthemas der Millenniums-Entwicklungsziele für die Forumssitzungen der Jahre 2005 und 2006. Ein weiteres erklärtes Ziel prominenter Vertreter des Forums ist es, in Anlehnung an den UN-Fonds für Frauen (UNIFEM) oder den für Kinder (UNICEF), einen Fonds für Indigene zu

1 Für eine detaillierte Analyse der Erfolge der ersten UN-Dekade indigener Völker siehe Dahl 2005. 
schaffen (eigene Aufzeichnungen 16.05.2005). Ferner soll während der zweiten UN-Dekade indigener Völker (2005-2014) die Forderung nach einem diplomatischen Korps Indigener aufgestellt werden. Im ersten Jahrzehnt, so die Begründung, habe es eine Diplomatin, Rigoberta Menchú Tum, gegeben. Eine einzelne Person würde aber nicht ausreichen, um die indigenen Völker angemessen im UN-Kontext zu repräsentieren. Auch wenn viele Teilnehmer der Sitzungen betonen, dass für sie Themen wie >politische Partizipation ^oder >bewaffnete Konflikte< wichtig seien, wurden zum Beispiel die MillenniumsEntwicklungsziele vom Sekretariat und den Mitgliedern des Forums als zu diskutierendes Thema vorgegeben. Die Kenntnis der MDGs wird demnach zur notwendigen Voraussetzung für eine aktive Teilnahme an den entsprechenden Sitzungen. Das Forum verfolgt in diesem Sinne einen pragmatischen Ansatz: Die derzeit bestehenden UNO-Aktionspläne werden aufgegriffen und angeeignet, um eine indigene Präsenz in dem Bereich zu etablieren. Doch gerade eine Idee wie die Einrichtung eines UN-Fonds für Indigene oder die Ausrichtung an den Millenniums-Entwicklungszielen wirft die Frage auf, inwieweit indigene Politiker dadurch das Feld der UNO reformieren oder aber, im Gegenteil, von diesem Feld absorbiert werden. So werden im Forum die MDGs zwar kritisiert - zum Beispiel mit dem Argument, dass Armut als absolute Größe - »living with less than a dollar a day « - und nicht als ein Verarmungsprozess definiert würde, dem Indigene durch den Verlust ihrer straditionellen Siedlungsgebiete ausgesetzt werden. Dennoch wird das Forum durch seine Ausrichtung auf die UN-Entwicklungsrichtlinien von vielen älteren Teilnehmern als ein Forum für die sindigene Jugend ‘ bezeichnet, da es um das Thema >Entwicklung` ginge. Die indigene Agenda der >Gründergeneration< bestünde hingegen aus den Themen Selbstbestimmung und Landrechte (Gespräch Lázaro 21.06.2004). Vieles deutet darauf hin, dass in diesem Sinne am Forum einer `Entpolitisierung « der indigenen Bewegung Vorschub geleistet wird. Dies konstatiert zum Beispiel Matías Alonso, als er über die Aktivitäten des Sekretariats des Forums während seiner Zeit als Mitglied reflektiert:

»Ich denke, sie haben sich vor allem administrativen Aufgaben zugewandt, was bis zu einem gewissen Grad korrekt ist. Ich denke dennoch, dass das Politische marginalisiert wurde. Wenn ich vom >Politischen Themen für indigene Völker« (Interview Matías Alonso 19.05.2004).

Diese Einschätzung wird, wie im Kapitel V deutlich wurde, von vielen erfahrenen Teilnehmern des Forums geteilt. Das \Mainstreaming` indigener Interessen ist in diesem Sinne ein doppelt wirksamer Prozess: Man erreicht, dass Indigene als Zielgruppe in entwicklungspolitischen Programmen erscheinen, aber auch, dass ihre Organisationen die programmatischen Ziele der UNO und einflussreicher entwicklungspolitischer Organisationen übernehmen. Bei- 
de Phänomene - sowohl Sahlins (1993) postulierte »Indigenisierung der Moderne«, als auch die von Hannerz (1996) konstatierte »Modernisierung der Indigenität« - lassen sich somit am Ständigen Forum für indigene Angelegenheiten beobachten. In der Sprache der Organisationsethnologie können diese Prozesse als Isomorphisierung und Heteromorphisierung bezeichnet werden: Der Begriff `Isomorphisierung〈 dient der Beschreibung von Prozessen, in deren Verlauf sich unterschiedliche Institutionen bzgl. ihrer Organisationsstruktur und Kultur zunehmend ähnlicher werden. Die gegenteilige Entwicklung nennt Wimmer (2002: 80) »Heteromorphisierung«.

Mary Douglas (1989) vermerkt, dass Institutionen unsere Wahrnehmung kanalisieren, damit sie ins etablierte Klassifizierungssystem passen. Ein solcher Standardisierungsprozess des Indigenitätsdiskurses ist am Forum offensichtlich. Eine neue politische Gruppe hat es geschafft, in das Feld der internationalen Beziehungen - verkörpert durch die UNO - einzudringen, indem sie sich als >indigene Völker definierte. Sie hat, wie beschrieben, die Beitrittsrechte zu dieser zwischenstaatlichen Institution teilweise reformiert. Die jährlich wachsende Teilnehmerzahl am Forum beweist, dass das Label sindigen es sehr unterschiedlichen Akteuren ermöglicht, das politische Feld zu betreten. Doch einmal eingetreten, müssen die neu Hinzugekommenen ihren Diskurs dem Bestehenden anpassen. Zudem findet eine Trennung im Inneren des Feldes statt: Repräsentationsfachleute stehen Lokalpolitikern diametral gegenüber.

Ein weiteres markantes Beispiel für den Professionalisierungs- und Anpassungsprozess, bei dem sich verschiedene Klassen Indigener herausbilden, ist das Projekt »Indigenous to Indigenous Cooperation« des 1953 ins Leben gerufenen Saami Council (vgl. Javo 2004). Der Saami Council besitzt einen Beraterstatus am ECOSOC und stellt eine der leitenden Stimmen im Forum dar. Hinter dem Begriff >Indigenous to Indigenous Cooperation ‘ verbergen sich von der Organisation durchgeführte Entwicklungsprojekte in indigenen Gemeinden in Tanzania, Sierra Leone, Bangladesh, Indien oder auch Guatemala. Ein wichtiger Aspekt der Arbeit ist für Áile Javo, Mitglied des Saami Council und aktiver Teilnehmer an den Sitzungen des Ständigen Forums für indigene Angelegenheiten, die Förderung des Austauschs zwischen Saami und anderen indigenen Völkern. So schickt seine Organisation Praktikanten in die Projektregionen und lädt Bewohner dieser Gebiete im Gegenzug zu einem Aufenthalt in Mitgliedsgemeinden der Organisation ein. Áile betont, dass diese Art der Kooperation keine `Entwicklungshilfe « sei - auch wenn sie die Projekte in `Entwicklungsländern ` durchführten. Er bezeichnet es stattdessen als »Kooperation zwischen Indigenen«, im Zuge derer der Saami Council die Projektpartner mit dem notwendigen Fachwissen in den Bereichen Menschenrechte, Strategieentwicklung und Organisationsstärkung unterstütze (Javo 2004: 184 ff.). 
Der Einstieg indigener Organisationen in die internationale Entwicklungszusammenarbeit markiert zunehmend den Übergang zu einer neuen Schwerpunktsetzung innerhalb indigener Bewegungen. Hodgson (2002: 1088) beschreibt entsprechende Verschiebungen für die in den 1990er Jahren in großer Zahl gegründeten Maasai-Organisationen in Tanzania, die sich zuerst für Landrechte und soziale Gerechtigkeit einsetzten und sich später stärker an 〉Entwicklung « und Bereitstellung von Serviceleistungen wie Wasser- und Gesundheitsprojekten, Schulen etc. orientierten. Auch die Einschätzung älterer Teilnehmer der Arbeitsgruppe indigene Völker verdeutlicht diese Tendenz. Sie bezeichnen das Forum als >Plattform für die Jugend in der Auseinandersetzung mit Entwicklungsfragen<.

\section{Das Ständige Forum für indigene Angelegenheiten - ein selbstreferentieller politischer Mikrokosmos?}

Wenn es in der Politik darum geht, andere von der eigenen Weltsicht zu überzeugen, ist die UNO als zwischenstaatliche Einrichtung ein schwieriges Feld für indigene Lokalpolitiker. Die dem politischen Feld inhärente Tendenz zur Entwicklung eines Eigenlebens, der Abkoppelung von der sozialen Realität, tritt auf internationaler Ebene verstärkt zutage. Die notwendige Abstraktion der eigenen Lebenswirklichkeit, um Kommunikation mit anderen zu ermöglichen, führt dazu, dass kaum etwas anderes als Expertenseminare oder Strategiepapiere als Lösungsansätze am Forum produziert werden können. Zu hinterfragen bleiben die realen Möglichkeiten, die Verbindungen zwischen lokaler und internationaler Gemeinschaft (UNO) direkter und verbindlicher zu gestalten. Bezeichnend ist diesbezüglich die durchgängige Klage, dass es an der Umsetzung der Programme mangele. Dies hängt sicherlich auch eng mit der Stellung des Forums als beratendes Organ des ECOSOC, dem in der UNGründungscharta keine Durchsetzungsbefugnisse gegeben wurden, zusammen. Angesprochen auf Umsetzungsdefizite antworten die entsprechenden Redner beim Forum meist, dass die Umsetzung der in diesem Handlungsraum entwickelten Forderungen nicht in den eigenen Zuständigkeitsbereich falle. Gleichzeitig weisen sie entweder darauf hin, wer eigentlich die Realisierung der Programme und Normen in die Hand nehmen müsse, oder aber, dass ihnen vor allem ein offizielles Mandat zur Umsetzung fehle.

Jedes Feld ist, einmal institutionalisiert, primär daran interessiert, sich selbst zu reproduzieren. Das Ständige Forum für indigene Angelegenheiten stellt diesbezüglich keine Ausnahme dar. Die schwache Präsenz indigener ১Basisorganisationen` aus Lateinamerika legt auch einen weiteren Rückschluss nahe: Die UNO, die von vielen als wichtige Instanz der transnationalen panindigenen Bewegung dargestellt wird, besitzt derzeit keine hervorge- 
hobene Bedeutung für die regionale, nationale oder lokale indigene Selbstorganisation in Lateinamerika.

Das Forum stellt im Sinne Bourdieus (2001) einen relativ autonomen Mikrokosmos dar, der aber gleichfalls Entwicklungen widerspiegelt, die sich auch auf nationaler Ebene beobachten lassen. Dies gilt es im Folgenden im peruanischen Kontext zu untersuchen. 


\section{Teil 3: \\ Die indigene Bewegung im peruanischen Amazonasgebiet}

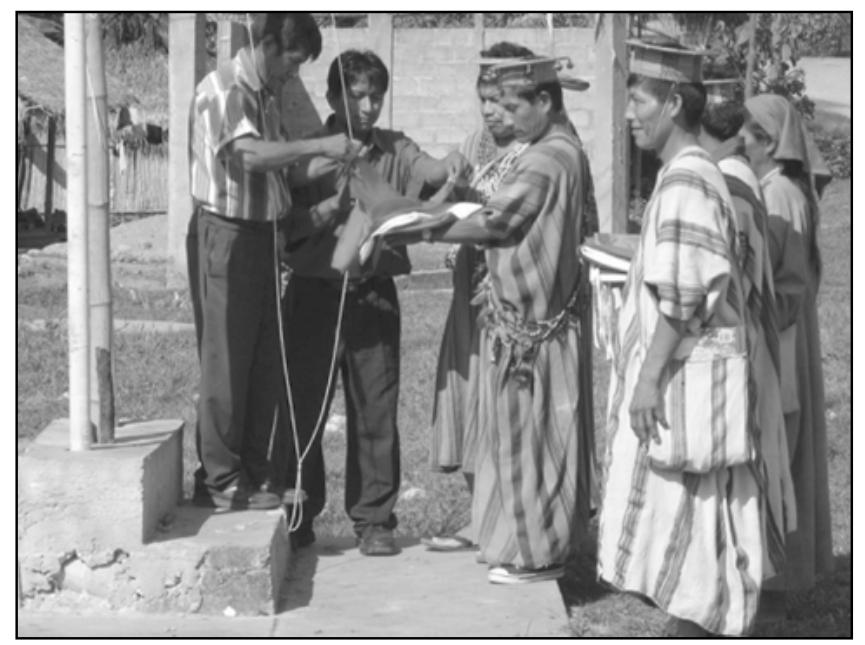

Abbildung 13: Asháninka in der Nähe von Satipo zu Beginn einer Versammlung ihrer Föderatin beim Hissen der peruanischen Nationalflagge und ihrer Organisationsflagge (Foto: Maren Rößler 2005). 



\section{Kapitel VII \\ Leitmotive: Politische Integration und kulturelle Abgrenzung}

»Wir sind schon Peruaner, wir unterstehen schon einer Staatsregierung, die uns aber nicht gehört. Deshalb müssen wir klug sein. [...] Wir müssen uns die Instrumente der westlichen Kultur aneignen, um unsere eigene Kultur zu stärken« (César Sarasara/Aguaruna, Präsident CONAP $\left.{ }^{1}, 21.01 .2004\right)$.

»[Die] indigene politische Arbeit [...] besteht aus dem Schutz des Gemeindelandes, dem Schutz der indigenen Rechte. Wir betreiben keine Parteipolitik [...] um zum Beispiel Präsident zu werden« (Haroldo Salazar/Asháninka, Vize-Präsident AIDESEP, 14.01.2004).

Vom 1. bis 3. Juli 1969 fand die erste Konferenz von Amuesha-Führern in Oxapampa, Selva Central, statt. ${ }^{2}$ Repräsentanten aus 20 Amuesha-Gemeinden trafen sich, um ein Memorandum an die peruanische Regierung zu schreiben. Die Idee für diese Zusammenkunft, so der damalige Peace Corps Mitarbeiter Richard Smith, sei in einem Gespräch mit einem zweisprachigen AmueshaLehrer entstanden. Folgende praktische Überlegungen lagen dem Treffen zu

1 Confederación de Nacionalidades Amazónicas del Perú; Dt. «Konföderation der Nationalitäten des Amazonasgebietes Perus`, eine der beiden nationalen Organisationen. Die andere ist die bereits im Kapitel IV.3 erwähnte Asociación Interétnica de Desarollo de la Selva Peruana (AIDESEP).

2 Die Amuesha nannten sich später in der politischen Repräsentation ihrer Organisationen >Yaneshar. Die Campa wiederum begannen, sich >Asháninka zu nennen. In beiden Fällen bedeuten die Begriffe (Yanesha und Asháninka) übersetzt «Menschen und stellen die Eigenbezeichnungen in Abgrenzung zu anderen ethnischen Gruppen oder den >Peruanern dar. Zu einer kritischen Auseinandersetzung mit der Benutzung der jeweiligen Etnonyme durch die Akteure der indigenen Bewegungen sowie ihre nicht-indigenen Unterstützer siehe Gow 2004. 
Grunde: Die bislang kaum offiziell erfassten, verstreut siedelnden Amuesha könnten dem Staat gegenüber kollektiv ihre Forderungen vortragen und Behördengänge sowie Projekte gemeinsam durchführen. Für staatliche Institutionen wiederum wäre es leichter, wenn sie die Angelegenheiten mit einer Gruppe von Repräsentanten und nicht mit jeder Gemeinde einzeln regelten (vgl. Smith 1969: 6).

Im Memorandum wurde die peruanische Regierung aufgefordert, die Siedlungsgebiete der Amuesha als gemeinschaftliche Schutzgebiete ${ }^{3}$ zu titulieren. Die Anwesenden wollten Folgendes erreichen:

- Schutz vor Landbesetzung durch Siedler aus den Anden,

- Möglichkeit der Inanspruchnahme von technischer Hilfe sowie Krediten,

- Möglichkeit der Bildung von Kooperativen zur Produktionssteigerung und Vermarktung,

- Möglichkeit, Schulgründungen zu beantragen.

Des Weiteren forderten die Unterzeichner des Dokuments die peruanische Regierung auf, den Amuesha die bürokratischen Vorgänge zur Beantragung von Personalausweisen zu erleichtern (Conferencia de Líderes Amuesha 1969: 13f.) Somit umfassten die Forderungen der Repräsentanten sowohl kollektive als auch individuelle Rechte. Sie traten als Sprecher einer ethnischen Gemeinschaft - dem »Stamm der Amuesha« (vgl. Memorarial 1969: 14) auf, die der peruanischen Nation gegenüber Sonderrechte geltend machte, ebenso als Staatsbürger, die einen verfassungsrechtlichen Anspruch auf Gleichstellung einforderten.

Die Art und Weise, wie die Konferenz zustande kam, zeigt, dass die Amuesha auf wichtige Verbündete bei der Bildung ihrer Zusammenschlüsse zählen konnten. 1953 siedelte sich das Summer Institute of Linguistics (SIL) ${ }^{4}$ in Oxapampa an und führte zweisprachigen Schulunterricht in den Gemein-

3 Span. reservas comunales.

4 Das SIL kam um 1950 nach Peru. Während die Institution in einigen lateinamerikanischen Staaten auf großen Widerstand stieß, was zum Beispiel zu ihrer Ausweisung aus Ecuador, Brasilien, Mexiko und Panama Ende der 1970er Jahre führte, pflegte die Organisation in Peru mit den verschiedenen Machthabern relativ gute Beziehungen. So konnte das SIL 1953 in Yarinacocha eine Ausbildungsstätte für zweisprachige indigene Lehrer eröffnen. Im ersten Kurs bildete es 15 Mitglieder sechs verschiedener ethnischer Gruppen aus, die zuvor die Grundschule besucht hatten und lesen sowie schreiben konnten. Gleichzeitig fing das SIL an, die einheimischen Sprachen mit Hilfe der ausgebildeten Lehrer $\mathrm{zu}$ verschriftlichen. Diese trugen wiederum die vom SIL verwendeten ethnolinguistischen Einteilungen in ihre Gemeinden zurück und übertrugen sie damit teilweise auf die Selbstdefinition der Gruppen - vor allem im Rahmen der Organisationsgründungen der 1970er Jahre (vgl. Greene 2004: 273 ff.; Lozano Vallejo 2000; 35f.). Die doppelte Aufgabe der Organisation - Mission und Linguistik - wird zum Beispiel von Stoll (1982) kritisch analysiert. 
den ein. Zusammen mit den Freiwilligen des Peace Corps waren die SILMitarbeiter die ausschlaggebenden Kräfte, um das Treffen zu ermöglichen (Santos Granero und Barclay 1998: 285). Aber auch die Ende der 1960er Jahre gebildete Militärregierung unterstützte die neuen indigenen Organisationsprozesse, welche an verschiedenen Orten im Amazonasgebiet begannen. Ihr übergreifendes Ziel war es dabei jedoch, den von ihr beanspruchten Teil des Amazonasbeckens unter staatliche Kontrolle zu bringen. Dem bei der Konferenz anwesenden Ethnologen Alberto Chirif lag hingegen vor allem die Einforderung kollektiver Rechte von Seiten der Amuesha - verstanden als Wahrung kultureller Eigenständigkeit - am Herzen (vgl. Chirif 1969). Er und viele seiner Kollegen hofften, diese sowie die anderen indianischen Gesellschaften des peruanischen Tieflands könnten möglichst viele Aspekte ihrer bisherigen Lebensführung beibehalten. $\mathrm{Zu}$ diesem Zweck stand für sie die Sicherung bzw. Rückgewinnung von Land im Zentrum der Bemühungen.

Die erste Konferenz der Amuesha-Führer steht exemplarisch für die Veränderungen politischer Organisationsformen der indianischen Tieflandgesellschaften in der zweiten Hälfte des 20. Jahrhunderts. Sie zeigt, dass die Aushandlung der Integrationsbedingungen Motivation und Auslöser der suprakommunalen Zusammenschlüsse war.

Der Begriff >Integration « deckt sich im nationalstaatlichen Verständnis in Lateinamerika meist mit dem der >Assimilation « und ruft deshalb ambivalente Reaktionen hervor. So bedeutet er laut Ramos (2002: 225) im brasilianischen Kontext in der offiziellen Auslegung die totale Verschmelzung der Indigenen mit der nationalen Gesellschaft. Ramos verweist aber auch auf die inhaltliche Umdeutung des Begriffs von Seiten einiger indianischer Repräsentanten, die damit sowohl gleich- als auch sonderrechtliche Forderungen verknüpfen. Wenn ich in dieser Arbeit im Zusammenhang mit der indigenen Bewegung im peruanischen Amazonasgebiet von Integration spreche, dann in seinen folgenden etymologischen Grundbedeutungen: `Zusammenschluss`, >Eingliederung s sowie die vom lateinischen Lehnwort integrāre abgeleitete Bedeutung >erneuern` (Etymologisches Wörterbuch des Deutschen 1995: 585). All diese Aspekte äußern sich in den rezenten Formen politischer Selbstorganisation von Seiten der indigenen Tieflandbewohner. Zusammenschluss und Eingliederung waren dabei Prozesse, die sowohl nach außen als auch nach innen Bedeutung erlangten. Die Unterstützerorganisation Survival International pries die (multi)ethnischen Föderationen in einer Presseerklärung zur Verleihung des alternativen Nobelpreises (1986) an den Aguaruna Evaristo Nugkuag ${ }^{5}$ mit

5 Nugkuag war maßgeblich an den indigenen Organisationsgründungen auf lokaler und nationaler Ebene in Peru sowie auf internationaler Ebene - bei der Gründung des panamazonischen Zusammenschlusses COICA - beteiligt. Er nahm den alternativen Nobelpreis im Namen vom Consejo Aguaruna Huambisa (der von ihm gegründeten Föderation), AIDESEP und COICA entgegen. 
folgenden Worten: »The formation of Indian organisations is a clear demonstration of the Amazonian peoples' ability to forget traditional feuding in order to promote the welfare of all tribes as a united group « (Survival International, 10.10.1986).

Das Zitat verdeutlicht die (romantisch eingefärbte) Außenwahrnehmung der Organisationsprozesse, die auf selbige zurückwirkte. Die neuen Repräsentationsinstanzen dienten auch dem (Gegen)Angriff auf das nationale Gemeinschaftsverständnis der staatslenkenden Eliten Perus. Jene setzten bis dato diskursiv auf die kulturelle Assimilation der Tieflandbewohner, bei einer gleichzeitigen Praxis der Diskriminierung. ${ }^{6}$ Die indianischen Gesellschaften des Amazonasgebietes wurden nicht als legitime politische Akteure in der nationalen Öffentlichkeit wahrgenommen. Die rezenten Organisationsprozesse stehen somit für eine Rebellion gegen politische Unsichtbarkeit im nationalen und internationalen Kontext (vgl. Ramos 2003a: 232).

Indigene Zusammenschlüsse verbanden zwei scheinbar widersprüchliche politische Forderungen: der Staat sollte ihren Mitgliedern als Individuen Integrationsangebote machen, gleichzeitig aber ihren suprakommunalen Zusammenschlüssen von $>$ Stämmen ${ }^{7}$ Autonomierechte einräumen (vgl. Santos Granero und Barclay 1998: 280). Somit forderten >Stammesgesellschaften $<$ den auf ihren Gebieten unerwünscht errichteten Nationalstaat auf, mit ihnen Kompromisse auszuhandeln. Die Eigendefinition als >Stamm`, >ethnische Gruppe $<$ oder später $>$ Volk $<$ wurde dabei zur Möglichkeit, ihre Forderungen auszudrücken, ohne von bestehenden Lobby-Institutionen (z.B. Bauerngewerkschaften) absorbiert zu werden (vgl. Brown 1993: 316). Die Verbände traten damit einem immer stärker werdenden Verdrängungsprozess entgegen. Anfang der 1970er Jahre lebten im peruanischen Tiefland ca. 1,5 Millionen Menschen, nur geschätzte 220.850 davon zählten sich zu einer der 65 ethnolinguistischen Gruppen. Diese Bevölkerungsminderheit war der aggressiven Kolonisierung sowie industrieller Ausbeutung der Rohstoffe des Amazonasgebietes ausgesetzt. Autonomie wäre auf Grund der mächtigen externen Interessen nur mit Gewalt einzufordern gewesen. Diese hätte wohl vor allem fatale Folgen für die Tieflandindianer gehabt. Zudem standen Anfang der 1970er Jahre mehr als siebzig Prozent von ihnen bereits in permanenten Handels- und Arbeitsbeziehungen zu Mitgliedern der nationalen Gesellschaft (Varese 1972: 11f.). Diese oftmals schon Jahrhunderte währende Kontaktsituation bewirkte

6 Bei >Assimilation` wird der Gegenüber angeglichen und soll mit der Gesellschaft verschmelzen - er verliert seine Besonderheit. Diskriminierung setzt hingegen auf die Betonung der differenten Aspekte des Anderen und dient dessen Ausgrenzung.

7 Span. tribu. Bezeichnung, die am Anfang der Organisationsgründungen noch verwendet wurde (vgl. z.B. Smith 1969). In den 1980er Jahren ersetzte man den Begriff durchgängig mit dem Wort \Volk«(pueblo). 
tiefgreifende Veränderungen in den indianischen Gesellschaften des Amazonasgebietes.

Wie hatte man die Tieflandindianer bis dahin von peruanisch-nationalstaatlicher Seite aus wahrgenommen? Vor allem in den ersten hundert Jahren seiner Existenz war Peru ein Staat ohne klares Nationsprojekt. Die rhetorischen Versuche der Zusammenführung wurden von der Realität überholt: Der Staat bestand aus vielen >Nationen $<$. Auch heute noch unterscheiden sich die Lebensrealitäten der Menschen in den Anden, an der Küste und im Amazonasgebiet tiefgreifend voneinander. Diese Unterschiede bestehen nicht nur zwischen, sondern auch innerhalb der Regionen und umfassen wirtschaftliche, soziale sowie kulturelle Aspekte. Die Bewohner des peruanischen Staatsgebietes kulturell zu einer Gemeinschaft zu vereinen, war, wenn überhaupt, immer nur ein zweitrangiges Projekt. Wie anders hätten die peruanischen Eliten zum Beispiel bis weit ins 20. Jahrhundert hinein davon ausgehen können, es handele sich beim Amazonasgebiet um eine nahezu unbewohnte Region? Wohl nur, wenn sie vergaßen, dass dort bereits potentielle `Staatsbürger lebten bzw. wenn sie annahmen, dass es sich bei diesen Menschen um >unzivilisierte Wesen handelte. Ihr Interesse galt aber von jeher den wirtschaftlichen Möglichkeiten, die vor allem eine Aneignung der natürlichen Ressourcen des Amazonasgebietes versprachen.

Die indigenen Andenbewohner - Quechua und Aymara - bezog man hingegen von Anfang an stärker als die Tieflandindianer ins koloniale und postkoloniale System ein. Aber auch sie wurden im 19. und beginnenden 20. Jahrhundert nicht als vollwertige Mitglieder einer gleichrechtlichen nationalen Gemeinschaft, sondern vielmehr als Hindernis für den >Fortschritt` des Landes betrachtet. Dabei übertrug man geografische Wahrnehmungen auf die Bewohner dieses Gebiets, deren Wesensart als >phlegmatisch`, >isoliert >traurig`stereotypisiert wurde (vgl. Orlove 1993).

Negative Stereotypisierungen der indigenen Tieflandbewohner als >Gottlose $\prec$, >Primitive $<$ oder $>$ Unzivilisierte $<$ prägten derweil nachhaltig die Fremdwahrnehmung sowie das Selbstbild einiger Gruppen und führten durch die permanente Kontaktsituation auch zur Selbststigmatisierung. Daraus resultierte manchmal der Wunsch, diese >Eigenschaften` abzustreifen (vgl. Gasché 1998: o.S.). Dass die Mitglieder der indianischen Gesellschaften des Tieflands sich die negative Fremdwahrnehmung nicht zu eigen machen, war einer der Beweggründe, aus dem peruanische Ethnologen, wie zum Beispiel Stefano Varese, Alberto Chirif, Margarita Benavides, Lucy Trapnell oder ihre ausländischen Kollegen wie Richard Smith, Thomas Moore, Andrew Gray, Anthony Stock und viele andere die indigene Selbstorganisation unterstützten. Sie wollten den Tieflandindianern helfen, kulturelle sowie politische Eigenständigkeit zu bewahren. Es stellt sich jedoch die Frage, ob die Vertreter der neuen indigenen Organisationen (oder auch die Mitglieder in den Dörfern) die 
gleichen Ziele wie ihre nicht-indigenen Unterstützer verfolgten; ob auch ihr Blick ein konservierender war, den \Schutz der Kulturen $>$ auf dieselbe Art fokussierend. Oder, ob nicht vor allem Begriffe wie >Wandel $<$ und >Aneignung ihre Bemühungen charakterisierten. Häufig traf ich während meiner Forschung Repräsentanten und Dorfbewohner, die mit Nachdruck und Stolz betonten: »Ich bin Asháninka« oder »ich bin Huitoto«. Im gleichen Atemzug versicherten sie, dass sie auch peruanische Staatsbürger seien und nicht zur Lebensform der Gruppen zurückkehren wollten, die auch heute noch in sogenannter >freiwilliger Isolation< leben. Greene (2004: 497) weist in seiner Studie zur Selbstorganisation der Aguaruna darauf hin, dass viele politische Repräsentanten zwischen >indios modernos` und $\nmid$ far away aguarunas unterschieden. Haben die >modernen Indianer` sich von ihrer >ursprünglichen $\mathrm{Kul}-$ tur entfremdet? Nur mit einem essentialistischen Verständnis von Kultur als Konglomerat starrer, unwandelbarer Traditionen könnte man diese Position vertreten. Tieflandexperten wie Erikson (1993, 1996), Fausto (1992), Viveiros de Castro (1992) oder Vilaça (1996) betonen, dass Wandel und >Aneignung/ des Anderen die soziale Reproduktion indianischer Tieflandgesellschaften bestimmen. Die Funktion indigener Zusammenschlüsse und ihrer Repräsentanten besteht also wohl eher darin, eine führende Rolle in der »Tradition des Traditionsbruchs« (Münzel 1993) einzunehmen. Dabei entstehen immer wieder neue Bündnisse, aber auch Spannungen sowie Differenzierungsprozesse innerhalb der organisierten Gruppen. Die von Survival International in den 1980er Jahren für >überwunden` erklärten >traditionellen Fehden` äußern sich in zeitgenössischen Formen.

\section{Eingrenzung der Forschungsergebnisse}

Für die folgenden Betrachtungen gilt: Wenn ich diese Form indigener Selbstorganisation im nationalstaatlichen Kontext global behandele, werde ich zwangsläufig der Heterogenität der Lebenswelten im peruanischen Amazonasgebiet nicht gerecht. Die unter dem vereinheitlichenden Begriff >indigen< oder >indianisch zusammengefassten Gesellschaften sind sehr unterschiedlich. Nicht alle sind gleichermaßen in das nationalstaatliche System integriert, nicht in allen Regionen haben sich im gleichen Umfang ethnische bzw. multiethnische Föderationen gebildet. Im Rahmen dieser Studie scheint es mir für analytische Zwecke sinnvoll, zwischen vier abgestuften Graden der Intensität des Kontaktes mit nicht-indianischen Akteuren zu unterscheiden. Hierfür greife ich eine Einteilung von Lehm (2003: 10f.) auf, die ich in einigen Details ergänze bzw. verändere. Dabei lege ich primär wirtschaftliche Aspekte sowie die Nähe bzw. Zugangsmöglichkeiten zu urbanen Zentren als Unterscheidungsmerkmale zugrunde. In vielen Fällen wirkt sich diese relative Nähe bzw. Distanz zu Städten aber auch auf Aspekte wie die politische und soziale 
Organisation sowie Sprachgewohnheiten (bilingual/monolingual) aus. Die Übergänge zwischen den vier eingeteilten Gruppen sind relativ fließend und deshalb am besten als Kontinuum vorstellbar:

- indianische Bevölkerung in urbanen Zentren; stehen in Lohnarbeit oder arbeiten als Straßenhändler.

- indianische Gemeinden, die an Straßen oder stark frequentierten Flüssen liegen, in denen auch Siedler aus dem Anden- und Küstenraum leben; die Bewohner leben von selbst angebauten Produkten und produzieren für den Markt oder stehen in Lohnarbeit; sie können auf Grund von Landmangel nur eingeschränkt Jagd- und Sammeltätigkeiten nachgehen; auch wenn ihnen günstige Transportmittel zur Verfügung stehen, können sie ihre Produkte in den Städten meist nur zu niedrigen Preisen verkaufen.

- indianische Gemeinden in relativer Entfernung zur nächsten Stadt; leben größtenteils von der Subsistenzwirtschaft durch Brandrodungsfeldbau und einer Kombination aus Jagd, Fischfang und Sammeln; produzieren oftmals auch kleine Mengen für den Markt. Den Bewohnern stehen meist größere zusammenhängende Territorien zur Verfügung; keine oder geringe Durchmischung der Bevölkerung mit Siedlern aus anderen Landesteilen.

- nicht-kontaktierte Gruppen, die vor allem vom Sammeln und Jagen leben und sozio-politisch unabhängig sind. Es wird geschätzt, dass gegenwärtig ca. 20 solcher Gruppen im Grenzgebiet zwischen Peru und Brasilien sowie zwischen Peru und Bolivien leben. Rummenhöller (2005: 10) weist darauf hin, dass >nicht-kontaktiert nicht synonym $\mathrm{zu}$ >unberührt` oder sursprünglich $\mathrm{zu}$ verstehen ist. Wahrscheinlich haben sich die entsprechenden Gruppen durch negative Erfahrungen (z.B. Kautschukboom, Aggression von Holzfällern etc.) für Rückzug und Kontaktvermeidung mit der Nationalgesellschaft entschieden. Es ist jedoch belegt, dass sie Metallgegenstände sowie andere Güter meist friedlich von benachbarten Siedlern oder Holzfällergruppen entwenden.

Im Rahmen meiner Forschung habe ich verschiedene Gemeinden der Asháninka, Huitoto (sowie Bora, Yagua und Ocaina) und Cocama-Cocamilla besucht, die sowohl der zweiten als auch der dritten Kategorie zuzuordnen sind. Einige indigene Organisationen treten gegenwärtig verstärkt als Fürsprecher für die vierte Gruppe auf, während die erste Gruppe von den $\mathrm{Zu}$ sammenschlüssen in ihrer politischen Ausrichtung nicht berücksichtigt wird. Die von mir besuchten Dörfer liegen in zwei unterschiedlichen geografischen Zonen des Amazonasgebietes: Die Asháninka-Dörfer befinden sich in der ceja de selva ${ }^{8}$. Mit diesem Ausdruck bezeichnet man den Ostabhang der An-

8 Dt. «Augenbraue des Waldes`. 
denkordillere von 2000 bis 1000 m Höhe. Das Gebiet besteht aus einer dicht bewaldeten, zerklüfteten Hügellandschaft, zwischen denen die Flüsse tiefe Schluchten gegraben haben. Unterhalb von $1000 \mathrm{~m}$ beginnt die sogenannte selva baja ${ }^{9}$. Dort siedeln die von mir besuchten Huitoto (sowie Bora, Yagua und Ocaina) und Cocama-Cocamilla. Diese Tiefebene ist von einem dichten Netz von Flüssen und Flussarmen durchzogen. Insgesamt macht das Amazonasgebiet sechzig Prozent des nationalen Territoriums Perus aus, mit einer relativ geringen Bevölkerungsdichte von elf Prozent, die sich vor allem in den großen Hafenstädten wie Iquitos, Pucallpa oder Puerto Maldonado konzentriert. Wie in anderen Ländern Lateinamerikas auch konzentrieren sich die meisten Einwohner Perus in der an der Küste gelegenen Hauptstadt Lima.

\section{Ethnografische Daten}

Im Folgenden möchte ich kurz einige Aspekte der Geschichte, sowie der sozialen und politischen Besonderheiten der Asháninka, Cocama-Cocamilla und Huitoto darstellen, um die Heterogenität der Lebenswirklichkeiten eines Großteils meiner Gesprächspartner exemplarisch zu verdeutlichen.

\section{Asháninka (Campa)}

Die zur Arawak-Sprachfamilie gehörenden Asháninka siedeln hauptsächlich am Ostabhang der peruanischen Anden. Seit den 1980er Jahren hat sich im Zuge der Selbstorganisation im nationalstatlichen Kontext die Bezeichnung Asháninka unter einem Großteil der zuvor im Spanischen Campa genannten Gruppen durchgesetzt ${ }^{10}$. Man unterscheidet sieben Hauptgruppen: Campa Asháninka, Campa Pajonalino (Ashéninka), Campa del Alto Perené (Ashéninka), Campa Nomatsiguenga (Matsiguenga), Campa del Pichis, Campa Caquinte und Campa Ucayalino (Ashéninka). Dabei bilden die Campa Asháninka mit einer Bevölkerungsstärke von 40518 Menschen die größte Gruppe (INEI und UNICEF 1997: 13). ${ }^{11}$ Die Asháninka sind bekannt für ihren über Jahrhunderte dauernden Widerstand gegen die europäischen Kolonisierer. So entzogen sie sich lange Zeit den in ihre Gebiete eindringenden Franziskanern und befreiten 1742 das zentrale Tiefland in der von Juan Santos Atahualpa geleiteten millenaristischen Bewegung für über ein Jahrhundert von der Fremdherrschaft (vgl. Brown 1991). Mit Gründung der Peruvian Corporation 1889 änderte sich ihre Situation jedoch auf dramatische Weise. Zum Abbau externer Schulden, die der Staat im Zuge seines Krieges mit Chi-

9 Dt. >Tiefer Wald.

10 Zur Problematisierung dieser >Umbenennung« im Zuge der Herausbildung ihrer politischen Organisationen siehe Gow 2004.

11 Damit sind sie nach den Aguaruna (45 137 Personen) die größte indigene Gruppe des peruanischen Tieflands. 
le angesammelt hatte, wurden zwei Millionen Hektar Land entlang der Flüsse Perené und Ené an eine englische Firma abgetreten. Nach der Übergabe des Landes rentdeckter man, dass darauf Amuehsa (Yanesha) und Campa (Asháninka) siedelten, die der Firma als $>$ Besitz automatisch mit überschrieben wurden (Chirif und Mora 1977: 32). In der Folge drangen Industrie und Siedler massiv in das Gebiet der Asháninka vor. Im Zuge des Kautschukbooms im frühen 20. Jahrhundert wurden weitere Asháninka-Gruppen in groBem Umfang zur Zwangsarbeit herangezogen. Epidemien reduzierten ihre Bevölkerungszahlen. Ab Mitte des 20. Jahrhunderts breitete sich das SIL und andere evangelikale Missionen in ihrem Siedlungsgebiet aus (Flowers 1994a: 90f.; vgl. auch Santos Granero und Barclay 1998) .

Die von mir besuchten Dörfer liegen um die Stadt Satipo und entlang des río Tambo. Ihre Einwohner gehören zur Gruppe der Campa Asháninka. Die Bewohner lassen sich gegenwärtig der 2. und 3. Kategorie in Bezug auf ihre relative Integration in die nationale Gesellschaft zuordnen. Vor allem in den Dörfern in unmittelbarer Umgebung von Satipo gehören Konflikte mit Siedlern aus anderen Landesteilen und Landknappheit (auch auf Grund von zunehmender individueller Parzellierung des Gemeindelandes) zu den dringlichsten gegenwärtigen Problemen. Traditionell lebten die Asháninka dieser Region in kleinen, semi-nomadischen Gruppen, in denen die Familienoberhäupter als politische Autoritäten fungierten. Die ungünstige Bodenbeschaffenheit (die Kombination von teilweise steilen Hängen und hohen Niederschlägen führt zu Erosionsgefahr) und die besondere Bedeutung der Jagd prägten ihre Lebensweise. Handel mit anderen Gruppen war immer ein zentraler Bestandteil ihres wirtschaftlichen Systems. Heute siedeln viele in größeren Dörfern, bauen unter Anwendung des Brandrodungsfeldbaus unter anderem Mais, Reis, Bohnen, Kaffee und Zitrusfrüchte an und betreiben teilweise Viehzucht. Viele Bewohner der Gemeinden am Tambo verbringen jedoch Teile des Jahres weiterhin in Häusern weit abgelegen im Wald. So bilden die Einzelfamilien zwar zusammen Dörfer, aber in Form einer eher flexiblen sozialen Einheit. Diese Unabhängigkeit wird nur in Krisenzeiten zu Gunsten eines Bündnisses unter der Leitung einer starken Führungspersönlichkeit aufgegeben (Flowers 1994a: 90f.; vgl. auch Lindig und Münzel 1978: 174f.). In den 1980er und 90er Jahren breitete sich die terroristische Gewalt des Leuchtenden Pfades in diesem Teil des Tieflands aus. Die Folgen für viele Asháninka waren wiederum verheerend. Jedoch zeigten sie erneut ihre politische Mobilisierungsstärke und Widerstandskraft, indem viele Dörfer zum Mittel der Selbstverteidigung griffen und die Terroristen aktiv bekämpften. 


\section{Cocama-Cocamilla}

In Peru ${ }^{12}$ leben die meisten Cocama in den breiten Tälern der selva baja, an den Flussläufen des Marañón, Pastaza, Nucuray und Uritiuyacu. Die am Huallaga siedelnden Gruppen werden Cocamilla genannt. Der letzte Zensus von 1993 gibt ihre Bevölkerungsstärke mit 10705 Personen an (INEI und UNICEF 1997: 13). Die Cocama gehören zur Sprachfamilie der TupíGuaraní. Neuere Studien belegen, dass sowohl die Cocama als auch die benachbarten Omagua vor der Kolonialzeit in großen Siedlungen mit sozialer Stratifizierung und zentralisierter Führung lebten: Jede Ansiedlung besaß eine ständige Autorität und mehrere zusammen einen übergeordneten Chef. Ein System der Arbeitsteilung bildete sich heraus, bei dem eine untergeordnete >bäuerliche`Klasse für die Mitversorgung der Spezialisten (politisch/religiös) verantwortlich war. Soziale Stratifizierung und Arbeitsteilung waren durch eine über das Subsistenzminimum weit hinausgehende Produktion von Lebensmitteln möglich. Der Überschuss wurde in Lagern konserviert und das Jahr über verbraucht (Chirif 2003: 16). Die Cocama kamen bereits 1549 bei einer von Juan de Salinas geleiteten Expedition mit den Spaniern in Kontakt. Im 17. Jahrhundert waren sie sowohl von Spaniern als auch von benachbarten Gruppen für ihre Raubüberfälle gefürchtet. Sie schlossen sich einer Rebellion der Jebero im Jahr 1644 an. Die Spanier unternahmen zahlreiche Versuche, die Cocama zu besiegen, und Jesuiten drangen in ihre Siedlungsgebiete ein, um sie zu missionieren. Eine Pockenepidemie reduzierte schließlich drastisch die Bevölkerung. Nachdem die Jesuiten 1767 aus Peru ausgewiesen wurden, wurden die Cocama zur Arbeit auf großen haciendas und in der Holzindustrie gezwungen. Anfang des 20. Jahrhunderts hatten auch sie unter dem Kautschukboom zu leiden. Heute sprechen nur noch wenige Cocama ihre eigene Sprache, viele haben erst im Zuge der rezenten Organisationsgründungen wieder angefangen, sich selber als Cocama zu bezeichnen. Sie leben in Dörfern, die zwischen 100 und 500 Personen umfassen. Die (erweiterte) Kernfamilie bewohnt zusammen ein Haus. In den breiten Tälern, in denen sie siedeln, sind die Bedingungen für Landwirtschaft relativ günstig: Die Cocama sind heute sesshafte Brandrodungsfeldbauern, die unter anderem Mais, Süßkartoffeln, Bohnen, Yams, Bananen, aber auch Baumwolle und Tabak anpflanzen (vgl. Flowers 1994b: 130). Kommerzieller Fischfang und Holzschlag gehören jedoch bei vielen von ihnen mit zu den zentralen wirtschaftlichen Aktivitäten. Sie stehen dabei weiterhin meist in Abhängigkeit von lokalen $p a-$ trones (Chirif 2003: 23). Die von mir besuchten Cocama-Cocamilla siedeln am Rand bzw. innerhalb des Nationalparks Pacaya Samiria (vgl. Prolog).

12 Einige wenige Cocama leben in Kolumbien und Brasilien (Flowers 1994b: 130). 


\section{Huitoto}

Ursprünglich siedelten die Huitoto zwischen dem Putumayo und Caquetá im heutigen Kolumbien. Um 1910 wurden viele Hunderte von ihnen (zusammen mit Bora und Ocaina) an den Ampiyacu und eine kleinere Anzahl bis an den Nanay in unmittelbarere Nähe der Stadt Iquitos verschleppt, wo sie von den patrones unter Anwendung der Schuldknechtschaft zur Kautschukgewinnung sowie später zur Rodung von Edelhölzern gezwungen wurden. Das Huitoto bildet eine eigene Sprachfamilie, zu der zum Beispiel auch die Sprachen der Bora, Ocaina und Muinane gezählt werden. Während sie Anfang des 20. Jahrhunderts noch ca. 50000 Menschen umfassten, wurde ihre Bevölkerung im Zuge des Kautschukbooms auf 7000 bis 10000 reduziert. Heute leben in Peru ca. 1900 Huitoto am Ampiyacu, Putumayo und Nanay. Die Huitoto kultivieren bitteren und süßen Maniok im Brandrodungsfeldbau. Daneben pflanzen sie unter anderem Bananen, Yams, Süßkartoffeln, Papaya, Erdnüsse, Kakao, aber auch Tabak und Coca an. Jagd und Fischfang vervollständigen ihre Subsistenzwirtschaft. Heute produzieren sie kleinere Mengen für den Markt und beteiligen sich auch an der Holzwirtschaft und kommerzieller Tierjagd. Historische Dokumente belegen, dass die politische Organisationsform der Huitoto relativ komplex und hierarchisch war: Die politische Grundeinheit bildete das Dorf mit einer Einwohnerstärke von 25 bis 500 Personen, in dem mehrere patrilineare Abstammungsgruppen zusammen siedelten. Die malocas (Gemeinschaftshäuser) $^{13}$ dominierten das Siedlungsbild. In diesen spielte sich das soziale und zeremonielle Leben des Dorfes ab. In jeder Siedlung gab es einen Vorsteher, dessen Autorität jedoch nicht über die Dorfgrenzen hinausreichte. Sein Amt erbte er vom Vater oder Bruder nach Zustimmung durch den Ältestenrat des Dorfes. Eine Reihe von Dörfern schloss sich in einer Föderation unter Leitung eines chiefs zusammen. Kriegerische Auseinandersetzungen zwischen Dörfern bzw. Föderationen waren relativ häufig. Auch gegenwärtig besitzt die Einteilung in mehr oder weniger prestigeträchtige patrilineare Abstammungsgruppen vielerorts weiterhin eine relativ große Bedeutung für die soziale Organisation (FORMABIAP-AIDESEP 2005: 251ff.; Flowers 1994c: 364f.).

\section{Zielsetzung}

Nach diesem kurzen, exemplarischen Einblick in Geschichte und Organisation der von mir besuchten Gruppen, möchte ich erneut darauf hinweisen, dass es mir in dieser Studie nicht darum geht, an objektiven Kriterien den

13 Früher waren die malocas die Wohnhäuser des Kerns einer patrilinearen Abstammungsgruppe: In ihr wohnten das Familienoberhaupt mit seiner Frau, seinen Kindern und den Ehefrauen seiner Kinder sowie den Enkelkindern. 
Grad der >Indigenität` der Gruppen festzustellen, die politische Zusammenschlüsse auf Grundlage >kultureller Kriterien` gründen. Vielmehr steht für mich in diesem Teil des Buches die Frage im Vordergrund, für wen, unter welchen Umständen und in welcher Form >Indigenität` als politische Handlungsressource im lokalen und nationalen Kontext an Bedeutung gewinnt. Festhalten möchte ich ferner Folgendes: Die Genese indigener Verbände ist zwar ein globales, nicht aber ein gleichförmiges oder flächendeckendes Phänomen. Sie wurde (und wird) beeinflusst von den regional unterschiedlichen historischen und gegenwärtigen politischen und sozialen Bedingungen sowie den kulturellen Besonderheiten der sich zusammenschließenden Gruppen. Dennoch lassen sich allgemeine Tendenzen aufdecken und grundlegende Gemeinsamkeiten der Organisationsprozesse finden. Mir geht es um die Darstellung und Analyse dieser Aspekte. Zentrale Bedeutung erlangen deshalb auch die Einschätzungen, die Dorfbewohner, Repräsentanten und ihre nichtindigenen Unterstützer in Bezug auf die Organisationen sowie deren Vertreter vornehmen. Mein Ziel ist es dabei nicht, indigene Organisationen und ihre Protagonisten selbst normativ zu (be)werten. Damit würde ich kaum den Akteuren und den komplexen historischen Prozessen gerecht. Aus meiner Sicht spiegeln die Einschätzungen hingegen Erwartungen und Ansprüche wider, die von unterschiedlichen Seiten an die Zusammenschlüsse und deren Repräsentanten gerichtet werden. Sie verdeutlichen die Idealbilder politischer Macht und Repräsentation und zeigen die Brüche zwischen und Überlagerungen von verschiedenen gesellschaftlichen Formationen, deren Mitglieder in einem diffusen, asymmetrischen Machtverhältnis zueinander stehen.

Ich möchte zeigen, wie die Akteure indigener Bewegungen den an sie gerichteten Hoffnungen und Forderungen nachkommen oder auch nicht; von wem sie dabei jeweils abhängen, welche eigenen Interessen sie verfolgen können und welche Konsequenzen ihr politisches Engagement im interethnischen Kontakt nach sich ziehen kann. Ich möchte die unterschiedlichen politischen Legitimationsmodelle sichtbar machen, nach denen sich die Repräsentanten indigener Zusammenschlüsse auf den verschiedenen Organisationsebenen richten müssen. Durch die Veranschaulichung dieser Thematik, so meine These, wird auch das spannungsgeladene Verhältnis zwischen >Profis` und >Laien` im politischen Feld der indigenen Repräsentanten auf internationaler Ebene verständlicher.

Ich werde mich deshalb den indigenen Organisationsprozessen aus verschiedenen Perspektiven nähern. Zunächst konzentriere ich mich auf die historische Makroebene, um Kontinuitäten und Brüche in der Gestaltung der interethnischen Beziehungen sichtbar zu machen. Dabei setze ich zwei Schwerpunkte: die Entwicklungen im Amazonasgebiet sowie die gesamtgesellschaftlichen Debatten um den Status indigener Bevölkerungsgruppen. Danach betrachte ich, aus einer stärker soziologisch und politologisch geprägten Per- 
spektive, die Genese indigener Organisationen im nationalen Kontext. So finden am empirischen Beispiel die theoretischen Ausführungen zum Phänomen >soziale Bewegungen< ihre Bestätigung (vgl. Kapitel II.1): Markante Abgrenzungs- und Differenzierungsprozesse, unter anderem in Form von Fraktionsbildungen und Schismogenese, prägen die Herausbildung und Institutionalisierung indigener Zusammenschlüsse im peruanischen Tiefland. Schließlich übernehme ich die `klassischeく, auf den Mikrokosmos fokussierte Blickrichtung der Ethnologie, welche die Überlagerung verschiedener Legitimationsmodelle politischer Macht am besten zu erfassen versteht. Jedes Kapitel beleuchtet somit eine unterschiedliche Facette indigener Organisationsprozesse im nationalstaatlichen Kontext und erweist sich als fundamentaler Baustein einer `Ethnologie indigener Bewegungen〈, welche die politische Bedeutung neuer Formen indigener Selbstorganisation jenseits ideologisch geprägter Debatten adäquat zu erfassen versucht (vgl. Kapitel II.4). 



\section{Kapitel VIII \\ Ein- und Ausschlussprozesse im kolonialen und nationalen Kontext}

»[...] Peru bildet nur auf der Landkarte eine Einheit« (Chirif 1969: 8; eigene Übersetzung aus dem Spanischen).

Seit der Kolonialzeit diente das peruanische Amazonasgebiet verschiedenen politischen Projektionen: Es war das »El Dorado«, die letzte »frontier«, Schauplatz von Grenzkonflikten, die »Kornkammer« der Nation oder schlicht der »Devisenbringer« (vgl. Chaumeil 1990: 95). Im Folgenden steht die koloniale und postkoloniale Geschichte Perus im Zentrum der Betrachtungen. Ein besonderer Fokus liegt dabei auf dem Umgang der Herrschenden mit den Tieflandindianern in den verschiedenen Epochen. Die komplexen, asymmetrischen Austauschbeziehungen, welche die Herausbildung neuer politischer Führungspersönlichkeiten innerhalb der indianischen Gesellschaften des Amazonasgebietes prägten, bilden den historischen Kontext für die Entstehung der indigenen Organisationen. Anknüpfend an Eric Wolf (1986: 532) bin ich der Meinung, dass man die wechselseitigen Beziehungen zwischen indigenen Tieflandbewohnern und externen Akteuren nur begreifen kann, wenn man auch von den politischen und ökonomischen Beziehungen ausgeht, die diese Verbindungen hervorgebracht, verändert und aufrecht erhalten haben. Deshalb habe ich mich für eine relativ ausführliche Darstellung des historischen Kontexts seit der Kolonialzeit entschieden. Zudem erscheint es mir zur umfassenden Kontextualisierung der neuen Formen indigener Selbstorganisation wichtig, im Anschluss an den geschichtlichen Abriss kurz auf den peruanischen Indigenismus und Indianismus einzugehen. 


\section{Die Kolonialzeit}

In der kolonialen Ordnung Perus wurden historisch bedingte rassische Unterschiede zwischen Personen betont. Das legale und administrative System der Kolonialzeit basierte auf der Einteilung in verschiedene castas $^{1}$ : Spanier, indios, Afrikaner und die gemischte casta. Individuen wurden auf Grund der Zugehörigkeit ihrer Eltern zu einer dieser Gruppen gezählt. Die indios des Hochlands definierte man dabei als unterworfenes Volk, mit einem inferioren administrativen Status und einer Reihe von Verpflichtungen gegenüber dem Staat. Sie bildeten die Bevölkerungsmehrheit, ihre Kopfsteuer sowie Arbeitskraft hielt die koloniale Wirtschaft aufrecht. Die Tieflandbewohner standen als >Wilde $<$ außerhalb des Systems. Sie gerieten jedoch unter den direkten Einfluss der Missionen von Jesuiten (1638-1768) und Franziskanern, welche die indios infieles (>ungläubigen Indianer $`$ ) >zivilisieren` wollten. Sie führten das Modell der reducciones im Amazonasgebiet ein. Hiermit wurden die Tieflandbewohner nicht nur in feste dörfliche Gemeinschaften >reduziert<, sondern auch zum Christentum bekehrt. Dadurch entstanden die ersten extern vorgenommenen Differenzierungen in >Christen zeichnete auf pejorative Weise die nicht-konvertierten >Wilden $<$. Damit einhergehend schufen die Missionare eigene lokale Regierungsstrukturen, welche die ersten großen Veränderungen in den politischen Systemen der indianischen Gesellschaften des Amazonasgebietes markierten: Es wurden formale Führungsposten geschaffen und die Figur des Vermittlers (Brokers) eingeführt. Im politischen Ordnungsprinzip von Jesuiten und Franziskanern erlangte dabei der curaca zentrale Bedeutung - ein von den Missionaren bestimmter Indianer, der Spanischkenntnisse besaß und auf Grund einer besonders >gelungenen< Konversion als >vertrauenswürdig \&alt. Im Innern der neu geordneten Gruppen bestanden jedoch auch zuvor praktizierte Führungssysteme, die meist informeller Art waren, weiter. An unterschiedlichen Orten im Amazonasgebiet kam es immer wieder zu Rebellionen gegen die fremden Ordnungskräfte. Vielen Aufständen lag eine Mobilisierung von beträchtlichem Umfang zugrunde. So schlossen sich bei der von Juan Santos Atahualpa geführten messianischen Bewegung mehrere ethnische Gruppen zusammen Piro, Campa (Asháninka), Amuesha (Yanesha), Conibo und Shipibo. Sie schafften es, das zentrale Tiefland für über ein Jahrhundert (1742-1850) von den Kolonialmächten zu befreien. ${ }^{2}$

1 Dt. \Kaste<; in der Bedeutung, die es im Kontext dieser Einteilung im damaligen Spanisch annahm, aber mit $>$ Rasse $<$ zu übersetzen.

2 Andere bekannte Beispiele für Rebellionen indianischer Tieflandgesellschaften waren die der Cocama, Avijiras, Oas von 1664-67, der Shipibo-Conibo im Ucayali 1695/98, sowie verschiedene Aufstände der Aguaruna (vgl. Chaumeil 1990; Greene 2004). 
Nach der Ausweisung der Jesuiten 1768 und bis zur Ausrufung der Unabhängigkeit 1821 drangen verstärkt nicht religiös, sondern vor allem wirtschaftlich motivierte Siedler ins Amazonasgebiet vor. Sie übernahmen die von den Missionaren eingeführten sozio-politischen Strukturen: Die lokalen curacas fungierten weiterhin als zentrale Vermittlerfiguren zwischen den neuen und den alten Bewohnern des Tieflands. Es etablierte sich ein Patronage-System $^{3}$, das sich Stück für Stück über das gesamte peruanische Amazonasgebiet ausbreitete und die Beziehungen zwischen beiden Gruppen lange und nachhaltig prägte (vgl. Chaumeil 1990: 95f., 106f.; vgl. auch Stocks 1981).

\section{Der junge Nationalstaat}

Eine der ersten gesetzlichen Maßnahmen nach der Loslösung Perus von der spanischen Krone im Jahr 1821 war die formale Abschaffung des Kastensystems. Verdeckt durch die offizielle Gleichstellung der indigenen Bevölkerung erfolgte jedoch weiterhin eine rassische Einteilung, die sich nun an drei geografischen Regionen orientierte: Küste, Hochland, Tiefland. Der Kategorisierung zufolge lebten an der Küste die >Peruaner<. Im Hochland siedelten hingegen weiterhin die indios. Dieser Begriff stand synonym für >Fortschrittshemmnis $\prec$. Dem Verständnis der machthabenden Eliten zufolge blockierten die indios die nationale Integration. Letztere verstand man primär wirtschaftlich, als Bewegung von Gütern aus dem Tiefland an die Küste, die durch das bergige Gebiet der Anden erschwert wurde. Die Bewohner des Amazonasgebietes, zu Kolonialzeiten indios infieles, wurden nun $\mathrm{zu}>$ Ureinwohnern ihre Gemeinschaften >primitive Stämme genannt. Damit standen sie in der sozialen Hierarchie noch unterhalb der Quechua und Aymara des Hochlands. Das frühe Nationsprojekt zielte nicht primär auf die Schaffung einer alle Bevölkerungsgruppen umschließenden imagined community (Anderson 1983), sondern auf die wirtschaftliche Erschließung des >Hinterlands` ab. Das Amazonasbecken wurde in der Imagination der Eliten zur peruanischen frontier einem gefährlichen Ort großen Reichtums, den es zu erobern und zu besiedeln galt (Orlove 1993: 321 f.; von Oertzen 1988: 57ff.; vgl. auch Santos Granero und Barclay 2000).

Durch Industrialisierung und weltweite Ausbreitung des Kapitalismus entstanden neue Möglichkeiten, die Bodenschätze des Amazonasgebietes ge-

3 Nicht formalisierter, asymmetrischer Austausch zwischen ungleichen Partnern (Patron und Klient). Der Patron verfügt über wichtige Ressourcen (materielle und symbolische), zu denen der Klient keinen direkten Zugang hat. Getauscht werden meist Dienstleistungen und/oder Loyalität (von Seiten des Klienten) gegen Güter (von Seiten des Patrons). 
winnbringend auszuschöpfen. Die Zentralregierung zeigte dementsprechend ein großes Interesse an der Integration seiner frontier in die nationale Wirtschaft und traf schon kurz nach der Unabhängigkeit von Spanien entsprechende Maßnahmen. Durch Gesetze, die Kolonisierung, Landwirtschaft und Handel im Amazonasgebiet unterstützten, antwortete man damit aber auch auf zwei geopolitische Herausforderungen: erstens, die brasilianische Expansion nach Westen, die es zu stoppen galt und zweitens, die ecuadorianischen sowie kolumbianischen diplomatischen Ansprüche auf Teile der peruanischen Amazonasregion, die man neutralisieren wollte. ${ }^{4}$

Ab Mitte des 19. Jahrhunderts erleichterte die Einführung von Dampfbooten auf dem amazonischen Flussnetz den Handel, und der Ende des Jahrhunderts einsetzende Kautschukboom (1885-1914) festigte das Interesse des Staates an der Nutzung der natürlichen Ressourcen im Tiefland. Man öffnete das Gebiet ebenso für englische und nordamerikanische Unternehmen. Vor allem der Kautschukboom hatte fatale Folgen für die Tieflandindianer. Die beiden großen \Kautschukbarone` Arana und Fitzcarrald errichteten Handelsreiche, die auf Sklavenhaltung beruhten. Die Arbeitskraft besorgten sie sich unter anderem mit Hilfe sogenannter correrías. ${ }^{5}$ Ferner festigten sich die PatronageBeziehungen durch die Einführung des Systems der habilitación. Dieses bestand in einem vom Händler geleisteten Vorschuss an Waren, der durch Arbeitskraft zurückgezahlt werden musste. Der asymmetrische Austausch beruhte auf einer konstanten Verschuldung von Seiten der Arbeiter. Zwei Wirtschaftslogiken trafen aufeinander: Die indigenen Tieflandbewohner wollten 'westliche< Güter für ihr internes Tauschsystem, Ziel der patrones war es, möglichst kostengünstig ihr Vermögen zu mehren (Santos Granero und Barclay 2000: 37, 54f.). Die meisten Gruppen, die so in Abhängigkeit gerieten, konnten sich davon erst durch die endgültige politische Einbindung in das staatliche System ab Mitte des 20. Jahrhunderts weitestgehend befreien.

Die `Peruaner` an der Küste erfuhren wenig von den Vorgängen im Amazonasgebiet. Die Existenz Dutzender indianischer Tieflandgesellschaften trat bis in die zweite Hälfte des 20. Jahrhunderts hinein selten ins Bewusstsein der peruanischen Öffentlichkeit. Das Tiefland blieb ein ökonomisch wichtiger, aber politisch, kulturell und sozial unbedeutender Appendix: Bis in die 1960er Jahre hinein fanden die >primitiven Stämmeく bei Diskussionen über die sozia-

4 Gleichzeitig bestand jedoch eine relative Unkenntnis staatlicher Repräsentanten über die eigenen Grenzregionen. Die erste bedeutende Landkarte wurde 1862 in Paris gedruckt, 1865 erschien der erste Atlas, wobei mehrere eingezeichnete nationale Grenzen fraglich und den staatlichen Repräsentanten mehr als 50\% des Gebietes unbekannt waren (vgl. Greene 2004: 91).

5 Dt. >Jagd auf Indigene<; es wurden auch Konflikte zwischen einzelnen ethnischen Gruppen genutzt, indem man diese dazu animierte, correrías zu veranstalten. Die Huitoto waren besonders stark von dieser Praxis betroffen, rund 40.000 verloren so ihr Leben (Chaumeil 1990: 94). 
le Stratifizierung Perus keine Erwähnung (vgl. Greene 2004: 88ff.; Orlove 1993: 307; Varese 1975: 67; Stock 1981: 17f.). Auch die Ethnologie vernachlässigte bis dahin die Frage nach dem Verhältnis zwischen den indianischen Tieflandbewohnern und dem Nationalstaat. ${ }^{6}$ Stefano Varese war in den 1960er Jahren einer der ersten peruanischen Ethnologen, der sich dem Studium des Integrations- bzw. Assimilationsprozesses der indigenen Tieflandbewohner widmete. Er etablierte einen entsprechenden Forschungszweig an der Universidad Nacional de San Marcos in Lima (Gespräch Chirif 20.07. 2005; vgl. auch Stock 1981: 20; Morin 1992: 66; Greene 2004: 91). ${ }^{7}$

\section{Peru in der ersten Hälfte des 20. Jahrhunderts}

Mit der Gesetzgebung aus dem Jahr 1909 bewies die Zentralregierung in Lima Kontinuität in Bezug auf ihren Umgang mit dem Amazonasgebiet: Mit der Ley de Tierras de Montaña No.1220 ${ }^{8}$ sicherte sie sich die exklusiven Nutzungsrechte der natürlichen Ressourcen des Landes. Auch wurden Migranten animiert, in die Region zu ziehen. Ansonsten fiel die Besiedlungs- und Zivilisierungsaufgabe weiterhin der katholischen (sowie später auch der evangelischen) Mission zu. Diese nahm eine Vermittlerrolle bei Konflikten zwischen lokalen patrones und ihren indianischen Arbeitskräften ein. Neben dem System der habilitación nutzten die patrones die von den Missionaren zwei Jahrhunderte zuvor eingeführte politische Funktion der curacas und ergänzten es durch ein compadrazgo-System ${ }^{9}$ (vgl. Barclay 1991: 54f.; Chaumeil 1990: 97).

6 Die indigenen Tieflandbewohner waren in Peru vor allem für ausländische Wissenschaftler von Interesse. So gehörten Tessmann (1930) und Karsten (1935) zu den ersten >modernen< Ethnographen, die das Amazonasgebiet erforschten. Aber die beiden konzentrierten sich - wie auch ihre Nachfolger - in ihren Arbeiten vor allem auf die Erforschung der >kulturellen Wurzeln gegenwärtigen Lebensbedingungen dieser Gruppen. Ethnologische Studien, die auch diesen Aspekt im Blick hatten, wurden in Peru vor allem im Andenraum durchgeführt.

7 Barclay (1991: 49) hebt hervor, dass Arbeiten über die Amazonasregion ab den 1970er Jahren entstanden, weil zu diesem Zeitpunkt die starke Interventionspolitik des Staates als natürlich, aber noch nicht ausreichend empfunden wurde. Auch Stefano Varese arbeitete unter der linken Militärregierung von Alvarado Velasco in der staatlichen Behörde SINAMOS (Sistema Nacional de Apoyo a la Movilización Social) mit. Sein Engagement für die indigene Selbstorganisation und die Etablierung des Forschungszweigs zu den Tieflandbewohnern an der Universität San Marcos muss also auch unter diesem Aspekt betrachtet werden.

8 Dt. >Bodengesetz für das Waldgebiet Nr. 1220<.

9 Dt. >Patenschaft<; Teil der Patronage-Beziehungen. Der Patron übernimmt die Patenschaft für Kinder des Klienten und bindet diesen so langfristig an sich. Nicht so sehr die Beziehung zwischen dem Paten und dem Patenkind steht dabei 
Nach dem Ende des zweiten Weltkrieges erwachte ein neues Interesse des peruanischen Staates am Amazonasgebiet. Diese Entwicklung muss als Teil der nationalstaatlichen Modernisierungsstrategie und des damit im Zusammenhang stehenden international dominanten Entwicklungsparadigmas gesehen werden: Die Rolle der Regierung wurde nun als treibende und lenkende Kraft der wirtschaftlichen Entwicklung definiert. Folgende Elemente waren dabei besonders wichtig für den staatlichen Eingriff in die politische und wirtschaftliche Ordnung verschiedener Regionen des Amazonasgebietes:

- die Sicherung des peruanischen Territoriums gegenüber den Nachbarn: Konflikte zwischen Peru und Kolumbien (Verträge von 1922 und 1938) und Peru und Ecuador (1943) erhöhten die Sorge darum, die territoriale Integrität aufrechtzuerhalten. Vermeiden wollte man eine weitere traumatische Niederlage wie die in den Grenzkonflikten mit Chile im 19. Jahrhundert erlittene.

- der weiterhin zunehmende Wunsch nach wirtschaftlicher Nutzbarmachung des Amazonasgebietes: Der Ausbruch des zweiten Weltkrieges verschaffte diesbezüglich allen Anrainerstaaten des Amazonasbeckens besondere wirtschaftliche Anreize.

Schon 1933 hatte der damalige Präsident Benavides angefangen, eine Route auskundschaften zu lassen, welche die Küste mit dem Amazonastiefland verbinden sollte. Auch übernahm er die Ausbesserung von Wegen, die bis dahin in der Verantwortung von Missionen lagen. Der Straßenbau bestimmte den Strom von Migranten aus den Anden ins Tiefland, der sich zwischen 1940 und $1960 \mathrm{zu}$ entwickeln begann. Da die Tieflandbewohner, vermittelt durch die Missionen, anfingen, sich über den Zuzug der Migranten aus den peruanischen Anden zu beschweren, schloss die Regierung Anfang der 1950er Jahre einen Vertrag mit dem Summer Institute of Linguistics (SIL): Das SIL sollte die indianische Amazonasbevölkerung alphabetisieren und hispanisieren, um sie >integrationswilliger zu machen (Barclay 1991: 55ff.).

Präsident Fernando Belaúnde Terry öffnete nach Antritt seiner ersten Amtszeit 1963 endgültig den Zugang zum Tiefland. Von Beruf Architekt, waren Straßen für ihn der >Weg zur Entwicklung〈. Er verband den Straßenbau mit der geografischen Dreiteilung Perus in Küste, Anden und Amazonastiefland und stellte folgende These auf: Wenn alle drei Regionen durch Wege vernetzt wären, würde die nationale Integration gelungen sein (Orlove 1993: 329). Mit der sogenannten carretera marginal ${ }^{10}$ wollte er das Hinterland mit dem Rest der Republik verbinden. Außerdem sollten damit Verbindungswege

im Vordergrund, sondern die Festigung der Bindungen zwischen Ersterem und den Eltern.

10 Dt. >marginale Schnellstraßeく. 
nach Ecuador, Kolumbien und Venezuela im Nordosten sowie Argentinien im Südosten geschaffen und dadurch das gesamte Amazonasgebiet >zivilisiert werden. Belaúnde wollte mit diesem Plan der Migration in die urbanen Zentren an der Küste sowie den um sich greifenden Protesten der Kleinbauern in den Anden - eines der explosivsten Themen in den 1950er und 60er Jahren entgegenwirken.

$\mathrm{Ab}$ den 1940er Jahren wuchs die Zahl von Bauerngewerkschaften in den Anden, und eine Reihe von Landbesetzungen begann. ${ }^{11} 1964$ verabschiedete Belaúnde deshalb ein Landreformgesetz, mit dem er die an die Küste strömenden Migranten ins Tiefland >umlenken` wollte. Dadurch sollte einerseits die landwirtschaftlich genutzte Fläche vergrößert und andererseits menschliches >Arbeitskapital` für Ölförderung, Holzeinschlag und Bergbau sichergestellt werden. Belaúndes Projekte wurden jedoch bald von einem Militärschlag durch linkspolitische Kräfte durchkreuzt. Einer der Hauptgründe für selbigen war seine liberale Wirtschaftspolitik in Bezug auf die Ölförderung. Das Militär unter Führung von General Juan Velasco Alvarado übernahm nun im >Namen des Volkes` die Regierungsgeschäfte (vgl. Greene 2004: 325ff.; 331). ${ }^{12}$ Die Überführung der Ölförderung in staatliche Hände blieb nicht der einzige Zugriff auf das Kapital ausländischer Unternehmen. Dennoch zielte Velasco Alvarado nicht auf eine ausschließlich staatlich gelenkte Wirtschaftspolitik nach sozialistischem Vorbild ab, sondern wollte eine Mischung aus staatlichen Betrieben, Privatunternehmen und Kooperativen errichten. Zwischen 1970-80 übernahm die Regierung zu diesem Zweck so stark wie zu keiner anderen Zeit auch im peruanischen Amazonasgebiet eine ordnende Funktion (vgl. Barclay 1991: 71; von Oertzen 1988: 85 f.).

11 Nach Brown und Fernandez (1991: 81) hielten bis in die 1960er Jahre 0.1\% der Bevölkerung 90\% des wirtschaftlich rentablen Bodens. An der Küste überwogen Zuckerrohrplantagen, während in den Anden 90\% des Landes von einer kleinen oligarchischen Schicht gehalten wurde.

12 Schon in den 1950er Jahren zeichnete sich ein Gesinnungswandel im Militär ab, das sich nun verantwortlich sah für die Förderung >nationaler Entwicklung`. Die soziale Zusammensetzung dieser bis dahin auf die Vertretung der Interessen der Großgrundbesitzer konzentrierten Einrichtung veränderte sich, junge Männer aus dem Kleinbürgertum und Söhne von Bauern und Arbeitern fanden Aufnahme. Gleichzeitig hatte durch die kubanische Revolution und der vom US-Präsidenten John F. Kennedy ausgerufenen >Allianz für den Fortschrittく auf dem gesamten lateinamerikanischen Kontinent eine entwicklungspolitische Debatte eingesetzt, die dem Militär neue soziale und politische Aufgaben zuschrieb (von Oertzen 1988: 81f.). 


\section{Die Militärregierungen: 1968-1980}

Unter der Militärregierung von Juan Velasco Alvarado (1968-75) fing die für die politische und soziale Organisation der Tieflandindianer bedeutendste Reformwelle der jüngeren Geschichte Perus an. Velasco Alvarado verfolgte einen >populistischen Korporativismus ${ }^{13}$ (Wiarda 1997: 80). Er förderte die Bildung neuer korporativer Gruppen (z.B. Arbeiter, Bauern) und schränkte die Macht bis dato herrschender Interessengruppen ein. Im Zuge der von ihm eingeleiteten Reformen erhielten die Tieflandindianer zum ersten Mal einen legalen Status und damit unter anderem Zugang zu Landrechten. Aber auch Velasco musste letztendlich seine radikalen Erneuerungspläne mit größeren nationalen und internationalen wirtschaftlichen Interessen in Einklang bringen. Die slinke Revolution` seiner Regierung verlief zudem hierarchisch von oben nach unten, mit drei Schwerpunktsetzungen beim angestrebten sozialen Wandel:

- Landrechtsreform

- Reform des Bildungssystems

- Stärkung institutioneller Strukturen

\section{Landrechts- und Bildungsreform}

1972 führte Velasco Alvarado ein zweisprachiges Schulprogramm für alle Gebiete ein, in denen Spanisch nicht Muttersprache war. Die Gesetzgebung der Militärregierung führte zu einem größeren Bewusstsein für die multilinguale Situation Perus und letztendlich zu einer Verfassungsreform unter General Francisco Morales Bermudez im Jahre 1979, in der Quechua, Aymara und >andere indigene Sprachen 2004: 318, 330ff.; Lowenthal 1983: 425).

Mit der Agrarreform von 1969 war die Kolonisierung des peruanischen Amazonasgebietes durch Andenbewohner nicht länger das politische Mittel zur Lösung der Landkonflikte im Hochland. Das neue Gesetz befähigte die Regierung, Küstenplantagen aufzulösen und haciendas in staatliche Kooperativen zu verwandeln. Dem Plan zufolge sollte die Verwaltung der Kooperativen am Ende in die Hände der Bauern und Arbeiter selbst übergehen. Im Hochland sollten die comunidades indigenas an der Verwaltung und dem Gewinn der aus den früheren haciendas hervorgehenden Betriebe beteiligt werden. Gleichzeitig wollte Velasco sie von ihrer Stigmatisierung als >Ent-

13 Korporativismus: Die Regierung eines Staates funktioniert durch eine begrenzte Zahl von Interessengruppen, die das Vertretungsmonopol innehaben. Dahinter steht die Idee, dass Individuen ihre Rechte und Identität durch Gruppenmitgliedschaft erhalten, jede Organisation spricht in diesem Sinne für alle ihre Mitglieder und die Regierung macht Politik in Absprache mit den Organisationsführern. 
wicklungshemmer befreien. Er benannte deshalb die 1921 verfassungsrechtlich anerkannten comunidades indígenas in >bäuerliche Gemeinden (comunidades campesinas) um. Der 24. Juni, bis dahin 〉Tag des indio〈, wurde zum >Tag des Bauern . Durch die Umbenennung der Hochlandgemeinden in $\mathrm{co}$ munidades campesinas nahm die Entwicklung einer >indigenen Bewegung in Peru einen anderen Verlauf als zum Beispiel in Ecuador. In den Anden organisierten sich indianische Gemeinden bis in die 1990er Jahre bevorzugt als bäuerliche Vereinigungen, und auch heute noch ist der Begriff >indigen` unter der dortigen Bevölkerung umstritten.

Während Velasco die Andenbewohner zu >deindigenisieren` versuchte, verfolgte er im Tiefland die entgegengesetzte Politik: Im Juni 1974 verabschiedete die Regierung zum ersten Mal ein Gesetz, das die legale Existenz sogenannter comunidades nativas im Amazonasgebiet anerkannte und diese als Vertragskörper juristisch etablierte. ${ }^{14}$ Das Gesetz sah vor, dass die Gemeinden zusammenhängende Landstücke, Schutz kollektiven Eigentums sowie technische Unterstützung und Kredite vom Staat beanspruchen konnten (vgl. Varese 1972: 20).

Das Ley de Comunidades Nativas von 1974 eröffnete den Tieflandindianern einen gewissen Grad an rechtlicher Autonomie - zivilrechtliche Probleme wurden zur internen Angelegenheit titulierter Gemeinden erklärt und die Bewohner der Steuerpflicht enthoben. Das Gesetz schrieb ferner vor, dass der kollektive Landbesitz der Gemeinden unveräußerlich, unverjährbar und unpfändbar sei. Allerdings mussten sich die Tieflandindianer, um überhaupt die neue Gesetzgebung in Anspruch nehmen zu können, in staatlich anerkannten politischen Einheiten organisieren. Als comunidad nativa ${ }^{15}$ entwickelten die Siedlungen ein internes Statut, schufen eine Struktur kommunaler Autoritäten und richteten eine Gemeindeversammlung als höchstes Entscheidungsorgan ein. Diese Strukturen basierten auf dem Organisationsmodell der indigenen Gemeinden in den Anden. Im Amazonasgebiet stellten sie zumeist einen neuen Typ von Dorfgemeinschaften dar. Sie verstanden sich oftmals nicht als dörfliche Kollektive im korporativen Sinne der Anden (vgl. Dandler 1998: 69ff.; Smith 1996: 84, 88ff.). Während die Gesetzgebung von 1974 also lediglich die dörflichen Einheiten anerkannte, schlug der Ethnologe Stefano Varese als Mitarbeiter einer staatlichen Behörde noch während der Ausarbeitung des

14 Das Ley No. 20653 de comunidades nativas y de promoción agropecuaria de las regiones de selva y ceja de selva; dt.: >Gesetz Nr. 20653 der comunidades nativas und zur Förderung von Landwirtschaft und Viehzucht im Gebiet des Andenabhang und des Tieflands

15 Varese schlug 1972 folgende operationale Definition des Begriffs vor: »[...] the stable socio-economic unit, bound to a specific territory, with a type of settlement which can be either nuclear or dispersed, which recognize itself as a community and which is distinguished from neighbouring socio-economic units, native or not« (Varese 1972: 12). 
Gesetzes vor, dass die zersplitterten Gemeinden in zusammenhängende Förderationen gruppiert werden könnten. Dies lehnte die Regierung unter Velasco Alvarado ab (vgl. Montoya et al. 2001: 99; Greene 2004: 351).

Vor der Gesetzgebung von 1974 hatte es bereits im März 1957 einen Versuch gegeben, indigene Landrechte im Amazonasgebiet geltend zu machen. Dem damals entworfenen Gesetz zufolge sollte das Landwirtschaftsministerium für die tribus selvicolas ${ }^{16}$ Siedlungsgebiete reservieren - bevorzugt in den Gegenden, in denen sie sschon immer gelebt hatten. Allerdings blieb die Umsetzung des Dekrets beschränkt auf Gebiete, die in der Nähe bereits etablierter Kommunikationsnetze lagen. Gleichzeitig verstand die Regierung die Markierung von Schutzgebieten nur als einen ersten Schritt hin zur Assimilation der Amazonasbewohner. Das Land sollte laut Dekret letztendlich individuell parzelliert und genutzt werden (vgl. Beteta 1993: 207). Bis 1974 wurden außerdem nur 114 von ca. 1000 beantragten Reservaten anerkannt (Greene 2004: 346). Interessant ist jedoch, dass die Gesetzgebung von 1957 parallel zu ähnlichen Prozessen auf internationaler Ebene verlief. Die ILO verabschiedete im selben Jahr (5. Juni 1957) die Konvention 107 - das erste internationale Abkommen, das sich mit der Situation Indigener auseinander setzte und Bestimmungen zu ihrem Schutz vorschlug. ${ }^{17}$

\section{Stärkung institutioneller Strukturen}

Der Militärregierung fehlte eine Vermittlungsinstanz zwischen Bevölkerung und Staatsführung, da die Gründung einer politischen Partei von der Mehrheit der militärischen Führung abgelehnt worden war. So rief man 1971 das Sistema Nacional de Apoyo a la Movilización Social (SINAMOS) ${ }^{18}$ ins Leben. SINAMOS sollte die Bevölkerung überall dort organisieren, wo bisher keine politischen Ausdrucksformen nach staatlichem Verständnis bestanden. Dies galt sowohl für die Bewohner der Elendsviertel an den Stadträndern als auch für die ländliche Bevölkerung an der Küste, in den Anden und im Tiefland. SINAMOS wurde mit Büros in allen Regionen sowie umfangreichem Personal und materiellen Möglichkeiten ausgestattet. In den Anden schuf die Institution den Bauernverband Confederación Nacional Agraria (CNA) - in Konkurrenz zur unabhängig entstandenen Confederación Campesina del Perú

16 Dt. >Waldstämme<.

17 Peru war maßgeblich an der Ausarbeitung der ILO Konvention 107 beteiligt, ausgehend vom Proyecto Puno/Tambopata (Gespräch Christiam Beteta, 10.07. 2005).

18 Dt. >Nationales System zur Unterstützung der sozialen Mobilisierungく. SINAMOS stand gleichzeitig für >sin amos $<->$ ohne Herren $<-$ und verkörperte so den revolutionären Anspruch der Regierung. 
(CCP), die der Militärregierung kritisch gegenüberstand. ${ }^{19}$ Im Tiefland half SINAMOS großen Teilen der Landbevölkerung, sich aus der Abhängigkeit von patrones zu lösen und zu unabhängigen Kleinbauern zu werden. Es bildeten sich Gremien auf lokaler sowie regionaler Ebene: Zusammenschlüsse von Bauern und Bündnisse auf ethnischer Grundlage (vgl. Barclay 1991: 79ff.).

Jedoch bildete SINAMOS bald eine institutionelle Hierarchie von staatlichen Bürokraten und praxisbezogen arbeitenden Akademikern aus, die als Vermittler zwischen Bauern und Arbeitern auf der einen Seite sowie Militärführung und Ministern der Regierung auf der anderen Seite fungierten. Dabei versuchte man, bereits existierende Formen populärer Selbstorganisation entweder in das neue System einzubinden oder aber zu unterdrücken, so dass sich die soziale und politische Zerklüftung des Landes letztendlich noch verstärkte (vgl. Greene 2004: 334ff.; von Oertzen 1988: 94). Symptomatisch hierfür ist zum Beispiel die Entwicklung des bereits erwähnten Congreso Amuesha, der kurz nach seiner Gründung Unterstützung durch SINAMOS erhielt. Durch die Anwesenheit von Staatsbeamten bei den Treffen wurde die Organisation nach und nach von der Regierung kooptiert (Santos Granero und Barclay 1998: 286). Ein anderer Aspekt ist der Einfluss, den SINAMOS auf die Veränderung der Autoritätsstrukturen in den comunidades nativas ausübte. Die Politik der Behörde zielte darauf ab, straditionelle tätsfiguren miteinander zu verbinden. Den lokal anerkannten, meist informellen Führungspersönlichkeiten der Siedlungen wurden zweisprachige Lehrer zur Seite gestellt, die ihnen im Umgang mit den staatlichen Institutionen helfen sollten. Es entwickelte sich schnell ein Ungleichgewicht: Auf der einen Seite wurden die Lehrer wegen ihrer Lese- und Schreibkenntnisse in alle offiziellen Angelegenheiten einbezogen. Auf der anderen Seite entkamen sie dank ihrer ökonomisch und intellektuell privilegierten Stellung zumeist den lokal geltenden Zwängen der Solidarität und den sozialen Regeln (Gasché 2001: 5ff.; vgl. auch Chaumeil 1990: 108; Greene 2004: 372).

\section{General Francisco Morales Bermudez}

1975 kam es zu einer Regierungskrise, in deren Folge Velasco Alvarado abdanken musste. Die ızweite Phase der peruanischen Militärregierung unter Führung des General Francisco Morales Bermudez begann. Die Entschei-

19 Von Oertzen bemerkt im Zusammenhang mit der CNA und anderen Basisorganisationen, die von SINAMOS geschaffen wurden und sich in der Folge in Institutionen verwandelten, mit denen sich Teile der Bevölkerung identifizierten: »[...] sobald sie wirklich in der Bevölkerung Fuß fassen konnten und begannen, die Forderungen ihrer Anhänger offensiv zu vertreten, zog sich der Staat zurück und reagierte schließlich sogar mit polizeilichen Repressionen « (von Oertzen 1988: 94). 
dungsbefugnisse wurden zurückverlagert auf die Streitkräfte, SINAMOS wurde 1978 geschlossen und damit der systematische Ausbau des staatlichen Apparats auf lokaler und regionaler Ebene gestoppt. Im gleichen Jahr ersetzte die neue Regierung das ursprüngliche Gesetz der comunidades nativas durch eine neue Gesetzgebung. ${ }^{20}$ Die Gemeinden im Tiefland hatten nun nur noch ein Besitzrecht auf den Teil ihres Landes, der für Landwirtschaft nutzbar war. Am verbleibenden Territorium genossen sie lediglich Nutzungsrechte. Damit sicherte sich der Staat die Gebiete, die für Holzeinschlag, Ölförderung oder andere gewinnbringende wirtschaftliche Projekte nutzbar waren. Zudem schlief der Prozess der juristischen Anerkennung der Gemeinden fast vollständig ein: Zwischen 1975 und 1982 wurden von den mehr als $1000 \mathrm{Ge}-$ meinden im Amazonasgebiet nur 372 tituliert. In der Folge, vor allem ab den späten 1980er Jahren, ging die Hauptaktivität der Landtitulierung vom nationalen Zusammenschluss der ethnischen Föderationen des Tieflands, Asociación Interetnica de Desarrollo de la Selva Peruana (AIDESEP), aus - im Verbund mit einem internationalen Netzwerk von Unterstützer-NGOs.

An den Universitäten, an denen sich viele Anhänger maoistischer Parteien befanden, begann sich ab 1977 heftiger Widerstand gegen die Militärregierung zu regen. Auch der Druck von außen erhöhte sich: Internationale private Banken knüpften ihre Kreditvergabe an Bedingungen, die der IWF vorgab. Subventionskürzungen, Preiserhöhungen und Lohnsenkung waren die Folge. Morales Bermudez beschloss, die Regierungsgeschäfte an zivile Politiker zurückzugeben.

\section{Die Zeit nach $\mathbf{1 9 8 0}$}

Zwischen 1980 und 1990 wurde das Tiefland zur `Kornkammer` der Nation die Produktion der Grundnahrungsmittel Mais und Reis im Amazonasgebiet nahm zu. Ab Mitte der 1980er Jahre intensivierte sich gleichfalls der Kokaanbau, außerdem griff die terroristische Gewalt des Leuchtenden Pfades und des Movimiento Revolucionario Túpac Amaru (MRTA) ${ }^{21}$ von den Anden ins zentrale Tiefland über. Dadurch wurde die Präsenz des Staates in einigen Gebieten reduziert, und die wirtschaftliche sowie politische Wahrnehmung des Integrationsprozesses der Region wandelte sich (vgl. Barclay 1991: 82). Der 1980 erneut gewählte Präsident Belaúnde Terry erließ im November desselben Jahres ein Agrargesetz, das sowohl die Vermarktung landwirtschaftlicher Produkte wieder privaten Zwischenhändlern überließ als auch die Aufteilung des genossenschaftlichen Bodens auf kleine Gruppen oder Einzelpersonen er-

20 Das Ley de Comunidades Nativas No. 22175.

21 Dt. >Revolutionäre Bewegung Túpac Amaruく. 
laubte. Zudem wurde das Kolonisierungsprogramm wieder aufgegriffen und die Titulierung indigenen Territoriums nahezu vollständig eingestellt (vgl. Dean 2002: 211). Finanziert durch internationale Kredite baute Belaúnde Terry das Straßennetz weiter aus und unterstützte großangelegte wirtschaftliche und infrastrukturelle Entwicklungsprojekte in einigen Gebieten des Tieflands.

Jedoch stellten sich bei diesen Projekten am Ende der Regierungszeit von Belaúnde Terry (1980-85) Finanzierungsschwierigkeiten ein. So wurden sie ab Mitte der 80er Jahre nach und nach abgebaut, Präsident Alan García Pérez (1985-90) stellte schließlich auch die Subventionierung der Mais- und Reisbauern im Amazonasgebiet ein. Gleichzeitig verhinderte die Vergrößerung der Kokaanbaufläche unter Ausnutzung der verbesserten Transportwege in der Amazonasregion die Integration in den nationalen Markt: Produzenten und Händler hatten sich eigene Finanzierungs- und Kommerzialisierungswege geschaffen. Die Regierung versuchte auf Druck der USA gegen die Kokahändler vorzugehen, allerdings weitestgehend erfolglos. Diese Machtlosigkeit erschütterte, so Barclays (1991: 91) Überzeugung, den Glauben der indianischen Bevölkerung des Tieflands an die Autorität des Staates. Durch die wirtschaftliche Krise sahen sich viele Bewohner der Region zudem vor immer größere Überlebensprobleme gestellt. Ein Umstand, der wiederum die Ausbreitung des Drogenhandels auch unter der indigenen Bevölkerung begünstigte (Chirif 1995: 361). ${ }^{22}$ Ende der 1980er Jahre erlebte Peru eine tiefe Wirtschaftskrise: Hyperinflation, Bankrott und Verweigerung internationaler Kredite kennzeichneten die schwierige Situation.

1990 trat Alberto Fujimori als neuer Präsident mit drei Zielen an:

- Beseitigung des Terrorismus'

- Beendigung der Wirtschaftskrise

- Lösung der Grenzkonflikte mit Chile, Bolivien und Ecuador

Im Gegensatz zu Belaúnde und García setzte er dabei auf die erneute Stärkung des Militärs sowie auf den Ausbau des Geheimdienstes zur Bekämpfung des Terrorismus. Ferner unterstützte die neue Regierung die Organisation von lokalen Selbstverteidigungsgruppen, während politische Organisationen gleichzeitig schnell unter Terrorismusverdacht gerieten. Dies erschwerte auch den inzwischen sehr zahlreichen ethnischen Föderationen erheblich die Arbeit. Auf wirtschaftlichem Gebiet verfolgte Fujimori eine neoliberale Strategie, die von IWF und Weltbank gefördert wurde: Beseitigung von Preiskontrollen, Abschaffung der Subventionen, Anwerbung ausländischer Investoren, Privatisierung staatlicher Unternehmen sowie Abbau des bürokratischen Apparats (vgl. Santos Granero und Barclay 2000: 309f.; Soria 2001: 49f.).

22 Mitte der 1990er Jahre konzentrierte sich $60 \%$ des weltweiten Kokaanbaus auf Peru. 
Fujimori trieb die Privatisierung und Parzellierung der indigenen Gemeindeländer im Amazonasgebiet weiter voran. 1993 verabschiedete er zum Beispiel ein Gesetz, welches das Wachstum der Erdölindustrie begünstigte. Den comunidades nativas wiederum verweigerte seine Regierung besondere Nutzungsrechte der natürlichen Ressourcen in ihren Territorien. Dem Staat gehört bis heute das exklusive Recht der Nutzung der Bodenschätze. Jedoch nahm Fujimori gleichzeitig formal eine wichtige gesetzliche Änderung in Bezug auf den Status der indigenen Bevölkerung vor: Peru unterzeichnete im November 1993 die ILO Konvention 169 zu »indigenen und tribalen Völkern in unabhängigen Ländern«. Im selben Jahr wurde das Land verfassungsrechtlich zum multiethnischen, plurikulturellen Staat erklärt und Respekt für >die indigenen Kulturen` sowie Schutz für ihr Gemeindeland versprochen. 1995 schuf Fujimori allerdings per Gesetz Bestimmungen, welche die Unveräußerbarkeit und Unpfändbarkeit indigener Territorien einschränkte. Damit erleichterte er transnationalen Unternehmen den Zugang zu diesen Gebieten. Indigene Organisationen konnten in den 1990er Jahren 10\% des Amazonasgebietes titulieren (7 Millionen Hektar). Im Vergleich dazu vergab die Regierung drei Mal so viel Land in Form von Konzessionen an Erdölfirmen. Die Politik der wirtschaftlichen Liberalisierung setzte auch Fujimoris Nachfolger im Präsidentschaftsamt, Alejandro Toledo, fort (vgl. Dandler 1998: 25; García und Lucero 2003: 17; Dean 2002: 213).

\section{Von der politischen Atomisierung zum panethnischen Zusammenschluss}

Hinsichtlich der >Integration< eines großen Teils der Tieflandbewohner in das koloniale und postkoloniale System zeichnen sich rückblickend folgende Phasen und Tendenzen ab:

- Christianisierung, formale Abschaffung der bis zu diesem Zeitpunkt gültigen indianischen Führungssysteme ${ }^{23}$ (die aber im Innern der Gruppen weiterhin ihre Gültigkeit besaßen) und Einführung der Figur des Vermittlers in Gestalt des curaca durch die Missionare in der Kolonialzeit.

23 Unter sindianische Führungssysteme verstehe ich die lokalen Formen politischer Organisation, die vor der Ankunft der Spanier bzw. Missionare gültig waren. Da viele Gruppen nach segmentären Prinzipien geordnet waren, besaß zum Beispiel das Statusführerprinzip eine herausgehobene Bedeutung in weiten Teilen des Amazonasgebietes. Ein Statusführer besitzt keine Zwangsgewalt und muss seine Gefolgschaft vor allem durch Großzügigkeit und Eloquenz überzeugen und halten. Die damit verbundenen sozio-politischen Ideale lassen sich unter den Begriffen `Gleichheit` und `Unabhängigkeit`subsumieren. Auf diesen Punkt komme ich in Kapitel X.3 ausführlich zu sprechen. 
- Von Anfang des 19. Jahrhunderts (Gründung des Nationalstaats) bis Mitte des 20. Jahrhunderts Fortsetzung des von den Missionaren eingeführten curacazgo-Systems ${ }^{24}$ in modifizierter Form als Patronage-System.

- Im gleichen Zeitraum Intensivierung der territorialen Eingliederung des Tieflands in den peruanischen Staat aus ökonomischen und geopolitischen Motiven unter Missachtung der Belange der indigenen Tieflandbewohner.

- Synchron zu bzw. resultierend aus Punkt drei nicht nur territoriale Enteignung und politische Missachtung, sondern auch Entwicklung von Formen der Versklavung der indigenen Tieflandbewohner. Sie wurden als >menschliches Zubehör zum ökonomisch nutzbaren Amazonasgebiet betrachtet.

- Ab Mitte des 20. Jahrhunderts veränderten die evangelikalen Missionen und der Schulunterricht des SIL, die Migrantenströme aus den peruanischen Anden sowie die Landreform unter General Velasco Alvarado das Verhältnis zwischen Regierung und indianischen Gesellschaften des Amazonasgebietes. Der Staat förderte massiv die Einbindung der indigenen Tieflandbewohner in die >nationale Gemeinschaft.

- Ab den späten 1970er Jahren sukzessive Abschwächung der unter Velasco geschaffenen (Sonder-)rechte für die indigenen Tieflandbewohner. Der Staat öffnete das Amazonasgebiet wieder verstärkt für ausländisches Kapital.

Mitte des 20. Jahrhunderts begann die Herausbildung hierarchisch und zentral organisierter ethnischer sowie panethnischer Zusammenschlüsse. Die Mehrzahl der neuen offiziellen Repräsentanten der Föderationen waren >Produkte der zweisprachigen Erziehung. Sie brachten das >eingespielte Zusammenwirken zwischen curacazgo-System und informellen Führungsstrukturen insofern aus dem Gleichgewicht, da sie den anderen Dorfbewohnern in ihrer Beziehung zur nationalen Gesellschaft unter anderem durch ihre Schreib- und Lesekenntnisse im Spanischen meist überlegen waren. Ein Generationen- und Wertekonflikt innerhalb der indianischen Tieflandgesellschaften zeichnete sich ab. Gleichzeitig wurden die indigenen Tieflandbewohner aber zum ersten Mal zu formal anerkannten Rechtssubjekten, die aus der politischen Unsichtbarkeit im nationalen und internationalen Kontext hervortraten. Sie begannen, eigene Forderungen gegenüber dem Staat zu formulieren sowie einen Kulturdiskurs zu entwickeln, der sich gegen die dominanten Vorstellungen einer homogenen peruanischen Nationalgemeinschaft richtete. Hierbei schrieben sie sich in bestehende Diskurstraditionen alternativer Gesellschaftsmodelle ein bzw. veränderten diese. Darauf möchte ich im Folgenden kurz eingehen.

24 Curacazgo: Mit diesem Begriff bezeichnet Chaumeil (1990: 107) das von den Missionaren etablierte politische System, mit dem die Figur des curaca als lokalem Vermittler eingeführt wurde. 


\section{Exkurs: peruanischer Indigenismus und Indianismus}

Der peruanische Indigenismus (indigenismo) ${ }^{25}$ begann um 1860-70. Der Begriff bezeichnet diverse Etappen und Ausrichtungen dieser Weltanschauung. Die verschiedenen Strömungen verbindet jedoch mehrheitlich das Nachdenken über das `Nationsprojekt Peru < sowie im weitesten Sinne das Grübeln von >nicht-Indigenen über ein >Indigenenproblem২. Manuel Gonzales Prada, prominenter Literat der Wende vom 19. zum 20. Jahrhundert, beeinflusste nachhaltig die späteren Ausformungen des peruanischen Indigenismus. Er sah in der schulischen Bildung des indio den entscheidenden Beitrag zur Lösung der sozialen Probleme des Landes sowie zur Konstruktion der nationalen Gemeinschaft. Würde man den indio in das staatliche Bildungssystem einbeziehen, wäre seine Integration möglich.

Gemeinsam war den folgenden Ausprägungen des Indigenismus in Kunst, Literatur, Politik und Soziologie in der ersten Hälfte des 20. Jahrhunderts, dass moralische sowie kulturelle statt biologische Aspekte >indigener Identität betont wurden. Die Tieflandindianer fanden jedoch keine Berücksichtigung im Denken der Indigenisten dieser Epoche. Stattdessen verband man den indigenismo mit einem regionalen andinen Nationsprojekt: Die königlich-staatlichen Aspekte der Inkavergangenheit der indios wurden als das >Eigene gegen die Zentralregierung in Lima als >Fremdherrscher in Stellung gebracht. Die politischen Absichten reichten von einem romantisch-utopischen Streben nach der Rückkehr zum Inkareich bis zu Revolutionsforderungen marxistischer Prägung. Beides verband sich in den Schriften José Carlos Mariáteguis. Auch in seinem Denken fanden das peruanische Amazonasgebiet und dessen rakephale Stammesgesellschaften verband Mariátegui die >Indigenenfrage « mit dem Agrarproblem. Dies führte in den folgenden Jahrzehnten zur Kategorisierung der Hochlandbewohner als >Bauern`, wodurch wichtige kulturelle Aspekte ihrer Marginalisierung außer Acht gelassen wurden (vgl. Maihold 1988: 207ff; Gonzales 1990: 102f.). Parallel zur gegenwärtig anzutreffenden Tendenz, die >indigene Zivilisation` als Gegenbild zur >westlichen $>$ zu entwerfen, wurde die andine Lebenswelt im indigenismo der Welt der criollos entgegengestellt. Das Hochland erklärte man dabei zur authentischen Basis für die zu schaffende Nation. Der indigenismo wurde durch einen seiner radikalsten Vertreter, Luis E. Valcárcel, auch

25 Es gibt eine umfangreiche wissenschaftliche Literatur zum peruanischen indigenismo (siehe z.B. Maihold 1987; Martínez und Samaniego 1977; Franco 1990; Kristal 1991). In diesem kurzen Exkurs sollen lediglich seine grundsätzliche Stoßrichtung sowie einige interessante Aspekte im Zusammenhang mit der Herausbildung der indigenen Bewegung in der zweiten Hälfte des 20. Jahrhunderts dargestellt werden. 
zum Ursprung der peruanischen Ethnologie. Valcárcel, von 1945-48 Bildungsminister, eröffnete 1946 ein Institut für Ethnologie und Archäologie an der Universität San Marcos in Lima. Der Lehr- und Forschungsplan dieser Einrichtung war fast ausschließlich auf die andine Lebenswelt fokussiert. Valcárcel studierte in den 1920er Jahren in Cuzco die Inkakultur und stilisierte in der Folge die Hochlandbewohner zum auserwählten Volk (vgl. Maihold 1988: 268; Ávila 2000: 418; Degregori 2000: 31; Laufer 2000: 137).

Eine staatliche Form des indigenismo begann sich in den 1920er Jahren auszubilden. Ursächlich hierfür war auch der Druck, den eine Reihe zivilgesellschaftlicher Organisationen auf die Regierung ausübte. Bereits 1866 hatte sich der erste Verein gegründet, der sich für die indigenen Andenbewohner einsetzte: die Sociedad Amiga de los Indios ${ }^{26}$ (Lima, Puno, Cusco). Daneben gab es aber auch eine »authentische Bewegung der Indios" (Maihold 1988: 222), unter anderem verkörpert durch das von 1920 bis zu seinem Verbot 1927 agierende Comité Pro-Derecho Indígena Tawantinsuyo ${ }^{27}$. Das Komitee forderte »die Einsetzung einer gerechten Regierung, die der inkaischen Epoche ähnlich sein sollte« (Maihold 1988: 222). Man kann dieses Komitee als erste indigene Organisation Perus im 20. Jahrhundert bezeichnen und damit als eine Art > Vorläufermodell der Zusammenschlüsse, die sich in der zweiten Hälfte des 20. Jahrhunderts formierten (vgl. Maihold 1988: 225).

Pünktlich zum hundertsten Jahrestag der Republikgründung 1921 erkannte die Regierung formal den >Jahrhundertelangen Kampf der indios« an. Ein neues Grundgesetz wurde verabschiedet. In diesem erklärte man die (koloniale) Institution des kommunalen Landbesitzes in den Anden, bekannt als comunidad indígena, zum festen Bestandteil der modernen peruanischen Nation (vgl. Smith 1983: 594). Für Degregori (2000: 37f.) zeichnete sich die staatliche Form des indigenismo auch mit der Einrichtung einer >Sektion für indigene Angelegenheiten im nationalen Entwicklungsministerium, ebenfalls im Jahre 1921, ab. 1947 gründete die peruanische Regierung, in Folge des ersten Interamerikanischen Indigenistenkongress, der 1940 in Mexiko stattfand, das Instituto Indigenista Peruano (IIP) ${ }^{28}$. Es existierte bis 1969 und wurde dann 1986 für einige Zeit wieder zum Leben erweckt. Das Institut besaß den Auftrag, die Integrationsprozesse der indigenen Bevölkerungsgruppen in die Na-

26 Dt. >Freundesgesellschaft der Indianer`; ihr folgten eine Reihe weiterer Vereinsgründungen, u.a. die der deutschstämmigen Dora Mayer im Jahre 1909 (Asociación Pro-Indigena), zusammen mit Pedro Zulen (vgl. Smith 1983: 594).

27 Dt. >Komitee für die indigenen Rechte des Tawantinsuyo<.

28 Bei der Gründung des IIP war wiederum Luis E. Valcárcel federführend. Während das Institut für Ethnologie der Universität San Marcos die akademische Reflektion der >Indigenenfrage bestimmte, wurde das IIP zum wichtigsten Koordinator von Programmen der angewandten Ethnologie. Valcárcel selbst wandelte sich in der Folge endgültig vom >utopistischen und militanten Indigenisten der 1920er Jahre zum Staatsfunktionär der 50er Jahre` (Ávila 2000: 418). 
tion zu begleiten. Zu diesem Zweck wurden Studien und Entwicklungsprogramme ausgearbeitet. Aufbauend auf Laufer (2000: 140) kann man diese Form des Indigenismus weitestgehend als »weichen Rassismus« bezeichnen: Da man die Bevölkerungsmehrheit des Landes nicht pauschal als >entwicklungsunfähig^verdammen konnte, ohne die angestrebte Modernisierung nach europäisch-amerikanischem Vorbild für unerreichbar erklären zu müssen, setzte man auf die Assimilation der Indianer durch Bildung und Heranführung an den >technischen Fortschritt . In der Regierungszeit von General Velasco Alvarado (1968-75) wollte man einerseits die Diskriminierung der Hochlandbevölkerung durch eine staatlich verordnete >Deindigenisierung $<$ beenden und schaffte andererseits im Tiefland eine neue Kategorie von >Indigenität $<$ mit der comunidad nativa. Das >Indigenenproblem Amazonasgebiet und wollte es hier unter veränderten Vorzeichen erneut lösen, damit die Konstruktion einer >genuinen Nation< endlich gelingen konnte. Maihold (1988: 46) hält fest, dass die staatlich verordnete nationalistische Revolution ihre Hoffnung auf Wohlstand in agrarisch-kommunitären Strukturen verkörpert sah, deren Bildung sie, wie im geschichtlichen Abriss beschrieben, förderte.

Als Antwort auf die staatliche Indigenismus-Politik etablierte sich jedoch von Seiten der Betroffenen in der zweiten Hälfte des 20. Jahrhunderts der sogenannte Indianismus. Dieser definierte sich nicht als Beitrag zur Konstruktion einer homogenen Nation, sondern vielmehr als Versuch, ethnische bzw. panethnische Gemeinschaften in Abrenzung zur nationalen zu schaffen. Der Indianismus kehrte ferner den indigenistischen Grundsatz um: Nicht mehr die Mestizisierung der Indigenen, sondern die Reindianisierung der Mestizen wurde zur Lösung des Gesellschaftsproblems erklärt (vgl. Brown 1993: 318f.). Dabei standen den Indianisten die sogenannten >Neoindigenisten intellektuelle Vertreter einer neuen Variante indigenistischer Politik zur Seite - Wirtschafts- und Sozialwissenschaftler, die sich unter Velasco zum Beispiel in SINAMOS engagierten und später eigene NGOs gründeten. Sie kritisierten den vorherrschenden entwicklungspolitischen Ansatz als Reduzierung des gesellschaftlichen Problems auf ein technisch-produktives und forderten den Einbezug sozio-ökonomischer Faktoren (vgl. Erazo-Heufelder 1994: 100; Ávila 2000: 424). Die Neo-Indigenisten wollten ferner nicht mehr für die Indianer sprechen, sondern mit ihnen zusammen Politik gestalten. Dabei gingen sie davon aus, dass sich ihre indigenen Aktionspartner auf Grund gemeinsamer historischer Erfahrungen zu einer stabilen politischen Schicksalsgemeinschaft zusammenfinden würden.

Mit Blick auf die Ausführungen im zweiten Teil dieser Studie kann man festhalten, dass auf internationaler Ebene indianistische Strömungen bereits im 19. und Anfang des 20. Jahrhunderts bestanden. Doch erst mit den sich in den 1960er Jahren herausbildendenden neuen indigenenen Bewegungen ge- 
wann der Indianismus im Lichte des Entkolonisierungsprozesses und des Kalten Krieges an Profil und Durchschlagskraft.

Auch wenn Indianismus als emischer Diskurs Indigener über ihr Verhältnis zum Nationalstaat zu verstehen ist, sind die Grenzen zwischen Indigenismus und Indianismus meiner Meinung nach fließender als es das idealtypische Modell verspricht. Wer sich zum Beispiel selbst als indigen definierte, sorgte in der Folge (und bis heute) für politische Auseinandersetzungen zwischen den neuen Organisationen. Gerne bezichtigt man den jeweiligen Gegner oder Mitkonkurrenten, kein Indigener zu sein und sich somit eines Diskurses zu opportunistischen bzw. paternalistischen Zwecken zu bemächtigen. Ferner steht zum Beispiel auch der Consejo Indio de Sudamerica $(\mathrm{CISA})^{29}$, der 1980 als >indianistischeく Organisation gegründet wurde, teilweise in der Tradition des indigenismo-Diskurses. Eine Gruppe von Universitätsprofessoren, die im Movimiento Indio Peruano zusammengeschlossen waren, organisierten 1980 mit Unterstützung des World Council of Indigenous Peoples eine Konferenz, auf der CISA ins Leben gerufen wurde. Die neue Organisation beanspruchte, die internationale, repräsentative Stimme der indios Südamerikas zu sein. Ihre Vertreter forderten die Rückkehr zum Tawantinsuyu $^{30}$ als kollektives, kommunitäres Organisationsmodell einer neuen Gesellschaft. Diese Idee hatte zwar schon die messianische Bewegung unter Juan Santos Atahualpa geleitet, aber gleichfalls die intellektuellen >Gründungsväterく des Indigenismus geprägt, auch wenn letztere mit der Idealisierung der Inkavergangenheit keine direkte Übernahme ihres Organisationsmodells anstrebten, sondern ein nationalistisches Projekt moderner Prägung verfolgten.

Den politischen Entwurf des CISA kann man jedoch als ein utopisches Gesellschaftsmodell bezeichnen, das kaum realpolitische Forderungen im Rahmen der bestehenden Ordnung formulierte. Eine andere Zielsetzung entwarfen hingegen die sich in verschiedenen Teilen des Amazonasgebietes formierenden ethnischen Zusammenschlüsse. Auch aus ihren konkreten Forderungen nach Land und Anerkennung entwickelte sich mit der Zeit ein ideologischer Diskurs, dessen Grundlagen ich bereits nachgezeichnet habe (vgl. Kapitel III.4). Dieser warb jedoch nicht für Revolution, sondern für legale Reformen: Das Nationskonzept sollte dahin gehend verändert werden, dass die Anerkennung der multiethnischen, vielsprachigen Realität des Landes möglich werde. Aus der Perspektive der indigenen Tieflandbewohner ließ sich Peru nicht als kulturell homogene Nation begreifen. Auch wünschten sie nicht eine Rückkehr zum Tawantinsuyu. Die sich zur gleichen Zeit wie CISA etablierende Organisation Asociación Interétnica de Desarrollo de la Selva

29 Dt. >Indiorat Südamerikas<.

30 Name des Inkareiches. 
Peruana (AIDESEP) bestritt deshalb den Repräsentationsanspruch ersterer für die von Ihnen vertretenen indianischen Tieflandbewohner. ${ }^{31}$

Der Ethnologe Richard Smith (1985) entwickelte in der Folge eine idealtypische Dreiteilung indigener Organisationen: bäuerliche Gewerkschaften, indianistische Organisationen (CISA) und ethnische Föderationen (AIDESEP). Während, so Smith, die Gewerkschaften dem marxistisch geprägten Klassendiskurs verhaftet blieben, sei CISA das Produkt städtischer Intellektueller mit ausschließlich andinem Hintergrund. In Bezug auf die Tieflandbevölkerung maß er alleine den ethnischen Föderationen eine genuine Repräsentativität bei. Inwieweit diese Einschätzung sich bewahrheitete, gilt es beim Blick auf die Entstehungsprozesse und gegenwärtigen Erscheinungsformen der indigenen Bewegung des Amazonasgebietes im Folgenden näher zu untersuchen.

31 Einzelne Föderationen schlossen sich dennoch CISA an. 


\section{Kapitel IX \\ Entwicklung der sneuen, indigenen Bewegung im Amazonasgebiet}

\section{Erste Organisationsgründungen}

Die ersten ethnischen Föderationen im Tiefland entstanden in der zweiten Hälfte des 20. Jahrhunderts im Gebiet der Asháninka (Campa) und Yanesha (Amuesha) am Ostabhang der Anden. Vorausgegangen waren erhebliche Gebietsverluste - vor allem seit der Unabhängigkeisterklärung und Gründung des Nationalstaats im Jahre 1821 - denen folgende Ursachen zugrunde lagen:

- Kolonisierung durch Ausländer, die der Staat durch eine entsprechende Gesetzgebung Mitte des 19. Jahrhunderts unterstützte.

- Begleichung von Staatsschulden durch Überschreibung von Land an ausländische Unternehmen im Siedlungsgebiet der Asháninka Ende des 19. Jahrhunderts.

- Vordringen von Migranten aus dem peruanischen Hochland ab den 1940er Jahren (vgl. Chirif 1997: o.S.).

Der Einfluss der Kirchen, vor allem der evangelikalen, spielte eine wichtige Rolle bei der Gründung ethnischer Zusammenschlüsse der Asháninka und Yanesha. So hatten zum Beispiel junge Asháninka-Männer im Perené durch ihre Aktivitäten in Adventisten-Kirchen Erfahrungen in supralokaler Organisation gewonnen. 1959 bildeten sie die Asociación de Nativos Campas del Perené $e^{1}$ und boten ihre Hilfe dem Nationalen Kolonisierungskomitee andiner Migranten an. In einer gemeinsamen Agenda legten die Organisationen fest, dass Schulen für beide Gruppen errichtet sowie Möglichkeiten des direkten Vertriebs ihrer Produkte geschaffen werden müssten. Sie erreichten den Bau

1 Dt. `Zusammenschluss der nativen Campas des Perenéく. 
einer Reihe von Flugpisten und Schulen sowie die Demarkierung von Schutzgebieten - auf Grundlage der bereits erwähnten staatlichen Gesetzgebung aus dem Jahr 1957. 1961 klagte die Asociación de Nativos Campas del Perené jedoch die Kolonisten an, weil diese den Asháninka nicht die ebenfalls ausgehandelten Löhne für ihre Arbeitskraft zahlten. Mit dem Bruch des Bündnisses endeten zudem auch alle Aktivitäten des ethnischen Zusammenschluss. Erst unter General Velasco, vor allem mit Verabschiedung des Ley de Comunidades Nativas, gründeten sie erneut eine Organisation, die als Handelskomitee zur Vermarktung ihrer Produkte fungieren sollte - die Central de Comunidades Nativas de la Selva Central (CECONSEC) ${ }^{2}$ (Santos Granero und Barclay 1998: 282ff.; vgl. auch Casanto Shingari 1986; Chirif 1997).

In der benachbarten Region Satipo begannen einige indigene Autoritäten in den 1950er Jahren, lokalen Machthabern gegenüber Landrechte einzufordern und den Migranten Vergehen an der einheimischen Bevölkerung vorzuwerfen. Zwar ging daraus kein ethnischer Zusammenschluss hervor, aber es wurden Kontakte zu nicht-indigenen Organisationen hergestellt, wie zum Beispiel zur Federación Nacional de Campesinos del Perú oder zur Federación de Campesinos de Satipo ${ }^{3}$. Während also im Perené Allianzen zwischen ethnischen Zusammenschlüssen der Asháninka und nicht-indigenen Organisationen kreiert wurden, traten in Satipo einige Autoritäten auf individueller Basis nicht-indigenen Organisationen bei. Santos Granero und Barclay (1998: $287 \mathrm{ff}$.) begründen dies vor allem damit, dass in Satipo die Tieflandbewohner nur teilweise in die kommerzielle Produktion involviert und gleichzeitig stärker sozial fragmentiert waren. Erst Anfang der 1980er Jahre wurde hier ein ethnischer Zusammenschluss gegründet. Dieser untergrub aber seine eigene Legitimität und Akzeptanz unter der Bevölkerung, da er enge Beziehungen zur Regierung aufnahm. Das führte zur Auflösung der Organisation Ende der 1980er Jahre.

In der Ucayali-Region begannen die Shipibo-Conibo ab Ende der 1960er Jahre sich zusammenzuschließen. Hier führt Morin (1992: 59) die Organisationsgründungen auf die Unterstützung von katholischen Missionaren zurück, die sich unter dem Einfluss der Befreiungstheologie sindigenisierten<, sowie auf die Unterstützung von Ethnologen, die der neuen `Indigenenpolitikı von General Velasco folgten. Zu einem ersten Treffen im Jahre 1971 reisten 150

2 Dt. `Zentrale der nativen Gemeinden der Selva Central (1978 ins Leben gerufen). Mit der Unterstützung von SINAMOS-Mitarbeitern begannen Asháninka des Perené und Pichis allerdings schon 1970 eine Reihe von Versammlungen abzuhalten, die zur Gründung des Congreso de Nativos Campas führte. Der Kongress forderte die Schaffung einer eigenen Gesetzgebung zum Schutz der Tieflandbevölkerung (vgl. Chirif 1997).

3 Dt. >Nationale Föderation der peruanischen Bauern sowie Föderation der Bauern von Satipor. Beide Organisationen hatten enge Bindungen zur APRA, einer wichtigen sozial-demokratischen Partei. 
Shipibo-Conibo aus teilweise bis zu sieben Tagesreisen entfernten Gemeinden an. $\mathrm{Zu}$ einem sieben Monate später einberufenen zweiten Kongress fanden sich bereits ca. 1000 Personen ein. Darüber hinaus nahmen auch Mitarbeiter des Landwirtschaftsministerium und von SINAMOS (Stefano Varese) teil. ${ }^{4}$ Morin zeichnet vor allem die kritischen Aussagen der wenigen bei der ersten Zusammenkunft anwesenden Frauen nach, die unter anderem folgende Aspekte umfassten: Zwietracht in den Gemeinden durch die lange Abwesenheit der Männer, die für die patrones arbeiten mussten; Mangel an Material, das die Frauen zum Kochen und für ihre Handwerksarbeiten von den Männern forderten; außerdem notwendige organisatorische Veränderungen, um von der Landwirtschaft leben zu können. In diesen Beschwerden verdeutlichen sich für Morin die Probleme, welche die matrilokal organisierten Shipibo-Conibo durch das System der habilitación hatten. Sie verweist aber auch auf einen wichtigen Aspekt der Repräsentationsfrage, der bei allen frühen Organisationsgründungen eine Rolle spielte: der Konflikt zwischen lokalen Führungspersönlichkeiten und zweisprachigen Lehrern, die auf die Schaffung legaler Ämter in den Gemeinden drängten:

»Formés par l'Instituto Lingüístico de Verano (I.L.V.), les maîtres bilingues de cette époque sont plus souvent les agents de l'intégration a la société nationale [...] Fascinés par la modernité, ils sont souvent les seuls dans la communauté, grâce a leur salaires, à arborer certains biens de consommation tels qu'un radio-transistor, une machine à écrire, des vêtements neufs et constituent en quelque sorte un embryon de classe sociale« (Morin 1992: 69f.).

Die wichtige Rolle der zweisprachigen, vom SIL ausgebildeten Lehrer bei den Organisationsgründungen hebt auch Gasché (2001) hervor. Dennoch schreibt Morin (1992: 70, 72), dass die Shipibo-Conibo beim ersten Kongress einen Repräsentanten wählten, der sowohl charismatisch und traditional legitimiert als auch ein vom SIL ausgebildeter zweisprachiger Lehrer war. ${ }^{5} \mathrm{Zu}$ mindest bei der ersten Generation von Repräsentanten indigener Organisationen scheint es somit ein wichtiges Erfolgskriterium gewesen zu sein, eine solide Kenntnis beider Lebenswelten zu besitzen: der >nationalen >indianischen<. Diesen Schluss legt auch die Studie von Greene (2004) zur politischen Selbstorganisation der Aguaruna nahe.

4 Höhepunkt dieser staatlichen Teilnahme an den Kongressen der Shipibo-Conibo war das Erscheinen von Präsident Velasco Alvarado zur vierten Zusammenkunft im Oktober 1972.

5 Das Erwachsen von Autorität aus einer gelungenen Verbindung beider Aspekte, also die Einnahme einer >authentischen Vermittlerposition`, beschreibt auch Oakdale (2004) anhand einer Gegenüberstellung der politischen Diskurse zweier Kayabi-Repräsentanten in Brasilien. 
Während sich in der selva central und im Ucayali Asháninka, Yanesha sowie Shipibo-Conibo organisierten, begannen im nördlichen Teil des peruanischen Amazonasgebietes auch die Aguaruna und die Cocamilla Föderationen zu gründen. Die Jesuitenmission unterstützte im Oberlauf des Marañón eine Gruppe junger Freiwilliger aus Spanien, die sich Desarrollo del Alto Marañón ${ }^{6}(\mathrm{DAM})$ nannten und die dort lebenden Aguaruna in Genossenschaften organisierten. Noch vor Ablauf des ersten Jahres gerieten DAM und Jesuitenmission in Konflikt miteinander, woraufhin sie getrennte Wege gingen. DAM unterstützte in der Folge die Organisation von AguarunaGemeinden nach Flussläufen. 1975 gründete sich so der Consejo Aguaruna Huambisa $^{7}(\mathrm{CAH})$ unter Leitung des charismatischen Aguaruna Evaristo Nugkuag Ikanan, der in den 1980er Jahren auch den panethnischen Zusammenschluss auf nationaler und internationaler Ebene entscheidend prägte. Im unteren Lauf des Huallagas organisierten sich derweil mit Unterstützung des US-amerikanischen Ethnologen Anthony Stocks die Cocamilla, die 1977 die Federación de Comunidades Cocamillas ${ }^{8}$ (FEDECOCA) gründeten.

\section{Entstehung des nationalen Zusammenschlusses AIDESEP}

Vor allem im Laufe der 1970er Jahre entstanden somit in verschiedenen Regionen des Amazonasgebietes ethnische Föderationen. Deren Repräsentanten reisten nach Lima, um in den Ministerien die Dörfer zu vertreten: Landdemarkierung, Schaffung grundlegender Infrastruktur, Einrichtung zweisprachiger Schulen sowie zivile Registrierung gehörten meist zu ihren zentralen Forderungen. Evaristo Nugkuag erinnert sich, dass sie sich immer wieder auf den Fluren von Ämtern und Institutionen über den Weg liefen (Gespräch Nugkuag 02.08.2005). Auf der anderen Seite gab es die individuellen Unterstützer unterschiedlicher Berufsrichtungen, darunter viele Ethnologen, die zu dieser Zeit zumeist in NGOs oder wissenschaftlichen Einrichtungen arbeiteten. Hinzu kamen studentische Vereinigungen, denen vorwiegend angehende Ethnologen angehörten. Sie setzten sich ebenfalls für die ethnischen Interessenvertretungen ein. Diese Personen, die alle relativ unabhängig voneinander arbeiteten, begannen ab 1977 regelmäßig Treffen in Lima abzuhalten. Anlass des ersten Treffens, das vom nordamerikanischen Ethnologen Richard Smith einberufen wurde, war die Verhaftung von Eth-

\footnotetext{
6 Dt. >Entwicklung des Oberen Marañón<.

7 Dt. >Rat der Aguaruna-Huambisar.

8 Dt. >Föderation der Cocamilla-Gemeinden<.
} 
nologen in Paraguay, die sich für die Rechte der dortigen Indianer eingesetzt hatten. Im Mittelpunkt der Zusammenkünfte standen der Austausch von Erfahrungen und die Festlegung gemeinsamer Arbeitsschwerpunkte. Ab dem zweiten Treffen dieser Gruppe, die sich zuerst Grupo de Investigadores de la Selva ${ }^{9}$ und später COPAL, Solidaridad con los grupos nativos ${ }^{10}$ nannten, nahmen auch Repräsentanten einzelner ethnischer Föderationen teil (vgl. Chirif 1997: o.S., 2005: 8; Smith 1996: 95f.). Es kam aber bald zu Konflikten, die von beiden Seiten im nachhinhein mit leicht unterschiedlichen Schwerpunktsetzungen thematisiert wurden.

Die Ethnologin Margarita Benavides erinnert sich, dass sie sich bereits mehrfach mit den indianischen Repräsentanten getroffen hatten, als 1978 Evaristo Nugkuag in einer der Zusammenkünfte an die Tafel trat und ein Schema aufmalte. Bei diesem stand auf oberster Ebene das Wort >Finanzinstitutionen $<$, in der Mitte `Ethnologen/NGOs $<$ und auf unterster Ebene >Indigene . Alle drei Ebenen verband er jeweils mit einem Pfeil und strich am Ende die mittlere Ebene der \Ethnologen « durch, um eine direkte Linie zwischen $>$ Indigenen dazu ausgeführt, so Benavides, dass die Repräsentanten der ethnischen Föderationen beschlossen hätten, in Zukunft selbst die Verträge und Projekte mit den Finanzinstitutionen aushandeln zu wollem. Sie (die versammelten nicht-indigenen Unterstützer) hätten sich von diesem Auftreten vor den Kopf gestoßen gefühlt (Gespräch Benavides 01.07.2005). Chirif (1995) und Smith (1996), die bei dieser Zusammenkunft auch zugegen waren, betonen in ihrer Darstellung der Ereignisse vor allem deren politische Folgen: die Gründung des nationalen Zusammenschlusses AIDESEP als wichtigen Schritt der >indigenen Emanzipation und politischen Bewusstseinsbildung (Gespräch Chirif 28.01.2004; Gespräch Smith 30.04.2004). Smith (1996: 94) charakterisiert den neuen nationalen Zusammenschluss als:

- eine freiwillige Allianz autonomer lokaler Gemeinden;

- eine von den Gemeinden gewählte und diese repräsentierende Führung, die diesen gegenüber Rechenschaft ablegen muss,

- eine Organisation, die politische Funktionen der Repräsentation und Lobbyarbeit mit technischen Funktionen für Verbesserung der Infrastruktur in den Gemeinden verbindet,

9 Dt. >Forschergruppe zum Tiefland «. Die Gruppe von Wissenschaftlern, die unter diesem Namen zusammentraten, nannten sich selbst in ihrem ersten internen Dokument $»$ Die Erben der Denkrichtung von Barbados«. Dies hing auch damit zusammen, dass 1977 die zweite Barbados-Konferenz abgehalten worden war. Zur Gruppe gehörten u.a. Richard Smith, Alberto Chirif, Carlos Mora, Frederika Barclay, Fernando Santos, Margarita Benavides, Lucy Trapnell, Carolyn Heath, Dominique Temple und Mitglieder des Grupo DAM (Chirif 2005: 8; Greene 2004: 436f.).

10 Dt. Solidarität mit den >Eingeborenengruppen 
- ein Zusammenschluss mit föderativem Charakter, dessen verbindendes Element eine gemeinsame ethnische Identität ist (bzw. auf nationaler Ebene das $>$ Indigen-Sein $<$,

- eine Organisation, die das Ideal der Autonomie gegenüber Parteien, Staat und Kirche aufrechterhält.

Carlos Mora, wie Chirif ehemaliger SINAMOS-Mitarbeiter, betont hingegen in seiner Erinnerung des Entstehungsprozeeses, wie Benavides, dass es den AIDESEP-Gründern vor allem um die eigenständige Verwaltung von Entwicklungsprojekten und -geldern ging. Aus diesem Grund hätten sie sich auch für einen Namen entschieden, der das Wort >Entwicklung< beinhaltete. Gleichzeitig hebt er hervor: »Es waren hauptsächlich diese Delegierten ohne eine Repräsentation der Basis, es gab keinen großen indigenen Kongress mitten im Regenwald, um eine politische Entscheidung zu treffen« (Interview Mora 15.01.2004).

Er zweifelt die Legitimation AIDESEPs als politische Repräsentationsinstanz der Tieflandindianer an und erblickt, im Gegensatz zu Smith und Chirif, darin nicht die Formation einer neuen, im lokalen Kontext relevanten politischen Gemeinschaft.

Auch Evaristo Nugkuag verweist in seiner Darstellung der Gründungsphase von AIDESEP auf den Hauptkonfliktpunkt zwischen den Repräsentanten der ethnischen Föderationen und ihren nicht-indigenen Unterstützern. Er betont wie Chirif und Smith den Emanzipationswunsch. Hierbei definiert er aber den Zugang zum institutionalisierten Wissens- und Ressourcenmanagement als zentralen Aspekt des Organisationsprozesses. Ihm geht es nicht um einen allgemeinen >politischen Bewusstseinsbildungsprozess $\triangleleft$, sondern um Aneignung von technischem Wissen, das er als zentral für den Zugang zu politischer Macht innerhalb der nationalen Gesellschaft definiert:

»Ich kam im Auftrag von CAH ab 1977 regelmäßig nach Lima.[...] In dieser Zeit wurde CIPA ${ }^{11}$ gegründet, von ehemaligen SINAMOS Mitarbeitern wie Alberto Chirif und Carlos Mora. Gleichzeitig gründete sich ein Zusammenschluss von Ethnologen wie Alberto [Chirif], Lucy [Trapnell], Flica [Barclay]. Alle leisteten solidarische Unterstützung für uns, die wir ja nicht in Lima bleiben konnten, sondern in unsere Gemeinden zurückkehren mussten. [...] Wir gaben ihnen unsere Dokumente, und sie erledigten viele Angelegenheiten in unserem Namen. Alberto und Carlos gründeten CIPA, um die Bedürfnisse der Gemeinden vertreten zu können. Sie sagten, dass sie die Unterstützungsarbeit nicht umsonst machen könnten, da sie ja auch

11 Centro Privado de Investigación-Acción; dt. >Privates Zentrum für Forschung und Aktion<, eine peruanische NGO, die sich am Anfang vor allem für die Titulierung indigener Territorien einsetzte und bis heute Projekte in indigenen Gemeinden durchführt. 
von etwas leben müssten. $\operatorname{HIVOS}^{12}$ unterstützte CIPA und ermöglichte die Anmietung eines eigenen Büros und die Bezahlung von Gehältern. Wir hatten gute Beziehungen zu Alberto und Carlos, begannen aber nun auch einen eigenen nationalen Zusammenschluss zu gründen. [...] Wir wollten aufhören, von anderen abhängig zu sein. So geschah es im November 1979, dass wir ein Treffen mit unseren nichtindigenen Unterstützern einberiefen, um ihnen unsere Idee zu unterbreiten: Wir wollten einen unter uns auswählen, der in CIPA mitarbeiten sollte, damit dieser lernen und danach den anderen beibringen könne, nicht von anderen abhängig zu sein. Doch die Mitarbeiter von CIPA lehnten unseren Vorschlag ab mit der Begründung, dass ihre Organisation eine von Fachleuten in Lima sei« (Gespräch Nugkuag 02.08.2005).

Der Gründungsprozess von AIDESEP erweist sich in diesem Sinne als ein »battlefield of knowledge« (Long 1996) der involvierten Akteure. Während die Unterstützer in Nugkuags Erinnerungen zu diesem Zeitpunkt ein gemeinsames Projekt von >(Neo)Indigenisten $<$ und >Indianisten $<$ anstrebten, mit einer Arbeitsteilung zwischen nicht-indigenen Fachleuten und indigenen Repräsentanten, verstand er den Emanzipationsprozess anders. Die >Unabhängigkeitserklärung des sich neu formierenden nationalen Zusammenschlusses zielte für ihn auf die vollständige Durchbrechung der Vermittlerkette ab bzw. deren Substitution durch >eigene Leute`. Auch die solidarischen Unterstützer wurden als überlegene Vermittler betrachtet, von denen man sich in der näheren Zukunft emanzipieren wollte.

Weiteren Aufschluss über die Zielsetzungen der zentralen indigenen Akteure bei der Entwicklung der Amazonas-Bewegung gibt die Umbenennung des ersten nationalen Zusammenschlusses: 1979 vereinigten sich die Repräsentanten der Amuesha, Asháninka, Aguaruna-Huambisa, Shipibo-Conibo und Cocamilla zunächst im Consejo de Comunidades Nativas de la Selva Peruana (COCONASEP) ${ }^{13}, 1980$ benannten sie diesen dann in AIDESEP um. Evaristo Nugkuag begründet den Schritt wie folgt: »Wir wollten eine Gewerkschaft gründen, aber Belaúnde war gegen Gremien. Er nannte deren Mitglieder >Kommunisten〈. Deshalb wechselten wir zur Bezeichnung >Verband Und, weil die Regierungen immer von 〉Entwicklung〈 reden, warum also nicht auch wir« (Gespräch Nugkuag 02.08.2005)?

Das Zitat von Nugkuag verdeutlicht, in welchem schwierigen politischen und historischen Kontext die Genese der Organisationen stattfand und wie sie durch nationalstaatliche Kategorisierungen geprägt wurde: Der Verband regelt soziale Beziehungen in der modernen Gesellschaft. Er kann somit als zivilgesellschaftliche Einrichtung innerhalb des Nationalstaates verstanden werden

12 >Humanistisch Instituut voor Ontwikkelingssamenwerkingく; niederländische NGO.

13 Dt. >Rat der nativen Gemeinden des peruanischen Regenwaldes`. 
(vgl. Kramer 2000: 127). Auch die Benutzung des Begriffs `Entwicklung/ ging konform mit offiziellen Diskursen der Regierung. Durch die wirtschaftlichen Sanktionen von internationaler Seite in Reaktion auf den >politischen Sonderweg`Perus zwischen 1968 und 1980 sowie vor allem durch den Beginn der terroristischen Aktivitäten des Leuchtenden Pfades war das politische Klima in Peru um 1980 sehr gespannt. Die neu in Erscheinung tretenden Akteure aus dem Tiefland mussten sich von rallzu linken` Kräften distanzieren, um als eigenständige politische Subjekte wahrgenommen zu werden und ungehindert arbeiten zu können. Nugkuags Ausführungen belegen in diesem Zusammenhang das politisch-strategische Geschick, mit dem er und seine Mitstreiter ihre Zielsetzungen umzusetzen wussten.

1985 legalisierte sich AIDESEP und erhielt den Status einer NGO. ${ }^{14}$ Damit fügte sich der Zusammenschluss endgültig in die moderne Organisationslogik ein. Nur so war es den Verantwortlichen in AIDESEP auf Grund der peruanischen Gesetzgebung möglich, autonom zu agieren: Verträge zu unterzeichnen, Spenden entgegenzunehmen, ein Bankkonto zu eröffnen, Kredite zu beantragen, Angestellten Verträge auszustellen etc. Jedoch blieb gleichzeitig die Abgrenzung von NGOs - definiert als politisch nicht-repräsentative Organisationen - ein wichtiger Pfeiler ihres nach außen gerichteten Diskurses. Auch wurde der >Emanzipationsprozess` von den Unterstützern in der Folge vor allem in der politischen Außendarstellung wichtig. De facto arbeiteten die indigenen Repräsentanten jedoch weiterhin eng mit den Ethnologen und anderen nicht-indigenen Sympathisanten zusammen, da deren Fachwissen und deren Verbindungen zu internationalen Finanzinstitutionen für die eigene Arbeit noch immer unabdingbar waren. Die Unterstützer verfügten über den privilegierten Zugang zu wichtigen »Ressourcen erster und zweiter Ordnung « (Boissevain 1974) ${ }^{15}$ : spezifisches Fachwissen sowie strategische Kontakte zu Finanzgebern.

\section{Organisationsstruktur und Arbeitsschwerpunkte von AIDESEP}

AIDESEP ist hierarchisch gegliedert und weist in seinem Aufbau Ähnlichkeiten mit Gewerkschafts- oder Parteistrukturen auf - mit dem Unterschied, dass Mitgliedschaft nicht individuell, sondern kollektiv (Dorfgemeinschaft)

14 Vor allem die Asháninka, Shipibo-Conibo und Aguaruna-Huambisa erlangten in der Folge eine hervorgehobene Bedeutung in der Organisation. Diese Dominanz ist einer der latenten Konfliktpunkte des Zusammenschlusses, der inzwischen ca. 47 lokale Föderationen umfasst.

15 Boissevain (1974) unterscheidet zwischen Ressourcen 1. Ordnung (Land, Geld, Arbeitskraft, spezialisiertes Wissen), die der patron kontrolliert und Ressourcen 2. Ordnung (strategische Kontakte), über die Vermittler (auch broker oder Makler genannt) verfügen. 
erlangt wird. Hierarchie und Zentralisierung im Zusammenschluss werden jedoch durch die relative politische Autonomie der Föderationen und regionalen Mitgliedsorganisationen durchbrochen. Wie Smith (1996) schreibt, kennzeichnet Freiwilligkeit und lokale Unabhängigkeit die Vereinigung. AIDESEP spricht von vier Organisationsebenen, von denen die Gemeinde die primäre Kollektivierungsinstanz darstellt (vgl. AIDESEP 2005).

\section{1. comunidad und Föderation}

Ungefähr 1350 Gemeinden des Tieflands bildeten 2005 die Basis der Organisation. Diese primären Einheiten sind Teil suprakommunaler Zusammenschlüsse - manche nennen sich 〉Föderationen`, andere >Rat`, wieder andere tragen die Bezeichnung `Entwicklungsorganisation`. Manche von ihnen schließen sich auf Grund ethnischer Kriterien zusammen, aber in vielen Fällen bilden sie geografische Einheiten, die mehrere ethnische Gruppen umfassen können. Im Jahre 2005 gehörten, laut eigenen Angaben der Organisation, 56 solcher supralokalen Zusammenschlüsse AIDESEP an (AIDESEP 2005: 36f.). Koordination und Durchführung ihrer Arbeit erfolgt weitestgehend unabhängig vom nationalen Zusammenschluss.

\section{2. regionale Organisation}

Als weitere Zwischeninstanz wurden ab Anfang der 1990er Jahre regionale Organisationen aufgebaut, welche die Kommunikation zwischen nationaler und lokaler Ebene erleichtern sollten. Diese regionalen Organisationen sind jedoch ihrerseits alle seit Ende der 1990er Jahre administrativ vom nationalen Verband unabhängig. In ihren politischen Richtlinien stimmen sie sich mehr oder weniger eng mit AIDESEP ab. Die sechs regionalen Organisationen umfassen unterschiedlich viele lokale Föderationen - in der Region Madre de Dios, im Südosten Perus, ist der supralokale Zusammenschluss Federación Nativa de Madre de Dios (FENAMAD) ${ }^{16}$ zum Beispiel gleichzeitig auch die regionale Vertretungsinstanz der darin zusammengeschlossenen Gemeinden.

\section{3. nationaler Zusammenschluss}

Der Vorstand von AIDESEP wird derzeit alle drei Jahre von Vertretern der Föderationen sowie der regionalen Organisationen neu gewählt. Er besteht aus einem Präsidenten, einem Vize-Präsidenten und Koordinatoren einzelner Programme sowie dem Schatzmeister. Der Vorstand trifft sich alle drei Monate im erweiterten Koordinationsrat mit den Präsidenten der regionalen Organisationen, um über die tagespolitische Arbeit zu beraten. Ferner gibt es ein Kontrollorgan, das mit Vorstandsmitgliedern einzelner Regionen besetzt ist und die Arbeit der nationalen Direktive überwachen soll.

16 Dt. >Native Föderation von Madre de Dios`. 
Abbildung 14: Organisationsstruktur AIDESEP

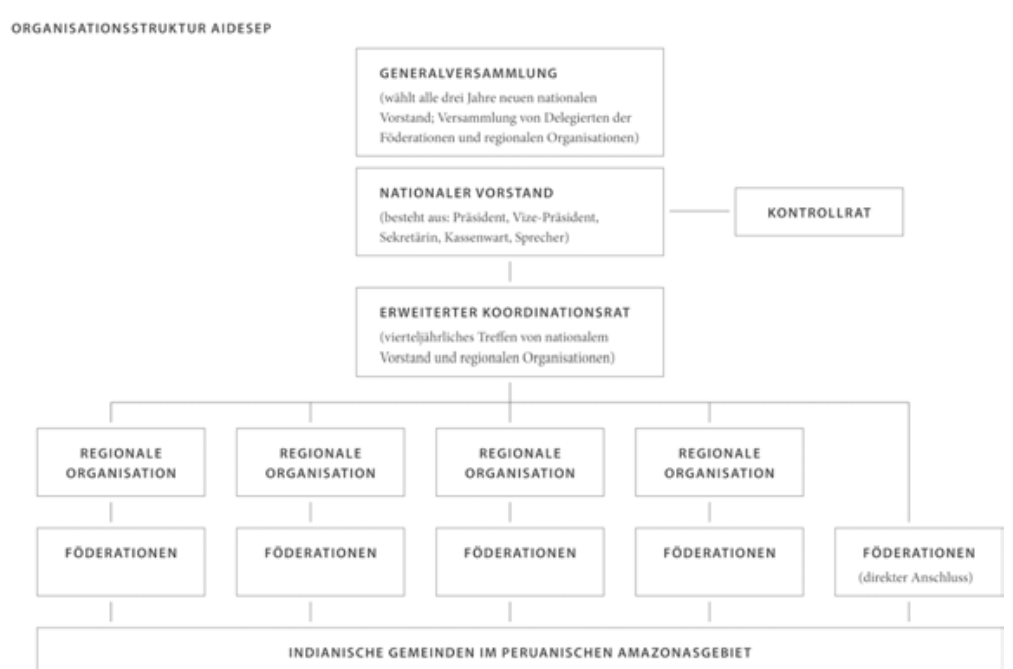

Entwurf: Torsten Hartmann 2006; Vorlage: AIDESEP 2005

2005 arbeitete AIDESEP laut eigener Darstellung zu folgenden Bereichen:

- Territorium und natürliche Ressourcen: Seit dem Bestehen von AIDESEP konnte die Titulierung von 8 Millionen Hektar Land (ca. 10\% des Tieflands) für mehr als 1000 Gemeinden erreicht werden, die Ausweisung von fünf Schutzgebieten für isolierte Völker und von fünf reservas comunales ${ }^{17}$. Die diesbezügliche Arbeit der Organisation wird von einem technischen Informations- und Planungszentrum für Territorialfragen unterstützt (CIPTA), das seinen Sitz in Iquitos hat.

- Ausbildung zweisprachiger Lehrer: 1988 wurde das Ausbildungsprogramm für zweisprachige Grundschullehrer FORMABIAP (Programa de Formación de Maestros Bilingües de la Amazonía Peruana $)^{18}$ ins Leben gerufen. Es ist in die staatliche universitäre Struktur eingebunden und wird von AIDESEP mit koordiniert. Über 300 indigene Lehrer wurden bisher ausgebildet, 129 haben das Programm mit einem Titel abgeschlossen.

17 Dt. >Kommunales Schutzgebiet<; Gebiete, die an titulierte Gemeinden angrenzen und die diese kollektiv zur Subsistenzwirtschaft nutzen können. Siehe auch Kapitel VII.4.

18 Dt. >Ausbildung zweisprachiger Lehrer des peruanischen Amazonasgebietes`. 
- Interkulturelle Gesundheitsversorgung: Mitte der 1990er Jahre begann die regionale Mitgliedsorganisation von Atalaya (OIRA) ein Pilotprojekt, bei dem indigene und westliche medizinische Kenntnisse zusammengeführt und durch Ausbildung vermittelt werden sollten. 2005 wurde ein zweites Pilotprojekt mit ähnlichen Zielen gestartet.

- Indigene Frauen: 1998 schaffte es die erste Frau in den Vorstand von AIDESEP, die Yanesha Teresita Antazú. 1999 wurde ein eigener Posten für $>$ Frauenfragen ' geschaffen und 2002 ein entsprechendes Programm zur technischen Unterstützung eingerichtet.

- Indigene Völker in sfreiwilliger Isolation : siehe Punkt 1 (Territorium und natürliche Ressourcen) (AIDESEP 2005: 50ff).

Ein wichtiges Thema von AIDESEP war, wie schon den Ausführungen Nugkuags zu entnehmen ist, von Anfang an die Ausbildung von indigenen Fachleuten - Juristen, Ökonomen etc. Sie sollten in Zukunft die Aufgaben übernehmen, die bis dato noch von den nicht-indigenen Unterstützern geleistet wurden. Diese Idee unterstützten ausländische Ethnologen wie Andrew Gray oder Thomas Moore. Sie erreichten ab Anfang der 1980er Jahre, dass Stipendien für Schul- und Hochschulausbildungen an einzelne Jugendliche aus den Dörfern vergeben wurden. Hector Sueyo, Harakmbut aus der Region Madre de Dios, war einer der ersten Stipendiaten. Er erinnert sich, dass vor allem von Seiten der Ethnologen die Angst bestand, dass die Stipendiaten nach dem Studium in Lima nicht in ihre Heimatregionen zurückkehren würden. ${ }^{19}$ Gleichzeitig betont er, dass die Unterstützung durch Nicht-Peruaner von grundlegender Bedeutung für die Genese ihrer regionalen Organisation war (Gespräch Sueyo 09.06.2005).

\section{Voz Indígena - Sprachrohr AIDESEPs}

Ab 1982 gab AIDESEP eine eigene Zeitschrift heraus, die Voz Indigena ${ }^{20}$. Die thematische Entwicklung der Zeitschrift sowie der Wandel der Darstellungsform verweisen auf einen markanten Institutionalisierungsprozess, den die Organisation seit ihrer Gründung durchlaufen hat. ${ }^{21}$ Im Folgenden möchte ich deshalb einen Blick auf die Verschiebungen inhaltlicher, terminologischer und gestalterischer Schwerpunktsetzungen der einzelnen Jahrgänge werfen,

19 Eine Befürchtung, die sich in vielen Fällen später bewahrheitete.

20 Dt. >Indigene Stimmeく. Diese Zeitschrift erschien am Anfang vier bis fünf Mal im Jahr, später in unregelmäßigen Abständen.

21 Vgl. hierzu die theoretischen Ausführungen im Kapitel II.1. Ich danke Käthe Meentzen, die mir 2005 Zugang zu ihrem privaten AIDESEP-Archiv gewährte. So war es mir möglich, sämtliche bis dato erschienenen Ausgaben der Zeitschrift bei der Analyse zu berücksichtigen. 
um der Frage nachzugehen, welche spezifische Funktion die Zeitschrift als Sprachrohr der Organisation heute besitzt: Wer kommuniziert mit wem und worüber wird gesprochen?

In den ersten Jahren war die Voz Indígena ein vor allem auf die Kommunikation zwischen lokaler und nationaler Ebene konzentriertes Informationsblatt mit Berichten über Probleme, Seminare, Kurse und Versammlungen in einzelnen Mitgliedsgemeinden. Ferner wurden Besuche von Repräsentanten aus den Föderationen in Lima thematisiert sowie Briefe von Mitgliedern an AIDESEP veröffentlicht, aus denen die Hoffnung der Gemeindemitglieder sprach, dass ihre Kinder mit Hilfe der Organisationen studieren könnten. Die Herausgeber der Zeitschrift zeigten vor allem Interesse an konkreten Problemen in einzelnen Mitgliedsregionen von AIDESEP, das Thema `Kultur $<$ - im Sinne einer materiellen Bestandsaufnahme - interessierte sie kaum (vgl. AIDESEP 1982 (1-4), 1983 (5-7), 1984 (8-9)). So erzählt die Deutsche Käthe Meentzen, Unterstützerin der ersten Stunde, dass sie und andere darauf drängten, die Zeitschrift auch »zur Darstellung der indianischen Kulturen« zu nutzen. Dieser Vorschlag fand jedoch nur ganz allmählich Aufnahme: »Die Indigenen wollten über Probleme und Versammlungen berichten, auch Fotos waren ihnen nicht wichtig« (Gespräch Meentzen 02.05.2005). Lediglich die Shipibo hätten schon 1979 eine Kooperative für Kunsthandwerk gehabt. Meentzen schlussfolgert daraus, dass es unter den Shipibo ein ausgeprägteres Bewusstsein für >Kulturく gab als in den anderen Gruppen. Ansonsten sei das Thema von den >Weißen $<$ in der Voz Indígena eingeführt worden. Die ersten fünf bis zehn Jahre habe es kein Bewusstsein unter den Organisationsmitgliedern dafür gegeben.

Themenschwerpunkte der ersten Jahre bildeten hingegen vor allem die Bereiche zweisprachige Erziehung, Gesundheit, Landprobleme und Invasion von Holzfällern in den Gemeindeländern. Gleichfalls wurden regionale, nationale und internationale Treffen beschrieben sowie Neugründungen von Föderationen. Man setzte sich kritisch mit dem SIL und allgemein mit der Arbeit der Missionare im Tiefland auseinander. Ab 1984 rückte dann die internationale Arena stärker ins Zentrum der Berichterstattung. Es wurde das Gründungstreffen der COICA beschrieben und der Zweck des Zusammenschlusses begründet (vgl. AIDESEP 1984 (9-11)). Allerdings stammten diese Beiträge hauptsächlich aus der Feder von Käthe Meentzen (Gespräch Meentzen 02.05.2005). Das lässt darauf schließen, dass die Verbreitung von Informationen über die internationalen Instanzen zu diesem Zeitpunkt vor allem für die nicht-indigenen Unterstützer eine große Bedeutung zu besitzen schienen. Auffällig ist, dass bis dahin die Terminologie zur Eigenbezeichnung in der Zeitschrift variierte: Es war von nativos, ethnischen Gruppen, indigener Bevölkerung und vereinzelt schon von indigenen Völkern die Rede (vgl. AIDESEP 1982 (1-4), 1983 (5-7), 1984 (8)). Mit dem Gründungstreffen der COICA 
setzte sich jedoch in der Voz Indígena die Bezeichnung >indigene Völker durch: zuerst im Editorial der Mai/Juni-Ausgabe (AIDESEP 1984 (10)), dann wurde die Bedeutung des Begriffs in der darauf folgenden Ausgabe (AIDESEP 1984 (11)) erklärt.

Ein Jahr später berichtete man erneut von der Teilnahme AIDESEPs am Treffen der Arbeitsgruppe indigene Völker in Genf und postulierte »vida, tierra, autodeterminación « ${ }^{22}$ als zentrale indigene Forderungen (vgl. AIDESEP 1985 (13-14)). In der ersten Ausgabe des Jahres 1989 verwies man ferner im Editorial der Zeitschrift darauf, dass die Umsetzung des indigenen Territorialrechts die zentrale und erste Aufgabe der Organisation darstelle.

Eine weitere Neuerung im Jahr 1989 war die Berichterstattung von einem Treffen indigener Frauen. In diesem Zusammenhang wurde auf andere Themensetzungen der Frauen verwiesen: Misshandlung, Vergewaltigung, schlechte Arbeitsbedingungen, Krankheiten und Waisenkinder wären die zentralen Themen des Treffens gewesen (AIDESEP 1989 (23-24)). ${ }^{23}$ Ferner berichtete man in derselben Ausgabe von der ersten Wahl eines lokalen indigenen Kandidaten in ein politisches Amt. Dieser drohte einem Wahlbetrug zum Opfer zu fallen, konnte sich aber erfolgreich dagegen wehren. Die Ausgaben von 1989 bestimmten ferner die Auseinandersetzungen mit der neu sich etablierenden nationalen Konkurrenzorganisation CONAP. Man beschuldigte nicht-indigene NGOs, an der Gründung dieses Zusammenschlusses maßgeblich beteiligt gewesen zu sein, um AIDESEP zu schwächen und die eigene Position auszubauen. Während das Feindbild Missionar im Laufe der Zeit etwas verblasste, rückten andere Gegner ins Zentrum: in erster Linie NGOs, denen ein paternalistischer Umgang mit dem \Thema Indigene` vorgeworfen wurde (AIDESEP 1989 (21-24)).

Ab 1991 bekam die Zeitschrift eine feste Struktur. Die Rubriken Gesundheit, Frauen, Territorium, Bildung, Umwelt, Menschenrechte und politische Rechte wurden dauerhaft eingerichtet. Auch die Darstellung internationaler Entwicklungen und die der internationalen Vernetzung AIDESEPs erhielten mit Beginn der 1990er Jahre breiten Raum in der Zeitschrift. Zudem wurde der Zuwachs an lokalen Föderationen, vor allem im Lichte der Auseinandersetzungen mit der nationalen Konkurrenzorganisation CONAP, zu einem wichtigen Gradmesser der eigenen Organisationsstärke. So hielt man in der ersten Ausgabe von 1992 fest, dass fünfundzwanzig Föderationen AIDESEP angehörten und sich im letzten Kongress fünf neue angeschlossen hätten. Es wurden sieben indigene Abgeordnete in regionalen Parlamenten und ebenso viele indigene Bürgermeister gezählt (AIDESEP 1992 (30-31)).

22 Dt. >Leben, Land, Selbstbestimmung<.

231991 berichtet die Voz Indigena von der Einrichtung eines Frauensekretariats in der Leitung der AIDESEP. Allerdings bleibt der Posten unbesetzt und wird ab der darauf folgenden Ausgabe auch nicht wieder erwähnt. 
Von 1991-93 standen die Gründungen anderer internationaler Zusammenschlüsse ${ }^{24}$, denen AIDESEP beitrat, eine Evaluierung des indigenen Aufstands in Ecuador, die Unterzeichnung der ILO 169 durch Peru sowie die Verleihung des Friedensnobelpreises an Rigoberta Menchú im Zentrum der Berichterstattung. Ende 1993 wurde die Zeitschrift eingestellt (AIDESEP 1993 (36-37)) und erschien erst ab 2003 in unregelmäßigen Abständen erneut. $^{25}$

Die neuen Ausgaben tragen die Zahlen 25, 26, 27 und verstehen sich damit wohl als Anschlussnummern zu den Zeitschriften des Jahres 1989. Sie sind professionell gestaltet und fokussieren vor allem die Darstellung der Arbeit im Kontext nationaler Entwicklungen. Die Voz Indigena 26 richtet sich in einer kurzen Einleitung an folgende Leser: »die Brüder der Basis, unsere Mitbürger und unsere Freunde aus Peru und der Welt« (AIDESEP 2004b: 3). Die `Brüder der Basis k kommen jedoch selber nicht mehr direkt zu Wort bzw. hauptsächlich vermittelt durch die regionalen Instanzen. Im Gegensatz zu den Zeitschriften der frühen Jahre steht vor allem die Präsentation der legalen Erfolge und institutionellen Weiterentwicklungen der nationalen Instanz im Vordergrund. Die Vorstellung einzelner Projekte erfolgte hingegen schon in den 1980er Jahren, in den neuen Ausgaben nehmen sie jedoch die Form von >Programmen an. Dies verweist auf einen Institutionalisierungsprozess der thematischen Arbeitsschwerpunkte AIDESEPs. Viele farbige Fotos veranschaulichen die Inhalte der einzelnen Artikel, die eine gefestigte Terminologie vorweisen: Im Vergleich mit den ersten Ausgaben der Zeitschrift sticht unter anderem die durchgängige Verwendung der Begriffe >indigene Völkerく und >Territorium ২ hervor, die sich allerdings schon in den späteren Ausgaben der 1980er Jahre duchgesetzt hatte. In der Jubiläumsausgabe zum 25-jährigen Bestehen AIDESEPs (AIDESEP 2005) rückt die Geschichte der Organisation ins Zentrum der Darstellung. Neben den ehemaligen Präsidenten kommen auch einige ihrer langjährigen Unterstützer zu Wort.

Insgesamt belegt die Durchsicht der Zeitschrift aus den verschiedenen Epochen der Organisationsgeschichte den Professionalisierungsprozess AIDESEPs, der deutlich einhergeht mit einer Perspektivveränderung: Nicht mehr so sehr einzelne lokale Probleme, sondern die von der nationalen Instanz AIDESEP eingenommenen, politischen Positionen stehen im Vordergrund. Die

24 So entstand unter anderem 1990 das Klimabündnis, ein Zusammenschluss europäischer Städte und Gemeinden, die eine Partnerschaft mit indigenen Völkern der Regenwälder eingingen, die sie als wichtige Partner im Kampf um den Erhalt des globalen Klimas ansehen. Auch wurde 1992 die Alianza Mundial de los Pueblos Indigenas de los Bosques Tropicales auf einer Konferenz in Malaysia gegründet, ein Bündnis, das sich für die Rechte indigener und tribaler Völker und für deren Vernetzung untereinander einsetzt.

25 Bis 2005 erschienen drei neue Ausgaben. 
Zeitschrift hat sich zu einem Sprachrohr entwickelt, das weniger der Rückkoppelung zwischen 〉Basis` und `Führung als Repräsentationszwecken gegenüber Staat und externen Unterstützern dient. Sie dokumentiert die Arbeitserfolge der Organisation und kann zur Legitimation des eigenen Führungsanspruchs herangezogen werden - auch, aber eben nicht primär, gegenüber der eigenen politischen Gemeinschaft. Ob die Zeitschrift auf lokaler Ebene verteilt und gelesen wird, lässt sich schwer belegen. Anzunehmen ist jedoch eine eher geringe Verbreitung, da mündliche Kommunikationsformen im Tiefland schriftlichen vorgezogen werden und in den von mir besuchten Gemeinden kaum AIDESEPPublikationen vorhanden oder bekannt waren. Das igeschriebene Wort « erreicht und beeindruckt vor allem diejenigen, die für den Erhalt der Organisation am wichtigsten sind: europäische und nordamerikanische Unterstützer.

\section{Wachstum und Fragmentierung}

»Es gibt keine einzige Organisation eines indigenen Volkes, die [ausreichend] Legitimität genießt, um alle Gemeinden zusammenrufen zu können « (Interview Mora 15.01.2004).

In dem Maße, in dem die Organisation wuchs, neue Föderationen auf lokaler Ebene gebildet wurden und auch international ein übergeordneter Zusammenschluss entstand, wurde die Frage nach der politischen Legitimität AIDESEPs von verschiedenen Seiten immer eindringlicher gestellt. Wie wir im Folgenden sehen werden, entwickelte sich dieser Konflikt parallel auf zwei Ebenen: im nationalen und im lokalen Kontext.

Ab Mitte der 1980er Jahre erhielt AIDESEP die ersten Projektgelder in kleinerem Umfang zur eigenen Verwaltung. Evaristo Nugkuag erinnert sich, wie schwierig es am Anfang war, finanzielle Unterstützung für die nationale Organisation zu erhalten:

»Unterstützung bekommt man erst, wenn die Geldgeber Erfolge der Organisation sehen. Brot für die Welt und Oxfam América, die zu diesem Zeitpunkt bereits meine lokale Föderation $\mathrm{CAH}$ unterstützten, ließen sich davon überzeugen, dass auch eine Unterstützung von AIDESEP gut sei [...]«(Gespräch Nugkuag 02.08.2005).

Zuvor waren einzelne lokale Organisationen direkt bzw. über NGOs unterstützt worden. Nun schienen die externen Geldgeber auch zu AIDESEP Vertrauen zu fassen und die Verwaltungsvorteile einer zentralen Instanz für sich zu erkennen. Ende der 1980er Jahre hatte AIDESEP ca. 40 Angestellte und konnte über Programmgelder in Höhe von Hundertausenden von Dollars verfügen. Das »Finanzierungssyndrom« (Smith 1996: 99) drang ins Innere von AIDESEP vor: der Druck, möglichst viele Gelder einzutreiben. Daran 
wurde der Erfolg der Repräsentanten gemessen. Der umfangreiche Geldfluss unterstützte einerseits den Prozess neuer Föderationsgründungen auf lokaler Ebene - häufig angeschoben von AIDESEP (vgl. Greene 2004). Andererseits kam es bald zu den ersten öffentlich gemachten Korruptionsfällen in den Organisationen, sowohl auf Ebene des internationalen Zusammenschlusses der COICA als auch in AIDESEP. Dies führte in der Folge, auf Druck der internationalen Geldgeber, zu einem Dezentralisierungsprozess. Auf regionaler Ebene gegründete Zweigstellen von AIDESEP begannen, sich als unabhängige Organisationen legal zu konstituieren und eigene Projektverträge mit internationalen Finanzinstitutionen und Unterstützer-NGOs abzuschließen. Zuvor waren Projektgelder bereits in AIDESEP Lima hängengeblieben und für andere Zwecke ausgegeben worden. Allerdings erwies sich die direkte Zuweisung von Projekten an die regionalen Koordinationsinstanzen oftmals als ebenso problematisch, was zu weiteren Korruptionsfällen führte.

AIDESEP stand zudem von Anfang an in Konflikt mit verschiedenen anderen Organisationen: zum einen mit CISA, zum anderen mit nicht-indigenen NGOs, die Projekte ohne Abstimmung mit AIDESEP in Gemeinden des Amazonasgebietes durchführten. Der Konflikt war für Smith (1996: 98) vor allem ökonomisch begründet: ein Streit um Fördergelder. Nach dem Ende der Militärregierungen und durch die Rücknahme vieler unter General Velasco durchgeführter Reformen war die Nachfrage nach nicht-staatlicher technischer Hilfe und Weiterbildung sowohl in den urbanen Zentren als auch auf dem Land groß (vgl. Ávila 2000). Alberto Chirif (1995: 352) führt dazu aus, dass das Erscheinen von AIDESEP einen Einschnitt in die Aktionsfelder der etablierten Lobby-Institutionen bedeutete, sowie den Verlust ihrer hervorgehobenen Vermittlerfunktion zwischen indigenen Gemeinden, Staat und Finanzinstitutionen. Viele lokale Föderationen wollten nun selbst diese Funktion ausfüllen oder aber AIDESEP als ihrer nationalen Vertretungsinstanz diese Aufgabe überantworten. Die internationalen Finanzinstitutionen fingen im Gegenzug an, ihre Geldvergabe davon abhängig zu machen, ob die peruanischen NGOs ihre Arbeit mit AIDESEP abstimmten. Dieser Konflikt um Gelder und Kontrollfunktionen begünstigte die Entstehung einer weiteren nationalen Interessenvertretung der Amazonasbewohner, der Confederación de Nacionalidades Amazónicas del Perú (CONAP). 


\section{Der Konflikt zwischen AIDESEP und CONAP}

1987, nach einem Treffen des Präsidenten Alan García mit Hunderten von Vertretern von comunidades nativas in Pucallpa, wurde CONAP gegründet. ${ }^{26}$ Fünfzehn Föderationen aus dem Amazonasgebiet kamen zu einem von CISA organisierten Kongress in Lima zusammen und bildeten den neuen nationalen Zusammenschluss. Chirif (1995) und Smith (1996) interpretieren die Gründung von CONAP als Schachzug nicht-indigener NGOs und von CISA, um AIDESEP zu schwächen und ihre eigene Position zu stärken. Jedoch bietet sich auch eine andere Lesart an: Während in AIDESEP in den 1980er Jahren die Aguaruna unter Leitung von Evaristo Nugkuag dominierten, waren die Gründer und Hauptakteure von CONAP in der Anfangszeit Amuesha (vgl. Pacheco 2000: 256). Dies lässt darauf schließen, dass auch interne Interessenkonflikte und Machtkämpfe die Entstehung einer weiteren nationalen Vertretungsinstanz begünstigten (vgl. Greene 2004: 445f.). Die ethnische Abgrenzung wurde in der transethnischen Organisation nicht >überwunden - wie Survival International postulierte (vgl. Kapitel VII) - sondern blieb weiterhin relevant.

AIDESEP versagte in der Folge CONAP öffentlich die Legitimität als Repräsentationsorgan. In Zeitungsartikeln nannten sie sich selbst die >authentischen Repräsentanten, zum Ausdruck gebracht in ihrer rakkreditierten Arbeit mit internationalen Organisationen und als Empfänger des alternativen Nobelpreises (Greene 2004: 443). Auch auf lokaler Ebene wiederholte sich der Streit zwischen AIDESEP und CONAP. Dort äußerte er sich in neuen Föderationsgründungen, die sich von bestehenden abspalteten. So entstanden zum Beispiel an verschiedenen Orten im departamento ${ }^{27}$ Amazonas Ende der 1980er und Anfang der 1990er Jahre neue Aguaruna Föderationen. Diese schlossen sich CONAP an bzw. lösten sich vom AIDESEP-Gründer Evaristo Nugkuag und seinem bereits vorgestellten Consejo Aguaruna Huambisa (CAH) als der bis dahin in der Region dominanten Organisation.

Neben der von AIDESEP-Unterstützern meist propagierten negativen Beurteilung, derzufolge die Fragementierung der Organisationen sowie die beständigen Neugründungen die politische Bewegung der Tieflandindianer schwächten, bieten sich auch zwei alternative Einschätzungen des Prozesses an:

- Man kann diesen, bezogen auf den nationalen Kontext, politikwissenschaftlich als demokratischen Ausdruck vielfältiger Meinungen interpretieren. Demzufolge gibt es nicht eine nationale Vertretung, sondern zwei

261986 begann Alan García seine sogenannten rimanakuy (Quechua; dt. >Dialog`) - direkte Treffen mit Vertretern aus Gemeinden, um Probleme zu diskutieren und Lösungen zu suchen.

27 Peru ist in 24 politisch-administrative Einheiten unterteilt, die departamentos. 
>Parteien`. Auch wenn beide Organisationen ihre Arbeit als >überparteilich definieren, vertreten sie letztendlich nur die jeweiligen Ansichten eines Teils der Tieflandindianer. Nicht alle können sich mit den Zielsetzungen AIDESEPs identifizieren. CONAP stellt sich diesbezüglich als Alternative mit teilweise unterschiedlichen politischen Forderungen dar.

- Man kann die Abspaltungen sowie Neugründungen von Organisationen ethnologisch als Manifestation des dominanten akephalen Vergesellschaftungsprinzips der Tieflandindianer deuten. Misstrauen gegenüber >korrupten< Repräsentanten und die ständige Herausbildung neuer Fraktionen innerhalb der Dörfer bzw. auf suprakommunaler Ebene verhindern die Machtanhäufung in den Händen Einzelner.

Der Konflikt zwischen AIDESEP und CONAP hält bis heute an, jedoch gibt es inzwischen auch Situationen, in denen beide Zusammenschlüsse kooperieren und sich gemeinsam gegen einen externen Dritten verbünden. ${ }^{28}$ Allgemein unterscheidet beide Organisationen die Schwerpunktsetzung in ihrem jeweiligen offiziellen Diskurs: Während AIDESEP die Interessen von Regierung und privaten Unternehmen am Abbau der natürlichen Ressourcen im Siedlungsgebiet Indigener vollständig ablehnt, glaubt CONAP, dass es vor allem um eine gerechtere Beteiligung der Indigenen an der Nutzung dieser Ressourcen gehen muss. Cesar Sarasara, Präsident der CONAP, meint diesbezüglich: »Idealismus ist sehr gut, aber lasst uns Realisten werden. [...] Wir sind Peruaner, [...] Teil eines Staates, der uns nicht gehört [...]. Deshalb müssen wir weise sein« (Interview Sarasara 21.01.2004).

Dieser >pragmatische Realismus « lässt sich vielleicht auch mit der Entstehungszeit CONAPs erklären. Zu diesem Zeitpunkt zeichnete sich, auf nationaler wie internationaler Ebene, ein entwicklungspolitischer Diskurswechsel ab. War in den 1970er und frühen 80er Jahren politische Bildungsarbeit, die sogenannte >Bewusstseinsbildung`, Fokus der NGOs (sowie, wie im geschichtlichen Rückblick gesehen, zeitweise der peruanischen Regierung), änderte sich dies mit der globalen Dominanz neoliberalen Gedankenguts ab Mitte der 1980er Jahre. In den 1990er Jahren standen so vor allem wirtschaftliche Projekte auf den Aktionsprogrammen vieler peruanischer und interationaler NGOs (vgl. Ávila 2000).

28 Jedoch steht CONAP in nicht-indigenen Unterstützerkreisen stärker in der Kritik als AIDESEP. Der Organisation wird vorgeworfen, einen top-down Ansatz zu verfolgen und wenig demokratische Erneuerung (in Form von Wahlen) der Führungsspitzen zuzulassen. Hinzu kommen Verhandlungen mit Ölgesellschaften, die dem Ansehen der Organisation geschadet haben. Meist wird in der Unterstützer-Szene in Peru zwischen CONAP- und AIDESEP Sympathisanten auf exklusive Weise unterschieden. 
CONAP setzt stark auf das Thema >Wirtschaft $<$ und plädiert, wie gerade beschrieben, für eine Beteiligung der Tieflandindianer an der ökonomischen Nutzung der Ressourcen des Amazonasgebietes. Sarasara drückte dies wie folgt aus:

»Das indigene Volk muss sich aktualisieren, muss an heute denken, vom Jetzt ausgehend die Zukunft in Angriff nehmen. Es sieht, wie die verschiedenen Firmen über Verträge mit dem Staat seinem Territorium die Ressourcen entnehmen, seit langem schon und alle verdienen daran. Ein großes Unternehmen präsentiert sich, und alle fordern Geld - die NGOs, die Kirche, der Staat, [...] alle Welt fischt nach dem Geld, nur der Indigene nicht, der sieht, dass seine Bodenschätze entnommen werden und wartet, dass der Staat ihm irgendwann hilft. Aber der hilft ihm auch nicht. Ich glaube deshalb, dass wir anfangen müssen, selber Dialoge zu führen und direkte Programme mit ihnen [den Unternehmen] abzuschließen« (Interview Sarasara 21.01.2004).

\section{Zukunftsvisionen von AIDESEP und CONAP: Autonomie versus Integration}

In der politischen Sphäre gilt ein einfacher Grundsatz: Einem jeden Anführer gedeiht es zum Vorteil, eine produktive Gesellschaft zu leiten (vgl. Kurtz 2001: 34). In zentralisierten Systemen ist die Kontrolle und Nutzung der wirtschaftlichen Produktion einer politischen Gemeinschaft sogar eine zentrale Ressource zur Etablierung politischer Macht. Was aber macht eine Führung, die ihre politische Gemeinschaft als freiwilligen Zusammenschluss definiert, die nicht auf die ökonomische Unterstützung ihrer Gefolgschaft zählen kann und ihrerseits von externen Unterstützern abhängig ist?

Sieht man das vorangegangene Zitat von Sarasara im Lichte dieser Frage, spricht er die zentrale Herausforderung an, denen die indigenen Organisationen gegenüberzustehen scheinen: der Entwicklung wirtschaftlicher Alternativen für die von ihnen Vertretenen, die unausweichlich in das von staatlicher Seite geförderte marktwirtschaftliche System einbezogen sind. Dieses funktioniert im Tiefland vor allem auf Grundlage von Tätigkeiten, die auf Überschussproduktion und Ausbeutung der natürlichen Ressourcen ausgerichtet sind: extensive Landwirtschaft, Viehzucht, Erdöl- und Gasförderung, Kupferabbau, Goldsuche, Abholzung von Edelhölzern - Aktivitäten, die in Konflikt stehen mit einem für indianische Gesellschaften des Amazonasgebietes als charakteristisch dargestellten Wirtschaftsmodell. Bei Letzterem steht nicht Akkumulation, sondern Umverteilung und Versorgung sowie Vielfalt der Nutzungsweisen der natürlichen Umwelt im Zentrum. Es ist eine Form der Ökonomie, die auf dem Prinzip der symmetrischen Reziprozität basiert - auf Austauschbeziehungen innerhalb und zwischen wirtschaftlichen Einheiten, 
deren Ziel der Aufbau sozialer Verpflichtungen ist. Im Gegensatz zur Marktwirtschaft zielt das Individuum in der Logik dieses Wirtschaftsmodells somit nicht auf die Vergrößerung des eigenen finanziellen Kapitals ab, sondern stärkt oder vergrößert über sozial und ökonomisch relevante Transaktionen seine bestehenden Netzwerke mit anderen Personen.

Trotz Einschluss in die Marktwirtschaft bleibt dieses System als normative Vorgabe für die Regelung sozialer Beziehungen im lokalen Kontext vielerorts im Tiefland weiterhin durchaus relevant (vgl. u.a. García 2003; Lehm 2003; Smith 2002b; Gasché 2004). Gasché (2004: 112) verweist in diesem Zusammenhang auf drei Ebenen, die für die Etablierung reziproker Austauschbeziehungen unter der indianischen Bevölkerung im peruanischen Tiefland bedeutsam sind: Arbeit, Distribution und Zeremonien. Wirtschaftlich (und damit auch sozial und politisch) relevante Kollektive entstehen durch Kooperation bei produktiven Tätigkeiten, durch das Teilen von Nahrungsmitteln und anderen Gütern sowie das gemeinsame Feiern von Festen und Riten. Diese verpflichtenden sozialen Bindungen werden durch Verwandtschaftsbeziehungen markiert und gestärkt. Das abstrakte, weitestgehend unpersönliche Arbeits- und Tauschmodell marktwirtschaftlicher Provenienz steht somit dem idealtypischen >indianischen Modelk des miteinander Wirtschaftens konzeptionell entgegen. Allerdings lässt sich, wie auch Smith (2002b: 163) festhält, diese dichotome Gegenüberstellung in der Realität nicht aufrechterhalten: `Kapitalistisches Denken`, die marktwirtschaftliche Ausrichtung, findet sich auch unter Tieflandindianern. Smith verweist in diesem Zusammenhang auf Bora und Huitoto im Ampiyacu, die uneingeschränkte Jagd auf Tiere machen, deren Fleisch auf dem Markt viel Geld einbringt. Auch bei meinen Besuchen in Asháninka-, Huitoto- und Cocama-Cocamilla-Siedlungen erzählten mir Dorfbewohner und Organisationsvertreter immer wieder von Konflikten, die auf Grund ähnlicher Aktivitäten von Mitgliedern ihrer Gemeinden vor Ort entstünden. Es gibt zudem kaum noch Gegenden, in denen kein Geld benötigt wird, um handeln und Gegenstände des täglichen Bedarfs erwerben zu können. Die Teilnahme am marktwirtschaftlichen Tauschsystem gestaltet sich jedoch in den meisten Fällen weiterhin über Zwischenhändler: Das über Jahrhunderte gefestigte Patronage-System kennzeichnet die Beziehung zwischen indigenen Tieflandbewohnern auf der einen Seite und Händlern, Arbeitgebern sowie Repräsentanten des Staates auf der anderen Seite. 


\section{AIDESEPs Antwort: Konzentration auf die ১Rückeroberung indigenen Territoriums}

In Bezug auf die Frage, wie man dem Problem der Dominanz marktorientierten Denkens und dem gefestigten Patronage-System im Amazonasgebiet begegnen kann, nehmen die Vertreter von AIDESEP und CONAP unterschiedliche Positionen ein. AIDESEP lehnt zwar Verhandlungen mit multinationalen Konzernen ab, konnte aber bisher im Gegenzug keine erfolgreiche, praxiserprobte Strategie zur Umsetzung eigenbestimmter Wirtschaftsweisen in den bereits titulierten Gebieten entwickeln: »[...] der wirtschaftliche Druck auf die natürlichen Ressourcen der indigenen Völker wächst beständig. [...] Auch wenn das wirtschaftliche Problem [...] ganz oben auf der Liste der Forderungen steht, hat AIDESEP dieses Thema bisher nicht tiefgreifend behandeln können, « heißt es selbstkritisch in einem Memorandum der Organisation (AIDESEP 2002: 36; eigene Übersetzung aus dem Spanischen). AIDESEPs Plan de vida ${ }^{29}$ (2003b) und ihr Vorschlag für eine »integrale indigene Wirtschaftsweise für eine Entwicklung mit Identität« (2004a) zielen zwar auf die Konkretisierung wirtschaftlicher Alternativen ab, formulieren aber weiterhin abstrakte Ziele: Es sind strategische Konzepte, die auf die Frage eingehen, was geschehen soll, wenn indigene Territorien demarkiert sind. Auf Föderations- oder Dorfebene zirkulieren diese Pläne selten. Unter den gegebenen Konflikten mit Siedlern aus anderen Landesteilen, illegalen Holzfällern, Händlern von Tierfellen, bezeichneten sie viele meiner lokalen Gesprächspartner zudem als »kaum umsetzbare Visionen«. Auf nationaler Ebene ist man sich dieses Problems bewusst. So hält der Plan de vida einleitend fest, dass »die Gemeinden sich in Bezug auf ihre wirtschaftlichen Probleme nicht von den Organisationen repräsentiert fühlen« (AIDESEP 2003b: 9). Als Gegenstrategie wird die Gründung selbstverwalteter, kommunaler Unternehmen vorgeschlagen, zum Beispiel im Bereich des Ökotourismus und im Bereich der Kommerzialisierung von Handwerkskunstprodukten (AIDESEP 2003b: 25). Doch wie eine Studie von Lehm (2003) nachweist, sind diesbezügliche Initiativen bisher relativ erfolglos. Die Autorin spricht ein grundsätzliches Dilemma an: Zwar ist >indigenes Wissen` gegenwärtig durchaus gefragt - zum Beispiel von Pharamzieunternehmen oder im Bereich des Ökotourismus - aber der reale Nutzen für die lokale Bevölkerung bleibt dennoch meist gering.

Der Erfolg indigener Organisationen auf internationaler Ebene hat derweil zum Einschluss der >Zielgruppe indigene Völker` in die Programme der Weltbank und anderer multilateraler Institutionen geführt. In den Wirtschaftsplänen dieser Einrichtungen erscheinen die indigenen Völker jedoch unter der

29 Dt. >Lebensplan . 
Rubrik >Arme $<$, denn sie werden auf Grundlage ihres mangelhaften Zugangs $\mathrm{zu}$ wirtschaftlichen Märkten und einem unterdurchschnittlichen Pro-KopfEinkommen kategorisiert (Lehm 2003: 8f.; vgl. auch García 2003). Der Wohlstand der Bevölkerung eines Landes wie Peru wird von Weltbank und IWF an Hand der Fähigkeit seiner Regierung beurteilt, die zur Verfügung stehenden natürlichen Ressourcen in Waren des freien Handels zu verwandeln (vgl. Coronil 2000). Der Diskurs dieser Institutionen ist vom Expansionsdrang marktwirtschaftlicher Logik geprägt, der alternativen Wirtschaftskonzeptionen kaum Raum zur Entfaltung lässt. Eine weitere Konsequenz dieser >Diskursdominanz besteht in dessen Wirkung auf die Vertreter indigener Organisationen: Wie beschrieben steht die Kanalisierung bzw. Sicherstellung des Geldflusses für viele Repräsentanten im Mittelpunkt ihrer Arbeit - auch auf Druck ihrer >Wählerschaft $\measuredangle$. Dies macht die Vertreter in erster Linie zu Empfängern bzw. Verwaltern von humanitären Hilfsgeldern und ihre Verbände $\mathrm{zu}>$ Rentierorganisationen $<$.

\section{Der Traum vom indigenen Territorium}

Im Angesicht des erdrückenden politischen Ungleichgewichts nimmt der Kampf um die sindigenen Territorien « weiterhin eine zentrale Stellung in den organisatorischen Zielsetzungen AIDESEPs ein. Denn, »das Thema Territorium ist das einzige, das sich in allen Köpfen Amerikas, vielleicht in der ganzen Welt, festsetzen konnte«, konstatiert der AIDESEP-Unterstützer Pedro García (Gespräch García 10.06.2005). Und Haroldo Salazar, 2004 VizePräsident sowie 2005 Präsident von AIDESEP, umreisst mit folgenden Worten das, was er als »das Herzstück indigener Politik« bezeichnet:

$»$ Wir haben mehr als 8 Millionen Hektar Land ${ }^{30}[\ldots]$ wir wollen [...] das indigene Territorium Perus erkämpfen. [...] unser Kampf hat sich bisher nicht darum gedreht Bürgermeister oder Kongressabgeordneter zu werden, nein, unser Kampf dreht sich darum, wie wir mehr Territorium gewinnen können [...] Wenn wir das einmal erreicht haben [...] können wir gewinnen, denn wir sind nicht viele Menschen, haben dann aber ein großes Territorium. Dann können wir in den Kongress einziehen.« (Interview Salazar 14.01.2004).

Der Kampf um die indianischen Siedlungsgebiete gilt - zumindest auf nationaler Ebene - erst dann als abgeschlossen, wenn zusammenhängende Territorien mit relativer Autonomie gegenüber der peruanischen Regierung bestehen.

30 Rummenhöller (2005: 2) spricht von bislang etwa 7500.000 ha demarkierter Fläche, die ca. $10 \%$ des peruanischen Amazonastieflandes ausmacht. $1.500 \mathrm{co}$ munidades nativas konnten erfolgreich Land titulieren lassen, einige hundert Gemeinden sind noch nicht demarkiert. 
Dabei gilt dieses Vorhaben unter den gegenwärtigen nationalen und internationalen Vorzeichen durchaus als eine sutopische Vision`. Im Gegensatz zu Ländern wie Kolumbien oder Brasilien muss das Land in Peru Stück für Stück, Dorf um Dorf, von den Organisationen >zurückerobert` werden (Interview Salazar 14.01.2004; Gespräch Antazú 26.05.2005; Gespräch García 10.06.2005; vgl. auch AIDESEP 2005).

García schildert die Komplexität des Problems an Hand eines Beispiels: In den 1970er Jahren half er, zusammen mit anderen Mitgliedern der bereits vorgestellten Grupo DAM, Aguaruna-Gemeinden am Cenepa, in Nordwestamazonien, bei der Titulierung ihrer Territorien. Ausgangspunkt ihrer Bemühungen war es, ein zusammenhängendes indianisches Gebiet zu schaffen bzw. zu erhalten. Dieses entwarfen die beteiligten indianischen Vertreter und ihre nicht-indigenen Unterstützer auf dem Papier wie ein Puzzle: Innerhalb eines festgelegten Bereichs wollten sie kommunale Landstücke erwerben, die sich derart aneinander fügten, dass keine nicht-indigenen Siedler mehr dazwischen Platz fänden. Allerdings mussten zu diesem Zweck einige Aguaruna-Familien innerhalb des Gebiets umsiedeln und neue comunidades gründen. Es waren allesamt sauf dem Reißbrett geschaffene Zuvor hatten die einzelnen Familien zwar auch an bestimmten Stellen bevorzugt gesiedelt, waren aber zum Jagen an andere Stellen innerhalb des Gebiets gezogen. Die zum Zwecke der Landtitulierung neu geschaffenen dörflichen Einheiten verwandelten sich jedoch mit der Zeit in feste Größen. Familien begannen, sich gegenseitig das Jagen in den Gebieten zu verbieten, die nun zur eigenen comunidad gehörten. Heute, so García weiter, würden vor allem die jungen Leute die comunidades nativas wie politische Einheiten behandeln, die seit jeher bestanden hätten. Sie interessierten sich nicht für das Thema >Territorium`, das eine umfassendere Vision von politischer Gemeinschaft enthielte. Sie sähen keine Möglichkeiten mehr, das Leben ihrer Vorväter zu führen. Die Anfangsidee der 1970er Jahre, intern alles wieder zu einem zusammenhängenden Territorium zu erklären, sobald das Gebiet vollständig mit Einzeltiteln versehen worden wäre, ließe sich heute wohl kaum noch realisieren. Ein großer Teil des Problems läge aber, so García, auch auf staatlicher Seite: Die comunidades gehören alle zu größeren politischen Einheiten, in denen Indigene selten das Sagen haben - zu Kreisverwaltungen und regionalen Regierungen. Die Funktionäre dieser politischen Instanzen verfolgen eigene Absichten, die zu Interessenkonflikten zwischen ihnen und den indigenen Tieflandbewohnern führen - vor allem in Gebieten, in denen Öl und andere Bodenschätze gefunden werden. Der Staat sowie privatwirtschaftliche Unternehmen können dabei letztendlich nahezu ungehindert in indianisches Gebiet eindringen. Vor allem diese makropolitischen Prozesse, welche die indigenen Organisationen weiterhin kaum politisch beeinflussen können, stehen der Umsetzung des Traums eines indigenen Territoriums, aus Perspektive des AIDESEP- 
Unterstützers, im Wege (Gespräch García 10.06.2005). Das Ideal eines autonomen indigenen Lebensraumes hat sich in der Realität vielerorts in eine von nationalstaatlichem Grenz- und Besitzdenken geprägte >Kleingärtneranlage` verwandelt (vgl. hierzu auch Dean 2002: 210).

Dieser von García beschriebene Prozess veranschaulicht das von Appadurai (1996: 178ff.) konstatierte dialektische Verhältnis zwischen lokalen Subjekten und ihrer Umwelt. >Nachbarschaften als Kategorie der real existierenden sozialen Formationen, in denen Lokalität als Wert bedeutsam wird, sind immer historisch und kontextgebunden. Sie stehen in Opposition zu anderen und gehen aus ihnen hervor. Nachbarschaften sind einerseits die Vorbedingung für lokale Subjekte. Gleichzeitig tragen diese zur Veränderung, Ausgestaltung und Bestätigung derselben bei. Doch darüber hinaus gibt es größere Formationen, die die Fähigkeit zur Kontextproduktion von Nachbarschaften beeinflussen: Staaten, transnationale Unternehmen etc. Im Fall der indianischen Gesellschaften des Tieflands, die unter den Einfluss der komplexen Organisationsform eines Kolonialreichs und später eines Nationalstaats gerieten, generierte das Gesetz der comunidades nativas in den 1970er Jahren unter weiten Teilen von ihnen ein neues lokales Selbstverständnis, das sich am staatlichen Denken orientierte. Die offizielle Umdeutung der zuvor lose und flexibel definierten lokalen Nachbarschaften in feste politische Einheiten ermöglichte zwar die Sicherung und Rückeroberung von Landtiteln mit staatlichen Mitteln, unterhöhlte aber gleichzeitig die praktische Umsetzung des anvisierten Ziels der Schaffung eines zusammenhängenden indigenen Territoriums: Das Beispiel der Aguaruna-Gemeinden am Cenepa verdeutlicht, wie nachhaltig der nationalstaatlich ordnende Eingriff auf das lokale Selbstverständnis vielerorts im peruanischen Tiefland zurückgewirkt hat.

Andere engagierte Unterstützer der indianischen Gesellschaften des Amazonasgebietes bewerten den Traum des zusammenhängenden indigenen Territoriums deshalb eher kritisch. So meint Alberto Chrif:

»Er [Pedro García] träumt davon, dass das indigene Territorium eines Tages wieder eins wird. Ich halte das für gefährlich und nicht mehr machbar. Der Einschluss in die Marktwirtschaft ist zu weit fortgeschritten. Was passiert, wenn alles ein zusammenhängendes Territorium wird und ein jefe beschließt, Holz zu verkaufen? Nein, die Parzellierung bietet größeren Schutz gegen den totalen Ausverkauf« (Gespräch Chirif 20.07.2005).

Allerdings führt Chirif (2005: o.S.) auch das Gegenbeispiel der Matsé an, die ihr Territorium nach den Einzeltitulierungen wieder erfolgreich zusammenschlossen.

AIDESEP setzt sich in den letzten Jahren verstärkt für die Schaffung von Schutzgebieten für die >indigenen Völker in freiwilliger Isolation` ein. Zu- 
mindest bei diesen Gruppen ist eine weitestgehende Autonomie der sozialen, politischen und wirtschaftlichen Ordnung weiterhin gegeben und kann durch entsprechende Schutzmaßnahmen auch in Zukunft garantiert werden. Für die Gemeinden, welche die Basis ihrer Organisation bilden, scheint diese Option jedoch gegenwärtig nicht mehr relevant zu sein.

\section{CONAPs Antwort: Integration in marktwirtschaftliche Zusammenhänge}

CONAP schlägt andere Wege ein. Die Organisation hat zwar die »Verteidigung der Kultur und Biodiversität indigener Völker« (CONAP o.J.: o.S.) als Leitspruch der Organisation gewählt, sieht aber dennoch im Abschluss von Verträgen mit Erdölunternehmen und Pharmaziekonzernen keinen Widerspruch zu diesem Grundsatz. In ihren institutionellen Richtlinien legt die Organisation als Aktionsfelder explizit »den Einschluss der indigenen Völker in die wirtschaftliche Aktivität« sowie »die Entwicklung von Unternehmen der indigenen Völker« fest (CONAP o.J.: o.S.). Während der wenig aufschlussreiche Ausdruck >wirtschaftliche Aktivität nur im Zusammenhang mit dem Beiwort >Einschluss` verrät, dass die Organisationsvertreter dabei an die marktwirtschaftlich orientierte Form des Wirtschaftens denken, verdeutlicht die >Entwicklung von Unternehmen` vielleicht besser die eingenommene Perspektive. CONAP arbeitete bisher unter anderem mit den in das CAMISEAGasförderungsprojekt ${ }^{31}$ involvierten Unternehmen zusammen und hat einen Vertrag mit einer US-amerikanischen Universität abgeschlossen, in der die Kooperation beider Institutionen bei der Suche nach Heilpflanzen zur Entwicklung neuer pharmazeutischer Medikamente festgelegt wurde (Interview Sarasara 21.01.2004). Diese Aktivitäten bringen CONAP sowohl von Seiten AIDESEPs als auch von deren nicht-indigenen Unterstützern massive Kritik ein. Wie stark Letztere sich in die politische Ausrichtung der Organisationen einzumischen versuchen, verdeutlicht Sarasara, 2004 Präsident von CONAP:

»Einmal kam eine Deutsche zu mir, die die Asháninkas kennt, und sagte mir: Du verkaufst indigenes Wissen. Da habe ich ihr geantwortet: Ich verkaufe [indigenes Wissen]? Na gut, wenn du nicht willst, dass ich [es] verkaufe, wenn du mir eine andere Alternative bringst, dann werden wir die umsetzen« (Interview Sarasara 21.01.2004).

31 Camisea-Projekt: Bau einer 700 Kilometer langen Gasleitung durch das peruanische Amazonasgebiet, die Zugang zu mehr als 11 Trillionen Kubikmetern natürlichem Gas und mehr als 600 Millionen Barrel Petroleumgas bietet. Entlang der Gasleitung und Bohrstationen leben u.a. die Kugapakori und Nahua. Bisher von indigenen Organisationen angezeigte Probleme sind u.a.: massive Bodenerosion, Verschlechterung der Nahrungsmittelversorgung durch Abnahme von Fischbeständen und Verschlechterung der Wasserqualität. 
Der Aguaruna Sarasara ist studierter Ökonom. Er nennt CONAP eine »Organisation von Armen« - arm im ıwestlichen Verständnis`, aber ১reich in Bezug auf die kulturellen Kenntnisse über indianische Lebens- und Wirtschaftsweisen (Interview Sarasara 21.01.2004). Da die Beziehung zwischen Staat und Indigenen eine asymmetrische ist, sieht Sarasara momentan jedoch keine Chance dafür, indianischen Reichtum auf >traditionelle Art und Weise< einzusetzen. In diesem Zusammenhang verweist er zum Beispiel auf die Missachtung der ILO-Konvention 169 von Seiten der Regierenden, obwohl Peru die Konvention bereits 1993 unterschrieben hat. Damit verpflichtete sich der Staat eigentlich dazu, auch Gebiete als indigenes Territorium anzuerkennen, in denen Sammel- und Jagdwirtschaft sowie andere kulturelle Nutzungsformen (z.B. spirituelle Aktivitäten) vorliegen. In der Praxis peruanischer Funktionäre, die die Anträge für die Titulierung der Territorien von comunidades nativas bearbeiten, bestimmen jedoch >positive Fakten « wie Häuserbau, Pflanzungen, Rinderzucht, Holznutzung etc. meist darüber, wie viel Land den Bewohnern zugesprochen wird. Zudem gehören Flüsse, Seen, Schluchten sowie alle unterirdischen Bodenschätze weiterhin dem Staat, auch wenn diese in den titulierten Gebieten liegen (Interview Sarasara 21.01.2004; vgl. auch García 2003: 22). Für Sarasara diktiert der ungleiche Zugang zu politischer Macht, der massive Auswirkungen auf die Umsetzungsmöglichkeiten für unabhängige Wirtschaftspläne hat, den Aktionsplan von CONAP. Er definiert den Ansatz seiner Organisation deshalb wie folgt:

»Der Indigene [...] muss jetzt, wenn sich ihm ein Unternehmen nähert, abschätzen können, welche Schäden diese Firma verursachen kann und welche Vorteile sie ihm bringen kann. Dann muss der Indigene darüber nachdenken, in welcher Form er sich beteiligen kann, damit die Schäden ausbleiben [...] und vor allem sagen, wie er am Gewinn beteiligt werden möchte. Denn, ob wir uns widersetzen oder nicht, der Staat, der sich als Besitzer des Territoriums fühlt, wird in jedem Fall die Ressourcen ausbeuten. Wir müssen auch eine praktische Philosophie entwickeln, ohne die ideologische Seite ganz zu vergessen« (Interview Sarasara 21.01.2004).

\section{Produktionsorientierte versus politische Organisationen}

Vielleicht möchte Sarasara mit seinem Ansatz auch die vorhandenen Spannungen zwischen sproduktionsorientierten schlüssen unter den indigenen Tieflandbewohnern überwinden. Lehm (2003: 23) beschreibt die Tendenz unter Tieflandindianern, produktiven Organisationen (also Zusammenschlüssen mit wirtschaftlichen Zielsetzungen) eine größere Legitimität zuzuerkennen als solchen, die auf die politische Repräsentation abzielen, da erstere spezifische und konkrete Funktionen besitzen. Beide Organisationsformen werden demnach intern als im Wettstreit miteinander 
stehend wahrgenommen. Unter diesen Vorzeichen ist in Peru 1995 ein nationaler Zusammschluss entstanden, der »technische und politische Vorschläge aus indigener und bäuerlicher Sichtweise« entwickeln möchte, »um die natürlichen Ressourcen zu nutzen« (Interview Rufner 05.05.2004): die Coordinadora Agroforestal Indígena y Campesina del Perú (COICAP) ${ }^{32}$. Die Organisation fördert zum Beispiel die Entwicklung von Holzunternehmen in indigenen Gemeinden im peruanischen Amazonasgebiet - auf Grundlage bestehender wirtschaftlicher Einheiten (Familien bzw. Netzwerke von Personen, die in direkten Austauschbeziehungen zueinander stehen). Damit wird auch der Erkenntnis Rechnung getragen, dass bisherige Projekte, die auf die Etablierung kommunal geführter Unternehmen abzielten, größtenteils fehlschlugen. Nicht die Dörfer sind in den meisten Fällen die kleinste wirtschaftlich (und politisch) relevante Einheit, sondern unabhängig davon agierende Netzwerke von miteinander in reziproken Austauschbeziehungen stehenden Individuen. Dieses Netzwerk beschränkt sich nicht unbedingt auf Mitglieder des eigenen Dorfes, sondern überwindet diese Grenzen (vgl. COICA und Oxfam 1995; Smith 2002b; Gasché 2004). Hildebrando Rufner, 2004 Mitglied im Vorstand von COICAP, definiert die Herausforderungen, vor denen die Tieflandindianer stehen, wie folgt:

$»$ Wir müssen jetzt in die Etappe der Produktion und des Gebrauchs der Ökosysteme und Biodiversität durch die indigenen und bäuerlichen Gemeinden eintreten [...] Wir müssen die Macht von AIDESEP und CONAP dezentralisieren [...] die politischen Gremien können nicht für die Menschen Entscheidungen treffen, die dort [in den Gemeinden] herausragen möchten [...] (Interview Rufner 05.05.2004).

Wenn man sich die Genese indigener Organisationen erneut ins Gedächtnis ruft, fällt auf, dass die Zusammenschlüsse anfangs gerade auch in Bezug auf wirtschaftliche Aspekte von Bedeutung waren. So wollten die Anwesenden bei der ersten Konferenz von Amuesha-Führern im Jahre 1969 unter anderem deshalb als Rechtssubjekte innerhalb des Nationalstaates anerkannt werden, um Zugang zu Krediten sowie die Möglichkeit zur Bildung von produktionsund marktorientierten Kooperativen zu erhalten (vgl. Kapitel VII). Auch der Zusammenschluss von Asháninka-Gemeinden im zentralen Tiefland, CECONSEC, war anfangs eine Genossenschaft für die Vermarktung von Kaffee gewesen. Der Ethnologe Carlos Mora reflektiert die Entwicklung indigener Organisationen in diesem Zusammenhang wie folgt:

»[...] eine Sache, die nicht erfolgreich entwickelt wurde und die es nicht geschafft hat, den allgemeinen Entwicklungsprozess zu begleiten, ist das wirtschaftliche Thema. Es gelingt [den Organisationen] nicht [...], ein Modell wirtschaftlicher Entwick-

32 Dt. >Forstwirtschaftlicher indigener und bäuerlicher Zusammenschluss Perus〈. 
lung und wirtschaftlicher Alternativen für die Gemeinden zu schaffen. [...] die Einschlussbedingungen in die regionalen Ökonomien haben sich beständig erschwert für die Gemeinden« (Interview Mora 15.01.2004).

Die wirtschaftlichen Beziehungen zwischen Mitgliedern indianischer Dörfer und externen Akteuren konnte bisher nicht grundlegend verändert werden. Auch wenn dieses Anliegen eines der zentralen Motive früher Organisationsgründungen war, erfüllten sich diesbezügliche Erwartungen an die Zusammenschlüsse nicht. Im Gegenteil: Die Organisationen waren und sind selbst abhängig von internationalen Zuwendungen. Damit verlieren zumindest die übergeordneten regionalen und nationalen Instanzen eine wichtige Quelle ihrer politischen Legitimation im lokalen Kontext. Es gibt keine konkreten gegenseitigen Verpflichtungen zwischen Direktive und Wählerschaft, wohl aber zwischen Repräsentanten und Geldgebern. CONAP schlug in dieser Hinsicht neue Wege ein und versuchte, eine größere wirtschaftliche Unabhängigkeit $\mathrm{zu}$ erreichen. Vielleicht schaffte es die Organisation auch deshalb, sich innerhalb kurzer Zeit zu einem ernstzunehmenden Konkurrenten AIDESEPs zu entwickeln.

\section{Die staatliche slndigenenpolitik am Anfang des 21. Jahrhunderts}

»Die verschiedenen Regierungen haben versucht, den indigenen Völkern Lösungen anzubieten. So entwickelt jede Regierung ein Programm [...], aber wenn sie aus dem Amt scheidet, stirbt auch ihr Programm« (Interview Sarasara 21.01.2004).

Nach dem abrupten Ende der Präsidentschaft von Fujimori im Jahre 2000 konnte die indigene Bewegung der Tieflandindianer kurzfristige politische Erfolge unter der Übergangsregierung von Valentín Paniagua verzeichnen. Aus der Selva Central reisten Abgesandte der Asháninka, Nomatsiguenga und Yanesha nach Lima. Sie wurden von Paniagua persönlich empfangen. Er bestätigte den Repräsentanten, dass die Probleme der Tieflandindianer struktureller Natur seien und versprach die Einsetzung einer Kommission, um Vorschläge bezüglich ihrer Forderungen zu erarbeiten. So kamen Anfang 2001 Delegierte von AIDESEP sowie CONAP mit Sozialwissenschaftlern und Regierungsbeamten zusammen, um am runden Tisch Probleme sowie Lösungsvorschläge zu diskutieren. Der Dialog wurde als `Öffnung` und Hoffnungsschimmer für eine Institutionalisierung indigener Interessenvertretung betrachtet (vgl. García und Lucero 2003; vgl. Lehm 2003; Smith 2001; Gespräch Meentzen 
20.01.2004). ${ }^{33}$ Diese Hoffnung setzte sich auch unter Alejandro Toledo anfangs noch fort - dadurch, dass er bewusst Gebrauch von indigenen Symbolen machte. So inszenierte er zum Beispiel seine Einsetzung zum Präsidenten mit einer Zeremonie in Machu Picchu. Außerdem unterzeichnete er zusammen mit den Präsidenten Boliviens, Ecuadors, Kolumbiens und Venezuelas die Deklaration von Machu Picchu - ein Dokument, das die >Verteidigung indigener Rechte in der gesamten Region versprach. Die Unterzeichner wollten damit unter anderem die Ausarbeitung und Verabschiedung der parallel zur UN-Erklärung indigener Rechte angestrebten Amerikanischen Deklaration zu den Rechten indigener Völker in der OAS vorantreiben. ${ }^{34}$

Toledos belgische Ehefrau Eliane Karp, (Hobby-)Ethnologin ${ }^{35}$ und des Quechua mächtig, machte das >Thema Indigene< auch zu ihrem offiziellen Anliegen als Präsidentengattin. Sie rief sich zur Vorsitzenden einer neuen Kommission aus - der Comisión Nacional para los Pueblos Andinos, Amazónicos y Afro-Peruanos (CONAPA) ${ }^{36}$. Die 1998 von Fujimori geschaffene Secretaría Técnica de Asuntos Indigenas (SETAI) ${ }^{37}$, welche die Funktion des Instituto Indigenista übernommen hatte, wurde derweil zum technischen Arm der CONAPA. Kritiker verwiesen bald auf den Umstand, dass damit die unter Paniagua erarbeiteten Vorschläge zunichte gemacht wurden, da die Kommission weder den Rang eines Ministeriums noch Eliane Karp ein offizielles Mandat innerhalb der Regierung besaß (García und Lucero 2003: 13). CONAPA wurde mit Mitarbeitern unterschiedlicher Ranghöhe aus verschiedenen Ministerien besetzt und besaß keinerlei Entscheidungsbefugnis, sondern bekam lediglich die wenig spezifische Funktion »Vorschläge zu erarbeiten« (vgl. Servindi 18, 2002: 1). Auch die Zusammensetzung des Gremiums

33 Die Ergebnisse dieses runden Tisch wurden in einer Publikation zusammengefasst und veröffentlicht unter den Titel Defendamos los derechos de los pueblos indígenas amazónicos. Memoria de un proceso de interlocución 2001 (ARPI o.J.).

34 Als weiteres Indiz für eine Wandlung der Beziehungen zwischen Regierung und Indigenen wurde auch die Wahl der Aymara Paulina Arpasi als Kongressabgeordnete durch Toledos Partei Perú Posible gesehen.

35 García und Lucero (2003: 23) bemerken in ihrer Analyse der indigenen Bewegung des peruanischen Amazonasgebiet, dass Eliane Karp entgegen der allgemeinen Annahme, in Stanford, wo sie Toledo kennen lernte, nicht Ethnologie sondern Französisch studiert hätte.

36 Dt.>Nationale Kommission für die Völker der Anden, des Amazonas und für die Afro-Peruaner<.

37 Dt. >Sekretariat für indigene Angelegenheiten`. Das Sekretariat wurde Teil des Frauen- und Entwicklungsministeriums, während das Instituto Indigenista dem Landwirtschaftsministerium zugeordnet worden war. Durch die Umstrukturierung des Instituts in ein Sekretariat sowie dessen Zuweisung zu einem relativ unbedeutsamen Ministerium verwies Fujimori de facto die Einrichtung auf unterste Ebene der staatlichen Bürokratie (Gespräch Barclay 16.04.2004; vgl. auch Dean 2002: 203). 
wurde als unzureichend kritisiert: die indigenen Repräsentanten seien von Karp ausgesucht worden, lautete der Vorwurf der Gegner. Der Präsident von CONAP, César Sarasara, bringt die Kritik folgendermaßen auf den Punkt:

»Diese Regierung hat das Modell der CONAPA ins Leben gerufen, das interessant ist. Aber die Regierenden denken immer noch, dass wir selbst nicht fähig sind, uns zu beteiligen, einen akademischen, intellektuellen Beitrag zu leisten. Deshalb versuchen sie, ihre Denkweise durch eine Institution wie CONAPA durchzusetzen« (Interview Sarasara 21.01.2004).

Die neue Kommission erhielt fünf Millionen Dollar von der Weltbank, ein Kredit, der für Projekte zu Gunsten der indigenen Bevölkerung gewährt wurde. Um die Verwendung dieser Gelder spitzte sich im April 2004 ein öffentlicher Streit zu, in dem CONAPA der Misswirtschaft angeklagt wurde (vgl. IWGIA 2005: 174f.). Zu diesem Zeitpunkt war die Präsidentengattin bereits auf Grund massiven Drucks in ihrem Amt durch den jungen Shipibo Miguel Hilario ersetzt worden, der aber weder von AIDESEP noch von CONAP als legitimer Repräsentant anerkannt wurde. Eliane Karp und ihre private Stiftung Fundación Pacha wurden zur Zielscheibe des öffentlichen Korruptionsvorwurfs in Bezug auf die Verwendung des Weltbankkredits. An dem Ärger, der sich über ihre Person verbreitete, war auffallend, dass ihr als NichtPeruanerin der Vorwurf gemacht wurde, in quasi kolonialer, paternalistischer Manie >für die Indigenen` sprechen zu wollen. Wenn auch meist die internationalen Unterstützer die wichtigsten Verbündeten indigener Organisationen sind, können sich diese spositiven Attribute in politischen Auseinandersetzungen schnell in ihr Gegenteil verwandeln. In zahlreichen Gesprächen, die ich mit indigenen Aktivisten führte, wurde Eliane Karp vorgeworfen, dass sie sich eines Themas bemächtige, in dem sie als Ausländerin Zurückhaltung üben müsse.

CONAPA wurde im Laufe des Jahres 2004 aufgelöst, und an seine Stelle trat eine neue Institution: Am 16. Dezember 2004 verabschiedete der Kongress eine Resolution zur Schaffung eines autonomen Organismus mit ministerialem Rang, das den Namen Instituto Nacional de Desarrollo de los Pueblos Andinos, Amazónicos y Afroperuanos (INDEPA) ${ }^{38}$ erhielt. Neun indigene Repräsentanten aus den Anden und dem Amazonasgebiet sowie der Afroperuaner sollten, so die Gesetzgebung, direkt in die Direktive von

38 Dt. >Nationales Institut für die Entwicklung der Völker der Anden, des Amazonas und der Afro-Peruaner indigene Angelegenheiten werden. Es soll die Ausführung von Projekten und Programmen koordinieren, die die $»$ Rechte und die Entwicklung mit Identität der Völker der Anden, des Amazonas und der Afro-Peruaner unterstützen« (vgl. IWGIA 2005: 174ff.). 
INDEPA gewählt und nicht, wie bei der Zusammensetzung von CONAPA, von der Regierung zugewiesen werden. ${ }^{39}$ Jedoch würde der Konstitutionsprozess der neuen Institution im Angesicht der Präsidentschaftswahlen im Jahr 2006 nur schleppend vorangehen, wie Vertreter indigener Organisationen sowie ihre Unterstützer im Juni 2005 zu Bedenken gaben (Gespräch Meentzen 07.06.2005; Gespräch Orozco 01.06.2005; Gespräch Agurto 16.06.2005). Die neu gewählte Regierung unter Präsident Alan García Pérez beschloss per Dekret im Februar 2007, die Eigenständigkeit INDEPAs aufzuheben und das Organ mit dem Ministerio de la Mujer y Desarrollo Social $(\mathrm{MIMDES})^{40} \mathrm{zu}$ fusionieren. Jedoch verabschiedete der Kongress im Oktober desselben Jahres einen Gesetzesentwurf, der diese Fusion wieder aufhob.

Die indigene Bevölkerung Perus scheint für die Regierenden vor allem dann zu einem Thema zu werden, wenn der Blick von außen auf das Land gerichtet wird - sei es auf Grund der Ausrufung einer entsprechenden UNDekade, weil Institutionen wie der IWF die Vergabe von Krediten an die Durchführung von Maßnahmen zum Einbezug der indigenen Bevölkerung knüpft, oder weil die Weltbank Kredite für Projekte zu vergeben hat. Das mäßige Interesse wurde auch eindrücklich durch ein Symposium zur staatlichen >Indigenenpolitik « am 30.Mai 2005 belegt, das von Abteilungen verschiedener Ministerien in Kooperation mit indigenen Organisationen (u.a. AIDESEP) organisiert worden war. Mehrere Teilnehmer der Veranstaltung bedauerten, kaum bzw. keine Abgeordneten unter den Besuchern zu sehen. Auch von den angekündigten hochrangigen Politikern, die auf der Rednerliste standen, erschien niemand. Anwesend waren hingegen die Vertreter nationaler und internationaler Entwicklungsorganisationen sowie Repräsentanten der indigenen Organisationen.

39 Die nationale Organisation CONAP kritisierte in einem öffentlichen Schreiben an Präsident Toledo vom 31.10.2005, dass entgegen der Forderungen nach paritätischer Besetzung (Hälfte Regierungsvertreter Hälfte Repräsentanten indigener Organisationen) nur 9 der 23 Mitgliedern von INDEPA von indigener Seite gestellt werden könnten. Ferner wird bemängelt, dass den Organisationen des Amazonasgebietes lediglich eine Beobachterfunktion bei den Wahlen zugewiesen werde, nicht aber eine ausführende, die ihnen eigentlich zustehe (CONAP 2005: o.S.).

40 Dt. >Ministerium für die Frau und soziale Entwicklungく. 


\section{Die COPPIP: Idee einer nationalen panindigenen Bewegung}

1997 entstand als Resultat eines Forums über indigene Rechte, das in Cuzco stattfand, die Conferencia Permanente de Pueblos Indígenas del Perú $(\text { COPPIP })^{41}$. An diesem Zusammenschluss beteiligten sich unter anderem Föderationen aus dem Amazonasgebiet sowie bäuerliche Gewerkschaften aus dem Andenraum (wie die CNA und CCP). Mit der Unterstützung einer kanadischen NGO führte die COPPIP in der Folge Seminare durch, um Vorschläge für Verfassungsänderungen zu erarbeiten. Der Zusammenschluss stand allen Organisationen offen, die sich mit indigenen Themen identifizierten und stellte den ersten Versuch in Peru dar, eine geschlossene nationale politische Bewegung zu kreieren, an der sich Anden, Küste und Amazonas gleichermaßen beteiligten. Bald jedoch entstanden die ersten Konflikte, die in einer Zweiteilung des Zusammenschlusses resultierten. Unter Führung der zwei stärksten Organisationen, AIDESEP und CONACAMI (Coordinadora Nacional de Comunidades Adversamente Afectadas por la Minería) ${ }^{42}$, erhielt die eine Hälfte in der Folge Unterstützung großer internationaler Entwicklungsorganisationen. Dahinter stand die Hoffnung, dass COPPIP sich als >peruanische Variante tionalen Zusammenschlusses indigener Organisationen in Ecuador, CONAIE, etabliert. Auch wollte man damit die >Reindigenisierung der Andenorganisationen unterstützen (Gespräch Rojas 14.04.2004). Im Falle CONACAMIs waren diese Bemühungen erfolgreich: Die Organisation war ursprünglich auf Grund von Problemen der darin zusammengeschlossenen Gemeinden mit Bergbauunternehmen entstanden. Letzteren waren unter Fujimori und Toledo große Konzessionen in Gebieten zugeteilt worden, die eigentlich in Besitz von comunidades campesinas waren. Nach und nach entwickelte CONACAMI jedoch auch einen Diskurs, der auf ihre $>$ Rechte als Indigene verwies (Gespräch Orozco 31.05.2005; Gespräch Agurto 18.05.2005).

AIDESEP und CONACAMI einigten sich auf einen wechselnden Vorsitz in der COPPIP. Gleichzeitig betonten vor allem die Vertreter von AIDESEP, dass die COPPIP lediglich eine Art runder Tisch der indigenen Organisationen aus ganz Peru sei, nicht aber die neue nationale Repräsentationsinstanz. Der damalige Vize-Präsident von AIDESEP, Haroldo Salazar, verwies in diesem Zusammenhang auf den Umstand, dass COPPIP bis 2004 kein eigenes Büro besessen hätte, sondern innerhalb der Räumlichkeiten seiner Organisation funktioniert habe. Er betonte nachdrücklich, dass AIDESEP seinen nationalen Vertretungsanspruch auf keinen Fall mit der COPPIP teilen oder gar an diese abgeben wolle (Interview Salazar 14.01.2004).

41 Dt. >Ständige Konferenz der indigenen Völker Perus<.

42 Dt. >Nationale Koordination von Gemeinden, die vom Bergbau betroffen sind . 
Miguel Palacín, Präsident von CONACAMI und 2003-2004 mit dem Vorsitz in der COPPIP betraut, erklärt die Bedeutung des Zusammenschlusses wie folgt:

»In den Anden mobilisieren wir viele Menschen und stellen unsere Forderungen, leisten Widerstand, es wird wenig verhandelt. Im Gegensatz dazu wird im Amazonas sehr wohl verhandelt, warum? Weil es in den Anden wenig Land gibt und wir viele Völker sind, gibt es nichts zu diskutieren, im Amazonas ist das anders herum: Es gibt viel Land und wenige Völker. Um nicht unterworfen zu werden, müssen sie verhandeln. So gibt es einen Austausch: Wir vermitteln die Erfahrung, dass man Widerstand leisten muss. AIDESEP hatte viel Angst davor zu mobilisieren, sie sagten, wir mögen diese Dinge nicht, aber jetzt mobilisieren sie, und wir lernen, dass es wichtig ist, politische Vorschläge zu haben. Deshalb wollen wir unsere beiden Regionen politisch zusammenschließen in der COPPIP« (Interview Palacín 14.04.2004).

Jedoch schienen in der Realität die Eigeninteressen auf Seiten AIDESEPs sowie CONACAMIs über den Wunsch der Zusammenarbeit zu dominieren. COPPIP startete 2004 einen Versuch, sich von der nationalen Ebene aus auch auf regionaler zu etablieren. Dafür teilte man Peru geografisch in vier Regionen ein, die sich nicht an dem klassischen Muster Küste, Anden, Amazonas ausrichteten, sondern eine horizontale Aufteilung vorwiesen. Dadurch wollte man erreichen, dass der Amazonas innerhalb der Strukturen der COPPIP nicht als ein regionaler Block den anderen beiden gegenüberstünde. Denn, so das Argument, die indigene Amazonasbevölkerung sei den indigenen Andenbewohnern numerisch unterlegen. Sie würde, da sie ja bereits über eine starke nationale Repräsentation verfügte, sonst vielleicht den neuen Zusammenschluss boykottieren (Interview Palacín 14.04.2004).

In den vier eingeteilten Regionen fanden im Laufe des Jahres $2004 \mathrm{Zu}-$ sammenkünfte statt, um lokale Organisationen zum Beitritt zu animieren sowie regionale Zusammenschlüsse zu kreieren (sogenannte `Makro-Regionen $<$ ). Höhepunkt bildete ein nationales Treffen im Dezember des Jahres. Jedoch war es schon zuvor erneut zu Differenzen innerhalb der nationalen Leitung der Organisation gekommen. Verschiedene Gesprächspartner äußerten deshalb die Vermutung, dass Miguel Palacín die Treffen primär dazu benutzte, lokale Organisationen als Mitglieder von CONACAMI zu werben. So wolle er die Position seines Zusammenschlusses stärken (eigene Aufzeichnungen 18.05.2005, 31.05.2005, 02.06.2005). Nachdem Palacín zudem keinen Kongress einberief, um die Präsidentschaft von COPPIP turnusgemäß an AIDESEP abzugeben, ruhten die Aktivitäten der Organisation seit Dezember 2004.

Die bisherige Geschichte der COPPIP verdeutlicht die unterschiedlichen Interessen von Tief- und Hochlandbewohnern sowie die historisch vorbelastete Beziehung. Wie tief der Graben ist, wird zum Beispiel deutlich, wenn mich 
der Präsident von CONAP im Gespräch auf die unterschiedlichen Lebensbedingungen von >Bauern hin, wer die >Bauern und wer die >Indigenen〈 seien, sagt: »Die Bauern wohnen in den Anden, Indigene im Amazonasgebiet « (Interview Sarasara 14.01.2004). Eine nationale Repräsentantin von AIDESEP wiederum erzählte mir von ihrer gemeinsamen Reise zu einer Konferenz mit einer Vertreterin aus den Anden. Sie seien immer wieder aneinander geraten, und im Streit hätte sie die Andenrepräsentantin dann schuncha genannt. ${ }^{43}$ Die Repräsentantin sah diese Auseinandersetzungen in grundlegenden Differenzen zwischen indigenen Hochland- und Tieflandbewohnern begründet (eigene Aufzeichnungen 27.07.2005).

Auch Palacín führte aus, dass bei der geografisch-organisatorischen Neuaufteilung Perús mit Protesten von Seiten der Andenorganisationen zu rechnen sei. Diese fühlten sich als zahlenmäßig größere Bevölkerungsgruppe bei derlei Aufteilung unterrepräsentiert (Interview Palacín 21.04.2004). Die starke finanzielle Unterstützung, die COPPIP von internationalen NGOs erhielt, lässt hingegen vermuten, dass die Idee einer nationalen panindigenen Bewegung wohl vor allem die nicht-indigenen Unterstützer begeistert und von den beteiligten indigenen Akteuren für andere politische oder persönliche Ziele genutzt wird. Miguel Palacín wurde derweil am 17.Juli 2006 in Cusco zum Vorsitzenden eines neuen transnationalen Zusammenschlusses gewählt, der Coordinadora Andina de Organizaciones Indígenas (CAOI) ${ }^{44}$.

\section{Schluss: Indigene Akteure auf den sbattlefields um politische Macht, Wissen und Projekte}

Bisher habe ich gezeigt, wie sich die Föderationen und ihre regionalen und nationalen Dachverbände aus dem Zusammenspiel lokaler, nationaler und internationaler politischer Prozesse heraus entwickelt haben. Die detaillierte Nachzeichnung dieser Prozesse lässt die Brüche und Neustrukturierungen sowie Spannungen und Konflikte in der politischen Organisation der indianischen Gesellschaften des Amazonasgebietes deutlich werden.

43 Chuncho (chuncha) ist eine Bezeichnung für die indigenen Bewohner des peruanischen Tieflands. Es wird meist als Schimpfwort gebraucht, das große Verachtung zum Ausdruck bringen soll (vgl. Kapitel VII.1).

44 Dt. >Andine Koordinationsstelle indigener Organisationen<, ein Zusammenschluss von Organisationen aus Chile, Bolivien, Peru, Ecuador und Kolumbien, der sich für den Aufbau plurinationaler Staaten und interkultureller Gesellschaften einsetzt und dabei vor allem den Schutz indigener Territorien, die eigenständige Verwaltung der natürlichen Ressourcen dieser Gebiete durch indigene Gemeinden sowie die Umsetzung der ILO Konvention 169 fordert. 
Die ethnischen und panethnischen Zusammenschlüsse entwickelten sich im Verlauf der Organisationsprozesse zu nationalstaatlich geprägten Kategorien. Eine in der Vergangenheit stärker »performative Ethnizität« (Hutchinson 2000), flexibel und fließend, machte im Kontext der modernen Organisationsprozesse dem Entwurf >indigener Nationalitäten` im politischen Diskurs der neuen Repräsentanten Platz: Die indianischen Gesellschaften des Tieflands wurden in den Schriften und Reden dieser Vertreter zu Völkern, die Gebiete, in denen sie siedelten, zu Territorien, und ihre kulturellen Besonderheiten zu einem (bedrohten) Eigentum. Der politische Einschluss in die peruanische Nation bewirkte, dass viele indigene Repräsentanten ihrerseits begannen, »wie ein Staat zu sehen« (Scott 1998) - entweder, indem sie für die Erschaffung eines autonomen indigenen Territoriums kämpften (AIDESEP) oder, indem sie einen >selbstbestimmten « wirtschaftlichen Einschluss in die bestehenden nationalen Zusammenhänge anstrebten (CONAP). Dabei erwies sich als grundlegendes Problem, dass sie nicht über die gleichen politischen und wirtschaftlichen Ressourcen wie die Regierenden eines Staates verfügten. Auch wenn sie es schafften, nationale, panethnische Vertretungsinstanzen zu etablieren, blieben die lokalen Gemeinden und die supralokalen Föderationen politisch unabhängig. Das für die indianischen Tieflandgesellschaften typische segmentäre Vergesellschaftungsprinzip setzte sich immer wieder gegen Zentralisierungsbestrebungen durch und verhinderte somit die Etablierung neuer Herrschaftsverhältnisse. Während die Ausbildung eines politischideologischen Diskurses das grundlegende politische Kapital der neuen indigenen Interessenvertreter im Umgang mit staatlichen Funktionären und vor allem den Unterstützern bildete, blieben die Verhältnisse im Innern der indigenen Bewegung diffus. Sie durchliefen die in den theoretischen Ausführungen als `typisch beschriebene Entwicklung sozialer Bewegungen (vgl. Kapitel II.1): Wachstum und Institutionalisierungsprozess der indigenen Bewegung, exemplarisch nachvollzogen an Hand einer Auswertung der AIDESEPZeitschrift Voz Indigena, gingen einher mit Schismogenese und Fraktionsbildungen. Die Zusammenschlüsse besaßen eher den Charakter loser und flexibler strategischer Netzwerke als den stabiler, »moralischer Teams $\aleph^{45}$ (Bailey

45 Im Rahmen der Entwicklung transaktionaler Ansätze unterschied der Ethnologe Bailey (1969) in der Politik zwischen moralischen und transaktionalen Teams. Ein moralisches Team besteht aus einem politischen Führer und einem Kern von Gefolgsleuten, die an ihn glauben und mit ihm gemeinsame Überzeugungen und Werte teilen. Eine Reihe wichtiger normativer Regeln, denen öffentlich und ethisch zugestimmt wird, bestimmen die politische Stärke und das Spiel moralischer Teams. Sie entwickeln sich leicht zu bürokratischen Apparaten. Transaktionale Teams bestehen hingegen aus einem politischen Führer mit einer kleinen Gruppe Anhänger sowie einer großen Zahl von Personen, die diesem folgen, solange es ihnen konkrete Vergünstigungen bringt. Transaktionale Teams sind lockere Bündnisse, die von konkreten Zielen bestimmt werden und an Bedeutung 
1969). Noch komplizierter wurde die Situation für die neuen indigenen Repräsentanten beim Versuch, einen Zusammenschluss zwischen Hochland- und Tieflandindianern zu bewirken. Die diskursive Betonung einer >panindigenen Schicksalsgemeinschaft $<$ konnte sich in der Realität nicht gegen gefühlte Differenzen zwischen den verschiedenen Interessengruppen durchsetzen.

Die peruanische Regierung unterstützte durch die Gesetzgebung zu den comunidades nativas im Tiefland den Fragmentierungsprozess der neu proklamierten politischen Gemeinschaft unter staatlichen Vorzeichen: Eher willkürlich gezogene Dorfgrenzen wurden zu politisch-administrativen Grenzen, die mit der Zeit eine reale Bedeutung für die Bewohner gewannen. Während sich die Gemeinden somit zu neuen Körperschaften mit eigenständigen administrativen und politischen Rechten entwickelten, blieben die supralokalen Zusammenschlüsse Lobbygruppen außerhalb des institutionalisierten politischen Feldes. Auch wenn sie sich selbst als >Volksvertreter sahen, gelang es den Repräsentanten der indigenen Zusammenschlüsse auf keiner Organisationsebene, ein dauerhaftes System von >Tributzahlungen`zu errichten, durch welches sie an politischer Macht im Innern und an Autonomie gegenüber dem Staat und den externen Unterstützern gewonnen hätten. Sie schienen keine Möglichkeit zu besitzen, ihre Wählerschaft zur Kooperation zu zwingen. Die Organisationen erfüllten stattdessen folgende Funktionen:

- Die Zusammenschlüsse sollten materielle und finanzielle Ressourcen unter Ausschaltung möglichst vieler Vermittlungsinstanzen kanalisieren;

- sie dienten in diesem Zusammenhang dem Aufbau eines klientelistischen Netzwerkes, auch innerhalb der organisierten Gruppen;

- sie waren Plattform politischer Kämpfe zwischen verschiedenen Fraktionen innerhalb der und zwischen den einzelnen Föderationen.

Der peruanische Staat bewies noch auf eine andere Art, dass ihm seinerseits nichts daran gelegen war, zur Stärkung der politischen Macht der föderativen Zusammenschlüsse der indigenen Tieflandbewohner beizutragen: Durch die Zuweisung des Status von NGOs erklärte man die Assoziationen zu zivilgesellschaftlichen Lobbygruppen und Empfängern von `Entwicklungsgeldernく. Die Einrichtung repräsentativer, staatlicher Instanzen mit realen Machtbefugnissen für die und durch die indigene Bevölkerung des Landes wurde, trotz Verfassungsänderung im Jahre 1993 und finanzieller Unterstützung der Weltbank, bis heute nicht effektiv umgesetzt. Auch wenn seit Einrichtung des Instituto Indigenista immer wieder Abteilungen für >indigene Belange innerhalb staatlicher Regierungsstrukturen geschaffen werden, so haben sich bis heute vor allem die Namen der jeweiligen Institutionen verändert, kaum jedoch die politischen Praktiken.

verlieren, wenn die Ziele, die ihren Zusammenschluss bestimmten, erreicht sind oder verloren gehen. 


\section{Kapitel X \\ Die indigenen Organisationen im Tiefland als Vermittlungsinstanz: Funktionszuweisungen an die Zusammenschlüsse sowie ihre Vertreter}

Nach dem Studium der Makroebene des Organisationsprozesses gilt es, die indigenen Zusammenschlüsse des peruanischen Amazonasgebietes aus der Mikroperspektive zu beleuchten. Nur so kann man sich jenseits der oftmals sehr hitzig geführten politischen Debatten fundiert der Frage nähern, welche widerstreitenden Kräfte in der indigenen Organisationswelt aufeinander treffen. In diesem Zusammenhang stellen sich folgende Fragen: Wie werden die Zusammenschlüsse von Dorfbewohnern, Repräsentanten, Unterstützern wahrgenommen? Welche Ansprüche stellt man an die Vertreter? Welche Fertigkeiten müssen diese mitbringen, um Erfolg zu haben? Die Auseinandersetzung mit diesen Fragen soll helfen, die Verschachtelung verschiedener Legitimationsmodelle politischer Macht im peruanischen Tiefland zu erfassen und die komplexe Dynamik indigener Organisationsprozesse offen zu legen.

Bereits im Prolog der Arbeit wurden einige der konkreten Probleme auf lokaler Ebene sichtbar. Um einen weiteren Einblick in den Forschungsprozess zu gewähren, schildere ich im Folgenden zunächst meine Erlebnisse während meiner beiden Besuche in einer comunidad nativa Huitoto im Februar 2004 und Juli 2005. 


\section{Juli 2005: \\ Besuch in einer comunidad nativa Huitoto}

Die von mir im Juli 2005 zum zweiten Mal besuchte Gemeinde ist eine comunidad nativa, die am Nanay in der Nähe von Iquitos in der Region Loreto liegt. Sie besteht aus rund 200 Einwohnern mit unterschiedlichem ethnischen Hintergrund. Da die Siedlung jedoch um 1930 herum von einer Gruppe von patrones in die Gegend verschleppten Murui (Huitoto) gegründet wurde, haben sich die Gemeindemitglieder bei ihrem Antrag auf Anerkennung als comunidad nativa offiziell für diese Identität entschieden. Im öffentlichen Register werden sie somit seit Februar 2000 als Huitoto-Gemeinde geführt.

Loreto gehört geografisch zum flachen Tiefland (selva baja) und ist flächenmäßig die größte administrative Einheit im peruanischen Amazonasgebiet. Während die Einwohnerzahl Loretos nur 3,3 Prozent der Gesamtbevölkerung Perus ausmacht ${ }^{1}$, ist der indigene Anteil mit 11,4 Prozent der höchste im Amazonasgebiet. Gleichzeitig findet sich in Loreto die größte ethnische Vielfalt. Chayahuita (22\%), Quichua-Napo-Pastaza (17\%), Cocama-Cocamilla (15\%) und Aguaruna (8\%) sind die zahlenmäßig umfangreichsten ethnischen Gruppen. Die Region liegt im Nordosten des Landes und grenzt an Brasilien, Kolumbien und Ecuador. Die Hauptstadt Iquitos ist nur über den Luftoder Wasserweg von Lima aus zugänglich (INEI und UNICEF 1997: 56). Ab 1851 wurde Loreto von staatlicher Seite zum neuen Kolonisierungsgebiet proklamiert (Santos Granero und Barclay 2000: 1). In den 1960er Jahren, unter der ersten Präsidentschaft von Terry Belaúnde, warb der Staat verstärkt für die landwirtschaftliche Nutzung der Region Loreto auf Grund ihrer geografischen Lage in der selva baja. Das von der Regierung zu diesem Zweck eingerichtete Programm führten nachfolgende Präsidenten fort, die vor allem den Anbau von Reis, Mais, Bananen und Jute förderten. Reis wurde in der Folge zum Exportschlager Loretos. Ende der 1960er Jahre begann man jedoch auch den heimlichen Koka-Anbau für den internationalen Drogenhandel. Das dadurch erwirtschaftete Geld wurde wiederum in die Holzindustrie gesteckt. Zwar gibt es auch Konzessionen zur Erdölförderung, dennoch ist der Holzhandel nach wie vor die wichtigste ökonomische Aktivität der Region. Um legalen und illegalen Holzschlag in indigenen Territorien gibt es in zahlreichen Gebieten Loretos Konflikte.

In Loreto existieren derzeit neunundzwanzig Föderationen, die AIDESEP 2005 offiziell zu ihrer Basis zählte (vgl. AIDESEP 2005: 39). ${ }^{2}$ Sie lassen sich

1 Als Vergleichszahl kann die Bevölkerungsdichte der Hauptstadt Lima herangezogen werden, die 1993 bei 28\% lag (UNICEF 1997).

2 Ich habe keine genauen Angaben, wie viele Föderationen CONAP angehören bzw. wie viele der neunundzwanzig Föderationen, die AIDESEP zu ihrer Basis zählt, sich gleichzeitig als Mitglieder von CONAP bezeichnen. Auch besitze ich 
zwei regionalen Instanzen mit eigenem juristischen Status zuordnen - der Organización Regional de Asociaciones Indígenas (ORAI) und der Coordinadora Regional de Pueblos Indígenas San Lorenzo (CORPI). ${ }^{3}$ Die Huitoto-Gemeinde gehört einer Föderation an, die Teil des regionalen Zusammenschlusses ORAI ist. ORAI hat ihren Sitz in Iquitos und umfasst 13 Föderationen. Die Organisation gilt, seit einem Korruptionsfall in der zweiten Hälfte der 1990er Jahre, als politisch geschwächt. Während meiner Aufenthalte 2004 und 2005 verfügte sie nur über geringe Fördermittel.

An einem Sonntagmorgen im Juli 2005 machte ich mich auf den Weg in das Dorf von Hernán ${ }^{4}$, in dem ich mich bereits im Februar 2004 für einige Zeit aufgehalten hatte. Die comunidad nativa liegt eine halbe Bootsstunde plus eine Stunde Fußmarsch von Iquitos entfernt. Die Bewohner des Dorfes leben von der Bewirtschaftung ihrer Felder und dem wöchentlichen Verkauf ihrer spärlichen Produkte auf einem kleinen Markt an einem der Häfen von Iquitos. Die Gemeinde kämpft seit langem für die Titulierung ihres Territoriums. Ich wollte herausfinden, was sie diesbezüglich in den 16 Monaten meiner Abwesenheit erreicht hatten.

Am Hafen von Iquitos erwartete mich Hernán. Auf dem Weg in sein Heimatdorf fragte ich ihn nach Ester ${ }^{5}$, seiner Frau, mit der zusammen wir am Tag zuvor auf dem Markt in Iquitos Lebensmittel für meinen Besuch bei ihnen zu Hause eingekauft hatten. Hernán erklärte mir, dass sie noch zu einem Patienten gegangen sei und erst am Nachmittag das Boot zurück nach Hause nehmen würde. Hernán, Ester und ihre sechs Kinder lebten seit einigen Jahren von der Berufung der beiden: Sie waren curanderos ${ }^{6}$. Beide Mitte Dreißig, sahen sie sich selbst am Anfang ihres Weges als Heiler. In dem Jahr meiner Abwesenheit hatte sich der Kreis ihrer einheimischen Patienten in Iquitos und in ihrer Heimatgemeinde aber bereits erheblich vergrößert. Ihre Einnahmen kamen jedoch hauptsächlich von den Ausländern, die sie zu Hause empfingen.

keine gesicherten Informationen über Föderationen, die unabhängig von beiden nationalen Zusammenschlüssen bestehen. Der Präsident der CONAP sagte mir, dass seine Organisation keinen offiziellen Sitz aber einen regionalen Koordinator in Iquitos habe (Interview Sarasara 21.01.2004). Diesen konnte ich jedoch während meiner beiden Aufenthalte in der Region nicht ausfindig machen.

3 Dt. ORAI: >Regionale Organisation der indigenen Zusammenschlüsse<; CORPI: $>$ Regionale Koordination der indigenen Völker von San Lorenzo<.

4 Personenname geändert.

5 Personenname geändert.

6 Dt. >Heiler . 
Dort tranken die Besucher unter Hernáns' Anleitung ayahuasca ${ }^{7}$ und ließen sich in die Heilkräfte der lokalen Pflanzen einweisen.

Auch meinem Anliegen gegenüber - dem Interesse an der politischen Organisation seiner comunidad - zeigte Hernán sich aufgeschlossen. Seine Gemeinde war Mitglied einer ethnischen Föderation, die 1993 gegründet wurde und sich in der Folge AIDESEP anschloss. Daneben gehörten 2005 fünf weitere Gemeinden der Organisation an. In Hernáns Gemeinde lebte nicht nur der Gründer der Föderation, Don Sebastiano ${ }^{8}$, sondern auch ihr aktueller Vize-Präsident. Allerdings gab es wohl seit längerem keine nennenswerten Aktivitäten der Organisation zu verzeichnen.

Jeden ersten Sonntag im Monat berief die comunidad nativa ihre Vollversammlung ein, in der die aktuellen Probleme diskutiert und die Arbeitspläne des nächsten Monats beschlossen wurden. Bei der Zusammenkunft im Februar 2004 war dem aktuellen Vize-Präsidenten der Föderation vom Versammlungsleiter das Wort erteilt worden: Er sollte Bericht erstatten über die Arbeit der Organisation. Doch stattdessen fing er an, seine Meinung zu den aktuellen Problemen des Dorfes kundzutun und versprach, später etwas zu den Aktivitäten des Verbandes zu sagen. Jedoch kam dieses >später im Verlauf der Sitzung nicht mehr zustande. Eine stypische Situation`, wie mich der Präsident der Gemeinde in einem anschließenden Gespräch aufklärte. Die Organisation >läge am Boden`, die aktuelle Direktive würde sich nur zu gemeinsamen Trinkgelagen treffen, aber keinen Arbeitsplan entwickeln.

In der Versammlung hatte man im Allgemeinen über die Probleme des Dorfes und im Speziellen über die Grenzen des Gemeinschaftslandes diskutiert: Freiwillige wurden gesucht, die in den Grenzzonen chacras ${ }^{9}$ anlegen sollten, um das Dorf vor Eindringlingen zu schützen und dem Staat zu zeigen, dass man das Land nutze. Bei der aktuellen Gesetzeslage in Bezug auf die Territorien der comunidades nativas war dies äußerst wichtig: Nicht genutztes Land konnte schnell in die Hände des Staates fallen. >Nutzung wurde dabei vor allem im landwirtschaftlichen Sinne verstanden und an sobjektiven Kriterien wie Hausbau und Feldbestellung festgemacht. Zudem kämpften die Einwohner des Ortes mit einem noch viel grundsätzlicheren Problem: Sie besaßen keine offizielle Titulierungsurkunde ihres Territoriums. Und das, obwohl sie sich seit Anfang der 1990er Jahre darum bemühten.

Erst im Februar 2000 erhielt die Gemeinde ihre offizielle Anerkennung als comunidad nativa Huitoto mit 100 erwachsenen Einwohnern. Die Gemeindemitglieder waren allerdings nicht mehr nur Huitoto, sondern unter-

7 Dt. >Liane der Geister`; Drogenzubereitung aus Naturdrogen, welche einerseits den halluzinogenen Wirkstoff DMT und andererseits MAO-Inhibitoren aus der Harmala-Reihe (zB. Harmalin) enthalten.

8 Personenname geändert.

9 Dt. $>$ Felder . 
schiedlicher Herkunft: Cocama, Quichua, Bora, Yagua und Huitoto. Darüber hinaus sprachen nur drei ältere Dorfbewohner fließend Huitoto. Die Kinder lernten einige Worte der Sprache im zweisprachigen Unterricht an der Grundschule der Gemeinde. Präsident der Gemeinde war während meiner beiden Aufenthalte (Februar 2004 und Juli 2005) Guillermo Ortega ${ }^{10}$, ein Quichua, der ursprünglich aus der Region San Martín stammte. Guillermo hatte drei Jahre lang an einem theologischen Seminar studiert. Er war bereits zum zweiten Mal in Folge im Amt des presidente comunal bestätigt worden. Eine sherausfordernde Tätigkeit, wie er mir im Februar 2004 erklärt hatte, bei der man viel Geduld und Engagement mitbringen müsse: »Man muss bei allen Aktivitäten mit gutem Beispiel vorangehen und dadurch die anderen von der Notwendigkeit des Vorhabens überzeugen. Zwingen kann ich hier niemanden. Und Kritik gibt es trotzdem ständig, vor allem, da wir immer noch nicht unser Gemeindeland titulieren konnten."

Als Hernán und ich an jenem Sonntag im Juli 2005 nach einer kurzen Bootsfahrt und einem kraftraubenden Marsch durch die mittägliche Hitze mit unseren Rucksäcken und Einkaufstüten in Hernáns' Gemeinde ankamen, liefen wir Guillermo Ortega zufällig in die Arme. Er trat gerade aus dem Versammlungshaus und verabschiedete sich von einem jungen Mann, den Hernán mir als neuen zweisprachigen Grundschullehrer der Gemeinde präsentierte. Guillermo erkannte mich sofort wieder und erkundigte sich nach dem Stand meiner Forschung. Er fragte, wann ich ihn besuchen käme, damit er mir vom Fortschritt der Bemühungen um die Titulierung des Gemeindeslandes berichten könne. Wir verabredeten uns für den nächsten Morgen. Ich wollte nicht nur mehr über die aktuellen Entwicklungen erfahren, sondern auch darüber, wann und wie die Idee im Dorf aufgekommen war, sich als comunidad nativa anerkennen zu lassen. Bereits im Vorjahr hatte mir Guillermo nämlich erzählt, dass es in den 1990er Jahren einen Streit gegeben hatte, in dessen Verlauf sich das Dorf in zwei Hälften teilte - die einen wollten offiziell als nativos anerkannt werden, die anderen als campesinos ${ }^{11}$.

Als ich mit Hernán tags darauf bei Guillermo eintraf, war dessen Frau gerade damit beschäftigt, Maniokwurzeln zu schälen. Guillermo begrüßte uns und führte uns in eine Wellblechhütte, in der zwei wacklige Bänke und ein mit Büchern, Plastiktüten und Töpfen überladener Tisch standen. Nachdem wir zusammen ein paar Scherze und Bemerkungen - vor allem über Hernáns' umfangreichen Kontakte zu Ausländern - gemacht hatten, bat ich Guillermo, mir die Probleme seines Dorfes zu schildern. Er fing bereitwillig an zu erzählen: "Das Problem in unserer Gemeinde begann mit der Ankunft neuer Dorfbewohner von der Küste Anfang der 80er Jahre. Die Neulinge behaupteten, In-

10 Personenname geändert.

11 Dt. >Bauern<. 
digene seien entweder Sklaven oder Terroristen. Daraufhin begannen viele Dorfbewohner, die sich vorher als Indigene bezeichnet hatten, sich als Bauern zu definieren. Anfang der 1990er Jahre wollten wir einen juristischen Status als eigenständige Gemeinde beantragen, um an einem staatlichen Programm zur Fischzucht teilnehmen zu können. Wir glaubten, dass man auch mit Geld unterstützt würde. Als wir feststellten, dass die Hilfe allein technischer Natur war, zogen sich viele enttäuscht zurück. Daraufhin wurde aber in einer Dorfversammlung die Idee diskutiert, sich als comunidad nativa zu organisieren, da wir gehört hatten, dass dies Vorteile in Bezug auf Land und Entwicklungsprojekte versprach.«

Hernán unterbrach Guillermo an dieser Stelle seiner Erzählung und erinnerte ihn an zwei wichtige Ereignisse, die auch zu ihrem Entschluss beigetragen hätten: Zum einen hätten Mitte der 80er Jahre Mormonen, die sich in ihrer Nähe angesiedelt hatten, begonnen, Land, das eigentlich zu ihrem Dorf gehörte, vom Staat zu kaufen. Zum anderen hätten sie Anfang der 1990er Jahre erfahren, dass es eine Einrichtung der Regierung gab, die Projekte in comunidades nativas förderte. Diese nannte sich IRCON (Instituto Regional de Comunidades Nativas). ${ }^{12}$ IRCON förderte unter anderem die Stärkung der indigenen Identität und half zu jener Zeit einer Reihe von Dörfern, Gemeinschaftsland zu titulieren. In ihrer Gemeinde sei es auf Grund des internen Streits jedoch während der Anwesenheit der Mitarbeiter von IRCON nicht zur Titulierung gekommen.

Guillermo räumte daraufhin ein, dass er zu Zeiten von IRCON in Iquitos gelebt und gearbeitet hätte. Er sei erst mit Ausbruch des Streits in das Dorf zurückgekehrt. Dann fuhr er in seiner Erzählung fort: »In einer zweiten Versammlung, an der 106 Erwachsene der Gemeinde teilnahmen, protestierten lediglich zwei Frauen gegen die Idee, sich als comunidad nativa zu organisie-

12 Dt. >Regionales Institut für native Gemeinden<. IRCON existierte von 1990-92 und wurde von Harvey Rivadeneyra Maldonado geleitet, Chemiker mit einer Zusatzausbildung in Erziehungswissenschaften. Das Institut hatte ca. fünf zweisprachige Lehrer als Mitarbeiter. Harvey Rivadeneyra Maldonado arbeitete als Planer und später als regionaler Koordinator (Pucallpa, Moyobamba) in SINAMOS und organisierte in dieser Funktion in Moyobamba eine Bauernorganisation. Er beendete seine Arbeit für SINAMOS, als General Bermúdez an die Macht kam und kehrte nach Iquitos zurück, wo er zuvor gelebt hatte. Gegen Ende der Regierungszeit von Alan García sollte der Staat dezentralisiert werden, Loreto wurde zum Laboratorium für diese Pläne. In diesem Zusammenhang entstand IRCON, allerdings ohne große finanzielle Ausstattung oder wirkliche Befugnisse. So kam das Projekt unter Fujimori schnell zum erliegen. Als damaliges Ziel von IRCON bezeichnet Harvey folgendes: indigene Kulturen identifizieren, ihren Grad der Zerstörung erkennen, Widerstandspotential ihrer soziokulturellen Werte erkennen und fördern (Gespräch Rivadeneyra 22.07.2005). 
ren. Der damalige teniente gobernador ${ }^{13}$ des Dorfes behauptete jedoch zwei Wochen später in einer erneuten Versammlung, der gobernador habe verboten, dass wir uns als comunidad nativa organisierten. Er war mit einem Mal der Ansicht, dass es jetzt keine indigenen Gemeinden mehr geben dürfe, dass diese der Vergangenheit angehörten. Er sagte, es sei ein Rückschritt, sich zur comunidad nativa zu erklären. So hat unser Problem angefangen. Der teniente gobernador wollte alle dazu verpflichten, Bauern zu sein. Und er konnte auch eine Reihe von Leuten davon überzeugen, dass dies vorteilhafter sei. Denn am Anfang haben viele Dorfbewohner die Notwendigkeit kollektiven Landbesitzes nicht verstanden. Sie wollten parzellierte Grundstücke, um zum Beispiel Zugang zu Krediten zu bekommen, das Land verpachten oder verkaufen zu können. Lebt man in einer indigenen Gemeinde, ist dies nicht möglich. Es bildete sich aber eine kleine Gruppe von Dorfbewohnern, die sich für die Anerkennung als comunidad nativa einsetzten. Don Sebastiano ${ }^{14}$ war ihr Anführer. Er trat entschieden für seine Abstammung von den Huitoto-Murui ein. Ein erbitterter Streit brach aus, der sogar Familien entzweite. So bildeten sich zwei Gemeinden: eine comunidad campesina und eine comunidad nativa. Manche Familien sind heute noch geteilt: Eine Hälfte lebt im bäuerlichen Teil, die andere im indigenen. Viele Familien, die im indigenen Teil wohnen, schicken ihre Kinder jedoch trotzdem lieber im bäuerlichen Teil zur Schule. Sie glauben, dass die Ausbildung dort besser sei als in der zweisprachigen Schule im indigenen Teil. Das hat auch mit dem Streit der 1990er Jahre zu tun. Damals zeigte sich, dass die mestizischen Migranten in unserem Dorf die Gesetze besser kannten, während die Indigenen wenig Bildung besaßen.

Der Streit in den 1990er Jahren ging sogar bis vor die Präfektur. Am 17. August 1993 wurde eine Friedensakte aufgesetzt, nach der sich die potentiellen Mitglieder der comunidad nativa zusammenschließen mussten, um anerkannt zu werden. Eine Dorfversammlung wurde einberufen, und 55 Erwachsene entschieden sich für die Mitgliedschaft in der comunidad nativa. Das entsprechende Territorium wurde dabei noch nicht festgelegt. Die unterzeichneten Dokumente wurden dem Landwirtschaftsministerium ausgehändigt. Am 11. Mai 1994 kam eine Kommission des Ministeriums zu einer Versammlung mit beiden Parteien, in der sich jeder erneut jeweils für eine Seite entscheiden sollte: Bauern oder Indigene. 77 identifizierten sich als Indigene,

13 Dt. >Stellvertreter des Landrats`; der teniente gobernador repräsentiert die staatliche Exekutive auf lokaler Ebene. Er wird von seinem direkten Vorgesetzten, dem gobernador des Distrikts (Landrat) gewählt und besetzt somit die unterste Ebene des Innenministeriums. Er kann großen politischen Einfluss im Dorf gewinnen, weil ihm eine Vermittlungsfunktion zwischen Staat und Gemeinde zufällt (vgl. Damonte 2000: 113 f.).

14 Einer der drei älteren Bewohner, die noch Huitoto sprechen. Gründer der lokalen indigenen Föderation. 
85 als Bauern. Für beide Seiten wurde das respektive Territorium festgelegt. Die Kommission versprach, innerhalb der nächsten zwei Wochen die Grenzziehung vorzunehmen. Aber nichts passierte. Im darauffolgenden Jahr, am 17. Juli 1995, wurde die comunidad campesina staatlich anerkannt. Doktor Donayre - der zu diesem Zeitpunkt Mitarbeiter der ORAI ${ }^{15}$ war - half uns nativos daraufhin, damit auch wir uns noch im gleichen Jahr als Zusammenschluss in die öffentlichen Register einschreiben konnten. Ich hatte mich zu diesem Zeitpunkt endgültig für eine Mitgliedschaft in der comunidad nativa entschieden, nachdem man mich von der bäuerlichen Seite lange mit Versprechungen, vor allem finanzieller Art, gelockt hatte. Als Donayre uns half, war ich Sekretär der Gemeinde. Ich ließ mich von ihm in die notwendigen Schritte einweisen, die nach der Einschreibung in die öffentlichen Register zur Anerkennung als comunidad nativa und zur Titulierung des Gemeindelandes noch fehlten. Er gab uns auch den Text der ILO 169, den die peruanische Regierung ratifiziert hat und der unser Recht als Indigene auf Territorien unterstreicht.

Im September 2000 erkannte das Landwirtschaftsministerium unser Dorf als comunidad nativa an. Aber die Titulierung des Territoriums steht bis heute aus. Zurzeit zählt die Gemeinde ca. 200 Einwohner, davon 72 Erwachsene. Seit dem Jahr 2000 haben einige die Seiten gewechselt und gehören nun zum bäuerlichen Teil. Sie haben individuell titulierte Parzellen. Zurzeit zweifeln viele daran, dass wir jemals unser Gemeindeland tituliert bekommen. Das Ministerium erfindet, trotz Erhebung des Lageplans unseres Territoriums, immer wieder neue Gründe, warum die Anerkennung und endgültige Zuweisung des Landes nicht durchgeführt werden kann.«

Guillermo erklärte mir auch, dass inzwischen nicht nur Bewohner ihrer Dorfhälfte entschieden hätten, campesinos zu werden, sondern auch Mitglieder - vor allem Jugendliche - des bäuerlichen Teils zu ihnen zurückkehrten. >Drüben gäbe es Landprobleme. Wenn ihr Land hingegen endlich offiziell tituliert sei, hätte ihre Gemeinde 5301 Hektar. Stolz zeigte mir Guillermo den Plan des Territoriums seiner Gemeinde. Als ich mich nach gut zwei Stunden von ihm verabschieden wollte, hielt er mich zurück und suchte nach seinem Stempelkissen. Schließlich drückte er mir ein Blatt Papier in die Hand. Auf diesem befand sich ein Stempelaufdruck, der ihm als Präsidenten seiner comunidad nativa als offizielles Siegel diente. Damit ich mir sicher sein könne, mit dem Präsidenten geredet zu haben, fügte er lächelnd hinzu.

15 Alberto Chirif sagte mir in einem Gespräch im Juli 2005, Donayre sei zu jenem Zeitpunkt Mitarbeiter der Defensoría del Pueblo gewesen. Wichtig erscheint mir nicht, wer von beiden Recht hat, sondern welche Instanzen von Guillermo als bedeutsam und hilfreich erachtet werden bzw. wie stark er die jeweiligen Einrichtungen als Vertreter der Interessen seines Dorfes wahrnimmt. 
Hernán kommentierte Guillermos Ausführungen auf dem Heimweg und bemerkte: »Unsere Nachbargemeinde hat sich bereits in den 1970er Jahren ihr Territorium als indigene Gemeinde gesichert. Dort hatten sie einen zweisprachigen Lehrer, der von dem entsprechenden Programm wusste. Der hat den Gemeindevorstehern geholfen. «Den Rest des Weges sann ich weiter über Guillermos Worte nach und blieb einsilbig gegenüber Hernáns Versuchen, mich in ein Gespräch über die heilende Kraft verschiedener Pflanzen zu verwickeln. Das größte Problem der Zukunft, so hatte mir Guillermo erklärt, sei der Schutz des Gemeindelandes. Innerhalb der 5301 Hektar der Gemeinde gäbe es noch Vorkommen von Edelhölzern. Seit Februar 2005 erreichten ihn aber Nachrichten, dass illegale Holzfäller in ihr Gebiet eindrängen. Ausführlich hatte mir Guillermo in diesem Zusammenhang eine abenteuerliche Geschichte erzählt, wie er zusammen mit zwei weiteren Dorfbewohnern, einem funktionierenden und einem kaputten Gewehr, die Eindringlinge bei ihrer Arbeit aufgesucht hatte. Um die anderen beiden Dorfbewohner zu diesem Inspektionsgang zu motivieren, sei sehr viel Überzeugungsarbeit von seiner Seite aus notwendig gewesen. Nicht ohne Stolz erläuterte Guillermo seine rhetorischen Strategien in diesem Zusammenhang. Sie hätten drei Arbeiter getroffen, die er, Guillermo, gleich gefragt habe, ob die anderen Dorfbewohner, mit denen sie zum Jagen unterwegs seien, schon vorbeigekommen wären. Danach habe er angefangen, die Holzfäller vorsichtig auszufragen, um sich einen Eindruck vom Fortschritt ihrer bisherigen Arbeit zu verschaffen. »Viele edle Hölzer hatten sie schon geschlagen, aber Riesenprobleme mit dem Abtransport! Ich habe sie gleich am nächsten Tag in Iquitos angezeigt, aber was bringt das schon? In der zuständigen Behörde gelten eigene Gesetze, die machen doch gemeinsame Sache mit den Holzfällern.« Dann drückte Guillermo seinen Wunsch aus, dass die Gemeindemitglieder die Holzvorkommen selbst nutzen könnten: »Wenn jemand aus unserer Gemeinde Geld braucht, kann er einen Vertrag mit einer Firma machen, um Holz fällen zu lassen. Oder wir könnten auch einen kommunalen Beschluss fassen. Denn alles liegt in den Bäumen, aber nichts im Geldbeutel.«Ich wusste, dass Guillermo von einem zementierten Weg träumte, der das neu entstehende Zentrum der Gemeinde mit dem Hafen verbinden würde, damit die Dorfbewohner ihre Waren mit einem motocarro ${ }^{16}$ zum Anlegeplatz transportieren könnten. Auch gab es immer wieder Pläne von den wechselnden Bürgermeistern in Iquitos, eine Straße zu bauen, die durch die Gemeinde führen würde und diese mit der Stadt verbände. Das, so Guillermos Überzeugung, würde der Gemeinde viele Vorteile bringen. In einer Versammlung hätten sie zweierlei Arten von Entwicklungsprojekten beschlossen: gemeinschaftliche und individuelle. Auf diese Art könne jedes Gemeindemitglied für sich selbst Projekte starten. Erfolg und

16 Eine Art motorisierte Rikscha. 
Misserfolg derselben kämen nur der entsprechenden Person zugute bzw. fielen nur ihr zu Lasten. Guillermo selbst plante verschiedene gemeinschaftliche Projekte: zum Beispiel eines zum Aufbau von zwei Fischfarmen und zwanzig chacras. Dafür hatte er Kontakt mit einer NGO aufgenommen. Ein anderes lief über die nationale Organisation CONAP und wurde gerade der Weltbank präsentiert. Dabei ging es zum einen um Forstwirtschaft, zum anderen auch um Fischfarmen.

Den regionalen Koordinator der CONAP hatte Guillermo auf einem Seminar in Iquitos kennen gelernt. Dieser kam danach zu einer Gemeindeversammlung in sein Dorf und stellte das Projekt vor. Auf meine Frage, wie es denn vereinbar sei, dass die lokale Föderation AIDESEP angehöre, sie in ihrer Gemeinde nun aber ein Projekt mit der >Konkurrenzorganisation CONAP machen wollen, betonte Guillermo, dass dies eine persönliche Übereinkunft sei und nur ihre Gemeinde beträfe. Es hätte also nichts mit der lokalen Föderation zu tun. Guillermo hatte festgestellt: »Jede Gemeinde kämpft für sich selbst. Es ist hart, aber man muss alleine kämpfen. « Auf dem letzten Kongress der ORAI, an dem Guillermo teilgenommen hatte, hätten sie »schön geredet«: Sie müssten alle gemeinsam die Wälder schützen. Aber, wenn es dann ernst würde, so Guillermo, sei von diesen Reden nichts mehr zu spüren: »Wenn es darum geht, Farbe zu bekennen, ist keiner mehr da. «Nach dem Tod ihres ersten Präsidenten sei es mit ihrer regionalen Organisation, der ORAI, genauso bergab gegangen wie mit der lokalen Föderation.

Bereits bei meinem Besuch im Februar 2004 hatte ich Guillermo gefragt, was er über AIDESEP und COICA als ihr nationales bzw. internationales politisches Vertretungsorgan denke. Guillermo hatte damals erzählt: »Von der COICA weiß ich, dass es eine internationale Organisation ist, ich weiß nicht genau, wie viele Länder Mitglieder sind, aber AIDESEP gehört dazu. Von der COICA kommt keinerlei Information hier an, was sie für die indigenen Völker tun. Da schweigt die AIDESEP. Ich denke, es ist ein Zusammenschluss, eine soziale Organisation auf der Ebene Lateinamerikas. « Auch über die ORAI hatte er zu jenem Zeitpunkt nicht viel berichten können: »Die ORAI ist ja eigentlich unsere Verbindung zur AIDESEP. Aber wenn wir in der Vergangenheit über die ORAI Papiere an AIDESEP schicken wollten, zum Beispiel per Fax, kam nie etwas bei AIDESEP in Lima an. Wir wollen jetzt lieber für neue Projekte direkt mit NGOs Kontakt aufnehmen, um die Finanzierung zu erreichen. Das Problem der ORAI sind die Personen, die dort arbeiten. Die Repräsentanten sind entweder unfähig oder nicht ehrlich genug, um sich für das Wohl aller Gemeinden zu interessieren." Anfang 2005 hatte jedoch ein neuer Präsident die Amtsgeschäfte der ORAI übernommen. Seitdem traf man Guillermo öfter im Büro der Organisation in Iquitos an.

Bei meinem ersten Besuch im Februar 2004 hatte die Huitoto-Gemeinde bereits ein neues Gemeindehaus aufgebaut. Nach der Trennung vom bäuerli- 
chen Teil der Gemeinde waren die nativos umgezogen. Einige von ihnen lebten zwar noch im anderen Teil des Dorfes, bauten nun aber Häuser um den neuen Dorfkern, das Gemeindehaus, herum. Diese Baumaßnahmen waren auch im Juli 2005 noch nicht abgeschlossen. Allgemein zeichnete sich die comunidad nativa, genauso wie ihre indigene Nachbargemeinde, durch eine auseinandergezogene Siedlungsweise aus. Hernán erklärte mir, als wir auf dem Heimweg von unserem Besuch bei Guillermo am Gemeindehaus und den neu gebauten Häusern auf dem Hauptweg durch die Siedlung kamen, dass er nicht gerne so nah auf den anderen ’hocken wolle und deshalb niemals in den neuen Dorfkern umziehen würde. Er und seine Familie lebten im Wald, eine halbe Stunde Fußmarsch von jenem Dorfkern entfernt.

Am nächsten Tag machten Hernán und ich uns abends auf den Weg zu Don Alfonso ${ }^{17}$, einem der drei älteren Gemeindemitglieder, die noch Huitoto sprachen. Don Alfonso erzählte mir von einer maloca, die es früher einmal im Dorf gegeben hatte. Auch Hernán konnte sich noch an sie erinnern, wie er in das Gespräch einwarf. Allerdings sei sie in seiner Kindheit schon nicht mehr gepflegt worden und langsam in sich zusammengefallen. Don Alfonso berichtete uns, dass in den 1950er Jahren die maloca benutzt wurde, um Schulunterricht abzuhalten. Das sei die Zeit gewesen, in der man in seinem Dorf selbigen eingeführt habe. Zuerst seien die Kinder von der Kirche unterrichtet worden, dann habe der Staat dies übernommen. Heute würde man, besäße man wieder eine maloca, diese für Zusammenkünfte sowie als touristische Attraktion nutzen. Ein früherer Bürgermeister von Iquitos habe sie eine Zeit lang bei diesem Vorhaben unterstützt. Dann sei er aus dem Amt geschieden, und daraufhin sei das Projekt abgebrochen worden. Somit stünde der Bau der maloca weiterhin aus.

Als Don Alfonso mir von den unvollendeten Plänen des Baus einer neuen maloca berichtete, erinnerte ich mich an eine individuelle Initiative zu einem solchen Neubau, von der mir im Februar 2004 erzählt worden war. Damals hatte ich Don Sebastiano, den Begründer der lokalen Föderation, besucht. Als ich eines abends bei ihm eingetroffen war, waren gerade drei argentinische Touristen bei ihm zu Besuch, mit denen Don Sebastiano später eine ayahuasca-Zeremonie durchführen wollte. Zuerst hatte jedoch die Unterrichtung seiner achtköpfigen Tanzgruppe auf dem Programm gestanden. Denn Karneval nahte und damit ein Wettbewerb in Iquitos, bei dem die umliegenden comunidades nativas ihre traditionellen Tänze aufführen konnten. Die Sieger sollten Preise bekommen. Der größte Teil von Sebastianos Tanzgruppe bestand aus Kindern seines weiteren Familienkreises. Aber auch Hernán gehörte dazu, weil Sebastiano sein Onkel war. Nach der Probe hatte mir Don Sebastiano damals bedeutet, ich solle am darauffolgenden Tag wiederkommen. Dann

17 Personenname geändert. 
würde er mir von der indigenen Organisation erzählen. Als ich tags darauf eintraf, hatte er mir erzählt, wie es zur Gründung des Zusammenschlusses gekommen war:

»Man hat mir gesagt: Du musst dich organisieren, die Regierung, deine Kultur. Und da habe ich angefangen zu organisieren. Ich habe angefangen, meine Kultur zu organisieren, nicht eine andere Kultur. Ich habe angefangen, die Organisation aufzubauen. Nachdem die Organisation gegründet war, wurde ich zum Präsidenten der Organisation gewählt. Zehn bis zwölf Jahre hatte ich diesen Posten inne, es ist noch nicht lange her, dass ich aus dem Amt geschieden bin, das heißt, man hat mich aus dem Amt entfernt. Und seitdem geht es mit der Organisation bergab, jetzt hat sie keine Kraft, keinen Wert, jetzt verteidigt jeder nur sein Volk, wir verteidigen uns jetzt allein. Ich aber bitte weiterhin den Vater. Worum bitte ich ihn? Dass er die Kinder mit einem Beruf ausstattet, das ist meine Vision für mein Volk, nicht mehr für die Organisation. Ich bin Indigener, deshalb bin ich in der Organisation. Es ist nicht, weil sie [AIDESEP] uns geholfen hätten. Sie haben mir meine Rechte weggenommen, als sie mir sagten: \Wir sind keine Bettler, warum willst du also als Präsident einer Organisation ein Bettler sein«? Sie sagten das, weil ich die Regierung um Sachen bat. Ich reiste dafür nach Lima. Ich brachte der Gemeinde etwas von der Regierung mit, ich bat nicht AIDESEP. Ich brachte Lebensmittel, Materialien mit, damit sie vereint arbeiteten. Aber das Volk hat das nicht zu nutzen gewusst. Wir sind zum Beispiel zurückgeblieben. Andere indigene Organisationen, auch innerhalb Perus, sind viel weiter. Sie kennen ihre eigene Kultur. Denn wir dürfen jetzt nicht mehr die spanische Sprache sprechen. Wir als indigene Völker sollen unsere eigene Kultur unter uns sprechen. Und die spanische Sprache mit denen, die unsere nicht sprechen können. Wer hat die Schuld an unserer Situation? Der peruanische Staat, der uns patrones ins Volk schickte, die ihre Nachnamen hinterlassen haben. Meine Mutter zum Beispiel wuchs als Sánchez auf. Und so ist das bei jedem hier, und deshalb sagen sie hier in Peru, hier in Loreto, ich sei kein Indigener. Ich danke unserem Herrn im Himmel. Ich danke ihm, er hat nicht gewollt, dass ich studiere, aber er hat mir Weisheit, Intelligenz gegeben. Deshalb habe ich organisiert, weil ich unsere Kultur kenne. Wenn ich nämlich ein studierter Mann gewesen wäre, hätte ich niemals dieses Wissen erlangt. «

Nachdem er zu Ende gesprochen hatte, holte Don Sebastiano einen Plan hervor. Er würde gerne ein Touristenzentrum auf seinem Grundstück aufbauen, erklärte er mir. Auf der Zeichnung sah man einen großen Torbogen, auf dem die Besucher willkommen geheißen wurden. Des Weiteren waren Bäume sowie einige Häuser eingezeichnet, von denen eines durch seine Größe und Form besonders auffiel. Kernstück werde die maloca, erläuterte mir Don Sebastiano, wobei er auf das besonders große Gebäude zeigte. Auch seien Unterkünfte für die Touristen geplant. Er hoffte, dass die Straße von Iquitos 
bald an seinem Haus vorbeigeführt würde. Dann, so seine Überzeugung, hätte das Projekt eine Chance.

Auch sein Neffe Hernán verfolgte 2004 bereits ähnliche Ideen, war allerdings nun, sechzehn Monate später, einen Schritt weiter als sein Onkel. Während Don Sebastiano noch immer plante, hatte Hernán während meiner Abwesenheit bereits die Pfosten und das Dach eines Hauses gebaut, das seinen Gästen zukünftig als Unterkunft dienen sollte. Als wir am letzten Abend meines Aufenthalts in Hernáns und Esters Küche zusammensaßen, erzählte er mir, dass ihm sein Erfolg von manchen im Dorf geneidet würde und sie ihm vorwarfen, er entferne sich von der Gemeinschaft. Man habe ihm auch schon einmal nahegelegt, ein Amt, wie zum Beispiel das des Präsidenten, zu übernehmen. Aber für ihn sei diese Aufgabe nichts. Er suche die Kommunikation mit den Pflanzen und wolle auf diese Art anderen Menschen helfen. Ein politisches Amt verlange hingegen große Aufopferungsbereitschaft für die Gemeinschaft. Man würde selten Dankbarkeit erfahren, aber ständig mit Ansprüchen konfrontiert.

Im Gegensatz zu Hernán hatte seine Frau Ester schon verschiedene politische Funktionen im Dorf ausgeübt, unter anderem war sie zwei Jahre lang Elternsprecherin an der Schule gewesen. Doch auch sie erläuterte mir an meinem letzten Abend, was ich schon von so vielen anderen gehört hatte, die einmal ein Amt in einer comunidad oder Föderation bekleidet hatten: »Wenn $d u$ Repräsentantin deiner Gemeinde bist, musst du viel Leid und Entbehrungen ertragen. Du musst andauernd in die Stadt auf verschiedene Ämter fahren, dort warten und hungern. Du bekommst dafür kein Geld, und deine Arbeit zu Hause bleibt liegen. Auch waren manche Eltern sehr schwierig im Umgang und haben mir mehr Probleme bereitet als mich bei meiner Arbeit zu unterstützen. Jetzt will ich keinen Posten mehr. Aber wenn wir Besuch von Ausländern bekommen, schicke ich sie immer zur Schule und fordere sie auf, etwas zu spenden «.

Am nächsten Morgen, eine Woche nachdem ich in der comunidad nativa Huitoto angekommen war, brachen Hernán und Ester, die ihre jüngste, zwölf Monate alte Tochter auf dem Arm trug, gemeinsam mit mir wieder zusammen in Richtung Iquitos auf. Sie begleiteten mich, da Hernán und Ester verschiedene Dinge in der Stadt zu erledigen hatten und einige Patienten besuchen wollten. Als wir uns am Hafen voneinander verabschiedeten, sagte mir Hernán mit einem fast unmerklichen Lächeln: »Wenn du das nächste Mal kommst, sprechen wir wieder mehr über die Pflanzen." 


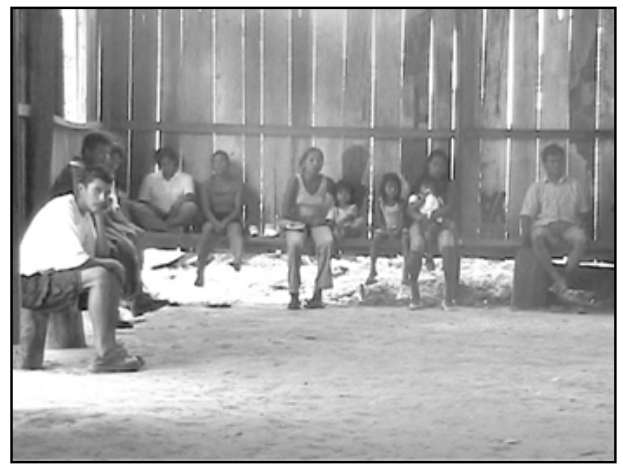

Abbildung 15: Einwohner einer indigenen Gemeinde bei der monatlichen Dorfversammlung (Videobild: Maren Rößler 2004).

Abbildung 16: Bei der Tanzprobe vor dem Haus von Don Sebastiano (Videobild: Maren Rößler 2004).
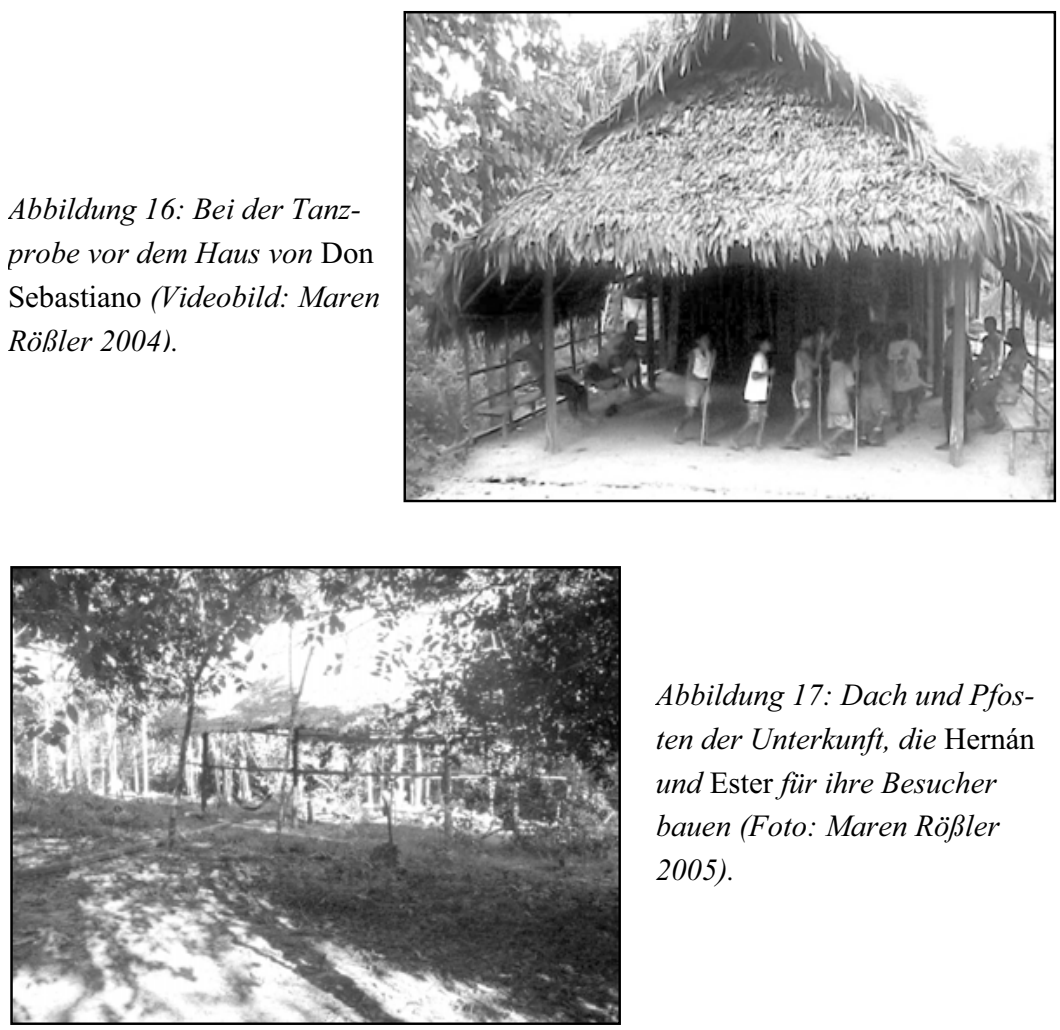

Abbildung 17: Dach und Pfosten der Unterkunft, die Hernán und Ester für ihre Besucher bauen (Foto: Maren Rößler 2005). 
Abbildung 18: Jahresversammlung der Mitglieder einer Föderation (Foto: Maren Rößler 2005).

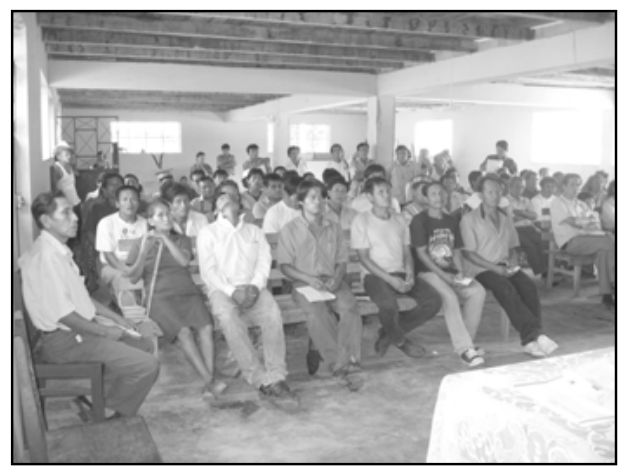

\section{Don Sebastiano und die Organisationsgründung}

Don Sebastiano thematisierte in seiner Gründungsgeschichte der Föderation drei wesentliche Aspekte der Organisationsprozesse:

- Aufgabe und Zweck des Zusammenschlusses,

- die >Rückständigkeit « der eigenen Gruppe

- Erfolge und Misserfolge der Organisation.

Seine Ausführungen stehen exemplarisch für sehr viele Gespräche, die ich während meiner Feldforschung mit Dorfbewohnern und ehemaligen sowie amtierenden Organisationsvertretern führte. Daher halte ich es für sinnvoll, seine Aussagen genauer zu beleuchten.

Don Sebastiano hatte eine Vision: Eine bessere Zukunft für >sein Volkı, die er in der Überwindung des asymmetrischen interethnischen Verhältnisses begründet sah. Man hatte ihm gesagt: »Du musst dich organisieren, die Regierung, deine Kultur«. Daher glaubte Sebastiano an die ethnische Organisation als das Instrument, das >seinem Volk die Kraft geben würde, die >eigene Kultur $\mathrm{zu}$ >verteidigen<. Die Ziele waren: Kulturelle Abgrenzung statt Assimilation, politische Selbstbestimmung statt Unterlegenheit und Abhängigkeit. Der Weg dahin: Die >Organisation` der Gemeinschaft, Bewusstwerden der eigenen Wurzeln. Die Pflege und den Gebrauch der eigenen Sprache in der Kommunikation untereinander sah er dafür als Voraussetzung an. Sebastiano war sich sicher, dass er die Kultur seines Volkes kannte, denn >der Herr hatte ihm >Weisheit und Intelligenz` gegeben. Er fühlte sich berufen. Ein Studium aber hätte ihn von diesem Kulturbewusstsein entfernt - so seine Überzeugung. Er erkannte die Schwierigkeiten, sich der eigenen Wurzeln bewusst zu werden, er sah eine Gefahr, die von den >Nicht-Indigenen` ausging: Man durf- 
te ihre Kultur nicht annehmen, aber man musste sie nutzen. Das Erlernen und der Gebrauch des Spanischen waren für diesen Zweck die Voraussetzung: Daraus ergab sich die Möglichkeit, die Güter der anderen zum eigenen Vorteil zu nutzen. Denn ein >fortschrittliches Volkı war für Sebastiano eines, das den >fremden〈 und den >eigenen〈 Bereich meisterte: »Man sollte mit den Weißen Spanisch sprechen, aber untereinander die eigene Sprache benutzen«.

Organisation verstand er aber auch als kreative Tätigkeit des >Organisierens $\prec$ Sich Güter von denjenigen zu beschaffen, von denen er sich abgrenzen wollte, war für ihn durchaus ein entscheidendes Mittel, das >Eigene〈 zu stärken. Er erwies sich als unermüdlicher Sammler von Gegenständen, die er gleich im Anschluss wieder verteilte. Gleichfalls sah er für die Zukunft >seines Volkes` die Bildung und Ausbildung der Kinder als unerlässlich an. Diese Bildung bestand aber nur zu einem Teil im Erwerb eines formalen Schulabschlusses bzw. Titels. Wichtig war auch die Kenntnis der eigenen Geschichte und Gebräuche. Unter Letzterem verstand Sebastiano vor allem Sprache und Zeremonien - aus diesem Grund brachte er Interessierten im Dorf die Tänze der Huitoto bei. Im Aufbau eines Tourismuszentrums sah er schließlich die Möglichkeit, die (vermarktungsfähigen) Besonderheiten der eigenen kulturellen Identität für andere sichtbar und erlebbar zu machen. Der damit einhergehende Erwerb von Geld sollte wiederum den ethnischen Stolz festigen und fördern, aber auch ihm und seiner Familie die Zukunft sichern.

Sebastianos Idee, die Güter der anderen zu nutzen, um die eigene Identität und Gemeinschaft zu stärken und zu entwickeln, fand sowohl bei seinem Dachverband als auch bei >seinem Volkı keinen ungeteilten Beifall: Mitglieder des Vorstandes von AIDESEP bezeichneten ihn als >Bettler . Sie missbilligten sein Verhalten. Das >Volk sinnvoll einzusetzen. Denn für Sebastiano stand fest: Andere indigene Organisationen im peruanischen Amazonasgebiet waren weiter entwickelt als seine eigene. Jene würden »ihre eigene Kultur besser kennen«.

Für Sebastiano galten drei Grundsätze:

- Identifikation durch die eigene Kultur, die sich vor allem an der Sprache und den öffentlich präsentierbaren costumbres ${ }^{18}$ wie Tänzen oder der Durchführung von Ayahuasca-Zeremonien für Touristen festmachen ließ.

- Abgrenzung von der anderen Kultur, die das >Eigene zerstörte. Die peruanische Regierung repräsentierte diese zerstörerische Kraft, die sich unter anderem in der Oktroyierung der spanischen Sprache und spanischer Familiennamen manifestierte.

- Kenntnis und Nutzung der mächtigen, anderen Kultur und ihrer Güter zur Stärkung und Aufwertung des >eigenen Volkes`.

18 Dt. >Gebräuche`, >Gewohnheiten`. 
Der Wert und die Kraft der Organisation bestanden für Don Sebastiano darin, diese Prinzipien durch eine starke Führungspersönlichkeit zu realisieren. Seine diesbezügliche Begabung hatte er durch unermüdliche Redistributionstätigkeiten unter Beweis gestellt. Seit man ihn aus dem Amt des Präsidenten entfernt hatte, ging es seiner Meinung nach >bergab< mit seiner Organisation. Jetzt besaß sie keine Kraft und keinen Wert mehr. Offensichtlich hielt sich Sebastiano für einen politischen Führer, der nicht einfach durch Amtseinsetzung eines anderen zu ersetzen war. Der seinen Ausführungen zufolge von höherer Organisationsebene vorgenommene Eingriff in die Autonomie seines Zusammenschlusses hatte nicht nur die lokale Föderation geschwächt, sondern auch AIDESEP als politische Repräsentationsinstanz für ihn bedeutungslos werden lassen. Zudem hatte der nationale Zusammenschluss von Anbeginn an für Sebastiano nur eine Bedeutung besessen, weil dieser eine Organisation von Indigenen war. Das Teilen einer gemeinsamen kulturellen Identität führte jedoch nicht dazu, dass Don Sebastiano sich als Teil einer größeren politischen Gemeinschaft begriff. Denn: AIDESEP tat nichts für ihn und seinen Zusammenschluss. Und das Ergebnis des regulierenden Eingriffs von Seiten der nationalen Repräsentanten lag zudem nun klar auf der Hand: Die Arbeiten der lokalen Föderation ruhten, die aktuellen Amtsinhaber genossen wenig Ansehen. Sie wurden aber gleichfalls kaum zur Rechenschaft gezogen. In Don Sebastianos Gemeinde wählte man einen anderen Weg: Die meisten kehrten der Organisation schlicht und einfach den Rücken.

\section{Indianische Führungspersönlichkeiten im peruanischen Tiefland: Statusführer, Despoten, Amtsinhaber}

»The tradition of criticizing tendencies toward self-aggrandizement dies hard in egalitarian Amazonia« (Brown 1993: 318).

Sowohl die im Prolog beschriebenen Probleme von Manuel Ijuma, des Präsidenten der Organisation der Cocama-Cocamilla, als auch die in Kapitel X.1 dargestellte Situation der indigenen Föderation in der Nähe von Iquitos sowie die Erzählung Don Sebastianos verweisen auf den Umstand, dass die indigenen Organisationen je nach Geschick und Einsatz des jeweiligen Vorstands aufblühen oder erschlaffen. Die individuellen Persönlichkeiten der Repräsentanten bestimmen Erfolg und Misserfolg der Zusammenschlüsse. Indigene Organisationen sind institutionell in den lokalen Gemeinschaften lose verankert. Sie gewinnen nur temporär an Bedeutung. Die Gründe für diesen >unvollständigen Institutionalisierungsprozess s sind vielfältig. Sie ergeben sich aus mehreren Umständen, die sowohl im Fall der Föderation der Cocama- 
Cocamilla als auch des in Kapitel X.1 vorgestellten indigenen Zusammenschlusses sowie in anderen von mir besuchten Föderationen eine Rolle spielten:

- Kommunikationsprobleme zwischen Repräsentanten und Repräsentierten sowie zwischen den verschiedenen Organisationsebenen;

- mangelnder Unterstützungswillen für die Repräsentanten von Seiten der Dorfbewohner;

- vor allem auf Ebene der supralokalen Föderationen Schwierigkeiten, externe Unterstützer zu gewinnen;

- mannigfache Probleme in den Gemeinden (z.B. ausstehende Anerkennung als indianische Gemeinde und damit einhergehend ausstehende Titulierung von Land, unkontrolliertes Eindringen von Holzfällern und Tierfellhändlern etc., ausbleibende Infrastrukturmaßnahmen von staatlicher Seite etc.);

- die Organisationsvergangenheit, die vielerorts auch dem Prestige gegenwärtiger Repräsentanten schadet, vor allem, wenn durch umfangreiche finanzielle Unterstützung von außen (wie zum Beispiel im Fall der im Prolog vorgestellten Föderation der Cocama-Cocamilla) bestimmte Vorstellungen von der Lukrativität des Repräsentantenpostens unter Dorfbewohnern entstanden sind.

$\mathrm{Zu}$ überlegen ist jedoch auch, inwiefern die Probleme nicht ihren zentralen Ursprung im Widerstreit konträrer Modelle politischer Führung besitzen, die sich in den Organisationszusammenhängen überlappen und sich dabei tendenziell gegenseitig behindern. In diesem Zusammenhang stellen sich folgende Fragen: In welchem Verhältnis stehen egalitäre und hierarchischzentralistische politische Ordnungsprinzipien in den organisierten Gruppen zueinander? Und: Wie wirkt sich diese Beziehung auf die politische Legitimation der indigenen Repräsentanten aus?

\section{Starke und schwache Führer}

1948 publiziert Robert H. Lowie einen Essay zur »politischen Organisation der amerikanischen Eingeborenen« (Lowie 1948). Mit diesem schafft er ein die folgenden Jahrzehnte bestimmendes Paradigma unter Amerikanisten, demzufolge die Führungspersönlichkeiten dieser Gesellschaften keine politische Macht in Form von Zwangsgewalt besitzen. Lowie schlägt eine Unterteilung in strong chiefs and titular chiefs vor. Die starken Führer mit nicht hinterfragter Autorität seien auf dem amerikanischen Kontinent rar und tendierten zudem dahin, diese Macht nur zeitweise zu besitzen. Der häufiger anzutreffende Typus sei der titular chief - ein Statusführer, der drei essentielle Charakteristiken aufweist: 
- Er ist ein Friedensstifter.

- Er muss großzügig sein.

- Er muss ein guter Redner sein.

Ferner unterteilt Lowie in zivile und in kriegerische Anführer. Letztere verfügen über Zwangsgewalt und verkörpern somit den Typus des strong chief, aber ihre Macht besteht nur im Rahmen der spezifischen, zeitlich begrenzten Aufgabe.

Aufbauend auf Lowie beschreibt der französische Strukturalist Pierre Clastres (1977: 28) den >klassischen Führertypus im Amazonasgebiet wie folgt: Der Chef einer Gruppe plant wirtschaftliche und zeremonielle Aktivitäten, hat aber keine Entscheidungsmacht; er kann sich niemals sicher sein, dass seine Anweisungen ausgeführt werden. Die Macht des Anführers hängt vom guten Willen der Gruppe ab, sie basiert vor allem auf seiner Eloquenz und Großzügigkeit. Bezüglich der Generosität übertreffen die Erwartungen der Indianer oft die unmittelbaren Möglichkeiten des Gruppenchefs.

Macht bzw. der Mangel an dauerhafter Macht von Führungspersönlichkeiten ist ein Leitthema ethnografischer Studien zur politischen Ordnung indianischer Gesellschaften im südamerikanischen Tiefland. Die meisten Wissenschaftler (z.B. Clastres 1977; Rivière 1984; Lévi-Strauss 1967, 1973; Rabineau 1975; Brown 1993; Santos Granero 1993) führen dabei vor allem zwei Gründe an, um die schwache Position politischer Führungspersönlichkeiten zu belegen:

- Eine starke Abhängigkeit des Anführers von seiner Gefolgschaft sowie

- sein fast vollständiger Mangel an Zwangsgewalt.

Anführer scheinen keine Position zu besitzen, in der sie ihrer Gefolgschaft Anweisungen geben können. Passt dieser das Verhalten ihres primus inter pares nicht, wenden sie sich enttäuscht von ihm ab und bestrafen ihn nicht selten mit sozialer Ächtung, die zum Beispiel auch zu seinem Ausschluss aus der Gruppe führen kann (vgl. Rosengren 1987: 6).

Dan Rosengren (1987: 6ff.) unterscheidet dabei zwei generelle Positionen, die Ethnografen bei der Betrachtung politischer Macht bzw. deren Mangel im südamerikanischen Tiefland einnehmen: Die einen betonen die Bedeutung von individuell erlangtem Prestige. Ein Anführer zeichnet sich durch besondere Qualitäten und Charakteristiken aus. Je mehr Prestige er durch gelungene Aktionen erlangt, desto größer ist seine politische Macht. Die Schaffung und Erhaltung einer Gruppe von Anhängern durch Austauschbeziehungen zwischen Führer und Gefolgschaft wird zum zentralen Fokuspunkt dieser Studien. Diesem Ansatz zufolge gründet die Macht des Statusführers im Amazonasgebiet auf dem von Max Weber (1921) als »charismatische Herrschaft« 
bezeichneten politischen Legitimationsmodell. ${ }^{19}$ Claude Lévi-Strauss (1967, 1973) ist ein herausragender Vertreter dieser Position. Er geht dabei soweit zu betonen, dass man in den indianischen Tieflandgesellschaften Führerschaft als Berufung ansieht, der Statusführer muss eine außerordentliche psychologische Prädisposition mitbringen. Er ist der Typ des >geborenen Anführersく.

Die anderen erklären das Phänomen aus der formalen Bedeutung bestimmter sozialer Positionen. Ob zugeschriebene Macht in Form eines vererbten Status wie im Falle der chiefs oder erlangte Macht wie im Falle bedeutender Schamanen - in beiden Fällen hängt sie vor allem von formalen Regeln und Normen der politischen Organisation ab. Politische Macht ist für diese Wissenschaftler, der Einteilung Webers folgend, durch Traditionen legitimiert. Pierre Clastres ist ein herausragender Vertreter dieser Position. Er erblickt dabei in den indianischen Gesellschaften des Tieflands den Prototyp einer egalitären, hierarchiefreien politischen Organisationsform: In Friedenszeiten stehe die verwandtschaftlich organisierte Gesellschaftsstruktur indianischer Tieflandgesellschaften per se Ambitionen Einzelner oder einer Gruppe entgegen, Herrschaft ${ }^{20}$ auszuüben. Die Möglichkeit, dass sich zentralisierte Regierungsstrukturen herausbilden, die in die Gründung eines Staates münden könnten, würde damit grundsätzlich verhindert. Clastres definiert die Geschichte indianischer Völker als »Geschichte ihres Kampfes gegen den Staat« (Clastres 1977: 186).

\section{Segmentäre versus hierarchische politische Ordnungsprinzipien}

Pierre Clastres Egalitarismus-These wird bis heute kontrovers diskutiert. David Maybury-Lewis $(1967,1979)$ relativiert dieses Bild südamerikanischer Tieflandindianer, indem er das komplexe System von Altersklassen und Moieties bei den zentralbrasilianischen Gê und Bororo beschreibt. Auch wenn Gê und Bororo keine zentralisierten Regierungsinstanzen besäßen, so ließen sich in diesen Gesellschaften hierarchische, asymmetrische politische Ordnungen beobachten. Terence Turner $(1979,1980)$ wiederum beschreibt hierarchische Elemente in der sozio-politischen Organisationsstruktur der Kaya-

19 Weber (1980 [1921]: 124) unterscheidet drei Typen von politischer Legitimität, denen er drei Herrschaftsformen zuordnet: 1. Rationale Herrschaft: gründet im Glauben an einen Satz legaler Ordnungen und Normen (verkörpert im System des modernen Rechtsstaat); 2. traditionale Herrschaft: gründet im Glauben an die Heiligkeit von jeher gültigen Traditionen; 3. charismatische Herrschaft: gründet auf individuellen Fähigkeiten eines Führers, der sich in der Praxis bewähren muss, seine Legitimität ständig neu beweisen muss.

20 Herrschaft verstehe ich, aufbauend auf Max Weber (1984: 89), als institutionalisierte und monopolisierte Form der Macht einer Person oder einer Gruppe, die das Recht zu befehlen und die Pflicht zu gehorchen impliziert. 
po, die für ihn vor allem auf einer Generationen- und Geschlechterasymmetrie beruht. Diese wird seinen Beobachtungen zufolge durch vielfältige Initiationsriten aufrechterhalten und bekräftigt. Und Philippe Descola (1988: 819) meint, dass der von Clastres postulierte Egalitarismus vieler indianischer Gesellschaften des Amazonasgebietes ein Produkt der kolonialen Kontaktsituation sei. Präkolumbische, archäologische Befunde sowie Chroniken aus der Eroberungszeit bewiesen die Existenz stratifizierter, komplexer Gesellschaften mit Zentralgewalt. Diese seien nicht nur Ausnahmeerscheinungen gewesen, wie Clastres es vermutet, sondern in zahlreichen Regionen anzutreffen. Dazu trug auch bei, dass die Tieflandgesellschaften bereits vor der Ankunft der Spanier keineswegs isoliert lebten. Im Gegenteil: Viele standen über Handelsbeziehungen und kriegerische Auseinandersetzungen in mehr oder weniger engem Kontakt zu den Inka und ihren Vorläuferkulturen.

\section{Herrschaft durch Gewaltandrohung}

Bei der historischen Betrachtung der indianischen Tieflandgesellschaften lässt sich ferner auch der Gegenpart zum machtlosen Statusführer finden. Brown (1993: 310f.) sieht ihn zum Beispiel im despotischen gantatsirira bei den Matsigenka verkörpert. Diese Kriegerfigur erlangte Gefolgschaft durch Gewaltandrohung. Auch unter den Asháninka, im Putumayo und an anderen Orten in West-Amazonien existierte diese Form der Führerschaft. Sie etablierte sich im Zuge von Grenzkonflikten. Die auf Zwang basierende Macht des gantatsirira wurde allerdings erst durch Kollaboration mit Plantagenbesitzern und Missionaren ermöglicht. Sie muss somit als Produkt der anhaltenden Kontaktsituation mit den Kolonisierern gesehen werden. Ferner verweist Brown (1991) auf millenaristische Bewegungen bei den Asháninka, ${ }^{21}$ im Zuge derer versucht wurde, politische Macht dauerhaft zu institutionalisieren und damit Herrschaftsstrukturen $\mathrm{zu}$ etablieren. Auch diese Bestrebungen entstanden durch die Kontaktsituation mit externen Akteuren. Dennoch bietet die Zeit nach der Eroberung in Amazonien, im Gegensatz zu anderen Weltteilen, wenige Beispiele für die Hervorbringung regionaler oder nationaler Allianzen durch millenaristische Bewegungen (vgl. Brown 1993). Zentralisierte Zusammenschlüsse der Tieflandbewohner zu militärisch-politischen Zwecken gewannen auch in der Auseinandersetzung mit den fremden Kolonialmächten meist nur kurzfristig einen formalen Charakter und verloren schnell wieder an Bedeutung. Ein übermäßiges Verlangen nach politischer Macht in Form von Zwangsgewalt sowie der Wunsch nach Verfestigung dieser Strukturen, so

21 Wie zum Beispiel die bereits erwähnte millenaristische Bewegung unter Leitung von Juan Santos Atahualpa (1742-1850). 
Browns' (1993: 314) Fazit, ruft normalerweise die gegenteilige Reaktion unter der potentiellen Gefolgschaft im südamerikanischen Tiefland hervor.

Auch wenn Clastres Beschreibung der indianischen Tieflandbewohner als `Staatsfeinde $<$, die politische Macht vollständig negieren, sich als einseitig erweist, prägen der Typ des Statusführers, die Ablehnung von physischem Zwang zur Erreichung von Gefolgschaft sowie eine starke Betonung individueller Autonomie gegenwärtig vielerorts die politische Organisation: Ethnografische Studien belegen, dass indianische Führer im Amazonasgebiet ihre Anhängerschaft am wirkungsvollsten mit eloquenter Rede und positivem Beispiel mobilisieren. Ihre Macht gründet sich dabei auf zugeschriebener und erlangter Autorität. Erstere besitzen sie durch Verwandtschaft und Heiratsallianzen, letztere, indem sie den anderen Gruppenmitgliedern ein Vorbild an Generosität, Takt und Kompetenz sind (vgl. Brown 1993; Descola 1988; Santos Granero 1993). Politische Macht ist damit, der Einteilung Webers folgend, sowohl traditional als auch charismatisch begründet. Beides, Position und Prestige, sind meist notwendige Bedingungen für politische Führerschaft im lokalen Kontext (vgl. Rosengren 1987: 12).

\section{Der Vermittler als politisch relevanter Führertypus}

Mit Beginn der Missionstätigkeit von Franziskanern und Jesuiten entwickelte sich während der Kolonialzeit ein neuer, politisch relevanter Führertypus in Form des curaca. Da die Missionare den curaca als Repräsentanten der lokalen Bevölkerung behandelten, kam ihm eine wichtige Rolle als Vermittler (Broker) zu. Dieses von außen eingeführte, institutionalisierte Amt stand im Wettstreit mit dem Prinzip informeller Führerschaft, das weiter existierte und politisch relevant blieb. Rosengren (1987: 176f.) analysiert am Beispiel der Matsigenka die unterschiedlichen Karriereverläufe zweier curacas, von denen der eine durch seine Vermittlertätigkeit auch im Innern der Gruppe an politischer Macht gewinnt, während der andere auf Ablehnung stößt und aus der Gruppe ausgeschlossen wird. Auschlaggebend für die Akzeptanz des einen und die Ablehnung des anderen sind die jeweiligen Bemühungen, sich den Erwartungen der lokalen Bevölkerung entsprechend zu verhalten. Der erfolgreiche curaca erweist sich als taktvolle, eloquente und großzügige Persönlichkeit, die nicht offen gegen die Ideale der Matsigenka - Unabhängigkeit und Gleichheit - verstößt. Der mit Ausschluss aus der Gruppe bestrafte curaca hingegen versucht, seine privilegierte Position als Vermittler offen zum eigenen Vorteil zu nutzen. In ihm erkennt die politische Gemeinschaft einen potentiellen Despoten, dessen sie sich entledigen möchte.

Im Zuge der Gesetzgebung zu den comunidades nativas in den 1970er Jahren wird der curaca als Vermittler im lokalen Kontext ersetzt durch die Figur des presidente comunal, des Gemeindepräsidenten bzw. Dorfvorstehers. 
Aus Sicht des Staates verkörpert der Dorfvorsteher die Repräsentation des »rationalen Herrschaftsmodells« auf unterster Organisationsebene. ${ }^{22}$ Ein entscheidender Unterschied zwischen curaca und presidente comunal liegt darin, dass letzterer von der lokalen Bevölkerung selbst gewählt und nicht von externen Akteuren bestimmt wird. ${ }^{23}$ Dennoch gewinnt der in den >neuen< Dörfern zu wählende Vorsteher in der Folge seinerseits wiederum vor allem im Außenkontakt mit dem peruanischen Staat und internationalen Hilfsorganisationen an Bedeutung, im Innern bleiben seine Machtbefugnisse stark eingeschränkt (vgl. Gasché 2001: 12ff.). Auch der presidente comunal kann sich bestenfalls zum primus inter pares entwickeln: Er muss seine politische Gemeinschaft, trotz seines formalen Amtes, das ihn mit gewissen rationalen Herrschaftsmitteln ausstattet, mit gutem Beispiel überzeugen, kann sie kaum zu etwas zwingen. Seine privilegierte Stellung im Kontakt mit der >Außenwelt< bietet zwar die Grundlage für den Aufbau eines asymmetrischen Tauschverhältnisses zwischen ihm und seiner Gefolgschaft. Da er aber unter der direkten Kontrolle seiner politischen Gemeinschaft steht, kann er sich kaum zum strong chief mit unhinterfragter Macht entwickeln. Die Positionen des curaca und presidente comunal stellen unbestritten eine Erweiterung des Repertoires der Möglichkeiten lokaler Akteure dar, an politischer Macht zu gewinnen. Die diesen Ämtern von außen zugedachte Bedeutung wird dabei jedoch mit intern gültigen Normen und Vorstellungen vermischt und dadurch verändert.

Parallel zur Schaffung vom Staat anerkannter dörflicher Strukturen vollzogen sich die neuen ethnischen bzw. panethnischen Kollektivierungsbestrebungen. Auch in diesem Prozess wurden neue Ämter geschaffen, das prominenteste darunter war das des Föderationspräsidenten. Dieser galt nun in der Außendarstellung als Repräsentant einer Vielzahl von Dörfern bzw. als Vertreter eines oder mehrerer Völker, ohne dass ihm dabei besondere Machtbefugnisse von der Gefolgschaft zugestanden wurden. Aus der geschichtlichen Betrachtung wurde deutlich, dass zumindest am Anfang in der Regel charismatische Persönlichkeiten den Organisationen vorstanden, die sowohl nach emischen Kriterien als herausragende Persönlichkeiten anerkannt als auch im Umgang mit der nationalen Gesellschaft geschult waren. Im Laufe des

22 Ich erinnere daran, dass die indianischen Dörfer ein internes Statut entwickeln, eine Struktur kommunaler Autoritäten schaffen und eine Gemeindeversammlung als höchstes Entscheidungsorgan einrichten mussten, um von der Regierung offiziell anerkannt zu werden (vgl. Kapitel VII.4).

23 Ein weiterer entscheidender Unterschied liegt in der primären Funktion, die beiden Ämtern jeweils zugedacht wurde: Das Amt des curaca wurde von den Missionaren eingeführt, um die lokale Bevölkerung besser zum christlichen Glauben bekehren zu können; die Einführung des Status' der comunidad nativa und damit einhergehend das Amt des presidente comunal zielte auf die Integration der indianischen Tieflandbewohner in nationalstaatliche Zusammenhänge ab. 
Wachstums- und Fragmentierungsprozess der indigenen Bewegung sind die Möglichkeiten, in die Position des Präsidenten einer Organisation gewählt zu werden, vielfältiger geworden. Eine Reihe von Kandidaten stehen meist zur Auswahl, und vielerorts wird beklagt, dass die Repräsentanten eine >Funktionärsmentalität ‘ bei der Ausübung ihres Amtes an den Tag legen würden (Gespräch Nugkuag 02.08.2005; Interview Rubio 04.03.2004; Gespräch Mishari 14.06.2005; Gespräch García 10.06.2005; Gespräch Chirif 20.07.2005; Versammlung Pucaurquillo 03.03.2004, Versammlung Nueva Fortuna 13.02. 2004). Jedoch können die neuen supralokalen Führungspersönlichkeiten in den Augen der lokalen Gemeinschaften bestenfalls als Big Men im Sinne Maurice Godeliers (1987) politische Relevanz erlangen: Ein Big Man gelangt in seine Führungsposition auf Grund persönlicher Fähigkeiten, vor allem durch Organisationstalent und Redistributionsgeschick. Er muss sich durch Geschenke eine Gruppe von Schuldnern und Getreuen schaffen, die ihm helfen, seinen Namen zu vergrößern. Er ist ein Statusführer, der beständig die Hoffnung seiner Anhänger nähren muss, von seinem Ruhm und seiner Großzügigkeit zu profitieren. So kann er über sein Dorf hinaus Bedeutung erlangen und temporär supralokale Allianzen leiten. Es sind jedoch lockere Bindungen, die Führer und Gefolgschaft einen. Sie können leicht zerbrechen. Der Big Man steht in ständigem Konkurrenzkampf mit anderen Männern, die ihm seine Position und die damit verbundene politische Macht streitig machen wollen. Um den eigenen Status zu halten, bedarf es somit der konstanten Pflege und Vergrößerung des »sozialen Kapitals« (Bourdieu 1997). Macht beruht auf dem Prinzip der Gegenseitigkeit (vgl. Godelier 1987: 220). Dadurch wird die Verselbstständigung von Macht, die Herausbildung zentraler, hierarchischer Führungsinstanzen letztendlich verhindert.

Für Godelier (1987: 247), der die politische Ordnung segmentärer Gesellschaften Melanesiens untersucht, entstehen Big Man - Systeme dort, wo der Tausch mit Wettstreitcharakter die relative Bedeutung des Krieges verdrängt hat. Der Big Man ist für ihn ein politischer Führungstypus, der sich vor allem unter dem Einfluss von Kolonialmächten herausgebildet hat. Deren Ziel war es, die >kriegerischen Wilden $\mathrm{zu}$ `zivilisieren`. Auch in diesem Punkt ergeben sich eindeutige Parallelen zwischen dem melanesischen Big Man und dem neuen indianischen Repräsentanten: indigene Organisationen entstanden im Kontext einer intensivierten Kontaktsituation zwischen Staat und Tieflandindianern, im Verlauf derer letztere in die nationale Gemeinschaft integriert und zu peruanischen Staatsbürgern gemacht werden sollten (vgl. Kapitel VIII und IX).

Der südamerikanische Big Man unterscheidet sich aber von seinem melanesischen >Verwandten $<$ unter anderem in einem wichtigen Punkt: Er kann seine Führungsposition nicht auf eigenen Produktionsleistungen (bzw. denen seiner Gefolgschaft) aufbauen. Während in Melanesien die Schweinezucht 
eine zentrale Bedeutung für die Erlangung des Status eines Big Man besitzt, ist es in Südamerika vor allem das besondere Geschick beim Aufspüren und Umleiten begehrter, lokal nicht verfügbarer und nicht produzierbarer Ressourcen. In diesem Sinne verkörpern diejenigen, die in den indigenen Organisationen im peruanischen Tiefland politische Bedeutung gewinnen, eine >moderneく Variante des Sammlers und Jägers bzw. eine zeitgenössische Form des Kriegers.

Die neuen indianischen Repräsentanten mit supralokaler Bedeutung hängen jedoch in ihrer Arbeit - wie zuvor die von Missionaren eingesetzten $\mathrm{cu}$ racas - von snicht-indigenen Akteuren ab. Ihre Position erlangt vor allem dadurch innerhalb der organisierten Gruppen eine ambivalente Bedeutung, dass sie als Vermittler leicht der direkten Kontrolle ihrer Gefolgschaft entgleiten. So macht zum Beispiel Ismael Vega Díaz (2000) - im Falle der Achuar die soziale und vor allem geografische Distanzierung der neuen politischen Führungspersönlichkeiten für den Umstand verantwortlich, dass ihnen ihre Gemeinschaft mit Misstrauen begegnet: Verlassen die Repräsentanten den lokalen Kontext, kann die Gefolgschaft nicht mehr überprüfen, ob die mit der Interessenvertretung betrauten Männer wirklich in ihrem Sinne handeln. Dieses allgemeine Misstrauen in die Absichten und Beweggründe der Repräsentanten gehörte zum Grundtenor der Antworten von mir befragter Dorfbewohner in verschiedenen Regionen des Amazonasgebietes.

Bei der dauerhaften Mobilisierung einer größeren politischen Gemeinschaft ergibt sich auch daraus ein Problem für den supralokalen Repräsentanten, dass die einzelnen Haushalte relativ autark wirtschaften. Ein allgemeines >Tributsystem< konnte, wie berichtet, bis heute innerhalb der Organisationszusammenhänge nicht erfolgreich etabliert werden. Auch wenn Wissenschaftler wie Jackson (1976), Menget (1993), Erikson (1993) und Renard-Casevitz (1993) auf die Bedeutung supralokaler Netzwerke zum Zwecke des Handels sowie für politisch relevante Heiratsallianzen verweisen, so bleibt doch der einzelne Haushalt als Wirtschaftseinheit der zentrale Ausgangspunkt dieser Netzwerkbildungen, und die Etablierung eines »balancierten Reziprozitätsverhältnisses« (Sahlins 1974) steht im Mittelpunkt der Bemühungen. Auch Münzel (1993: 253f.) hält fest, dass radikale Individuumsbezogenheit - das Individuum mit quer zu den Gruppengrenzen verlaufenden Netzwerken stärker das Verständnis politischer Beziehungen in weiten Teilen des Tieflands charakterisiert als dauerhafte ethnische Kollektivierungsbestrebungen. Das Zugehörigkeitsgefühl des Einzelnen zu einer bestimmten Gruppe bleibt mobil und äußerst flexibel. Es basiert fundamental auf sozial wirksamen Austauschbeziehungen; dieses Prinzip leitet auch das Verhältnis zwischen politischem Führer und Gefolgschaft. Für den Vertrauensvorschuss, den Dorfbewohner heute ihrem Organisationsrepräsentanten geben, indem sie ihn in sein Amt wählen, erwarten sie Gegenleistungen. Diese gleichen denen, die schon 
Lévi-Strauss, Clastres und viele andere Wissenschaftler beschrieben haben und lassen sich unter zwei Begriffe subsumieren: Projekte und Kommunikation.

\section{Formale Amtsinhaber mit informellem Status}

Unbestritten liegt der Ursprung indigener Organisationen in den veränderten Bedingungen der interethnischen Kontaktsituation, die ich im geschichtlichen Rückblick dargestellt habe: Mission, Einführung zweisprachigen Unterrichts sowie Landrechtsprobleme beeinflussten die Entwicklung neuer kommunaler Strukturen und supralokaler, indigener Zusammenschlüsse. Letztere wurden anfangs auch von Seiten des Staates, aber von Anbeginn an vor allem durch zivilgesellschaftliche Akteure, die im Kontext der Entwicklungszusammenarbeit tätig waren, gefördert. Obwohl die neuen supralokalen ethnischen $\mathrm{Zu}$ sammenschlüsse der Indianer von der peruanischen Regierung nicht als autonome politische Instanzen anerkannt wurden, entwickelten sie dennoch, ähnlich wie eine nationale Regierung, bald umfassende Programme in den Bereichen Bildung, Gesundheit, Kultur. Dabei blieben sie jedoch von externer Unterstützung abhängig: NGOs übernahmen die Finanzierung der von staatlicher Seite auf lokaler Ebene vernachlässigten Pflichten im Bereich des Dienstleistungssektors. Neben Staat und indigene Organisationen traten somit die Vertreter von nationalen und internationalen NGOs als weitere politisch relevante Akteure auf und erhöhten die Komplexität lokaler politischer Prozesse. Schon Ende der 1980er und verstärkt ab Mitte der 1990er Jahre präsentieren sich zudem indianische Kandidaten in verschiedenen Regionen des Amazonasgebietes bei Wahlen auf Provinz- und Distriktebene. Zu den Kommunalwahlen 1995 gründete OIRA $^{24}$, eine regionale Mitgliedsorganisation von AIDESEP, zum Zwecke der Unterstützung organisationsnaher Kandidaten das Movimiento Indígena de la Amazonía Peruana (MIAP) ${ }^{25}$. Der Institutionalisierungsprozess der indigenen Bewegung im Tiefland war damit in eine neue Etappe eingetreten. Bei den darauffolgenden Kommunalwahlen im Jahr 1998 übernahm auch AIDESEP die Bezeichnung MIAP für die Ausweisung indigener Kandidaten, die von der Organisation offiziell unterstützt wurden.

Indigene, die sich für politische Ämter auf lokaler oder regionaler Ebene bewerben, sind oft zuvor oder zeitgleich auf Föderationsebene oder sogar regionaler und nationaler Ebene in den Zusammenschlüssen aktiv. Der damit erworbene Bekanntheitsgrad kann ihnen bei den Wahlen zum Vorteil gereichen (vgl. Chirif 1998: 73ff.). Einerseits haben sich aus diesen Entwick-

24 Organización Indígena de la Región de Atalaya; dt. >Indigene Organisation der Region Atalayar.

25 Dt. >Indigene Bewegung des peruanischen Amazonasgebietes $\measuredangle$ 
lungen neue Verknüpfungspunkte zwischen indigenen Organisationen und staatlichen Stellen ergeben und damit auch neue politische Handlungsressourcen für die entsprechenden Repräsentanten. Ihre Wahl in lokale und regionale staatliche Regierungsstrukturen weckt andererseits hohe Erwartungshaltungen der Gefolgschaft in ihren jeweiligen Herkunfstregionen. In Gesprächen mit vielen Akteuren, die bereits einmal als Bürgermeister oder regidor ${ }^{26}$ auf Provinz- oder Distriktebene tätig waren, wurde dies deutlich. Die Ansprüche von Seiten der Dorfbewohner übersteigen meist die realen finanziellen und politischen Möglichkeiten der betreffenden Politiker. In diesem Sinne bleiben lokale politische Organisationsmuster erhalten: Auch als Amtsinhaber gewinnt man nur nach dem Prinzip des Statusführers an Prestige und kann den hohen Erwartungshaltungen der Gefolgschaft selten gerecht werden. Gleichzeitig verdeutlichen diese Entwicklungen aber auch, dass für indianische Akteure inzwischen eine Reihe neuer Möglichkeiten besteht, auf lokaler und regionaler Ebene an politischer Macht zu gewinnen. Politische Prozesse erreichen dadurch auf allen Organisationsebenen der indigenen Bewegung im Tiefland einen hohen Grad an Komplexität. Das folgende Zitat einer indigenen regidora bringt dies zum Beispiel zum Ausdruck: »Viele denken heute, warum sollen wir uns von der $\mathrm{CAH}$ abhängig machen, wenn wir Bürgermeister werden können« (zitiert nach Chirif 1998: 71)? ${ }^{27}$

\section{Fazit}

Die entscheidenden Veränderungen in der internen politischen Ordnung indianischer Gemeinschaften, die durch die Gesetzgebung zu den comunidades nativas und die Herausbildung ethnischer Föderationen erfolgten, lassen sich in zwei Punkten zusammenfassen:

- Es wurden politische Ämter eingeführt, deren Inhaber durch >allgemeine` Wahlen bestimmt werden sollten - der Gemeindepräsident auf lokaler Ebene und der Organisationsrepräsentant auf suprakommunaler Ebene. Letzterem wurde durch stetig zunehmende externe finanzielle Unterstützung die Möglichkeit verschafft, sich der direkten sozialen Kontrolle seiner >Wählerschaft zu entziehen. Dennoch besaß er weiterhin keine allein kraft seines Amtes gewonnene Möglichkeit, Zwangsgewalt auszuüben. In diesem Sinne blieben der Institutionalisierungsprozess und damit die dauerhafte Durchsetzung intern wirksamer politischer Hierarchisierungsprozesse unvollständig.

26 Dt.>Stadtrat<.

27 Im spanischen Original heisst es: »Muchos piensan ahora ¿por qué vamos a depender del CAH si podemos ser alcaldes? « CAH steht für Consejo Aguaruna Huambisa, den vom ehemaligen AIDESEP-Präsidenten Evaristo Nugkuag gegründeten indianischen Zusammenschluss (siehe Kapitel VIII.1). 
- Anders als bei den zuvor für die supralokale Organisation wichtigen herausragenden Kriegern oder Schamanen standen bei den modernen ethnischen Zusammenschlüssen junge zweisprachige Männer, die eine formale Bildung erhalten hatten, an der politischen Spitze. Alphabetisierung und die Aneignung von Fachwissen zur Erschließung finanzieller Ressourcen erlangten im Zuge dieser Entwicklung hervorgehobene Bedeutung. Die Quellen der Macht veränderten sich somit, neue Fähigkeiten wurden von den entsprechenden Kandidaten verlangt, vermischten sich aber mit zuvor gültigen Prinzipien der Legitimierung von Autorität.

Fest steht: Da sich die indigenen Organisationen inzwischen seit über zwanzig Jahren halten, sind sie nicht nur ein von außen aufgesetztes Modell politischer Organisation, das keinerlei Akzeptanz im Innern besitzt. Im Gegenteil: Die Zusammenschlüsse erfüllen wichtige Funktionen als Vermittlungsinstanzen zwischen Mitgliedern der organisierten Gruppen und kontextabhängig zu definierenden $>$ Außenstehenden $<$. Sie sind in lokale politische Beziehungsmuster integriert worden. Dabei kann ein Blick auf die kategoriale Wahrnehmung der Repräsentanten von Seiten der Dorfbewohner weiteren Aufschluss darüber geben, welche Bedeutung den Organisationen und ihren Vertretern auf lokaler Ebene gegenwärtig beigemessen wird.

\section{Die kategoriale Wahrnehmung der Repräsentanten als Spiegelung sozialer Differenzierungsprozesse}

Die theoretischen Ausführungen über das politische Feld haben gezeigt, dass das Verhältnis zwischen Politikern und denen, die sie vertreten, komplex ist. Die Komplexität wächst dabei proportional zur geografischen und sozialen Distanz von der >Basis〈. Der Lokalpolitiker ist seinen Wählern auf viel unmittelbarere Weise verpflichtet als zum Beispiel der Abgeordnete im nationalen Parlament. Die Auswirkungen seiner Arbeit zeigen sich meist schneller bzw. sind für den Wähler besser zuzuordnen. Dieser hat somit das Gefühl, ihn leichter kontrollieren zu können. Distanz hingegen fördert ein Klima des Misstrauens. Sowohl am Ständigen Forum für indigene Angelegenheiten als auch im Kontext der indigenen Organisationen des peruanischen Amazonasgebietes treten diese Konstellationen zutage. Oft sprachen indigene Repräsentanten auf nationaler Ebene das Kommunikationsproblem an, das zwischen ihnen und den Bewohnern der comunidades nativas bestünde. Kritische Anmerkungen zu den Zusammenschlüssen und vor allem zu den dirigentes waren auch in den Gemeinden zu hören - wie zum Beispiel in der Heimatgemeinde von Hernán. Das Ansehen der Organisationsvertreter im lokalen Kon- 
text ist offenbar nicht sehr hoch. Sprach ich nationalen Repräsentanten oder Unterstützern gegenüber die Thematik an, rechtfertigten sie die Kommunikationsprobleme mit den großen geografischen Distanzen, die durch mangelnde finanzielle Ressourcen sowie zeitliche Probleme schwer überwindbar wären. Darüber hinaus verwiesen sie auf regionale Unterschiede bzw. solche zwischen den ethnischen Gruppen, wodurch ihre Arbeit erschwert würde. Zuweilen führte man auch >mangelndes politisches Bewusstsein der Dorfbewohner sowie deren unrealistische Vorstellungen über Projektentwürfe und -anträge an. Man wies auf die unterschiedlichen Aufgaben lokaler Organisationen einerseits und regionaler sowie nationaler Organisationen andererseits hin: Die regionalen und nationalen Organisationen vertreten die Interessen der zusammengeschlossenen Gruppen gegenüber der peruanischen Regierung und kämpfen für strukturelle, legale Veränderungen. Lokale Vertreter sind für den Entwurf konkreter Projekte für die Mitgliedsgemeinden zuständig. In der Zentrale von AIDESEP zum Beispiel erstellt man die generellen Richtlinien der politischen Arbeit in Abstimmung mit den Vertretern der Regionen, mit denen man sich turnusmäßig trifft.

Der Mitarbeiter einer europäischen NGO reagierte gereizt, als ich ihn auf das Misstrauen der Dorfbewohner gegenüber den dirigentes ansprach: Die beschwerten sich immer, das dürfe man nicht ernst nehmen, das sei sogar kontraproduktiv, denn dadurch würde die politische Arbeit der Organisationen im nationalen Kontext gefährdet. Ließe man sich öffentlich über die vermeintliche Zerstrittenheit aus, zögen sich Geldgeber zurück, und der Staat habe wieder neue Argumente in der Hand, mit denen er seine eigenen Entwicklungspläne für das Amazonasgebiet rechtfertigen könne. Diese Argumentation war mir bereits in einer anderen Form geläufig - aus der Auseinandersetzung um den Begriff der sindigenen Völkerく (vgl. Kapitel IV). Aus wissenschaftlicher Sicht, aber auch im Interesse der Organisationen, so meine Meinung, muss dieses Problem jedoch erörtert werden. Das, was die Dorfbewohner über die Organisationen und deren Repräsentanten denken, ist keineswegs irrelevant. Die kategoriale Wahrnehmung der Repräsentanten verdeutlicht die Komplexität der historisch geformten interethnischen Beziehungen, die durch asymmetrischen Austausch geprägt sind. Sie verweist auf den Widerstreit zwischen unterschiedlichen politischen Legitimationsmodellen, denen die Repräsentanten bei ihrer Arbeit gerecht werden müssen. Der Repräsentant einer indigenen Organisation besitzt, im Gegensatz zum Funktionär nationalstaatlicher Prägung, allein auf Grund seines Amtes in einer Organisation keinerlei Weisungsbefugnis - auch wenn er zuvor in dieses gewählt wurde. Verweigert er Geschenke oder handelt er nicht im Interesse seiner Gefolgsleute, entstehen Abspaltungen und neue Führungspersönlichkeiten. Oder aber, das Interesse an der Organisation von Seiten der Dorfbewohner erlischt, und sie wenden sich von ihren politischen Vertretern ab (vgl. Kapitel X.2 und X.3). 


\section{Der Protorepräsentant}

»Die Vision, die mit dem Repräsentantendasein verbunden ist, ist ein bißchen widersprüchlich: Einerseits gilt es als harter Job, in dem man viel opfern muss, schlecht isst und weit weg von seiner Familie ist. Andererseits gilt es als Tür zum Geldsegen und zur Macht und wenn du Glück hast, kommst du in 5-Sterne Hotels« (Interview Smith 21.01.2004).

Diese widersprüchlichen Vorstellungen traten in meinen Gesprächen mit Dorfbewohnern und Organisationsmitarbeitern immer wieder hervor. Vor allem Dorfbewohner zeichneten gern das Bild des idealen Repräsentanten, der von einer angeborenen Bestimmung berufen, selbstlos und aufopferungsvoll der Gemeinschaft dient. Auch gegenwärtige und ehemalige Repräsentanten sahen sich gern im Lichte dieses Idealbilds: Sie verwiesen auf ihre persönlichen Entbehrungen, mit denen sie durch ihre Amtsführung konfrontiert worden seien. Konnten sie sich jedoch offensichtlich mehr leisten als andere, kritisierten sie die stereotype Darstellung des Indigenen als sarmen zerlumpten Hinterwäldler^. Sie betonten, dass sie sich von diesem Image endlich distanzieren wollten. So rechtfertigte zum Beispiel die Organisatorin eines kontinentweiten Treffens indigener Frauen in Lima ihre Entscheidung, die Konferenz in einem 5-Sterne Hotel abzuhalten, mit einer Gegenfrage: »Warum gerät man als Indigener immer in Kritik, wenn man auch einmal eine schöne, teure Umgebung für eine Zusammenkunft auswählt« (Gespräch Rivera 03.03.2004)?

\section{Der Repräsentant aus Sicht der Dorfbewohner}

Die gegenwärtige Wahrnehmung der Repräsentanten durch Dorfbewohner und in die Gemeinden zurückgekehrte ehemalige Organisationsmitarbeiter ist eine kritische: Repräsentanten nehmen heutzutage dieses Amt nur an, weil sie auf den Geldsegen hoffen. Gegenwärtig befindet man sich somit in einer Krise: Auf die Repräsentanten ist kein Verlass mehr. Sie sind egoistisch, korrupt und nur auf den eigenen Vorteil bedacht. So die oft zu vernehmende Pauschalverurteilung. Der Protorepräsentant - also der selbstlose, aufopferungsvolle und vor allem charismatische Statusführer - existierte in der Wahrnehmung der Dorfbewohner nur in der Vergangenheit. Oder aber, man entwarf ihn als Wunschprojektion für die Zukunft der Organisationen. Ähnlich wie Don Sebastiano aus der in Kapitel X.1 vorgestellten Huitoto-Gemeinde betonten viele Gesprächspartner mir gegenüber oft, dass die Föderationen >früher ihren Sinn erfüllt hätten: »Die Organisation kämpft für die Territorien, für ihre Bevölkerung, damit es keine Invasionen gibt. Dafür wurde sie gegründet. [...] Aber heute möchte sie der Präsident in eine Stadtverwaltung 
verwandeln, die eine Menge Geld bewegen soll« (Gespräch García 04.03. 2004).

Früher, so die Meinung vieler, hätte man in der Organisation über Probleme der Gemeinschaft debattiert und dann die Repräsentanten mit klar umrissenen Aufgaben in die Städte geschickt. Auch die Kommunikation zwischen den Dörfern und den nationalen Vertretern habe am Anfang funktioniert. Heute hätten sich zwar Transport und Kommunikation technisch verbessert, doch bekäme man vor allem die nationalen, aber auch die regionalen Repräsentanten selten oder gar nicht zu Gesicht. Man wisse nicht viel über ihre Arbeit. Ein Informant bringt seine Meinung zu den Organisationen wie folgt auf den Punkt:

$»$ Heute sind die dirigentes nur am Erhalt der Organisation interessiert - aus Selbstzweck. [...] wenn man die Würmer ausfegen würde, könnte man die Organisation vielleicht zu neuem Leben erwecken. [...] Wenn du dich in der Organisation engagierst, musst du eine starke Position haben, sonst lässt du dich vom Geld verführen« (Gespräch Crispín 18.06.2005).

Ein anderer Gesprächspartner, der selbst früher einen Posten in einer regionalen Organisation inne hatte, analysiert die Organisationsprobleme wie folgt:

»Die dirigentes, die jetzt bis in die AIDESEP aufsteigen, haben kein Interesse mehr an ihrer Basis. Nein, was die wollen als Kandidaten ist Lima kennen lernen, nach Lima reisen [...]. Zu unserer Zeit hat man die Präsenz der Repräsentanten auch in dieser abgelegenen Ecke des Amazonasgebietes gesehen. Die Direktive von AIDESEP reist heute nur noch ins Ausland, man spricht sich nicht ab und entwickelt keine langfristigen Ziele. Man führt die Arbeit aus, da man dafür bezahlt wird. Als wir nichts hatten, haben wir mehr gearbeitet« (Interview Rubio 04.03.2004).

Neben der Unterscheidung zwischen früher und heute kommt in dieser Aussage vor allem ein zentraler Aspekt zum Ausdruck: Rubio unterscheidet zwischen denen, die Organisationsarbeit als Berufung verstehen und solchen, die darin einen Beruf sehen. Diese Unterscheidung wurde in vielen Gesprächen getroffen, sowohl auf lokaler Ebene als auch im regionalen und nationalen Kontext. Heutige Repräsentanten führen ihre Aufgabe nicht mit Leidenschaft und auf Grund einer >natürlichen Berufung a aus, sondern verhalten sich wie Funktionäre. Ein häufig in diesem Zusammenhang zitierter Spruch lautet: »Man wird als dirigente geboren, dazu kann man nicht ausgebildet werden«. Vielen der heutigen Repräsentanten wirft man dementsprechend vor, ihre Aufgabe nur als Job zu verstehen, mit dem sie hoffen, ihren Lebensunterhalt zu verdienen. Es wird hingegen auf die harten Entbehrungen verwiesen, die ein >richtiger Repräsentant in der Lage sein müsse auf sich zu nehmen. Prestige kann sich ein dirigente diesem Idealbild folgend vor allem erwerben, 
wenn er oder sie immer zuerst an die anderen denkt, offensichtlich nicht wesentlich mehr besitzt als diese. Macht erlangt man dementsprechend nicht allein durch die Wahl in das Amt des Repräsentanten, sondern vor allem, wenn man seine besonderen Fähigkeiten unter Beweis stellt. Vor allem auch für die nationale Ebene wünschte man sich einen charismatischen Kopf, der es verstünde, Differenzen in den Organisationen zu überwinden. Man verglich sich derweil mit einem »Körper ohne Kopf« (Versammlung Pucaurquillo 03.03.2004). Das dieser Vorstellung zugrunde liegende machtpolitische Legitimtätsmodell lässt sich somit Max Webers Idealtypus des »charismatischen Herrschers« zuordnen. Der Führer muss sich in der Praxis bewähren, seine Herrschaft gründet auf individuellen Fähigkeiten und Überzeugungskraft. Wie von Lévi-Strauss beschrieben, ist er mit einer besonderen psychologischen Prädisposition für das Amt geboren.

Aber die Kommentare verweisen gleichfalls auf die Sehnsucht nach einem starken, zentralen Führer, einem Symbol der politischen Einheit, die bislang auf Grund auseinanderdriftender Interessen partikulärer Gruppen und schwachen Führungspersönlichkeiten nicht herstellbar zu sein scheint.

\section{Der Repräsentant aus Sicht der Unterstützer}

Auch die Unterstützer thematisierten gerne den >moralischen Verfall der Repräsentanten. Alberto Chirif (1995: 348) interpretiert dabei das >deviante< Verhalten der dirígentes indigenas als Widerspiegelung eines allgemeinen, strukturellen Problems der peruanischen Gesellschaft: der Korruption und des caudillismo. ${ }^{28} \mathrm{Je}$ mehr die Repräsentanten am Leben der nationalen Gesellschaft teilnähmen, desto mehr orientierten sie sich auch an deren Haltung. Auch Richard Smith (1996: 115) sieht dies ähnlich und spricht von den neuen »amazonischen caudillos«. Viele indigene Repräsentanten nähmen Aspekte des »kreolischen Führungsstils« an: öffentliche Lügen, Zurückhaltung von Informationen bzw. deren Manipulation zu persönlichen Zwecken. So beobachtete Smith in der COICA Ende der 1980er Jahre bei den Wahlen für eine neue Direktive die Verdrängung inhaltlicher Themen und eine Hinwendung zu »klassischen parteipolitischen Diskussionen«. Je mehr die hierarchische und geografische Distanz zwischen den Repräsentanten und den Gemeinden wüchse, desto stärker entzögen sich diese auch der sozialen Kontrolle ihrer >Basis`(Smith 1996: 110). Der von Oxfam América mit der Analyse eines

28 caudillo, dt. >Anführer . Politischer Führertypus, der sich in Südamerika mit den Unabhängigkeitskriegen im 19. Jahrhundert herausbildete. Die ersten caudillos waren meist charismatische Generäle, die ihren militärischen Rang nutzten, um in den neuen unabhängigen Staaten an Macht zu kommen. Ihre Macht entzieht sich jeglicher Kontrolle. Sie nutzen ihr Amt, um persönliche Interessen zu verfolgen. 
Korruptionsfalls in einer regionalen Organisation beauftragte Mourik Bueno de Mesquita kommt wiederum zu dem Schluss, dass die Repräsentanten »nicht die indigenen sozio-kulturellen Prinzipien und Gewohnheiten kultivieren, sondern die Laster der Mehrheitsgesellschaft reproduzieren« (Bueno de Mesquita 2001: 9). Allerdings lässt er offen, was er unter den sindigenen Werten $<$ versteht.

Den eben zitierten Unterstützern ist gemeinsam, dass sie von den indigenen Repräsentanten einen Politikstil erwarten, der Max Webers »rationales Herrschaftsmodell« mit dem >traditionalen« verbindet: Die neuen Amtsträger sollen sowohl eine bürokratische Verteilungslogik verfolgen, als auch ein System »balancierter Reziprozität« (Sahlins 1974) aufrechterhalten, das auf horizontalem, nicht vertikalem Tausch beruht und damit nach Ausgleich strebt. Sie betrachten ausschließlich die normative Ebene und erschaffen eine dichotomisierende Gegenüberstellung von indigenen und nicht-indigenen Werten. \Kulturelle Entfremdung`ziehen Bueno de Mesquita und die anderen eben erwähnten Unterstützer als Erklärungsmuster für von ihren Idealen abweichendes Verhalten heran: Je weiter die Repräsentanten sich von ihrer >eigenen Tauschlogikı geografisch entfernten, desto stärker würde der Assimilationsdruck - die indigenen Politiker tragen damit im nationalen Kontext nicht mehr zur von den Unterstützern angestrebten Systemveränderung des peruanischen Staates, sondern zum Erhalt der von ihnen identifizierten >Mängel desselben bei: der Perpetuierung asymmetrischer PatronageBeziehungen. Dieses Interpretationsschema bleibt implizit dem modernen Paradigma verhaftet, das sich in einer Dichotomisierung von $>$ Tradition $<$ und >Moderne` ausdrückt. >Indigene Traditionen` werden zudem bei diesem Prozess idealisiert, der Kontakt mit der Mehrheitsgesellschaft letztendlich als >kulturschädigend ‘ definiert.

Jedoch findet sich bei Smith (1996: 114) auch ein kurzer Verweis auf die vorhandenen Parallelen zwischen caudillismo und ‘amazonischem< Führungsstil: Demzufolge wird besonderes Wissen als Familiengeheimnis behandelt, verwandtschaftliche Bande zudem stärker gepflegt als kommunitäre. Die Verpflichtung der Repräsentanten gegenüber einer ethnischen oder gar panindigenen \Schicksalsgemeinschaft $\iota$, die im politischen Diskurs beschworen wird, spiegelt im Lichte dieser Erklärung nicht unbedingt die realen >WirGefühle` und Erwartungen der Organisierten wider. In einem späteren Artikel merkt Smith (2002b: 167ff.) zudem (selbst)kritisch an, dass die nichtindigenen politischen und religiösen Aktivisten der 1960er und 70er Jahre in den indianischen Tieflandgesellschaften die Bestätigung ihres Glaubens an Werte wie Gleichheit und Solidarität sahen. Als Referenzkategorie stilisierten sie dabei die neue organisatorische Grundeinheit der comunidad nativa zur urchristlichen oder urkommunistischen $>$ Protogemeinschaft $<$. Unter den indianischen Tieflandbewohnern bestimmt hingegen in Vergangenheit und 
Gegenwart vor allem die wirtschaftliche Einheit die Gruppensolidarität des Individuums.

\section{Verpflichtungen gegenüber der eigenen Gruppe: kontextabhängige Definition der politischen Gemeinschaft}

Neben dem allgemeinen Misstrauen, das Dorfbewohner den heutigen Repräsentanten gegenüber hegen, existiert eine ganz besondere Erwartungshaltung: die Erwartung, der Repräsentant möge sich gegenüber der >eigenen Gruppeく großzügig erweisen. Gleichgültig, aus welcher Quelle die Großzügigkeit gespeist wird, wirkt sie bei denjenigen, denen sie gewährt wird, vertrauensbildend. Mit dem Amt wird, unabhängig von seinem Träger, eine bestimmte sozial höherstehende Position im gesamtgesellschaftlichen Kontext verbunden. Deshalb besitzt zwar der Repräsentant nicht allein kraft seines Amtes »symbolisches Kapital« (Bourdieu 1983) in Form von Prestige innerhalb seiner politischen Gemeinschaft, aber an die Position sind bestimmte Normen und Regeln geknüpft. Der Repräsentant muss sich diesen Vorgaben entsprechend verhalten, um an politischer Macht zu gewinnen. Ein Beispiel dafür: Ein ehemaliger nationaler Repräsentant, unter dessen Präsidentschaft nicht alle Gelder für die eigentlichen Projektzwecke verwendet worden waren, wurde von Mitgliedern seiner ethnischen Gruppe in Gesprächen oft respektvoll erwähnt. Man erklärte, er habe stets geholfen, wenn jemand mit einer Bitte an ihn herangetreten sei. Er sei immer großzügig gewesen. Einen anderen verurteilte man hingegen für die Zweckentfremdung von Organisationsgeldern allerdings vor allem, weil er dabei >nur an sich`, nicht aber >an seine Leute` gedacht habe. Er habe seine Position zu persönlichen Zwecken missbraucht. Politisch richtig gehandelt hätte er, wenn er die neuen Möglichkeiten, die ihm sein Amt verschafft hatte, zur Umverteilung der Ressourcen unter der Anhängerschaft genutzt hätte.

Wenn sich ein Repräsentant nicht als großzügig gegenüber der >eigenen Gruppe ‘ erwies und seine Gewinne für sich behielt, wurde ihm meist ein >mestizischer Führungsstil zugeschrieben. Wer jedoch jeweils zur >eigenen Gruppe` zählte, unterlag subjektiven Zuweisungskriterien: Hierbei konnte man wahlweise auf die Familienzugehörigkeit, die ethnische Abstammung oder das >indigene Kollektiv` verweisen - je nachdem, in welchem Verhältnis zum Repräsentanten der Sprecher sich befand. Oft wurde zum Beispiel darauf verwiesen, dass man von einem bestimmten Repräsentanten besonders enttäuscht sei - dieser stamme schließlich aus der gleichen Region wie man selber, sei auch Huitoto oder Asháninka etc. Daraus erwüchse eine besondere Verpflichtung, sich um die >eigenen Leute` zu kümmern.

Konsequenterweise warfen Dorfbewohner deshalb den Repräsentanten, die aus einer anderen Gruppe bzw. Gegend kamen, deren >Bevorzugung〈vor. 
Hierbei beriefen sich dann die kritischen Stimmen auf die Pflicht der Repräsentanten, >an alle Indigenen zu denken Instanz verträten. Dies kommt unter anderem in dem Kommentar eines ehemaligen Repräsentanten der ORAI zum Ausdruck, der zum Zeitpunkt unseres Gesprächs keine Ämter mehr bekleidete:

»Seit drei Jahren bin ich im Dorf zurück und habe noch nichts von AIDESEP gehört. Früher gab es jeden Tag Kontakt über Funk. [...] Die Verantwortlichen vergessen ihre Basis, ich weiß nicht warum. Nicht mal aus Versehen kommen sie, um mit uns zu reden. Als Indigene müssen wir stärker kommunizieren. [...] Die nationalen Repräsentanten sollten nicht nur ihre soziolinguistische Gruppe unterstützen, sondern alle. Denn schließlich repräsentieren sie uns alle! Vielleicht haben die in ihren Regionen viele Informationen, wir hier aber nicht« (Interview Rubio 04.03.2004).

Diese Kritik verdeutlicht, dass die angeprangerte Bevorzugung nicht nur auf materielle Güter beschränkt bleibt, sondern auch Information und Kommunikation einschließt. Im Folgenden macht der ehemalige regionale Repräsentant die Mestizen für die Schwäche seiner Organisation verantwortlich: »Am Anfang war unsere Organisation stark [...], aber mit der Zeit hat unsere Stärke abgenommen, vor allem durch die Mestizen, die in unsere Gemeinde gekommen sind und unsere Mädchen geheiratet haben« (Interview Rubio 04.03. 2004).

Diese Erklärung begegnete mir auch in Hernáns' Heimatgemeinde. Guillermo Ortega, der Präsident des Dorfes, hatte in unseren Gesprächen immer wieder darauf verwiesen, dass die Mestizen am Zerwürfnis seiner Gemeinde schuld seien. Dabei bezog er sich auf die Migranten von der Küste und aus den Anden, die in den 1980er Jahren in seine Gemeinde gekommen seien und den Einheimischen immer wieder erzählt hätten, Indigene seien Terroristen bzw. >der Vergangenheit Zugewandte`.

Auch ein Korruptionsskandal in der regionalen Organisation ORAI in den 1990er Jahren wurde den Machenschaften eines Mestizen zugerechnet, der sich >für einen Indigenen ausgegeben habeく. Der Betreffende hätte sich als >mestizisierter` Indigener nicht so benommen wie >die Kultur und Kosmovision< es vorschreibe. Die »indigene Kultur und Kosmovision« basiere unter anderem auf der politischen Ausrichtung an der "Abstammungsgemeinschaft« (Gespräch Manihuari 13.03.2004). Eine Definition von >indigener Identität`, die häufig angeführt wurde. Wobei aber unter der Gemeinschaft von Seiten der befragten Dorfbewohner und Organisationsmitarbeiter kontextabhängig und flexibel entweder die lokale bzw. die ethnische Gruppe verstanden wurde, oder aber man bezog sich damit, wie beschrieben, auf die >panindigene Gemeinschaft $\iota$, die nationale aber auch regionale Repräsentanten eigentlich dazu verpflichten müsse, an das >Wohl aller zu denken. 
AIDESEP oder CONAP erklärte man in diesem Zusammenhang jeweils zur inoffiziellen $>$ Regierung der Indigenen`.

\section{Die nationale Vertretung als sinoffizielle Regierungr}

Befragte ich Repräsentanten von AIDESEP, so bezeichneten auch diese ihre Organisation oft als eine solche inoffizielle Regierung der Indigenen des Amazonasgebietes (Interview Salazar 14.01.2004; Gespräch Cusurichi 10.06.2005; Gespräch Antazú 25.05.2005). Inoffiziell deshalb, weil ihnen von Seiten des peruanischen Staates nur der Status einer Nichtregierungsorganisation zugebilligt werde. Dieses Selbstbild der Organisation als inoffizielle Regierung der Indigenen des Amazonasgebietes wurde dementsprechend von Dorfbewohnern bestätigt. Man war trotz aller Kritik an einzelnen Repräsentanten stolz darauf, ein politisches Sprachrohr zu besitzen und in der nationalen Öffentlichkeit wahrgenommen zu werden. Das Gefühl, einer größeren Gemeinschaft der indígenas anzugehören, legte sich in diesen Momenten über die Kritik an den Organisationen. Diejenigen, die ihren Zusammenschlüssen Schaden zufügten, mussten folglich in der Außendarstellung als >Mestizen kategorisiert und damit von der eigenen Gruppe abgegrenzt werden.

Das Konzept einer Regierung als zentralisierter und institutionalisierter politischer Vertretungsinstanz hat sich mit den Föderationsgründungen unter den dergestalt organisierten Tieflandbewohnern teilweise als Vorstellung durchgesetzt. Allerdings besitzt die sinoffizielle Regierung der Indigenen v vor allem eine saußenpolitische< Funktion: Sie soll die Forderungen und Bedürfnisse der indianischen Tieflandbewohner gegenüber dem peruanischen Staat repräsentieren. Mit Ausübung einer Repräsentationsfunktion erhalten die entsprechenden indigenen >Regierungsvertreter/ dennoch nicht automatisch einen übergeordneten Status in der Gemeinschaft. Prestige und Anerkennung müssen sie sich wie ein Big Man erwerben (vgl. Kapitel X.3). Es ist sogar im Gegenteil zu fragen, ob die Statuszuweisung als >inoffizielle Regierungsvertreter nicht Ausdruck des Misstrauens der Dorfbewohner gegenüber den Organisationsvertretern ist. In keinem Gespräch fehlte der Verweis auf das geringe Vertrauen, dass man staatlichen Behörden und lokalen Verwaltungen entgegenbrachte. Ebenso vertrauten die meisten ihren regionalen oder nationalen Vertretungsinstanzen nicht, wie sowohl in der comunidad nativa Huitoto in der Nähe von Iquitos deutlich wurde als auch in den Mitgliedsgemeinden des im Prolog vorgestellten Zusammenschlusses der Cocama-Cocamilla.

Die Repräsentantin einer Frauenorganisation, die sich trotz politischer Erfahrungen auf nationaler und internationaler Ebene für Basisarbeit in ihrem Heimatdorf und ihrer Region entschieden hatte, bringt das sensible Verhältnis zwischen den Dorfbewohnern und Organisationsvertretern wie folgt auf den Punkt: »Als dirigentes merken wir oft nicht, dass das Volk bestimmt und 
nicht wir. Deshalb muss man als dirigente kleiner sein als das Volk. Sonst sagt das Volk, dass derjenige nicht mehr Asháninka, sondern Mestize ist. Dann erntest du Misstrauen« (Gespräch Chirisente 13.06.2005).

\section{Der Mestize als Verkörperung des potentiellen Despoten}

Die Bezeichnung >Mestize< erweist sich als oft reproduzierte, negative Kategorisierung für Repräsentanten, die nicht an die seigene Gruppe « dachten bzw. sich dieser gegenüber nicht großzügig erwiesen. Diesen Personen wird der Führungsanspruch aberkannt. Ihnen wird vorgeworfen, sie seien entweder durch ihre Tätigkeit zu Mestizen geworden oder aber von Anfang an als >Indigene verkleidete $<$ Mestizen gewesen - eine Art >Wolf im Schafspelz . Beide Typen suchen einmal mehr zu Lasten der indigenen Tieflandbewohner ihren persönlichen Vorteil. Einige Male begegnete mir auch die bildliche Gleichsetzung der Mestizen mit Fledermäusen - Tiere, die keine eindeutige Identität besäßen, da sie weder Vogel noch Maus seien. Dieses Bild provoziert eine weitere Assoziation: Vor Fledermäusen muss man sich schützen, da sie parasitär von der Lebenskraft anderer - deren Blut - leben. Der als >Mestize ২ titulierte Vermittler wird zur Verkörperung des potentiellen Despoten - der modernen Version eines gantatsirira (vgl. Kapitel X.3).

Die negativen, stereotypen Kategorisierungen >Nicht-Indigener an frühe ethnologische Gemeindestudien im peruanischen Hochland aus den 1940er und 50er Jahren. In diesen kulturalistisch argumentierenden Arbeiten wurden die Mestizen als ethnische Kategorie überwiegend in der Negation der als >typisch indigen k klassifizierten Merkmale definiert. Sie waren auf Grund ihrer >kulturellen Orientierungslosigkeit ` dazu bestimmt, Indigene auszubeuten. Indios und mestizos standen sich als monolithische Blöcke gegenüber. Während erstere als wertkonservativ dargestellt wurden, waren letztere die vermeintlich kulturell prädisponierten Profiteure dieser >Veränderungsresistenzı. Die damaligen Wissenschaftler verkannten, dass die `mestizischen Merkmale auf die Vermittlerposition dieser Personen innerhalb der andinen Welt zurückgingen (vgl. Laufer 2000: 144ff.). Die Klassifizierung >schlechter Repräsentanten als Mestizen knüpft an diese negativen Stereotypisierungen an. >Indigen-Sein « ist hingegen mit positiv konnotierten Werten belegt, deren hervorstechendster Gruppensolidarität ist. ${ }^{29}$

Allerdings wurden die Grenzen zwischen indigenas und mestizos von Seiten der befragten indigenen Tieflandbewohner als fließend empfunden - im

29 Die negative Stereotypisierung des Mestizen lässt sich in Peru bis in die Kolonialzeit zurückverfolgen: Die Auffassung, der Mestize sei ein aggressiver und frustrierter Mensch, der zwischen zwei Welten zerrissen ist, begründete sich bereits damals. Es hielt sich als Konzept bis in die modernen Sozialwissenschaften hinein (vgl. Laufer 2000: 84ff.). 
Gegensatz $\mathrm{zu}$ den eben erwähnten frühen ethnologischen Arbeiten: Man konnte jederzeit seinen positiv besetzten Status als Indigener bzw. als Asháninka, Aguaruna, Huitoto etc. verlieren und zum Mestizen werden. Die Möglichkeit dieses \Statusverlustes` war dabei besonders gegeben, wenn man einen leitenden Posten in einer Organisation anstrebte. Man konnte aber im Gegenzug auch als >indigen k klassifiziert werden, obwohl man zuvor als Mestize gesehen wurde, wenn man sich für die >Gemeinschaft $<$ einsetzte. Dies wurde in einem Kommentar von Haroldo Salazar über den ehemaligen nationalen Präsidenten von AIDESEP, Miqueas Mishari, deutlich: Obwohl man diesem vorwarf, Mestize zu sein, hatte er eine »reine Bewegung« ins Leben gerufen und damit Ansehen erworben (Interview Salazar 14.01.2004). Die Kategorisierung in >Indigene< oder >Mestizen ২ verweist somit auf das Prestige, das der entsprechenden Person vom jeweiligen Kommentator zugewiesen wird. Die ethnischen Bindungen sind aus Sicht der befragten Dorfbewohner und vieler Organisationsmitarbeiter keineswegs >primordial ‘ bestimmt, sondern dienen der flexiblen Konstruktion kontextabhängig relevanter politischer Gemeinschaften. In der Beurteilung der Repräsentanten wird ein moralischer Raum abgesteckt, in dem ein Mindestmaß an balancierter Reziprozität eingefordert wird. Der Bezug auf eine >ethnische` oder >indigeneく politische Gemeinschaft birgt dabei unter einer essentialistisch anmutenden Oberfläche viel Raum für Aushandlungsprozesse. >Indigenität ২ ist in diesem Sinne weit davon entfernt ein mit der Geburt erworbener Status zu sein, sondern vielmehr Ausdruck gefühlter sozialer Nähe oder Distanz. Diese kann auch unabhängig von realen geografischen Entfernungen existieren. Dennoch ist, wie in den Aussagen der Unterstützer, kulturelle Identität mit bestimmten Werten belegt. Befolgt ein politischer Führer diese Maßgaben nicht, verliert er die Gruppenzugehörigkeit.

\section{Verstädterung: Verlust indigener Identität oder Chance zum sozialen Aufstieg}

»Wenn die Repräsentanten in die Stadt kommen, sind sie auf dem Niveau der Stadtgesellschaft« (Interview Rubio 04.03.2004).

Diese Einschätzung von Rubio spiegelt die Ansicht vieler Dorfbewohner wider. Die Organisationen hatten in ihren Augen im Alltag eine vordergründige Funktion: Sie boten ambitionierten Gemeindemitgliedern eine Chance, `Städter zu werden. Gleichzeitig bestärkte es bei denen, die keine politischen Ambitionen oder nicht den nötigen Einfluss besaßen, das Gefühl, von den Organisationsvertretern für persönliche Zwecke benutzt $\mathrm{zu}$ werden. Wenn nicht mehr die Verantwortung gegenüber der Gemeinschaft im Vordergrund stünde, sondern persönliche Interessen, dann hätten die Organisationsvertreter den 
>mestizischen` Führungsstil angenommen und wären zu >Städtern` geworden. Als solche entfernten sie sich von der Basis, denn die Stadt verändere ihre Sichtweise: Die >städtische Sicht $\prec$ bedeute, dass man Organisationsgelder zu persönlichen Zwecken verwende. Man nähme den Führungsstil mestizischer Funktionäre an, der auf Machterhalt und Ausbau der eigenen Position abziele, nicht aber auf eine Verbesserung der Lebensumstände in den Gemeinden (Interview Rubio 04.03.2004; Gespräch Chirisente 23.04.2004; Gespräch Ortíz 25.04.2004; Versammlung Pucaurquillo 03.03.2004). So führte die Präsidentin einer regionalen Frauenorganisation in Satipo in einem Gespräch aus: »Wenn die dirigentes ihre Gemeinden verlassen und nach Huancayo oder Lima gehen, nehmen sie eine personalisierte Sicht an und gründen ihre eigenen NGOs« (Gespräch Chirisente 25.04.2004). Die Präsidentin einer AsháninkaGemeinde in der Nähe von Satipo sagte: »Wenn wir unsere Gemeinde verlassen und uns vermischen, verderben wir« (Gespräch Espíritu 27.04.2004).

Im Zusammenhang mit der Abwertung der Repräsentanten als sambitionierte Städter`, als Mestizen, möchte ich noch auf einen anderen Aspekt der Kategorisierung hinweisen. Dieser gibt Aufschluss über ein dahinter stehendes Diskursmodell: die Dichotomisierung Stadt-Land, mit einer einhergehenden Idealisierung der dörflichen Gemeinschaft. Sie manifestiert sich in den oben angeführten Aussagen von Dorfbewohnern und Repräsentanten, die im lokalen Kontext agieren. Ein Diskurs, der die Organisationsprozesse begleitet hat, kommt darin zum Ausdruck. Bekanntlich wurde die comunidad als Grundeinheit der neuen indigenen Selbstorganisation im Amazonasgebiet proklamiert. Die Rückbindung an die Dorfgemeinschaft wurde in diesem Zusammenhang zum stärksten Argument, um die eigene Legitimität als Repräsentant gegenüber den Unterstützern und dem Staat zu untermauern. Die Gemeinde als korporative Einheit folgte aber dem Modell der andinen Gemeinschaften. Im Amazonasgebiet stellte sie eine neue Form der Vergemeinschaftung dar. Greene (2004: 134) verweist in diesem Zusammenhang auf eine Aussage Evaristo Nugkuags. Auf die Frage nach dem Leben im Gebiet der Aguaruna als er ein Kind war, habe dieser folgendes geantwortet: Die Gemeinden waren damals nicht wirklich Gemeinschaften im heutigen Sinne, sondern lose Ansammlungen der engeren und weiteren Familie, mit der man an einem Ort lebte, um in Kommunikation zu bleiben. Das Konzept der comunidad wurde erst mit den Missionarsschulen (ab den 1950er Jahren) eingeführt. Auch Haroldo Salazar hob im Gespräch die Neueinführung des Konzepts der Gemeinschaft im Amazonasgebiet hervor: "Wir wussten bis in die 1970er Jahre nicht, was eine comunidad war [...] danach sahen wir, dass man es so nennen musste« (Interview Salazar 14.01.2004).

Die indigenen Gemeinden des Hochlands bildeten, wie bereits ausgeführt, lange Zeit das bevorzugte Studienfeld der peruanischen Ethnologie. Bis in die 1960er Jahre hinein betrachtete man sie als nach außen geschlossene, nach 
sozio-ökonomischem Status undifferenzierte und kollektivistisch organisierte Bauerngemeinschaften. In den 1950er Jahren, als die Community Studies in Mode waren, verbrachten die von der nordamerikanischen Cultural Anthropology stark geprägten peruanischen Fachvertreter längere Zeit zu Studienzwecken in Hochlandgemeinden - vorzugsweise indigenen. Sie orientierten sich dabei in ihrer theoretischen Ausrichtung stark an Robert Redfields FolkUrban-Continuum (1941). Redfield hatte dieses Modell auf Grundlage von Tönnies' Gemeinschaftskonzept sowie dem Ansatz der Chicagoer Schule entwickelt. ${ }^{30}$ Er siedelte vier unterschiedlich große ländliche Gemeinden in Mexiko auf einem Kontinuum zwischen ländlich bzw. tribal und städtisch als jeweiligen Endpunkten an. Je mehr man sich vom ländlichen Pol zum städtischen hinwegbewege, so seine These, desto mehr verfalle eine vom Kollektivgedanken geprägte Kultur und werde zu einer ausgeprägt individualistischen. Laufer merkt dazu an:

»Redfields Modell einer bipolaren Moral, das dem ländlichen/tribalen Kontext alle guten, dem städtischen Umfeld dagegen alle schlechten Eigenschaften zuordnete, bestätigte nicht nur die Idealisierung der indigenen Gemeinden, sondern auch das negative Stereotyp des Mestizen als traumatisiertem, frustriertem Individuum« (Laufer 2000: 36).

Die Übertragung des Gemeinschaftsmodells aus den Anden in das Amazonasgebiet ist inzwischen mehrfach kritisch analysiert worden, sowohl von Wissenschaftlern (vgl. zum Beispiel Chirif 2003; Smith 2002b; Dandler 1998; COICA und Oxfam América 1995) als auch von indigenen Repräsentanten (siehe Zitate weiter oben). Es entsprach auch nicht dem eigentlichen Ziel, das der Ethnologe Stefano Varese mit der Ausarbeitung des Gesetzes zu den comunidades nativas im Sinn hatte. Er wollte dorfübergreifende Einheiten fördern und war damit der Zielstellung der Schaffung eines sindigenen Territoriums verpflichtet, wie sie in Brasilien oder Kolumbien in der Folge geschaffen wurden. Wie gesehen scheiterte dieser Plan an den Vorstellungen der Regierung. Dessen Angestellte besaßen, wie Varese in einem Interview aus dem Jahre 2001 rückblickend festhält, wenig oder nur verzerrte Vorstellungen von der Lebensweise in indianischen Gesellschaften des Amazonasgebietes (vgl. Montoya, Burgos und Paredes 2001).

Dennoch scheint sich das andine Gemeinschaftsmodell als kommunitaristische Idealvorstellung unterschwellig durchgesetzt zu haben - und zwar vor allem in der dichotomisierenden Gegenüberstellung von Dorf und Stadt, bei

30 Tönnies (1887) führte in der Soziologie den Begriff der Gemeinschaft als ein >natürlich gewachsenes`, durch ein hohes Maß an Einheitlichkeit in Denken und Handeln geprägtes menschliches Gebilde ein. Er stellte dieser die Gesellschaft als rationalen Zweckverband gegenüber. 
der mit `Stadt`, wie in Redfields Folk-Urban-Continuum, stets negative Bilder evoziert werden. Zum einen ist dieses Phänomen in Aussagen von Unterstützern zu beobachten, auch wenn diese ansonsten kritisch auf die Heterogenität innerhalb der Gemeinden und ihren Konstruktionscharakter auf Grundlage der Gesetzgebung von 1974 verweisen. So bemerkt zum Beispiel Chirif (1995: 364), dass in den Gemeinden die >Verstädterung ‘ wachse, eine Entwicklung, die er an häufigen Anschuldigungen von Raub und Hexerei, oder Teilung der Gemeinden durch unterschiedliche religiöse Konfessionen, festmacht. Smith wiederum bestätigt in einem Interview, dass »die Repräsentanten am Anfang stärker ihren Gemeinden verbunden waren und sich von diesen mit der Schaffung regionaler, nationaler und internationaler Instanzen entfernten« (Interview Smith 21.01.2004). Und der Soziologe Reátegui meint:

»Die jungen Indigenen möchten in der Stadt leben. Ihr Orientierungsmodell ist der urbane Mensch: Ich gebe meine indigene Identität auf und werde Mestize, weil der Mestize Macht hat. Es ist eine Suche nach Macht, nicht mehr. In der Stadt sind sie abhängig, während sie sich in ihren Gemeinden selbst ernähren können und dadurch eine größere Autonomie haben. Die Gemeinden, die am weitesten von der Stadt entfernt sind, sind deshalb am besten organisiert« (Interview Reátegui 21.02.2004).

Bei dieser häufig anzutreffenden Einschätzung kristallisiert sich das Modell des Redfieldschen Folk-Urban-Continuum nahezu in Reinform heraus. Auch Repräsentanten und Dorfbewohner, die in den Gemeinden bleiben, griffen in Gesprächen mit mir diese Vorstellungen auf. In den angeführten Zitaten kam dies deutlich zum Ausdruck.

Doch existierte auch die entgegengesetzte Vorstellung, bei der sich das Bild von der positiven >Traditionsverbundenheit $\triangleleft$ und dem gemeinschaftlichen Zusammenhalt der weit von den Städten entfernt liegenden comunidades in sein Gegenteil verkehrte. Hier wurde Verstädterung positiv gedeutet - ein Diskurs der 〉Modernisierung « und des Liberalismus, dem ebenso Dorfbewohner und Repräsentanten verpflichtet waren und der wiederum sein Pendant in einer wissenschaftlichen Theorie findet.

Oscar Lewis (1966) kritisierte das Redfieldsche Modell der Idealisierung >dörflicher`Mentalität und entwickelte eine gegenläufige These: Mit Hilfe von George Fosters Konzept des Image of the Limited Good ${ }^{31}$ (1965) bezeichnete er Bauern als ‘abergläubig und ignorant<. Migration und Verstädterung deutete er im Gegenzug als Chance zur freien Entfaltung des Individuums, die sich allerdings in ihr Gegenteil verkehren und zu einer »Kultur der Armut« werden konnte (vgl. Laufer 2000: 151). Nicht-indigene Unterstützer der ethnischen Föderationen argumentierten mir gegenüber nie in dieser

31 Fosters Konzept beschreibt eine bäuerliche Vorstellung, nach der alle Güter nur in begrenztem Umfang zur Verfügung stehen. 
Denktradition. Zu stark spielte sie Modernisierungsdiskursen in die Hände, die in der vermeintlichen Traditionsverhaftung Indigener ein Hindernis für die Konsolidierung moderner Nationen sahen. In Opposition zu diesem Diskurs war aber die indigene Selbstorganisation ab den späten 1960er Jahren von Sozialwissenschaftlern unterstützt worden: Der `Erhalt der Kulturen`stand für sie im Vordergrund und damit eine positive Umwertung der sentwicklungshemmenden Traditionen<.

Das \Lewis'sche Paradigmar spiegelt sich hingegen in Reflexionen einiger Dorfbewohner und Repräsentanten wider. So meint ein regionaler Repräsentant im Gespräch über die in sogenannter freiwilliger Isolation lebenden Gruppen: »Wir setzen uns dafür ein, dass sie ungestört bleiben. Aber selbst wollen wir nicht mehr zu dieser Lebensweise zurückkehren. Wir verstehen uns als Teil der modernen peruanischen Gesellschaft« (Gespräch Rodriguez 10.02.2004).

In einem Dorf bezeichneten sich die Einwohner bei Nachfrage mehrheitlich als Mestizen, während ihre Gemeinde gleichzeitig einer indigenen Organisation angehörte. Sie begründeten dies damit, dass »die Indigenen weiter draußen im Wald lebten und seltsame Gewohnheiten hätten«. Ein ehemaliger dirigente einer lokalen Föderation wiederum, der inzwischen in der Stadt lebte und für das Amt des Bürgermeisters kandidieren wollte, erläuterte mir sein Wahlprogramm: Er wolle Verträge mit Unternehmen abschließen, um indigenen Gemeinden einen Absatzmarkt für ihre Produkte zu sichern.

»Es gibt schon Gemeinden, die in die Zivilisation eingetreten sind. Wenn sie aber immer noch siebzig oder achtzig Prozent ihrer Tradition haben, dann kann man keine Verträge mit Unternehmen für sie abschließen. Die Dörfer, die Anbindung an Städte haben, haben die besten Entwicklungschancen« (Gespräch Vegas 16.06. 2005).

Ein zweisprachiger Lehrer wiederum erläuterte mir, er und ein paar >Gleichgesinnte< würden bewusst nicht in comunidades nativas leben. Sie seien eine kleine Gruppe von `Zukunftsorientierten`, die sich durch die Zwänge in den Gemeinden in ihrer Entwicklung gehemmt fühlten (Gespräch Vásquez 18.06. 2005).

Die Präsidentin einer stadtnahen comunidad nativa vertrat folgende, ebenfalls häufig anzutreffende Meinung: Sie sagte den indigenen Organisationen ein baldiges Ende voraus, wenn auch die weiter entfernt liegenden Dörfer eine bessere Anbindung an die Städte hätten. Die Bewohner dieser Dörfer würden aber momentan noch auf die Repräsentanten vertrauen, und letztere hätten dadurch ein leichtes Spiel mit ihnen. 
»Die Armen haben doch kaum Bildung, können manchmal nur ein paar Brocken Spanisch sprechen. Das nutzen die Repräsentanten aus und etablieren sich als Vermittler zwischen ihnen und den NGOs sowie den Behörden. Aber eigentlich leben sie selbst von den Projekten, die sie im Namen dieser Gemeinden beantragen. Sie verhalten sich nicht mehr nach unseren gemeinschaftlichen Vorstellungen « (Gespräch Espíritu 26.04.2004).

Dieses Zitat verdeutlicht, dass beide Einstellungen - eine kommunitaristische Werteorientierung und ein >Modernisierungsdiskurs $<$ - in der Argumentation auch miteinander kombinierbar sind: Die Stadtnähe kann als hilfreich verstanden werden, um die seigenen Werte zu bewahren - weil man dadurch Vermittler ausschalten kann und damit die Ungewissheit, ob die entsprechende Person wirklich im Sinne der Gemeinschaft handeln wird.

Eine nationale Repräsentantin schließlich beschreibt die ihrer Meinung nach notwendigen Veränderungen, welche die Tieflandindianer aktiv gestalten müssten, wie folgt:

»Früher kannten wir die Schule nicht, meine Mutter zum Beispiel ist nicht zur Schule gegangen. Meine Generation ging schon zur Schule, und meine Kinder gehen zur Universität. [...] Wir müssen die Veränderungen akzeptieren und uns einbringen. Nur weil ich aus einer Gemeinde komme, ich Arme, werde ich dort bleiben und nicht zur Schule gehen, weil ich aus der Gemeinde komme? Nein. Denn dann werden wir bei allen Veränderungen immer zurückbleiben. Heute möchten die Schüler studieren und arbeiten, das ist schon eine ganz andere Mentalität. Wenn wir unsere Mentalität ein wenig verändern, heißt das ja noch lange nicht, dass wir unsere Gebräuche aufgeben müssen [...] [Meine Kinder] werden hier [in Lima] studieren. Wir können ihnen helfen, damit sie das Studium abschließen können. Dann werden sie etwas machen oder in die Gemeinde zurückkehren, um zu helfen, um in der Gemeinde zu arbeiten. Aber dann haben sie wenigstens schon eine Ausbildung « (Interview Antazú 19.01.2004).

Antazú wandte sich damit gegen eine Festschreibung indigener Identität als einer lokalen, im dörflichen Kontext verankerten und definierte diese stattdessen als ein historisch-politisches Bewusstsein über die eigene Herkunft.

>Verstädterung< kann somit sowohl negativ als auch positiv konnotiert sein - je nach Perspektive des Gesprächspartners. Dahinter stehen zwei normative Weltbilder:

- Dem einen zufolge ist die wertekonservative face-to-face Gemeinschaft das erstrebenswerte Ideal. Nur in dieser walten Gruppensolidarität sowie ein moralischer Wertekanon, die dem Individuum Schutz und Orientierung gewährleisten. Nur hier, im kommunitären Raum, kann >Indigenität als Lebensform aufrecht erhalten werden. In der anonymen >Stadtgesellschaft $<$ ist das Individuum hingegen Versuchungen und Gefahren ausge- 
setzt, und solidarische, auf die Herstellung von Gleichheit abzielende Werte verlieren an Gültigkeit. >Verstädterung` wird gleichgesetzt mit $>$ Kulturverlust $<$ bzw. `negativem Wertewandel .

- Dem anderen Weltbild zufolge ist >die Stadt p positiv belegt. Sie wird zum Ort, der dem Individuum neue begehrenswerte Güter gewährleistet und es unabhängig macht. Diese Unabhängigkeit gilt als erstrebenswert, da sie Freiheit und Mündigkeit im Sinne der Aufklärung verspricht - im Gegensatz zum Gemeinschaftsideal. Dieses Weltbild ist vom Glauben an ein liberales Gesellschaftmodell geprägt.

Eine Zusammenführung beider Perspektiven erfolgt in der Aussage der Gemeindevorsteherin, die Stadtnähe als notwendige Voraussetzung sieht, um die >eigenen kulturellen Werte` aufrechterhalten zu können. Sie strebt, wie auch die nationale Vertreterin, eine >modernisierte〈 Version von indigener Identität an, die sich in ihrem Fall immer noch an einer bestimmten Lebensweise (der dörflichen Gemeinschaft) festmachen lässt, im Fall der nationalen Vertreterin aber zu einem abstrakten, `nationalen< Bewusstsein für die eigenen Wurzeln und die Geschichte der Vorväter wird.

\section{Hierarchische Binnendifferenzierung: sfortschrittliche، und srückständige، Indianer}

In den \Zivilisationsdiskursen der Dorfbewohner wurde noch ein weiterer Aspekt sichtbar: Viele Gesprächspartner nahmen eine Binnendifferenzierung nach \Fortschrittlichkeit` in der Organisation der verschiedenen ethnischen Gruppen vor. Ein Beispiel dafür lieferte die Aussage der Dorfpräsidentin, welche stadtnahe >fortschrittliche` Gemeinden weit entfernt liegenden >rückständigen $<$ - da von Vermittlung abhängigen - Dörfern gegenüberstellte. Alfonso García, curaca einer Huitoto-Gemeinde am Ampiyacu, verwies in unseren Gesprächen immer wieder auf den von ihm konstatierten >Traditionsverlust « in seiner Gemeinde. Dies, so seine Meinung, sei bei anderen Völkern anders. So würden zum Beispiel die Aguaruna, Asháninka und Shipibo ihre Traditionen viel stärker pflegen als die Huitoto. Don Sebastiano aus der von mir besuchten Huitoto-Gemeinde hatte diese Unterschiede wiederum im $\mathrm{Zu}-$ sammenhang mit der Bewertung der indigenen Zusammenschlüsse formuliert: Er betonte die Forschrittlichkeit anderer indigener Organisationen, da sie »ihre eigene Kultur kennen würden«. Diese von Alfonso García und Don Sebastiano getroffene Einschätzung war eine häufig anzutreffende. Es hieß: Die Asháninka oder Aguaruna seien weiter als die Huitoto oder die CocamaCocamilla, da sie diesen Gruppen zweierlei voraus hätten: 
- den Erhalt des `Eigenen<, der sich vor allem im Gebrauch des Awajun oder Asháninka, aber auch meist nicht näher spezifizierten >Traditionen< (costumbres) manifestierte;

- den häufigeren Erwerb formaler Titel als Voraussetzung für einen sozialen Aufstieg im nationalen Kontext.

»Die Asháninka haben schon viele zweisprachige Lehrer« glaubten die einen zu wissen. »Unter den Aguaruna gibt es viele Studierte« sagten die anderen. Auch pekuniärer Wohlstand wurde als Kriterium der Gruppenabgrenzung herangezogen: »Die Shipibo wissen, wie man an Geld kommt«. Die besondere Betonung der postulierten \Fortschrittlichkeit` der Aguaruna und Asháninka trifft dabei auch mit der Tatsache zusammen, dass diese beiden ethnischen Gruppen bisher die meisten Landtitulierungen erreichen konnten (vgl. Greene 2004: 316).

Auch wenn diese Definitionen von $>$ Fortschrittlichkeit< und ethnischer Identität den modernisierenden Impetus der Entwicklungshilfe der 1950er bis 70er Jahre widerspiegeln, ist dennoch darin eine Wertschätzung eigener ’kultureller Errungenschaften $<z u$ erkennen. In diesem Sinne verweisen die Kommentare auf einen wichtigen, die Organisationsprozesse bestimmenden Aspekt: »Ethnischer Scham« (Laufer 2000: 56), der Verleugnung der eigenen ethnischen Identität mit Nachahmung der durch andere vorgegebenen Wertemuster, wird `ethnischer Stolz « entgegengesetzt. Wichtig war nicht nur die Erlangung formaler Titel und ein sozialer Aufstieg innerhalb der nationalen Gesellschaft, sondern gleichfalls die Pflege einer spezifischen ethnischen Identität durch die Weitergabe bestimmter Werte, der eigenen Sprache, Geschichte und Gebräuche an die Kinder. Sonst lief man Gefahr zum murcielago $^{32} \mathrm{zu}$ werden - dem als >identitätslos` negativ stigmatisierten Mestizen.

Durch den internationalen Erfolg der indigenen Bewegungen wurde ethnische bzw. indigene Identität in vielen Situationen zu einer privilegierten politischen Handlungsressource, um sich im nationalen Kontext behaupten zu können. Ich verweise diesbezüglich auf das Beispiel der Bewohner der comunidad nativa Huitoto in der Nähe von Iquitos, die inzwischen zumindest in Bezug auf Landbesitz im Vorteil gegenüber ihren >bäuerlichen< Nachbarn sind. Auch Greene (2004: 389) betont den Aspekt des ethnischen Stolzes in seiner Studie zum Organisationsprozess der Aguaruna. Das `Eigene〈, das belegt seine Studie eindrücklich, ist dabei gleichfalls eine flexible Kategorie und widersetzt sich starren, ausschließlich vergangenheitsbezogenen Fremdbildern >indigener Identität` bzw. >indigener Kulturく. In der Binnenhierarchisierung der organisierten ethnischen Gruppen sowie auf individueller Ebene besitzen

32 Dt. >Fledermaus $\measuredangle$. 
diejenigen am meisten Prestige, die sowohl institutionalisiertes als auch inkorporiertes Kulturkapital vorweisen können. ${ }^{33}$

\section{Die sneuen` Statussymbole im peruanischen Tiefland}

Boissevain (1974: 86) definiert Bildung als wichtige Ressource. Sie stellt eine Form der Macht dar: Indem man Wissen erlangt, das nicht alle haben, hebt man sich von der Menge ab und erlangt so Prestige. Auch im peruanischen Kontext zeigt sich, dass institutionalisiertes Kulturkapital in gesamtgesellschaftlichen Zusammenhängen hervorgehobene Bedeutung besitzt, um Zugang zu wirtschaftlichem und politischem Kapital zu erlangen. Der Erwerb formaler Titel, der für einen sozialen Aufstieg in gesamtgesellschaftlichen Zusammenhängen notwendig erscheint, genießt deshalb in den organisierten Gruppen auch auf individueller Ebene die meiste Wertschätzung. Als prestigeträchtiges Statussymbol verkörpert er die Hoffnung auf eine >bessere $\mathrm{Zu}$ kunft<. Ich möchte in diesem Zusammenhang noch einmal auf das Zitat von Antazú zurückkommen, die von der »notwendigen Mentalitätsveränderung der Indigenen« sprach. Sie sah die formale Ausbildung der Kinder als eine Möglichkeit der positiven Veränderung. Die Shipibo Metsa Wesna (Ketty Judith Sánchez), Linguistin und 2005 Mitarbeiterin von AIDESEP, drückte dies so aus: »Ich bleibe indigena, auch wenn ich eine Fachkraft bin« (Sánchez 2005: 24). In Antazús und Sánchez Aussagen spiegelt sich eine Vorstellung wider, die von Seiten der Dorfbewohner im Zusammenhang mit den Organisationen genannt wurde: Diese mögen Möglichkeiten schaffen, damit die Kinder aus den Gemeinden studieren können. Formale Bildung wird als Weg aus der durch informelle Patronage- bzw. Brokerage-Verbindungen gekennzeichneten Beziehung zwischen `Indigenen Gesellschaft`gesehen. Dabei wird eifersüchtig darüber gewacht, wie viele Mitglieder der eigenen ethno-linguistischen Gruppe zum Beispiel schon die Ausbildung am AIDESEP-Programm FORMABIAP durchlaufen haben. Ständig vermutet man, da gerade ein Repräsentant einer anderen ethnolinguistischen Gruppe in der regionalen Organisation Präsident ist, dass Studenten aus seiner Region bevorzugt würden.

Die Hoffnung, die man in eine formalisierte Ausbildung der Kinder setzt, lässt sich schon aus den ersten Zeitschriften der Voz Indígena herauslesen (vgl. Kapitel IX.2). Sie stellt somit eine Konstante in der Organisationsentwicklung dar. Bezeichnend in diesem Zusammenhang ist auch, dass eines der ersten finanzierten Programme von AIDESEP 1985 die Förderung von 70 Studenten aus unterschiedlichen Gebieten des Amazonasgebietes war. Und bei den Organisationsgründungen war die an den Staat gerichtete Forderung

33 Zur Definition der verschiedenen Kapitalarten bei Bourdieu siehe Kapitel II.5. 
der Einrichtung bilingualer Schulen immer ein zentrales Thema. Die Organisationen verkörpern somit eine Instanz, über die man Zugang zu den entsprechenden Möglichkeiten der Inkorporation »institutionalisierten Kulturkapitals« bekommen möchte. Die Zusammenschlüsse sind für die Aneignung des mächtigen, im interethnischen Kontakt mit einem höheren sozialen Status verbundenen Wissens zuständig. Nur so eröffnen sich Erwerbschancen auf dem formalen Arbeitsmarkt. Diese stellen in den Augen vieler die heute bedeutsamste Möglichkeit dar, sowohl innerhalb der eigenen Gruppe als auch in gesamtgesellschaftlichen Zusammenhängen Prestige zu erlangen. Dieser Umstand wird zum Beispiel für Shipibo-Gemeinden in der Region Ucayali in einer vom peruanischen Gesundheitsministerium in Auftrag gegebenen Studie belegt: Bei einer repräsentativen Befragung von Frauen über dreißig und solchen unter dreißig, stellte sich heraus, dass beide Altersgruppen unterschiedliche Ansprüche an potentielle Partner stellen. Die älteren Frauen führten an, ihr Mann solle gut Kanus und Häuser bauen, jagen und fischen können sowie gerne auf dem Feld arbeiten. Die jüngeren Frauen hingegen wünschten sich einen Mann mit Diplom und regelmäßigem Einkommen, zum Beispiel einen Angestellten des öffentlichen Dienstes. Die jungen Männer hofften parallel dazu, eine >moderne $<$ Frau zu finden, gerne mit Diplom (Peru Ministerio de Salud 2002: 53, 63).

Die Mitarbeiterin einer NGO wiederum erzählte mir von der >Autoritätsorientierung « der Asháninka, mit denen sie seit langen Jahren arbeitete. Sie erläuterte ihre diesbezügliche Meinung anhand eines Beispiels: Ihre NGO hätte Mediatoren für Konfliktsituationen ausgebildet. Diese lokalen Vermittler würden nun darauf bestehen, dass ihnen Westen mit der Aufschrift `Mediator sowie entsprechende Ausweise zur Verfügung gestellt würden. Dies, so die NGO-Mitarbeiterin weiter, laufe jedoch ihrem Projektansatz entgegen - Mediatoren sollten gerade den informellen Weg suchen, um Konflikte zu lösen (Gespräch Bock 30.06.2005). Statussymbole wie Weste und offizielle Dokumente sind in den Dörfern schwer zugängliche Ressourcen, denen großes Prestige beigemessen wird: Sie markieren einerseits für die eigene Gruppe die hervorgehobene Position des Besitzers dieser Gegenstände. Andererseits können sie den Umgang mit staatlichen Behörden erleichtern. Offizielle Papiere, Dokumente oder auch Uniformen sind Zeichen der mächtigen, nationalen Ordnungskräfte, mit denen man sich arrangieren muss. Auch oder gerade weil wenig Vertrauen in das Funktionieren staatlicher Strukturen besteht, wird ihren Vertretern eine übergeordnete, gleichfalls gefährliche Form politischer Macht zugesprochen. Uniformen und Dokumente symbolisieren diese Macht, die auf Willkür, Zwang und oftmals auch Gewalt beruht. Sie stellen die effektivsten >Kriegswaffen $<$ im interethnischen Kontakt dar, der von Konkurrenzkampf sowie sozialer Aus- und Abgrenzung innerhalb der Gruppe und vor allem im Kontakt mit der nationalen Gesellschaft geprägt ist. 
So betonte der Präsident der in Kapitel X.1 vorgestellten Huitoto-Gemeinde die Wichtigkeit, offizielle Texte - wie zum Beispiel die ILO 169 - zu kennen, um Forderungen legitimieren und durchsetzen zu können. Der Stempel, der ihn als Präsident der Gemeinde auswies, war gleichzeitig sein Statussymbol und Legitimationsbeweis gegenüber Staat und Entwicklungsinstitutionen. Auch Greenes (2004) Studie belegt die große Bedeutung, die offiziellen Dokumenten innerhalb der Welt indigener Organisationen beigemessen wird. Diese manifestiert sich nicht nur bei Auftritten von Repräsentanten auf nationaler und internationaler Ebene, sondern auch bei Wahlen der Vorsitzenden ethnischer Föderationen auf lokaler Ebene. Hier nimmt, so Greene, unter anderem die feierliche Übergabe von für die Organisation wichtigen Dokumenten einen zentralen Platz bei der Einsetzungszeremonie neuer Repräsentanten ein. Die Personen, die Zugang zur Welt der Bücher und Verwaltung, Geld und prestigeträchtigen Gütern gewinnen, sind durch die rezenten Transformationsprozesse in der zweiten Hälfte des 20. Jahrhunderts zu den neuen Autoritätsfiguren der Tieflandindianer geworden. Nutzen sie diesen Zugang jedoch nur zur Selbstvergrößerung, verstoßen sie gegen das weiterhin im lokalen Kontext gültige Führungsideal. Sie werden zu potentiellen Despoten und damit zur Verkörperung des Gegenparts zur normativen Autoritätsfigur. Diesen Repräsentanten gegenüber gilt es Distanz zu wahren bzw. ihren politischen Führungsanspruch im lokalen Kontext zu negieren. Die Vermittlung im interethnischen Kontakt erweist sich als eine macht- und prestigeträchtige, aber auch gefährliche Aufgabe. Die Personen, die diese wahrnehmen, können viel gewinnen, aber auch alles jederzeit verlieren.

\section{Die instabile Vermittlerposition des Repräsentanten: Ordnungsprinzipien im entwicklungspolitischen Feld}

Autoren wie Gow (1996), Taussig (1987) und Carneiro da Cunha (1997) sehen im Schamanen den prototypischen Vorreiter in der interethnischen Vermittlung im Amazonasgebiet. ${ }^{34}$ Die Schamanen nützten ihr akkumuliertes Wissen über andere Plätze sowie fremde Menschen zur Neuformulierung der Bedeutungen des lokalen Selbst. Greene (2004) weist hingegen bei den Aguaruna der Figur des visionären Kriegers diese Rolle zu. Geschichtlich gesehen seien bei den Aguaruna immer Krieger und nicht Schamanen diejenigen gewesen, die den intensivsten Kontakt mit fremden Akteuren hatten. Er weist in

34 Beth Conklin (2002) untersucht in diesem Zusammenhang, wie in Brasilien Schamanen in jüngerer Zeit verstärkt als politische Repräsentanten auftreten. Im peruanischen Amazonasgebiet ist diese Entwicklung bisher jedoch nicht zu verzeichnen. 
seiner Studie nach, dass zentrale Aguaruna-Akteure der indigenen Organisationen aus emischer Perspektive weiter nach dem Vorbild des visionären Kriegers agieren und auch beurteilt werden.

Schamanen sowie visionäre Krieger sind somit zwei paradigmatische Figuren, die herausragende Vermittlerfunktionen in der Vergangenheit erfüllten und gegenwärtige Akteure in der Selbstwahrnehmung ihrer Rolle leiten können. Heutige >Schamenengesänge〈 und >Kriegswaffen` im interethnischen Kontakt sind dabei zumeist Stifte, Blätter, Gesetze, die spanische Sprache sowie rhetorische Fähigkeiten. Die Vermittler nennt man zum Beispiel jefe, ápu, dirigente, Präsident, Repräsentant; die Gruppe, der sie verpflichtet sind, Volk. Ihre Rückführung auf `klassische` Figuren wie visionäre Krieger oder Schamanen sowie die Orientierung an diesen als Rollenmodelle, verweisen auf die besonderen Herausforderungen, denen sich die Betreffenden als Vermittler stellen müssen. Sie sind Grenzüberschreiter. In komplexen Gesellschaften ist Vermittlung eine sozial notwendige, aber ebenso gefährliche Aufgabe, durch die der Einzelne eine herausgehobene, prestigeträchtige Stellung gewinnen kann. Der Vermittler ist einerseits respektiert und gefürchtet, läuft aber andererseits ständig Gefahr, von seinen Gegnern >beseitigt« zu werden. Auch seiner Gefolgschaft kann er sich nie absolut sicher sein, sondern muss sich ihr gegenüber stetig neu beweisen.

In der wissenschaftlichen Beschäftigung mit der Figur des Brokers diskutiert man vor allem den Grad seiner Manipulations- bzw. Handlungsmöglichkeiten. Zwei grundsätzliche Perspektiven auf die Bewertung der Zwänge, denen der Vermittler ausgesetzt ist, können dabei unterschieden werden (Bierschenk et al. 2001: 2):

- Der Vermittler ist als Bindeglied zwischen einer »einschließenden« und einer »eingeschlossenen« Gesellschaft (Gluckman 1949) ein Gefangener zwischen beiden Welten. Er hat keine oder nur äußerst geringe Möglichkeiten, die jeweiligen Machtkonstellationen zu beeinflussen.

- Der Vermittler ist ein aktiver »Unternehmertyp« (Boissevain 1974), der zwischen zwei sozialen Einheiten vermittelt. Seine Tätigkeit übt er in Konkurrenz zu anderen Brokern aus, die er aber auch gegeneinander ausspielen kann. Dabei ergibt sich nicht nur eine Konkurrenzsituation zwischen den Vermittlern, sondern auch zwischen verschiedenen sozialen Positionen. Die Machtverhältnisse sind zahlreich, instabil und diffus.

Beiden Ansätzen gemeinsam ist, dass sie ihr Augenmerk auf Konflikt und Asymmetrie in der sozialen Interaktion richten. Während bei der ersten Position jedoch die Rolle des Vermittlers eher passiv definiert und sein Dilemma hervorgehoben wird, sieht die zweite Perspektive einen größeren Handlungsspielraum, den der Broker aktiv zum eigenen Vorteil nutzt. Bierschenk et al. (2001: 2) zufolge hat die Forschung inzwischen die erste Perspektive aufge- 
geben und die zweite angenommen: Dichotomisierende Gegenüberstellungen von >herrschenden` und >unterdrückten`Gesellschaften weichen der Beschreibung komplexer, diffuser politischer Felder, in denen kulturelle Grenzen verwischen und beständig neue Differenzierungen produziert werden. Die Kapazität des Staates, die Beziehungen zwischen lokalen Gemeinschaften und Außenwelt zu kontrollieren, wird durch unzählige Faktoren limitiert (vgl. auch Bierschenk und Olivier de Sardan 2000: 10). ${ }^{35}$ Neben die klassischen politischen Vermittler zwischen Staat und lokalen Gemeinschaften treten heute über NGOs neue Akteure, die externe Ressourcen kanalisieren und Einfluss nehmen. Diese bezeichnen die beiden Autoren als `Entwicklungsmakler«. Sie verkörpern die zentralen Figuren im entwicklungspolitischen Feld.

\section{Exkurs: Entwicklung der NGOs in Peru}

In Peru entstanden die ersten NGOs ${ }^{36}$ in den 1960er Jahren. Sie zielten auf die Weiterbildung und Organisation verschiedener Sektoren aus den unteren gesellschaftlichen Schichten ab. Dadurch sollte das politische Bewusstsein dieser Gruppen gefördert werden - im Sinne der Regierung Velascos, die, wie beschrieben, bis dahin marginalisierte gesellschaftliche Sektoren stärker in die nationale Gemeinschaft einbinden wollte. In Anlehnung an zu dieser Zeit dominante Modernisierungstheorien glaubte man, durch soziale Mobilisierung die angestrebte gesellschaftliche und wirtschaftliche >Entwicklung ২ vorantreiben zu können und die >traditionalen<, >rückständigen< Sektoren der peruanischen Gesellschaft zu modernisieren (vgl. Eisenstadt 1965, 1970). So zielte die Arbeit der NGOs auf die Ordnung ländlicher und marginaler urbaner Siedlungen $a b$, wie auch aus der Genese der ersten indigenen Zusammenschlüsse abzulesen ist: Die Föderationen institutionalisierten sich als ein Mechanismus, um Zugang zu staatlichen Infrastrukturangeboten zu erhalten. Nach dem Ende der Regierungszeit Velascos und durch die Rücknahme vieler von ihm angestoßener Reformen boomte der NGO-Sektor ab den 1980er Jahren. Während es 1988 ca. 218 NGOs in Peru gab (Ávila 2000: 429), registrier-

35 Für eine detaillierte Definition des Begriffs der >lokalen Arena`vgl. Bierschenk und Olivier de Sardan 2001: 10.

36 Ávila (2000: 430-431) weist zu Recht darauf hin, dass der Begriff >NGO< eine sehr heterogene Organisationslandschaft kennzeichnet: neben in der Entwicklungszusammenarbeit tätigen Institutionen gibt es marktwirtschaftlich orientierte, an Unternehmen gebundene NGOs, akademische, kirchliche und kulturelle Einrichtungen, etc. Er bietet ferner eine Minimaldefinition des Begriffs $>$ NGO an: private Organisationen, nicht profitorientiert, die sich der Ausarbeitung und Ausführung von Entwicklungsprojekten verschreiben und Gelder zu diesem Zweck kanalisieren, die sie hauptsächlich aus dem Ausland erhalten. Den Kern einer NGO bilden ihre Projekte. 
te 2005 die Agencia Peruana de Cooperación Internacional (APCI) ${ }^{37} 1009$ NGOs (APCI 2005).

Ávila (2000: 429f.) nennt drei Faktoren, um diese Entwicklung zu erklären:

- Ab den 1980er Jahren gab es eine wachsende Zahl von Sozialwissenschaftlern, die mit dem nötigen Know-how für die Durchführung von Projekten ausgestattet waren und auf den Arbeitsmarkt drängten.

- Es gab ein wachsendes Angebot internationaler Fonds für die Entwicklungszusammenarbeit, die im Zuge einer Neuorientierung der Richtlinien nun zunehmend nicht-staatlichen Akteuren offen standen. ${ }^{38}$

- Es gab eine große Nachfrage ländlicher und urbaner Akteure nach Weiterbildung und technischer Hilfe.

Im Gegensatz zu staatlichen Entwicklungsprogrammen, so Ávila weiter, besaßen die NGOs als Kooperationspartner für die internationalen Geldgeber folgende Vorteile:

- geringere Bürokratie,

- höhere Effizienz in der Durchführung der Projekte und

- eine größere Flexibilität.

Sie experimentierten schneller mit neuen Projektformen und pflegten zudem eine direktere Verbindung zu den Zielgruppen. Die Finanzinstitutionen bekämen im Gegenzug eine größere Garantie, dass ihre Mittel in gewünschter Weise angewendet würden - die Kontrollmechanismen seien effektiver als im Umgang mit staatlichen Einrichtungen. Jedoch, so Ávila, gerieten NGOs dadurch oftmals in eine starke Abhängigkeit von rakademischen Moden oder unterschiedlichen Interessen der Finanzinstitutionen. Die Fachsprache würde komplizierter, und bei Projektanträgen dürften heutzutage wichtige Begriffe wie zum Beispiel `Gender oder `Gobernabilität` nicht fehlen.

Auch stellt Ávila einen Wandel in den Denkmustern der NGOs in den 1990er Jahren fest, den man mit globalen wirtschaftspolitischen Entwicklun-

37 Dt. >Peruanische Agentur für internationale Zusammenarbeit`. Bei dieser von Regierungsseite eingerichteten Stelle können sich NGOs bewerben, um Gelder der internationalen Entwicklungsinstitutionen in Anspruch nehmen zu können. Der Antrag muss jedes Jahr erneuert werden, und die entsprechende NGO muss einen bestimmten Kriterienkatalog erfüllen. Das bedeutet, dass hier nur ein Teil der NGOs erfasst ist und ihre Gesamtzahl im peruanischen Kontext wohl um ein Vielfaches höher ist.

38 Auch Bierschenk und Olivier de Sardan (2000: 11f.) betonen, dass dezentralisierte Ansätze in der Entwicklungszusammenarbeit sowie die Dezentralisierung der Staatsstrukturen zur Proliferation von Vermittlern führte. Seitdem sind staatliche Akteure in diesem Bereich nicht mehr die einzigen Autoritäten. Viele neue NGOs entstanden im Zuge dessen seit den 1970er Jahren. 
gen parallel setzen kann: Während NGOs in den 1970er und 80er Jahren meist einen politischen, oftmals antistaatlichen Ansatz hatten, konzentrierte man sich ab den 1990er Jahren auf ökonomische Projekte. Das Modell, das sich auf den Staat konzentrierte, implizierte die Politisierung, das auf die Wirtschaft ausgerichtete hingegen die Technifizierung der Akteure (Ávila 2000: 432).

2005 trugen sich in Peru 117 internationale NGOs ins APCI-Verzeichnis ein (APCI 2005). Diese Organisationen haben eine spezielle Rolle in der Entwicklungszusammenarbeit inne. Sie sind nicht nur Projektausführer, sondern auch Vermittler von Geldern. Die Repräsentanten dieser Organisationen sind Broker, die am asymmetrischen Tausch teilnehmen. Sie verteilen die Finanzmittel, zu denen sie Zugang haben, nicht immer nach unpersönlichen, bürokratischen Kriterien, sondern lassen sich auch von Vertrauensbindungen und Freundschaften leiten (vgl. Ávila 2000: 430). Damit können sie Einfluss auf die politische und inhaltliche Ausrichtung der Organisationen ausüben, an die sie die Gelder weiterverteilen. Den Kriterien Boissevains (1974) folgend stehen die Vertreter internationaler NGOs in einem Patron-Klient Verhältnis zu Vertretern lokaler NGOs sowie indigener Organisationen: Sie kontrollieren die Ressourcen, an die letztere nur durch den Aufbau eines dichten Beziehungsnetzwerkes gelangen können. Im peruanischen Kontext, vor allem auch für die Arbeit der indigenen Organisationen, ist dieser Umstand von Relevanz. Auch die Vertreter nationaler und lokaler Organisationen sind Broker, die in ihrem Verhältnis zu den Empfängern der Hilfsleistungen zum Patron werden. Allerdings stehen sie auf einer niedrigeren Stufe in der Maklerkette, da ihre Ressourcenverteilungsmacht abhängig ist von den internationalen Finanzgebern und durch diese in einem gewissen Maß kontrolliert werden kann. Lokale bzw. nationale NGOs stehen in der Maklerkette oftmals auf einer Ebene mit indigenen Organisationen und sind deshalb deren potentielle Konkurrenten. Aus Sicht der ethnischen Verbände gilt es, diese Vermittler sauszuschalten<. Dies wurde im geschichtlichen Rückblick auf die Genese der indigenen Selbstorganisation im Tiefland deutlich. In diesem Zusammenhang wird auch die Betonung des anderen Status für Vertreter indigener Organisationen wichtig: Sie legen Wert auf die Feststellung, dass ihre Zusammenschlüsse keine NGOs, sondern durch Wahlen legitimierte >Volksvertretungen sind. Da >indigene Völkerく im entwicklungspolitischen Feld inzwischen eine eigenständige, legitimierte Kategorie bilden, sehen sie in der Betonung dieser Tatsache ihren Wettbewerbsvorteil gegenüber NGO-Vertretern.

Welche Eigenschaften und Fertigkeiten braucht nun aber der indigene Repräsentant, um sich in der Position des Vermittlers zu halten bzw. in der Vermittlungskette aufzusteigen und dabei Mitkonkurrenten erfolgreich rauszuschalten $<$ ? 


\section{Vermittlerkarrieren: Vom Statusführer zum Funktionär}

\section{Dorf- und Föderationsebene}

Die unterste Stufe in der im Kontext der indigenen Bewegung relevanten Vermittlerkette bildet der presidente comunal. Dieser wird in der Gemeindeversammlung von den Dorfbewohnern jährlich gewählt. Grundsätzlich besteht die Möglichkeit der Wiederwahl. Die mit dem Amt verknüpften Aufgaben bestehen, wie beschrieben, hauptsächlich in der Aufrechterhaltung der internen sozialen Ordnung und Repräsentation gegenüber staatlichen Stellen sowie Institutionen der Entwicklungszusammenarbeit. Auch wenn der Amtsinhaber kraft peruanischer Gesetzgebung Zwangsgewalt besitzt - so kann er in einer Notsituation Polizei zu Hilfe rufen - basiert seine Autorität de facto auf sozialer Zustimmung (vgl. Kapitel X.1 und X.3). Eine grundlegende Fertigkeit, die dem Kandidaten auf das Amt des Dorfvorstehers Wahlvorteile bringt, ist eine solide Alphabetisierung im Spanischen. Daraus folgt, dass ein gewisses Maß an formaler Bildung, also institutionalisiertem Kulturkapital in Bourdieus Sinne, bereits auf Dorfebene von Vorteil ist. Dennoch bestimmen verwandtschaftliche Netzwerke, das Prestige der Familie, dem der Kandidat angehört, weitestgehend die Auswahlkriterien. Häufig besetzen die (meist männlichen) jüngeren Mitglieder aus ein, zwei Familien im Dorf die wichtigsten politischen Ämter (Gespräch Chirif 20.07.2005; Gespräch García 10.06.2005; Gespräch Morales 17.06.2005; Gespräch del Aguila 21.07.2005). ${ }^{39}$ Prestige im lokalen Kontext erreicht der Präsident einer Gemeinde, wenn er es schafft, ein konkretes Projekt umzusetzen (z.B. den Bau einer Schule).

Auch auf Ebene der supralokalen Föderationen braucht vor allem der Präsident in besonderem Maße das gerade beschriebene Basiswissen: Alphabetisierung im Spanischen, Eloquenz, gut ausgebaute soziale Netzwerke auf lokaler Ebene und im Kontakt mit relevanten externen Akteuren. Wie der presidente comunal regelt er in erster Linie den Kontakt mit staatlichen sowie entwicklungspolitischen Einrichtungen. Charakteristisch für viele Verbände auf dieser Ebene ist es sogar, dass der Präsident oftmals der einzige Akteur bleibt - auch wenn in den meisten Organisationen eine Reihe weiterer Posten existiert: vom Schriftführer über den Sekretär für Erziehungsfragen und die Frauenbeauftragte hin zum Schatzmeister werden manchmal bis zu dreizehn Posten vergeben (vgl. Prolog). Jedoch gestaltet sich die Koordination dieser vielköpfigen Direktive schwierig, da sie meist Mitglieder verschiedener Dörfer umfasst. Der Präsident einer Föderation erläutert hierzu:

39 Ullán de la Rosa (2004: 215) listet die gleichen Fähigkeiten als notwendige Voraussetzungen für Bewerber auf das Amt des presidente comunal in TikunaGemeinden auf. 
$»$ Von den elf Sekretären [der Organisation] hilft dir fast niemand, weil wir alle in verschiedenen Gemeinden leben und man als Präsident sehr stark sein muss, viel Hunger und alles ertragen muss. Sie haben ihre Familien und ihre Felder, um die sie sich kümmern müssen. Ich auch, aber einer muss ja die Arbeit machen. Also bleiben viele Sachen an mir hängen « (Interview López 04.03.2004).

Auf wen das Amt des Präsidenten zurückfällt, ist auf dieser Ebene jedoch schon von vielfältigeren Bedingungen abhängig. Da in der Föderation in der Regel mindestens fünf, in Extremfällen bis zu hundert und mehr Gemeinden ${ }^{40}$ zusammengeschlossen sind, können hier bei der Wahl viele unvorhersehbare Faktoren ausschlaggebend werden. So berichteten mir meine Gesprächspartner immer wieder, dass es oft schwierig sei, sich überhaupt auf einen Kandidaten zu einigen, und oftmals falle auch auf solche die Wahl, die sich im Vorfeld gar nicht für einen Posten interessiert hätten (vgl. auch Prolog).

Dorfvorsteher und Präsidenten lokaler Föderationen müssen vor allem lokal relevante Projekte in Angriff nehmen: Territorialprobleme, Kontakte mit staatlichen Behörden zum Aufbau und zur Pflege der Infrastruktur, Kontakte zu NGOs. Während erstere sich dabei ausschließlich um die Belange ihrer Gemeinde kümmern, sind die Föderationsrepräsentanten eigentlich für übergreifende Probleme der zusammengeschlossenen comunidades verantwortlich. Jedoch kann ihre Kompetenz und Zuständigkeit dabei nicht nur durch die politischen Ambitionen einzelner Dorfvorsteher untergraben werden, sondern auch von Seiten staatlicher Funktionäre und NGOs. Beide Instanzen suchen ihrerseits meist den direkten Kontakt zu lokalen Autoritäten. Vor allem die Funktionäre staatlicher Einrichtungen wenden sich oftmals lieber direkt an die Dorfvorsteher, da sie, aus ihrer Perspektive, die relevanten Ansprechpartner darstellen (Gespräch Arirama 05.02.2004; Gespräch Asunción 20.03.2004; Gespräch Gonzalez 05.06.2005). Hinzu kommt die Möglichkeit eines Konkurrenzverhältnisses zwischen Föderationsrepräsentanten und indigenen Politikern, die in bezahlte Ämter innerhalb regionaler Regierungsstrukturen gewählt werden - als Bürgermeister, regidor oder consejero - und nun durch ihren direkteren Zugang zu staatlichen Fördermitteln zu privilegierten Ansprechpartnern der dörflichen Gemeinschaften werden (vgl. Kapitel X.3).

Sowohl der Dorfvorsteher als auch der Föderationspräsident werden im Gegensatz zu diesen Politikern für ihre Tätigkeit nicht bezahlt. Das wirft vor allem für letztere besondere Probleme auf: Wenn sie Behördengänge erledigen oder die Mitgliedsgemeinden besuchen wollen, sind sie auf die Zuwen-

40 Die Anzahl der Mitgliedsgemeinden gehört zum >politischen Kapital des Präsidenten und seiner Organisation. Je größer die >Basis $<$ ist, desto >repräsentativer wird der Vertreter bei öffentlichen Auftritten. Deshalb schwanken die Angaben zu den assoziierten Dörfern einer Föderation je nachdem, ob der Gesprächspartner der Organisation angehört oder zu ihren >Gegnern zählt. 
dungen von staatlicher Seite sowie von Entwicklungsinstitutionen angewiesen. Die Transportkosten in die nächste Stadt können, je nach Entfernung, die Einkünfte des Repräsentanten um ein Vielfaches übersteigen. Zudem ruht zu Hause während der Abwesenheit die Arbeit. Das führt zu Konflikten mit den Ehepartnern. Vor allem Frauen versuchen aus diesem Grund oft, ihre Männer vom Engagement auf Föderationsebene abzuhalten (Gespräch Arirama 07.02.2004; Gespräch Antazú 30.06.2005; Gespräch del Aguila; Gespräch Asunción 20.03.2004). In den Gemeinden ist, wie beschrieben, der Unterstützungswille für die Repräsentanten gering. Ein Föderationspräsident schafft es meist nur, eine finanzielle Beteiligung zu mobilisieren, wenn ein direkter Nutzen für die jeweiligen Unterstützer erkennbar ist. Damit wird zwar das eigene soziale Netzwerk gemäß dem Reziprozitätsprinzip gestärkt, der eventuelle Ertrag der organisatorischen Bemühungen kommt aber immer nur einem kleinen Teil der Föderationsmitglieder - den jeweiligen Unterstützern zugute. Das Ergebnis: Autoritätsverlust, Misstrauen und gezielte Korruptionsvorwürfe von Seiten der Nicht-Begünstigten.

Vermittlung auf Dorf-, aber vor allem auf Föderationsebene, erfordert einen hohen persönlichen Einsatz, bei dem der Nutzen ausbleiben kann. Es ist ein Risikogeschäft, das ständige Aktivität verlangt, um auch lukrativ für den Ausführenden zu werden. Deshalb sagten mir viele Gesprächspartner, die einmal ein Amt, vor allem auf Föderationsebene, ausgeübt hatten, dass es eine undankbare Aufgabe sei, die sie nicht mehr übernehmen wollten. Auf Ebene des supralokalen Zusammenschlusses begleiten häufige Neuwahlen das Auf und $\mathrm{Ab}$ der Organisationsgeschichte. Vor allem bei kleineren Zusammenschlüssen haben Dorfbewohner noch direkten Zugriff auf die Vertreter und können ausbleibende oder nicht zufriedenstellende Aktionen unmittelbar sanktionieren. Gerüchte verbreiten sich schnell, und bestehende Konflikte zwischen einzelnen Dörfern oder zwischen Fraktionen innerhalb der Gemeinden können zudem die Abwahl des Repräsentanten beschleunigen. Als primus inter pares sind Dorf- und Föderationspräsident ständiger Kritik von Seiten der Dorfbewohner ausgesetzt. Dementsprechend muss die Kanalisierung von Projekten für beide höchste Priorität haben, um sichtbare Erfolge vorweisen zu können. Beim Aufbau der dazu benötigten Netzwerke spielen ideologischpolitische Erwägungen eine untergeordnete Rolle, wie die Entscheidung des Präsidenten der in Kapitel X.1 vorgestellten Huitoto-Gemeinde zeigt: Er ist sehr interessiert an einer Zusammenarbeit mit der CONAP, obwohl diese Organisation nicht `seine` nationale Vertretung repräsentiert. Nicht nur auf Dorfebene spielt offizielle Mitgliedschaft bzw. ideologische Ausrichtung eine untergeordnete Rolle. Auch viele lokale Föderationen haben sich für eine Doppelmitgliedschaft in AIDESEP und CONAP entschieden (vgl. Greene 2004; Chirif 1997). 
Das Wissen, wie man ein Projekt entwirft, sowie direkter Kontakt zu den >großen Financiers der Entwicklungszusammenarbeit sind Ressourcen, die kaum ein Dorfvorsteher oder Präsident einer Föderation besitzt. Diesbezüglich sind sie meist auf erfahrene Vermittler angewiesen. Sie stellen somit das unterste Glied in der Vermittlungskette dar und sind bemüht, Kontakte zu solchen Personen aufzubauen, die Zugang zu den entsprechenden Ressourcen haben. Ihr Netzwerk ist, der Einteilung Boissevains (1974) folgend, hauptsächlich zweiter Ordnung. ${ }^{41}$ Wie das Beispiel des Präsidenten der HuitotoGemeinde zeigte, verlassen sie sich dabei keinesfalls auf ihre regionale Organisation, sondern suchen vor allem den direkten Kontakt zu staatlichen Funktionären und NGOs. Sie durchbrechen damit die hierarchische Organisationsstruktur AIDESEPs. Dies verdeutlicht auch, wie gering die politische Autorität der regionalen und nationalen Repräsentanten im lokalen Kontext ist: Im Spiel der Vermittlung gilt es, das eigene Netzwerk erster Ordnung ständig zu vergrößern bzw. das zweiter Ordnung so >direkt` wie möglich zu halten. Je mehr Mittelsmänner eingeschaltet werden müssen, desto geringer wird der eigene Nutzen. Das Motto des presidente comunal »Jeder kämpft für sich alleine« wiederholte nicht nur dieser mir gegenüber mehrfach. Es handelt sich um einen Leitsatz, der vielerorts proklamiert wird. Das beschriebene Misstrauen der Dorfbewohner gegenüber den Organisationsvertretern verstärkt sich wiederum im Lichte der Konkurrenzsituation zwischen den Vermittlern, bei denen auch in regionale Regierungsstrukturen gewählte Dorfbewohner mitspielen. Im Kontext der Dorf- und Föderationspolitik operieren die >lokalen Entwicklungsmakler`, die bei geschicktem Agieren Macht, Prestige und Ansehen gewinnen können, dabei aber sozial am stärksten von der - situationsabhängig zu definierenden - >eigenen Gruppe deutlichsten dem Statusführerprinzip verpflichtet.

41 Boissevain (1974: 24) unterscheidet zwischen Netzwerken erster und zweiter Ordnung. Netzwerke erster Ordnung bestehen aus direkten Beziehungen, die zweiter Ordnung aus den >Freunden von Freunden $<-$ Menschen, mit denen der Betreffende über sein primäres Netzwerk in Beziehung treten kann. Dabei kann das Netzwerk zweiter Ordnung noch beliebig ausdifferenziert werden, wobei die Beziehungen ständig distanzierter werden ( $>$ Freunde von Freunden von Freunden`). Den Begriff `Netzwerk benutzt Boissevain dabei hauptsächlich im egozentrierten Sinn. 


\section{Regionale und nationale Ebene}

Die Repräsentanten regionaler Organisationen haben ihren Sitz in der Stadt, wo ihnen ein Büro zur Verfügung steht. Sie reisen zu Seminaren und Sitzungen nach Lima bzw. in andere Städte und führen einen relativ beständigen Dialog mit anderen regionalen Repräsentanten, Staatsbeamten sowie ihren Kontaktpersonen in Entwicklungsorganisationen. Die Finanzierung ihres Unterhalts hängt ausschließlich von Projektgeldern ab, da sie in der Stadt besonders hohe Lebenshaltungskosten haben und zudem keine Zeit mehr für den Anbau eigener Produkte finden. Nicht selten folgen ihnen ihre Familien in die Stadt. So werden sie zu seltenen Gästen in ihren Heimatdörfern. Häufig bleiben sie auch nach Ende ihrer Tätigkeit im urbanen Raum wohnen. Dies steht oft in Zusammenhang mit einem Prestige- und Vertrauensverlust in ihrem Heimatdorf, den sie durch das zuvor ausgeübte Amt erleiden.

Sie müssen sich mit den tagesaktuellen entwicklungspolitischen Fachbegriffen vertraut machen. Darüber hinaus müssen sie versuchen, eigene Projekte zu entwickeln und sich innerhalb der überregionalen Organisationszusammenhänge zu profilieren. Ziel dieser Vertreter ist es meist, nach Ende der Amtszeit auf die nationale Ebene auf- oder in eine andere Organisation umzusteigen. Meist kommen deshalb Personen in diese Ämter, die bereits umfassende Erfahrungen außerhalb ihrer Gemeinde gesammelt haben und über ein überdurchschnittliches $\mathrm{Ma}$ an institutionalisiertem Kulturkapital verfügen. Die folgende Beschreibung der Ausbildung und Laufbahn eines ehemaligen Vize-Präsidenten der regionalen Organisation ORAI kann diesbezüglich als exemplarisch gelten:

»Zuerst lebte ich nach dem Ende meiner Militärzeit für neun Jahre in Iquitos, bevor ich in meine Gemeinde zurückkehrte. Dort lebte ich die ersten vier Jahre, ohne ein Amt auszuüben, dann aber übernahm ich zweieinhalb Jahre den Posten des agente municipa $l^{42}$ und dann trat ich von meinem Amt zurück, um einige persönliche Arbeiten durchzuführen, und nach drei Monaten wählte mich mein Volk, auf Grund des Vertrauens, das ich mir durch meine Tätigkeit als agente municipal erworben hatte, zum presidente comunal. Ich war drei Jahre Präsident meiner Gemeinde. [...] Aber schon vor diesen politischen Posten hatte ich angefangen, als Pastor einer evangelischen Gemeinde zu arbeiten [...] Später wurde ich Vize-Präsident unserer Föderation. Danach habe ich drei Monate in einem Projekt zu Naturschutzgebieten in Iquitos gearbeitet [...] 1999 gab es Neuwahlen des Vorstandes meiner Föderation, und

42 dt. >Gemeindevertreter/; der agente municipal wird vom Bürgermeister ernannt und fungiert als dessen Ansprechpartner in einer kleinen Ortschaft. Er besitzt reine Verwaltungsaufgaben, führt zum Beispiel das Zivilregister und leitet den Schriftverkehr weiter. 
man wählte mich überraschend mit achtzig Prozent der Stimmen zum Präsidenten [...] 2001 wurde ich Vize-Präsident der ORAI« (Interview Manihuari 05.03.2004).

Wie Bierschenk und Olivier de Sardan (2000: 28) für den afrikanischen Kontext festhalten, und wie sich schon bei der Analyse der kategorialen Wahrnehmung der Präsidenten abzeichnete, sind die Fähigkeiten, die ein Broker sich aneignen muss, schwer im dörflichen Kontext zu erlernen. Reisen und längere Aufenthalte außerhalb der Gemeinde sind deshalb von Vorteil. Auch, so halten die Autoren fest, sind »militante Erfahrungen« (Bierschenk und Olivier de Sardan 2000: 28), wie die Mitgliedschaft in einer Kirche oder Partei, oft Grundvoraussetzungen. Der ehemalige Vize-Präsident der ORAI erfüllte alle diese Kriterien. Bereits im geschichtlichen Rückblick auf die Genese der indigenen Organisationen verwies ich auch auf das Beispiel der jungen Asháninka-Männer im Perené. Diese hatten durch ihre Aktivitäten in Adventisten-Kirchen Erfahrungen in supralokaler Organisation gewonnen und ihre Kenntnisse 1959 genutzt, um die Asociación de Nativos Campas del Perené $\mathrm{zu}$ gründen. Einige Autoren verweisen wiederum auf den großen Einfluss evangelischer Missionen und des SIL bei der Herausbildung indigener Organisationen (vgl. u.a. Santos Granero und Barclay 1998, 2000; Greene 2004; Ullán de la Rosa 2004).

Auch der Repräsentant einer regionalen Organisation ist stark von seinen sichtbaren Erfolgen abhängig, um sich halten zu können. Schafft er es nicht, Projekte an Land zu ziehen und sich ein breites Netzwerk von Unterstützern sowie zu den Mitarbeitern der Ämter und Ministerien aufzubauen, versiegen die Finanzquellen. Deshalb gilt wohl auch hier: Die politisch-ideologischen Gräben sind oft nicht so tief wie sie von nationalen Repräsentanten und den nicht-indigenen Unterstützern gerne gezeichnet werden. Mehrfachmitgliedschaften in übergeordneten Organisationen sind durchaus möglich: So gehört zum Beispiel die regionale Organisation Federación Nativa de Madre de Dios (FENAMAD) ${ }^{43}$ sowohl CONAP als auch AIDESEP und darüber hinaus auch noch der Bauerngewerkschaft CCP an (vgl. García 2003: 294). Allerdings besteht die soziale Bezugsgruppe des regionalen Repräsentanten nur noch in sehr eingeschränktem Maße aus Dorfbewohnern der föderativen Zusammenschlüsse. Zwar kann ein regionaler Repräsentant jederzeit abgewählt werden, aber zu diesem Zweck müssen potentielle Gegner in den supralokalen Föderationen einen größeren Zusammenschluss mobilisieren und im Kongress eine Mehrheit auf ihre Seite bringen. Der Manipulationsspielraum des regionalen Vertreters gegenüber seiner >Basis` wächst somit beträchtlich - eine Analyse des Korruptionsfalls in der regionalen Organisation ORAI belegt dies eindrücklich (vgl. Bueno de Mesquita 2001). Proportional zur abnehmenden Ab-

43 Dt. >Native Föderation der Region Madre de Dios`. 
hängigkeit des Repräsentanten von der >Basis` wachsen jedoch die Kontrollmöglichkeiten der Finanzgeber, die seine Projektpartner werden. Ihnen gegenüber ist er Rechenschaft schuldig, sie können weitere Zahlungen verweigern, legt er keine überzeugenden Abrechnungen vor. Da sie zumeist auch in den Städten ihre Büros haben, sind sie der eigentlich relevante Bezugspunkt des indigenen Vermittlers.

Der zitierte ehemalige Vize-Präsident von ORAI schaffte den Sprung auf die nationale Ebene nicht. Nach Ende seiner Amtszeit kehrte er auch nicht in seine Gemeinde zurück, sondern zog in ein Dorf an der Straße zwischen Iquitos und Nauta. Sowohl in seiner Gemeinde und supralokalen Föderation als auch auf regionaler Ebene war er Kritik ausgesetzt. Er hatte es nicht geschafft, die für einen Aufstieg notwendigen sichtbaren Erfolge zu erarbeiten. Erschwerend kam das Erbe hinzu, das er angetreten hatte: ORAI war zuvor von einem Korruptionsfall erschüttert worden, infolge dessen sich die Kooperationspartner der Entwicklungszusammenarbeit größtenteils zurückgezogen hatten. Darüber hinaus war es dem Repräsentanten nicht gelungen, ein gut funktionierendes Netzwerk aufzubauen. Denn: Um auf die nationale Ebene in der Organisation zu gelangen, wird es wichtig, strategische Allianzen in den eigenen Organisationsreihen zu schmieden. So erzählte mir ein regionaler Repräsentant von den Vorbereitungen für die Wahl der nächsten AIDESEPDirektive: Er habe sich mit anderen Organisationsvertretern, die zur Abstimmung anreisen würden, verbündet, um gemeinsam Kandidaten für die verschiedenen Ämter auszuwählen. Man wolle sich noch einmal kurz vor dem Kongress treffen, um das Bündnis zu stärken (Gespräch Colina 21.07.2005). Ein anderer Vertreter, der bereits in der Direktive war, berichtete mir, sein größter Ehrgeiz sei es gewesen, sich gegen einen anderen Konkurrenten durchzusetzen, der über ein breites Netzwerk auf nationaler Ebene verfüge aber, so fügte er einschränkend hinzu, vor allem in Bezug auf Kontakte zu nicht-indigenen Unterstützern. Diese würden ihn stets gegen Kritik in Schutz nehmen. In den eigenen Reihen würde der Betreffende aber schon länger hinterfragt. Das hätte sich positiv auf seine eigene Wahl in die Direktive ausgewirkt - so die Überzeugung meines Gesprächspartners (Gespräch Joaquín 25.07.2005). Auch ein ehemaliger Student, der in den 1980/90er Jahren mit Hilfe des Stipendienprogramms seiner Organisation die Universität besuchen konnte, berichtete mir von den Fraktionsbildungen bei AIDESEPKongressen. Die >eigentlichen Wahlen< fänden im Vorfeld hinter verschlossenen Türen statt (Gespräch Casanto 09.06.2005).

Hat man es einmal auf die nationale Ebene geschafft, so gilt es auch hier, Projekte zu entwerfen. Dies, so eine Gesprächspartnerin, sei ihr am Anfang bei ihrer Arbeit besonders schwer gefallen. Projektwissen identifizierte sie als eine zentrale Fähigkeit, die ein nationaler Repräsentant brauche. Ferner müsse man sowohl gute Beziehungen zu den Unterstützer-Organisationen pflegen 
als auch zur Basis der Organisation (Interview Antazú 19.01.2004). Jedoch wird der Kontakt zu Dorfbewohnern seltener - auch auf Grund der großen Distanzen zwischen Lima und den entsprechenden Regionen im Amazonasgebiet. Die Kommunikation gestaltet sich zäh und wird von Seiten der Mitgliedsgemeinden als äußerst mangelhaft beurteilt. Potentielle Wähler und Gegner nationaler Repräsentanten befinden sich verstärkt innerhalb der Organisationszusammenhänge. Kontaktpflege betreiben die Mitglieder der nationalen Direktive vor allem mit den nicht-indigenen Unterstützern. Diese finanzieren ihre Reisen im In- und Ausland sowie Projekte, die den Lebensunterhalt absichern. Aufbauend auf Bourdieus Charakterisierung des politischen Feldes, lässt sich der Abkoppelungsprozess zwischen Repräsentanten und Repräsentierten nachvollziehen: Auf regionaler und nationaler Ebene ergreift die Logik des Feldes die Akteure, und die sozialen Bande zwischen Profis und Laien lösen sich nach und nach auf. Die indigene Organisation wird zu einem autonomen Mikrokosmos mit eigenen Gesetzen und Spielregeln.

\section{Vom Big Man zum großen Vermittler}

Je nach Vermittlungskontext sind somit unterschiedliche Voraussetzungen notwendig: Während auf lokaler Ebene vor allem Lösungen für konkrete Probleme angeboten werden müssen, besitzt das Wissen um die Erarbeitung eines Projektes auf regionaler und nationaler Ebene große Bedeutung. Zudem ist ein umfangreiches Diskurswissen vonnöten - einerseits die rhetorischen Fähigkeiten, andererseits die Kenntnis der entwicklungspolitischen Fachbegriffe und der speziellen Ausrichtung der Organisation. Bierschenk und Olivier de Sardan (2000: 28) unterscheiden deshalb zwischen den Vermittlern, die nur im lokalen Kontext bestehen können und den >großen Maklern', die Spezialisten ihres Faches sind. Ein großer Vermittler wird man als indigener Repräsentant im peruanischen Tiefland nur, wenn man über die strategischen Netzwerke hinaus spezielles Wissen erlangt und sich nicht nur als Projektbeschaffer, sondern auch als Projektvermittler oder gar Kontrollinstanz in der Projektausführung etablieren kann. Großer Vermittler ist man gleichfalls immer nur für Personen, die über ein weniger bedeutsames Netzwerk und keinerlei Spezialistenwissen verfügen. Man bleibt Klient im Verhältnis zu den internationalen Finanzgebern. Gleichzeitig verliert man im lokalen Kontext an politischem Ansehen und direkten Einflussmöglichkeiten. Grund dafür ist die soziale und geografische Distanz zwischen regionalem bzw. nationalem Vorstand und den von ihnen gegenüber der peruanischen Regierung und Repräsentanten internationaler Entwicklungsorganisationen vertretenen Gemeinden. Der Schluss liegt somit nahe, dass es sich bei regionalen und nationalen Vertretern zwar um entwicklungspolitische Profis - um große Vermittler -, jedoch nicht mehr um lokal relevante politische Führungspersönlichkeiten han- 
delt. Welche Auswirkungen hat dies auf ihren weiteren Karriereverlauf? Mit welchen Problemen werden die Repräsentanten konfrontiert, wenn sie >ganz oben angekommen sind?

\section{Am Ende der Organisationskarriere: Was kommt danach?}

1998 hatte es der Aguaruna Gil Inoach geschafft: Nach zwölf Jahren war er »auf dem Schlachtfeld angekommen«. Mit diesen Worten erzählte der ExPräsident von AIDESEP anlässlich des 25-jährigen Jubiläums der Organisation im Mai 2005 seine Geschichte des >klassischen Aufstiegs` von der Gemeinde in das höchste Amt des nationalen Zusammenschlusses: Er habe mit der Machete in der Hand zusammen mit den Bewohnern seines Heimatdorfes hart arbeiten müssen, bis man ihn dafür eines Tages mit dem Posten des Präsidenten der supralokalen Föderation belohnt habe. Danach trat er in die regionale und schließlich in die nationale Organisation ein. Eines Tages sei er Präsident geworden - das Volk habe ihm die Autorität zugesprochen, Entscheidungen zu treffen. Niemanden habe er mehr konsultieren können, denn plötzlich habe es keine Person mehr gegeben, die ein größeres Wissen über das `Schlachtfeld ‘ besaß. Er stand nun, so erzählte er, einer Organisation vor, die im Gegensatz zu Hilfsorganisationen ein »tiefes umfassendes Projekt« verfolgte, »das aus dem Leben selbst der indigenen Völker entsteht: ihr Territorium zu verteidigen« (Rede Inoach, 27. Mai 2005). ${ }^{44}$ Das Präsidentenamt in AIDESEP oder danach noch die Koordinatorenstelle in der COICA verkörpern derzeit die oberste Stufe der politischen Karriereleiter indigener Repräsentanten im peruanischen Amazonasgebiet. ${ }^{45}$ Doch was passiert, wenn die Amtszeit vorbei ist?

Evaristo Nugkuag, der erste Präsident von AIDESEP, hatte durch die Unterstützung seines älteren Bruders, der ein vom SIL geschulter zweisprachiger Lehrer war, die weiterführende Schule besuchen können. Danach studierte er zwei Jahre lang Medizin in Lima, musste aber mangels finanzieller Mittel das Studium abbrechen. Er kehrte in seine Heimatgemeinde am Cenepa zurück und begann bald darauf den Congreso Aguaruna Huambisa (CAH) zu organisieren. Wie bereits beschrieben, übernahm er auch bei der Gründung des nationalen Zusammenschlusses AIDESEP eine führende Rolle und domi-

44 Auch er nahm die übliche Abgrenzung zu NGOs vor, die Teil des allgemeinen indigenen Organisationsdiskurses war. Auf diesen Punkt komme ich im Abschnitt >Die Rolle der Unterstützer` zurück.

45 Parallel dazu gilt natürlich auch die Präsidentschaft der CONAP als solch höchstes Amt. Doch gab es hier seit Gründung der Organisation 1987 weniger Wechsel an der Führungsspitze, die Strukturen gleichen stärker denen einer NGO, in der man nicht durch Wahl, sondern durch Fachwissen die Leitung beanspruchen kann. 
nierte lange Jahre dessen Ausrichtung. Während seiner Präsidentschaft baute die Organisation internationale Kontakte auf, nahm an Sitzungen der UNO teil und bekam sogar einen Gesprächstermin mit dem damaligen Chef der Weltbank. Nach Ende seiner Präsidentschaft übernahm er die Koordination des internationalen Zusammenschlusses COICA, den er wiederum mit ins Leben gerufen hatte. Nugkuag konnte sich zwölf Jahre lang in den höchsten politischen Ämtern der Organisationen der pueblos indígenas des Amazonasgebietes halten - so lange wie kein ihm bis heute nachfolgender Präsident von AIDESEP. Nach dem Ende seiner Amtszeit in der COICA 1992 wurde Nugkuag erneut zum Präsidenten der CAH gewählt, bevor er 1998 versuchte, eine politische Karriere außerhalb der indigenen Organisationswelt zu starten. Er trat als Kandidat bei der Bürgermeisterwahl seiner Heimatprovinz Condorcanqui an. AIDESEP-Unterstützer Alberto Chirif bewertete seine Kandidatur im Vorfeld der Wahlen kritisch: Nugkuag habe in den letzten 20 Jahren nicht in der Region, sondern in Lima gelebt, auch wenn er die letzten Jahre die Präsidentschaft der $\mathrm{CAH}$ innegehabt habe. Seine Arbeit als dirigente würde schon seit längerem kritisiert, »vor allem, wegen seinem Mangel an demokratischem Geist « (Chirif 1998: 77). Der Erfolg gab Nugkuag jedoch Recht: Er gewann die Wahlen und wurde neuer Bürgermeister. Doch wie schon gegen Ende seiner Amtszeit auf nationaler und internationaler Ebene in der indigenen Organisationswelt, schlug ihm Widerstand entgegen, und er geriet unter Korruptionsverdacht. Dennoch schaffte Nugkuag es, nach einer kurzen Abwesenheit, seine Amtszeit zu Ende zu führen. Nach zweijähriger Pause wurde er 2003 abermals Präsident der CAH und pendelte 2005, laut eigenen Angaben, zwischen Lima und seiner Heimatregion. Er besuchte regelmäßig das Büro von AIDESEP, in dem auch einer seiner Söhne arbeitete und versuchte, alte Kontakte aufzufrischen und neuen Einfluss zu gewinnen (Gespräch Nugkuag 02.08.2005).

Nach dem Aguaruna Evaristo Nugkuag trat der Asháninka Miqueas Mishari den Präsidentenposten von AIDESEP an. Als junger Mann engagierte er sich politisch in einem Streit seiner Gemeinde mit einem englischen Unternehmen um das Siedlungsgebiet seines Heimatdorfes. ${ }^{46}$ Danach baute er die CECONSEC $^{47}$ - eine der Gründerorganisationen von AIDESEP - mit auf und leitete sie. Mishari war, laut eigenen Angaben, ein erfolgreicher Kaffeeproduzent, bevor er sich intensiv der politischen Arbeit in den Organisationen widmete. Wie Nugkuag bestand er zwei Amtsperioden und wird noch heute von vielen als freizügiger Vorsitzender erinnert, der »schon am Tag, wenn sein monatliches Gehalt ausgezahlt wurde, nichts mehr in der Tasche hatte, da er

46 Zur Geschichte dieser Auseinandersetzungen vgl. Casanto 1985.

47 Die CECONSEC war als Produktionsgenossenschaft für Kaffee ins Leben gerufen worden und hatte sich erst danach umdefiniert zu einer Organisation, die sich für die Rechte Indigener einsetzt. Vgl. hierzu auch das Kapitel IX. 
es an alle Bittsteller verteilte « (Gespräch Chirif 20.07.2005; Gespräch García 10.06.2005; Gespräch Salazar 08.06.2005). Er ist der älteste unter den ExPräsidenten und der mit der geringsten Schulbildung. 2005 besuchte ich ihn in La Merced, einer Stadt in der Nähe seiner Heimatgemeinde. Während seine Frau und Töchter nach Ende seiner Amtszeit in Lima wohnen blieben, ging er schließlich zurück in seine Gemeinde. Er pendelte zwischen seinem Haus in der comunidad und seinem knapp zehn Quadratmeter großen Büro in La Merced, das ihm gleichzeitig als Schlaf-, Wohn- und Arbeitsraum diente. Mishari versuchte, in der indigenen Organisationswelt auf regionaler Ebene erneut Fuß zu fassen, doch im Gegensatz zu Nugkuag schaffte er es nicht mehr in den Vorsitz seiner Föderation. Dazu fehlten ihm unter anderem die stabilen Kontakte zu Finanzinstitutionen. Dies hatte sicherlich auch damit zu tun, dass in seine Amtszeit bei AIDESEP die Aufdeckung schwerwiegender >Misswirtschaft in der Organisation fiel. Diesbezügliches Fehlverhalten seinerseits gestand Mishari in seiner Ansprache auf dem AIDESEP-Jubiläum ein und betonte, viel daraus gelernt zu haben.

Während meines Besuches in La Merced kamen Mishari und ich auch auf das Ständige Forum für indigene Angelegenheiten bei der UNO zu sprechen. Mishari hielt mir ein Empfehlungsschreiben des aktuellen AIDESEP-Präsidenten hin und meinte, mit diesem würde er sich um eine Teilnahme am Forum im nächsten Jahr bewerben. Auf meine Frage, was er sich von einer Reise nach New York erhoffe, nannte er mir an erster Stelle die Kontaktaufnahme mit europäischen und nordamerikanischen NGOs. Als Zweites betonte er, es sei wichtig, sich über die international aktuellen Themen zu informieren, um »nicht den Anschluss zu verpassen « (Gespräch Mishari 14.06.2005). Der AIDESEP-Unterstützer Pedro García, der Ende der 1980er und Anfang der 90er Jahre eng mit Mishari zusammenarbeitete, verglich dessen Amtszeit mit der seines Vorgängers Nugkuag: Mikeas Mishari sei zwar kein großer Redner gewesen, dafür aber ein Mann der Tat. Ausführlich erzählte er mir vom mutigen Engagement Misharis in politisch gefährlichen Zeiten. ${ }^{48}$ Während Evaristo Nugkuag für García die Öffnung AIDESEPs zur internationalen Ebene verkörperte, symbolisierte Mishari die Basisarbeit. Eine nahezu identische Charakterisierung der Personen Nugkuags und Misharis sowie ihrer Amtszeiten lieferte mir auch Alberto Chirif (Gespräch Chirif 20.07.2005).

Gil Inoach, der eingangs erwähnte Ex-Präsident, hatte sich vor seiner Wahl in den Vorstand von AIDESEP bei den Bürgermeisterwahlen 1995 in seiner Heimatregion auf Distriktebene als Listenkandidat einer Partei für das Amt des regidor beworben, allerdings ohne Erfolg. Er fand nach dem Ende seiner Zeit bei AIDESEP eine Projektanstellung beim WWF und wechselte

48 Der Leuchtende Pfad und MRTA waren ins Siedlungsgebiet der Asháninka vorgedrungen. 
damit in eine NGO. Sein neuer Job brachte ihm allerdings einen ambivalenten Status in der indigenen Organisationswelt ein. Während meiner Forschungszeit stand AIDESEP großen Umweltschutzorganisationen wie dem WWF, nach einer kurzen Phase der Annäherung Anfang der 1990er Jahre, wieder skeptisch gegenüber. Die Naturschutzprojekte dieser Organisationen stehen oftmals in Konflikt mit den Forderungen indigener Zusammenschlüsse bezüglich des indigenen Territoriums im Amazonasgebiet (vgl. Rummenhöller 2005; vgl. auch Kapitel III.4). Es wurde ferner vermutet, dass sich der WWF mit der Vergabe dieses Postens an Inoach Zugang zu AIDESEP erkaufen wolle. In persönlichen Kommentaren bewunderten viele Gesprächspartner jedoch Inoach dafür, dass er einen Vertrag beim WWF bekommen hatte. Man vermutete, er würde dabei gut verdienen. Inoachs Vorgänger im Amt, der Shipibo Juan Chávez Muñoz, hatte mit nur drei Jahren Amtszeit eine weniger bedeutende Rolle in der bisherigen AIDESEP-Geschichte gespielt. Er fand danach jedoch eine Anstellung bei einer NGO in Pucallpa, für die er auch während meiner Forschung 2005 arbeitete.

Die erste Frau, die auf nationaler Ebene in ein Amt in AIDESEP gewählt wurde, ist die Yanesha Teresita Antazú. Sie bezeichnet die indigenen $\mathrm{Zu}-$ sammenschlüsse als »integralen Bestandteil« ihres Lebens, da sie sich schon früh für politische Organisation interessiert habe. Oft sei ihr gesagt worden, sie würde sich »mehr wie ein Junge als wie ein Mädchen benehmen«. Das habe daran gelegen, dass sie immer ihre Meinungen und Ansichten geäußert und sich als Wortführerin profiliert habe. Dabei sei es nicht immer einfach gewesen, sich gegenüber ihren männlichen Geschwistern zu behaupten. Vor allem der Vater habe diese immer bevorzugt behandelt (Gespräch Antazú 30.06.2005). Seit ihrem siebzehnten Lebensjahr hat sie, zuerst auf Ebene des Dorfes, dann sukzessive in der Föderation, im regionalen Zusammenschluss und schließlich ab 1998 auf nationaler Ebene gearbeitet. In den 1990er Jahren kamen zunehmend Frauen auf Posten innerhalb der Föderationen und regionalen Organisationen, meist als Verantwortliche für Frauenfragen. Bis zum Jahr 1999 gab es jedoch auf nationaler Ebene keine entsprechende Stelle, auch wenn die Durchsicht der AIDESEP-Zeitschrift Voz indigena belegt, dass es bereits bei der Wahl des Vorstandes im Jahr 1991 eine diesbezügliche Initiative gab (vgl. AIDESEP 1991) . Das damals eingerichtete Amt wurde jedoch, so Antazú, nie besetzt. 1999 musste dann in einer großen Versammlung unter Einbezug der Föderationen und regionalen Organisationen zuerst die Satzung von AIDESEP erweitert werden. Wurde bis dahin Frauen lediglich das Wahlrecht zugestanden, durften sie nun auch explizit für Ämter kandidieren. Als Teresita Antazú 1999 als erste Frau in den Vorstand von AIDESEP gewählt wurde, zog sie mit ihren Kindern nach Lima. Von ihrem Mann lebte sie schon zuvor getrennt. Sie berichtete, dass die Kinder anfangs große Schwierigkeiten hatten, sich in Lima zurechtzufinden: andere klimatische Be- 
dingungen, ungewohntes Essen, Sprachprobleme sowie die nie verfügbare, weil ständig arbeitende Mutter erschwerten ihnen die Eingewöhnung (Interview Antazú 19.01.2004; Gespräche Antazú 24.05.2005, 30.06.2005). Trotz vieler Probleme hielt Teresita ihre erste Amtszeit durch und wurde bei den nächsten Wahlen in ihrem Posten bestätigt. Sie verweist auf die Schwierigkeiten, sich als Frau in der nach wie vor von Männern dominierten indigenen Organisationswelt durchzusetzen:

»Die Männer haben Angst, von uns Frauen aus den zentralen Positionen abgedrängt zu werden. [...] Darüber hinaus nehmen sie die Probleme indigener Frauen als politisches Thema oft nicht wirklich ernst. Für sie zählt in erster Linie der Kampf um unser indigenes Territorium. [...] Als ich meinen Posten 1999 antrat, überreichte mir der damalige Präsident zwei Blätter, die er als >Projektentwurf für ein Frauenthema bezeichnete. Danach ließ man mich alleine mit der Arbeit und versuchte auch oft, mich aus wichtigen Entscheidungen herauszuhalten - entweder, indem man Sitzungen ohne mich abhielt oder indem man meine Redebeiträge nicht ernst nahm. [...] Auch auf lokaler Ebene ist die Arbeit zu Frauenthemen manchmal sehr schwierig. Das Gender-Konzept wird einfach nicht verstanden [...] und die Männer lehnen es oft pauschal als westliches Konzept ab« (Gespräch Antazú 30.06.2005).

Im Dezember 2005 kandidierte Antazú für das Amt der Präsidentin von AIDESEP, konnte sich jedoch gegen ihre männlichen Konkurrenten nicht durchsetzen. Danach arbeitete sie punktuell im Frauenprogramm von AIDESEP weiter mit und engagierte sich wieder verstärkt in ihrer lokalen Föderation. $^{49}$

Das Ende der Amtszeit, so verdeutlichen die unterschiedlichen Karriereverläufe bisheriger AIDESEP-Präsidenten sowie der von der ersten Frau im Vorstand, ist mit Schwierigkeiten der Neudefinition des eigenen Aufgabenfeldes verbunden. Wo kann man die erworbenen Fähigkeiten anbringen und sich damit seinen Lebensunterhalt verdienen? Eine Rückkehr in den dörflichen Kontext scheint nur bedingt möglich. So unterhielt zum Beispiel Mishari zwar sein eigenes Feld in seiner Heimatgemeinde und suchte, laut eigenen Angaben, bewusst die Nähe zum Dorf. Aber vom Vorschlag eines Freundes, sich ganz von der politischen Arbeit zurückzuziehen und sich dort »zur Ruhe zu setzen« hielte er nichts, ließ er mich im Gespräch wissen (Gespräch Mishari 20.07.2005). Während Inoach für die Beschreibung seines Aufstiegs die Schlachtfeldmetapher benutzte, sprach auch Mishari am liebsten von seinen teilweise lebensgefährlichen politischen Kämpfen zu Zeiten des Leuchtenden

49 Eine detaillierte Auseinandersetzung mit der Genderdebatte in Bezug auf die indigenen Organisationen ist eine wichtige Aufgabe, die aber den Rahmen der vorliegenden Studie sprengen würde. Die Thematik verdient eine gesonderte, ausführliche Analyse. 
Pfades. Doch im Gegensatz zu ihm verstand es Inoach als junger lider der zweiten Generation, in seiner Ansprache zum Jubiläum mit dem Fachvokabular aktueller Diskurse der Entwicklungszusammenarbeit umzugehen. So sprach er unter anderem von den "wichtigen Themen Gobernabilität, Partizipation, Demokratisierung« (Rede Inoach 27.05.2005). Mishari konzentrierte sich hingegen in seinem Beitrag ganz auf die Darstellung und Analyse der Vergangenheit. Dabei benutzte er kaum Fachvokabular jenseits der schon in den 1980er Jahren etablierten Begriffe des >indigenen Volks`, des Kampfs für >Selbstbestimmung^ oder des >indigenen Territoriums` (Rede Mishari 27.05.2005). Nachdem seine Amtszeit vorbei war, hatte er durch die Korruptionsvorwürfe sein wichtigstes Kapital als Vermittler verspielt: die Beziehungen zu Vertretern internationaler NGOs. Auf regionaler oder lokaler Ebene hatte er sich auf Grund seiner `Basisarbeit zwar ein gewisses Prestige erworben, doch besaß er nun als Vermittler auch dort keine große Bedeutung mehr. Seine Geschäfte als Kaffeeproduzent waren schon vor dem Aufstieg auf die nationale Ebene nicht mehr gut gelaufen. Er war somit von den bisherigen Präsidenten vielleicht in der schwierigsten persönlichen Situation. Weder be$\mathrm{sa} ß$ er auf lokaler Ebene politischen Einfluss, noch konnte er sich als Experte im entwicklungspolitischen Feld etablieren. Auch gegen Nugkuag war am Ende seiner Laufbahn in AIDESEP und der COICA der Vorwurf einer »personalisierten « Politik erhoben worden (vgl. Greene 2004: 483). Da er aber über ein gutes Netzwerk sowie umfangreiches Spezialistenwissen verfügte und es international durch die Entgegennahme von Auszeichnungen zu größerer Bekanntheit gebracht hatte als Mishari, behielt Nugkuag auch nach dem Ende seiner Karriere auf lokaler Ebene den Status einer politischen Führungspersönlichkeit und konnte sich, mit Einschränkungen, auch auf nationaler Ebene weiter im Vermittlungsgeschäft halten. Hierbei halfen ihm sicher auch die Verbindungen nach Frankreich, wo eine seiner Töchter inzwischen lebte und Lobbyarbeit für die Aguaruna betrieb.

Angesprochen auf das Problem, in welchem Bereich indigene Repräsentanten nach dem Ende ihrer Organisationstätigkeit unterkommen könnten, meinte eine Mitarbeiterin der GTZ, dass ihr spezielles Wissen sehr hilfreich wäre für den NGO-Sektor. Leider sei es ein Nachteil, dass die politischen Repräsentanten kein Diplom besäßen. Deshalb könnten sie im NGO-Sektor meist doch keine Arbeit finden. Dieser brauche diplomierte Fachkräfte (Gespräch Werner 02.08.2005). Es ist gleichermaßen auffällig, dass keiner der Repräsentanten - außer Mishari - zu einem Leben im dörflichen Kontext zurückkehrte. Auch Teresita Antazú kam in unseren Gesprächen häufig auf dieses Phänomen zu sprechen. Sie selber könne sich mit dem Gedanken an eine Rückkehr in ihr Dorf sehr wohl anfreunden, aber ihre Kinder nicht mehr. So würden sie wohl in Lima bleiben - zumindest bis ihre Kinder die Ausbildung beendet hätten (Interview Antazú 19.01.2004). 
Eine Option nach Ende der Amtszeit in einer Organisation ist auch die Neugründung einer eigenen NGO, um vom bereits aufgebauten Netzwerk zu profitieren. Diese Option wählte keiner der bisherigen Präsidenten. Dennoch ist es eine durchaus gängige Form der »Überlebenswirtschaft« (Gespräch Espinoza 21.01.2004). Doch ist dies ein beschwerlicher Weg. Bierschenk und Olivier de Sardan (2000: 29) weisen in diesem Zusammenhang auf das Vertrauenskapital hin, auf dem der Erfolg des Vermittlers basiert. Dieses ist, wie gesehen, ständigen Angriffen ausgesetzt und kann leicht >verspielt « werden. Wichtig ist in diesem Zusammenhang auch, dass der Makler die von Wolf (1956) beschriebene Janusköpfigkeit besitzen muss. Je nach Situation ist das Vertrauen der Organisationsbasis oder das der Geldgeber zu gewinnen. Sowohl Nugkuag als auch Mishari verloren während ihrer Amtszeiten das Vertrauen der Unterstützer. Während Nugkuag noch in der COICA und Mishari Präsident von AIDESEP war, gerieten die Organisationen unter Korruptionsverdacht (vgl. hierzu Smith 1996). Für AIDESEP resultierte daraus eine zeitweilige Abgabe aller Verantwortlichkeit für Projektgelder an eine von den Geldgebern bestimmte Verwaltungsinstanz. Nugkuag sah sich zudem auch organisationsintern Angriffen ausgesetzt (vgl. Greene 2004: 483). Gil Inoach hingegen erarbeitete sich unter den Unterstützern das Ansehen eines »Organisationserneuerers «, der in schwierigen Zeiten Umstrukturierungen gestaltete (vgl. AIDESEP 27, 2005: 11f.). Im Zuge des Professionalisierungsprozess eines Vermittlers, dies zeigen die beschriebenen Karriereverläufe, sind für das persönliche Weiterkommen nach dem Ende der Organisationskarriere die Beziehungen zu den Geldgebern von herausgehobener Bedeutung.

\section{Dirigentes und profesionales ${ }^{50}$}

In meinen Gesprächen mit Dorfbewohnern hörte ich immer wieder, dass ihre Kinder, anstatt sich zu stark in den Organisationen zu engagieren, lieber studieren möchten, um einen Job als Lehrer oder Angestellter zu bekommen. Die politische Karriere in einer indigenen Organisation wurde von Dorfbewohnern und von Studenten in Lima oder Iquitos meist kritisch gesehen und einer >formalen` Karriere gegenüber abgewertet. Man wollte einen >offiziellen` Titel, da dieser mit Prestige verbunden sei, was eine größere >persönliche Sicherheit « versprach, auch im Hinblick auf einen sozialen (Teil)aufstieg im lokalen und nationalen Kontext. Viele junge Studenten in Lima redeten oft davon, dass sie nach Ende ihrer Ausbildung für ihre Heimtadörfer arbeiten wollten, indem sie Tourismusprojekte oder Unternehmen aufbauen würden und so 〉Entwicklung` in die Gemeinden brächten.

50 Dt. >Repräsentanten und Fachkräfte〈. 
Eine Studie aus dem Jahr 2005 analysiert jedoch die Probleme, die Studenten aus dem Tiefland bei ihrem Eintritt in die Universität San Marcos in Lima haben (vgl. Tejada 2005). Bereits 1999 ergab eine Umfrage unter 31 Studenten, die zu 87 Prozent direkt aus ihren Heimatdörfern im Amazonasgebiet nach Lima gekommen waren: Der kulturelle Hintergrund sei verantwortlich für ein schlechtes akademisches Abschneiden und hohe Abbrecherquoten. Sie begründeten dies unter anderem mit mangelnden Kenntnissen des Spanischen, unzureichender akademischer Vorbereitung, umweltbedingten Anpassungsschwierigkeiten, fehlenden finanziellen Ressourcen und Diskriminierung auf Grund ihres ethnischen Hintergrunds. Die Befragten gaben dennoch mehrheitlich an, dass sie die Kenntnis ihrer eigenen Sprache als sehr wertvoll einschätzten und ihr Studium begonnen hätten, um im Anschluss für ihre Heimatgemeinde zu arbeiten.

Bereits zwei Jahre später jedoch hatte sich diese Einschätzung grundlegend geändert: Alle sagten in Übereinstimmung, dass gute Kenntnisse des Spanischen wichtiger seien als die Muttersprache. Ferner sahen sie große Schwierigkeiten darin, ihr Wissen in der Herkunftsregion nach Ende des Studiums anzuwenden - aus Mangel an professionellen Einsatzmöglichkeiten. Sie fühlten einen Verlust ihrer ethnischen Identität, die alleine auf Festen und zu >Aufführungszwecken` Relevanz erlangen würde, nicht aber im täglichen Studium: 80 Prozent der Befragten klagten über Diskriminierung und Ausgrenzung. Diese fange schon bei der Einteilung in studentische Arbeitsgruppen an, bei der sie meist übrig blieben, da keiner mit ihnen kooperieren wolle (Cortez Mondragón 2005: 24f.; Tejada 2005: 76f.).

Bereits Mitte der 1980er Jahre hatte AIDESEP als eines ihrer ersten Projekte siebzig Studenten aus dem Amazonasgebiet ein Studium ermöglicht. Jedoch brachten nur vier davon dieses auch zu Ende (vgl. Smith 1996: 101). Mitglieder der Direktive der Organisation sprachen 2005 von sechs indigenen profesionales, die mit AIDESEP-Stipendien studiert hätten und in Lima lebten. Sie stünden in mehr oder weniger engem Kontakt zur Organisation. Die Mehrzahl sei mit Mestizinnen verheiratet, nur zwei arbeiteten in der Organisation. Die Hoffnungen, die man in den 1980er Jahren in das Stipendienprogramm gesteckt habe, hätten sich nicht erfüllt. Nun wolle man bei zukünftiger Vergabe stärker auf die Rückbindung der Kandidaten an die Föderationen achten und sie zu einem Dienst für den Zusammenschluss im Anschluss an ihr Studium verpflichten. Die interviewten Mitglieder der Direktive sahen ihr Verhältnis zu den >Diplomierten` kritisch und begründeten dies offiziell mit einer als mangelhaft empfundenen Solidarisierung mit den Zielen von AIDESEP (Gespräch Antazú 23.05.2005; Gespräch Salazar 08.06.2005; Gespräch Cusurichi 10.06.2005).

Auf Seiten der profesionales ergab sich fast spiegelbildlich die entgegengesetzte Sichtweise: Die dirigentes der Organisationen würden sie nicht zu 
Rate ziehen. Es wurde vermutet, dies geschehe aus Angst, ihre Posten an die Fachkräfte zu verlieren. Sie würden lieber nicht-indigene Unterstützer anstellen, da sie von diesen keine Konkurrenz zu fürchten hätten. Gleichzeitig wiesen die Befragten darauf hin, wie schwierig es sei, ohne Titel eine Anstellung zu finden - auch wenn man studiert habe. Das Diplom sei das entscheidende Einstellungskriterium. Einige studierte indigenas konnten aber gerade dieses nicht vorweisen und hatten deshalb Probleme. Warum, so ihre Frage, gäbe man ihnen nicht innerhalb der Organisation eine Chance, nachdem genau aus diesem Grund auch für ihre Ausbildung gesorgt worden sei? Sie bezeichneten es ferner als problematisch, in ihre Heimatgemeinden zurückzukehren. Einer der von mir Befragten erzählte von den Versuchen, die er unternommen habe, um seinem Sohn das Leben in seinem Heimatdorf nahe zu bringen. Dieser sei in der Stadt geboren und wäre mit der anderen Lebensweise nicht zurechtgekommen, sei krank geworden und habe gelitten. Seitdem habe er seine diesbezüglichen Versuche aufgegeben (Gespräch Sueyo 09.06.2005; Gespräch Kentehuari 28.06.2005).

Studenten, Organisationsvertreter, Diplomierte - sie alle kämpfen mit ähnlichen Problemen: Sobald sie die Dörfer verlassen und nach Lima oder in andere größere Städte kommen, werden sie mit einer grundlegend verschiedenen Lebensrealität konfrontiert. Ihr inkorporiertes Kulturkapital stellt in manchen Fällen die >Eintrittskarte` in den nationalen Kontext dar. Zum Beispiel, wenn für die Studenten aus dem Tiefland gesonderte Aufnahmeprüfungen an den Universitäten gestaltet werden, oder, wenn sie sich auf lokaler Ebene als erfolgreiche Big Men erweisen und dadurch in höhere Organisationsebenen aufsteigen. Doch einmal eingetreten, bestehen die >weit Gereisten « nur, wenn sie sich institutionalisiertes Kulturkapital aneignen. Zudem besitzt derjenige im nationalen Kontext die besten Chancen und das größte Prestige, der seine Bildung durch ein Diplom dokumentieren kann. Institutionalisiertes Kulturkapital steht außerhalb des lokalen Kontexts nicht so sehr in einem komplementären als vielmehr in einem exklusiven Verhältnis zum inkorporierten Kulturkapital. So offenbarte sich in der Umfrage unter den Studenten, dass der Eintritt in die nationale Gesellschaft und das Sich-Bewähren darin nahezu zwangsläufig als eine fortschreitende Distanzierung von der eigenen Gruppe wahrgenommen wird. Den Aussagen der Studenten war zu entnehmen, dass sie einen Kulturschock durchlaufen - ausgelöst u.a. durch andere klimatische Bedingungen, Essensumstellung, Sprache, Entfernung von der Familie etc. Zwei Reaktionsweisen darauf waren laut der eben erwähnten Umfrage unter den Studenten zu beobachten: Entweder entschieden sie sich für eine Übernahme der Werte des universitären Systems und distanzierten sich von ihren ursprünglichen Plänen, oder sie zogen sich aus dem Studium zurück. Dennoch blieben sie auch bei Umsetzung der zweiten Option oftmals in Lima. Hierfür sind mehrere Gründe ausschlaggebend: 
- die Angst, bei einer Rückkehr in die Heimatgemeinde als >Versager $\measuredangle$ zu gelten;

- Perspektivlosigkeit bezüglich ihrer Arbeitsmöglichkeiten in den Dörfern, da sie sich gegen eine dörfliche Lebensweise entschieden haben;

- das Misstrauen der Zurückgebliebenen, das Vega Díaz (2000) in einer Studie zur Wahrnehmung der indigenen Repräsentanten in AchuarGemeinden konstatiert; das in den Aussagen von Dorfbewohnern über die >städtischen` Repräsentanten zum Ausdruck kam.

\section{Beziehungsprobleme: das asymmetrische Verhältnis zwischen indigenen Repräsentanten und Entwicklungsexperten. Der janusköpfige Broker}

In einem Gespräch im Juli 2005 berichtete mir die peruanische Mitarbeiterin einer europäischen Entwicklungsorganisation in Iquitos mit genervtem Unterton von ihrer täglichen Arbeit: Sie müsse wohl bald darüber nachdenken, Sprechstunden einzurichten. Täglich bekäme sie Besuche von Delegationen verschiedener Föderationen oder auch einzelner comunidades, die um Hilfe in Form von Geld oder Sachleistungen bäten. Die Dorfbewohner sammelten Geld, um zwei oder drei Personen mit einem entsprechenden Auftrag in die Stadt zu schicken. Dann erzählte sie mir von einem Fall, den sie für symptomatisch hielt: Neulich erst hätte sie eine Bitte um Unterstützung für die Ausrichtung des Kongresses einer Föderation erhalten. Der Repräsentant habe in seinem Brief Essen für achtzig Teilnehmer erbeten. Ihr europäischer Chef, der besonders für sindigene Themen sensibilisiert und deshalb in derlei Fällen meist zu Hilfe bereit sei, habe schon eine entsprechende Anweisung ausgegeben, der Bitte nachzukommen. Doch dann habe sie zufällig im Gespräch mit dem Mitarbeiter einer anderen Organisation den Kongress erwähnt. Es habe sich herausgestellt, dass der Präsident der betreffenden Föderation mit der gleichen Anfrage auch erfolgreich an diese Institution herangetreten sei. Daraufhin habe sie noch mit anderen Einrichtungen vor Ort telefoniert, wobei sich herausstellte, dass insgesamt vier Institutionen den gleichen Brief erhalten hätten. In der Mehrzahl hätten sie sich für eine Unterstützungszusage entschieden, die sie aber nach dem Gespräch mit ihr reduzierten. Sie beendete ihre Ausführungen mit leisem Lächeln: Der Präsident dieser Föderation hatte sich wahrscheinlich schon darauf gefreut, die vielen Säcke Lebensmittel zum Hafen zu schaffen und den Überschuss zu verteilen.

Die Rolle der Institutionen der Entwicklungszuammenarbeit als Vermittlungsinstanzen zu erforschen, erwies sich als problematisches Unterfangen. So wurde mir zum Beispiel nur in einem Fall eine Projektevaluierung der Zusammenarbeit mit indigenen Organisationen zugänglich gemacht. Ansonsten 
verwies man mich immer mehr oder weniger direkt darauf, dass diese Dokumente zu den internen Unterlagen der jeweiligen Institution zählten und Wissenschaftlern nicht für unabhängige Forschungszwecke zur Verfügung gestellt werden könnten.

Smith verweist in einem rezenten Artikel auf die wenigen sozialwissenschaftlichen Studien über indigene Organisationen (Smith 2002a). Zum einen führt er dies, zumindest für die Ethnologie, auf die bisherige Vernachlässigung des gesamten Themenbereichs >indigene Bewegungen « zurück. Zum anderen verweist er aber auch auf die Verschlossenheit der Organisationen gegenüber Außenstehenden. Dieses Phänomen gilt natürlich nicht nur für indigene Verbände, sondern allgemein für den Bereich der Entwicklungszusammenarbeit. Auch Rottenburgs (2002) »Parabel der Entwicklungshilfe« weist auf diesen Umstand hin.

Erzählungen wie die der peruanischen Mitarbeiterin sowie Andeutungen anderer entwicklungspolitischer Fachkräfte gaben mir fragmentarische Einblicke in die Rolle der NGOs im Vermittlungsprozess. Einige nicht-indigene peruanische Mitarbeiter indigener Organisationen wiesen mich zum Beispiel immer wieder darauf hin, dass die Repräsentanten Gefahr liefen, zum Spielball der politischen Interessen der internationalen NGOs zu werden. Ständig würden sie in die Büros der Geldgeber zitiert, um neue Richtlinien durchzusprechen. Sie kämen nie dazu, eigene Kriterien für die Zusammenarbeit zu entwickeln (Gespräch López 01.07.2005). Eine ähnliche Kritik äußerte auch der ehemalige Koordinator des internationalen Zusammenschlusses der indigenen Organisationen des Amazonasbeckens COICA, Sebastião Haji Manchineri (Interview Manchineri 24.10.2003). Mitarbeiter kleinerer indigener Organisationen, die nicht an ein nationales Netzwerk angeschlossen waren, beklagten mir gegenüber wiederum häufig die Abgeschlossenheit des entwicklungspolitischen Feldes in Peru: Große, vor allem ausländische NGOs, hätten etablierte Kontakte mit einigen national agierenden indigenen Verbänden. Neue Organisationen fänden nur Aufnahme in diesem Netzwerk, wenn sie es schafften, Allianzen mit den etablierten Zusammenschlüssen zu formen. Letztere dagegen wollten sich als exklusive Vertretungsinstanz der Föderationen profilieren. Sie zeigten vor allem auch wenig Neigung, mit von Fachkräften ins Leben gerufenen indigenen Organisationen, deren Direktive nicht durch regelmäßige Wahlen bestätigt oder erneuert würde, zu kooperieren. Auch wenn diese sich selbst als indigene Organisationen verständen, wiesen ihnen die politischen Zusammenschlüsse mit ihren gewählten Vertretern den Status der >feindlichen`, >paternalistischen< NGOs zu. Dieses Misstrauen gegenüber NGOs dominiere auch unter den Unterstützern, die alleine durch gewählte Vertreter eine Basisanbindung und damit auch ihre Vorstellung von Demokratie gewährleistet sähen. Gleichzeitig hätte die starke Fluktuation der Repräsentanten für die Unterstützer den Vorteil, dass sie ihren eigenen Einfluss auf die Politik indigener Orga- 
nisationen stärker geltend machen könnten (Gespräch Morales 25.04.2004; Gespräch Ramírez 23.01.2004; Gespräch Sánchez 01.06.2005; Gespräch Casanto 30.07.2005).

Die Profile einzelner Institutionen der Entwicklungszusammenarbeit verweisen wiederum auf die große Bandbreite von Faktoren, die ihre spezifische Ausrichtung und Arbeitsweise bestimmen konnte. So wurde ich zum Beispiel bei meinen Gesprächen mit Vertretern in Peru ansässiger UN-Organisationen immer wieder darauf hingewiesen, dass eine Fokussierung auf >die Zielgruppe Indigene stark von den jeweiligen Verantwortlichen abhinge. In deren Arbeitsbereich würde meist eine Fülle von Themen fallen, nicht alle könnten bearbeitet werden. So träfen die entsprechenden Personen eigene Entscheidungen bezüglich der Schwerpunktsetzungen. Die Akzentsetzung anderer internationaler Institutionen wird hingegen stärker von außerhalb Perus angesiedelten Zentralen bestimmt. ${ }^{51}$ Die entwicklungspolitischen Netzwerke sind weitverzweigte, diffuse Gebilde. Um in ihnen die jeweiligen Entscheidungsträger bzw. machtpolitische Zentren auszumachen, bedürfte es einer eigenen detaillierten Studie. Fest steht jedoch, dass die Vertreter großer, finanzkräftiger Organisationen einen entscheidenden Einfluss auf die Durchsetzungskraft einzelner indigener Organisationen haben, da diese, wie bereits erwähnt, zu hundert Prozent von externer Finanzierung abhängig sind. Ávila (2000: 430) weist darauf hin, dass Organisationen wie CARE oder Oxfam Gelder nicht immer nach Kriterien verteilten, die einer unpersönlichen und bürokratischen Logik entsprächen. Sie agierten auch gemäß eigener Vertrauensbindungen und Freundschaften, die sich zwischen diesen Einrichtungen und den Empfängern entwickelten. So antwortete eine Oxfam-Mitarbeiterin auf meine Frage, warum ihre Organisation nur AIDESEP, nicht aber die Arbeit des anderen nationalen Amazonaszusammenschlusses CONAP unterstütze: CONAP gestalte ihre Arbeit nicht sehr transparent, und der Informationsfluss zwischen Basis und nationaler Instanz sei bei ihnen schwach ausgebildet. Aber natürlich, so fügte

51 So beteiligte sich zum Beispiel die peruanische Delegation der EU-Kommission 2005 auf Anweisung aus Brüssel zum ersten Mal an den Feierlichkeiten des 9. August. Dieser Tag wurde von der UNO zum Internationalen Tag der Indigenen ausgerufen. In Peru lud man Journalisten verschiedener Tageszeitungen ein, zu EU-finanzierten Projekten zu reisen. Eigentlich war auch die Aufforderung aus Brüssel gekommen, eine große Konferenz in den Gebäuden der Kommission in Lima zu organisieren. Man erklärte mir aber, das entsprechende Schreiben sei viel zu spät eingetroffen; somit sei es der Kommission nicht möglich gewesen, eine solche Veranstaltung rechtzeitig zu organisieren. Das Thema Indigene ist kein sogenanntes >transversales Thema der EU-Entwicklungspolitik, aber es taucht in verschiedenen Unterbereichen auf. Projekte mit der Zielgruppe Indigene sind vor allem innerhalb der Finanzierungslinie >Menschenrechte $<$ angesiedelt. 1998 beteiligte sich die EU in Peru zum ersten Mal an der Finanzierung eines territorialen Demarkierungsprojekts von AIDESEP (Gespräch García 03.08.2005). 
sie nach erneuter Nachfrage hinzu, habe dies auch mit den historisch gewachsenen Beziehungen zwischen Oxfam und AIDESEP zu tun. Der Ethnologe Richard Smith etablierte Mitte der 1980er Jahre das Oxfam-Büro in Peru. Er war lange Jahre einer der Hauptunterstützer AIDESEPs (Gespräch Mills 21.04.2004).

Auch die Gesellschaft für technische Zusammenarbeit (GTZ) unterstützte im Rahmen eines neuen Projektes während meiner Forschungszeit AIDESEP. Dies, so eine Mitarbeiterin, sei das erste Projekt, das die GTZ ausschließlich mit einer indigenen Organisation als Partner durchführe (Gespräch Werner 13.04.2004). Jedoch blieb auch bei diesem Projekt die CONAP außen vor.

Auf dem bereits erwähnten 25-jährigen Jubiläum von AIDESEP im Mai 2005 war die Liste der durch Auszeichnungen gewürdigten nicht-indigenen Unterstützer und Institutionen der Entwicklungszusammenarbeit umfangreich. Auch hier wurden die besonders engen Beziehungen zu einigen unter ihnen durch Mehrfachauszeichnungen und Betonung der engen, freundschaftlichen Beziehungen unterstrichen.

Das Verhältnis zwischen Vertretern indigener Organisationen und internationalen NGOs ist zwar asymmetrisch, jedoch keinesfalls von einseitiger Abhängigkeit geprägt. Die Reaktionen auf Unregelmäßigkeiten in der Verwaltung von Projektgeldern sowohl in AIDESEP als auch in der COICA in den 1990er Jahren fielen zum Beispiel verhältnismäßig milde aus. Zumindest resultierte daraus nicht der vollständige Rückzug der Kooperationspartner aus dem Bündnis mit den indigenen Organisationen. Stattdessen wurden zum Beispiel im Falle von AIDESEP die Dezentralisierung der Organisationsstrukturen sowie eine vorübergehende externe Verwaltung der Projektgelder als Lösungen vorgeschlagen und durchgeführt. Anders gelagert war hingegen der Umgang mit ähnlichen Vorgängen innerhalb des Consejo Indio de Sudaméri$c a$ (CISA) Mitte der 1980er Jahre. Hier hatte die persönliche Bereicherung einiger Mitglieder der Direktive fatale Auswirkungen auf die finanzielle Unterstützung. ${ }^{52}$ Der Rückzug eines großen Teils der Unterstützer bewirkte den fast vollständigen Zusammenbruch der Organisation.

In beiden Fällen lassen sich die unterschiedlichen Reaktionen der Geldgeber teilweise mit der Beteiligung von Ethnolgen und anderen Unterstützern bei der Genese AIDESEPs erklären, die zeitgleich mit der CISAs stattfand. Während CISA sich zwar selbst als repräsentative `Stimme der Indios` verstand, verfolgte die Organisation einen vom Indigenismus geprägten AntiKolonialismus Diskurs. Die Mitglieder der Direktive galten in den Augen der-

52 Auch im Falle des Korruptionsskandals in der regionalen Organisation ORAI fiel die Reaktion der Geldgeber härter aus als in den 1990er Jahren im Falle AIDESEPs und der COICA. Zum Zeitpunkt meiner Feldforschung verfügte die Organisation kaum über finanzielle Ressourcen und hatte große Mühe, Kooperationspartner zu finden. 
jenigen, welche die neuen Zusammenschlüsse unterstützten, als städtische Intellektuelle mit andinem Hintergrund. Sie waren in ihren Augen nicht durch eine ländliche Basis legitimiert und somit keine explizit politische Repräsentationsinstanz. Richard Smith unterstützte zum Beispiel maßgeblich den Aufbau von AIDESEP und COICA und führte auf diskursiver Ebene einen Kampf gegen CISA (vgl. Smith 1985, 1987). Wie erwähnt, baute er Mitte der 1980er Jahre ein Büro von Oxfam in Peru auf und konnte so durch die Zuweisung von Projektgeldern AIDESEPs Position stärken. $\mathrm{Zu}$ einer ähnlichen Überzeugung wie Smith gelangten auch internationale NGOs wie IWGIA, die in der Folge des Korruptionsskandals ihre Unterstützung für CISA einstellten und sich AIDESEP zuwandten.

Weitere heftige Diskussionen entbrannten im Zuge der Formierung des zweiten nationalen Amazonaszusammenschluss CONAP. Hier bildete sich eine Allianz von AIDESEP und einer Reihe von Unterstützern, die als gemeinsamen ideologischen Gegner die neue Organisation sowie nicht-indigene >Drahtzieher im Hintergrund (NGOs bzw. einzelne Personen) ausmachten (vgl. z.B. AIDESEP 1989 (21-22); Chirif 1995: 353ff.). Die finanzielle Unterstützung des einen oder anderen Zusammenschlusses wurde in der Folge als politisches Bekenntnis gewertet und führte damit zu jeweils exklusiven Unterstützerkreisen. Die >flexible Solidarität \er Föderationen mit dem einen oder anderen nationalen Bündnis weichte diese Grenzen jedoch mit der Zeit teilweise wieder auf. Die großen ideologischen Auseinandersetzungen im nationalen Kontext erweisen sich auf lokaler Ebene als Nebenschauplätze, die nur interessant werden, wenn sie sich auf die eigenen Interessen und Ziele der jeweiligen Akteure auswirken. Auch in diesem Umstand manifestiert sich die geringe politische Bedeutung, die nationale Vertreter auf lokaler Ebene besitzen.

Ich erinnere daran, dass es den Vertretern der ethnischen Föderationen des Tieflandes gelang, eine breite Front von internationalen Unterstützern zu mobilisieren (vgl. Kapitel IX.1 und IX.2). Diese, unter ihnen viele Ethnologen, gelangten in der Folge an Positionen, von denen aus sie entwicklungspolitische Gelder nach Peru kanalisieren konnten. Seit der Etablierung der ethnischen Föderationen in den 1970er Jahren sind keine neuen Organisationsformen entstanden, die für diese Unterstützer einen höheren Grad an Repräsentationskraft für die `Stimmen der Tieflandbewohner« erlangen könnten. Zudem prägten die frühen Jahre ihre emotionalen und politischen Bindungen. Wem könnten sie ihre Unterstützung zuwenden, würden sie sich von den ethnischen Föderationen abwenden? Einzelne wie Smith sind inzwischen auf Distanz zu AIDESEP gegangen, aber die Mehrzahl der Unterstützer steht weiterhin in mehr oder weniger engem Kontakt zu der einen oder der anderen Organisation. Das Thema sindigene Völker ist, auch durch die Arbeit dieser Personen, inzwischen zu einem festen Bestandteil internationaler Entwicklungspolitik 
geworden. Die Allianz ist so lange nicht gefährdet, bis sich Akteure etablieren, die ihre Legitimität überzeugender darstellen könnten als die bislang agierenden. Zudem müsste ein allgemeiner Paradigmenwechsel im Bereich der Entwicklungszusammenarbeit damit einhergehen, um die zurzeit postulierte Relevanz zivilgesellschaftlicher Akteure bei Demokratisierungs- oder Entwicklungsprozessen durch ein neues politisches Credo abzulösen. NGOs haben sich als eine wichtige Kraft außerhalb der institutionalisierten Politik etabliert. Über die tatsächliche Rückwirkung, die sie auf die politische Ausrichtung staatlicher und zwischenstaatlicher Einrichtungen haben, gibt es dennoch kaum aussagekräftige Angaben (vgl. Kapitel II.1). Auch wenn die Unterstützer die Herstellung symmetrischer Beziehungen als Zielsetzung anvisieren, bleibt die Bindung zwischen ihnen und den indigenen Repräsentanten eine asymmetrische. Man kann sie mit Wolf (1966) als »instrumentelle Freundschaft « mit starker emotionaler Bindung bezeichnen, bei der die indigenen Repräsentanten die Klienten der im entwicklungspolitischen Feld etablierten Spezialisten sind.

Die Vertreter indigener Organisationen und ihre Geldgeber sind eng miteinander verwoben. Beide haben sich wechselseitig beeinflusst und brauchen sich gegenseitig für ihr Fortbestehen. Jedoch gibt es einen markanten Unterschied: Der Repräsentant einer Organisation oder lokalen Gemeinde kann die Gabe der Geldgeber als persönliche Schenkung auffassen, die den Grundstein für den Aufbau längerfristiger Beziehungen zwischen ihm und dem Geber legen (vgl. Smith 2002b: 172). Er handelt damit gemäß des Reziprozitätsgesetzes >indianischer Prägung . Der Repräsentant muss nicht primär die institutionellen, sondern vor allem die persönlichen, emotionalen Bindungen mit den Unterstützern festigen, um seine eigene Position zu sichern. Zumindest so lange, bis er sich das entsprechende Wissen angeeignet hat, um selber zum Spezialisten zu werden. Damit tritt er in die Welt der Unterstützer ein und ist nicht mehr primär vom Aufbau instrumenteller Freundschaften abhängig, um sich gegenüber den Föderationen und lokalen Gemeinden - seiner ursprünglichen politischen Bezugseinheit - als großer Vermittler etablieren zu können. Die Unterstützer können ihre freundschaftlichen Bindungen zu einzelnen indigenen Vertretern hingegen auf professioneller Ebene problemloser aufgeben, so lange für das Fortbestehen der Institution >indigene Organisation< gesorgt ist. Davon allein hängt letztendlich ihr Überleben als >Spezialist für indigene Themen $a b$. Sie verstehen den Transfer von Waren oder Geld zwischen sich und den Organisationsrepräsentanten folglich als unpersönliche, institutionelle Beziehung - auch wenn ihre persönlichen, emotionalen Bindungen eine wichtige Rolle spielen und diese ihre >bürokratische Verteilungslogik ‘ auf recht unbürokratische Weise beeinflussen können. Durch den Akt der Schenkung erhalten sie ein (Mit)bestimmungsrecht bei der Entscheidung, wofür die Gabe verwendet wird. 
Das eingangs erwähnte Beispiel der >Schlitzohrigkeit` eines Repräsentanten zeigt jedoch, dass

- die Gabe dennoch beständig Gefahr läuft >zweckentfremdetく zu werden, und

- den Organisationen von Seiten der Dorfbewohner eine wichtige Funktion als Ressourcenkanalisierer zugesprochen wird.

Die >Beschaffungslogikı der Repräsentanten trifft sich dabei auf verquere Weise mit der Zielsetzung der Unterstützer, Partizipation und Eigenengagement unter der lokalen Bevölkerung zu fördern: Vor allem von Dorfbewohnern selbst einberufene supralokale Versammlungen sowie neue Organisationsgründungen finden auf Unterstützerseite großen Anklang und werden gerne finanziell oder materiell unterstützt. Bleibt das Verfahren der Dorfbewohner unentdeckt, läuft das ungleiche Tauschgeschäft zu beiderseitiger $\mathrm{Zu}$ friedenheit. Wird es aufgedeckt, wirkt sich dies jedoch vor allem auf die Karriere des Big Man aus, der zwar die Logik der Empfänger befolgt, dabei aber das Vertrauen der Geber enttäuscht hat. Er ist der janusköpfige Broker (Wolf 1956), der zwei unterschiedlichen (politischen) Legitimationsmodellen verpflichtet ist und so ständig Gefahr läuft, zum großen Verlierer zu werden, dem das Vertrauen von der einen oder anderen Seite entzogen wird.

\section{Schluss: Statuswechsel - vom >Indianer zum sIndianisten}

Der Blick auf die Mikroebene indianischer Organisationsprozesse verdeutlichte, dass es innerhalb der Bewegung eine Vielzahl von Meinungen dazu gibt, wer zur politischen Gemeinschaft der Indigenen gehört. Die kategoriale Wahrnehmung der Repräsentanten durch die Repräsentierten belegte, dass die supralokalen politischen Verbände der Tieflandindianer weit davon entfernt sind, eine kohärente und geschlossene politische Gemeinschaft darzustellen. Viele Dorfbewohner widersetzen sich der >Staatsrhetorik « ihrer >Vertreter und entziehen diesen das Delegationskapital, sobald sie ihre Interessen nicht mehr repräsentiert sehen. Gleichzeitig thematisierten meine Gesprächspartner aber auch interne soziale Differenzierungsprozesse, die im Zuge der Organisationsentwicklung in den letzten dreißig Jahren stattfanden. Statussymbole, die im nationalen Kontext einen sozialen Aufstieg ermöglichen (vor allem formale Titel), erfuhren und erfahren eine starke Wertschätzung. Bestehende Herrschaftsstrukturen im gesamtgesellschaftlichen Kontext werden so tendenziell eher reproduziert als unterwandert bzw. verändert. Die indigenen Organisationen verkörpern damit auch eine neue Überlebensstrategie: Es sind Vehikel, um mächtigere Interaktionspartner - Staat und zivilgesellschaftliche 
Entwicklungsorganisationen - zu zwingen, ein »negatives Reziprozitätsverhältnis « ${ }^{53}$ (Sahlins 1974) einzugehen. Die Selbstidentifikation als >indigen möglicht es, `Sonderbehandlungen

Der Blick auf die Ordnungsprinzipien im entwicklungspolitischen Feld zeigte aber auch, dass der indigene Repräsentant nur als Big Man eine reale politische Mittlerfunktion für die von ihm Vertretenen besitzt. Innerhalb der Organisationsstrukturen ist der Präsident einer Föderation auf lokaler Ebene für die Beschaffung von Projekten zuständig. Er findet für die Ausübung seiner Tätigkeit jedoch nur selten (finanzielle) Unterstützung von Seiten der Mitgliedsgemeinden und ist deshalb gleichfalls von der Förderung durch NGOs und staatliche Funktionäre abhängig. Schnell gerät er in Kritik, wenn er keine sichtbaren Erfolge vorweisen kann. Häufige Neuwahlen sind die Folge. Mit dem Sprung auf die regionale Ebene muss der Repräsentant sich Expertenwissen (Projektwissen sowie entwicklungspolitisches Fachvokabular) aneignen, um weiterhin in der Organisationswelt bestehen zu können. Dieses Wissen bleibt die einzige Ressource erster Ordnung, zu der ein Repräsentant Zugang gewinnen kann. Es bildet gleichzeitig das zentrale Kapital, um sich längerfristig im entwicklungspolitischen Feld zu etablieren. Mit dem Schritt in die regionale und nationale Organisation nimmt die Abhängigkeit des Repräsentanten von der politischen Gemeinschaft ab, parallel dazu aber auch seine Bedeutung als Vertreter lokaler Interessen. Die Dependenz des Repräsentanten von den Unterstützern wächst. Er bekommt gleichzeitig eine reale Chance, zum großen Vermittler zu werden. Eine Rückkehr ins heimatliche Dorf gestaltet sich jedoch in der Folge schwierig, die geografische Distanzierung geht meist einher mit einer sozialen Entfernung von der einstmaligen Bezugsgemeinschaft. Die Konseuqenz ist ein Prestige- und Vertrauensverlust. Die Akkumulation von entwicklungspolitischem Spezialistenwissen und/oder einer möglichst mit Zertifikat abgeschlossenen akademischen Ausbildung kann dem Repräsentanten zur Position eines >Indianismus-Experten< verhelfen. Zwar ist er auch dann immer noch Klient und >Rentenempfänger « internationaler Financiers, gleichzeitig wird er aber zum wichtigen Anlaufpunkt lokaler Bittsteller sowie weniger erfolgreicher Vermittler.

Für Bierschenk und Olivier de Sardan (2000: 20) agieren Broker an den Schnittstellen zwischen verschiedenen sozialen Formationen, ohne dass diese notwendigerweise in eine Hierarchie integriert sind. Für die lokalen Entwicklungsmakler trifft diese Einschätzung auch im Falle der Vertreter indigener Organisationen im peruanischen Amazonasgebiet zu. Im regionalen und na-

53 Mit dem Begriff der >negativen Reziprozität bezeichnet Sahlins Austauschbeziehungen, in denen über die Transaktion hinaus keine sozialen Beziehungen bestehen. Das Ziel dieser Tauschhandlungen besteht darin, sie für sich selbst zum größtmöglichen Vorteil zu gestalten oder, wie Petermann (2004: 977) es ausdrückt: »)etwas für nichts` zu bekommen«. 
tionalen Kontext ist jedoch eine klare Hierarchisierung der sozialen Formationen zu erkennen. Ein frappierender Widerspruch begrenzt die Karrierechancen des Repräsentanten: Einerseits muss er sich, um im nationalen Kontext als großer Vermittler bestehen zu können, möglichst zertifiziertes, institutionalisiertes (Fach)wissen aneignen. Andererseits läuft er damit aber Gefahr, auch für einen Teil der Unterstützer nicht mehr >repräsentativ genug $\$ zu sein, da ihm nicht nur von Seiten seiner politischen Gemeinschaft, sondern auch von diesen eine `Entkoppelung von der Basis` vorgeworfen wird. Die Vermittlerkarriere in einer indigenen Organisation wird so zum Risikogeschäft. Nicht umsonst bemerkt Ramos (2002: 232), dass die Kosten für diese Personen sehr hoch sind. Ihre ständigen Begleiter: Alkoholismus, Marginalisierung zu Hause und auch andernorts, generalisiertes Misstrauen, Angst, Morddrohungen sowie die immer über ihnen schwebenden Möglichkeiten manipuliert und kooptiert zu werden. Auch wenn der indianische Repräsentant als homo manipulator (Boissevain 1974) kein passiver Gefangener zwischen zwei Welten ist, so können ihn doch jederzeit die diffuse Machtsituation und damit einhergehend die verschiedenen, im Wettstreit miteinander stehenden Legitimationsmodelle zu Fall bringen: Hält er sich an die »Ethik der Brüderlichkeit« (Rottenburg 1995: 101) und folgt dem bei Tieflandindianern letztendlich dominanten Reziprozitätsverständnis, gilt er bei den Unterstützern als >korrupt . Diese unterstützen Akteure der `Zivilgesellschaft«, um abstrakte politische Ziele wie `Demokratisierungsprozesse oder die `Rechte indigener Völker durchzusetzen. Zeigt er sich hingegen den Seinen gegenüber nicht großzügig, wird er zum >Mestizen` erklärt und gilt als unsolidarisch. Dazwischen liegt ein schmaler Pfad, auf dem der neue indigene Politiker mit >Unternehmergeist « auf der Suche nach dem Aufbau klientelistischer Netzwerke wandelt, während er versucht, sich vom Indianer zum Indianisten zu entwickeln. 


\section{KapiteI XI}

\section{Big Man oder Funktionär - Probleme indigener Selbstorganisation in nationalstaatlichen}

\section{Zusammenhängen}

\section{Fortbestand und Wandel indianischer Gesellschaften im Amazonasgebiet}

Der Leser erinnert sich an die Leitmotive der indigenen Bewegung im Amazonasgebiet: politische Integration und kulturelle Abgrenzung. Ich verwies auf die »Tradition des Traditionsbruchs« (Münzel 1993), die Fortbestehen und Wandel indianischer Gesellschaften im südamerikanischen Tiefland bestimmt. Der geschichtliche Rückblick lässt den Schluss zu, dass die Tieflandindianer auch unter den schwierigen, wechselhaften Bedingungen der kolonialen sowie postkolonialen Kontaktsituation die Kraft zur kulturellen Erneuerung nicht verloren haben. Die Entwicklung indigener Organisationen ist ein zeitgenössischer lebendiger Ausdruck dieser Fähigkeit. Weit davon entfernt, bloße >Agenten der Assimilierungskräfte < zu sein, sind sie aber auch keine >Instanzen der Traditionspflege $<$. Zwischen Widerstand und Anpassung oszillierend, erweisen sich die Akteure der Zusammenschlüsse als Chamäleons: als >Modernisierer८, >Integrations- und Differenzierungskraft $\iota$, als >Überlebens- und Verwandlungskünstler〈, >Rebellen gegen staatlich verordnete politische Unsichtbarkeit und >Kontrahenten in der Arena politischer Kämpfe und klientelistischer Netzwerkbildung`sowie als >institutionalisierte Ressourcenbeschaffer . In den organisierten Gruppen sind aus »nativos invisibles« (Stock 1981) >indígenas peruanos geworden: ${ }^{1}$ Nicht nur ethnischer

1 Nativos invisibles - dt.: >unsichtbare Eingeborene<; indígenas peruanos - dt. >peruanische Indigene $<$. 
Stolz und Widerstand, sondern auch die Aneignung dominanter nationaler Wertemuster prägen dabei ihre Statuskämpfe. Mit der offiziellen Einbindung der indigenen Tieflandbewohner in die nationale Gemeinschaft in den 1970er Jahren zeichnete sich eine qualitative und quantitative Veränderung der interethnischen Beziehungen ab. Diese erhielten einen staatlich geprägten, legalen Charakter, wodurch sich den Mitgliedern lokaler Gemeinschaften neue Aktionsmöglichkeiten eröffneten, die asymmetrischen Beziehungen $\mathrm{zu}$ ihrem Vorteil umzugestalten. Nichtsdestotrotz führten die Veränderungen auch dazu, dass die Machtverhältnisse im lokalen Kontext diffuser wurden. Einerseits bleibt die Durchsetzung staatlicher Regierungsstrukturen bis heute unvollständig, andererseits sind neue politische Akteure hinzugekommen - Repräsentanten ethnischer Zusammenschlüsse und Vertreter nationaler sowie internationaler NGOs. Dabei hat sich eine Überlagerung verschiedener politischer Legitimationsmodelle ergeben: Während die nationalstaatliche Ordnungslogik zwar ab der zweiten Hälfte des 20. Jahrhunderts den größten Teil der indigenen Bewohner des Amazonasgebietes formal erfasste, konnten sich segmentäre Prinzipien im lokalen Kontext auf informeller Ebene weiter halten. Diese beeinflussen auch das gegenwärtige Autoritätsmodell in der indigenen Organisationswelt. Politische Legitimität erlangt ein Repräsentant nicht allein durch die Wahl in das Amt des dirigente, er muss sich sein Prestige nach dem Prinzip des Statusführers weiterhin mühevoll erwerben und läuft dabei beständig Gefahr, es ohne weiteres wieder zu verlieren. Eine grundlegende Voraussetzung für seinen Erfolg ist es, dass die Kommunikation und der Austausch zwischen ihm und seiner politischen Gemeinschaft nicht abreißen. Auf regionaler und nationaler Ebene besitzen die Repräsentanten deshalb selten direkte politische Relevanz für die von ihnen offiziell vertretenen indianischen Dörfer im Amazonasgebiet. Eine authentische Repräsentation sindigener Interessen wird im lokalen Kontext an der Aufrechterhaltung sozialer Nähe und dem Bekenntnis zu spezifischen moralischen Werten festgemacht die hervorstechendsten sind: Ausrichtung am Reziprozitätsprinzip und die Trennung zwischen politischer Leitfunktion und sozialen sowie ökonomischen Privilegien. In diesem Sinne bleibt das Statusführerprinzip als normativer Richtwert weiterhin relevant.

\section{Individuelle versus kollektive Selbstbestimmung}

Es zeigte sich, dass indigene Organisationen auf keiner Ebene einen dauerhaften Status als privilegierte politische Institution erwerben können und damit in der Lage wären, anderen Instanzen ihre Logik und die ausschließliche Anerkennung ihrer Legitimität aufzuzwingen. Die wesentlichen politischen Probleme in den Dörfern werden kontextabhängig durch unterschiedliche Akteure bzw. Akteursgruppen gelöst. Die Repräsentanten indigener Organisationen 
sind nicht unbedingt die bevorzugten Ansprechpartner in diesen Prozessen. Ich erinnere in diesem Zusammenhang an den Kommentar Guillermo Ortegas, des Gemeindepräsidenten der comunidad nativa der Huitoto: »Jeder kämpft für sich allein.« Wenn sie in seinem Dorf beschlossen haben, sowohl kommunale als auch individuelle Projekte durchzuführen, verweist das auf die Bedeutung, die individueller Autonomie beigemessen wird. Diese Vorstellung von Selbstbestimmung orientiert sich nicht am Projekt der Schaffung einer nationalen politischen Gemeinschaft Indigener, sondern verläuft konträr zu selbiger. Nicht aufgezwungener Korporatismus, sondern selbst geknüpfte, quer zu Gruppengrenzen verlaufende Netzwerke kennzeichnen die politische Realität im peruanischen Tiefland. Aus den Erzählungen Guillermo Ortegas bei meinem Besuch in der Huitoto-Gemeinde nahe Iquitos wurde deutlich, dass er auch als presidente comunal allein kraft seines Amtes niemanden zwingen kann, bestimmte Dinge zu tun und andere zu unterlassen. Noch weniger gelingt dies den Vorständen der Föderationen, der regionalen oder nationalen Verbände. Die Autonomie der einzelnen Instanzen trägt im gesamtgesellschaftlichen Kontext entscheidend zur politischen Schwächung der indigenen Bewegung bei. Es gibt keine von Seiten der lokalen Bevölkerung klar anerkannte Über- und Unterordnung der Organisationsebenen, Entscheidungskompetenzen sind nicht formal geregelt und umfassend politisch legitimiert. Daraus ergibt sich die hochgradige Komplexität und Fluidität der politischen Landschaft innerhalb der indigenen Organisationswelt. $\mathrm{Zu}$ dieser Situation trägt paradoxerweise auch die relative Abwesenheit des Staates auf lokaler Ebene, vor allem im Dienstleistungssektor, bei. Aufgaben, wie die Bereitstellung grundlegender Infrastruktur, werden häufig von NGOs übernommen. Die Vertreter dieser Einrichtungen werden zu weiteren Konkurrenten der Repräsentanten ethnischer Föderationen, die sich dem Entwicklungsdiskurs angepasst haben und sich in der selbstdefinierten und zugeschriebenen Rolle als >inoffizielle Regierung der Tieflandindianer« nun ihrerseits als Dienstleister definieren. Die politischen Vertretungsinstanzen werden dadurch - wie im Falle des im Prolog vorgestellten Zusammenschlusses der CocamaCocamilla $-\mathrm{zu}>$ Rentierorganisationen .

Die indigene Bewegung ist somit Teil des entwicklungspolitischen Feldes, in dem die Ordnungsprinzipien und Machtstrukturen weitaus diffuser sind als im ’klassischen tionen bei akuten Problemen auch explizit politische Bedeutung als legitime, übergeordnete Kollektivierungsinstanz erlangen - zum Beispiel bei Konflikten mit Erdölkonzernen, Holzfirmen oder auch illegalen Holzfällergruppen. Diese politische Funktion bleibt aber immer nur temporär erhalten. Danach zerfällt die größere Gemeinschaft wieder in Fraktionen und Einzelinteressen. 


\section{Strategischer Essentialismus}

Bei der Betrachtung der Makro- und Mikroebene indigener Organisationsprozesse zeigte sich jedoch, dass die Zusammenschlüsse eine Projektionsfläche für politisch wirksame Idealisierungen bieten. Um die negative Stereotypisierung der Tieflandindianer als >Primitive $<$, >chunchos $<$ oder >Unzivilisierte $<$ zu überwinden, griffen die neuen Repräsentanten sowie ihre Unterstützer zu einem Mechanismus, den Laufer (2000) als »reaktiven Rassismus« bezeichnet: Sie benutzten positive Stereotype des >edlen Wilden`, >natürlichen Umweltschützers`, >solidarischen Gemeinschaftsvertreters` und entspannen dabei einen erfolgreichen Diskurs um die Begriffe `Territorium‘, >Volk«, >Selbstbestimmung〈. Dieses Vorgehen bezeichnete ich bereits als »strategischen Essentialismus" (Spivak 1988; vgl. Warren und Jackson 2003; Greene 2004). Am Beispiel der comunidad nativa Huitoto in der Nähe von Iquitos zeigte sich, dass die (Rück)besinnung auf indigene Identität legale Räume für lokale Ermächtigungsstrategien eröffnet: Im Gegensatz zu ihren >bäuerlichen` Nachbarn konnten die Einwohner der sindigenen< Dorfhälfte kollektive Landforderungen geltend machen und sich dadurch vor der Verarmung schützen. Die Zusammenführung der Begriffe `Kultur` und `Rechte`zeigte in ihrem Fall eine große Wirkkraft. Die Selbstdefinition als >indigenes Volkı gab ihnen die entscheidende Handlungsressource und ließ sie zu sichtbaren politischen Akteuren avancieren.

Allerdings bleiben Essentialisierungen, auch strategische, Festschreibungen. Einst flexibel gehaltene Größen wandelten sich unter dem Zugriff staatlicher Bürokratie und der internationalen indigenen Bewegung und ihrer Unterstützer in starre Kategorien. Der Kulturdiskurs zeigte diesbezüglich negative Auswirkungen. Die indigene Identität von Tieflandbewohnern wurde und wird oftmals an ihrer >Intaktheit` und >Abgeschlossenheit festgemacht. So erwähnten UN-Angestellte in Peru, wenn sie mit mir über ihre Arbeit zum >Thema Indigene` sprachen, meist die diesbezüglich im UN-Kontext gültige Definition >indigener Völker und wendeten sie ausschließlich auf die Tieflandindianer an. Eine >ursprüngliche Beziehung`zur Umwelt und ein möglichst geringer Vermischungsgrad mit der nationalen Gesellschaft sind letztendlich die ausschlaggebenden Kriterien zur Berurteilung von >Indigenitätく. Die Probleme, die aus dieser Festschreibung für indigene Aktivisten resultieren, liegen auf der Hand. Ich sprach sie bereits ausführlich in den Ausführungen zum Ständigen Forum für indigene Angelegenheiten an (vgl. Kapitel III.4).

Von Unterstützerseite wurde derweil im peruanischen Kontext angenommen, dass die >kulturellen Bindungen` indianischer Vertreter unabhängig von bestehenden politischen Strukturen Wirkkraft zeigen und die Umgestaltung der peruanischen Gesellschaft ermöglichen würden. Mit fortschreitender Insti- 
tutionalisierung der ethnischen Zusammenschlüsse schlichen sich jedoch Zweifel bei ihnen ein, ob die gemeinsame kulturelle Identität von Repräsentanten und Repräsentierten zwangsläufig das Teilen identischer Interessen implizierte. Infolge der ersten Korruptionsfälle analysierte man deshalb die Rolle und das Verhalten der Vertreter. Jedoch wurde nicht die komplexe Verknüpfung und Überlagerung unterschiedlicher politischer Legitimationsmodelle, zwischen denen die indigenen Repräsentanten kontextabhängig changieren mussten, sondern >kulturelle Entfremdung a als eine zentrale Ursache für ihre postulierte Korrumpierbarkeit ausgemacht. Die Dichotomisierung von >Moderne $<$ und >Tradition` wurde in dieser Argumentationslinie aufrechterhalten: Traten die Repräsentanten in die $>$ Welt der mestizos und criollos ein, verloren sie vor allem die kulturelle Rückbindung an ihre Gemeinschaft. Die Fähigkeiten, die sie besonders für die Vermittlungstätigkeit prädestiniert hatten (Zweisprachigkeit, Schulbildung, Erfahrungen außerhalb der Gemeinde oder in evangelikalen Kirchen), erwiesen sich als gefährliche Errungenschaften. In dieser Wahrnehmung indigener Interessenvertreter zeigen sich deutlich die widersprüchlichen Konsequenzen der Zuweisung von >Rechten` auf Grund >kultureller Identität‘. Den Repräsentanten wurde ihre hybride Identität zum Verhängnis. Sie scheiterten an den impliziten Forderungen einer nicht erfüllbaren kulturellen Authentizität und entpuppten sich als fragile Glieder in einer internationalen Mittlerkette. Ihre besonderen Talente und Fähigkeiten, die sie zur Tätigkeit als Broker ermächtigten, erwiesen sich als »mixed blessings« (Taylor 1996: 434).

\section{Die Gabe als Sinnbild von Politik in komplexen Gesellschaften}

Mit der Etablierung der Kategorie sindigenes Volk» im entwicklungspolitischen Feld entstand einerseits eine politisch relevante Gruppe von Akteuren, die sich gegen die Subsumierung unter bestehende Kategorien (z.B. als Bauern) erfolgreich zur Wehr setzten. Gleichfalls kurbelten diese Entwicklungen neue soziale Differenzierungsprozesse und die Herausbildung einer indigenen Elite auf nationaler und internationaler Ebene an. Die feldspezifischen Regeln zu erlernen, erfordert von den sozial und politisch aufstrebenden Repräsentanten einen hohen persönlichen Einsatz. Das belegten auch die Aussagen der Lokalpolitiker am Ständigen Forum für indigene Angelegenheiten. Mit Eintritt in die professionalisierte Repräsentationswelt entfernen sich die dirigentes zwangsläufig von ihrer Basis. Innerhalb der modernen Organisationswelt der internationalen Entwicklungszusammenarbeit, in die sich die indigenenen Bewegungen eingereiht haben, verdrängt die bürokratische Logik das Prinzip der »Ethik der Brüderlichkeit« (Rottenburg 1995), der Erfüllung der Reziprozitätsverpflichtungen - zumindest sobald das Festhalten an diesen sozialen Normen ans Licht der Öffentlickeit gezerrt wird. Erschwerend kom- 
men im peruanischen Kontext die klassischen Kennzeichen der sogenannten komplexen Gesellschaft hinzu: Eine nicht-funktionierende staatliche Bürokratie wird ergänzt durch ein informelles Patronage-System, um bestehende Machtverhältnisse aufrechterhalten zu können. >Politikı zeigt sich in Peru vor allem in Form von Geschenken. Der politische Erfolg der Repräsentanten ist auch aus diesem Grund eng mit Projektbeschaffung verbunden: Sie nehmen eine Rolle ein, die bereits vor ihrem Eintritt ins entwicklungspolitische Feld die >politische Kultur` und den Kontakt zwischen Tieflandindianern und Mitgliedern der nationalen Gemeinschaft in Peru prägte. Die hohe Wertschätzung redistributiver Großzügigkeit und Hilfsbereitschaft unter den Tieflandindianern spielt dem vertikalen Geben und Nehmen des vom Klientelismus geprägten nationalen Kontexts dabei letztendlich in die Hände. Nicht der Akt der Korruption an sich wird von Seiten der Dorfbewohner verurteilt, sondern eine mangelnde Bereitschaft zum Teilen (vgl. Streck 1995). Jedoch sind damit der Bereicherung Einzelner im dörflichen Kontext wiederum Grenzen gesetzt. Hier setzt sich das egalitäre Prinzip akephaler Gesellschaften erneut durch: Individuen, die zu viel Macht und Geld anhäufen, stellen eine potentielle Gefahr für das Fortbestehen des Ausgleichsprinzips dar. Häufige Neuwahlen auf Ebene der Föderationen sind deshalb die Regel in der indigenen Organisationswelt. Die normative Bindung an das Statusführerprinzip und die damit verbundene Kurzlebigkeit politischer Führungspersönlichkeiten erzeugt somit positive und negative Auswirkungen: Einerseits schränkt es die politische Wirkkraft der indigenen Bewegung stark ein, andererseits zeigt sich hierin auch eine Facette lokalen Widerstandspotentials und das >politische Bewusstsein « der Organisierten, die sich nicht so ohne weiteres für persönliche Zwecke ihrer >Vertreter missbrauchen lassen. Außerhalb des lokalen Kontexts haben Dorfbewohner jedoch nur wenige Sanktionsmöglichkeiten in der Hand, um einen Repräsentanten zu bestrafen, der sich der eigenen Gruppe gegenüber nicht verpflichtet fühlt. So lange noch ein Funken Hoffnung besteht, dass etwas »neben die Tasche« des Repräsentanten fällt (vgl. Streck 1995: 5), empfangen sie den Betreffenden trotzdem als einen distanzierten >Verwandten<, der Neuigkeiten und vielleicht Projekte` bringt.

Weil ihre politische Macht auf Grund der komplexen Beziehungsgeflechte extrem eingeschränkt ist, beschwören Repräsentanten hingegen in ihren öffentlichen Reden immer die solidarische Gemeinschaft gegenüber den $>$ Feinden $<$ - NGOs, Mestizen, Kirche oder Staat. Die Liste der Gegner indigener Zusammenschlüsse wuchs im Laufe der Organisationsgeschichte parallel zum Anstieg des Interesses der Finanzinstitutionen an sindigenen Themen< (vgl. Greene 2004: 431). Die fortlaufende Identifizierung der Feinde am Rande dient der Beschwörung des Kollektivsinns und soll das Vertrauen der Repräsentierten in die dirigentes stärken, ihnen Autorität sichern. Die Legitima- 
tionskrise im Zentrum wird zwar auf die Peripherie projiziert, dadurch aber nicht gelöst.

\section{Zusammenfassung}

Die indigenen Organisationen im peruanischen Amazonasgebiet konnten sich bisher nicht als einzige legitime politische Vertretungsinstanz der Tieflandindianer etablieren. Als entscheidende Gründe dafür erwiesen sich ihre anhaltende ökonomische Abhängigkeit von externen Ressourcen sowie eine diffuse Machtsituation. Die Akteure der Zusammenschlüsse konkurrieren beim Kampf um die Durchsetzung ihrer sozialen und politischen Teilungsprinzipien mit einer Vielzahl weiterer Interessengruppen, die oftmals über eine größere Menge an handlungsrelevantem Kapital verfügen. Das >Prinzip Indigenität ist sowohl Produkt der asymmetrischen Beziehungen zwischen staatlichen Instanzen, lokalen Gemeinschaften und NGOs, als auch zentraler Motor für den Wandel selbiger. Es steht mithin für die widersprüchlichen Konsequenzen, die politische Kämpfe unter dem Banner von `Kultur` hervorrufen.

Die Repräsentanten indigener Organisationen präsentierten sich in diesem Teil der Arbeit als ambitionierte Akteure im entwicklungspolitischen Feld, in dem um den Aufbau von politischer Macht und klientelistischen Netzwerken konkurriert wird. Sie verkörperten eine zeitgenössische Form des Big Man und janusköpfigen Brokers, der als lokaler Entwicklungsmakler erst mit zunehmender Professionalisierung den Verpflichtungen gegenüber der eigenen Gruppe entkommen konnte und dadurch die Chance erhielt, im nationalen und internationalen Kontext zum großen Vermittler zu werden. Damit einhergehend vollzog sich sein Wandel vom Statusführer zum Funktionär, der den Abkoppelungsprozess des professionellen >Indianisten $\prec-$ der Repräsentationsfachkraft - vom >Indianer`, dem Lokalpolitiker, markiert. Die bereits am Ständigen Forum für indigene Angelegenheiten beobachteten Differenzierungs- und Abgrenzungsprozesse erlangten somit auch im peruanischen Kontext hervorgehobene Bedeutung. 



\section{Schlussbetrachtungen: Politisches Engagement durch wissenschaftliche Objektivierung? Praxisrelevanz einer >Ethnologie indigener Bewegungen,}

»Die Erklärung [der Rechte indigener Völker] ist eine Erklärung, kein Gesetz. Jeder kann eine Erklärung abgeben. Es ist eine moralische Verpflichtung, aber keine zwingende. [...] Noch ist es notwendig, diese Art von Sicherheit, von Institutionalisierung durch Regierungen bzw. Gesetzgebungen zu bekommen. Aber für mich hängt davon nicht unsere Existenz ab, wir können auch unabhängig davon leben« (Interview Manchineri 24.10.2003).

13. September 2007: Die UN-Generalversammlung verabschiedet mit 143 JaStimmen, vier Gegenstimmen und elf Enthaltungen die Erklärung der Rechte indigener Völker. Vierzehn Jahre sind vergangen, seitdem die Arbeitsgruppe indigene Völker 1993 die vorläufige Erklärung zur Diskussion und Abstimmung an die nächst höhere Ebene weiterreichte. Zuvor hatte sie bereits ihrerseits fünf Jahre lang an der Erstellung der ersten Version des Dokuments gearbeitet (vgl. Kapitel III.3). Die in den Prozess involvierten Akteure der internationalen indigenen Bewegung sowie ihre Unterstützer feiern diesen Moment gebührend als einen >historischen`. Die Annahme der Erklärung symbolisiert einen Erfolg für die Verfechter multikultureller Staatsmodelle, die dem liberalen Modell der individuumsbezogenen Gleichrechtlichkeit den Ruf nach gruppenbezogenen Sonderrechten entgegensetzen. Die langjährigen Auseinandersetzungen zwischen Regierungsvertretern und indigenen Aktivisten über die Wortwahl des Textes verdeutlicht dabei, dass Diskussionen über die ideale Form des politischen Gemeinwesens auf allen politischen Ebenen kontrovers und leidenschaftlich geführt werden. Die Erklärung der Rechte indigener Völker kann in diesem Zusammenhang als ein Produkt des internationalen politischen Feldes, als materialisierte Bestätigung der langjährigen Arbeit vie- 
ler indigener Aktivisten gesehen werden. Diese haben den Kampf um das Schriftstück zu einem zentralen Inhalt ihrer Tätigkeiten gemacht. Eine offene Frage bleibt dabei jedoch zu diesem Zeitpunkt, in welcher Form die `Konsumenten des Produkts nun mit diesem umgehen werden: Welche Auswirkungen wird das Dokument auf politische Praktiken zeigen? Wer wird es sich aneignen und in welcher Form?

Die vorliegende Studie hat, mit ihrem Blick auf die komplexen historischen, wirtschaftlichen, kulturellen und sozialen Zusammenhänge, in denen sich die Entwicklung indigener Bewegungen vollzieht, zur Skepsis bezüglich einfacher Schlussfolgerungen über die >revolutionäre Kraft» des politischen Projekts indigener Bewegungen gemahnt. Gleichzeitig wurde deutlich, dass man schwerlich von nur einem Projekt, sondern besser von einer Vielzahl selbiger sprechen kann. Schon der Prolog, in dem ich die Probleme Manuel Ijumas und seines Zusammenschlusses von Cocama-Cocamilla Gemeinden im peruanischen Tiefland vorstellte, zeichnete ein sehr ambivalentes Bild der indigenen Organisationsprozesse.

Auch wenn ich die in dieser Studie praktizierte $>$ Ethnologie indigener Bewegungen jenseits politischer Programmatik verankert habe (vgl. Kapitel II.4), möchte ich in diesem Schlusskapitel - im Anschluss an Überlegungen zu den Rahmenbedingungen politischen Handelns, welche die empirischen Ergebnisse dieser Studie (vgl. Kapitel VI und XI) auf theoretischer Ebene weiterverarbeiten - versuchen, einige praxisbezogene Anmerkungen zur Unterstützung indigener Organisationsprozesse durch Institutionen der Entwicklungszusammenarbeit zu machen. Obwohl ich mich dabei für den peruanischen Kontext zu Illustrationszwecken auf ein konkretes Projekt der Gesellschaft für technische Zusammenarbeit (GTZ) beziehe, sind meine Überlegungen allgemeiner Natur und stellen keine Bewertung der Arbeit der gerade genannten Institution dar. Des Weiteren möchte ich meine Ausführungen nicht als Handlungsanweisungen verstanden wissen, sondern als generelle Überlegungen, welche die Erkenntnisse dieser Studie zusammenfassen und auf die Entwicklungszusammenarbeit mit indigenen Organisationen beziehen. 


\section{Das Problem der Entfremdung: Kongruenz und Inkongruenz zwischen politischem Handeln und politischem Verhalten ${ }^{1}$}

Der Ethnologe Frank Heidemann (2003: 160) nennt »jegliches Handeln, das die Herstellung, Veränderung oder bewusste Wahrung von allgemeinen Verbindlichkeiten, Normen, Regeln und Gesetzen beabsichtigt oder bewirkt« politisch. Eine wichtige Komponente ist in dieser Konzeption von Politik nur implizit enthalten: Es geht bei den genannten Handlungen immer um Regeln, welche die Organisationsform und oft auch Definition eines Kollektivs betreffen. In diesem Zusammenhang spielen Vorstellungen über die richtige Ordnung des Gemeinwesens eine zentrale Rolle. Wie komplex Auseinandersetzungen über bestehende und anzustrebende politische Organisationsformen sein können, war Thema dieser Studie. Sie hat auch gezeigt, dass parallel zur Diskussion der Frage, wie die richtige Ordnung eines Gemeinwesens auszusehen hat, oftmals genauso heftig darüber gestritten wird, wer überhaupt zu welchem politischen Kollektiv dazugehört und warum. Der Kampf um Mitglieder, genauso wie die Einteilung in sinnen auch als zentrale Elemente der Auseinandersetzungen um die und innerhalb der indigenen Bewegungen. Diese wichtigen Dimensionen der Repräsentationsfrage, vor allem in ihren Auswirkungen auf die politische Praxis der Akteure, bleiben in wissenschaftlichen Arbeiten über indigene Bewegungen oftmals unterbelichtet. Dabei hilft die Auseinandersetzung mit dieser Thematik, differente Vorstellungen von einer gerechten Ordnung des politischen Gemeinwesens zu verstehen und damit abstrakte theoretische Diskussionen um die politische Bedeutung indigener Zusammenschlüsse von ihrem normativen Impetus zu lösen (vgl. Kapitel II).

\section{Politisches Handeln und politisches Verhalten}

Politisches Handeln ist immer geknüpft an Vorstellungen über die richtige und gerechte Ordnung des Gemeinwesens (vgl. Rosa 2001: 26). Diese Ideen dienen den Mitgliedern einer politischen Gemeinschaft dazu, sowohl den Diskurs als auch die Praxis ihrer Repräsentanten zu bewerten. Eine überzeugende politische Ideologie - verstanden als ein System von ethischen Prinzipien und Postulaten, welche die Ausübung von Macht und Autorität legitimieren - bildet die Voraussetzung, um Anhängerschaft zu mobilisieren und den längerfristigen Zusammenhalt einer politischen Gemeinschaft zu gewährleisten. Der

1 Ich übernehme die Definitionen dieser beiden analytischen Kategorien von Hartmut Rosa, der sie, aufbauend auf dem Konzept des smenschlichen Handelns` von Charles Taylor (1985), in seinem Aufsatz »Politisches Handeln und die Entstehung des Neuen in der Politik« (2001) entwickelt. 
Ethnologe Donald Kurtz (2001: 33, 35) verweist auf den Umstand, dass politische Ideologien je nach Art des Gemeinwesens stark variieren können: Während zum Beispiel in modernen Staaten meist soziale Gerechtigkeit ein fundamentales Prinzip ist, wird in Gemeinschaften, in denen Führungspersönlichkeiten keine starke Macht in Form von Zwangsgewalt erlangen können, eher Großzügigkeit als verbindliche Norm geschätzt. Unabhängig von diesen entscheidenden Differenzen in den Vorstellungen über >richtiges` politisches Handeln und die >gerechte< Ordnung des Gemeinwesens gibt es jedoch eine universelle Konstante: Wenn die Aktionen eines politischen Führers den moralischen, aber auch materiellen Erwartungen seiner Anhänger entgegenstehen, versuchen diese, ihm die Repräsentations- und Entscheidungsmacht zu entziehen. Dies geht meist leichter, wenn die Gemeinschaft kleiner und Führerschaft informell geregelt ist und erweist sich oftmals als ein komplexer, widersprüchlicher Prozess in gesellschaftlichen Zusammenhängen mit zentralisierten Regierungsstrukturen. Fest steht jedoch in beiden Fällen: Politiker müssen ihre Entscheidungen stark an der Rationalität ihrer jeweiligen Bezugsgemeinschaft ausrichten, um sich in ihrer Position halten zu können. ${ }^{2}$

Eine wichtige Dimension bei der Analyse politischer Prozesse ist dabei auch die Unterscheidung zwischen politischem Handeln und politischem Verhalten. Letzteres kann durch die heterogensten Formen nicht-politischer Wertungen bestimmt sein und richtet sich auf die Durchsetzung entsprechender Interessen (vgl. Rosa 2001: 27). Hilfreich zum Verständnis dieser Differenzierung zwischen politischem Handeln und politischem Verhalten ist Frederik Baileys (2002 [1969]: 91ff.) Darstellung von Politik als einem spielerischen Wettstreit, der von einem Satz von Regeln bestimmt wird. Dabei unterscheidet er zwischen normativen und pragmatischen Regeln. Erstere sind das >öffentliche Gesicht` der Politik und verkörpern die ethischen und moralischen Grundwerte der Gemeinschaft. Letztere werden angewendet, um ein angestrebtes Ziel zu erreichen - die Durchsetzung der eigenen Interessen, die von der Gewährung gewisser Privilegien bis hin zur Erlangung der politischen Macht reichen können. Beide Regelsätze - normative und pragmatische - stehen sich jedoch in der Realität nicht gegenüber, sondern beeinflussen sich gegenseitig. Gleiches gilt für das Verhältnis zwischen politischem Handeln und politischem Verhalten. Beide zusammen definieren die politische Praxis. Diese wird zudem meist bestimmt durch Mischformen sozialen Handelns und Verhaltens, die auch von anderen Feldern als dem politischen (z.B. dem wirtschaftlichen oder religiösen) beeinflusst werden können. Aus dem komplexen

2 Auch in politischen Gemeinschaften, die unter Anwendung physischer und psychischer Gewalt >zusammengehalten « werden, brauchen der oder die politischen Führer eine Mindestzahl an Verbündeten, denen es lohnend erscheinen muss, die bestehenden Verhältnisse aufrechtzuerhalten. 
Zusammenspiel aller genannter Faktoren ergeben sich immer nicht vorhersehbare Konsequenzen für Form und Gestaltung des Gemeinwesens.

\section{Demokratische und egalitäre politische Gemeinwesen}

In Demokratien avanciert das Prinzip, das Handeln der politischen Eliten möglichst eng an die Vorstellungen der Wähler über die erstrebenswerte Form ihres Gemeinwesens zu binden, zur Kernidee politischer Überzeugungen. Dadurch soll gewährleistet bleiben, dass die Repräsentanten nur dann Erfolg haben, wenn sie die Vorstellungen der von ihnen Vertretenen umsetzen. Da dennoch auch die Bürger demokratischer Staaten von ihren Politikern weiterhin die Vertretung von Partikularinteressen erwarten, die sich meistens in einem gewissen Spannungsverhältnis zur normativen Vorstellung über das richtige Gemeinwesen befinden, werden starke Institutionen geschaffen, die über die Einhaltung der Prinzipien wachen (vgl. Rosa 2001: 28). Somit ist ein fundamentales Element des demokratischen Staatsmodells die Einrichtung wirksamer Kontrollmechanismen, die für den Zusammenhalt der Gemeinschaft als Kollektiv sorgen, indem sie den Partikularinteressen ihrer Einzelmitglieder entgegensteuern.

Kontrolle politischer Führungspersönlichkeiten ist auch in segmentären Gesellschaften ein zentrales Anliegen der Mitglieder eines Gemeinwesens. Hier jedoch gibt es meist keine, unserem staatlich geprägten Verständnis von Politik entsprechenden, sichtbaren Institutionen, welche als Korrektiv fungieren. Kontrolle wird hingegen durch andere soziale Instanzen ausgeübt, zum Beispiel entlang der Linien von Verwandtschaft, Altersklassen, Geheimbünden etc. und in Form sogenannter parapolitischer Mittel wie Hexereianschuldigung, Klatsch, öffentlichem Spott und anderen Formen sozialer Ächtung. Das Verhältnis zwischen Führung und Gefolgschaft ist somit stärker >personalisiert « als in modernen Demokratien >westlicher` Prägung und funktioniert nicht an Hand formal-bürokratischer, unpersönlicher Gesetzgebungen und durch die Institutionalisierung von Ämtern.

Inzwischen sind jedoch auch alle segmentär organisierten Gruppen weltweit von staatlichen Gebilden erfasst worden und werden mehr oder weniger stark von deren Ordnungsprinzipien geprägt. Demokratien gelten dabei in internationalen Zusammenhängen gegenwärtig als privilegiertes Modell politischer Organisation. Ein wichtiges Ziel >westlich`geprägter Entwicklungszusammenarbeit ist deshalb die Förderung entsprechender Strukturveränderungen in den jeweiligen Zielländern der Hilfsleistungen. In Bezug auf Lateinamerika gelten in diesem Zusammenhang vielen in der Praxis tätigen Entwicklungsexperten, aber auch Wissenschaftlern, die neuen indigenen Bewegungen als wichtige soziale Kräfte für die angestrebte Stärkung demokratischer Grundwerte (vgl. Kapitel II.3). Denn, die bestehenden politischen Sys- 
teme der meisten mittel- und südamerikanischen Länder werden in ihrem gegenwärtigen Zustand als >unvollständigeく Demokratien verstanden (vgl. Alvarez et al. 1998). Auch die geschichtliche Betrachtung Perus bewies, dass bislang immer nur ein zahlenmäßig geringer Prozentsatz dieses kulturell äuBerst heterogenen Nationalstaats seine Partikularinteressen und seine Vorstellungen eines gerechten Gemeinwesens durchsetzen konnte - zwangsläufig auf Kosten anderer Gruppen. Die indianischen Gesellschaften im Tiefland wurden dabei zum Beispiel bis in die 1970er Jahre vollständig aus der nationalen politischen Gemeinschaft ausgeschlossen. Starke Institutionen, die als wirksame und demokratische Kontrollmechanismen agieren und diesen Ausschluss hätten reklamieren bzw. dessen Missbrauch durch andere Interessengruppen verhindern können, fehlten bis zu jenem Zeitpunkt. ${ }^{3}$ Möglich war dieses politische Verhalten von Seiten der Machthabenden, weil sie ihr politisches Handeln so interpretierten, dass die bestehenden Verhältnisse zumindest ihnen gerecht erschienen und sie gleichzeitig anderen Vorstellungen die Möglichkeiten entzogen, sich durchzusetzen.

Doch dieses politische Selbstverständnis der Machthabenden wandelte sich - zumindest teilweise - in der zweiten Hälfte des 20. Jahrhunderts. Innerhalb des peruanischen Nationalstaats entstanden politische Handlungsräume, die den Aufbau neuer Organisationszusammenhänge auf Dorf- und supralokaler Ebene im Tiefland anfangs förderten sowie später zumindest duldeten und dadurch die Beziehungen zwischen nationaler Gesellschaft und nativos veränderten. Doch ist >neu< dabei ein trügerisches Wort, das nicht synonym $\mathrm{zu}$ >vollkommen anders` verstanden werden darf. Im Tiefland traf die Einführung dieser Institutionen (Gemeinderat und dauerhafte supralokale indigene Zusammenschlüsse) natürlich nicht auf einen politisch neutralen Raum. Die Ergebnisse der Untersuchungen im zweiten Teil dieser Studie zeigten, dass politisches Handeln von Seiten der organisierten Gruppen auch weiterhin implizit nach zuvor gültigen Normen beurteilt wurde und wird: Als `guten` Führer bezeichnet man denjenigen, der sich großzügig erweist und seine Anhängerschaft mit Geschenken und beständiger Kommunikation zu überzeugen weiß. Auch wenn dieser Big Man dabei ähnlich wie ein Politiker moderner Demokratien eng an den Willen seiner >Wählerschaft ‘ gebunden ist, liegt dem Prinzip eine andere politische Ideologie zugrunde, die erst einmal wenig mit demokratischen Diskursen über das ideale Gemeinwesen zu tun hat. Nicht eine abstrakte Vorstellung `sozialer Gerechtigkeit` und `Gleichstellung〈, sondern der Aufbau von sozial wirksamen Reziprozitätsbeziehungen bestimmt die diesbezüglichen Vorstellungen. Zudem ist nicht der autonom handelnde, seine Interessen eigenständig vertretende und dabei den legal verankerten

3 Bis heute bleibt ihre Einführung, wie gesehen, äußerst unvollständig (vgl. Kapitel VII und VIII). 
Prinzipien der Rechtsordnung treue Staatsbürger liberaler Prägung das Ideal (vgl. Rosa 2001: 36), sondern ein situationsabhängig nach größeren Allianzen suchendes, sich seiner Abhängigkeit von anderen dennoch bewusstes Mitglied einer durch beständige Kommunikation aufrechtzuerhaltenden, verwandtschaftlich geprägten politischen Bezugsgemeinschaft segmentären Charakters.

Dennoch existieren auch unter den indianischen Tieflandbewohnern Vorstellungen über die ideale Form des politischen Gemeinwesens, die sich an staatlichen Organisationsmodellen orientieren: Wie gesehen wird zum Beispiel der nationale Zusammenschluss der Tieflandindianer AIDESEP als (inoffizielle) Regierung der Indigenen des peruanischen Amazonasgebietes bezeichnet - und dies interessanterweise nicht nur von Seiten der Repräsentanten, sondern in manchen Situationen auch von Teilen der Wählerschaft. Doch in der Praxis stehen, wie gesehen, weder die zur Erfüllung dieser Aufgabe notwendigen ökonomischen und politischen Ressourcen bereits zur Verfügung, noch weist das politische Verhalten der Wählerschaft darauf hin, dass sie sich unter den gegenwärtigen Bedingungen diesbezüglich zur Kooperation bereit erklären würden. Gegen die Zentralisierung von Macht spricht das Streben nach direkter sozialer Kontrolle des politischen Führers durch seine Gefolgschaft. In der Realität stehen sich beide Ideen dennoch nicht einfach dichotom gegenüber, sondern vermischen sich - sowohl in den Vorstellungen der Akteure als auch in ihrem politischem Verhalten. Als wichtige Komponente, welche die politischen Organisationsprozesse der Tieflandindianer beeinflusst, kommt in diesem Vermischungsprozess das über Jahrhunderte gefestigte Patronage-System ins Spiel, das die asymmetrischen Beziehungen im interethnischen Kontakt begründete und festigte. Das generalisierte Misstrauen in Bezug auf die Authentizität der Repräsentanten, die auf höhere Organisationsebene aufsteigen, belegt, dass man in ihnen potentielle patrones sieht. $\mathrm{Zu}$ diesen sucht man zwar den Kontakt, um an begehrte, lokal nicht zugängliche Ressourcen zu gelangen, sieht sie aber deshalb keinesfalls als legitime politische Interessenvertreter der eigenen Gemeinschaft.

\section{Das Problem der sozialen Entfremdung}

Politisches Handeln und politisches Verhalten haben innerhalb der neuen indigenen Organisationszusammenhänge, vor allem auf höheren Organisationsebenen, eine äußerst geringe Deckungsgleichheit. Dies ist einer der wichtigsten Gründe für die mangelnde Übereinstimmung zwischen den Wir-Gefühlen von Dorfbewohnern und den von Seiten der Repräsentanten proklamierten. Der politische Philosoph Hartmut Rosa bietet einen plausiblen analytischen Schlüssel zum Verständnis dieses Dilemmas: 
»Fallen implizite und explizite Selbstdeutungen, oder Theorien und Praktiken, in einer Gesellschaft bzw. in einem ihrer Teilbereiche [...] auseinander, so wird dies zwangsläufig ein Gefühl der Entfremdung auf Seiten der Akteure erzeugen, da sie gezwungen sind, ihre Handlungen an zwei (oder mehreren) widersprüchlichen Selbstinterpretationen zugleich zu orientieren; und dieses Gefühl der Entfremdung wird notwendige Deutungs- und Entscheidungsunsicherheiten [...] erzeugen [...]« (Rosa 2001: 33).

Das Gefühl der Entfremdung ist sowohl auf beiden Seiten (Repräsentanten und Repräsentierte) als auch auf sämtlichen Organisationsebenen dominant: Dorfbewohner misstrauen ihren Vertretern, diese wiederum entfremden sich durch die Ausübung ihres Amtes von ihrer Wählerschaft. Am Ständigen Forum für indigene Angelegenheiten schließlich distanzieren sich auch Lokalpolitiker und Repräsentationsfachleute auf Grund ihrer verschiedenen Bezugsgruppen, der vorhandenen sozialen Statusunterschiede und divergierender Interessen voneinander. Diese Entwicklungen, so meine in den empirischen Teilen der Studie untermauerte These, sind vor allem dem Umstand geschuldet, dass die Akteure ihre Handlungen an verschiedenen, in Widerspruch zueinander stehenden, normativen Deutungen des idealen Gemeinwesens orientieren (müssen) und zudem ihre politischen Handlungen mit pragmatischen, oftmals existentiellen, meist ökonomischen Interessen in Konflikt geraten. Diese Nöte ergeben sich aus den systematischen Zusammenhängen, in denen die indigenen Akteure sich bewegen. Unter den gegebenen Bedingungen entsteht eine derart frappierende Inkongruenz zwischen politischem Handeln und politischem Verhalten, dass die von Repräsentanten ausgerufene politische Gemeinschaft von Seiten der Repräsentierten meist als nicht existent oder zumindest immer als äußerst fragil begriffen wird.

Geht man von der Prämisse aus, dass indigene Organisationen dennoch nicht grundsätzlich politisch bedeutungslos sind - ihr zeitweiliges Erstarken sowie die trotz allem immer wieder abgehaltenen Wahlen, auch auf Föderationsebene, belegen dies - erscheint das entwicklungspolitische Anliegen, die Zusammenschlüsse zu stärken, aus Perspektive einer anwendungsbezogenen Wissenschaft unterstützenswert. Es stellt sich dann jedoch folgende Frage: Welche Möglichkeiten gibt es, die vorhandenen Legitimationsprobleme, wenn auch nicht zu lösen - eine gewisse Inkongruenz zwischen politischem Handeln und politischem Verhalten wird, wie gesehen, immer bestehen -, so zumindest zu verkleinern und damit die indigenen Organisationsprozesse als authentischen politischen Ausdruck bislang in nationalstaatlichen Zusammenhängen marginalisierter Bevölkerungsgruppen zu stärken? 


\section{Praxisbezogene Überlegungen zur Unterstützung der ıneuen< indigenen Organisationsprozesse in Peru}

Auf Grund der Bedeutung, die indigenen Bewegungen von Seiten der internationalen Entwicklungszusammenarbeit für die Stärkung der Demokratien in Lateinamerika in den letzten Jahren beigemessen wurde, flossen auch in Peru in größerem Umfang Finanzmittel zur Unterstützung der >Institutionalisierungsprozesse $<$ indigener Organisationen. So führte die Gesellschaft für technische Zusammenarbeit erstmalig ein Projekt in direkter Kooperation mit AIDESEP durch - im Rahmen ihres Vorhabens der »Stärkung demokratischer Regierungsführung und zivilgesellschaftlicher Teilhabe« (GTZ 2005). Das Projekt zielt auf die »Ermächtigung« (empowerment) »ausgegrenzter Bevölkerungsgruppen « ab und bezieht sich vor allem auf eine indigene Organisationsstärkung auf nationaler Ebene. Ausgehend von der Annahme, dass »Organisationsentwicklung, Kommunikation und Gleichberechtigung der Stärkung der Legitimation der indigenen Dachverbände« dienen (GTZ 2005: 13), entwickelte die GTZ, zusammen mit Vertretern von AIDESEP und solchen der regionalen Dachverbände, im Vorfeld der Projektdurchführung einen Vier-Punkte-Plan:

- Grundsätzlich wurde festgestellt, dass AIDESEP als nationaler Dachverband einen wichtigen Rahmen für Erfahrungsaustausch zwischen den involvierten Akteuren und für die Verbreitung von gelungenen Operationsplänen bietet.

- Ins Auge gefasst wurde die Stärkung der horizontalen und vertikalen Kommunikation, um bestehenden Kommunikationsproblemen zu begegnen. Diese erklärten sich die Vertreter von GTZ und AIDESEP unter anderem aus folgenden Gegebenheiten: Dominanz indigener Sprachen, Defizite im Zugriff auf Kommunikationsmedien, räumliche Entfernungen, Mobilitätskosten. Als Lösungen wurden vorgeschlagen: Ausbildung indigener Kommunikatoren, Netzwerkbildung (z.B. durch lokale Radioprogramme) sowie Institutionalisierung der politischen Partizipation von Frauen.

- Des Weiteren sollten die Führungskompetenzen ausgewählter Individuen gestärkt werden, vor allem in Form eines mehrmonatigen Praktikums in der Zentrale von AIDESEP.

- Und schließlich wollte man Organisationsförderung (Satzung, Kommunikation, Planung) in ausgewählten Mitgliedsorganisationen betreiben und Operationspläne erarbeiten, um politische Vorschläge auch durchsetzen zu können (GTZ 2005: 14). 
Abgesehen davon, dass im Zuge der Umsetzung das ambitionierte Projekt verkleinert werden musste und sich in der Folge vor allem auf die Institutionalisierung der politischen Partizipation von Frauen sowie die Stärkung der Führungskompetenzen in Form von Praktika konzentrierte, sehe ich einige grundsätzliche Schwierigkeiten in der Anlage des Plans. Diese ergeben sich zum einen aus der vorgenommenen Deutung sowie der veranschlagten Lösungsansätze bezüglich der Kommunikationsprobleme, zum anderen aus der zugrunde gelegten Vorstellung von Institutionalisierung.

Kommunikationsdefizite wurden auch in der vorliegenden Studie als grundlegendes Problem der Organisationsprozesse ausgemacht. AIDESEP und GTZ machen diese Schwierigkeiten jedoch zu einem großen Teil an organisationsexternen Faktoren fest, denen sie primär mit Hilfe entsprechender technischer Mittel (Computer, Informationsbroschüren, Radioprogramme) Abhilfe schaffen wollen. Ich bin hingegen der Meinung, dass die Bereitstellung technischer Mittel zwar wichtig, aber nur eine Symptom- und nicht eine Ursachenbekämpfung darstellt. Die Akzentsetzung auf der Förderung einzelner Personen kann hingegen in der vorgeschlagenen Art und Weise sogar kontraproduktiv für die Stärkung der Organisationsstrukturen sein. Die Analyse der Situation in Peru und am Ständigen Forum für indigene Angelegenheiten ergab, dass vor allem die soziale Distanz zwischen den Akteuren, der Entfremdungsprozess, der durch Abkoppelungsdynamiken sowie durch die Überlagerung verschiedener politischer Legitimationsmodelle entsteht, die Kommunikationsprobleme hervorruft. Für diese lassen sich somit schwerwiegende organisationsinterne Probleme mit verantwortlich machen. Zur Lösung dieser Schwierigkeiten könnten deshalb Wege gesucht werden, soziale Nähe innerhalb der Zusammenschlüsse zu fördern und beständig zu bestätigen. Die derzeitigen Organisationsstrukturen indigener Bewegungen zeichnen sich vor allem durch mangelnde Kontrollmöglichkeiten der Repräsentanten durch die Repräsentierten aus.

Das GTZ-Projekt zielt auf die Stärkung des nationalen Zusammenschlusses ab, die aber nur erfolgen könnte, wenn eine enge und stabile Verzahnung der einzelnen Organisationsebenen gelänge. ${ }^{4}$ Unter den in diesem Buch dargelegten Umständen könnte dies allenfalls ein langfristiges Ziel sein, für das zuerst die grundlegenden Voraussetzungen auf lokaler Ebene geschaffen werden müssten. Fraglich ist deshalb, ob das Projekt an der richtigen Stelle ansetzt, wenn es sich auf die nationale Organisationsebene konzentriert. Die größten Probleme entstehen auf lokaler Ebene, bei der praktischen Einforde-

4 Abgesehen davon bleibt es für mich allerdings grundsätzlich fraglich, ob das veranschlagte Ziel das richtige ist. Eine nationale Organisation würde niemals die Interessen aller oder auch nur einer Mehrheit der in ihr zusammengeschlossenen Gruppen vertreten können, sondern immer nur Partikularinteressen. Sie entspricht in diesem Sinne eher einer Partei als einer `Regierung . 
rung legal gesetzter Rahmenbedingungen (z.B. ILO Konvention 169 bzw. Gesetzgebung zu den comunidades nativas) in konkreten Situationen. Es bedürfte somit der Förderung und längerfristigen Begleitung lokal verankerter Personen und Gruppen. Sinnvoll erschiene es, diese vor Ort und abgestimmt auf die jeweils bestehenden Probleme zu schulen, um den Prozess auch für die nicht involvierten Mitglieder der jeweiligen politischen Bezugsgemeinschaft transparent zu gestalten.

Geht man von der Vorstellung aus, dass AIDESEP eine Art inoffizielle Regierung der Tieflandindianer mit demokratischem Vorbildcharakter darstellen möchte, bedürfte es vor allem wirksamer Kontrollmechanismen, um die >Volksvertreter` eng an ihre Wählerschaft zu binden. Dementsprechend wäre die Ausarbeitung von Normen sinnvoll, die sich in einem größtmöglichen Maße mit den - allerdings wie gesehen auch innerhalb der Gemeinschaft und in sich widersprüchlichen - Vorstellungen der Vertretenen über das ideale Gemeinwesen decken. Das würde konkret bedeuten, >Operationspläne` auf Dorf- und Föderationsebene, in Einklang mit lokalen Interpretationen von $>$ Regierung`zu erarbeiten. Außerdem bedürfte es in einem weiteren Schritt unabhängiger Kontrollinstanzen über die Einhaltung der vorgeschlagenen Ordnungsprinzipien. Das würde zuerst einmal die Förderung der Etablierung entsprechender Räume des politischen Dialogs auf Dorf- und Föderationsebene voraussetzen, um sich über die adäquate Form der anzustrebenden $\mathrm{Zu}$ sammenschlüsse in kontinuierlicher Form zu verständigen.

Die Ausbildung einzelner >Multiplikatoren`, seien es indigene Kommunikatoren oder AIDESEP-Praktikanten, führt diesbezüglich nicht zur Stärkung des Korporativgedankens oder lokaler Vorstellungen vom >guten Führer`, sondern zur Förderung individueller Durchsetzungskraft in nationalstaatlichen Zusammenhängen. Denn: Ohne Zweifel empfinden die >Auserwählten〈 ihre persönliche Förderung als bedeutende Chance. Bei der großen Masse der Nicht-Begünstigten wird hingegen der Vertrauensverlust in die Organisationen verstärkt. Diese büßen dadurch ihre primär politische, d.h. gemeinschaftsbezogene Funktion ein. Zudem hat die hohe Misserfolgsquote vergangener Stipendien-Programme bewiesen, dass formale Bildung erstens kein Garant für eine >bessere Zukunft ist und zweitens die jungen Studenten ohne den entsprechenden sozialen Rückhalt in die gesellschaftliche Isolation getrieben werden (vgl. Kapitel X.5).

Auf lokaler Ebene besteht derweil die weitverbreitete Meinung, dass die begünstigten Personen ihre Stellung primär für partikuläre Interessen nutzen. Das Statusführerideal indianischer Prägung gibt zudem vor, dass politische Macht nicht, wie dies in zentralisierten Systemen der Fall ist, dazu genutzt werden kann, sich zum Beispiel auch ökonomisch zu bereichern. Dementsprechend werden individuelle Schulungen als persönliches Karrieresprungbrett für soziale Aufsteiger und >Gruppendissidenten` gesehen und nicht als 
politische Trainingsmaßnahmen für authentische, weil sozial verankerte Vertreter. >Authentisch $<$ definiere ich dabei mit Jonathan Friedman als »the state of integrity of the members of an identifying group. Inauthenticity would thus consist in the relative alienation from the cultural model, a lack of engagement, a social distance with respect to the values and categories embodied in a tradition or program of action « (Friedman 1993: 761). Geteilte Erfahrungen bestimmen den Erfolg und die Resonanz von Realitätsmodellen der sie Praktizierenden und Propagierenden. Um die postulierte gemeinsame Identität von Repräsentanten und Repräsentierten für letztere glaubhaft zu machen, muss ein Kern gelebter Erfahrungen die Konstituenten verbinden.

Die Träger entwicklungspolitischer Projekte zur institutionellen Stärkung indigener Bewegungen könnten derweil dem Entfremdungsprozess zwischen Repräsentanten und Repräsentierten schon alleine dergestalt entgegensteuern, dass sie sich selbst ihren >Zielgruppen` geografisch und sozial annähern. Von Lima aus kann man nur schwer in der von der GTZ anvisierten Art und Weise dazu beitragen, die Bevölkerung des Tieflands zu >ermächtigen ‘. Diese Arbeit vollständig an lokale Akteure zu delegieren, ist, meiner Meinung nach, eine falsche Interpretation ethischer Grundsätze einer spartnerschaftlichen $\mathrm{Zu}$ sammenarbeit`, wenn die entsprechenden Kontrollmechanismen zur Überprüfung dieser Akteure fehlen bzw. die dafür entwickelten Kriterien sich in erster Linie an den Vorgaben der Geldgeber ausrichten. Damit tragen diejenigen, die angetreten sind $\mathrm{zu}>$ demokratisieren<, letztendlich oftmals - entgegen ihrer Absichten - zur Festigung klientelistischer Strukturen bei. Die Repräsentanten können ihre privilegierte Position im Umgang mit den finanzkräftigen externen Akteuren dazu nutzen, um sich selbst zu großen Vermittlern zu entwickeln.

Das Ziel - die Stärkung und Unterstützung indigener Organisationsprozesse - könnte auch unter Zuhilfenahme einer etwas anders gelagerten Konzeption des Begriffs >Institutionalisierung`angestrebt werden. Aufbauend auf eine von Mary Douglas (1989) formulierte Definition des Begriffs >Institution meine ich: Institutionen sind mehr als ihre greifbaren Materialisierungen in Form von Organisationen. Sie sind ein kognitives Wahrnehmungsraster, das unsere politischen Handlungen beeinflusst. >Indigenität Institution - ein sozial konstruiertes Klassifizierungssystem, das die Wahrnehmungen der Menschen kanalisiert und ihnen Entscheidungshilfen gibt. Aus diesem Grund besitzt der Begriff sindigene Völker`, wie gesehen, eine nicht zu unterschätzende politische Wirkkraft auf lokaler Ebene. Das Beispiel der in Kapitel X.1 vorgestellten comunidad nativa Huitoto ist für mich in diesem Sinne richtungsweisend. Die Selbstdefinition als comunidad nativa hat in dem Fall konkrete Ermächtigungspotentiale für die lokale Bevölkerung gezeigt. Das bedeutet schlicht und einfach, dass die Dorfbewohner aktiv versucht haben, neue Handlungsmöglichkeiten zu nutzen. Sie, bzw. politisch en- 
gagierte Personen ihrer Gemeinschaft, haben gelernt, bestehende Gesetzgebungen (z.B. die ILO Konvention 169 und die Gesetzgebung zu den comunidades nativas) zur Umsetzung eigener Interessen anzuwenden. Diese Prozesse müssen in der Praxis unterstützt werden und nicht allein durch den Kampf um die Bereitstellung entsprechender Gesetzestexte oder Absichtserklärungen von Regierungsseite. >Ermächtigung ‘ erfolgt erst dann, wenn man weiß, wie diese Werkzeuge angewendet werden können.

Sensibilisierungsmaßnahmen von Seiten entwicklungspolitischer Akteure könnten derweil auch verstärkt in die andere Richtung laufen. Wie gesehen entscheiden staatliche Funktionäre über Titulierungsanträge indigener Gemeinden oft an Hand ihrer eigenen Wahrnehmungsmuster von >Landnutzung (vgl. Kapitel IX.3). Eine zentrale Aufgabe besteht somit wohl vor allem auch in der kontinuierlichen und hartnäckigen Lobbyarbeit auf allen Ebenen staatlicher Bürokratie, um ein neues politisches Verhalten unter den Entscheidungsträgern $\mathrm{zu}>$ institutionalisieren .

\section{Das Ständige Forum für indigene Angelegenheiten - eine Empfehlungsfabrik?}

»[Das Ständige Forum für indigene Angelegenheiten] ist eine Fabrik für Empfehlungen, in der niemand zu etwas verpflichtet wird « (Interview Matías Alonso 19.05.2004).

Das Ständige Forum für indigene Angelegenheiten definiert sich als Handlungsraum, in dem verschiedene soziale Kräfte - Regierungsvertreter und zivilgesellschaftliche Interessengruppen - zu einem Dialog zusammenkommen können, um sich über die wünschenswerte Form ihrer politischen Gemeinschaften $\mathrm{zu}$ verständigen. Dabei liegt das Hauptaugenmerk laut offiziellem UN-Diskurs auf indigenen Vorstellungen idealer Gemeinwesen. Die Veränderungsvorschläge indigener Repräsentanten werden in Form von Empfehlungen an die diversen UN-Einrichtungen und nationale Regierungen weitergeleitet. In diesem Prozess ergeben sich zwei Probleme: Zum einen das im Zitat von Matías Alonso angesprochene, das die Frage aufwirft, wie man gewährleisten kann, dass Worten Taten folgen. Zum anderen entsteht durch die grundsätzliche Öffnung der Sitzungen des Forums für alle gesellschaftlichen Gruppierungen eine paradoxe Situation. Einerseits ermöglicht diese Offenheit indigenen Akteuren durch eine zahlenmäßige Überlegenheit in den Sitzungen, an politischer Präsenz und damit an symbolischem Kapital zu gewinnen. Andererseits unterstützt die generalisierte Teilnahmemöglichkeit die Herausbildung grundlegender Konflikte und provoziert in der Folge Differenzierungsprozesse innerhalb der Gruppe indigener Akteure, die tendenziell zu ihrer 
politischen Schwächung führen. Dies hängt auch damit zusammen, dass eindeutige Kriterien zur Bestimmung der Authentizität politischer Repräsentanten fehlen. Das sorgt für Konfliktpotential innerhalb der Gruppe indigener Akteure sowie zu ihrer Diskreditierung in der Außenwahrnehmung.

Jedoch ist die UNO kein Ort, an dem über die Authentizität lokaler Repräsentanten differenzierte Aussagen getroffen werden könnten. >Produzenten und `Konsumenten` politischer Lösungen sind räumlich radikal voneinander getrennt, wodurch erstere in ihren Handlungen autonom werden. Jeder kann sich im Kontext des Forums zu einem politischen Repräsentanten indigener Völker erklären. Dementsprechend ist der Raum, der sich indigenen Akteuren scheinbar besonders weit geöffnet hat gleichzeitig ein Ort, an dem die realen Gestaltungschancen von Politik für sie dennoch gering bleiben.

Das von Matías Alonso angesprochene Gefühl der Verpflichtung zur Umsetzung von Empfehlungen sollten nicht nur Vertreter der UN-Agenturen und nationaler Regierungen entwickeln, sondern auch die indigenen Repräsentanten selbst. Sie könnten ihre politische Einflussnahme bei der UNO und im lokalen Kontext dadurch erhöhen, dass sie konkrete Rückbindungsarbeit zwischen beiden Ebenen leisten. Am Beispiel der Organisation AIDESEP könnte dies idealtypisch folgendermaßen aussehen: In den Föderationen werden jedes Jahr die wichtigsten Probleme aller Gemeinden zusammengetragen und besprochen; die Ergebnisse werden auf die nächst höhere Ebene weitergeleitet und abgeglichen mit den Beiträgen der anderen Föderationen. $\mathrm{Zu}$ guter letzt findet eine Systematisierung in AIDESEP statt, auf dessen Grundlage ein Bericht für die relevanten Adressaten erstellt wird: die eigene Regierung, UNOrganisationen, Weltbank, OAS etc. Dieser kann auch im Forum eingereicht bzw. in den entsprechenden Sitzungen vorgetragen werden. Im Gegenzug wird den lokalen Gemeinschaften von den bei den Sitzungen anwesenden Repräsentanten über die Entwicklungen am Forum Bericht erstattet. Nicht etwa nur in schriftlicher Form, sondern vor allem in Versammlungen. Bestünden entsprechende Kontrollmechanismen in der Organisation, um die Vertreter zur Rückmeldung zu zwingen, könnte diese Form der Anbindung vielleicht erfolgreich sein.

Des Weiteren erschiene es mir sinnvoll, in den Sitzungen des Forums eine Reduzierung der Themenvielfalt anzustreben. Das Mandat des Forums - die Erteilung von Ratschlägen an den Wirtschafts- und Sozialrat zu Fragen der wirtschaftlichen und sozialen Entwicklung, Kultur, Umwelt, Bildung, Gesundheit und Menschenrechte - ist zu umfangreich, um effektiv in jeder Sitzung bewältigt werden zu können. Die Informationsfülle bewirkt, dass vor allem unerfahrene Teilnehmer schnell den Überblick verlieren und letztendlich der von Matías Alonso geschilderte Eindruck überwiegt: Das Forum wird zur »Empfehlungsfabrik« ohne nachhaltige Wirkkraft. 


\section{Ausblick}

Eine in den theoretischen Ausgangsüberlegungen dieser Arbeit aufgeworfene Frage bestand darin, inwiefern bestehende Machtstrukturen von sozialen Bewegungen verändert werden können (vgl. Kapitel II.1). Die empirischen Untersuchungen verdeutlichten, dass diese Frage nur sinnvoll beantwortet werden kann, wenn neben den Diskursen auch die soziale Praxis der Akteure beleuchtet wird. Indigene bilden keinen homogenen Block der >Unterdrückten $\prec$ Zwar werden sie von außen oftmals als eine klar abgrenzbare Gruppe wahrgenommen und indigene Repräsentanten betonen ihrerseits diese Grenzen zu politischen Zwecken. Das bedeutet aber noch lange nicht, dass die Mitglieder ihrer proklamierten Gemeinschaften auf Grund kultureller Ähnlichkeiten gemeinsame Interessen besitzen oder ein einheitliches Identitätsgefühl ausbilden. Sie können sich hingegen als Mitglieder mehrerer Gruppen gleichzeitig verstehen. Dies wurde vor allem im zweiten empirischen Teil der Studie deutlich: Ethnizität oder Indigenität stellte für viele Dorfbewohner eine mögliche, aber keine ausschließliche Gruppenidentität dar. Blockbildung auf Grundlage eines essentialistischen Kultur- und Identitätsverständnisses kann im peruanischen Tiefland bisher keine dauerhaften Formen annehmen.

Dennoch können die indianischen Föderationen im Amazonasgebiet als authentische politische Institutionen der sie Konstituierenden gesehen werden. Denn, in akuten Konfliktsituationen gewinnen sie praktische Bedeutung und entsprechen somit politischen Handlungsmustern der Zusammengeschlossen. $\mathrm{Zu}$ untersuchen bleibt dabei jedoch, welche Dynamiken sich in den konkreten Fällen, in denen föderative Zusammenschlüsse auf ethnischer Basis relevant werden, auf lokaler Ebene entwickeln: Welche Personen übernehmen die Führung, wie sind sie in der Gemeinschaft verankert und wie lange bleiben sie politisch relevant? Was führt gegebenenfalls dazu, dass ihre Leitungsfunktion von großen Teilen der Gemeinschaft hinterfragt wird? An diese Fragen könnten weitere ethnografische Studien indigener Bewegungen anknüpfen, die sich somit vor allem als zeitintensive Studien der lokalen Machtverhältnisse verstehen müssten. Detaillierte Rekonstruktionen einzelner Föderationsgeschichten, die gleichfalls die impliziten und expliziten Vorstellungen der jeweiligen Bevölkerung über die ideale Form ihres politischen Gemeinwesens analysieren, sowie die detaillierte Rekonstruktion der Biografien einzelner Führungspersönlichkeiten könnten weitere wichige Beiträge liefern, um gegenwärtige Modelle indigener Selbstorganisation in nationalstaatlichen $\mathrm{Zu}$ sammenhängen systematisch und ohne normativen Impetus zu erfassen. Der Ansatz der multisited fieldwork böte sich dabei meiner Meinung nach in einer anderen als in dieser Studie verfolgten Art und Weise erneut an: $\mathrm{Zu}$ einer multilokalen Forschung zu indigenen Bewegungen gehört eine größere Zahl von Wissenschaftlern, die, an unterschiedlichen Stellen, aber in enger Ab- 
stimmung, zum gleichen Thema arbeiten. Denn, will man sich nicht auf eine Diskursanalyse beschränken, ist eine längere persönliche Präsenz an einem Ort letztendlich fundamental, um politische Alltagspraktiken und Dynamiken detailliert erfassen zu können. Die intensive Studie des Partikulären bleibt der zentrale Beitrag, den ethnologische Arbeiten leisten können, um - auch praxisrelevante - Diskussionen über globale politische Prozesse zu bereichern. 


\section{Epilog: Manuel Ijuma und seine Organisation im Juli 2005 - »lch denke, ich habe meine Pflicht als Präsident getan und Dinge in Bewegung gesetzt."}

»Die illegalen Holzfäller haben mich bedroht. Eines Tages, als ich mich nicht in meinem Dorf, sondern in Iquitos aufgehalten habe, um dort Arbeiten für meine Organisation zu erledigen, ist ein junger Mann aus der Gemeinde zu mir nach Hause gekommen. Er arbeitet mit den illegalen Holzfällern. Er hat meiner Frau gesagt: >Sag deinem Mann Bescheid, dass wir ihn suchen, dass ihm etwas passieren wird. Als ich in mein Dorf zurückgekehrt bin, haben mich meine Kinder am Hafen erwartet, sie haben mich umarmt, und wir sind nach Hause gegangen. Dort hat mir meine Frau gesagt: ‘XY war da und hat dir gedrohtr. Ich habe ihr geantwortet: 'Es ist in Ordnungr. Am nächsten Tag bin ich zu den Autoritäten der Gemeinde gegangen, dem teniente gobernador und dem agente municipal. Denen habe ich gesagt: >Ich möchte XY anzeigen, der zu mir nach Hause gekommen ist, um mir zu sagen, dass man mich umbringen wird. Ruft den Mann, damit er dazu Stellung nehmen kann. Sie haben ihn gerufen, und er ist gekommen und hat gesagt: >Ich bin nur zum Haus dieses Herrn gegangen, um ihn über etwas zu informieren, das ich gehört haber. Aber ich habe ihm geantwortet: ,Wenn du nicht in die Sache verwickelt bist, warum kommst du dann, um mich zu bedrohen? Ich mache dich dafür verantwortlich, wenn mir etwas passieren sollte. Ich möchte, dass Sie mir gut zuhören, und Sie sind meine Zeugen, verehrte Autoritäten. Ich mache diesen Herrn für mein Schicksal verantwortlich. Wenn mir etwas passiert, ist er schuld. Danach bin ich nach Iquitos gefahren, um mit einem Anwalt zu sprechen und den Autoritäten dort mitzuteilen, was mir passiert ist. Der Anwalt hat mir gesagt: 'Schreibe mir einen Bericht über das, was dir passiert ist, und ich werde sehen, was ich damit machen kann. 
Danach sind andere Holzfäller zu mir gekommen, um mir den Bau meines Büros für die Organisation anzubieten. Ich habe ihnen gesagt: >Nein, danke. Ich schätze den leichten Weg nicht, ich werde mich selbst um den Bau des Büros kümmern. Außerdem bin ich nicht alleine für den Widerstand verantwortlich. Elf indianische Gemeinden haben beschlossen, euch Einhalt zu gebieten, und ich bin nur ihr Sprecher als Präsident des Zusammenschlusses. Die Entscheidung liegt bei den elf Gemeinden`. Andere Holzfäller haben mich auf ein Getränk eingeladen, das ich immer angenommen habe. Ich trinke mit ihnen, aber mehr auch nicht. Das sage ich ihnen auch. Ich möchte nicht den gleichen Fehler wie andere Präsidenten machen, die das Geld in die eigene Tasche stecken und als Präsidenten versagen. Ich hätte schon längst sagen können: , Gut, gebt mir vierzehntausend soles ${ }^{1}$, und ich werde mich weit weg in einer anderen Gemeinde niederlassen،. Ich habe das nicht getan, weil ich nicht nur für mich, sondern für meine Kinder und mein Volk kämpfe. Mehr noch, ich kämpfe für die Welt, denn dieses Naturschutzgebiet ist sehr wichtig, damit die natürlichen Ressourcen erhalten bleiben. Wovon werden wir sonst leben? Mein Vater hat mich im Alter von zehn Jahren in das Dorf gebracht, in dem ich heute lebe. Ich bin in einer anderen Gemeinde am Ucayali geboren. Aber mein Vater hat mich dorthin gebracht auf Grund des Reichtums von Pacaya Samiria: der Tiere, Fische etc."

Als ich im Juli 2005 Manuel Ijuma in Iquitos treffe, erzählt er mir, was ich schon vorher von anderer Seite gehört hatte: Seine Organisation war durch die massiven Probleme einiger Gemeinden mit den illegalen Holzfällern zu neuem Leben erwacht. In einer konzertierten Aktion halfen Männer aus elf der dreizehn Mitgliedsgemeinden den personell unterbesetzten Wachposten an einem der Eingänge zum Naturschutzgebiet Pacaya Samirias dabei, eine Gruppe von illegalen Holzfällern zu stellen und ihnen die Bäume abzunehmen. Nach Verhandlungen mit den zuständigen Behörden konnten sie in der Folge erreichen, dass das Holz den Mitgliedsgemeinden der indigenen Organisation zugesprochen wurde. Der Bürgermeister des Bezirks, ebenso wie ein erfolgreicher lokaler Touristenführer, hatten sich zudem bereit erklärt, Benzin für den Transport ins Dorf und Öl für die Motorsägen zu spenden, damit das Holz von den Dorfbewohnern später zu Möbeln weiterverarbeitet werden konnte. Manuel Ijuma hatte im Vorfeld verschiedene Versammlungen organisiert, um diese Aktion zu planen: "Bereits im November 2004 habe ich eine Generalversammlung meiner Organisation einberufen, auf der beschlossen wurde, dass ich als Präsident durch alle Gemeinden reisen würde, um gemeinsam einen Plan zu erarbeiten, wie wir gegen die illegalen Holzfäller vorgehen können. Nur zwei Gemeinden wollten nicht mitmachen, eine davon war mein Dorf. Aber wir haben nach unserer Beschlagnahmungsaktion trotzdem

1 Peruanische Landeswährung. 
beschlossen, diese beiden Gemeinden am Gewinn zu beteiligen. Auch sie dürfen Männer in die Gemeinde schicken, in der das Holz weiterverarbeitet wird. Ich denke, ich habe einiges erreicht in meiner Zeit als Präsident. Manchmal, wenn ich in Iquitos bei der ORAI vorbeischaue, habe ich sogar das Gefühl, dass meine Organisation mehr besitzt als unser regionaler Dachverband. Aber jetzt möchte ich Neuwahlen für den Herbst dieses Jahres einberufen. Ich denke, ich habe meine Pflicht als Präsident getan und Dinge in Bewegung gesetzt. Jetzt soll ein anderer weitermachen." 

Anhang 


\section{Abkürzungsverzeichnis}

AIDESEP: Asociación Interétnica de Desarollo de la Selva Peruana; dt. >Interethnischer Entwicklungsverband des peruanischen Tieflands`, 1980 gegründet, eine der beiden nationalen Vertretungsinstanzen der indigenen Tieflandbewohner Perus.

CAH: Consejo Aguaruna-Huambisa; dt. >Rat der Aguaruna-Huambisaく, Mitte der 1970er Jahre von Evaristo Nugkuag Ikanan gegründet, der später auch AIDESEP und COICA mit ins Leben rief.

CCP: Confederación Campesina del Perú; dt. `Bauerngewerkschaft Perus‘; ein in den 1960er Jahren entstandener Zusammenschluss, welcher der Militärregierung unter General Juan Velasco Alvarado unabhängig und kritisch gegenüberstand.

CECONSEC: Central de Comunidades Nativas de la Selva Central; dt. ıZentrale der nativen Gemeinden der Selva Centralı, 1978 ins Leben gerufen. Fungierte zunächst primär als Handelskomitee zur Vermarktung von Kaffee, entwickelte sich dann aber zu einer politischen Organisation. CECONSEC gehört zu den Gründerorganisationen von AIDESEP.

CEPAL: Comisión Económica para América Latina; dt. >Wirtschaftskommission für Lateinamerika`, 1948 etabliert. Als eine der fünf regionalen Kommissionen untersteht CEPAL dem ECOSOC. Der Hauptsitz der Kommission befindet sich in Santiago de Chile. Das erklärte Ziel der CEPAL ist es, zur >wirtschaftlichen Entwicklung < Lateinamerikas beizutragen. In jüngerer Zeit fördert die Kommission auch Maßnahmen zur Unterstützung der >sozialen Entwicklung .

CISA: Consejo Indio de Sudamérica; dt. >Indiorat Südamerikas‘; internationale >indianistische< Organisation, die 1980 ins Leben gerufen wurde. CISA stand mit AIDESEP im Wettstreit um Mitgliedsorganisationen sowie Finanzierung durch die internationale Entwicklungszusammenarbeit. Die Organisation verlor im Zuge eines Korruptionsskandals Mitte der 1980er Jahre an Einfluss und Bedeutung.

CNA: Confederación Nacional Agraria; dt. >Nationale Agrargewerkschaft Die Gewerkschaft wurde von Velascos Militärregierung ins Leben gerufen, um die unabhängig entstandene $\mathrm{CCP}$ zu schwächen.

COICA: Coordinadora de las Organizaciones Indígenas de la Cuenca Amazónica; dt. >Koordination der indigenen Organisationen des Amazonasbeckens`, ein internationaler Zusammenschluss der indigenen Organisationen aus den Anrainerstaaten des Amazonasbeckens. COICA wurde 1984 ins Leben gerufen, Evaristo Nugkuag war der erste Präsident der COICA.

COICAP: Coordinadora Agroforestal Indígena y Campesina del Perú; dt. >Forstwirtschaftlicher indigener und bäuerlicher Zusammenschluss Perus`, eine 1995 gegründete, national agierende NGO von >Bauern` und >Indigenen mit Sitz in Lima. 
CONACAMI: Coordinadora Nacional de Comunidades Adversamente Afectadas por la Minería; dt. >Nationale Koordination von Gemeinden, die vom Bergbau betroffen sind`. CONACAMI erhielt 2000 einen legalen Status als NGO und entwickelte sich schnell mit AIDESEP zusammen zur tonangebenden Organisation innerhalb des nationalen Zusammenschlusses COPPIP. Präsident der Organisation ist seit ihrem Bestehen Miguel Palacín, der 2003 auch die Präsidentschaft der COPPIP übernahm. 2006 wurde Palacín zum Vorsitzenden eines neuen transnationalen Zusammenschlusses von Andenorganisationen, der Coordinadora Andina de Organizaciones Indígenas (CAOI; dt. >andine Koordinationsstelle indigener Organisationen (), gewählt. Der CAOI gehören Organisationen aus Ecuador, Kolumbien, Peru, Bolivien und Chile an. Die Koordinationsstelle setzt sich für die Schaffung plurinationaler Staaten und interkultureller Gesellschaften ein und fordert dabei vor allem Schutz und Anerkennung indigener Territorien, die Selbstverwaltung der Bodenschätze dieser Gebiete durch indigene Gemeinden sowie die Umsetzung der ILO Konvention 169.

CONAIE: Confederación de Nacionalidades Indígenas del Ecuador; dt. >Konföderation indigener Nationalitäten Ecuadors`, 1986 unter Beteiligung von 27 Organisationen des ecuadorianischen Hochlands, Tieflands und der Küstenregion als nationaler Dachverband ins Leben gerufen. 1990 gelang CONAIE eine Massenmobilisierung, seitdem ist die Organisation zentrale Verhandlungspartnerin der jeweiligen ecuadorianischen Regierungen.

CONAP: Confederación de Nacionalidades Amazónicas del Perú; dt. >Konföderation der amazonischen Nationalitäten Perus`. 1987 in Konkurrenz zu AIDESEP entstanden. Bis heute liegen die beiden Organisationen häufig im Streit und betonen ihre politischen Differenzen. Die Föderationen im Tiefland haben sich jedoch in einigen Fällen für eine Doppelmitgliedschaft in beiden nationalen Zusammenschlüssen entschieden.

CONAPA: Comisión Nacional para los Pueblos Andinos, Amazónicos y AfroPeruanos; dt. >Nationale Kommission für die Völker der Anden, des Amazonas und die Afro-Peruaner . Die Kommision wurde von Präsident Alejandro Toledo 2002 ins Leben gerufen; den Vorsitz hielt zunächst seine Frau Eliane Karp inne, musste diesen aber nach massiven Protesten abgeben. In Folge eines Streits um die Verwendung der von CONAPA verwalteten Weltbank-Gelder in Höhe von fünf Millionen Dollar wurde diese staatliche Institution aufgelöst. Ihre Nachfolgekommission heißt INDEPA.

COPPIP: Conferencia Permanente de Pueblos Indígenas del Perú; dt. >Ständige Konferenz der indigenen Völker Perus`. Die Konferenz wurde 1998 als Zusammenschluss der Küsten-, Hochland- und Tieflandorganisationen ins Leben gerufen; sie teilte sich bald in zwei Zusammenschlüsse auf, von 
denen der eine in der Folge mit finanzieller und technischer Unterstützung der internationalen Entwicklungszusammenarbeit versuchte, sich als nationale Vertretungsinstanz zu etablieren. Diese Versuche sind jedoch bis heute nicht erfolgreich verlaufen.

CORPI: Coordinadora Regional de Pueblos Indigenas San Lorenzo; dt. >Regionale Koordination der indigenen Völker von San Lorenzo<, eine der sechs regionalen indigenen Dachverbände, die AIDESEP angeschlossen sind.

DAM: Desarrollo del Alto Marañón; dt. >Entwicklung des oberen Marañón<. Organisation einer Gruppe spanischer Freiwilliger um den AIDESEPUnterstützer Pedro García Hierro, die in den 1960er Jahren ins peruanische Amazonasgebiet kamen und Aguaruna-Gemeinden beim Aufbau einer Kooperative und später bei der Gründung der Föderation CAH halfen.

ECOSOC: Economic and Social Council ; dt. >Wirtschafts- und Sozialrat<, eines der Hauptorgane der Vereinten Nationen. Das Ständige Forum für indigene Angelegenheiten untersteht dem ECOSOC. Die UN-Charta weist dem ECOSOC Aufgaben der Koordinierung, Politiküberprüfung und des Politikdialogs auf wirtschaftlichem, sozialem, kulturellem und humanitärem Gebiet zu. Der Rat kann Empfehlungen an die UN-Generalversammlung und die UN-Sonderorganisationen abgeben, Übereinkommen zur internationalen Zusammenarbeit auf diesen Gebieten vorlegen oder mit Genehmigung der Generalversammlung Verträge mit den Sonderorganisationen abschließen. Der ECOSOC besteht aus 54 Mitgliedern.

FAO: Food and Agricultural Organisation; dt. 〉Ernährungs- und Landwirtschaftsorganisation<, 1945 gegründet, Sonderorganisation der Vereinten Nationen. Die Tätigkeit der FAO gliedert sich in zwei Bereiche: 1. das reguläre Programm, das sich mit der Bereitstellung von finanzieller Hilfe und Politikberatung in allen landwirtschaftlichen Fragen beschäftigt und 2. die sogenannten Feldprogramme, die in Zusammenarbeit mit anderen UNOrganisationen oder nationalen Regierungen durchgeführt werden. FAO ist die größte Entwicklungshilfeorganisation im UN-System. Sie konzentriert sich vor allem auf Katastrophenhilfe.

FEDECOCA: Federación de Comunidades Cocamillas; dt. >Föderation von Cocamilla-Gemeinden`, 1977 mit Unterstützung des US-amerikanischen Ethnologen Anthony Stocks gegründet.

FENAMAD: Federación Nativa de Madre de Dios; dt. >Native Föderation der Region Madre de Dios`, 1982 gegründet. FENAMAD ist ein multiethnischer Zusammenschluss, der überwiegend aus Gemeinden der Harakmbut, Yine und Ese Eja besteht. Die Föderation fungiert gleichzeitig als regionale Organisation AIDESEPs, gehört aber auch CONAP an und pflegt darüber hinaus Allianzen mit nicht-indigenen Organisationen. 
FORMABIAP: Formación de Maestros Bilingües Indígenas de la Amazonía Peruana; dt. >Ausbildung zweisprachiger indigener Lehrer des peruanischen Amazonsgebiets`, 1988 als Ausbildungsprogramm für zweisprachige, indigene Grundschullehrer von AIDESEP ins Leben gerufen, mit Sitz in Iquitos. FORMABIAP ist in die staatliche universitäre Struktur eingebunden und wird von AIDESEP mit koordiniert. Über 300 indigene Lehrer wurden bisher ausgebildet, 129 haben das Programm mit einem Titel abgeschlossen.

FUNAI: Fundação Nacional do Índio; dt. >Nationale Stiftung des Indianersく. Kraft der brasilianischen Verfassung von 1988 ist die FUNAI das offizielle Ausführungsorgan der staatlichen, indigenistischen Politik in Brasilien. Ihre Aufgaben bestehen unter anderem im Schutz indianischer Gemeinden, der Demarkierung indianischer Territorien sowie der Durchsetzung von Grundschulbildung für alle indianischen Kinder.

IITC: International Indian Treaty Council; 1974 von US-amerikanischen, im urbanen Kontext lebenden Indianern gegründet. Bekam 1977 nach der National Indian Brotherhood of Canada als zweite indigene Organisation einen UN-Beraterstatus am ECOSOC. Zusammen mit dem WCIP dominierte der IITC vor allem in den 1980er Jahren die Ausrichtung der panindigenen Bewegung innerhalb der UNO. Auch heute noch zeigt die Organisation bei den Sitzungen des Ständigen Forums für indigene Angelegenheiten eine starke Präsenz.

ILO: International Labour Organisation; dt. >Internationale Arbeitsorganisation`, 1919 zusammen mit dem Völkerbund im Rahmen der Friedensverhandlungen von Versailles gegründet. 1946 wurde die ILO die erste Sonderorganisation der neu ins Leben gerufenen Vereinten Nationen. Ziel der Organisation ist es, völkerrechtliche Mindeststandards in Form eines internationalen Arbeitsrechts zu schaffen. Sie verabschiedet Empfehlungen und Übereinkommen. Mit der Entkolonisierung in den 1950er und 60er Jahren übernahm die ILO auch operative Tätigkeiten im Bereich der Bereitstellung technischer (Entwicklungs)hilfe.

INDEPA: Instituto Nacional de Desarrollo de los Pueblos Andinos, Amazóni$\cos y$ Afroperuanos; dt. >Nationales Institut für die Entwicklung der Völker der Anden, des Amazonas und der Afro-Peruaner<. Ende 2004 beschloss der peruanische Kongress, eine neue nationale Instanz für indigene Angelegenheiten ins Leben zu rufen - INDEPA. Das Institut agiert autonom und besitzt den Rang eines Ministeriums. Es soll die Ausführung von Projekten und Programmen koordinieren, welche die >Rechte und die Entwicklung mit Identität der Völker der Anden, des Amazonas und der AfroPeruaner unterstützen<.

IWF (IMF): International Monetary Fund; dt. >Internationaler Währungsfonds`, 1944 in Bretton Woods als Teil der sogenannten Weltbankgruppe 
zur Neuordnung der Weltwirtschaft ins Leben gerufen, seit 1947 im Besitz des Status' einer Sonderorganisation der UNO. Um sein Mandat - Kontrolle der Wechselkurspolitik seiner Mitgliedsstaaten - zu erfüllen, übernimmt der IWF Überwachungsfunktionen auf multi- und bilateraler Ebene.

IWGIA: International Work Group on Indigenous Affairs; dt. >Internationale Arbeitsgruppe zu indigenen Angelegenheiten<. International agierende NGO mit Hauptsitz in Kopenhagen, Dänemark. IWGIA entstand nach dem XXXVII. Südamerikanistenkongress in Stuttgart im August 1968 als Initiative politisch engagierter Ethnologen (Schüler Frederik Barths), die mit der Organisationsgründung auf Massentötungen an Indianern in Kolumbien und Brasilien reagierten.

MDGs: Millenium Development Goals; dt. >Milleniums-Entwicklungszieleく. Die Millenniums-Entwicklungsziele umfassen 8 übergeordnete Ziele: 1. extremen Hunger + Armut beseitigen; 2. Grundschulbildung für alle Kinder erreichen; 3. Gleichstellung und größeren Einfluss der Frauen durchsetzen; 4. Kindersterblichkeit senken; 5. Gesundheit der Mütter verbessern; 6. AIDS, Malaria und andere Krankheiten bekämpfen; 7. nachhaltigen Schutz der Umwelt gewährleisten; 8. globale Partnerschaft im Dienst der Entwicklung schaffen. Diese acht Ziele werden wiederum in insgesamt 18 Zielstellungen konkretisiert, wobei 48 Indikatoren zum Einsatz kommen. Die Ziele wurden von einer Expertengruppe, bestehend aus Mitgliedern des UN-Generalsekretariats, IWF, OECD und Weltbank, erstellt und im Jahr 2000 in einer Sondersitzung der Generalversammlung verabschiedet.

OAS: Organization of American States; dt. >Organisation amerikanischer Staaten . Die OAS zählt gegenwärtig 35 Mitgliedsstaaten (Cuba wurde als einziges amerikanisches Land 1962 vom Verbund ausgeschlossen). Der Hauptsitz der Organisation ist in Washington, ihre wichtigsten Organe sind die Generalversammlung, die einmal jährlich von den Außenministern aller Mitgliedsstaaten abgehalten wird sowie der Ständige Rat, der aus Diplomaten aller 35 Staaten besteht und regelmäßig in Washington zusammentritt. Jedes Land besitzt das gleiche Stimmrecht, der Vorsitz des Ständigen Rates wechselt alle drei Monate, wobei die einzelnen Mitgliedsstaaten in alphabetischer Reihenfolge zum Zuge kommen.

OIRA: Organización Indígena Regional de Atalaya; dt. >Regionale indigene Organisation von Atalaya<, eine der sechs regionalen Dachverbände, die AIDESEP angeschlossen sind.

ORAI: Organización Regional de Asociaciones Indigenas; dt. >Regionale Organisation indigener Verbänder. ORAI ist eine der beiden regionalen Instanzen von AIDESEP in der Region Loreto, im Nordosten des peruanischen Tieflands. 
SINAMOS: Sistema Nacional de Apoyo a la Mavilización Social; dt. >Nationales System zur Unterstützung der sozialen Mobilisierung^. SINAMOS stand gleichzeitig für sin amos (dt. >ohne Herren<) und verkörperte so den revolutionären Anspruch der Militärregierung unter General Velasco. 1971 ins Leben gerufen war SINAMOS als Vermittlungsinstanz zwischen Bevölkerung und Staatsführung gedacht, da die Gründung einer politischen Partei von der Mehrheit der militärischen Führung abgelehnt worden war.

SIL: Summer Institute of Linguistics; besitzt eine Doppelfunktion von Mission und linguistischer Forschung sowie Verschriftlichung indigener Sprachen. Das SIL kam 1950 nach Peru. Während die Organisation in einigen lateinamerikanischen Staaten auf großen Widerstand stieß, was zum Beispiel zu ihrer Ausweisung in Ecuador, Brasilien, Mexiko und Panama Ende der 1970er Jahre führte, pflegte sie in Peru mit den verschiedenen Machthabern relativ gute Beziehungen. So konnte das SIL 1953 in Yarinacocha eine Ausbildungsstätte zur Erziehung zweisprachiger indigener Lehrer eröffnen. Damit trug die Organisation indirekt zur Ausbildung der neuen indigenen Repräsentanten und ihrer Zusammenschlüsse bei.

UNDP: United Nations Development Programme; dt. `Entwicklungsprogramm der Vereinten Nationen`, 1965 von der Generalversammlung gegründet. 1966 nahm das UNDP seine Arbeit auf. Es ist die weltweit größte multilaterale Einrichtung für technische Zusammenarbeit, die auf der Basis von nicht rückzahlbaren Zuschüssen arbeitet. Finanziert wird sie durch die jährlichen freiwilligen Beiträge der UN-Mitgliedsstaaten.

UNESCO: United Nations Educational, Scientific and Cultural Organization; dt. >Organisation der Vereinten Nationen für Erziehung, Wissenschaft und Kultur<, 1945 von 37 Staaten in London gegründet. 1946 wurde der UNESCO der Status einer UN-Sonderorganisation zugewiesen. Offizielles Ziel der Organisation ist es, durch Förderung der Zusammenarbeit zwischen den Mitgliedsstaaten auf den Gebieten der Erziehung, Wissenschaft und Kultur zur internationalen Friedenssicherung beizutragen.

UNEP: United Nations Environment Programme; dt. >Umweltprogramm der Vereinten Nationen`, 1972 als Ergebnis der ersten UN-Umweltkonferenz in Stockholm gegründet. Die UNEP initiiert Kooperationen mit anderen globalen, regionalen oder nationalen Institutionen und versucht, auf diesen Ebenen die Beschäftigung mit Umweltfragen zu fördern und zu stärken. Ferner sammelt sie relevante Informationen zu umweltpolitischen Themen und stellt sie, in Kooperation mit anderen UN-Organisationen, Entscheidungsträgern zur Verfügung.

UNIFEM: United Nations Development Fund for Women; dt. >UN-Entwicklungsfonds für Frauen`. 1985 wurde der 1976 eingerichtete Fonds für die Finanzierung der UN-Frauendekade in einen ständigen Hilfsfonds umge- 
wandelt und ist seitdem mit dem UNDP assoziiert, rechtlich aber eigenständig. UNIFEM leistet technische und finanzielle Hilfe zur Unterstützung von Initiativen von Frauen in der sogenannten Dritten Welt.

UNFPA: United Nations Population Fund; dt. >Bevölkerungsfonds der Vereinten Nationen<, 1967 ursprünglich als UN Trust Fund gegründet. UNFPA ist ein eigenständiges Programm der Vereinten Nationen und gilt heute als Zentrum der weltweiten Unterstützung staatlicher Bevölkerungspolitik und >reproduktiver Gesundheitヶ. Gibt jährlich den Weltbevölkerungsbericht heraus.

UNHCHR: United Nations High Commissioner on Human Rights; dt. >Hoher Kommissar der Menschenrechte der Vereinten Nationen«. Schon 1946 rief die UNO ein Sekretariat für Menschenrechte ins Leben, das unter verschiedenen Bezeichnungen bis heute fungiert, seit 1997 als Amt des Hohen Kommissars für Menschenrechte.

UNHCR: United Nations High Commissioner for Refugees; dt. >Hoher Flüchtlingskommissar der Vereinten Nationen<, 1951 von der UN-Generalversammlung eingerichtetes Amt. Laut ihrer Satzung ist die Organisation strikt humanitär und nicht politisch ausgerichtet. Ihre Hauptfunktion besteht darin, Flüchtlingen internationalen Rechtsschutz zu sichern.

WCIP: World Council of Indigenous Peoples; dt. >Weltrat indigener Völker<, 1975 gegründeter Zusammenschluss, der aus einem Treffen in Port Alberni zwischen Vertretern nord- und lateinamerikanischer indigener Organisationen sowie Vertretern aus Europa und Neuseeland entstand. Diese transnationale indigene Organisation wollte bereits bestehende Kontakte zwischen Indigenen verschiedener Kontinente stärken und diese an der $\mathrm{UNO}$ vertreten.

WHO: World Health Organization; dt. >Weltgesundheitsorganisation«, 1948 als Sonderorganisation der Vereinten Nationen gegründet. Die Organisation besitzt zwei Hauptfunktionen: 1. ist sie Koordinierungsstelle für die internationale Gesundheitsarbeit und 2. bietet sie Regierungen auf Verlangen fachliche Unterstützung.

WIPO: World Intellectual Property Organization; dt. >Weltorganisation für geistiges Eigentum<, wurde 1967 in Stockholm gegründet und 1974 per Abkommen zur UN-Sonderorganisation. Die WIPO möchte geistiges Eigentum - verstanden als alle geistigen Tätigkeiten auf gewerblichem, wissenschaftlichem, literarischem und künstlerischem Gebiet - durch weltweite Zusammenarbeit der Staaten schützen. 


\section{Glossar spanischer und indigener Begriffe}

agente municipal: >Gemeindevertreter/; er wird vom Bürgermeister ernannt und fungiert als dessen Ansprechpartner in einer kleinen Ortschaft. Er besitzt reine Verwaltungsaufgaben, kann zum Beispiel das Zivilregister führen und den Schriftverkehr weiterleiten. Nicht jedes Dorf hat einen agente municipal.

ápu: in indianischen Gemeinden im peruanischen Tiefland vielerorts gebräuchliche Bezeichnung für eine straditionelle` politische Führungspersönlichkeit.

ayahuasca: >Liane der Geisterく; Drogenzubereitung aus Naturdrogen, die einerseits den halluzinogenen Wirkstoff DMT und andererseits MAOInhibitoren aus der Harmala-Reihe (zB. Harmalin) enthalten.

campesino: >Bauer`.

caudillo: >Anführer২. Politischer Führertypus, der sich in Südamerika mit den Unabhängigkeitskriegen im 19. Jahrhundert herausbildete. Die ersten caudillos waren meist charismatische Generäle, die ihren militärischen Rang nutzten, um in den neuen unabhängigen Staaten an Macht zu kommen. Ihre Macht entzieht sich jeglicher Kontrolle. Sie nutzen ihr Amt, um persönliche Interessen $\mathrm{zu}$ verfolgen.

chacra: >Feld<.

cholo: mit diesem Begriff werden in Peru Menschen mit indigenem, vor allem andinem Phänotypus bezeichnet; cholo kann sowohl als Eigenbezeichnung als auch als abwertende Fremdbezeichnung der Indigenen der Andenregion dienen.

chuncho: Bezeichnung für die indigenen Bewohner des peruanischen Amazonasgebietes; als Schimpfwort gebraucht, das Verachtung ausdrücken soll. comunidad: >Gemeinde <, >Gemeinschaft $<$; auch >Dorf $<$.

comunidad nativa: >Eingeborenengemeinde<; juristischer Status, den indianische Dörfer im peruanischen Tiefland seit 1974 erhalten können. Er garantiert ihnen ein Recht auf kommunalen Landbesitz und eingeschränkte autonome Selbstverwaltung.

consejero/a regional: >Mitglied des Regionalrats`; politisches Amt auf regionaler Ebene.

costumbres: >Gebräuche`, >Traditionen`, >Gewohnheiten`.

curaca: von den Missionaren unter der indigenen Bevölkerung im peruanischen Amazonasgebiet eingeführtes Amt; er fungierte als Vermittler zwischen Missionaren und lokaler Bevölkerung. In vielen Gebieten des peruanischen Amazonasgebietes werden aber auch traditionelle Autoritäten (ápus) curaca genannt.

curandero: >Heiler`. 
dirigente: >Leiter`, >Repräsentant`; mit diesem Begriff werden die Mitglieder der Direktive indigener Organisationen bezeichnet.

gantatsirira: Kriegerfigur bei den Matsiguenka; der gantatsirira erlangte Gefolgschaft durch Gewaltandrohung; er verkörpert die despotische Führungspersönlichkeit, die durch Kollaboration mit Plantagenbesitzern oder Missionaren Macht gewinnen konnte.

jefe: >Chef`; mit diesem Begriff werden oft politische Führungspersönlichkeiten, vor allem im lokalen (dörflichen) Kontext bezeichnet.

líder: >Anführer/; verweist auf besondere politische Führungsqualitäten und Autorität, die man dem Betreffenden zuschreibt.

maloca: >Gemeinschaftshaus〈; in den malocas spielt sich bei den Huitoto und anderen indianischen Gruppen im Amazonasgebiet das soziale und zeremonielle Leben einer Siedlung ab.

nativo: >Eingeborener`; in Peru seit der Gesetzgebung zu den comunidades nativas (1974) geläufige Fremd- und Eigenbezeichnung für die indigenen Tieflandbewohner.

patrón (patrones): >Patron<; auf Grund seines direkten Zugangs zu wichtigen Ressourcen (Land, Arbeit, Geld etc.) kann der patrón asymmetrische Tauschbeziehungen zu Personen aufbauen, die nicht über direkten Zugang zu diesen Ressourcen verfügen und sie von sich abhängig machen. Im peruanischen Tiefland über Jahrhunderte gefestigtes Beziehungsmuster (Patronage) zwischen Indianern und Plantagenbesitzern/Händlern etc.

presidente comunal: >Gemeindevorsteher<; Amt, das im Zuge der Gesetzgebung zu den comunidades nativas in den 1970er Jahren in indianischen Dörfern im peruanischen Tiefland eingeführt wurde.

profesional: >Fachkraft<; im Kontext der indigenen Bewegung in Peru wird häufig explizit zwischen Mitarbeitern von NGOs (profesionales) und den gewählten Leitern indigener Organisationen (dirigentes) unterschieden. pueblo indigena: >indigenes Volk<; im Zuge der modernen indigenen Organisationsprozesse zur weithin genutzten Bezeichnung der eigenen ethnischen Gruppe geworden.

regidor: ‘Stadtrat<; politisches Amt auf Bezirksebene.

teniente gobernador: >Stellvertreter des Landrats〈; er repräsentiert die staatliche Exekutive auf dörflicher Ebene und wird von seinem direkten Vorgesetzten, dem gobernador des Distrikts (Landrat) gewählt. Somit besetzt er die unterste Ebene des Innenministeriums. Nicht in jedem Dorf gibt es einen teniente gobernador. 


\section{Spanische Originalversionen verwendeter Interview- und Gesprächspassagen}

(in alphabetischer Reihenfolge der Personennamen)

Alarcón, Tomas: „Estoy de acuerdo con los hermanos que se quejan de la falta de informaciones por parte de sus representantes internacionales. Es la tarea de los organismos representativos mantener la comunicación con las bases. Nosotros, los expertos, tenemos más bien una función de consejeros. [...] Con placer aconsejamos a nuestros delegados. Pero muy poco nos preguntan«. (Kapitel V.6)

Antazú, Teresita: »Los representantes de los gobiernos van al Foro con mandatos limitados de negociación. Más bien aprovechan el espacio para cuidar de la buena apariencia de sus países«. (Kapitel V.3)

Antazú, Teresita: »Antes nosotros no conocíamos escuela, mi mamá p.e. no fue a la escuela. Nosotros ya fuimos a la escuela, mis hijos ya van a la universidad. [...] tenemos que ir aceptando el cambio y nosotros tenemos que ir enrollándonos en este cambio. Tampoco porque soy de la comunidad pobrecito ¿ahí me voy a quedar, no voy a la escuela? No. Porque entonces todo el cambio que viene nosotros siempre vamos a quedar retrasados. En cambio ahora los alumnos ya quieren estudiar y trabajar, es otra mentalidad. Si cambiamos un poco la mentalidad eso no quiere decir que tengamos que dejar nuestras costumbres. [...] Ellos van a estudiar acá. Podemos ayudarles a que terminen, que tengan un trabajo. Ya pues, algo harán, o volverán a la comunidad para apoyar. A trabajar en la comunidad, por lo menos ya teniendo una profesión, algo«. (Kapitel X.4)

Antazú, Teresita: »Los hombres tienen miedo de que nosotras, las mujeres, les desocupamos de sus puestos centrales. [...] Además no entienden los problemas de las mujeres indígenas como tema político. Para ellos lo más importante es la lucha por nuestro territorio indígena. [...] Cuando empezé mi cargo en el 99 el presidente de entonces me entregó dos hojas de papel diciendo que era una versión preliminar de un tema de mujer. Después me dejaron solita con el trabajo y además muchas veces trataron de echarme fuera de las tomas de decisiones importantes, ya sea a través de reuniones particulares o no tomando en serio lo que yo estaba diciendo. [...] También al nivel local a veces es muy dificil trabajar el tema de la mujer. No comprenden el concepto de genero [...] y los hombres muchas veces lo rechazan completamente, dicen entonces que es un concepto occidental«. (Kapitel X.5)

Aranda, Ofelia: „Cuando llegamos a este espacio de la ONU nos absorbe el sistema. Aquí cada uno va por su lado. No me siento como para hablar con los expertos indígenas del Foro. Ellos se mueven en otro nivel que yo«. (Kapitel V.3) 
Cabrera, Justa: »En este Foro hay niveles de preparación muy distintos. P.e., yo no puedo hablar inglés y hasta ahora nunca he tenido contacto con la ONU. Para realmente poder aprovechar este espacio necesitaría un año de preparación. No es para mí este espacio de la ONU. Yo puedo ser buen líder en mi comunidad pero no aquí. Hay que prepararse para llevar buenas propuestas y para poder hacer contactos«. (Kapitel V.3)

Cabrera, Justa: »Tengo poco conocimiento del Foro. Se dice que es un Foro para Cuestiones Indígenas, pero no somos parte de la elaboración de las normas del Foro. Ya está hecho el programa del Foro y no se puede salir de esto. Quise participar con una intervención y me inscribí en la lista, pero se me olvidó poner que era una intervención colectiva. Pero como le dan prioridad a éstas ya no me tocó a mí«. (Kapitel V.3)

Cabrera, Justa: »Hay representantes aquí que llevan su traje en la maleta. Se lo ponen para disfrazarse. Cuando llegué a Ginebra una señora me preguntó: ¿Por qué no se pone su traje tradicional? Pero yo ofendería a mis abuelos, porque allá en mi comunidad tampoco me pongo mi traje. Si un día lo hago, será para quedarme en el traje puesto«. (Kapitel V.4)

Cayuqueo, Nilo: »Por un lado es positivo que la ONU a través del Fondo Voluntario quiere promover la participación de organizaciones indígenas locales. Por otro lado en los foros de la ONU se discuten los lineamientos políticos del movimiento indígena internacional, y para eso se necesitan representantes con experiencia. Estas discusiones se dan muy pocas en el Foro. Más que nada hay luchas personales por posiciones y enfoques distintos. Eso le conviene a la ONU y a los gobiernos. Pero le hace daño al movimiento«. (Kapitel V.6)

Cayuqueo, Nilo: »El territorio y la autodeterminación siguen siendo, por supuesto, demandas fundamentales de nuestro movimiento. Pero en el Foro Permanente tenemos que concentrarnos en la exposición de como nos imaginamos nuestro desarrollo y las medidas que los gobiernos y la ONU deberían tomar«. (Kapitel V.6)

Chirif, Alberto: »El sueña con que el territorio indígena un día pueda ser uno sólo otra vez. Pero yo pienso que esto es peligroso y no se puede realizar. La inclusión en el mercado ya ha avanzado demasiado. ¿Qué pasa si todo llega a ser un sólo territorio y un jefe decide vender madera? No, no, las parcelas son mejor protección contra la liquidación total«. (Kapitel IX.3)

Chrisente, Luzmila: »Como dirigentes muchas veces no nos damos cuenta que el pueblo manda y nosotros no. Por eso hay que ser menos que el pueblo. Sino, el pueblo dice que tu ya no eres Asháninka, pero mestizo. Así te ganas desconfianza«. (Kapitel X.4)

Espíritu, Ana: »Los pobrecitos muy poca educación tienen, a veces sólo saben hablar algunas palabras en español. De eso se aprovechan los representantes y se convierten en intermediarios entre ellos y las ONGs y las insti- 
tuciones del estado. Pero en realidad son ellos mismos que viven de los proyectos que solicitan en nombre de las comunidades. Ya no se comportan conforme a nuestras costumbres«. (Kapitel X.4)

García, Pedro: »El tema de los territorios es el único que ha entrado en todas las cabezas de las Américas, quizás de todo el mundo«. (Kapitel IX.3)

García, Rudolfo: »La organización lucha por los territorios, para su población, para que no haya invasiones. Para esto se creó. [...] Pero hoy en día el representante la quiere volver en una municipalidad donde se mueve mucha plata« (Kapitel X.4)

Crispín, Manuel: »Hoy los dirigentes sólo se interesan por la continuación de la organización, eso se ha vuelto su objetivo. [...] si se limpiara de los gusanos, tal vez se podría ver un nuevo amanecer. [...] Si haces un compromiso con la organización tienes que ser fuerte, porque si no, te dejas manejar por la plata«. (Kapitel X.4)

López, Hernán: »[...] de las once secretarias casi nadies te ayuda porque todos vivimos en diferentes comunidades y para ser dirigente hay que ser muy fuerte, de pasar mucha hambre, de todos. Ellos no pueden abandonar sus hogares, tienen sus chacras, sus familias y yo también. Pero de todas maneras hay que estar ahí, entonces parece que uno sólo hay que hacer muchas cosas«. (Kapitel X.5)

Manchineri, Sebastião: »[...] los espacios internacionales son espacios políticos que no deja de tener su importancia por visibilizar una problemática. Pero no es el principal [...]. Al nivel internacional nosotros hacemos las fiestas, los eventos, pero a partir de ahí alguien tiene que hacer. Y este alguien para hacer no tiene «. (Kapitel III.1)

Manchineri, Sebastião: »P.e., conozco gente de Brasil que decía que era de un pueblo y no lo era. Otra vez hubo también en otra sesión alguien de Perú y vino por una organización pero no era. [...] Es un espacio abierto para todos donde todos pueden opinar [...] Pero es así: No queda claro quienes de los participantes realmente representan a una organización o a un pueblo. No hay que dar pruebas en las Naciones Unidas«. (Kapitel V.4)

Manchineri, Sebastião: »La gente que está en las Naciones Unidas dice: Nosotros queremos que venga la gente de bases, del pueblo, de la comunidad. [...] Pero es también un problema de conocimiento. Es que la gente viene de como es en la comunidad. Pero cuando llegamos a las Naciones Unidas los problemas son más amplios [...] por eso aparecen expertos en esos foros«. (Kapitel V.6)

Manchineri, Sebastião: »La declaración es una declaración, no es una ley. Cualquiera puede hacer una declaración. Es un compromiso moral. No es obligatorio. [...] Pero aún es necesario de tener este tipo de seguridad, de tener este tipo de apoyo, de institucionalización gubernamental o de legislaciones. Pero veo que no es la condición de la que depende nuestra 
existencia, nosotros podemos existir independientemente «. (Schlussbetrachtungen)

Manihuari, Miguel: »Yo viví primero aquí en la ciudad de Iquitos después de que salí del ejército. No volví a mi pueblo y luego después de nueve años volví a mi pueblo. Y ahí viví los primeros cuatro años sin un cargo, pero luego me eligieron como agente municipal de mi comunidad. Era agente municipal dos años y medio en mi comunidad y luego yo renuncié por algunos trabajos personales y a los tres meses mi pueblo con la confianza de mi gestión como agente municipal nuevamente me proponene como presidente comunal. Estaba como presidente comunal tres años. Pero antes de estos cargos políticos yo ocupaba el liderazgo de una iglesia evangélica [...] Más tarde me eligieron como vice-presidente de nuestra federación. Después trabajé tres meses en un proyecto de manejo de areas protegidas en Iquitos. [...] En el 1999 se hicieron las nuevas elecciones para la directiva de mi federación y de gran sorpresa me eligieron con ochenta por cientos de votos para la presidencia. [...] En el 2001 fui elegido para el puesto de vice-presidente de ORAI«. (Kapitel X.5)

Matías Alonso, Marcos: „Cuando se discuten temas culturales como la educación o el cuidado del propio idioma y de los costumbres, los gobiernos están tranquilos. Lo que no quieren es que se hable de temas políticas como autonomía, autodeterminación y cuestiones territoriales«. (Kapitel III.2)

Matías Alonso, Marcos: »Los temas de alta prioridad de los pueblos indígenas no coinciden con los temas prioritarias de los estados ni con los de las agencias de las Naciones Unidas. [...] p.e. los temas más discordantes pueden ser la demarcación de las tierras [...] para los pueblos indígenas a veces no les interesa mucho temas de biodiversidad o de protección de recursos naturales [...] a ellos les interesa más hacer la demarcación territorial y después ver lo que hay a dentro«. (Kapitel V.3)

Matías Alonso, Marcos: »Tal vez es bonito conocer Nueva York o Ginebra, pero si no conoces los temas que se tratan te aburres nucho. Hay una gran distancia entre los temas relevantes al nivel de los países o al nivel local y los que se discuten aquí«. (Kapitel V.3)

Matías Alonso, Marcos: »Creo que se dedicaron mucho a partes administrativas pero lo cual es hasta cierto punto correcto, pero creo que lo político se marginó, me refiero en lo político a los temas trascendentales para los pueblos indígenas«. (Kapitel VI)

Matías Alonso, Marcos: »[...] es una fábrica de recomendaciones en la cual no comprometen a nadie«. (Schlussbetrachtungen)

Mora, Carlos: »Fueron básicamente estos delegados sin una representación de las bases, no hubo un gran congreso indígena en medio de la selva para tomar una decisión política«. (Kapitel VIII.2) 
Mora, Carlos: »No hay una sóla representación de un pueblo indígena que tenga una legitimidad de convocatoria del conjunto de comunidades«. (Kapitel VIII.2)

Mora, Carlos: »Una cosa que no se desarrolló en términos exitosos y no logra acompañar este proceso de desarrollo, es el tema económico. No se avanza hacia [...] una propuesta de un modelo de desarrollo económico y de alternativas económicas para las comunidades [...] las condiciones de inserción de las comunidades en las economías regionales era cada vez más creciente«. (Kapitel VIII.3)

Nugkuag, Evaristo: »A partir del 77 vine enseguida a Lima, representando al CAH. [...] En estos tiempos se constituyó CIPA por personas que antes trabajaron en SINAMOS, Alberto Chirif y Carlos Mora. Al mismo tiempo se formó un grupo de antropólogos como Alberto, Lucy, Flica. Todos hicieron un trabajo solidario para nosotros ya que no podíamos quedarnos en Lima. [...] Les entregamos nuestros documentos y arreglaron muchas cosas en nombre de nosotros. Alberto y Carlos constituyeron CIPA a base de las necesidades de las comunidades. Dijeron que no podían apoyarnos de la nada, que tenían que vivir de algo. HIVOS apoyó a CIPA, compraron un local propio y recibieron sueldos. Teníamos buenas relaciones con Alberto y Carlos, pero empezamos también a formar nuestra propia asociación. [...] Queríamos dejar de depender de otros. Así fue que en noviembre del 79 invitamos a una reunión a los no-indígenas para plantearles nuestras ideas: Queríamos elegir uno para estar en CIPA, para que pueda aprender y después enseñarles a los demás a no depender de otros. Pero los que trabajaron en CIPA dijeron que no, que era una organización de profesionales en Lima«. (Kapitel VIII.2)

Nugkuag, Evaristo: „Queríamos hacer una confederación, pero Belaúnde era en contra de organizaciones gremiales que denominaba >comunistas $\prec$. Por eso cambiamos el nombre a sasociación<. Y porque los gobiernos siempre hablan de desarrollo, ¿por qué entonces nosotros no«? (Kapitel VIII.2)

Nugkuag, Evaristo: »Las financieras quieren ver éxitos para apoyarte. Pan para el Mundo y Oxfam América, que en este momento colaboraron con mi federación $\mathrm{CAH}$ se dejaron convencer que también sería bueno apoyar a AIDESEP [...] «. (Kapitel VIII.2)

Orozco, Adrián: »Hay que cambiar de concepción. Muchos antropólogos ven al indio como un ente folclórico: El indio es el que anda sin zapatos en su traje folclórico«. (Kapitel V.4)

Palacín, Miguel: »En los andes mobilizamos mucha gente y reclamamos, resistimos, en los ande se negocia muy poco. En cambio en la amazonia si se negocia, ¿por qué? Porque los territorios en los andes son pocos pero muchos pueblos, entonces no hay nada que discutir. En la amazonia es al revés: mucho territorio, pocos pueblos, para no ser sometidos lo que hacen 
es negociar. Hay un intercambio: Nosotros transmitimos la experiencia que hay que resistir. AIDESEP tenía mucho miedo a mobilizar, decía, a nosotros no nos gusta estas cosas pero ahora se mobilizan y nosotros estamos aprendiendo que es importante la preparación política, que es importante tener propuestas políticas. Por eso la estructura que estamos armando es andes y amazonía juntos«. (Kapitel IX.5)

Reátegui, Oraldo: »El jóven indígena quiere vivir en la ciudad. Su modelo de personas es el urbano: Renuncio a mi identidad indígena para ser mestizo, porque el mestizo tiene poder. Es una búsqueda de poder, nada más. En las ciudad son dependientes, mientras el indígena en su comunidad es autosuficiente y por eso tiene más autonomía. Las comunidades más distantes, más desconectadas del urbano son las que tienen los mejores niveles de organización«. (Kapitel X.4)

Rivera, Tarcila: ¿»Por qué le critican a uno como indígena cuando escogemos un lugar bonito y un poco más costoso para nuestro encuentro«? (Kapitel X.4)

Rodríguez, Arturo: »Luchamos para que los dejen tranquilos. Pero nosotros ya no queremos volver a vivir de esta forma. Nos identificamos como parte de la sociedad moderna del Perú«. (Kapitel X.4)

Rubio, Mauricio: »Los dirigentes que hoy suben hasta AIDESEP ya no tienen interés en su base. No, lo que ellos quieren como candidatos es conocer la ciudad de Lima, viajar a la ciudad de Lima. En nuestros tiempos se veía aquí en este rincón del Perú la presencia de los representantes. Hoy la directiva de AIDESEP sólo viaja al extranjero, no se intercambian opiniones, no se desarrollan visiones de largo tiempo. Se hace el trabajo porque se paga. Cuando no teníamos nada, trabajamos más«. (Kapitel X.4)

Rubio, Mauricio: »Hace tres años que estoy acá nuevamente, de AIDESEP nada. Antes nosotros teníamos contacto cada día, vía radiofonía. [...] Los hermanos que asuman la responsabilidad se olvidan de sus bases, no sé porqué. Ni por equivocación vienen a conversar. Como indígenas debemos estar más comunicados. [...] Los representantes nacionales no deberían sólo ver por su grupo sociolingüístico, tienen que querer a todos, porque nos están representando a todos! Tal vez tienen mucha información por su zona, aquí no tenemos«. (Kapitel X.4)

Rubio, Mauricio: $\gg \mathrm{Al}$ principio era fuerte, nuestra organización [...], pero con el tiempo se debilitó, sobre todo por los mestizos que llegaron a nuestra comunidad y se casaron con nuestras niñas«. (Kapitel X.4)

Rubio, Mauricio: »Cuando los representantes llegan a la ciudad ya están a nivel de la sociedad de la ciudad«. (Kapitel X.4)

Rufner, Hildebrando: »Ahora tenemos que entrar en la etapa de producción y uso de los ecosistemas y de la biodiversidad por las comunidades 
indígenas y campesinas [...] Tenemos que descentralizar los poderes de AIDESEP y CONAP [...] los gremios políticos no pueden decidir por la gente que quiere sobresalir allá [...]«. (Kapitel VIII.3)

Salazar, Haroldo: »El trabajo político indígena [...] son las tierras comunales, defender los derechos de los pueblos indígenas. No hacemos política de un partido [...] por ejemplo, no es política para ser presidente«. (Kapitel VII)

Salazar, Haroldo: „Son más de 8 millones de hectáreas que tenemos [...]. Queremos [...] luchar por el territorio indígena peruano. [...] nuestra lucha no ha sido para llegar a ser alcaldes, congresistas etc., no, no, nuestra lucha es cómo adquirir más territorios. Una vez logrado esto [...] podemos ganar, porque no somos mucha gente pero entonces tenemos un gran territorio. Entonces podemos llevar congresistas, podemos llegar al congreso«. (Kapitel IX.3)

Salazar, Haroldo: «No sabíamos hasta los años 70 que era comunidad, después vimos que si se debe llamar comunidad«. (Kapitel X.4)

Sarasara, César: "Ya somos peruanos, ya estamos dentro del esquema, dentro del régimen de un estado que no nos pertenece. Por lo tanto tenemos que ser sabios [...] Tenemos que adquirir los instrumentos de la cultura occidental para reforzar nuestra propia cultura«. (Kapitel VII)

Sarasara, César: »Es bueno ser idealistas, pero tenemos que desarrollar una filosofía práctica también. [...] somos peruanos, [...] dentro de un estado que no nos pertenece [...]. Por lo tanto tenemos que ser sabios«. (Kapitel IX.2)

Sarasara, César: »El pueblo indígena debe de actualizarse, debe de pensar hoy, a partir de ahora como afrontar el futuro. Ve que las diferentes empresas vía convenio con el estado sacan recursos de sus tierras, mucho tiempo, no es de ahora y todos se benefician de estos recursos. Se presenta una empresa grande, las ONGs piden dinero, la iglesia pide dinero, el estado saca dinero, todo el mundo saca, todo el mundo pesca pero el indígena nunca ha pescado, el indígena ve que sus recursos salen y espera que el estado le va a ayudar alguna vez pero tampoco el estado le apoya. Creo que tenemos que empezar entonces nuestro diálogo y establecer programas directamente con ellos«. (Kapitel IX.2)

Sarasara, César: »Una vez una alemana que conoce a los Asháninkas un día ha venido a mi oficina y me ha dicho: Tú estás vendiendo conocimiento indígena. Le digo: ¿Yo estoy vendiendo? Muy bien, si tu no quieres que se venda tráeme otra alternativa, si tu me traes otra alternativa vamos hacer otra alternativa«. (Kapitel IX.3)

Sarasara, César: »El indígena [...] ya debe de pensar que alguna empresa que se acerca, muy bien, qué daño va a hacer, debe saber exactamente, qué beneficio va a haber debe saber el indígena y cómo el indígena puede co- 
laborar que no se hagan este tipo de daños. [...] y sobre todo debe decir qué beneficios quiere. Porque nos opongamos o no nos opongamos el estado bajo el principio de que es dueño de todo igual saca los recursos, debemos de tener filosofía práctica también, no dejando una filosofía ideológica«. (Kapitel IX.3)

Sarasara, César: »Los diferentes gobiernos tratan de dar soluciones a los pueblos indígenas. Entonces cada gobierno establece un programa [...] pero cuando ellos salen este programa muere«. (Kapitel IX.4)

Sarasara, César: „Este gobierno ha construido este modelo, la CONAPA, que es interesante pero aún los gobernantes creen que no tenemos capacidad de participación, de aporte académico, intelectual. Entonces lo que hacen es que quieren implementar ellos su pensamiento a través de una institución como la CONAPA«. (Kapitel IX.4)

Sarasara, César: »Los campesinos viven en los andes, los indígenas en la amazonia«. (Kapitel IX.5)

Smith, Richard Chase: »Es un poco contradictoria la visión de ser dirigente porque hay una visión que es muy sacrificado, tienen que pasar mucho tiempo lejos de la familia, a veces ponerse en sitios muy incómodos, donde no hay plata, no comen bien. Pero hay otra visión que es puerta de acceso a dinero, poder y si las condiciones son tales termines durmiendo en hoteles de cinco estrellas«. (Kapitel X.4)

Tsawant, Rosa Marianita: »Antes de llegar aquí pensé que el Foro era como cualquier otra reunión, donde se puede hablar y se buscan soluciones. Pero no es así. Aquí sólo hablan los que tienen posiciones claves al nivel nacional e internacional. Hablan de otras cosas que yo. No puedo hablar como quiero, estoy aquí de observadora«. (Kapitel IV.4)

Tsawant, Rosa Marianita: »Tendría que prepararme muy intensamente durante un año para este encuentro del Foro: Estudiar inglés, aprender como manejar una computadora, aprender los temas relevantes, estudiar a toditas las organizaciones de la ONU. Pero entonces no me quedaría ni tiempo ni fuerza para los problemas de los comuneros. Así que la ONU no es para mi«. (Kapitel IV.6)

Vegas, Hernán: „Ya hay comunidades que han entrado a la civilización. Cuando tienen todavía sus tradiciones por un setenta, ochenta por ciento, no se pueden hacer contratos con las empresas para ellos. Las comunidades que quedan cerca de las ciudades son las que tienen las mejores posibilidades de desarrollo«. (Kapitel X.4) 


\section{Ethnolinguistische Karte des peruanischen Amazonasgebietes}

Abbildung 19

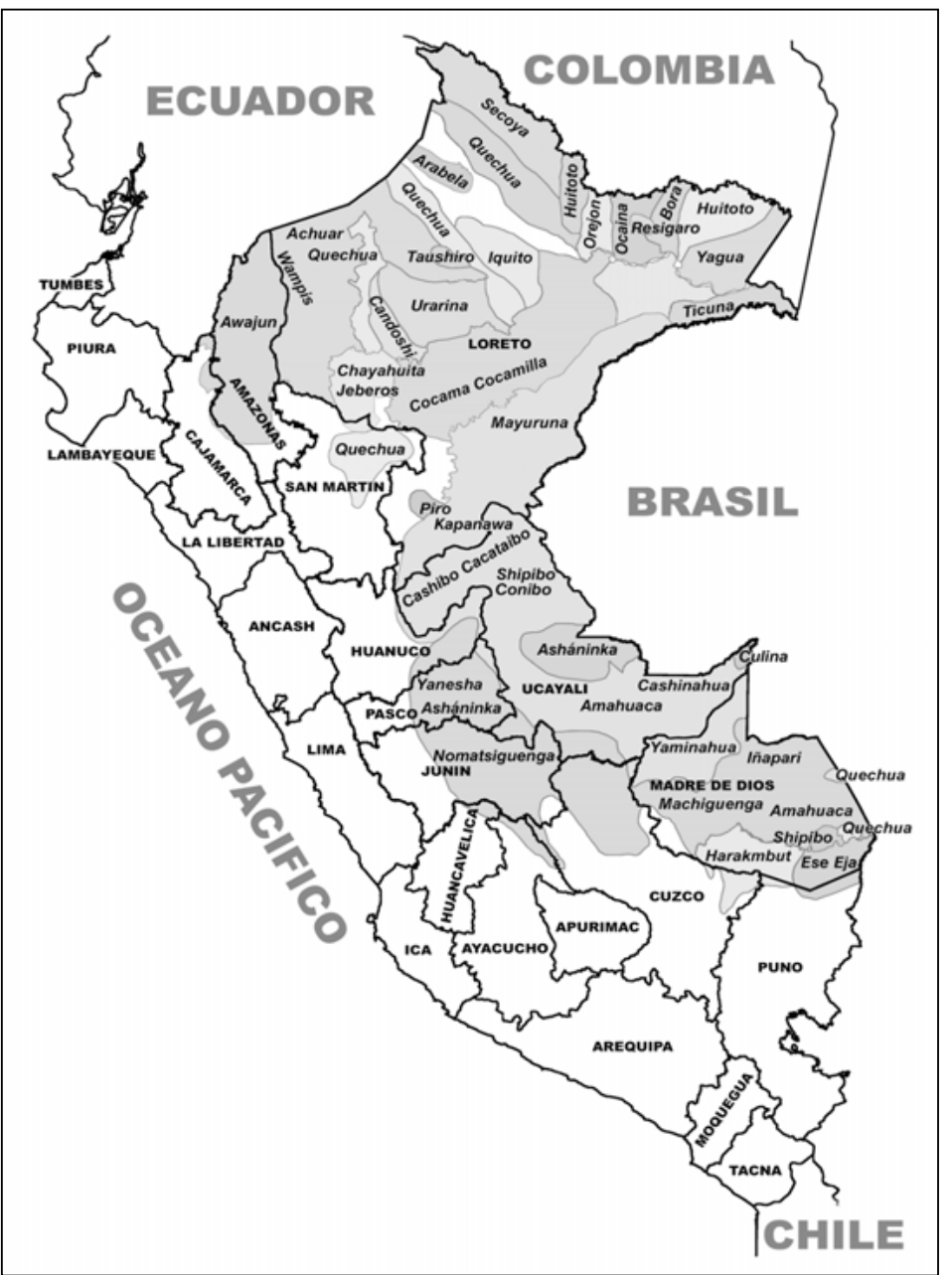

Entwurf: Carsten Möller 2007. 


\section{Schaubilder}

UN-Teilnehmer beim Forum und ihre institutionelle Bindung an das System der Vereinten Nationen

Abbildung 20

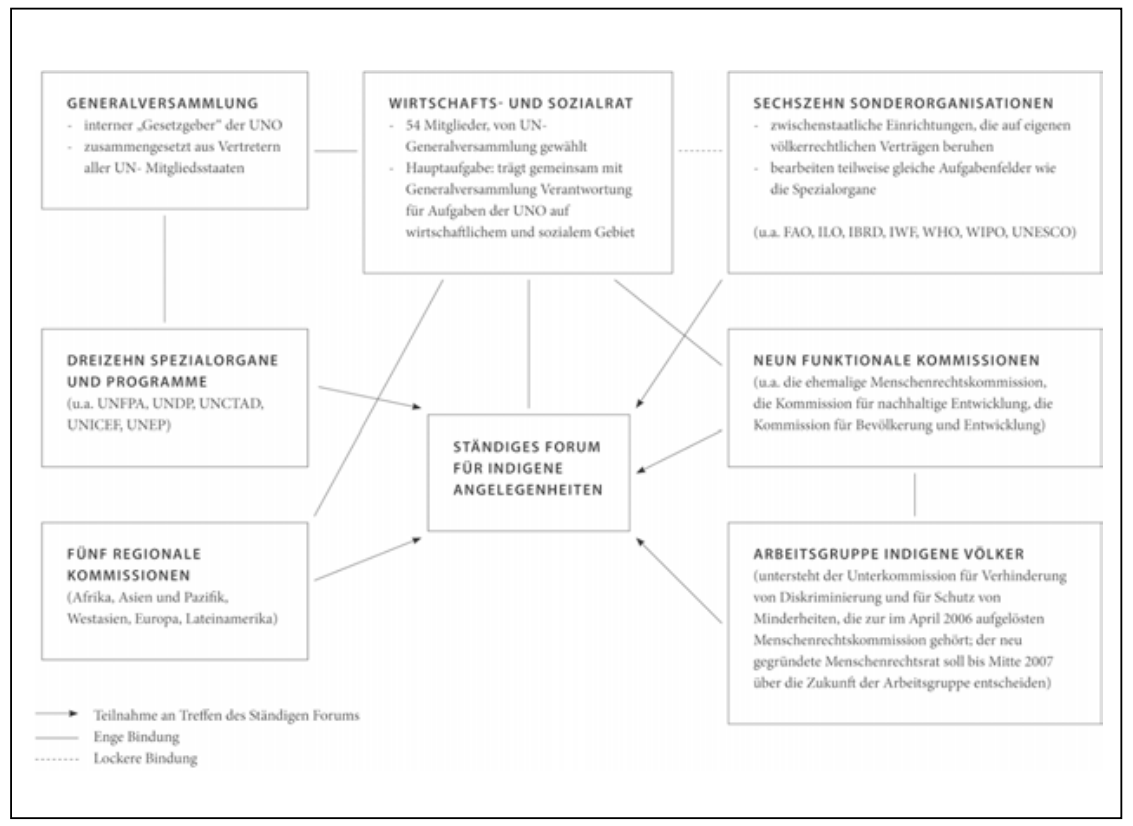

Entwurf: Torsten Hartmann 2006. 
Stellung des Ständigen Forums für indigene Angelegenheiten und der Arbeitsgruppe indigene Völker im UN-System

\section{Abbildung 21}

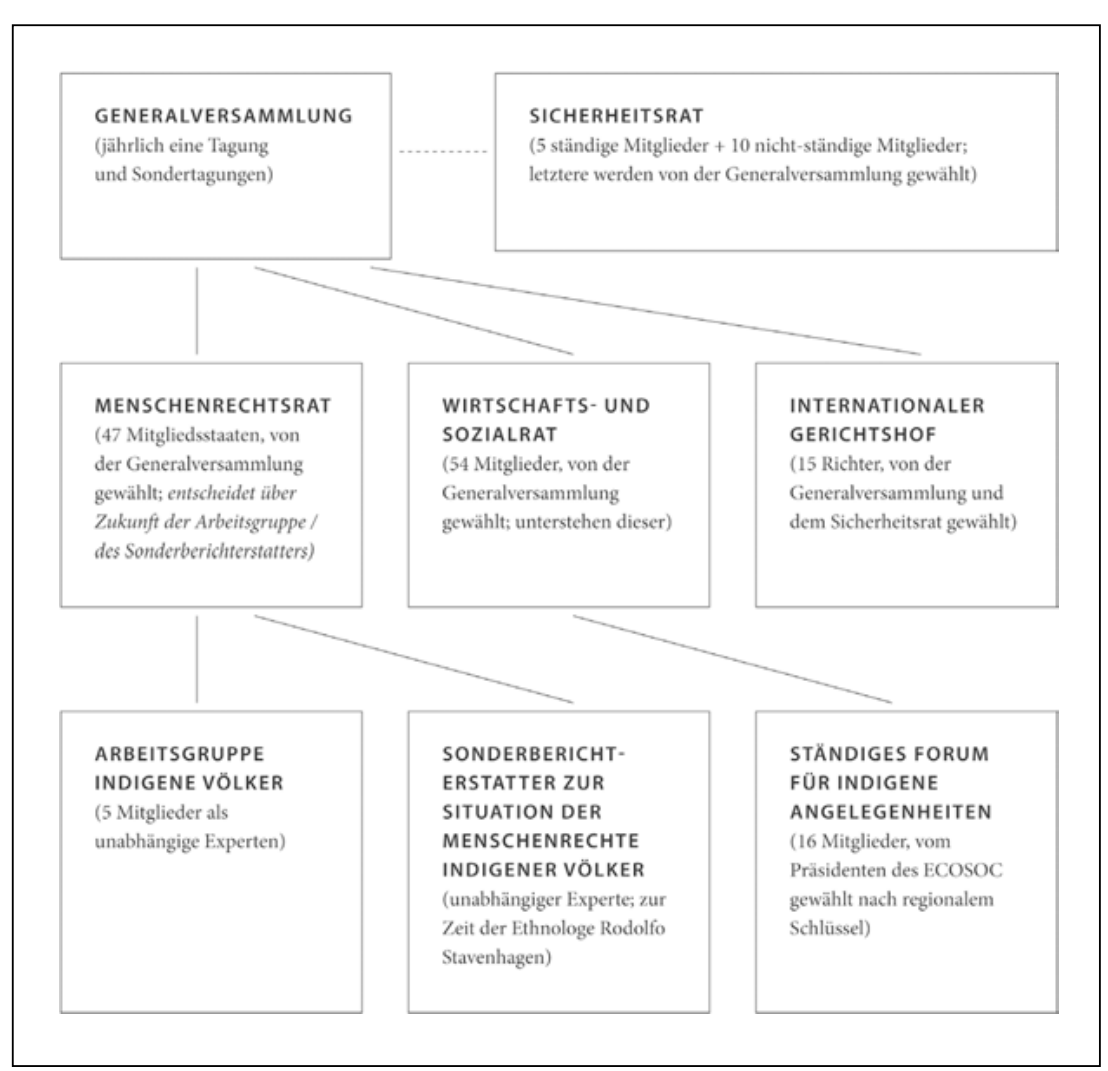

Entwurf: Torsten Hartmann 2006. 
Lokale, nationale und internationale Netzwerkarbeit der peruanischen Tieflandindianer

Abbildung 22

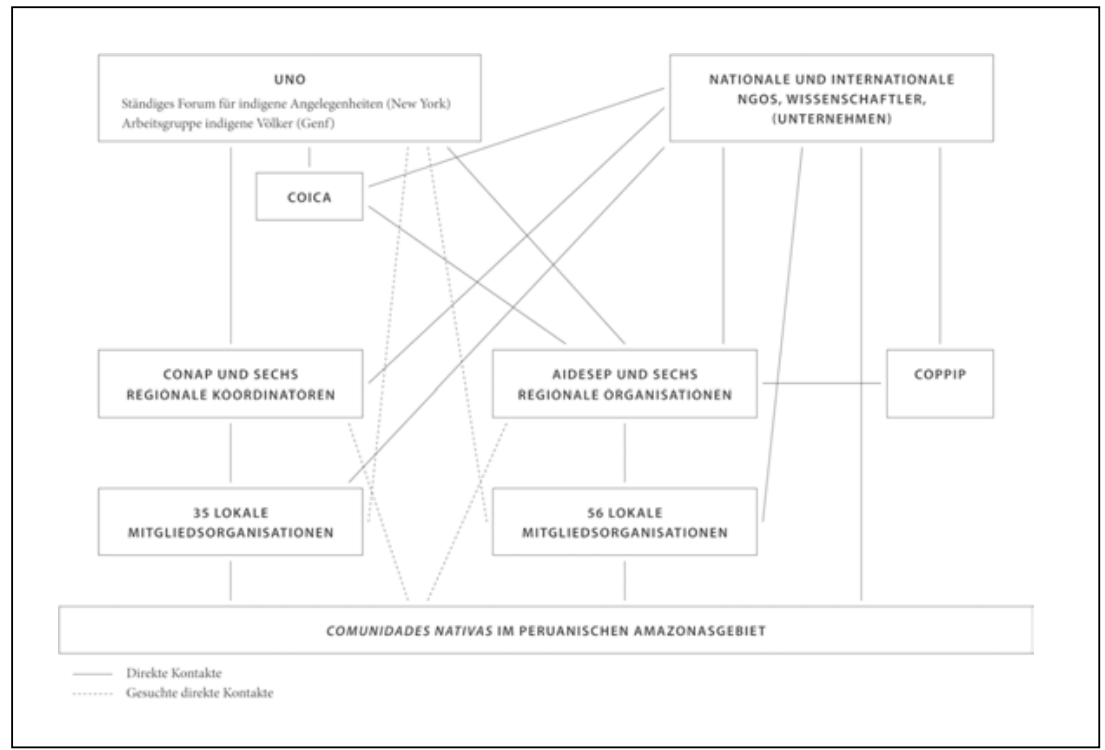

Entwurf: Torsten Hartmann 2006. 


\section{Chronologie: Indigene Repräsentation im UN-Kontext}

1923 Repräsentanten des Irokesen-Zusammenschlusses Six Nations reisen unter der Leitung von Chief Deskaheh nach Genf, um vor dem Völkerbund ihre Autonomie-Forderungen gegenüber der kanadischen Regierung vorzutragen. Der Zutritt bleibt ihnen verwehrt, dennoch kann Chief Deskaheh den Aufenthalt nutzen, um die internationale Öffentlichkeit auf die Situation der Irokesen aufmerksam zu machen. 1924 Eine MaoriDelegation reist nach London, um mit dem britischen König zu verhandeln - jedoch wird ihnen die Audienz verwehrt. Im darauffolgenden Jahr wird der gleichen Delegation auch der Zutritt zu einer Sitzung des Völkerbunds verwehrt.

1946 Der ECOSOC beauftragt die Menschenrechtskommission mit der Erarbeitung von Vorschlägen und Berichten zum Thema Minderheitenschutz. 1947 Die Menschenrechtskommission ruft eine Unterkommission ins Leben, die eine Reihe von Definitionen der Konzepte >Minderheiten`, >indigene Bevölkerungsgruppen` und sindgene Völker` erarbeitet.

1949 Der ECOSOC verabschiedet eine Resolution für eine Studie zu den »sozialen Problemen Eingeborener und anderer unterentwickelter Gruppen des amerikanischen Kontinents«. Doch die Umsetzung dieser Studie wird von den betroffenen Staaten verhindert.

1953 Die ILO veröffentlicht die Studie Indigenous Peoples: Living and Working Conditions of Aboriginal Populations in Independent Countries, die sie bereits 1921 durchgeführt hatte.

1957 Die ILO verabschiedet die Konvention 107 zum Schutz »tribaler und indigener Gruppen« mit einem grundsätzlich assimilatorischen Ansatz. Die Konvention 107 bleibt bis 1989 dennoch die weltweit einzige verbindliche Übereinkunft, die sich überhaupt mit >indigenen Bevölkerungsgruppen` beschäftigt, deren Rechte benennt und Regierungen auf ihre diesbezüglichen Verpflichtungen verweist.

1969 UN-Sonderberichterstatter Hernán Santa Cruz legt eine Studie zu Rassendiskriminierung auf wirtschaftlichem, politischem, sozialem und kulturellem Gebiet vor. In einem Kapitel dieser Studie befasst sich der Autor mit der Lage Indigener und regt seinerseits an, eine umfassende Studie zur Thematik zu erstellen.

1971 Der ECOSOC empfiehlt die Durchführung zweier Studien: eine zum Problem der Diskriminierung indigener Bevölkerungen, die zweite zur Situation von Minderheiten. Damit unterscheidet man im UNKontext erstmals beide Gruppen voneinander.

1974 Die National Indian Brotherhood of Canada erhält als erste indigene Organisation den Beraterstatus für NGOs am ECOSOC. Sie gibt diesen 
Status ein Jahr später an den neu gegründeten World Council of Indigenous Peoples (WCIP) ab.

1975 In Port Alberni, Kanada, kommen Vertreter nord- und lateinamerikanischer indigener Organisationen, aber auch Vertreter aus Europa und Neuseeland zusammen und gründen den WCIP. Diese transnationale indigene Organisation will bereits bestehende Kontakte zwischen Indigenen verschiedener Kontinente stärken und diese an der UNO vertreten.

1977 In Genf veranstaltet der NGO-Sonderausschuss der UNO eine Internationale NGO-Konferenz zur Diskriminierung indigener Bevölkerungsgruppen beider Amerikas, an der über 200 indigene Delegierte teilnehmen.

1978 In Genf findet die UN-Weltkonferenz zur Bekämpfung von Rassismus und Diskriminierung statt, an der erneut indigene Delegierte teilnehmen.

1981 In Genf organisiert die UNO eine Konferenz zum Thema Indigene Völker und ihr Land.

1982 Einrichtung der UN-Arbeitsgruppe indigene Völker, die zwei Mandate erhält: 1. Beobachtung nationaler Entwicklungen, welche die Förderung der Menschenrechte indigener Völker betreffen; 2. Ausarbeitung internationaler rechtlicher Standards für diese Völker.

1983 UN-Sonderberichterstatter Alfonso Martínez Cobo, ein Mitglied der Kommission zur Verhinderung von Diskriminierung und zum Schutz von Minderheiten, legt einen Bericht zur weltweiten Situation indigener Völker vor - bestehend aus fünf Bänden und auf der Grundlage von Informationen aus 37 UN-Mitgliedstaaten. Er empiehlt die Ausarbeitung einer Deklaration über die Rechte und Freiheiten indigener Völker als mögliche Grundlage für eine spätere Konvention. Ferner liefert Martínez Cobo eine bis heute im UN-Kontext gültige Definition des Begriffs >indigene Völker<.

1989 Die ILO-Konvention 169 zu den Rechten indigener und tribaler Völker in unabhängigen Ländern wird verabschiedet - bis heute das einzige verbindliche internationale Abkommen dieser Art.

1993 Die vorlaufige Erklärung der Rechte indigener Völker wird von der UNArbeitsgruppe indigene Völker angenommen und zur Diskussion und schnellstmöglichen Verabschiedung durch die UN-Generalversammlung an die nächst höhere Ebene weitergereicht.

1993 Die UNO erklärt das Jahr zum Internationalen Jahr indigener Bevölkerungsgruppen.

1994 Die UN-Generalversammlung ruft eine internationale Dekade der indigenen Völker der Welt aus (1995-2004). Die Friedensnobelpreisträgerin von 1992 und indigene Menschenrechtlerin Rigoberta Menchú Tum wird zur offiziellen UN-Botschafterin der Dekade erklärt. 
2000 Der ECOSOC beschließt die Einrichtung eines Ständigen Forums für indigene Angelegenheiten. Dessen Ziel ist die Beeinflussung und Kontrolle der Umsetzung indigener Interessen im gesamten UN-System. Neben acht von Regierungen entsandten Experten sind acht sogenannte unabhängige indigene Experten Mitglieder des Forums.

2002 Im Mai diesen Jahres findet die erste Sitzung des Ständigen Forums für indigene Angelegenheiten in New York statt.

2004 Die UN-Generalversammlung ruft eine zweite Dekade der indigenen Völker der Welt aus (2005-2014).

2007 Die UN-Generalversammlung verabschiedet im September mit 143 JaStimmen, vier Gegenstimmen und elf Enthaltungen die Erklärung der Rechte indigener Völker.

\section{Chronologie: Genese nationalstaatlich geprägter Formen indigener Selbstorganisation im peruanischen Tiefland (1959-1987)}

1959 Asháninka im Perené, selva central, gründen die Asociación de Nativos Campas del Perené und bieten ihre Hilfe dem Nationalen Kolonisierungskomitee andiner Migranten an. In einer gemeinsamen Agenda legen die Organisationen fest, dass Schulen für beide Gruppen errichtet, sowie Möglichkeiten des direkten Vertriebs ihrer Produkte geschaffen werden müssen. Sie erreichen den Bau einer Reihe von Flugpisten und Schulen sowie die Demarkierung von Schutzgebieten. 1961 kommt es jedoch zum Bruch des Bündnisses zwischen Migranten und Asháninka, womit auch die Aktivitäten des ethnischen Zusammenschlusses enden.

1969 In Oxapampa, selva central, findet die 1. Konferenz von Amuesha-Führern statt. Repräsentanten aus 20 Amuesha-Gemeinden treffen sich, um ein Memorandum an die peruanische Regierung zu schreiben. In diesem wird die peruanische Regierung aufgefordert, die Siedlungsgebiete der Amuesha als gemeinschaftliche Schutzgebiete zu titulieren, ihnen Zugang zu Krediten und technischer Hilfe zu gewähren sowie die Amuesha als peruanische Staatsbürger anzuerkennen. Der Congreso Amuesha wird ins Leben gerufen.

1970 Asháninka im Pichis und Perené gründen, mit Unterstützung von Funktionären der Regierung unter General Velasco, den Congreso de Nativos Campas.

1971 In der Ucayali-Region treffen sich 150 Shipibo-Conibo aus teilweise bis $\mathrm{zu}$ sieben Tagesreisen voneinander entfernten Gemeinden. $\mathrm{Zu}$ einem sieben Monate später einberufenen zweiten Kongress finden sich bereits ca. 1000 Personen ein. Darüber hinaus nehmen Mitarbeiter des peruanischen 
Landwirtschaftsministeriums und von SINAMOS teil. Die Federación de Comunidades Shipibas (FECONASH) entsteht, die kurze Zeit später durch die Organización de Desarrollo Shipibo (ORDESH) ersetzt wird. Später entsteht noch die Federación de Comunidades Nativas del Ucayali (FECONAU), eine der Gründerorganisationen von AIDESEP.

1975 Am Oberlauf des Marañón gründen Aguaruna und Huambisa unter der Leitung von Evaristo Nugkuag Ikanan und mit Hilfe der spanischen NGO Grupo DAM den Consejo Aguaruna Huambisa (CAH). Diese Chronologie endet mit dem Jahr 1987, in dem der zweite nationale Zusammenschluss CONAP ins Leben gerufen wird, da es mir lediglich um die Darstellung des Etablierungsprozesses indigener Organisationen im peruanischen Amazonasgebiet geht.

1975 In der selva central entsteht eine Vermarktungskooperative von Asháninka, das Comité de Comercialización Agropecuaria de Productos Asháninkas Campas de Marankiaria (CCAPACAM).

1976 entsteht, auch in der selva central, die Federación de Comunidades Nativas del Perené (FECONAPE).

1977 Im unteren Lauf des Huallagas organisieren sich, unterstützt durch das Engagement des US-amerikanischen Ethnologen Anthony Stocks, die Cocamilla, die 1977 die Federación de Comunidades Cocamillas (FEDECOCA) gründen.

1978 Gründung der Central de Comunidades Nativas de la Selva Central (CECONSEC), die unter anderem Namen bereits 1977 als Handelskomitee zur Vermarktung der Produkte der darin zusammengeschlossenen Asháninka entsteht und sich dann in eine politische Organisation wandelt.

1979 Gründung der Coordinadora de las Comunidades Nativas de la Selva Peruana (COCONASEP) durch folgende Organisationen: FECONAU, CAH, Congreso Amuesha und CECONSEC.

1980 Umbennung der COCONASEP in Asociación Interétnica de Desarrollo de la Selva Peruana (AIDESEP).

1980 Das Movimiento Indio Peruano und der WCIP organisieren einen internationalen Kongress, auf dem der Consejo Indio de Sudamérica (CISA) ins Leben gerufen wird, als >Stimme der südamerikanischen Indianer auf internationaler Ebene.

1981 Der Congreso Amuesha löst sich, in Folge einer Reihe interner Konflikte, auf und es entsteht die Federación de Comunidades Yanesha (FECONAYA). Die FECONAYA schließt sich CISA an.

1982 Die erste regionale Organisation entsteht in Madre de Dios: Die Federación Nativa del Río Madre de Dios y Afluentes (FENAMAD). FENAMAD besitzt gleichzeitig den Status einer Föderation, da sie einen direkten Zusammenschluss der Gemeinden darstellt. Sie schließt sich so- 
wohl AIDESEP als auch der Bauerngewerkschaft CCP an sowie Ende der 1980er Jahre der neu entstehenden CONAP.

1984 Gründung der Coordinadora de las Organizaciones Indígenas de la Cuenca Amazónica (COICA) durch AIDESEP und Organisationen aus Bolivien, Brasilien, Ecuador und Kolumbien. Evaristo Nugkuag wird ihr erster Vorsitzender.

1985 AIDESEP erhält den legalen Status einer NGO und kann nun selbstständig Verträge mit internationalen Entwicklungsorganisationen abschließen.

1986 Evaristo Nugkuag wird stellvertretend für AIDESEP, CAH und COICA der Alternative Friedensnobelpreis überreicht, für den Kampf um die Rechte der indigenen Völker des Amazonasgebietes.

1987 Nach einem Treffen des Präsidenten Alan García mit Hunderten von Vertretern von comunidades nativas in Pucallpa wird die Confederación de Nacionalidades Amazónicas del Perú (CONAP) gegründet. CISA organisiert zu diesem Zweck in einem Hotel in Lima einen Kongress für fünfzehn Föderationen aus dem Amazonasgebiet, die den neuen nationalen Zusammenschluss bilden. In der Folge entscheiden sich viele Föderationen für eine Doppelmitgliedschaft in CONAP und AIDESEP. Aber es entstehen im Verlauf der 1990er Jahre auch eine Reihe von Organisationen, Abspaltungen zuvor bestehender Zusammenschlüsse, die den auf nationaler Ebene bestehenden Konflikt zwischen AIDESEP und CONAP auf lokaler Ebene reproduzieren. 


\section{Abbildungs- und Literaturverzeichnis}

\section{Abbildungsverzeichnis}

Abbildung 1: Kongress einer indianischen Organisation im peruanischen Tiefland. Foto: Maren Rößler, 2005.

Abbildung 2: Indianische Repräsentanten aus dem peruanischen Tiefland bei der UNO in Genf. Foto: Dorothy Hodgson, 2004.

Abbildung 3: Sitzung des Ständigen Forums für indigene Angelegenheiten am UN-Hauptquartier in New York. Foto: Maren Rößler, 2005.

Abbildung 4: Teilnehmerzahlen 2002 - 2005. Entwurf: Maren Rößler, 2006.

Abbildung 5: Von indigenen Teilnehmern gestalteter Empfang zu Beginn jeder Sitzungsperiode des Forums. Foto: Maren Rößler, 2005.

Abbildung 6: Die Cafeteria - beliebter Treffpunkt der Teilnehmer während der Sitzungen des Ständigen Forums für indigene Angelegenheiten. Foto: Maren Rößler, 2005.

Abbildung 7: Teilnehmer des Forums, die auf den Lederbänken und an den Computern vor dem Sitzungssaal Netzwerkarbeit betreiben. Foto: Maren Rößler, 2005.

Abbildung 8: Vom Lateinamerika-Caucus bestimmte Sprecher tragen einen gemeinsam erarbeiteten Redebeitrag in der offiziellen Sitzung vor. Foto: Maren Rößler, 2005.

Abbildung 9: Neun der sechzehn Forumsmitglieder der Sitzungsperioden 2005 bis 2007. Am Rednerpult die Vorsitzende Victoria Tauli-Corpuz. Foto: Maren Rößler, 2005.

Abbildungen 10, 11 und 12: Grafische Darstellungen der Abgrenzungsprozesse zwischen indigenen Teilnehmern. Entwurf: Maren Rößler, 2006.

Abbildung 13: Asháninka in der Nähe von Satipo zu Beginn einer Versammlung ihrer Föderatin beim Hissen der peruanischen Nationalflagge und ihrer Organisationsflagge. Foto: Maren Rößler, 2005.

Abbildung 14: Organisationsstruktur AIDESEP. Entwurf: Torsten Hartmann, 2006.

Abbildung 15: Einwohner einer indigenen Gemeinde bei der monatlichen Dorfversammlung. Videobild: Maren Rößler, 2004.

Abbildung 16: Bei der Tanzprobe vor dem Haus von Don Sebastiano. Videobild: Maren Rößler, 2004.

Abbildung 17: Dach und Pfosten der Unterkunft, die Hernán und Ester für ihre Besucher bauen. Foto: Maren Rößler, 2005.

Abbildung 18: Jahresversammlung der Mitglieder einer Föderation. Foto: Maren Rößler, 2005.

Abbildung 19: Ethnolinguistische Karte des peruanischen Amazonasgebietes. Entwurf: Carsten Möller, 2007. 
Abbildung 20, 21 und 22: Schaubilder. Entwurf: Torsten Hartmann, 2006.

\section{Literaturverzeichnis}

AIDESEP (1982): Voz Indígena, Año 1(1-4).

AIDESEP (1983): Voz Indígena, Año 2(5-7).

AIDESEP (1984): Voz Indígena, Año 3(8-11).

AIDESEP (1985): Voz Indígena, Año 4(13-14).

AIDESEP (1989): Voz Indígena, Año 8(21-24).

AIDESEP (1991): Voz Indígena, Año 10(28-29).

AIDESEP (1992): Voz Indígena, Año 11(30-31).

AIDESEP (1993): Voz Indígena, Año 12(36-37).

AIDESEP (2002): Memoria Institucional. Consejo Directivo Nacional 19962002. Lima.

AIDESEP (2003a): Voz Indígena, No. 25. Edición Especial.

AIDESEP (2003b): Consolidado Marco de Plan de Vida de los Pueblos Indígenas de la Amazonía Peruana. Peru, 01.2003.

AIDESEP (2004a): Desafíos para una Economía Indígena Integral para un

Desarrollo con Identidad. Propuesta del Congreso de la Asociación Interétnica de Dearrollo de la Selva Peruana. Lima, 10.2004.

AIDESEP (2004b): Voz Indígena, No. 26.

AIDESEP (2005): Voz Indígena, No. 27. Edición Especial de Aniversario.

Alvarez, Sonia E. (1990): Engendering Democracy in Brazil, Princeton.

Alvarez, Sonia E./Dagnino, Evelina/Escobar, Arturo (Hg.) (1998): Cultures of Politics. Politics of Culture, Boulder.

American Anthropological Association (1947): »Statement on Human

Rights«. In: American Anthropologist 49(4), S. 539-43.

Anaya, James S. (1992): »Normas de Derechos Indígenas en la Ley Internacional Contemporánea«. In: América Indígena 1-2, S. 1-62.

Anaya, James S. (1995): Indigenous Peoples in International Law, New York.

Anderson, Benedict (1998 [1983]): Die Erfindung der Nation. Zur Karriere eines folgenreichen Konzepts, Berlin.

Appadurai, Arjun (1996): Modernity at Large. Cultural Dimensions of Globalization, Minneapolis.

ARPI (o.J.): Defendamos los Derechos de los Pueblos Indígenas Amazónicos. Memoria de un Proceso de Interlocución 2001.

Assies, Willem/Van der Haar, Gemma/Hoekema, André J. (Hg.) (2000):

Challenge of Diversity. Indigenous Peoples and the Reform of the State in Latin America, Amsterdam.

Ávila, Javier (2000): »Entre Archivos y Trabajo de Campo: La Etnohistoria en el Perú«. In: No Hay País Más Diverso. Compendio de Antropología Peruana, hg. v. Carlos Iván Degregori, Lima, S. 180-203. 
Bailey, Frederick, G. (2002 [1969]): »Strategems and Spoils«. In: The Anthropology of Politics. A Reader in Ethnography, Theory and Critique, hg. v. Joan Vincent, Oxford, S. 91-95.

Barclay, Frederica (1991): »Protagonismo del Estado en el Proceso de Incorporación de la Amaznía«. In: Amazonía 1940-1990: El Extravío de una ilusión, hg. v. Frederica Barclay et. al., Roma, S. 43-100.

Barnard, Alan (2004): Kalahari Revisionism, Vienna, and the >Indigenous Peoples` Debate, unveröffentlichter Beitrag im Rahmen des EASA Africanist Network, Bi-Annual Conference of the European Association of Social Anthropologists, Wien, 08-12.09.2004.

Barsh, Russel L. (1986): »Indigenous Peoples: An Emerging Object of International Law«. In: American Journal of International Law 80, S. 369-385.

Barsh, Russel L. (1991): »Political Diversification of the International Indigenous Movement«. In: European Review of Native American Studies 5(1), S. 7-10.

Barth, Frederik (1996 [1969]): »Ethnic Groups and Boundaries«. In: Ethnicity, hg. v. John Hutchinson/Anthony D. Smith, Oxford, S. 75-82.

Béteille, André (1998): »The Idea of Indigenous People«. In: Current Anthropology 39(2), S. 187-191.

Beteta, Christiam (1993): »Pueblos Indígenas de la Selva Peruana: El Desafío Aún No Resuelto de Tierras y Territorios«. In : Reconocimiento y Demarcación de Territorios Indígenas en la Amazonía Cárdenas, hg. v. Martha Correa/Hernán Darío Correa, Bogotá/Londres, S. 192-240.

Bierschenk, Thomas/Olivier de Sardan, Jean-Pierre (Hg.) (2000): Courtiers en développement. Les villages africaines en quête des projets, Paris.

Bierschenk, Thomas/Olivier de Sardan, Jean-Pierre/Chauveau, Jean-Pierre (2001): Politische Makler und Entwicklungsmakler in der Sozialanthropologie: Ein Literaturüberblick. In: Arbeitspapiere zu afrikanischen Gesellschaften, Nr. 49.

Blu, Karen (1980): The Lumbee Problem: The Making of an American Indian People, Cambridge.

Blum, Volkmar (1994a): »Ethnizität und Intervention: Indianerbewegungen und kollektive Menschenrechte als Schwert der Finsternis«? In: Peripherie 55/56, S. 122-138.

Blum, Volkmar (1994b): »Indianerbewegungen in Südamerika: Totengräber der mestizischen Nation«? In: Ibero-Amerikanisches Archiv, Jg. 19 (3-4), S. 213-242.

Blum, Volkmar (1995): »Rezente Indianerbewegungen und neue Identitäten in Lateinamerika«. In: Die fundamentalistische Revolution. Partikularistische Bewegungen der Gegenwart und ihr Umgang mit der Geschichte, hg. v. Wolfgang Reinhard, Reihe Historiae, Bd. 7, Freiburg, S. 249-271. 
Blum, Volkmar (2001): Hybridisierung von unten: Nation und Gesellschaft im mittleren Andenraum, Hamburg.

Boissevain, Jeremy (1974): Friends of Friends. Networks, Manipulators, Coalitions, Oxford.

Boris, Dieter (1998): Soziale Bewegungen in Lateinamerika, Hamburg.

Borofsky, Robert (2001): »WHEN: A Conversation about Culture $\ll$. In: American Anthropologist 103(2), S. 432-446.

Bourdieu, Pierre (1979): Entwurf einer Theorie der Praxis, Frankfurt/Main.

Bourdieu, Pierre (1985): Sozialer Raum und »Klassen«, Frankfurt/Main.

Bourdieu, Pierre (1987): Sozialer Sinn. Kritik der theoretischen Vernunft, Frankfurt/Main.

Bourdieu, Pierre (1991): Language and Symbolic Power, Cambridge.

Bourdieu, Pierre (1997): Die verborgenen Mechanismen der Macht, Hamburg.

Bourdieu, Pierre (2001): Das politische Feld. Zur Kritik der politischen Vernunft, Konstanz.

Bowen, John R. (2000): „Should We Have a Universal Concept of >Indigenous Peoples< Rights? Ethnicity and Essentialism in the Twenty-First Century«. In: Anthropology Today 16(4), S. 12-16.

Brown, John Childs/Delgado, Guillermo (1999): »On the Idea of the Indigenous«. In: Current Anthropology 40(2), S. 211- 212.

Brown, Michael F./ Fernández, Eduardo (1991): Wars of Shadows: The Struggle for Utopia in the Peruvian Amazon, Berkeley.

Brown, Michael F. (1993): »Facing the State, Facing the World: Amazonia's Native Leaders and the New Politics of Identity«. In: L'Homme 33 (126128), S. 307-326.

Brown, Michael F. (1996): »On Resisting Resistance«. In: American Anthropologist 98(4), S. 729-749.

Brysk, Allison (1995): »Turning Weakness into Strength. The Internationalization of Indian Rights«. In: Latin American Perspectives 89, Vol. 23(2), S. 38-57.

Brysk, Allison (2000): From Tribal Village to Global Village. Indian Rights and International Relations in Latin America, Stanford.

Bueno de Mesquita, Mourik (2001): Evaluación de la Gestión de la Organización Indígena AIDESEP-ORAI, Iquitos. Periodo 1998-2001, Oxfam América, Lima.

Casanto Shingari, Raúl (1985): »25 Años de Experiencia Organizativa en la Sociedad Asháninka del Perené«. In: Balances Amazónicos: Enfoques Antropológicos, hg. v. J.M. Arroyo/Jürg Gasché, Iquitos, S. 225-237.

Casanto Shingari, Raúl (1986): Entrevistas: Material para la Historia del Movimiento Organizativo en el Pueblo Asháninca, Manuskript, Iquitos.

Castells, Manuel (1997): The Rise of the Network Society, Malden, Mass. 
CEREC und Gaia Fundation (1993) : Reconocimiento y Demarcación de Territorios Indígenas en la Amazonía, Bogotá/Londres.

Chagnon, Napoleon (1992a): Yanomamö, 4. Auflage, Forth Worth.

Chagnon, Napoleon (1992b): Yanomamö: The Last Days of Eden, San Diego.

Chaumeil, Jean-Pierre (1990): »Les Nouveaux Chefs...Pratiques Politiques et Organisations Indigènes en Amazonie Peruvienne«. In: Problème d'Amerique Latine 96(2), S. 93-113.

Chernela, Janet M. (2005): »The UN and Indigenous Peoples. A Process«. In: Anthropology News, September 2005, S.12-14.

Chirif, Alberto (1969): »En Torno a la Primera Reunión de Líderes Amuesha«. In: Kiario. Boletín del Centro de Investigaciones de Selva (1), S. 712.

Chirif, Alberto (1995): »Movimiento Indígena Amazónico en Perú y Cambios Ocurridos en las Dos Últimas Décadas«. In: Articulación de la Diversidad: Pluralidad Étnica, Autonomías y Democratización en América Latina. Grupo de Barbados, hg. v. Georg Grünberg, Quito, S. 347-371.

Chirif, Alberto (1997): Pueblos Indígenas e Instituciones de Apoyo en la Región de Loreto, Unveröffentlichtes Dokument, Iquitos.

Chirif, Alberto (1998): Municipalidades y Movimiento Indígena. Consultoría Realizada por la Oficina Regional de IBIS para Sudamérica, Iquitos.

Chirif, Alberto (2003): Proyecto de apoyo organizativo, Iquitos.

Chirif, Alberto (2005): A Casi 40 Años de La Sal de los Cerros: Un Libro, un Proceso. Prefacio para una Nueva Edición de La Sal de los Cerros, Manuskript, Iquitos.

Clastres, Pierre (1977): Society Against the State, New York.

Cohen, Jean (1985): »Strategy or Identity: New Theoretical Paradigms and Contemporary Social Movements«. In: Social Research 52 (4), S. 663717.

CONAP (o.J.): Defensa de la Cultura y Biodiversidad de los Pueblos Indígenas, Faltblatt, Lima.

CONAP (2005): INDEPA: Un Proyecto de Institucionalidad Truncada. Pronunciamiento de la Confederación de Nacionalidades Amazónicas del Peru, Lima, 31.10.2005.

Conferencia de Líderes Amuesha (1969): »Memorial Presentado al Gobierno Peruano por la Tribú Amuesha «. In: Boletín del Centro de Investigaciones de la Selva, No. 1, Septiembre 1969, S. 13-17.

Conklin, Beth A. (2002): »Shamans versus Pirates in the Amazonian Treasure Chest «. In: American Anthropologist 104(4), S. 1050-1061.

Conklin, Beth A./Graham, Laura R. (1995): »The Shifting Middle Ground: Amazonian Indians and Eco-Politics«. In: American Anthropologist 97 (4), S. 695-710. 
Corntassel, Jeff J. und Tomas Hopkins Primeau (1995): »Indigenous >Sovereignty< and International Law: Revised Strategies for Pursuing >SelfDetermination<. In: Human Rights Quarterly 17(2), S. 343-365.

Coronil, Fernando (2000): »Towards a Critique of Globalcentrims: Speculations on Capitalism's Nature«. In: Public Culture 12(12), S. 351-374.

Cortez Mondragón, María (2005): »Identidad Cultural de los Pueblos Indígenas de la Amazonía Peruana: Visión y Análisis desde la Educación Superior y la EIB«. In: Los Estudiantes Indígenas Amazónicos de la UNMSM, hg. v. Luis Tejada Ripalda, Ciudad Universitaria, Lima, S. 2334.

Crawhall, Nigel (2004): »The Rise of Indigenous Peoples Civil Society in Africa 1994-2004«. In: Indigenous Affairs 3/4, S. 40-46.

Cunha, Manuela Carneiro da (1997): Points of View on the Amazon Forest: Shamanism and Translation. Robert Hertz Lecture. Association pour la Recherche en Antropologie Sociale. Paris, 09.07.1997.

Daes, Erika-Irene (1989): On the Relations Between Indigenous Peoples and States. In: Without Prejudice: The Eaford International Review of Racial Discrimination, Bd.2.

Daes, Erika-Irene (1994): »Dilemmas posed by the UN Draft Declaration on the Rights of Indigenous Peoples«. In: Nordic Journal of International Law 63(1), S. 205-212.

Dahl, Jens (2004): The UN Decade on Indigenous Peoples. In: Indigenous Affairs 3/4, S. 8-19.

Damonte, Gerardo (2000): »Apuntes sobre el Teniente Gobernador«. In: Autoridad en Espacios Locales. Una Mirada desde la Antropología, hg. v. Juan Ansión/Alejandro Diez/Luis Mujica, Lima, S. 91-108.

Dandler, Jorge (Hg.) (1998): Pueblos Indígenas de la Amazonía Peruana y Desarrollo Sostenible, Lima.

Dandler, Jorge, J.R./ Pulido, Hernández/ Swepston, Lee (1994): Rechte indigener Völker - zur Konvention 169 der OIT, (Reihe Entwicklungsperspektiven, ladok), Kassel.

Dean, Bartholomew (2002): »State Power and Indigenous Peoples in Peruvian Amazonia: A Lost Decade, 1990-2000«. In: The Politics of Ethnicity: Indigenous Peoples in Latin American States, hg. v. David Maybury-Lewis, Cambridge, S. 199-238.

Degregori, Carlos Iván (2000): »Panorama de la Antropología en el Perú: Del Estudio del otro a la Construcción de un Nosotros Diverso«. In: No Hay País Más Diverso. Compendio de Antropología Peruana, hg. v. Carlos Iván Degregori, Lima, S. 20-73.

Descola, Philippe (1988): »La Chefferie Amérindienne dans la l'Anthropologie Politique«. In: Revue Française de Sciences Politiques 38(5), S. 818-826. 
Douglas, Mary (1989): How Institutions Think. Syracuse, NY.

Dreher, Katja (1995): Die Arbeitsgruppe Indigene Völker bei der UNO: Partnerschaft oder Konfrontation? München.

Drostal, Walter (Hg.) (1975): Die Situation der Indios in Südamerika, (Bd. $1+3)$, Wuppertal.

Drostal, Walter (Hg.) (1976): Die Situation der Indios in Südamerika, (Bd. 2), Wuppertal.

Ebrecht, Jörg und Frank Hillebrandt (Hg.) (2004): Bourdieus Theorie der Praxis. Erklärungskraft, Anwendung, Perspektiven, Wiesbaden.

Eckstein, Susan (Hg.) (1989): Power and Popular Protest, Berkeley.

Edelman, Marc (2001): »Social Movements: Changing Paradigms and Forms of Politics«. In: Annual Review of Anthropology 30, S. 285-318.

Eder, Klaus (1989): »Klassentheorie als Gesellschaftstheorie. Bourdieus dreifache kulturtheoretische Brechung der traditionellen Klassentheorie«. In: Klassenlage, Lebensstil und kulturelle Praxis, hg. v. Klaus Eder, Frankfurt/Main, S. 15-43.

Eisenstadt, Shmuel N. (1965): »Transformation of Social, Political, and Cultural Orders in Modernization«. In: American Social Review 30(5), S. 659-673.

Eisenstadt, Shmuel N. (Hg.) (1970): Readings in Social Evolution and Development, Oxford.

Eisinger, Peter K. (1973): »The Conditions of Protest Behavior in American Cities«. In: American Political Science Review 67, S. 11-68.

Erazo-Heufelder, Jeanette (1994): Kultur und Ethnizität. Eine Begriffsrevision am Beispiel andiner Verhältnisse: Salasaca, Ecuador, (Curupira, Bd. 1), Marburg.

Erikson, Philippe (1993): »Une Nébuleuse Compacte: Le Macro-Ensemble Pano«. In: La Remontée de l'Amazone: Anthropologie et Histoire des Sociétés Amazoniennes, hg. v. Philippe Descola/Anne-Christine Taylor, Paris, S. 45-58.

Erikson, Philippe (1996): »Alterity Among the Huni Kuin People in the Amazon«. In: Homme 36(140), S. 144-148.

Escobar, Arturo (1995): Encountering Development: the Making and Unmaking of the Third World, Princeton.

Escobar, Arturo und Sonia E. Alvarez (Hg.) (1992): The Making of Social Movements in Latin America. Identity, Strategy, and Democracy, Boulder.

Field, Les W. (1999): »Complicities and Collaborations. Anthropologists and the >Unacknowledged Tribes` of California«. In: Current Anthropology 40(2), S. 193-209. 
Fischer, Edward F./Brown, McKenna R. (1996): »Introduction: Maya Cultural Activism in Guatemala«. In: Maya Cultural Activism in Guatemala, hg. v. Edward F.Fischer/McKenna R.Brown, Austin, S. 1-18.

Flowers, Nancy M. (1994a): »Campa«. In: Encyclopedia of World Cultures, Vol. VII, South America, hg. v. Johannes Wilbert, Boston, MASS., S. 9092.

Flowers, Nancy M. (1994b): »Cocama«. In: Encyclopedia of World Cultures, Vol. VII, South America, hg. v. Johannes Wilbert, Boston, MASS., S. 3031 .

Flowers, Nancy M. (1994c): »Witoto «. In: Encyclopedia of World Cultures, Vol VII, South America, hg. v. Johannes Wilbert, Boston, MASS., S. 364366.

FORMABIAP-AIDESEP (2005): El Ojo Verde. Cosmovisiones Amazónicas, Lima.

Foster, George (1965): »Peasant Society and the Image of the Limited Good In: American Anthropologist 67(2), S. 293-315.

Foweraker, Joe (1995): Theorizing Social Movements, London.

Franco, Carlos (1990): »Impresiones del Indigenismo«. In: Hueso Húmero 26, S. 44-68.

Friedman, Jonathan (1993): „Will the Real Hawaiian Please Stand: Anthropologists and Native in the Global Struggle for Identity«. In: Bijdragen tot de taal-, land- en volkenkunde, 149(4), S. 737-767.

Friedman, Jonathan (1999): »Indigenous Struggles and the Discreet Charm of the Bourgeosie«. In: Australian Journal of Anthropology 10(1), S. 1-14.

Friedrich, Paul (1970): Agrarian Revolt in a Mexican Village, Englewood Cliffs, New Jersey.

Fröhlich, Gerhard (1994): »Kapital, Habitus, Feld, Symbol. Grundbegriffe der Kulturtheorie bei Pierre Bourdieu«. In: Das symbolische Kapital der Lebensstile. Zur Kultursoziologie der Moderne nach Pierre Bourdieu, hg. v. Ingo Mörth/Gerhard Fröhlich, Frankfurt/Main (u.a.), S. 31-54.

Gabbert, Wolfgang (1993): »Das demokratische Potential sozialer Bewegungen in Lateinamerika«. In: Die Dritte Welt und wir, hg. v. Mohssen Massarat et. al., Freiburg, S. 427-434.

García, Maria Elena/Lucero, José Antonio (2003): Un País sin Indígenas: Repensando la Política Indígena en Perú, unveröffentlichter Vortrag, gehalten im Rahmen des internationalen Seminars >Movimientos Indígenas en Amércia Latina , 22-24.05.2003, Cochabamba, Bolivien.

García-Alix, Lola (1999): The Permanent Forum for Indigenous Peoples. The Struggle for a New Partnership, (Document No. 91), Copenhagen.

García-Alix, Lola (2003): The Permanent Forum on Indigenous Issues, Copenhagen. 
García Hierro, Pedro (2003): »Pueblos y Territorios Indígenas de la Amazonía Andina ante un Nuevo Milenio: Situación y Perspectivas«. In: A Tapestry Woven from the Vicissitudes of History, Place and Daily Life, CD, hg. v. Richard Chase Smith, Lima.

Gareis, Sven Bernhard/Varwick, Johannes (2002): Die Vereinten Nationen. Aufgaben, Instrumente, Reformen, Opladen.

Gasché, Jürg (1998): »Rapports interculturels entre les peuples indiens et la société natinale: portée politique et pédagogique des variétés de discours«. In: DiversCité Langues, En ligne, Vol. III, http://www.uquebec.ca/ diverscite, 03.04.2003.

Gasché, Jürg (2001): L'intellectuel organique dans les rapports interculturels. Relire Gramsci, unveröffentlichter Vortrag auf dem VIII. Congrès international de l'Arc, Genf, 24-28.09.2001.

Gasché, Jorge (2004): »Una Concepción Alternativa y Crítica para Proyectos de Desarrollo Rural en la Amazonía«. In: Crítica de Proyectos y Proyectos Críticos de Desarrollo. Una Reflexión Latinoamericana con Énfasis en la Amazonía, hg. v. Jorge Gasché, Iquitos, S. 105-118.

Geertz, Clifford (1987): Dichte Beschreibung. Beiträge zum Verstehen kultureller Systeme, Frankfurt/Main.

Geertz, Clifford (1997): Spurenlesen: der Ethnologe und das Entgleiten der Fakten, München.

GTZ (2005): Stärkung demokratischer Regierungsführung und zivilgesellschaftlicher Teilhabe, Eschborn, http:/www2.gtz.de/dokumente/bib/060122b.pdf, 10.06.2006.

Gledhill, John (2000): Power and its Disguises: Anthropological Perspectives on Politics, London.

Gleich, Utta von (1997): Indigene Völker in Lateinamerika: Konfliktfaktor oder Entwicklungspotential? Frankfurt/Main.

Godelier, Maurice (1987): Die Produktion der großen Männer, Frankfurt /Main.

Gonzales, José Marín (1990) : »El Estado y el Problema Étnico en el Perú«. In: Ethnicity in Latin America, hg. v. Jan-Åke Alvarsson/Hernán Horna, Uppsala, S. 89-112.

Gow, Peter (1996): »River People: Shamanism and History in Western Amazonia«. In: Shamanism, History and the State, hg. v. Nicholas Thomas/ Caroline Humphrey, Ann Arbor, S. 90-114.

Gow, Peter (2004): Authentic Autodenominations. An Ethnographic Account from Peruvian Amazonia, unveröffentlichter Vortrag im Rahmen der BiAnnual Conference of the European Association of Social Anthropologists, Vienna, 8-12.09.2004.

Graham, Laura (2003): »How Should an Indian Speak? Amazonian Indians and the Symbolic Politics of Language in the Global Public Sphere«. In: 
Indigenous Movements, Self-Representation and the State in Latin America, hg. v. Kay B.Warren/Jean Jackson, Austin, S. 181-228.

Greene, Shane (2004): Paths to a Visionary Politics: Customizing History and Transforming Indigenous Authority in the Peruvian Selva, Dissertation, Ann Arbor.

Grey Postero, Nancy (2006): Now We Are Citizens: Indigenous Politics in Post-Multicultural Bolivia, Stanford.

Grey Postero, Nancy und Leon Zamosc (2004): The Struggle for Indigenous Rights in Latin America, Sussex.

Gutiérrez Estévez, Manuel (2003): »Política Democrática y Pueblos Indios en un Tiempo Postcolonial«. In: Antropológica 21(21), S. 11-42.

Hall, Stuart (1997): »The Local and the Global: Globalization and Ethnicity«. In: Dangerous Liaisons: Gender, Nation and Postcolonial Perspectives, hg. v. Anne McClintock/Aamir Mufti/Ella Shohat, Minneapolis, S. 173187.

Hannerz, Ulf (1987): »The World in Creolisation«. In: Africa 57(4), S. 546557.

Hannerz, Ulf (1996): Transnational Connections: Cultures, Peoples, Places, London.

Hauser-Schäublin, Britta und Ulrich Brautkämper (Hg.) (2002): Ethnologie der Globalisierung: Perspektiven kultureller Verflechtungen, Berlin.

Hausotter, Carola (2002): »Neue Heimat UN«. In: Vereinte Nationen 50(3), S. 119.

Heidemann, Frank (2003): »Politikethnologie«. In: Ethnologie, hg. v. Hans Fischer/Bettina Beer, Berlin, S. 157-178.

Hodgson, Dorothy (1999): »Critical Interventions: Dilemas of Accountability in Contemporary Ethnographic Research«. In: Identities 6(2-3), S. 201224.

Hodgson, Dorothy (2002): »Introduction: Comparative Perspectives on the Indigenous Rights Movement in Africa and the Americas«. In: American Anthropologist 104(4), S. 1037-1049.

Hutchinson, Sharon (2000): »Nuer Ethnicity Militarized«. In: Anthropology Today 16(3), S. 6-13.

INEI/UNICEF (1997) : Perú: La Población de las Comunidades Indígenas de la Amazonía, Lima.

Inda, Jonathan Xavier/Rosaldo, Renato (Hg.) (2002): The Anthropology of Globalization. A Reader, Malden, MA.

IWGIA (2005): Mundo Indígena, Copenhagen.

Jackson, Jean (1976): »Vaupés Marriage: A Network System in the Northwest Amazon«. In: Regional Analysis. Social Systems, Bd. 2, hg. v. Carol A. Smith, New York, S. 65-93. 
Jackson, Jean (2003): „Contested Discourses of Authority in Colombian National Indigenous Politics: The 1996 Summer Takeovers«. In: Indigenous Movements, Self-Representation, and the State in Latin America, hg. v. Kay B. Warren/Jean Jackson, Austin, S. 81-122.

Janning, Frank (1991): Pierre Bourdieus Theorie der Praxis, Opladen.

Jaquette, Jane (1994): The Women's Movement in Latin America, Boulder, $\mathrm{CO}$.

Javo, Áile (2004): »Cooperation and Partnership«. In: Indigenous Views on Development and Cooperation, hg. v. AECI, Madrid, S. 181-199.

Jelin, Elizabeth (1998): »Toward a Culture of Participation and Citizenship: Challenges for a More Equitable World«. In: Cultures of Politics. Politics of Culture, hg. v. Alvarez, Sonia E. et al., Boulder, S. 405-421.

Karsten, Rafael (1935): The Head-Hunters of Western Amazonas: The Life and Culture of the Jibaro Indians of Eastern Ecuador and Peru, Leipzig.

Kenrick, Justin und Jerome Lewis (2004): »Indigenous Peoples' Rights and the Politics of the Term >Indigenous««. In: Anthropology Today 20(2), S. 4-9.

Kollewe, Carolin (2002): Die Neue Nation. Diskursstrategien der indianischen Befreiungsbewegung EZLN in Mexiko, Münster.

Kramer, Fritz (2000): »Körperschaft«. In: Wörterbuch der Ethnologie, hg. v. Bernhard Streck, Wuppertal, S. 126-129.

Kristal, Efraín (1991): Una Visión Urbana de los Andes. Génesis y Desarrollo del Indigenismo en el Perú: 1848-1930, Lima.

Kuper, Adam (2003): »The Return of the Native«. In: Current Anthropology 44, S. 389-402.

Kurtz, Donald V. (2001): Paradigms and Power, Cambridge, MA.

Kymlicka, Will (1999): »Theorizing Indigenous Rights«. In: University of Toronto Law Journal 49, S. 281-293.

Laufer, Anke (2000): Rassismus, ethnische Stereotype und nationale Identität in Peru, Ethnologische Studien Bd. 34, Münster.

Lehm, Zulema (2003): »Avizorando los Retos para los Pueblos Indígenas de Amércia Latina en el Nuevo Milenio: Economía Indígena y Mercado en la Amazonía Andina: Avances, Limitaciones y Reto«. In: A Tapestry Woven from the Vicissitudes of History, Place and Daily Life, CD, hg. v. Richard Chase Smith, Lima.

Lévi-Strauss, Claude (1967): »The Social and Psychological Aspects of Chieftainship in a Primitive Tribe: The Nambikuara of North Western Mato Grosso«. In: Comparative Political Systems, hg. v. Ronald Cohen /John Middleton, Garden City, S. 45-62.

Lévi-Strauss, Claude (1973 [1955]): Tristes Tropiques, Paris.

Lewis, Oscar (1966): La Vida. A Puerto Rican Family in the Culture of Poverty, New York. 
Lindig, Wolfgang/Mark Münzel (1978): Band 2: Mittel- und Südamerika, München.

Linnekin, Jocelyn (1992): »On the Theory and Politics of Cultural Construction in the Pacific«. In: Oceania 62 (3), S. 249-261.

Lipsky, Michael (1968): »Protest as Political Resource«. In: American Political Science Review 62, S. 1144-58.

Lowenthal, Abraham (1983): »The Peruvian Experiment Reconsidered«. In: The Peruvian Experiment Reconsidered, hg. v. Abraham Lowenthal/Cynthia MacClintock, Princeton, S. 415-430.

Lowie, Robert H. (1948): »Some Aspects of Political Organization among the American Aborigines«. In: Journal of the Royal Anthropological Institute 78(1-2), S. 11-24.

Lozano Vallejo, Ruth (2000): Análisis de la Problemática de la Educación Bilingüe en la Amazonía Peruana, Lima.

Lunnebach, Silke (2004): Neuere Entwicklungen indigener Interessenvertretungen in Ecuador anhand ausgewählter Beispiele, unveröffentlichte Magisterarbeit, Institut für vergleichende Kulturwissenschaften, Marburg.

Mader, Elke/Sharup, Francisco (1993): »Strategien gegen Ausgrenzung und Assimilierung. Die Föderation der Shuar und Achuar im ekuadorianischen Amazonasgebiet«. In: Kultur, Identität und Macht. Ethnologische Beiträge zu einem Dialog der Kulturen der Welt, hg. v. Thomas Fillitz et al., Frankfurt/Main, S. 109-122.

Mader, Elke (2001): »Kulturelle Verflechtungen. Hybridisierung und Identität in Lateinamerika«. In: Lateinamerika im Umbruch. Geistige Strömungen im Globalisierungsstress, hg. v. Axel Borsdorf et al., Innsbruck, S. 77-86.

Maihold, Günther (1986): Identitätssuche in Lateinamerika: das indigenistische Denken in Mexiko, Saarbrücken, Fort Lauderdale.

Maihold, Günther (1988): José Carlos Mariátegui: nationales Projekt und Indio-Problem. Zur Entwicklung der indigenistischen Bewegung in Peru, Frankfurt/Main.

Marcus, George (1995): »Ethnography in/of the World System: The Emergence of Multi-Sited Ethnography«. In: Annual Review of Anthropology 24, S. 95-117.

Markowitz, Fran (2004): »Talking about Culture«. In: Anthropological Theory 4(3), S. 329-352.

Martínez, Héctor/Samaniego, Carlos (1977): Política Indigenista en el Perú: 1946-1969. Cuadernos CEPES, No. 4, Lima.

Massey, Doreen (1994): Space, Place and Gender, Cambridge.

Maybury-Lewis, David (1967): Akwe-Shavante Society, Oxford.

Maybury-Lewis, David (Hg.) (1979): Dialectical Societies: The Ge and Bororo of Central Brazil, Cambridge. 
Maybury-Lewis, David (2002): The Politics of Ethnicity: Indigenous Peoples in Latin American States, Cambridge.

McAdam, Doug/Snow, David A. (1997): »Introduction: Social Movements: Conceptual and Theoretical Issues«. In: Social Movements. Readings on their Emergence, Mobilization, and Dynamics, hg. v. Doug McAdam /David A.Snow, Los Angeles, S. XVIII-XXVI.

McAdam, Doug/Tilly, Charles /Tarrow, Sidney (Hg.) (2001): Dynamics of Contention, Cambridge.

Menchú, Rigoberta (1998): Rigoberta: La Nieta de los Mayas, México D.F.

Menget, Patrick (1993): »Les Frontières de la Chefferie: Remarques sur le Système Politique du Haut Xingu (Brésil)«. In: La Remontée de 1'Amazone: Anthropologie et Histoire des Sociétés Amazoniennes, hg. v. Philippe Descola/Anne-Christine Taylor, Paris, S. 59-76.

Merton, Robert (1957): Social Theory and Social Structure, Glencoe, Ill.

Michels, Robert (1949): Political Parties: A Sociological Study of the Oligarchical Tendencies of Modern Democracy. Glencoe, Ill.

Minde, Henry (2005 [1995]): The International Movement of Indigenous Peoples: An Historical Perspective, http://www.uit.no/ssweb/dok/series /n02/en/003minde.htm, 12.02.2005.

Mintz, Sidney (1985): Sweetness and Power, New York.

Montejo, Victor (1993): »In the Name of the Pot, the Sun, the Broken Spear, the Rock, the Stick, the Idol, Ad Infinitum \& Ad Nauseam: An Exposé of Anglo-Anthropologists' Obsessions with the Invention of Mayan Gods«. In: Red Pencil Review: A Journal of Native American Studies 9(1), S. 1216.

Montejo, Victor/Akab', Q'anil (1992): Brevísima Relación Testimonial de la Continua Destrucción del Mayab' (Guatemala), Providence, R.I.

Montoya, Rodrigo/Burgos, Hernando/Paredes, Martín (2001): »En la Selva Sí Hay Estrellas: Una Entrevista con Stefano Varese«. In: Quehacer 128, S. 98-105.

Morin, Françoise (1992): »Vers une Déclaration Universelle des Droits des Peuples Autochtones«. In : Les Minorités en Europe: Droits Linguistiques et Droits de l'Homme, hg. v. Henri Giordan , Paris, S. 493-507.

Morin, Françoise/Saladin D’Anglure, Bernard (1994): Le Développment Politique des Peuples Autochtones dans les Etats-Nations. In: La Réinvention de la Démocratie: Ethnicité et Nationalismes en Europe et dans les Pays du Sud, Gosselin, hg. v. Gabriel Van Haecht/Anne Van Vecht, Paris, S. 189-204.

Muehlebach, Andrea (2001): ") Making Place at the United Nations: Indigenous Cultural Politics at the UN Working Group on Indigenous Populations«. In: Cultural Anthropology 16(3), S. 415-448. 
Muehlebach, Andrea (2003): »What Self in Self-Determination? Notes from the Frontiers of Transnational Indigenous Activism«. In: Identities: Global Studies in Culture and Power 10, S. 241-268.

Mühlmann, Wilhelm E. (1961): Chiliasmus und Nativismus, Berlin.

Münzel, Mark (1984): »Die vergessene Geschichte. Vom Anfang und vom Ende indianischer Sonderwege«. In: Journal für Geschichte 5, S. 36-41.

Münzel, Mark (1985): »Der vorläufige Sieg des indianischen Funktionärs über den indianischen Medizinmann in Lateinamerika. Anmerkungen zum europäischen Diskurs über ethnische Minderheiten in der Dritten Welt«. In: Peripherie. Zeitschrift für Politik und Ökonomie in der Dritten Welt, S. 5-17.

Münzel, Mark (1986): »Neue Formen der Opposition bei Indianern«. In: Lateinamerika vor der Entscheidung. Ein Kontinent sucht seinen Weg, hg. v. Theo Ginsburg/Monika Ostheider, Frankfurt/Main, S. 67-84.

Münzel, Mark (1993): »Traditionsbruch als Tradition. Indianisches in der indianischen ethnischen Bewegung in Brasilien«. In: Ibero-Amerikanisches Archiv. Zeitschrift für Sozialwissenschaften und Geschichte, S. 243-270.

Münzel, Mark (Hg.) (1978): Die indianische Verweigerung. Lateinamerikas Indianer zwischen Ausrottung und Selbstbestimmung, Reinbek bei Hamburg.

Nash, June (1997): »The Fiesta of the World: The Zapatista Uprising and Radical Democracy in Mexico«. In: American Anthropologist 99, S. 261274.

Niezen, Ronald (2003): The Origins of Indigenism. Human Rights and the Politics of Identity, Berkeley.

Oakdale, Suzanne (2004): »The Culture-Conscious Brazilian Indian: Representing and Reworking Indianess in Kayabi Political Discourse «. In: American Ethnologist 31(1), S. 60-75.

Ökumenischer Ausschuss für Indianerfragen (Hg.) (1982): Indianer-Reader : Dokumente und Aufsätze zum Aufbruch indianischer Völker in Mittelund Südamerika, red. v. Günter Dulon, Mettingen.

Orlove, Benjamin (1993): »Putting Race in its Place: Order in Colonial and Postcolonial Peruvian Geography«. In: Social Research 60(2), S. 301-336.

Ortner, Sherry (1984): »Theory in Anthropology since the Sixties«. In: Comparative Studies in Society and History 26 (1), S. 126-166.

Ortner, Sherry (1995): »Resistance and the Problem of Ethnographic Refusal«. In: Comparative Studies in Society and History 37(1), S. 173-93.

Oliver-Smith, Anthony (2005): »Ethnographic Snapshot of the UN Permanent Forum«. In: Anthropology News, September 2005, S.15-16.

Pacheco, Luis Calderón (2000): »Imágenes de Otredad y de Frontera : Antropología y Pueblos Amazónicos«. In: No Hay País Más Diverso. Compe- 
ndio de Antropología Peruana, hg. v. Carlos Iván Degregori, Lima, S. 235-277.

Paley, Julia (2001): Marketing Democracy: Power and Social Movements in Post-Dictatorship Chile, Berkeley.

Perú Ministerio de Salud (2002): Análisis de la Situación del Pueblo Shipibo Konibo, Lima.

Petermann, Werner (2004): Geschichte der Ethnologie, Wuppertal.

Posey, Darrel A./Dutfield, Graham (1996): Beyond Intellectual Property: Toward Traditional Resource Rights for Indigenous Peoples and Local Communities, Ottawa.

Pritchard, Sarah (2001): Der völkerrechtliche Minderheitenschutz. Historische und neuere Entwicklungen, Berlin.

Rabineau, Phyllis (1975): »Artists and Leaders: The Social Context of Creativity in a Tropical Forest Culture«. In: The Cashinahua of Eastern Peru. Studies in Anthropology and Material Culture, Vol. 1, hg. v. Kenneth M. Kensinger/ Jane Powel Dwyer, Bristol, S. 87-109.

Ramos, Alcida Rita (1994): »The Hyperreal Indian«. In: Critique of Anthropology 14(2), S. 153-171.

Ramos, Alcida (1998): Indigenism: Ethnic Politics in Brazil, Madison, WI.

Ramos, Alcida (2003a): „Cutting through State and Class: Sources and Strategies of Self-Representation in Latin America«. In: Indigenous Movements, Self-Representation and the State in Latin America, Kay B. Warren/Jean Jackson, Austin, S. 251-279.

Ramos, Alcida (2003b): »The Return of the Native. Comments«. In: Current Anthropology 44(3), S. 397-398.

Redfield, Robert (1941): The Folk Culture of Yucatan, Chicago.

Rehbein, Boike (2003): ») Sozialer Raum In: Pierre Bourdieus Theorie des Sozialen. Probleme und Perspektiven, hg. v. Boike Rehbein/Gernot Saalmann/Hermann Schwengel, Konstanz, S. 77-93.

Renard-Casevitz, Marie-France (1993): »Guerriers du Sel, Sauniers de la Paix«. In: La Remontée de l'Amazone: Anthropologie et Histoire des Sociétés Amazoniennes, hg. v. Philippe Descola/Anne-Christine Taylor, Paris. S. 25-43.

Rivière, Peter G. (1984): Individual and Society in Guiana: A Comparative Study of Amerindian Social Organization, Cambridge.

Rößler, Maren (2004): Ringen um Vielfalt in der Einheit. Rigoberta Menchú und das Movimiento Maya in Guatemala, Leipzig.

Rosa, Hartmut (2001): »Politisches Handeln und die Entstehung des Neuen in der Politik«. In: Konzepte politischen Handelns, hg. v. Harald Bluhm /Jürgen Gebhardt, Baden-Baden, S. 23-42. 
Roldán Ortega, Roque (2004): Territorios, Recursos Naturales y Convenciones Internacionales, Quito.

Rosengren, Dan (1987): In the Eyes of the Beholder. Leadership and the Social Construction of Power and Dominance among the Matsigenka of the Peruvian Amazon, Göteborg.

Rottenburg, Richard (1995): „OPP. Geschichten zwischen Europa und Afrika«. In: Kursbuch 120: Korruption, S. 90-106.

Rottenburg, Richard (2002): Weit hergeholte Fakten, Stuttgart.

Rummenhöller, Klaus (2005): Jäger und Sammler unter Naturschutz stellen: Kritische Überlegungen zur Ausweisung des Nationalparks Alto Purús (Perú), überarbeiteter Vortrag gehalten auf der Tagung INDIEGEGENWART, 04.2004, Berlin.

Sahlins, Marshall (1974): Stone Age Economy, New York.

Sahlins, Marshall (1993): »Goodbye to Tristes Tropes: Ethnography in the Context of Modern World History«. In: Journal of Modern History 65, S. $1-25$.

Saladin D’Anglure, Bernard (1992): »La Conférence Inuit Circumpolaire et la Protection des Droits Collectifs des Peuples«. In : Les Minorités en Europe. Droits Linguistiques et Droits de L'Homme, hg. v. Henri Giordan, Paris, S. 523-536.

Sam Colop, Luis Enrique (1991): Jub'aqtun Omay Kuchum K'aslemal: Cinco Siglos de Encubrimiento. Seminario Permanente de Estudios Mayas, Cuaderno No. 1, Ciudad de Guatemala.

Sánchez, Ketty Judith (2005): »La Voz de los Jóvenes«. In: Voz Indígena (27), S. 23-24.

Sanders, Douglas (1980): The Formation of the World Council of Indigenous Peoples,http://www.cwis.org/fwdp/International/wcipinfo.txt, 15.02.2005.

Santamaria, Angela (2006): »Indigenous Peoples and Legal Practices. Indigenous Jurisdiction in Colombia and the Production of International Law in the United Nations«. In: The Artifices of Government. On the Appropriation, the Use and the Formation of the State. Conference Reader, Halle /Saale, S. 42-44.

Santos Granero, Fernando (1993): »From Prisoner of the Group to Darling of the Gods«. In: L'Homme 126-128/33 (2-4), S. 213-230.

Santos Granero, Fernando (1996): »Introducción. Hacia una Antropología de lo Contemporáneo en la Amazonía Indígena«. In: Globalización y Cambio en la Amazonía Indígena, Vol. I, hg. v. Fernando Santos Granero, Quito, S. 8-43.

Santos Granero, Fernando/Barclay, Frederica (1998): Selva Central. History, Economy and Land Use in Peruvian Amazonia, Washington/London.

Santos, Granero, Fernando/Barclay, Frederica (2000): Tamed Frontiers: Economy, Society, and Civil Rights in Upper Amazonia, Boulder. 
Saugestad, Sidsel (2001): „»Contested Images: >First Peoples` or >Marginalised Minorities` in Southern Africa. In: Africa's Indigenous Peoples: >First Peoples $\prec$ or $>$ Marginalised Minorities $\prec$, hg. v. Alan Barnard/Justin Kenrick, Edinburgh.

Saudestad, Sidsel (2004): »On the Return of the Native«. In: Current Anthropology 45(2), S. 263-264.

Schlee, Günther (1985): »Mobile Forschung bei mehreren Ethnien: Kamelnomaden Nordkenias«. In: Feldforschungen, hg. v. Hans Fischer, Berlin, S. 203-218.

Scott, James (1998): Seeing Like a State, New Haven.

Selznick, Philip (1948): »Foundations of the Theory of Bureaucracy«. In: American Sociological Review 13, S. 25-35.

Siebert, Ute (1997a): Die Kategorie >indigen UNO, unveröffentlichte Magisterarbeit am Institut für Europäische Ethnologie, Philosophische Fakultät I, Humboldt-Universität zu Berlin.

Siebert, Ute (1997b): »Die Bedeutung des Indigenenbegriffs im UNO-System«. In: Tsantsa 2, S. 76-91.

Siedler, Rachel (2002): Multiculturalism in Latin America: Indigenous Rights, Diversity and Democracy.

Slater, David (Hg.) (1985): New Social Movements and the State in Latin America, Amsterdam.

Smith, Richard Chase (1969): La Conferencia de Líderes Amuesha. In: Kiario 1.

Smith, Richard Chase (1983): »La Ideología Liberal y las Comunidades Indígenas en el Perú Republicano«. In: América Indígena 43(3), S. 585600 .

Smith, Richard Chase (1996): »Las Políticas de la Diversidad. Coica y las Federaciones Etnicas de la Amazonia«. In: Pueblos Indios, Soberanía y Globalismo, hg. v. Stefano Varese, Quito, S. 81-125.

Smith, Richard Chase (2002a): »Los Indígenas Amazónicos Suben al Escenario Internacional: Reflexiones sobre el Accidentado Camino Recorrido«, Manuskript. [Veröffentlicht in: Françoise Morin/Roberto Santana (Hg.): Lo Transnacional: Instrumento y Desafío para los Pueblos Indígenas, Quito.]

Smith, Richard Chase (2002b): »El Don que Hiere. Reciprocidad y Gestión de Proyectos en la Amazonía Indígena«. In: El Ciudado de los Bienes Comunes, hg. v. Richard Chase Smith, Lima, S. 155-179.

Smith, Richard Chase/Wray, Natalia (Hg.) (1995): Amazonía: Economía Indígena y Mercado, Quito.

Soria, Carlos (2001): »Aportes para el Análisis de la Normatividad para el Desarrollo Sostenible de la Amazonía en la Década Fujimori «. In: Desarrollo Sostenible y Descentralizado de la Amazonía Peruana. I Encuentro 
Macroregional de Organizaciones indígenas y Campesinas, hg. v. COICAP/Foro Ecológico del Perú/Red Perú/Iniciativas de Concertación para el Desarrollo Local, Lima, 20-22.11.2001.

Spivak, Gayatri Chakravorty (1988): In Other Worlds. Essays in Cultural Politics, New York.

Stamatopoulou, Elsa (1994): »Indigenous Peoples and the United Nations: Human Rights as a Developing Dynamic «. In: Human Rights Quarterly 16, S. 58-81.

Stocks, Anthony W. (1981): Los Nativos Invisibles, Lima.

Stokes, Susan (1995): Cultures in Conflict: Social Movements and the State in Peru, Berkeley.

Stoll, David (1982): Fishers of Men or Founders of Empire? The Wycliffe Bible Translators in Latin America, London.

Streck, Bernhard (1995): »Geben und Nehmen«. In: Kursbuch 120: Korruption, 1-8.

Ströbele-Gregor, Juliana (1992): »Vom indio zum mestizo...zum indio«. In:

Die Wilden und die Barbarei. Lateinamerika - Analysen und Berichte Bd.

16, hg. v. Dietmar Dirmoser et al., Münster/Hamburg, S. 95-112.

Ströbele-Gregor, Juliana (1994): »Politische Kultur der Aymara und Quechua

in Bolivien - Formen des eigenständigen Umgangs mit der Moderne«. In:

Kosmos in den Anden, hg. v. Max Peter Baumann, Düsseldorf, S. 458488.

Ströbele-Gregor, Juliana (Hg.) (2000): »Zukunft gestalten: Herausforderungen an die indigenen Bewegungen in Lateinamerika«. In: Indiana 17/18, S. 9-29.

Survival International (1986): Amazonian Indians Receive Alternative Nobel Peace Price, Pressemitteilung, London, 10.10.1986.

Swartz, Marc J./Turner, Victor W./Tuden, Arthur (2002 [1966]): »Political Anthropology«. In: The Anthropology of Politics. A Reader in Ethnography, Theory, and Critique, hg. v. Joan Vincent, Oxford, S. 102-109.

Sylvain, Renée (2002): »)Land, Water, and Truth`: San Identity and Global Indigenism«. In: American Anthropologist 104(4), S. 1074-1085.

Taylor, Alan (1996): »Captain Hendrik Aupaumut: The Dilemmas of an Intercultural Broker«. In: Ethnohistory 43(3), S. 431-457.

Taylor, Charles (1985): »What is Human Agency«? In: Human Agency and Language (Philosophical Papers Bd. 1), hg. v. Charles Taylor, Cambridge, S. 15-16.

Taylor, Charles (1992): Multiculturalism and sthe Politics of Recognition<. An Essay, Princeton NJ.

Taylor, Charles (1994): »The Politics of Recognition«. In: Multiculturalism: Examining the Politics of Recognition, hg. v. Amy Gutman, Princeton NJ, S. 25-73. 
Taussig, Michael (1987): Shamanism, Colonialism, and the Wild Man: A Study in Terror and Healing, Chicago.

Tejada Ripalda, Luis (Hg.) (2005): Los Estudiantes Indígenas Amazónicos de la UNMSM, Ciudad Universitaria, Lima.

Tessmann, Günter (1930): Die Indianer Nord-Ost Perus: Grundlegende Forschungen für eine systematische Kulturkunde, Hamburg.

Tönnies, Ferdinand (1887): Gemeinschaft und Gesellschaft, Leipzig.

Touraine, Alain (2000): Can We Live Together? Equality and Difference, Stanford, CA.

Trauttmansdorf, Ferdinand (1999): »Die Organe der Vereinten Nationen«. In: Die Vereinten Nationen. Recht und Praxis, hg. v. Franz Cede/Lilly Sucharipa-Behrmann, Wien.

Turner, Terence (1979): »Kinship, Household and Community Structure among the Kayapo«. In: Dialectical Societies, hg. v. David Maybury-Lewis, S. 179-217, Cambridge.

Turner, Terence (1980): »The Social Skin«. In: Not Work Alone: A CrossCultural View of Activities Superfluous to Survival, hg. v. Jeremy Cherfas/Roger Lewin, London, S. 112-140.

Turner, Terence (1993): »Anthropology and Multiculturalism: What is Anthropology that Multiculturalism should be Mindful of It $\ll$ ? In: Cultural Anthropology 8(4), S. 411-429.

Turner, Terence (1997): »Human Rights, Human Difference: Anthropology's Contribution to a Emancipatory Cultural Politics«. In: Journal of Anthropological Research 53, S. 273-291.

Turner, Terence (1999): »The Role of Indigenous Peoples in Environmental Crisis: The Example of the Kayapo of the Brazilian Amazon«. In: Perspectives in Biology and Medicine 36(3), S. 526-545.

Ullán de la Rosa, Francisco Javier (2004): »Los Límites de la Ingeneiería Indigenista: La Reestructuración del Autogobierno entre los Indios Ticunas del Alto Amazonas«. In: Revista Española de Antropología Americana, Vol. 34, S. 203-224.

United Nations (1994): Draft Declaration on the Rights of Indigenous Peoples. Geneva, E/CN.4/Sub.2/1994/2/Add.1, 20.04.1994.

United Nations (1996): Review of Existing Mechanisms, Procedures and Programmes Within the United Nations Concerning Indigenous People. Report of the Sectretary General, A/51/493, New York.

United Nations (2000): Working Paper on the Relationship and Distinction Between the Rights of Persons Belonging to Minorities and Those of Indigenous Peoples. Report of Erike-Irene Daes and Asbjorn Eide, E/CN.4/Sub.2/2000/10, 19.07.2000.

United Nations (2002a): Report of the First Session of the Permanent Forum on Indigenous Issues, E/2002/43, New York. 
United Nations (2002b): In größerer Freiheit: Auf dem Weg zu Entwicklung, Sicherheit und Menschenrechte für alle. Bericht des Generalsekretärs, A/59/2005, New York.

United Nations (2003): Report of the Second Session of the Permanent Forum on Indigenous Issues, E/C.19/2003/22, New York.

United Nations (2004a): Report of the Third Session of the Permanent Forum on Indigenous Issues, E/C.19/2004/23, New York.

United Nations (2004b): The Concept of Indigenous Peoples. Background Paper Prepared by the Secretariat of the Permanent Forum on Indigenous Issues. Workshop on Data Collection and Disagregation for Indigenous Peoples, PFII/2004/WS.1/3, New York, 19.-21.01.2004.

United Nations (2005): Report of the Fourth Session of the Permanent Forum on Indigenous Issues. E/C.19/2005/9, New York.

United Nations (2006): Resolution Adopted by the General Assembly: 60/251, Human Rights Council, A/RES/60/251.

Unser, Günther (1997): Die UNO: Aufgaben und Strukturen der Vereinten Nationen, München.

Urban, Greg/Sherzer, Joel (Hg.) (1991): Nation-States and Indians in Latin America, Austin.

Urban, Greg (2001): Metaculture: How Culture Moves through the World, Minneapolis.

Van Cott, Donna Lee (Hg.) (1994): Indigenous Peoples and Democracy in Latin America, Houndmills/Basingstoke/Hampshire.

Van Cott, Donna Lee (2000): The Friendly Liquidation of the Past: The Politics of Diversity in Latin America, Pittsburgh.

Van Hasselt, Jutta (1998): »Kultur und nachhaltige Entwicklung: Das Kulturverständnis der UNESCO und der Aktionsplan von Stockholm«. In: Kultur und Entwicklung. Zur Umsetzung des Stockholmer Aktionsplans, hg. v. Roland Bernecker, Bonn, S. 61-76.

Varese, Stefano (1972): The Forest Indians in the Present Political Situation of Peru, IWGIA Document, Copenhagen.

Varese, Stefano (1975) : »Etnología de Urgencia, Conciencia Étnica y Participación Social en el Peru«. In : América Indígena 35(2), S. 251-263.

Varese, Stefano (1995): »Pueblos Indígenas y Globalización en el Umbral del Tercer Milenio«. In: Articulación de la Diversidad. Pluralidad Étnica, Autonomías y Democratización en América Latina, hg. v. Georg Grünberg, Quito, S. 123-159.

Vega Díaz, Ismael (2000): »Entre Guerreros y Concertadores: La Cultura Política de los Líderes Indígenas de la Amazonía«. In: Autoridad en Espacios Locales. Una Mirada desde la Antropología, hg. v. Juan Ansión/ Alejandro Diez/Luis Mujica, Lima, S. 125-148. 


\section{Kultur- und soziale Praxis}

Jonathan Everts

Konsum und Multikulturalität im Stadtteil

Eine sozialgeographische

Analyse migrantengeführter

Lebensmittelgeschäfte

Juni 2008, ca. 210 Seiten,

kart., ca. $22,80 €$,

ISBN: 978-3-89942-866-7

Serhat Karakayali

Blinde Passagen

Zur Genealogie illegaler

Migration in der

Bundesrepublik Deutschland

April 2008, ca. 26o Seiten,

kart., ca. $26,80 €$,

ISBN: 978-3-89942-895-7

Martin Sökefeld (Hg.)

Aleviten in Deutschland

Identitätsprozesse einer

Religionsgemeinschaft

in der Diaspora

April 2008, ca. 200 Seiten,

kart., ca. $24,80 €$,

ISBN: 978-3-89942-822-3

Martina Grimmig

Goldene Tropen

Zur Koproduktion natürlicher

Ressourcen und kultureller

Differenz in Guayana

März 2008, ca. 320 Seiten,

kart., ca. $34,80 €$,

ISBN: 978-3-89942-751-6

Maren Rößler

\section{Zwischen Amazonas}

und East River

Indigene Bewegungen und

ihre Repräsentation in Peru

und bei der UNO

Februar 2008, 394 Seiten,

kart., $36,80 €$,

ISBN: $978-3-89942-857-5$
Valentin Rauer

Die öffentliche Dimension der Integration

Migrationspolitische Diskurse türkischer Dachverbände in Deutschland

2007, 266 Seiten,

kart., 25,80 €,

ISBN: 978-3-89942-801-8

Alexander Jungmann

Jüdisches Leben in Berlin

Der aktuelle Wandel

in einer metropolitanen

Diasporagemeinschaft

2007, 594 Seiten,

kart., $41,80 €$,

ISBN: $978-3-89942-811-7$

Tina Jerman (Hg.)

Kunst verbindet Menschen Interkulturelle Konzepte für eine Gesellschaft im Wandel 2007, 264 Seiten,

kart., zahlr. Abb., 23,80 €,

ISBN: 978-3-89942-862-9

Antje Gunsenheimer (Hg.)

Grenzen. Differenzen.

Übergänge.

Spannungsfelder interund transkultureller

Kommunikation

2007, 308 Seiten,

kart., $29,80 €$,

ISBN: $978-3-89942-794-3$

\section{Birgit Glorius}

Transnationale Perspektiven

Eine Studie zur Migration

zwischen Polen und

Deutschland

2007, 340 Seiten,

kart., $29,80 €$,

ISBN: 978-3-89942-745-5

Leseproben und weitere Informationen finden Sie unter: www.transcript-verlag.de 


\section{Kultur- und soziale Praxis}

Christian Berndt,

Robert Pütz (Hg.)

Kulturelle Geographien

Zur Beschäftigung

mit Raum und Ort nach

dem Cultural Turn

2007, 384 Seiten,

kart., $29,80 €$,

ISBN: $978-3-89942-724-0$

Karsten Kumoll

Kultur, Geschichte und die

Indigenisierung der Moderne

Eine Analyse des Gesamtwerks von Marshall Sahlins

2007, 432 Seiten,

kart., $35,80 €$

ISBN: $978-3-89942-786-8$

Constanze Pfeiffer

Die Erfolgskontrolle der

Entwicklungszusammenarbeit und ihre Realitäten

Eine organisationssoziologische

Studie zu Frauenrechts-

projekten in Afrika

2007, 230 Seiten,

kart., $27,80 €$,

ISBN: 978-3-89942-771-4

Peter Kreuzer, Mirjam Weiberg

Zwischen Bürgerkrieg und

friedlicher Koexistenz

Interethnische Konfliktbearbei-

tung in den Philippinen,

Sri Lanka und Malaysia

2007, 602 Seiten

kart., $40,80 €$,

ISBN: $978-3-89942-758-5$
Martin Baumann, Jörg Stolz (Hg.)

Eine Schweiz -

viele Religionen

Risiken und Chancen

des Zusammenlebens

2007, 410 Seiten,

kart., $18,80 €$,

ISBN: 978-3-89942-524-6

Katharina Zoll

Stabile Gemeinschaften

Transnationale Familien

in der Weltgesellschaft

2007, 246 Seiten,

kart., $25,80 €$,

ISBN: $978-3-89942-670-0$

\section{Daniel Münster}

\section{Postkoloniale Traditionen}

Eine Ethnografie über Dorf,

Kaste und Ritual in Südindien 2007, 250 Seiten,

kart., $27,80 €$,

ISBN: 978-3-89942-538-3

Reinhard Johler, Ansgar Thiel, Josef Schmid,

Rainer Treptow (Hg.)

Europa und seine Fremden

Die Gestaltung kultureller

Vielfalt als Herausforderung 2007, 216 Seiten,

kart., $21,80 €$,

ISBN: 978-3-89942-368-6

Ulrike Joras

Companies in Peace

Processes

A Guatemalan Case Study

2007, 310 Seiten,

kart., $30,80 €$,

ISBN: $978-3-89942-690-8$

Leseproben und weitere Informationen finden Sie unter: www.transcript-verlag.de 


\section{Kultur- und soziale Praxis}

Magdalena Nowicka (Hg.)

Von Polen nach Deutschland und zurück

Die Arbeitsmigration und ihre Herausforderungen für Europa 2007, 312 Seiten,

kart., $30,80 €$,

ISBN: 978-3-89942-605-2

TRANSIT MIGRATION

Forschungsgruppe (Hg.)

Turbulente Ränder

Neue Perspektiven auf

Migration an den Grenzen

Europas (2. Auflage)

2007, 252 Seiten,

kart., $24,80 €$,

ISBN: 978-3-89942-781-3

Dieter Haller

\section{Lone Star Texas}

Ethnographische Notizen aus einem unbekannten Land

2007, 224 Seiten,

kart., zahlr. Abb., 22,80 €,

ISBN: 978-3-89942-696-o

Klaus Müller-Richter,

Ramona Uritescu-Lombard (Hg.)

Imaginäre Topografien

Migration und Verortung

2007, 244 Seiten,

kart., $25,80 €$,

ISBN: 978-3-89942-594-9

Pascal Goeke

Transnationale Migrationen

Post-jugoslawische Biografien

in der Weltgesellschaft

2007, 394 Seiten,

kart., $33,80 €$,

ISBN: $978-3-89942-665-6$
Halit Öztürk

Wege zur Integration

Lebenswelten muslimischer Jugendlicher in Deutschland 2007, 282 Seiten,

kart., $28,80 €$,

ISBN: 978-3-89942-669-4

\section{Holger Michael}

Kulturelles Erbe als

identitätsstiftende Instanz?

Eine ethnographisch-verglei-

chende Studie dörflicher

Gemeinschaften an der

Atlantik- und Pazifikküste

Nicaraguas

2007, 230 Seiten,

kart., $27,80 €$,

ISBN: 978-3-89942-602-1

Corinne Neudorfer

Meet the Akha -

help the Akha?

Minderheiten, Tourismus

und Entwicklung in Laos

2007, 300 Seiten,

kart., $29,80 €$,

ISBN: 978-3-89942-639-7

Elias Jammal, Ulrike Schwegler

Interkulturelle Kompetenz im Umgang mit arabischen

Geschäftspartnern

Ein Trainingsprogramm

2007, 210 Seiten,

kart., $21,80 €$,

ISBN: 978-3-89942-644-1

María do Mar Castro Varela

Unzeitgemäße Utopien

Migrantinnen zwischen

Selbsterfindung und

Gelehrter Hoffnung

2007, 304 Seiten,

kart., $29,80 €$,

ISBN: 978-3-89942-496-6

Leseproben und weitere Informationen finden Sie unter: www.transcript-verlag.de 